\title{
INGESTION AND INHALATION OF METAL(LOID)S THROUGH PRESCHOOL GARDENING: AN EXPOSURE AND RISK ASSESSMENT IN LEGACY MINING COMMUNITIES
}

by

Iliana Manjón

Copyright (C) Iliana Manjón 2019

A Thesis Submitted to the Faculty of the

DEPARTMENT OF SOIL, WATER, AND ENVIRONMENTAL SCIENCE

In Partial Fulfillment of the Requirements

For the Degree of

MASTER OF SCIENCE

In the Graduate College

THE UNIVERSITY OF ARIZONA 


\section{THE UNIVERSITY OF ARIZONA GRADUATE COLLEGE}

As members of the Master's Committee, we certify that we have read the thesis prepared by Iliana Manjón, titled "Ingestion and inhalation of metal(loid)s through preschool gardening: an exposure and risk assessment in legacy mining communities" and recommend that it be accepted as fulfilling the dissertation requirement for the Master's Degree.

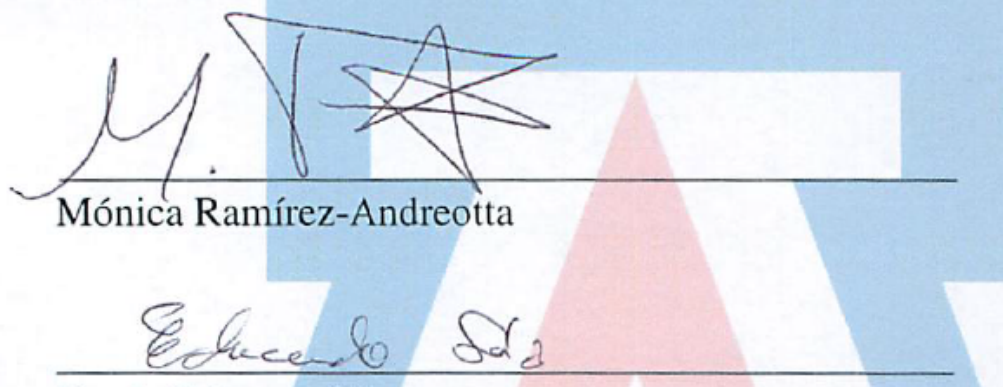

Dr. A. Eduardo Sáez

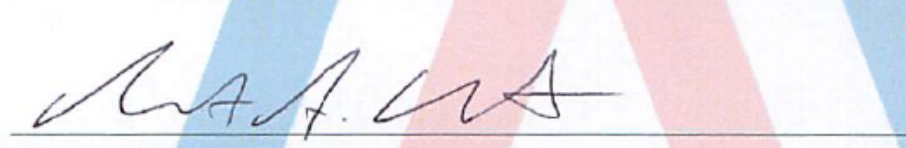

Dr. Robert A. Root
Date: April 292019

Date: $04 / 29 / 2019$

Date: 2019 Apr 29

Final approval and acceptance of this thesis is contingent upon the candidate's submission of the final copies of the thesis to the Graduate College.

I hereby certify that I have read this thesis prepared under my direction and recommend that it be accepted as fulfilling the Master's requirement.

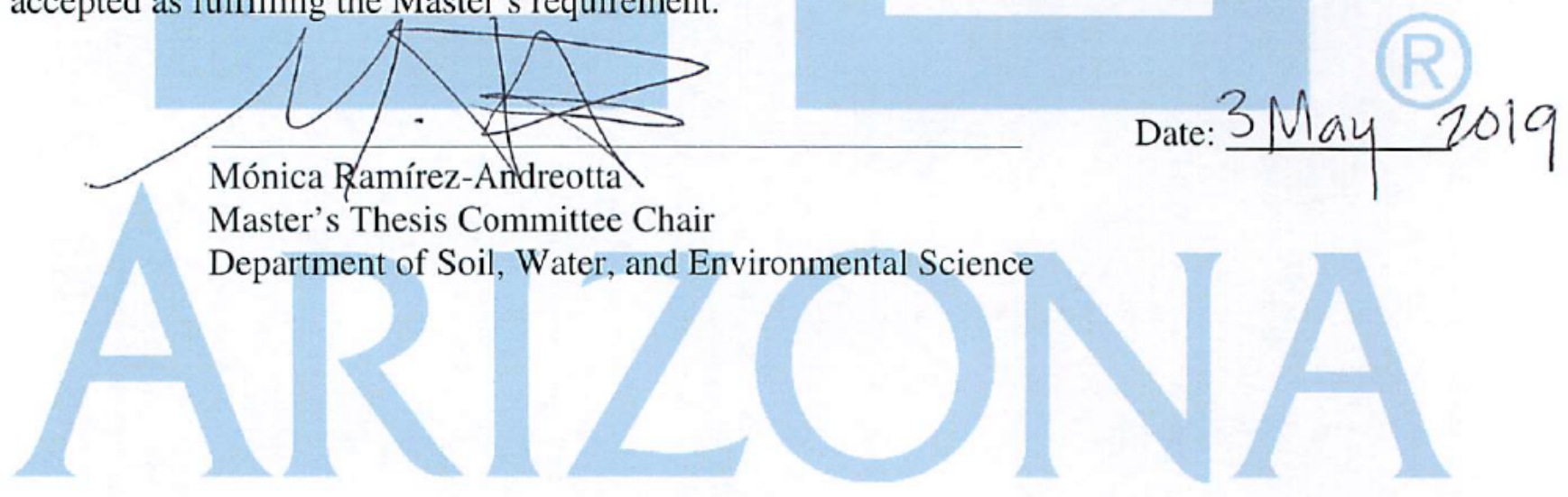




\section{ACKNOWLEDGEMENTS}

I would first like to thank my advisor, Dr. Mónica Ramírez-Andreotta for her immense support throughout my graduate career. She has played a cardinal role in my growth and success as a student, and I am eternally grateful to have her as a life-long mentor. I am truly honored to have had such a dedicated and inspiring mentor for the past 3 years.

It goes without saying that I am also tremendously thankful for the expertise and support from my committee members, Dr. A. Eduardo Sáez and Dr. Robert A. Root. This project had many unfamiliar components, each of which you helped me work through.

Thank you to all the Gardenroots participants and my Sierra Streams Institute partners for their critical roles in this project. Without them, this project wouldn't have been possible.

I am extremely thankful for my wonderful laboratory members that have never been short of helpful whenever necessary. Nikki Skelton and Christian Hegstrom, thank you for dedicating so much of your time to helping me sieve, build, clean, and everything in between. I wouldn't have gotten it all done without you.

A special thank you to Dr. Eric A. Betterton and Kyle Rine for their research expertise, mentorship, and support throughout the past 3 years. Also, Mary Kay Amistadi and the Arizona Laboratory for Emerging Contaminants for their immense help with sample analysis.

I would also like to thank my best friend, Barbara Moore for her endless support and selflessness throughout the past 6 years. I've never met anyone more willing to lend a helping hand regardless of the task or time commitment.

Lastly, I am grateful for my funders, the California Breast Cancer Research Program and the National Institute of Environmental Health Sciences Superfund Research Program at the University of Arizona. 


\section{TABLE OF CONTENTS}

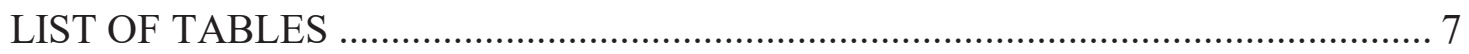

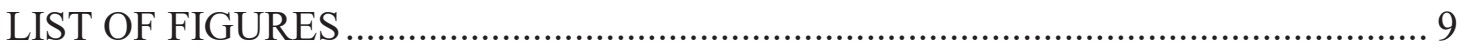

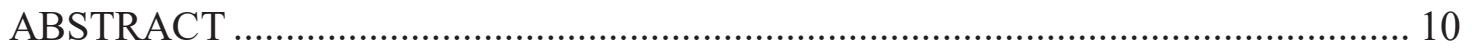

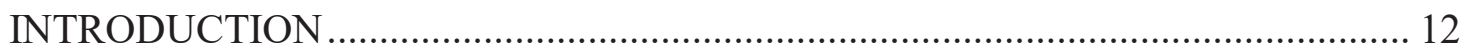

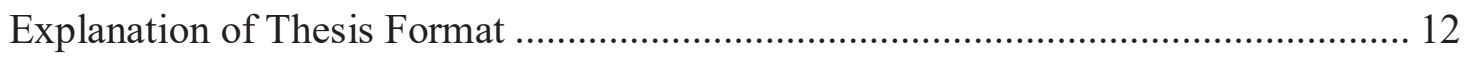

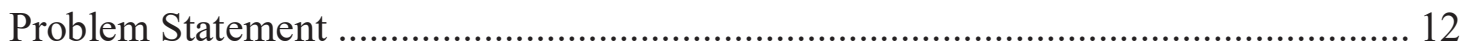

A Critical Review of Dietary Assessment Methodology to Improve for Future

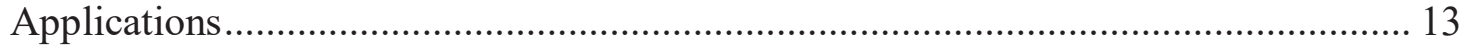

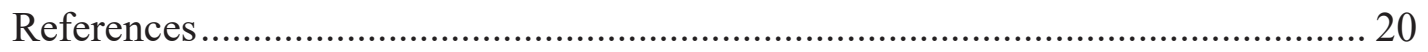

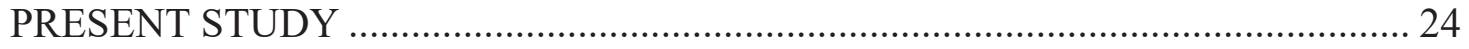

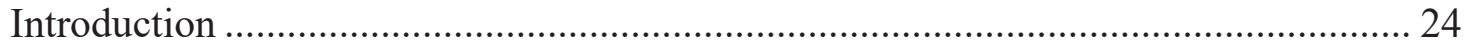

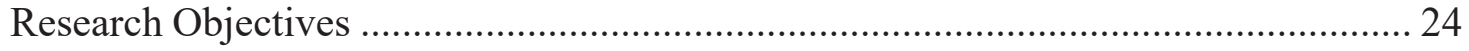

Conclusion and Research Implications ............................................................... 24

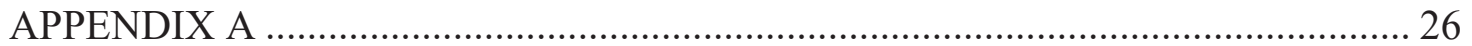

A Dietary Assessment Tool to Estimate Arsenic and Cadmium Exposures from

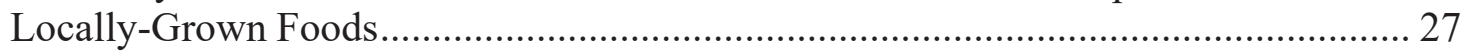

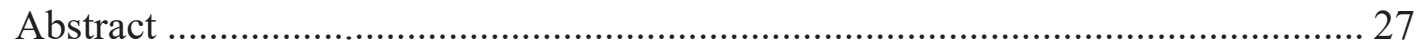

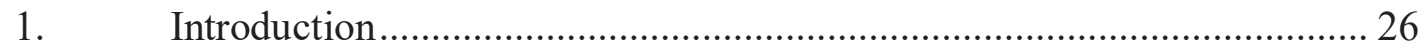

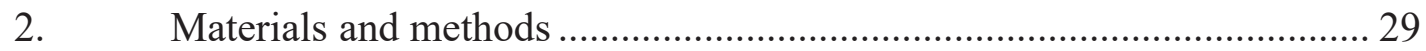

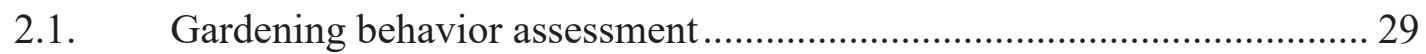

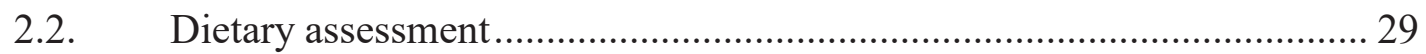

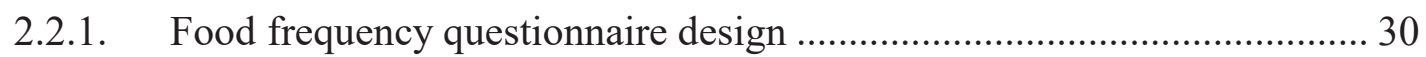

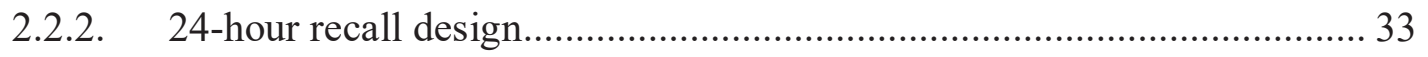

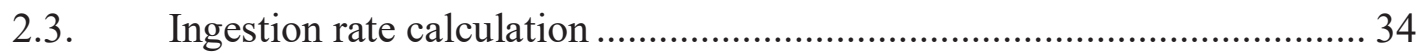

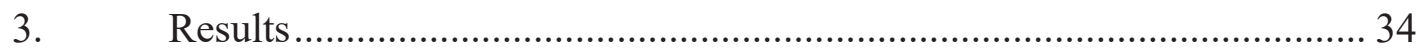

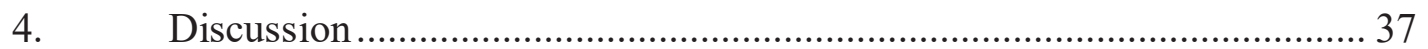

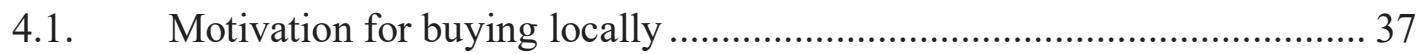

4.2. Socio-economic factors' impact on fruits and vegetable consumption .... 38

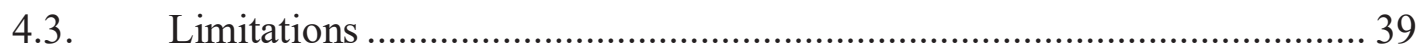

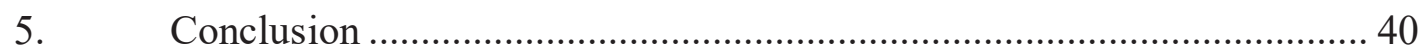

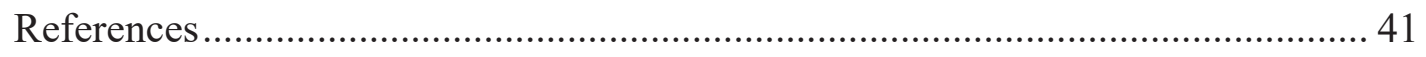

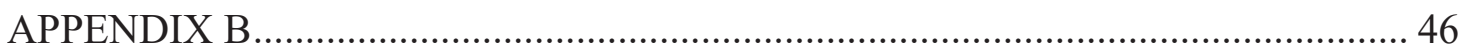


Ingestion and Inhalation of Metal(loid)s Through Preschool Gardening: An Exposure and Risk Assessment in Legacy Mining Communities ............................................ 47

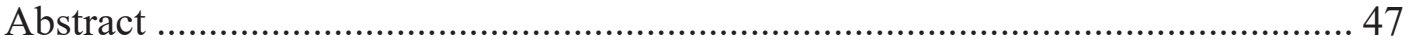

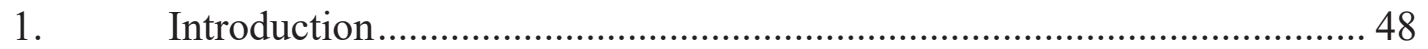

2. Materials and Methods .................................................................... 51

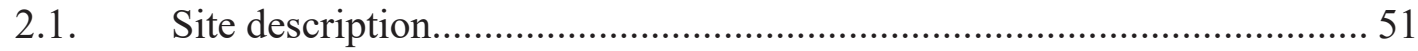

2.2. Dietary assessment and gardening description survey.......................... 53

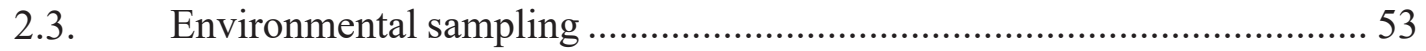

2.3.1. Water sampling, preparation, and analysis ........................................ 53

2.3.2. Soil/garden amendment sampling, preparation, and analysis .................. 54

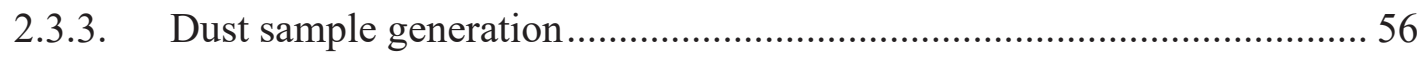

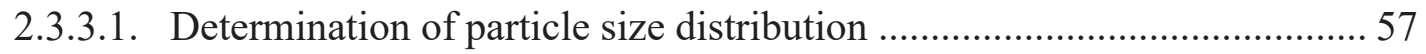

2.3.4. Plant amendment sampling, preparation, and analysis ......................... 58

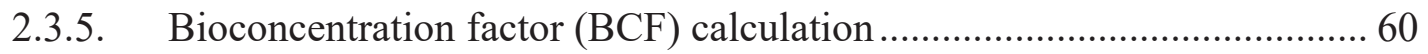

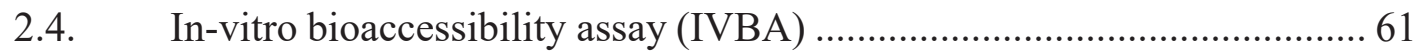

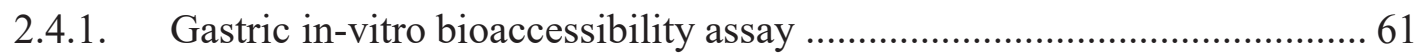

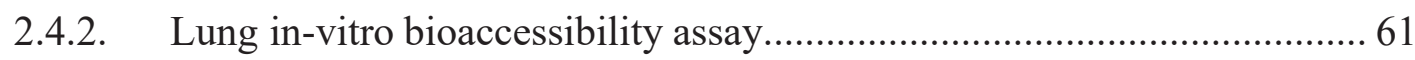

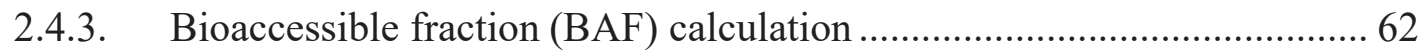

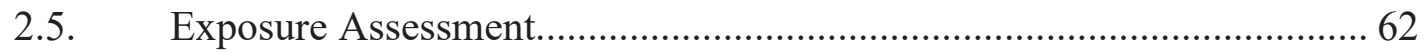

2.5.1. Average daily dose and lifetime average daily dose calculations ............ 62

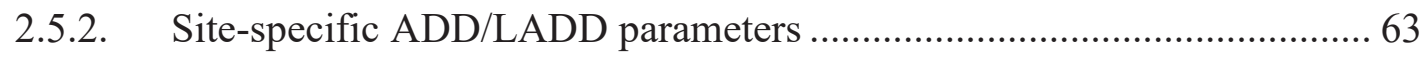

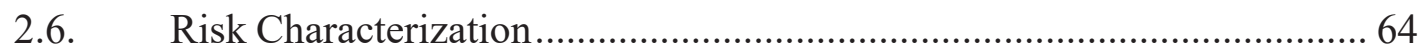

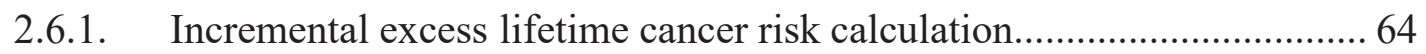

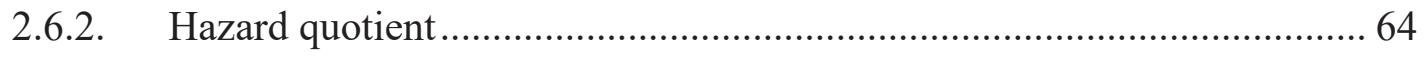

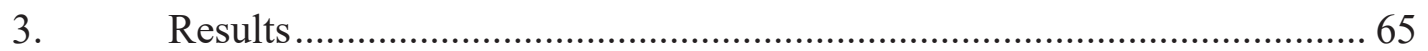

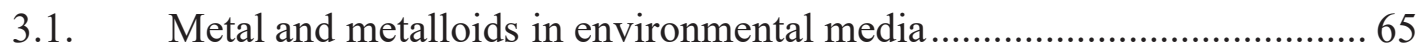

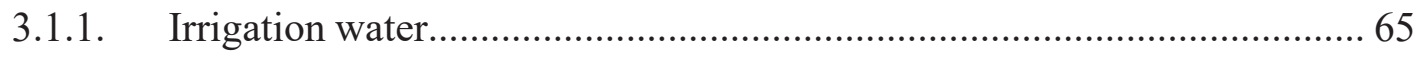

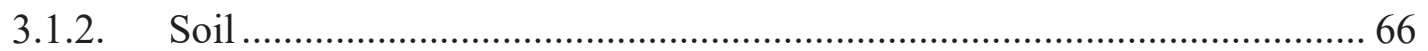

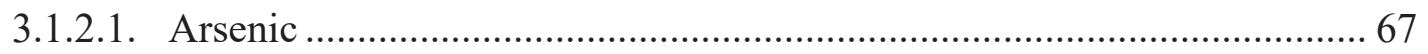

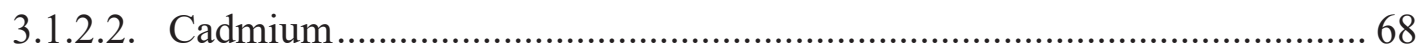

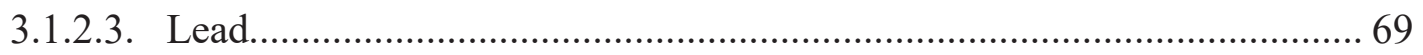

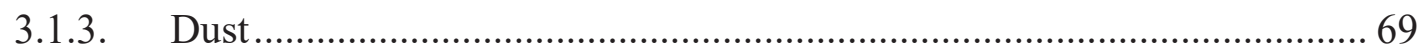

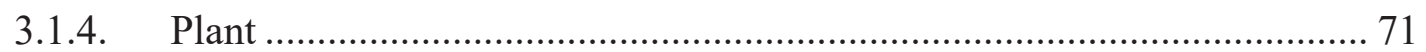

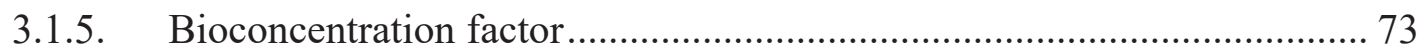

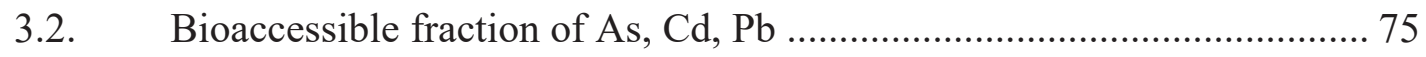


3.3. Exposure Assessment........................................................................ 76

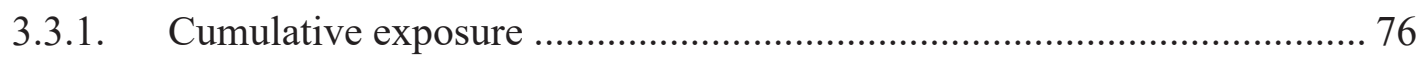

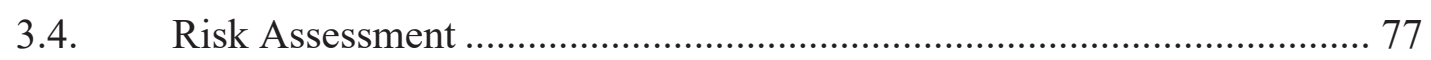

3.4.1. Incremental excess lifetime cancer risk ............................................ 77

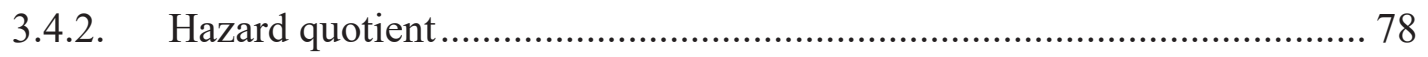

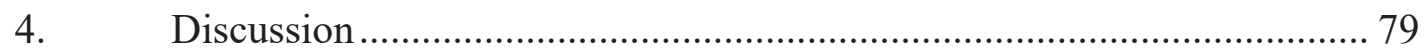

4.1. Cumulative exposure to arsenic, cadmium, and lead ............................ 79

4.2. Critique of risk assessment model parameters ...................................... 81

4.3. Critical issues in traditional bioavailability estimations ........................ 81

4.4. Limitations to estimating BAFs from in-vitro bioaccessibility assays ..... 82

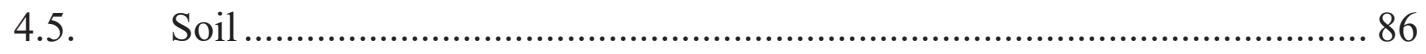

4.5.1. As and Cd levels in garden and playground soil.................................. 86

4.5.2. Elevated $\mathrm{Pb}$ levels in garden and playground soil ................................. 86

4.5.3. Site administrator awareness of potential contamination sources ............ 87

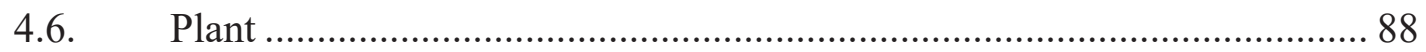

4.6.1. Metal(loid) accumulators and hyperaccumulators ................................ 88

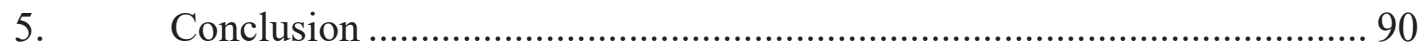

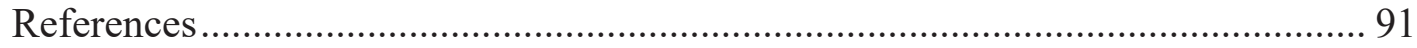

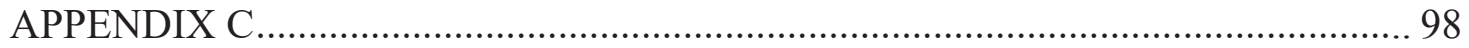

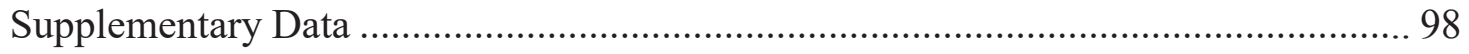

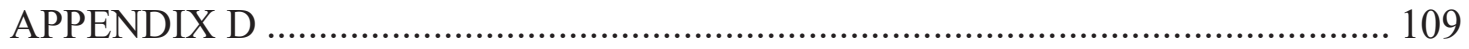

Sample Collection Instructions Manual (English/Spanish) ................................. 110

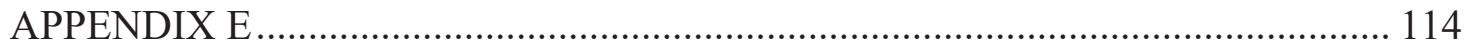

Food Frequency Questionnaire (English/Spanish) ......................................... 115

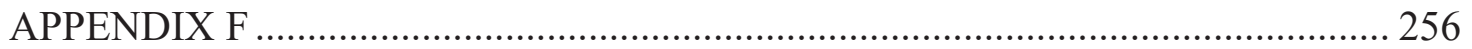

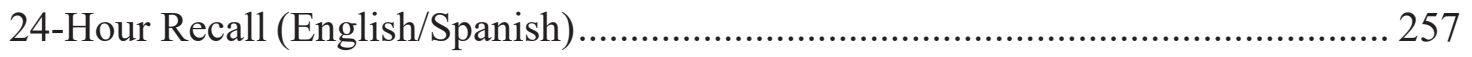

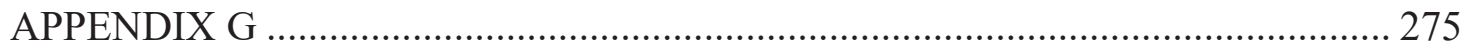

Dust Generator Operating Procedure ................................................................ 276

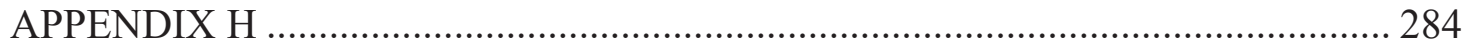

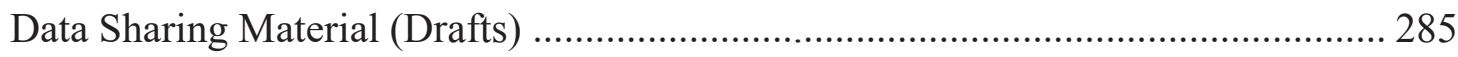




\section{LIST OF TABLES}

A Critical Review of Dietary Assessment Methodology to Improve for Future Applications

Table 1. Garden vegetables shown to uptake As and $\mathrm{Cd}$ in edible portions of the

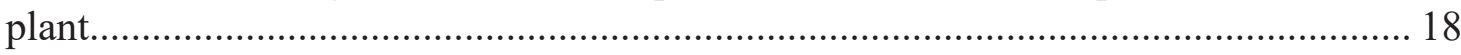

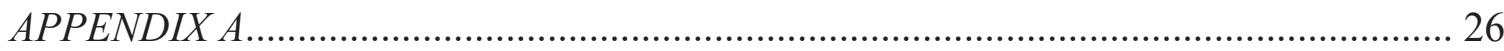

Table 1. Garden produce shown to uptake $\mathrm{As}$ and $\mathrm{Cd}$ in the edible portions of the plant..... 30

Table 2. Median percentage of child's yearly consumption of food groups from different sources as reported by participants. ......................................................... 34

Table 3. Age-specific ingestion rate per plant type. ............................................... 36

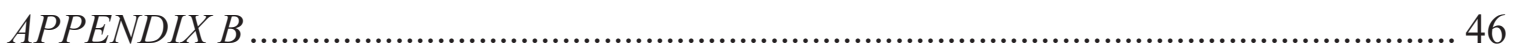

Table 1. ICP-MS quantifiable detection limits for metal(loid)s. ............................... 54

Table 2. Garden soil amendment description and sites to which they were

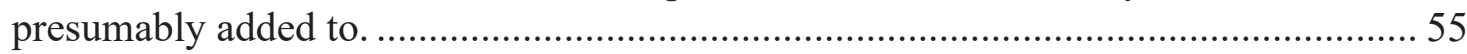

Table 3. General parameters used in ADD and LADD calculations. ......................... 63

Table 4. Mean metal(loid)-specific values for parameters used in ADD and LADD

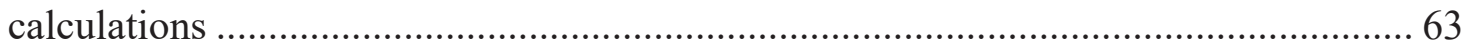

Table 5. Age-specific values for parameters used in ADD and LADD calculations. .. 64

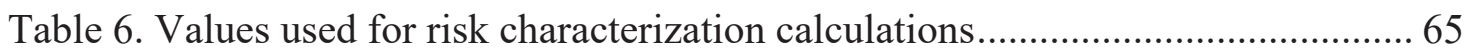

Table 7. Federal and state recommended residential soil screening levels.................. 68

Table 8. Median metal(loid) concentrations, and mean metal(loid) concentrations reported in the USFDA Total Diet Study, and WHO Codex Recommended Maximum Levels.

Table 9. Age-specific cumulative average daily dose and lifetime average daily

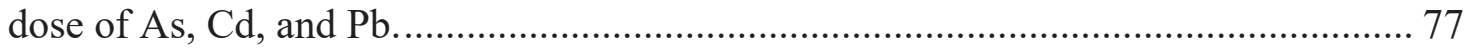

Table 10. Age-specific incremental excess lifetime cancer risk from As per exposure media.

Table 11. Hazard quotient for $\mathrm{As}, \mathrm{Cd}$, and $\mathrm{Pb}$ per exposure age group and exposure

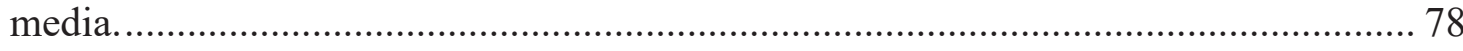

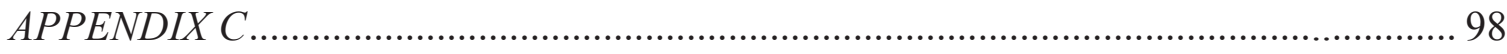

Table 1. Age-specific average daily dose (ADD) and lifetime average daily dose (LADD) of metal(loid)s from ingestion of irrigation water across all sites.

Table 2. Age-specific average daily dose (ADD) and lifetime average daily dose (LADD) of metal(loid)s from incidental soil $(<63 \mu \mathrm{m})$ ingestion across all sites. 
Table 3. Age-specific average daily dose (ADD) and lifetime average daily dose (LADD) of metal(loid)s from preschool garden plants across all sites.

Table 4. Age-specific average daily dose (ADD) and lifetime average daily dose (LADD) of metal(loid)s from inhalation of dust $(<10-\mu \mathrm{m})$ across all sites.

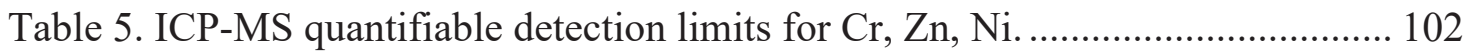

Table 6. Garden irrigation water $\mathrm{Cr}$, Zn, Ni concentrations.

Table 7. Federal and state recommended residential soil screening levels for $\mathrm{Cr}$, $\mathrm{Ni}, \mathrm{Zn}$, and $\mathrm{Hg}$. 106

Table 8. Median Cr, Zn, Ni concentrations measured from garden and playground dust samples $(<10 \mu \mathrm{m})$.

Table 9. Median $\mathrm{Zn}$ and Ni concentrations, and mean metal(loid) concentrations reported in the USFDA Total Diet Study, and WHO Codex Recommended Maximum Levels. 107

Table 10. Site-specific median BCF of Zn and Ni per plant type............................ 108

Table 11. Median BCF of Zn and Ni per plant type (across all sites). 108 


\section{LIST OF FIGURES}

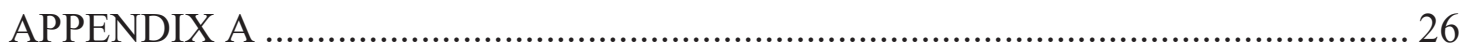

Figure 1. Flowchart of FFQ questions regarding potato intake.............................. 32

Figure 2. Reported motivations for buying locally or not buying locally and the percentage of participants that reported that motivation........................................... 35

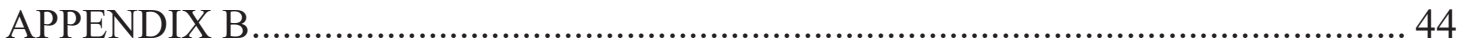

Figure 1. Schematic of a child's multi-route exposure considered in this study. .... 51

Figure 2. Process of determining particle size distribution by ImageJ..................... 58

Figure 3. Garden irrigation water metal(loid) concentrations. .................................. 65

Figure 4. Median metal(loid) concentrations measured from garden and playground soil samples $(<63 \mu \mathrm{m})$.

Figure 5. Metal(loid) concentrations measured from garden and playground dust samples $(<10 \mu \mathrm{m})$. 69

Figure 6. As, $\mathrm{Cd}$, and $\mathrm{Pb}$ concentration in preschool garden produce..................... 71

Figure 7. Site-specific median BCF of metal(loid) per plant type............................ 73

Figure 8. Median BCF of metal(loid) per plant type (across all sites). ………….... 74

Figure 9. BAF of metal(loid) determined by gastric and lung IVBA..................... 75

Figure 10. Percent contribution of exposure media to ADD of $\mathrm{As}, \mathrm{Cd}$, and $\mathrm{Pb}$, for hildren of different exposure groups, and significant difference among measured metal(loid) mean concentration by plant type per metal(loid)................ 76

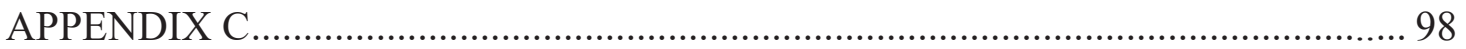

Figure 1. Cr concentration in garden soil.......................................................... 102

Figure 2. Cr concentration in playground soil.................................................... 103

Figure 3. Zn concentration in garden soil........................................................... 103

Figure 4. Zn concentration in playground soil..................................................... 104

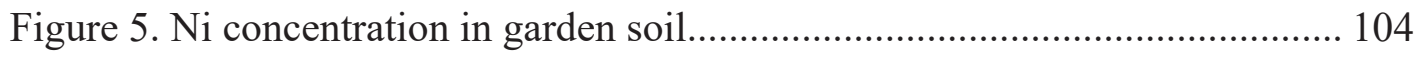

Figure 6. Ni concentration in playground soil................................................ 105

Figure 7. Hg concentration in garden soil....................................................... 105

Figure 8. Hg concentration in playground soil. .................................................. 106

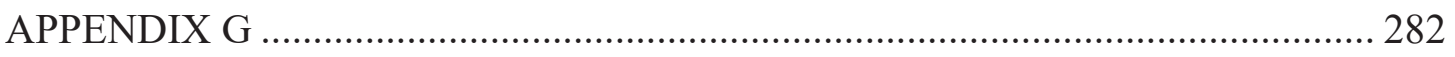

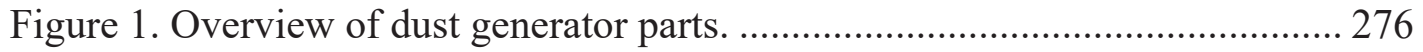

Figure 2. Overview of the assembled dust generator............................................. 279

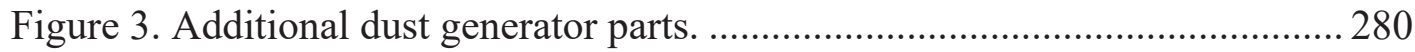




\section{ABSTRACT}

Children residing in legacy mining towns are potentially disproportionately exposed to metal(loid)s via ingestion (of food, water, and incidental soil), and dust inhalation, thus, increasing their risk of exposure when engaging in school or home gardening or playing outside in non-garden, playground soil. The purpose of this citizen-science study was to assess preschool children's potential metal(loid) exposure through these routes. Parents and teachers were trained to properly collect water, soil, and vegetable samples from their preschools throughout Nevada County, California. Arsenic (As), cadmium (Cd), and lead $(\mathrm{Pb})$ concentrations in garden irrigation sources did not exceed the U.S. EPA Safe Drinking Water Act and Lead and Copper Rule's maximum contaminant levels. In general, As and $\mathrm{Pb}$ concentration within garden and playground soil samples exceeded the U.S. EPA regional screening level (RSL), CalEPA's California Human Health Screening Level (CHHSL), and California Department of Toxic Substances Control Screening Level (DTSC-SL). In contrast, all Cd concentrations were below these recommended screening levels. Metal(loid) exposure via homegrown produce revealed that lettuce, carrot, and cabbage grown in the preschool gardens accumulated a higher concentration of metal(loid) than those store-bought nation-wide (USFDA Total Diet Study, 2006-2013). None of the vegetables exceeded the respective recommendation maximum levels for $\mathrm{Cd}$ and $\mathrm{Pb}$ set by the WHO Codex Alimentarius Commission. Dust samples $(<10-\mu m$ diameter $)$ were generated from surface garden and playground soil collected at the preschools. Soil and dust samples were then analyzed by in-vitro bioaccessibility assays using synthetic lung and gastric fluids to estimate the bioaccessible fraction of $\mathrm{As}, \mathrm{Cd}$, and $\mathrm{Pb}$ in the body. Lastly, this study employed a novel dietary assessment designed to estimate a child's potential exposure to metal(loid)s through consumption of locally-grown foods. Ingestion rates for As and $\mathrm{Cd}$ accumulating foods (cilantro, carrot, cabbage, kale, and lettuce) were calculated for different age groups and motivations for buying locally-grown foods were identified. The results of this study suggest that consumption of preschool-grown foods and incidental soil ingestion were major contributors to preschool-aged children's exposure to $\mathrm{As}, \mathrm{Cd}$, and $\mathrm{Pb}$. This comprehensive environmental monitoring and exposure assessment that includes child-specific dietary data, the average daily doses of contaminants through 
ingestion of soil, water, and vegetable and inhalation of dust informs future risk assessment and public health interventions related to childhood exposure to these metal(loid)s. 


\section{INTRODUCTION}

\section{Explanation of Thesis Format}

This thesis is composed of two manuscripts in preparation for publication, and 6 appendices that contain supplemental information referenced throughout. It begins with a literature review that informed the two studies in Appendix A, Appendix B, and documents in Appendix E, and Appendix F. Appendix A contains a manuscript that will be submitted to a peer-reviewed journal at a later date, while Appendix B contains the present study that will be submitted to the journal, Science and the Total Environment. Appendix $\mathrm{C}$ contains supplemental data regarding additional metals analyzed. Appendix $\mathrm{D}$ includes the bilingual (English/Spanish) sample collection instructions manual used during participant trainings, while Appendix E and F contains the bilingual (English/ Spanish) dietary assessment documents used in this thesis. Appendix G includes an operating procedure to guide future use of the dust generator used in the study described in Appendix B, and Appendix H contains the results report shared with the Gardenroots participants.

\section{Problem Statement}

Heavy metal(loid) contamination by active and legacy resource extraction sites is of increasing concern for neighboring communities that rely on foods locally grown throughout the area. Further, children of these communities are more vulnerable to the adverse health effects from exposures to these metal(loid)s than adults. Traditional exposure and risk assessments are prone to under- or overestimating one's exposures to contaminants due to the assumptions used in calculations. Thus, it is critical to employ site-specific tools to reduce the number of these assumptions and uncertainties to best evaluate a multi-route exposure and risk for children of these communities. 


\section{A Critical Review of Dietary Assessment Methodology to Improve for Future Applications}

\section{Introduction}

The impacts of contamination by active and legacy extraction sites is of increasing concern for neighboring communities that rely on locally grown foods through community and home gardens. Mining and smelting operations are commonly the source of release of metal(loid)s such as arsenic (As) and cadmium (Cd) that is transported in dust to nearby communities by wind and can contaminate groundwater by leaching (Csavina et al., 2012). Both As and $\mathrm{Cd}$ are classified as carcinogens by the International Agency for Research on Cancer (IARC) have been shown to be endocrine-disrupting agents associated with the increase risk of breast cancers. The U.S. Environmental Protection Agency, however, only classifies As as a human carcinogen and $\mathrm{Cd}$ as a probable carcinogen based on limited evidence of carcinogenicity in humans (U.S. EPA, 2006). Therefore, it is essential to evaluate the levels of these contaminants in neighboring communities.

Children, with air and caloric intake 2 and 3 times greater than adults and more rapid and complex body system development, are more susceptible to adverse health effects of environmental toxins (Landrigan et al., 2011). Children residing in communities at-risk of pollution are principally exposed to heavy metals via incidental ingestion of dust and soil as a result of hand-to-mouth transfer (Huang et al., 1997, Beamer et al., 2012). Since 2013, more schools have been incorporating gardening programs in their curriculum (Turner et al., 2014), therefore, increasing the risk of exposure to these contaminants. Furthermore, gardening is becoming a more prevalent hobby in the United States, allowing families to provide their families with essential fruits, vegetables, and herbs, but also presenting additional potential dietary exposures if soil or irrigation water is contaminated.

Dietary assessments are widely used to monitor and record dietary intakes for epidemiological studies. Dietary information from these assessments can be used to determine daily intake of foods that are shown to accumulate contaminants of concern such as As and Cd. Therefore, a person's daily dose of As and Cd through ingestion of produce from local gardens neighboring waste can be estimated using the dietary intake measurements from a dietary assessment and environmental monitoring data from 
vegetable analysis. Dietary assessments commonly include 24-hour recall (24HR) and/or dietary record (DR), and frequency food questionnaires (FFQ) administered through a combination of self-reporting and computer-based tools (Shim et al., 2014; Thompson et al., 2010).

\section{2. $\quad$ The Current Literature on Dietary Assessments \\ $2.1 \quad 24-H o u r$ Recall}

The 24HR asks participants to provide a detailed list of foods consumed over a 24hour time period. This survey should be administered unannounced and recorded for multiple nonconsecutive days to limit reactivity (change in diet as a result of having to record) (Thompson, 2015; Walton, 2015). When filled out correctly, the open-ended questions provide a detailed description regarding food and beverage ingredients, serving size, and preparation for that recorded day (Shim et al., 2014). Modification to the 24HR to include brands and preparation is optimal because it includes another level of detail not typically reported in traditional 24HRs. While the self-reporting approach provides little to no burden to the investigator, the subjective survey relies on respondents' ability to recall the details of their meals that are often overlooked (i.e. seasoning) as well as estimate portion size (Walton, 2015; Shim et al., 2014; Thompson, 2010). Therefore, the 24HR should be filled out by participants to the best of their ability within an hour of each meal to limit recall bias (Thompson, 2010; Baxter, 1997).

Integration of dietary assessment methods to better address research aims and improve time and cost effectiveness are becoming more common with the use of webbased programs (Thompson et al., 2010). A recent study using the self-reporting, webbased tool, DietAdvice suggests that participants are more likely to report food intake more accurately with limited face-to-face interviewing (Probst \& Tapsell, 2007). However, removing the role of the interviewer requires the participants to be highly motivated and have high literacy level in order to fill out the recall properly (Thompson \& Subar, 2017).

\subsection{Dietary record}

Like the 24HR, the DR also provides a list of foods and beverages consumed over a specified time period (Thompson \& Subar, 2017). However, DRs are typically structured as a checklist rather than an open-ended survey. 


\subsection{Food Frequency Questionnaire}

The FFQ provides information about usual intake of foods throughout a twelvemonth period (Thompson \& Subar, 2017). The survey asks participants about their intake frequency and usual serving size of specific foods (Shim et al., 2014; Thompson, 2010). One limitation of the FFQ is its susceptibility to recall bias (Shim et al., 2014; Thompson, 2010). A recent dietary assessment done on a cohort of Filipino-Americans reported that a significant amount of participants found it difficult to estimate portion sizes by using conventional cups and ounces, and thought that a picture would have been helpful (Johnson-kozlow et al., 2011). Thus, it is encouraged to provide a food atlas and visuals to better estimate food portions (Walton, 2015).

Advancement in technology has provided survey tools that are user friendly, as well as time and cost-effective for the investigator by allowing FFQs to be administered by computer with skip-logic features. These technologies reduce participant burden and ensure completion of the survey in comparison to paper-administrated FFQs not administered by interview.

\section{Critical Issues in Dietary Assessment Design}

FFQs are commonly derived from previously-completed national surveys such as the National Health and Nutrition Examination Survey (i.e. NHANES II) (CDC, 2016) and Diet History Questionnaires (i.e. DHQ-II) (National Cancer Institute, 2010). However, these national surveys may not adequately represent the average diet of a minority population. Therefore, modification to these FFQs is required to address the specific goals of the particular study, while considering regional, ethnical, cultural, and economical status influences of the study group (Shim et al., 2014; Thompson \& Subar, 2017; Garcia et al., 2000; Baxter, 1997).

Since FFQs are highly prone to recall biases such as under- and over- reporting (Hu et al., 1999), it is necessary to validate whether or not it can be used as a reasonable tool to estimate usual intake for the target population. It is recommended to validate the accuracy of usual intake reported by the FFQ using a less-biased method, such as the 24HR when unbiased methods like measured biomarkers are unattainable (Thompson \& Subar, 2017). Using data from the Eating at America's Table Study (1997-1998), Carroll et al. (2012), 
analyzed the combination of using a $24 \mathrm{HR}$ and FFQs versus the methods used alone. The authors determined that an 24HRs administered for 4-6 non-consecutive days is ideal to assess how well reported intakes in an FFQ match a participant's true usual intake of specific foods (Carroll et al., 2012).

\subsection{Spatial Factors}

Recent studies have characterized interest in locally-grown produce based on factors including proximity, quality, reduced price, health-related exposures, and overall being more aware of environmental consequences. Consumer interest in locally-grown foods varies regionally. A study done in North Carolina with almost $28 \%$ of families having children of under 5 years of age, found that families with children who ate relatively high amounts of fruits and vegetables daily, were more likely to buy their produce from a local vendor (Racine et al., 2013). The authors also reported that families living in rural areas, bought from local vendors more frequently than those residing in suburban regions. However, this can possibly be explained by the distance of local food vendors from their homes. People are more likely to buy locally-grown foods if they are in relatively close proximity (Grebitus et al., 2013). Therefore, providing evidence of the need to evaluate potential dietary exposures from local garden among children in rural at-risk communities.

\subsection{Socio-economic Factors}

Socio-economic barriers have been identified to impact the likelihood of consuming locally grown foods (Racine et al., 2013). The median household income of residents in Nevada County, CA is $\$ 60,610$, which is below the statewide income of $\$ 67,169$ (U.S. Census Bureau, 2017). The "What We Eat in America", which reports that low-income $(\$ 0-25,100)$ children generally ate more fruits and vegetables than children of the same age from higher-income families (USDA, 2018). This trend was also observed in a North Carolina study where low-income families also bought more local produce than those of higher income (Racine et al., 2013).

4. New Assessment Strategy

\subsection{Minority (culturally relevant) foods}


When adapting an FFQ from a commonly used database, it is important to incorporate culturally relevant foods that help better represent the target population. Furthermore, the addition of these foods themselves not only adds a wider variety of options for better representation, it also may affect perceived portion sizes. For example, Asian and Latino populations' perception of a small portion of rice, may be larger than the general population (Thompson \& Subar, 2017). This difference in estimated serving size could have a drastic impact on one's potential risk of exposure to adverse health effects from elevated levels in arsenic (As) in rice (Bhattacharya et al., 2010).

Preliminary information of the target population's usual diets is recommended either by focus groups, dietary record, or 24-hour recall (Johnson-kozlow et al., 2011). This allows the researchers to understand what foods are commonly eaten and how they are prepared within the study group, to better modify the FFQ. Previous FFQs like the one included in the Hispanic Health and Nutrition Examination Survey (CDC, 1984) provide a well-established list of commonly eaten foods in diverse cultures. The HHANES food glossary includes an extensive list of common cultural Mexican-American, Puerto Rican, and Cuban-American foods and their ingredients revised by people from those backgrounds. Commonly eaten garden produce is among this list including: Swiss chard, collard greens, potatoes, carrots, cabbage, and a variety of legumes (CDC, 1984). These foods would, therefore, be important to include in an FFQ to estimate the usual intake of garden produce among a majority Hispanic population of communities neighboring waste.

\subsection{As and Cd Accumulating Foods}

The uptake of As and Cd by vegetables and other foods may present a health hazard for the consumer. Consequently, those that accumulate As and $\mathrm{Cd}$ must also be included in such FFQ to determine the population's exposure through usual dietary intake. A recent study determined that As uptake in plants from contaminated soil decreased in the order: Asteraceae $>$ Brassicaceae $>$ Amaranthaceae $>$ Cucurbitaceae $>$ Liliaceae $>$ Solanaceae $>$ Fabaceae (Ramirez-Andreotta et al., 2013). The results of this study suggest that plants from these families can be characterized by the same As uptake capabilities as those evaluated (Table 1). By including common garden vegetables that have been shown to uptake As and Cd (Table 1) with those incorporated into Hispanic cuisine, an FFQ derived 
from commonly used national surveys can be designed to address the potential exposure to As and $\mathrm{Cd}$ through daily intake of those foods.

Table 1. Garden vegetables shown to uptake As and Cd in edible portions of the plant.

\begin{tabular}{|c|c|c|c|}
\hline & & \multicolumn{2}{|c|}{ Reference } \\
\hline Plant Family & Vegetable & As Accumulating & Cd Accumulating \\
\hline Asteraceae & Lettuce & $\begin{array}{l}\text { Avila et al., (2016); Zhang et al., } \\
\text { (2015); Ramirez-Andreotta et al., } \\
\text { (2013); Smith et al., (2008); Warren } \\
\text { et al., (2003); Bunzl et al., (2001); } \\
\text { Cobb et al., (2000) }\end{array}$ & $\begin{array}{l}\text { Zhang et al., (2015); Gaw et } \\
\text { al., (2008); Cobb et al., (2000) }\end{array}$ \\
\hline \multirow[t]{8}{*}{ Brassicaceae } & Radish & $\begin{array}{l}\text { Ramirez-Andreotta et al., (2013); } \\
\text { Bhattacharya et al., (2010); Gaw et } \\
\text { al., (2008); Smith et al., (2008); } \\
\text { Warren et al., (2003); Cobb et al., } \\
\text { (2000) }\end{array}$ & $\begin{array}{l}\text { Yu et al., (2017); Gaw et al., } \\
\text { (2008); Cobb et al., (2000) }\end{array}$ \\
\hline & Kale & Ramirez-Andreotta et al., (2013) & \\
\hline & Broccoli & $\begin{array}{c}\text { Ramirez-Andreotta et al., (2013); } \\
\text { Warren et al., (2003) }\end{array}$ & \\
\hline & Cabbage & $\begin{array}{c}\text { Avila et al., (2016); Bian et al., } \\
\text { (2015); Zhang et al., (2015); } \\
\text { Ramirez-Andreotta et al., (2013); } \\
\text { Bhattacharya et al., (2010); Li et al., } \\
\text { (2006) }\end{array}$ & $\begin{array}{c}\text { Yu et al., (2017); Bian et al., } \\
\text { (2015); Zhang et al., (2015); } \\
\text { Li et al., (2006) }\end{array}$ \\
\hline & Papaya & $\begin{array}{c}\text { Bhattacharya et al., (2010); Alam et } \\
\text { al., (2003) }\end{array}$ & \\
\hline & Turnip & & Ferri et al., (2015) \\
\hline & Cauliflower & $\begin{array}{l}\text { Bhattacharya et al., (2010); Warren } \\
\text { et al., (2003) }\end{array}$ & \\
\hline & $\begin{array}{l}\text { Mustard } \\
\text { seeds }\end{array}$ & Bhattacharya et al., (2010) & \\
\hline \multirow[t]{2}{*}{ Amaranthaceae } & Spinach & $\begin{array}{c}\text { Bian et al., (2015); Zhang et al., } \\
\text { (2015); Ramirez-Andreotta et al., } \\
\text { (2013); Bhattacharya et al., (2010); } \\
\text { Li et al., (2006); Warren et al., } \\
\text { (2003) }\end{array}$ & $\begin{array}{l}\text { Yu et al., (2017); Ferri et al., } \\
\text { (2015); Zhang et al., (2015); } \\
\text { Li et al., (2006) }\end{array}$ \\
\hline & Swiss chard & $\begin{array}{l}\text { Ramirez-Andreotta et al., (2013); } \\
\text { Smith et al., (2008); Bunzl et al., } \\
\text { (2001) }\end{array}$ & \\
\hline Cucurbitaceae & Pumpkin & Bhattacharya et al., (2010); Li et al., & Li et al., (2006) \\
\hline
\end{tabular}


(2006)

\begin{tabular}{|c|c|c|c|}
\hline & Squash & Alam et al., (2003) & \\
\hline & Cucumber & Zhang et al., (2015); Li et al., (2006) & $\begin{array}{l}\text { Yu et al., (2017); Zhang et al., } \\
\text { (2015); Li et al., (2006) }\end{array}$ \\
\hline \multirow[t]{2}{*}{ Liliaceae } & Garlic & $\begin{array}{c}\text { Bian et al., (2015); Bhattacharya et } \\
\text { al., (2010) }\end{array}$ & Bian et al., (2015) \\
\hline & Onions & $\begin{array}{l}\text { Ramirez-Andreotta et al, (2013); } \\
\text { Bhattacharya et al., (2010) }\end{array}$ & \\
\hline \multirow[t]{3}{*}{ Solanaceae } & Potato & $\begin{array}{l}\text { Avila et al., (2016); Bhattacharya et } \\
\text { al., (2010); Warren et al., (2003); } \\
\text { Alam et al., (2003) }\end{array}$ & Alam et al., (2003) \\
\hline & Tomatoes & $\begin{array}{c}\text { Bhattacharya et al., (2010); Cobb et } \\
\text { al., (2000) }\end{array}$ & Cobb et al., (2000) \\
\hline & Eggplant & Zhang et al., (2015); Li et al., (2006) & $\begin{array}{l}\text { Yu et al., (2017); Zhang et al., } \\
\text { (2015); Li et al., (2006) }\end{array}$ \\
\hline \multirow[t]{2}{*}{ Apiaceae } & Carrot & $\begin{array}{l}\text { Bunzl et al., (2001); Lee et al., } \\
\text { (1999) }\end{array}$ & Lee et al., (1999) \\
\hline & Celery & Bunzl et al., (2001) & Yu et al., (2017) \\
\hline Fabaceae & Bean & $\begin{array}{l}\text { Avila et al., (2016); Zhang et al., } \\
\text { (2015); Ramirez-Andreotta et al., } \\
\text { (2013); Bhattacharya et al., (2010); } \\
\text { Smith et al., (2008); Bunzl et al., } \\
\text { (2001); Cobb et al., (2000) }\end{array}$ & $\begin{array}{l}\text { Yu et al., (2017); Zhang et al., } \\
\text { (2015); Cobb et al., (2000) }\end{array}$ \\
\hline
\end{tabular}




\section{References}

Alam, M., et al. (2003). "Arsenic and Heavy Metal Contamination of Vegetables Grown in Samta Village, Bangladesh." Science of The Total Environment, vol. 308, no. 1-3, pp. 83-96., doi:10.1016/s0048-9697(02)00651-4.

Ávila, P. F., Ferreira da Silva, E., \& Candeias, C. (2016). Health risk assessment through consumption of vegetables rich in heavy metals: the case study of the surrounding villages from Panasqueira mine, Central Portugal. Environmental Geochemistry and Health, 39(3), 565-589. https://doi.org/10.1007/s10653-016-9834-0

Bhattacharya, P., et al. (2010). "Arsenic Contamination in Rice, Wheat, Pulses, and Vegetables: A Study in an Arsenic Affected Area of West Bengal, India." SpringerLink, Springer Netherlands, 9 Mar. 2010, link.springer.com/article/10.1007/s11270-010-03619.

Bian, B., Zhou, L. J., Li, L., Lv, L., \& Fan, Y. M. (2015). Risk assessment of heavy metals in air, water, vegetables, grains, and related soils irrigated with biogas slurry in Taihu Basin, China. Environmental Science and Pollution Research. https://doi.org/10.1007/s11356-015-4292-2

Baxter, S.D., Thompson, W.O., Davis, H.C., Johnson, M.H., (1997). Impact of Gender, Ethnicity, Meal Component, and Time Interval Between Eating and Reporting on Accuracy of Fourth-Graders' Self-Reports of School Lunch. J. Am. Diet. Assoc. 97, 1293-1298. doi:https://doi.org/10.1016/S0002-8223(97)00309-X

Beamer PI, Elish CA, Roe DJ, Loh M, Layton DW. (2012). Differences in Metal Concentration by Particle Size in House Dust and Soil. Journal of environmental monitoring: JEM;14(3):839-844. doi:10.1039/c2em10740f.

Bunzl, K., et al. (2001). "Availability of Arsenic, Copper, Lead, Thallium, and Zinc to Various Vegetables Grown in Slag-Contaminated Soils." Journal of Environment Quality, vol. 30, no. 3, 2001, p. 934., doi:10.2134/jeq2001.303934x.

Carroll, R. J., Midthune, D., Subar, A. F., Shumakovich, M., Freedman, L. S., Thompson, F. E., \& Kipnis, V. (2012). Practice of Epidemiology Taking Advantage of the Strengths of 2 Different Dietary Assessment Instruments to Improve Intake Estimates for Nutritional Epidemiology, 175(4), 340-347. https://doi.org/10.1093/aje/kwr317

Centers for Disease Control and Prevention (CDC) (1984). National Center for Health Statistics (NCHS). Hispanic Health and Nutrition Examination Survey Data. Hyattsville, MD: U.S. Department of Health and Human Services, Centers for Disease Control and Prevention. https://wwwn.cdc.gov/nchs/nhanes/Hhanes/Default.aspx

Centers for Disease Control and Prevention (CDC) (2016). National Center for Health Statistics (NCHS). National Health and Nutrition Examination Survey Data. Hyattsville, MD: U.S. Department of Health and Human Services, Centers for Disease Control and 
Prevention.

https://wwwn.cdc.gov/nchs/nhanes/continuousnhanes/default.aspx?BeginYear=2015

Cobb, G. P., Sands, K., Waters, M., Wixson, B. G., \& Dorward-King, E. (2000). Accumulation of Heavy Metals by Vegetables Grown in Mine Wastes.Environmental Toxicology and Chemistry, 19(3), 600-607.

Csavina, J., Field, J., Taylor, M. P., Gao, S., Landázuri, A., Betterton, E. A., \& Sáez, A. E. (2012). A review on the importance of metals and metalloids in atmospheric dust and aerosol from mining operations. Science of the Total Environment, 58-73. https://doi.org/10.1016/j.scitotenv.2012.06.013

Ferri, R., Hashim, D., Smith, D. R., Guazzetti, S., Donna, F., Ferretti, E., ... Lucchini, R. G. (2015). Metal contamination of home garden soils and cultivated vegetables in the province of Brescia, Italy: Implications for human exposure. Science of the Total Environment, 518-519, 507-517. https://doi.org/10.1016/j.scitotenv.2015.02.072

Garcia, R.A., Taren, D., Teufel, N.I., (2000). Factors associated with the reproducibility of specific food items from the southwest food frequency questionnaire. Ecol. Food Nutr. 38, 549-561. doi:10.1080/03670244.2000.9991596

Gaw, S. K., et al. (2008). "Uptake of $\Sigma$ DDT, Arsenic, Cadmium, Copper, and Lead by Lettuce and Radish Grown in Contaminated Horticultural Soils." Journal of Agricultural and Food Chemistry, vol. 56, no. 15, pp. 6584-6593., doi:10.1021/jf073327t.

Grebitus, C., Lusk, J. L., \& Nayga, R. M. (2013). Effect of distance of transportation on willingness to pay for food. Ecological Economics, 88, 67-75.

https://doi.org/10.1016/j.ecolecon.2013.01.006

Hu, F.B., Rimm, E., Smith-Warner, S.A., Feskanich, D., Stampfer, M.J., Ascherio, A., Sampson, L., Willett, W.C. (1999). Reproducibility and validity of dietary patterns assessed with a food-frequency questionnaire. Am. J. Clin. Nutr. 69, 243-9.

Huang YH, Bornschein RL, Grote J, Menrath W, Roda S. (1997) Environmental arsenic exposure of children around a former copper smelter site. Environ. Res.; 72: 72-81.

Johnson-kozlow, M., Matt, G.E., Rock, C.L., Rosa, R. De, Conway, T.L., Romero, R.A., (2011). Assessment of Dietary Intakes of Filipino-Americans: Implications for Food Frequency Questionnaire Design. J. Nutr. Educ. Behav. 43, 505-510.

doi:10.1016/j.jneb.2010.09.001

Landrigan, B. P. J., \& Goldman, L. R. (2011). Children's Vulnerability To Toxic Chemicals: A Challenge And Opportunity To Strengthen Health And Environmental Policy, 5(5), 842-850. 
Li, Yu, et al. (2006). "Risk Assessment of Heavy Metals in Soils and Vegetables around Non-Ferrous Metals Mining and Smelting Sites, Baiyin, China." Journal of Environmental Sciences, vol. 18, no. 6, pp. 1124-1134., doi:10.1016/s10010742(06)60050-8.

National Cancer Institute. (2010). National Institute of Health, Epidemiology and Genomics Research Program. Diet History Questionnaire, Version 2.0.

Probst, Y., Tapsell, L., (2007). Over- and underreporting of energy intake by patients with metabolic syndrome using an automated dietary assessment website. Nutr. Diet. 64, 280-284. doi:10.1111/j.1747-0080.2007.00220.x.

Racine, E. F., Mumford, E. A., Laditka, S. B., \& Lowe, A. E. (2013). Understanding Characteristics of Families Who Buy Local Produce. Journal of Nutrition Education and Behavior, 45(1), 30-38. https://doi.org/10.1016/j.jneb.2012.04.011 Thompson, Frances E., \& Subar, Amy F. (2001). Dietary Assessment Methodology Chapter 1. In Nutrition in the Prevention and Treatment of Disease (pp. 3-30).

Ramirez-Andreotta, M. D., Brusseau, M. L., Artiola, J. F., \& Maier, R. M. (2013). A greenhouse and field-based study to determine the accumulation of arsenic in common homegrown vegetables grown in mining-affected soils. Science of the Total Environment, 443, 299-306. https://doi.org/10.1016/j.scitotenv.2012.10.095

Shim, J.-S., Oh, K., Kim, H.C., (2014). Dietary assessment methods in epidemiologic studies. Epidemiol. Health e2014009. doi:10.4178/epih/e2014009

Smith, E., Juhasz, A. L., \& Weber, J. (2009). Arsenic uptake and speciation in vegetables grown under greenhouse conditions. Environmental Geochemistry and Health. https://doi.org/10.1007/s10653-008-9242-1

Thompson, F. E., Dixit-Joshi, S., Potischman, N., Dodd, K. W., Kirkpatrick, S. I., Kushi, L. H., ... Subar, A. F. (2015). Comparison of Interviewer-Administered and Automated Self-Administered 24-Hour Dietary Recalls in 3 Diverse Integrated Health Systems. American Journal of Epidemiology, 181(12), 970-978. https://doi.org/10.1093/aje/kwu467

Thompson, F. E., \& Subar, A. F. (2017). Dietary Assessment Methodology Chapter 1. In Nutrition in the Prevention and Treatment of Disease (pp. 3-30).

Thompson, F.E., Subar, A.F., Loria, C.M., Reedy, J.L., Baranowski, T., (2010). Need for Technological Innovation in Dietary Assessment. J. Am. Diet. Assoc. 110, 48-51. doi:10.1016/j.jada.2009.10.008

Turner, L., Eliason, M., Sandoval, A., \& Chaloupka, F. J. (2016). Increasing Prevalence of US Elementary School Gardens, but Disparities Reduce. Journal of School Health, 86(12), 906-912. 
U.S. Census Bureau. (2017). U.S. Census Bureau QuickFacts: Nevada County, California; California. Retrieved April 11, 2019, from

https://www.census.gov/quickfacts/fact/table/nevadacountycalifornia,ca/PST045218.

U.S. Department of Agriculture (USDA) (2018). What We Eat in America. NHANES 2015-2016, individuals 2 years and over (excluding breast-fed children), day 1 dietary intake data, weighted. Food Patterns Equivalents Database (FPED) 2015-2016. Available at: www.ars.usda.gov/nea/bhnrc/fsrg.

U.S. EPA. (2006). Integrated Risk Information System (IRIS). Office of Research and Development, National Center for Environmental Assessment. Washington, DC. http://www.epa.gov/iris/.

Walton, J., (2015). Dietary Assessment Methodology for Nutritional Assessment. Top. Clin. Nutr. 30, 33-46. doi:10.1097/TIN.0000000000000018

Warren, G. P., Alloway, B. J., Lepp, N. W., Singh, B., Bochereau, F. J. M., \& Penny, C. (2003). Field trials to assess the uptake of arsenic by vegetables from contaminated soils and soil remediation with iron oxides. Science of the Total Environment, 311(1-3), 1933. https://doi.org/10.1016/S0048-9697(03)00096-2

Yu, G., Zheng, W., Wang, W., Dai, F., Zhang, Z., Yuan, Y., \& Wang, Q. (2017). Health risk assessment of Chinese consumers to Cadmium via dietary intake. Journal of Trace Elements in Medicine and Biology. https://doi.org/10.1016/j.jtemb.2017.07.003

Zhang, C., Wang, Y., Zhang, Z., Wang, D., Luo, C., Xu, F. (2015). Health Risk Assessment of Heavy Metals and As in Vegetable and Soil System in Chongqing, Southwest of China. Journal of Residuals Science and Technology, 12(4), 231-240. 


\section{PRESENT STUDY}

\section{Introduction}

Communities throughout Nevada County, CA are impacted with heavy metal(loid) contamination from the historic Gold Rush in the mid 1800's. These heavy metal(loid)s can pose a human health risk if exposed through environmental media during gardening or other outdoor activity. The present study aims to assess a child's potential exposure and risk by using site-specific information to better inform future assessments in communities neighboring active and legacy resource extraction sites.

\section{Research Objectives}

The purpose of the present study is to assess a child's potential exposure to arsenic (As), cadmium $(\mathrm{Cd})$, and lead $(\mathrm{Pb})$ through ingestion of incidental soil, garden plants, irrigation water, and dust inhalation. This study also aims to improve human health exposure and risk assessments by providing a framework of tools and analyses to employ site specific information to reduce assumptions and uncertainties. The main objectives of this study were the following:

1. Implement a co-created citizen science environmental monitoring program to measure metal(loid) concentrations in irrigation water, soil, garden plants, and dust at preschools throughout Nevada County, CA

2. Design a novel dietary assessment including As and $\mathrm{Cd}$ accumulating foods to understand the consumption patterns of children at these preschools

3. Assess a child's multi-route exposure to metal(loid)s

4. Characterize a child's potential risk to adverse health effects by exposure to metal(loid)s at preschools

\section{Conclusion and Research Implications}

It was found that preschool-grown cilantro, lettuce, kale, and carrot were major contributors to the cumulative exposure of $\mathrm{As}, \mathrm{Cd}$, and/or $\mathrm{Pb}$ for children. We determined that child 2 to 3 years of age would have had an IELCR of one in a million from As exposure through the consumption of lettuce grown at the preschools. Further, it was found that children would have been at risk of adverse non-cancerous health effects of $\mathrm{Cd}$ from a cumulative exposure from ingestion of preschool-grown plants, incidental soil and irrigation water, and dust inhalation over the course of a year. The results of this study also identify metal(loid) accumulating and hyperaccumulating 
plants to avoid growing in untested contaminated gardens. Most importantly, this study provided the necessary framework to improve future exposure and risk assessments. 


\title{
APPENDIX A
}

\section{A Dietary Assessment Tool to Estimate Arsenic and Cadmium Exposures from Locally-Grown Foods}

\author{
Iliana Manjón¹, Mónica Ramírez-Andreotta ${ }^{1,2 *}$ \\ ${ }^{1}$ Department of Soil, Water and Environmental Science, University of Arizona \\ ${ }^{2} \mathrm{Mel}$ and Enid Zuckerman College of Public Health's Division of Community, \\ Environment \& Policy, University of Arizona
}

Prepared for:

International Journal of Hygiene and Environmental Health

*Corresponding Author: mdramire@email.arizona.edu University of Arizona

1177 E Fourth Street, Rm. 429, Tucson, AZ 85721

Phone: 520-621-0091; Fax: 520-621-1647 


\begin{abstract}
Dietary assessments are commonly used to monitor and record a person's usual dietary intake. These assessments can provide crucial information regarding potential exposures to contaminants of concern like arsenic and cadmium through ingestion of foods shown to accumulate these metal(loid)s. Traditional dietary assessments include a food frequency questionnaire (FFQ), 24-hour recall (24HR), and/or dietary record (DR) administered through interviews and self-reporting and internet-based tools. Current FFQs are designed from national surveys that may not adequately represent the average diet of a particular target population. Therefore, modification to these FFQs is required to consider spatial, demographic, and socioeconomic influences of target study groups. The present study employed a novel dietary assessment designed to estimate a child's potential exposure to arsenic (As) and cadmium (Cd) through consumption of locally-grown foods in legacy mining communities throughout Nevada County, California. Mean ingestion rates for As and $\mathrm{Cd}$ accumulating foods: cilantro, carrot, cabbage, kale, and lettuce were calculated for children 1 to $<2$ years, 2 to $<3$ years, and 3 to $<6$ of age. These ingestion rates were used to conduct a child- and site-specific comprehensive exposure and risk assessment to heavy metal(loid)s.
\end{abstract}

\title{
1. Introduction
}

In order to conduct a thorough exposure assessment of heavy metal(loid)s, it is critical to obtain site- and population-specific data to inform the exposure assessment model. In addition to environmental monitoring, dietary assessments are widely used to monitor and record dietary intakes for epidemiological studies. These assessments commonly include a food frequency questionnaire (FFQ), 24-hour recall (24HR), and/or dietary record (DR) administered through a combination of self-reporting and computerbased tools (Shim et al., 2014; Thompson et al., 2010). These assessments are valuable but are commonly critiqued for the lack of specificity of foods relevant to a study's particular population.

To evaluate a child's consumption patterns of locally-grown foods, a dietary assessment must consider the relevant factors that have been previously identified as influencing the consumption of these foods. These include proximity to a local farmer's 
market, income level, sociodemographic factors, and whether a person or family resides in an urban or rural community (Freedman at al., 2016; Feldman et al., 2015; Grebitus et al., 2013; Racine et al., 2013). General patterns have also been observed among rural communities: overall, families with children are more likely to buy fruits and vegetables locally (Racine et al., 2013) and community gardens increase consumption of fruits and vegetables (McCormack et al., 2010).

It is well documented that the soil, air, and water quality of communities can be impacted by contamination from neighboring active and legacy mining sites (RamirezAndreotta et al., 2013a \& 2013b; Csavina at al., 2012 \& 2011). Certain garden plants have been shown to accumulate or hyperaccumulate heavy metal(loid)s associated with mining operations such as arsenic (As) and cadmium $(\mathrm{Cd})$. Therefore, if foods are grown near mining waste sites, members of these rural communities may be at increased risk to exposures to these heavy metal(loid)s through their diet. In addition to garden produce, several other food commodities have also been shown to accumulate As and/or Cd including rice, wheat products, fish, meat, and fruit juices. Previous studies have determined that rice had largest contribution to one's intake of As in Taihu, China (Bian et al., 2015), while others describe rice as a major source of $\mathrm{Cd}$ intake as well (Yu et al., 2017; Chunhabundit, 2016). The historical use of lead arsenate and arsenite-based pesticides in apple orchards has left behind As and lead $(\mathrm{Pb})$ contamination in orchard soil (Cai et al., 2016, Newton et al., 2006). As a result, As concentrations have been measured in apple juices made from apples that may have been grown in impacted orchards, which has led the U.S. Food and Drug Administration to establish an action level of $10 \mu \mathrm{g} / \mathrm{kg}$ for As (Chen et al., 2014).

An understanding of the target populations demographic and cultural influences can greatly improve a study's evaluation of dietary patterns. For example, the Hispanic Health and Nutrition Examination Survey (HHANES) provides a well-established list of commonly eaten foods in Hispanic and Latin cultures (CDC, 1984). The HHANES food glossary includes an extensive list of common cultural Mexican-American, Puerto Rican, and Cuban-American foods and their ingredients revised by people from those backgrounds. Commonly eaten garden produce is among this list including: swiss chard, collard greens, potatoes, carrots, cabbage, and a variety of legumes (CDC, 1984). These 
foods would, therefore, be important to include in an FFQ to estimate the usual intake of garden produce among a majority Hispanic population of communities neighboring waste. Furthermore, serving size estimations may also be influenced by demographic and cultural influences. As an example, Asian and Latino populations' perception of a small portion of rice, may be larger than the general population (Thompson \& Subar, 2017). This difference in estimated serving size could have a drastic impact on one's potential risk to adverse health effects associated with an increased consumption of rice that has been shown to accumulate elevated levels in As (Bhattacharya et al., 2010).

These considerations guided the selection of foods included in the current study's dietary assessment to prevent underestimating a child's usual intake of garden produce. Dietary assessments can, therefore, play a crucial role in evaluating a minority child's potential exposure to contaminants through consumption of foods grown in community school gardens in legacy mining towns similar to Nevada County, CA.

\section{Materials and methods}

\subsection{Gardening behavior assessment}

A gardening questionnaire was created to characterize the preschool's environment and gardening practices using the online Qualtrics software (Qualtrics, Provo, UT, 2018). The survey was administered to the preschool's administrators and included questions regarding the garden and preschool site, gardening activities, and preschool children behavior. All respondents who completed the questionnaire and dietary assessment for the present study were consented under the University of California, San Francisco (UCSF) Institutional Review Board (IRB) rule as an approved project.

\subsection{Dietary assessment}

A dietary assessment was designed to determine child daily intake rates of various foods and evaluate consumption patterns of locally grown foods. For this study, the dietary assessment was comprised of a 24-hour recall (24HR) and a food frequency questionnaire (FFQ) to collect dietary information. Ten parents from 3 of the 4 preschools $(n=1$ for $\mathrm{S} 1$; $\mathrm{n}=5$ for S2; $\mathrm{n}=4$ for S3) were interviewed from October-December 2018. Of the 10 participants across 3 out of the 4 schools, only 4 completed and returned their $24 \mathrm{HR}$. 


\subsubsection{Food frequency questionnaire design}

A modified FFQs was designed based on national surveys National Health and Nutrition Examination Survey (NHANES) (CDC, 2016) and Diet History Questionnaires (DHQ-II) (National Cancer Institute, 2010). Since these national surveys do not adequately represent the average diet of a child in Nevada County, CA, a modified FFQ was designed to integrate the rurality, demographic and socio-economic status influences of the preschool families (Shim et al., 2014; Thompson \& Subar, 2017; Garcia et al., 2000; Baxter, 1997). Furthermore, this novel FFQ accounted for the potential exposure to As and $\mathrm{Cd}$ by including common garden vegetables that have been shown to uptake $\mathrm{As}$ and $\mathrm{Cd}$ (Table 1).

Table 1. Garden produce shown to uptake As and Cd in the edible portions of the plant.

\begin{tabular}{|c|c|c|c|}
\hline & & \multicolumn{2}{|c|}{ Reference } \\
\hline Plant Family & Vegetable & As Accumulating & Cd Accumulating \\
\hline Asteraceae & Lettuce & $\begin{array}{l}\text { Avila et al., (2016); Zhang et al., } \\
\text { (2015); Ramirez-Andreotta et al., } \\
\text { (2013a); Smith et al., (2008); Warren } \\
\text { et al., (2003); Bunzl et al., (2001); } \\
\text { Cobb et al., (2000) }\end{array}$ & $\begin{array}{l}\text { Zhang et al., (2015); Gaw et } \\
\text { al., (2008); Cobb et al., (2000) }\end{array}$ \\
\hline \multirow[t]{7}{*}{ Brassicaceae } & Radish & $\begin{array}{l}\text { Ramirez-Andreotta et al., (2013a); } \\
\text { Bhattacharya et al., (2010); Gaw et } \\
\text { al., (2008); Smith et al., (2008); } \\
\text { Warren et al., (2003); Cobb et al., } \\
\text { (2000) }\end{array}$ & $\begin{array}{l}\text { Yu et al., (2017); Gaw et al., } \\
\text { (2008); Cobb et al., (2000) }\end{array}$ \\
\hline & Kale & Ramirez-Andreotta et al., (2013a) & \\
\hline & Broccoli & $\begin{array}{l}\text { Ramirez-Andreotta et al., (2013a); } \\
\text { Warren et al., (2003) }\end{array}$ & \\
\hline & Cabbage & $\begin{array}{l}\text { Avila et al., (2016); Bian et al., } \\
\text { (2015); Zhang et al., (2015); } \\
\text { Ramirez-Andreotta et al., (2013a); } \\
\text { Bhattacharya et al., (2010); Li et al., } \\
\text { (2006) }\end{array}$ & $\begin{array}{l}\text { Yu et al., (2017); Bian et al., } \\
\text { (2015); Zhang et al., (2015); } \\
\text { Li et al., (2006) }\end{array}$ \\
\hline & Papaya & $\begin{array}{l}\text { Bhattacharya et al., (2010); Alam et } \\
\text { al., (2003) }\end{array}$ & \\
\hline & Turnip & & Ferri et al., (2015) \\
\hline & Cauliflower & Bhattacharya et al., (2010); Warren & \\
\hline
\end{tabular}




\begin{tabular}{|c|c|c|c|}
\hline & \multicolumn{2}{|r|}{ et al., (2003) } & \\
\hline & $\begin{array}{l}\text { Mustard } \\
\text { seeds }\end{array}$ & Bhattacharya et al., (2010) & \\
\hline \multirow[t]{2}{*}{ Amaranthaceae } & Spinach & $\begin{array}{l}\text { Bian et al., (2015); Zhang et al., } \\
\text { (2015); Ramirez-Andreotta et al., } \\
\text { (2013a); Bhattacharya et al., (2010); } \\
\text { Li et al., (2006); Warren et al., } \\
\text { (2003) }\end{array}$ & $\begin{array}{l}\text { Yu et al., (2017); Ferri et al., } \\
\text { (2015); Zhang et al., (2015); } \\
\text { Li et al., (2006) }\end{array}$ \\
\hline & Swiss chard & $\begin{array}{l}\text { Ramirez-Andreotta et al., (2013a); } \\
\text { Smith et al., (2008); Bunzl et al., } \\
\text { (2001) }\end{array}$ & \\
\hline \multirow[t]{3}{*}{ Cucurbitaceae } & Pumpkin & $\begin{array}{l}\text { Bhattacharya et al., (2010); Li et al., } \\
\text { (2006) }\end{array}$ & Li et al., (2006) \\
\hline & Squash & Alam et al., (2003) & \\
\hline & Cucumber & Zhang et al., (2015); Li et al., (2006) & $\begin{array}{l}\text { Yu et al., (2017); Zhang et al., } \\
\text { (2015); Li et al., (2006) }\end{array}$ \\
\hline \multirow[t]{2}{*}{ Liliaceae } & Garlic & $\begin{array}{l}\text { Bian et al., (2015); Bhattacharya et } \\
\text { al., (2010) }\end{array}$ & Bian et al., (2015) \\
\hline & Onions & $\begin{array}{l}\text { Ramirez-Andreotta et al, (2013); } \\
\text { Bhattacharya et al., (2010) }\end{array}$ & \\
\hline \multirow[t]{3}{*}{ Solanaceae } & Potato & $\begin{array}{l}\text { Avila et al., (2016); Bhattacharya et } \\
\text { al., (2010); Warren et al., (2003); } \\
\text { Alam et al., (2003) }\end{array}$ & Alam et al., (2003) \\
\hline & Tomatoes & $\begin{array}{l}\text { Bhattacharya et al., (2010); Cobb et } \\
\text { al., (2000) }\end{array}$ & Cobb et al., (2000) \\
\hline & Eggplant & Zhang et al., (2015); Li et al., (2006) & $\begin{array}{l}\text { Yu et al., (2017); Zhang et al., } \\
\text { (2015); Li et al., (2006) }\end{array}$ \\
\hline \multirow[t]{2}{*}{ Apiaceae } & Carrot & $\begin{array}{l}\text { Bunzl et al., (2001); Lee et al., } \\
\text { (1999) }\end{array}$ & Lee et al., (1999) \\
\hline & Celery & Bunzl et al., (2001) & Yu et al., (2017) \\
\hline Fabaceae & Bean & $\begin{array}{l}\text { Avila et al., (2016); Zhang et al., } \\
\text { (2015); Ramirez-Andreotta et al., } \\
\text { (2013a); Bhattacharya et al., (2010); } \\
\text { Smith et al., (2008); Bunzl et al., } \\
\text { (2001); Cobb et al., (2000) }\end{array}$ & $\begin{array}{l}\text { Yu et al., (2017); Zhang et al., } \\
\text { (2015); Cobb et al., (2000) }\end{array}$ \\
\hline
\end{tabular}

A research group was trained to administer the FFQ by face-to-face and phone interviews in English and Spanish. Food images and physical serving size props were used during face-to-face interviews for participants to better estimate food portions. Descriptive 
icons and/or an "object size comparison" was used for the question, "What was your child's usual serving size of [food]?" to reduce this possible recall bias for phone and selfadministered interviews. An example of the schematic of the flow of FFQ questions for this study is depicted in Figure 1.

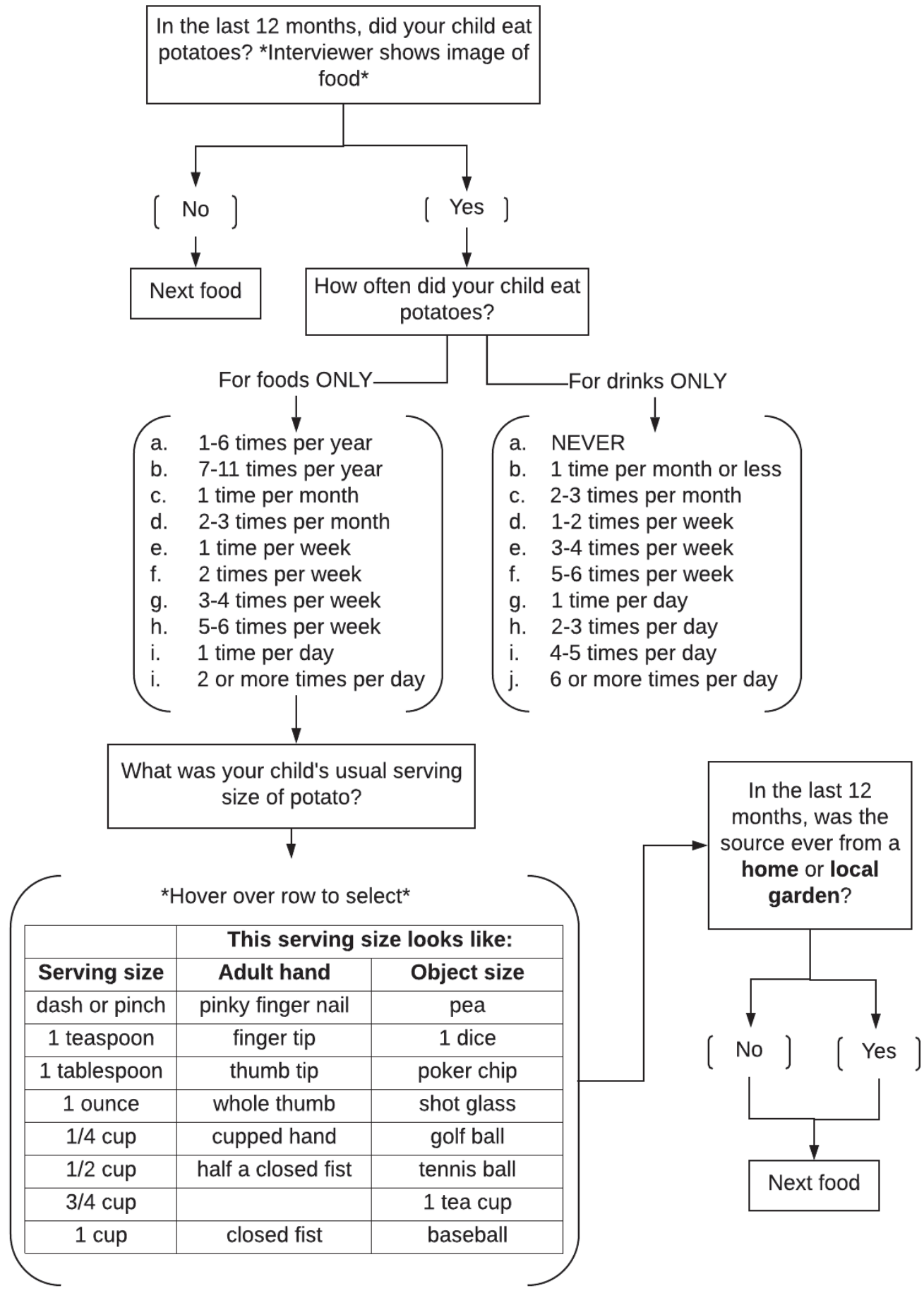

Figure 1. Flowchart of FFQ questions regarding potato intake. 
The FFQ was also designed and administered using Qualtrics software (Qualtrics, Provo, UT, 2018). Skip-logic features were used to reduce participant burden and fatigue and reduce the time that participants would need to complete the survey by omitting nonapplicable questions. Further, it reduced user error by preventing users from accidently answering those non-applicable questions. The force-response feature on the survey ensured completion of the survey in comparison to paper-administrated FFQs not administered by interview.

Recent studies have characterized interest in locally-grown produce based on factors including proximity, quality of product, price, health-related exposures, and overall being more aware of environmental consequences (Ramirez-Andreotta et al., 2019; Freedman et al., 2016; Brown, 2003). Thus, as part of the FFQ, participants were asked to select any and all applicable factors that they believe drive their motivation for buying or not buying locally (Freedman et al. 2016) (Appendix E).

\subsubsection{4-hour recall design}

The 24-hour Recall (24HR) asks participants to provide a detailed list of foods consumed over a 24-hour time period. The 24HRs were completed by the parents at home. Participants recorded their child's food and beverage intake for three nonconsecutive days to limit reactivity (change in diet as a result of having to record) (Thompson et al., 2015; Walton, 2015). When filled out correctly, the open-ended questions provide a detailed description regarding food and beverage ingredients, serving size, and preparation for that recorded day (Shim et al., 2014). Thus, modifications were made for this study in order to obtain more detail than typically reported in traditional 24HRs. Participants were asked to report the following details about their child's consumed foods and beverages (Appendix F):

- Meal/snack time

- Food/beverage ingredient

- Food type/brand

- $\quad$ Serving size (or dimension)

- Mode of preparation

- Food source 
While the self-reporting approach provides little to no burden to the investigator, the subjective survey relied on the respondents' ability to recall the details of their meals that are often overlooked (i.e. seasoning) as well as estimate portion size (Walton, 2015; Shim et al., 2014; Thompson, 2010). Therefore, participants were instructed to fill out the 24HR to the best of their ability within an hour of each of their child's meal to limit recall bias (Thompson, 2010; Baxter, 1997).

\subsection{Ingestion rate calculation}

A child's ingestion rate (IR) can vary by age. For ingestion of food, the ingestion rate is the amount (mass) of the food consumed averaged over a single day expressed by $I R\left(\mathrm{mg} \mathrm{d}^{-1}\right)=$ mass $_{\text {food }} /$ day. Average ingestion rates for plants grown at the preschools were calculated using the consumption frequency and usual serving size data reported from the dietary assessment (described in Appendix E). For comparison, the U.S. EPA Exposure Handbook estimations for foods including carrots, cabbage, romaine lettuce and kale were used (U.S. EPA. 2011).

\section{Results}

The dietary assessment was administered to 10 participants whom completed the FFQ $(n=10)$. Only 4 participants returned the $24 \mathrm{HR}$, however, each of the 4 was completed incorrectly. Thus, we were unable to validate each participant's responses in the FFQ.

Table 2. Median percentage of child's yearly consumption of food groups from different sources as reported by participants $(n=10)$.

\begin{tabular}{cccc} 
& Fruits and vegetables & $\begin{array}{c}\text { Corn, grains, oats, } \\
\text { and rice }\end{array}$ & $\begin{array}{c}\text { Meat (fish, poultry, } \\
\text { beef, pork, etc.) }\end{array}$ \\
\hline $\begin{array}{c}\text { Home-grown } \\
\text { Locally-grown/ }\end{array}$ & $1.5 \%(0-50 \%)$ & $0 \%(0-20 \%)$ & $0 \%(0-25 \%)$ \\
farmer's market & $37.5 \%(0-50 \%)$ & $0 \%(0-50 \%)$ & $0 \%(0-50 \%)$ \\
Store (organically grown) & $5 \%(0-50 \%)$ & $2.5 \%(0-100 \%)$ & $0 \%(0-100 \%)$ \\
Store (conventionally grown) & $47.5 \%(0-100 \%)$ & $77.5 \%(0-100 \%)$ & $65 \%(0-100 \%)$ \\
\hline
\end{tabular}

In the FFQ, participants reported the percentage of each child's yearly consumption of various food groups and source: home-grown, locally sourced, or store-bought (organically or conventionally-grown) (Table 2). The median percentage of a child's yearly consumption was greatest for store-bought (conventionally-grown) (47.5\%) and locally- 
grown $(37.5 \%)$ fruits and vegetables. Only $1.5 \%$ of a child's yearly consumption of fruits and vegetables originated from a home garden. For meats (fish, poultry, beef, pork, etc.) and corn, grains, oats, and rice, the median yearly consumption was comprised of $65 \%$ and $77.5 \%$, respectively from a store (conveniently-grown).

A

What is your motivation for buying locally?

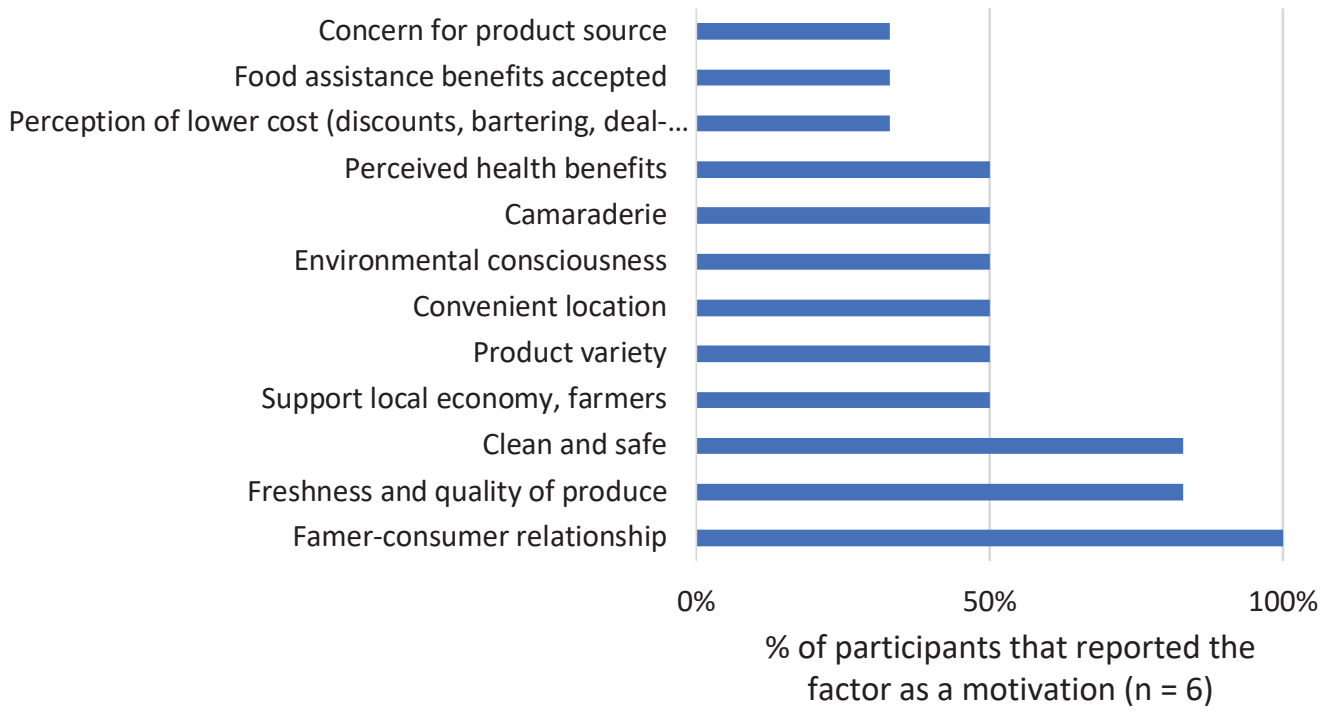

$\mathrm{B}$

What is your motivation for NOT buying locally?

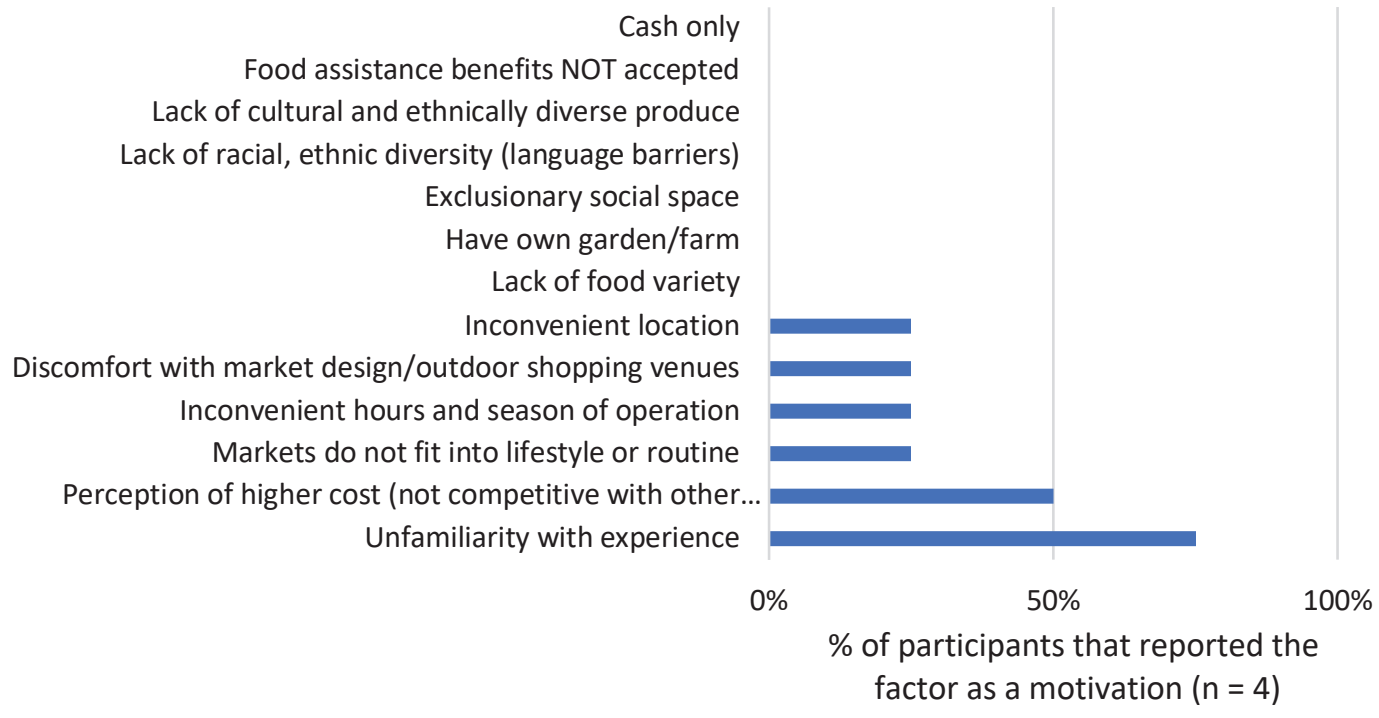

Figure 2. Reported motivations for buying locally (A) or not buying locally (B) and the percentage of participants that reported that motivation. 
Participants were asked to select any and all applicable motivations for buying or not buying foods locally. Of those that indicated that they prefer to buy foods from local sources, $100 \%$ of respondents reported their farmer-consumer relationship and $50 \%$ reported "environmental consciousness" as a motivation (Figure 2). All other motivations for buying locally were reported by at least two participants (Figure 2). "Unfamiliarity with experience" was the most reported motivation for not buying locally among the four participants whom do not prefer to buy foods from local sources. No participant reported that having his/her own garden or farm as a motivation to not buy locally.

Table 3. Age-specific ingestion rate per plant type.

\begin{tabular}{ccc}
\hline Plant (Family) & Exposure Age Group & Mean ingestion rate $\left(\mathrm{mg} \mathrm{d}^{-1}\right)$ \\
\hline \multirow{2}{*}{ Carrot (Apiaceae) } & 1 to $<2$ yrs & 3372 \\
& 2 to $<3$ yrs & 15389 \\
& 3 to $<6$ yrs & 2265 \\
\hline \multirow{3}{*}{ Cabbage (Brassicaceae) } & 1 to $<2$ yrs & 606.5 \\
& 2 to $<3$ yrs & 339.9 \\
& 3 to $<6$ yrs & 267.7 \\
Kale (Brassicaceae) & 1 to $<2$ yrs & 336.0 \\
& 2 to $<3$ yrs & 167.8 \\
\hline \multirow{2}{*}{ Lettuce (Asteraceae) } & 3 to $<6$ yrs & 0 \\
\hline \multirow{2}{*}{ Cilantro (Apiaceae) } & 1 to $<2$ yrs & 946.8 \\
& 2 to $<3$ yrs & 6960 \\
& 3 to $<6$ yrs & 77.72 \\
\hline
\end{tabular}

Ingestion rates of Brassicaceae, Astereraceae (lettuce), and Apiaceae (root vegetables) ranged from 0 to $606.5 \mathrm{mg} \mathrm{d}^{-1}, 77.72$ to $6969 \mathrm{mg} \mathrm{d}^{-1}$, and 2.597 to $15389 \mathrm{mg}$ $\mathrm{d}^{-1}$, respectively (Table 3 ). The oldest age group had the lowest ingestion rates for each garden plant. 


\section{Discussion}

Participant data reported in the dietary assessment was used to determine ageadjusted child ingestion rates. The ingestion rates for the preschool plants were below those reported for leafy (lettuce) (42.4 $\left.\mathrm{g} \mathrm{d}^{-1}\right)$, and root vegetables $\left(20.5 \mathrm{~g} \mathrm{~d}^{-1}\right)$ by Liu et al. (2010). Only the mean consumption of Brassicaceae $\left(0.4 \mathrm{~g} \mathrm{~d}^{-1}\right)$ plants including cabbage was within the range of ingestion rates calculated in this study (Liu et al. 2010). Similarly, the EPA Exposure Factors Handbook (U.S. EPA, 2011) provides a summary of recommended intake rates (normalized by body weight) based on rates reported in scientific literature and national surveys such as NHANES (U.S. EPA, 2018). The ingestion rates calculated from this study were modified to make a direct comparison to those reported in the EPA Exposure Handbook for various child age groups. In general, the mean intake $\left(\mathrm{g} \mathrm{kg}^{-\mathrm{d}^{-1}}\right)$ of carrots, cabbage, lettuce, kale, and cilantro for children 1-6 years of age were lower than the national average determined by NHANES (U.S. EPA, 2018). Thus, if ingestion rates for the average daily dose (ADD) determination were extrapolated from these values instead of calculated based on the dietary assessment data, the ADD estimations from garden plants would have been overestimated. However, it is important to consider the limitations of the ingestion rate estimations for this study. One limitation was the small sample size for dietary assessment responses. Another is the lack of correctly completed 24HRs, which would have served to validate each participant's responses on the FFQ.

Each preschool reported growing leafy vegetables regularly along with a variation of other garden produce such as fruiting plants, herbs, and/or roots. Site administers reported using less than $25 \%$ of their garden produce for school meals as often as once per day to 1-6 times per year. Further, each site reported that aside from students; families, teachers, and staff also consume the preschool-grown produce. Thus, future studies should include an assessment for adult exposure, as well as a wider range of produce including those regularly grown at the preschool and those shown to accumulate $\mathrm{Pb}$.

\subsection{Motivation for buying locally}

Results from the dietary assessment indicate that $60 \%$ of the parents prefer buying their food from local sources. A study done in North Carolina observed that families with children under the age of five who ate relatively high amounts of fruits and vegetables a day, were more likely to buy their produce from a local vendor (Racine et al., 2013). 
However, the authors also reported that families living in rural areas, bought from local vendors more frequently than those residing in suburban regions. In this study, $50 \%$ of the parents reported "convenient location" as a motivation for buying locally, while only $25 \%$ of those that did not prefer buying locally reported "inconvenient location" as a motivating factor. Thus, this study supports the finding by Grebitus et al. (2013) that families are more likely to buy locally-grown foods if they are in relatively close proximity. These findings also provide evidence of the need to evaluate potential dietary exposures from local garden among children of other rural at-risk communities.

All participants reported that the farmer-consumer relationship was a motivation for buying locally-grown foods. Additionally, 50\% report camaraderie and support of local economy and farmers as another motivation. Similarly, a previous study analyzing the extrinsic and intrinsic motivation for community gardening also found that building relationships among other gardeners and the community was a prominent motivation (Ramirez-Andreotta et al. 2019).

\subsection{Socio-economic factors' impact on fruits and vegetable consumption}

Socio-economic barriers have been identified to impact the likelihood of consuming locally grown foods (Racine et al., 2013). The median household income of participants in this study was $\$ 31,035$, almost half of the median household income of residents in Nevada County, CA $(\$ 60,610)$ and statewide $(\$ 67,169)$ (U.S. Census Bureau, 2017). In this study, children from low-income $(\$ 0-25,100)$ families $(n=3)$ generally consumed less carrot, cabbage, kale, lettuce, and cilantro than others of the same age groups from higher-income families. This is contrary to national trends reported by the "What We Eat in America", which reports that low-income children ate more fruits and vegetables than children of the same age from higher-income families (USDA, 2018). Furthermore, in a North Caroline study, low-income families also bought more local produce than those of higher income (Racine et al., 2013). This discrepancy may be due to the present study's special confinement to rural communities in which the perception of higher costs was more frequently reported than a spatially-related motivation (inconvenient location) for not buying locally (Figure 2). 


\subsection{Limitations}

The dietary assessment in the present study was subject to limitations. The small sample size ( $\mathrm{n}=10$ parents) may result in ingestion rates not accurately representing children of the area. Since FFQs are highly prone to recall biases such as under- and over reporting (Hu et al., 1999), a 24HR was administered to the participants to validate the accuracy of the usual intake reported in the FFQ. 24HRs provide a less-biased validation alternative when unbiased methods like measured biomarkers are unattainable (Thompson $\&$ Subar, 2017). However, due to the low response rate, the $24 \mathrm{HR}$ were not used and the FFQ was not validated.

Intrinsic motivation was a limiting factor in receiving completed 24HRs. Each participant that completed an FFQ was given a 24HR to complete on behalf of their child at home. Only $40 \%$ of participants returned their $24 \mathrm{HR}$, and all were incomplete suggesting respondent fatigue (Thompson \& Subar, 2017). However, of the participants whom completed the FFQ with an interviewer, $70 \%$ stated that the FFQ was extremely easy to complete and are likely to participate in future dietary assessments. Efforts to improve to dietary assessment via web-based programs are becoming more common and can reduce time commitments as well as administrative costs (Thompson et al., 2010). A recent study using the self-reporting, web-based tool, DietAdvice suggests that participants are more likely to report food intake more accurately with limited face-to-face interviewing (Probst $\&$ Tapsell, 2007). However, removing the role of the interviewer requires the participants to be highly motivated and have high literacy level in order to fill out the recall properly (Thompson \& Subar, 2017). Future considerations for dietary assessments include gathering preliminary information of the target population's usual diets and preferred administration methods using focus groups as recommended by Johnson-kozlow et al. (2011). This will allow the researchers to understand what foods are commonly eaten and how they are prepared within the study group, as well as how to improve response rates to better modify the FFQ and $24 \mathrm{HR}$ to limit recall bias and participant fatigue. 


\section{Conclusion}

Dietary assessments can provide valuable information to evaluate an individual's or population's exposures to metal(loid)s. When combined with site-specific environmental data, dietary assessments reduce the uncertainty associated with extrapolation of ingestion rates from the literature. Furthermore, these assessments can also inform mitigation strategies that addresses the specific dietary behaviors and needs of a community. This novel dietary assessment provides the framework for future studies evaluating a risk to metal(loid)s through diet, in a rural and minority community. This study also highlights the need for participant support through community-based participatory research efforts to increase participant recruitment and response rates to understand dietary patterns as best as possible.

\section{Acknowledgments}

This work was funded by the California Breast Cancer Research Program (Grant 23AB-1301A) and the National Institute of Environmental Health Sciences Superfund Research Program (P42ES04940). The authors are grateful to the families and site administrators that completed the dietary assessment for this study. 


\section{References}

Alam, M., et al. (2003). "Arsenic and Heavy Metal Contamination of Vegetables Grown in Samta Village, Bangladesh." Science of The Total Environment, vol. 308, no. 1-3, pp. 83-96., doi:10.1016/s0048-9697(02)00651-4.

Ávila, P. F., Ferreira da Silva, E., \& Candeias, C. (2016). Health risk assessment through consumption of vegetables rich in heavy metals: the case study of the surrounding villages from Panasqueira mine, Central Portugal. Environmental Geochemistry and Health, 39(3), 565-589. https://doi.org/10.1007/s10653-016-9834-0

Bian, B., Zhou, L. J., Li, L., Lv, L., \& Fan, Y. M. (2015). Risk assessment of heavy metals in air, water, vegetables, grains, and related soils irrigated with biogas slurry in Taihu Basin, China. Environmental Science and Pollution Research. https://doi.org/10.1007/s11356-015-4292-2

Baxter, S.D., Thompson, W.O., Davis, H.C., Johnson, M.H., (1997). Impact of Gender, Ethnicity, Meal Component, and Time Interval Between Eating and Reporting on Accuracy of Fourth-Graders' Self-Reports of School Lunch. J. Am. Diet. Assoc. 97, 1293-1298. doi:https://doi.org/10.1016/S0002-8223(97)00309-X

Bhattacharya, P., et al. (2010). "Arsenic Contamination in Rice, Wheat, Pulses, and Vegetables: A Study in an Arsenic Affected Area of West Bengal, India." SpringerLink, Springer Netherlands, 9 Mar. 2010, link.springer.com/article/10.1007/s11270-010-03619.

Brown, C. (2003). Consumers' preferences for locally produced food: A study in southeast Missouri. American Journal of Alternative Agriculture, 18, 213-224. https://doi.org/10.1079/AJAA200353

Bunzl, K., et al. (2001). "Availability of Arsenic, Copper, Lead, Thallium, and Zinc to Various Vegetables Grown in Slag-Contaminated Soils." Journal of Environment Quality, vol. 30, no. 3, 2001, p. 934., doi:10.2134/jeq2001.303934x.

Cai, M., McBride, M. B., \& Li, K. (2016). Bioaccessibility of $\mathrm{Ba}, \mathrm{Cu}, \mathrm{Pb}$, and $\mathrm{Zn}$ in urban garden and orchard soils. Environmental Pollution, 208, 145-152.

https://doi.org/10.1016/j.envpol.2015.09.050

Centers for Disease Control and Prevention (CDC) (1984). National Center for Health Statistics (NCHS). Hispanic Health and Nutrition Examination Survey Data. Hyattsville, MD: U.S. Department of Health and Human Services, Centers for Disease Control and Prevention. https://wwwn.cdc.gov/nchs/nhanes/Hhanes/Default.aspx

Centers for Disease Control and Prevention (CDC) (2016). National Center for Health Statistics (NCHS). National Health and Nutrition Examination Survey Data. Hyattsville, MD: U.S. Department of Health and Human Services, Centers for Disease Control and Prevention.

https://wwwn.cdc.gov/nchs/nhanes/continuousnhanes/default.aspx?BeginYear=2015 
Chen, Y., Reddy, R. M., McLaughlin, M. A., Taher, F. A., Yettella, R. R., Uhlig, S., \& Blaul, C. (2014). Method validation and proficiency testing for determination of total arsenic in apple juice by inductively coupled plasma/ mass spectrometry. Journal of AOAC International, 97(4), 1143+. Retrieved from http://link.galegroup.com.ezproxy3.library.arizona.edu/apps/doc/A382086459/AONE?u= uarizona_main\&sid=AONE\&xid=d20e3c63

Chunhabundit, R. (2016). Cadmium exposure and potential health risk from foods in Contaminated area, Thailand. Toxicological Research, 32(1), 65-72.

https://doi.org/10.5487/TR.2016.32.1.065

Cobb, G. P., Sands, K., Waters, M., Wixson, B. G., \& Dorward-King, E. (2000). Accumulation of Heavy Metals by Vegetables Grown in Mine Wastes.Environmental Toxicology and Chemistry, 19(3), 600-607.

Csavina, J., Field, J., Taylor, M. P., Gao, S., Landázuri, A., Betterton, E. A., \& Sáez, A. E. (2012). A review on the importance of metals and metalloids in atmospheric dust and aerosol from mining operations. Science of the Total Environment, 58-73. https://doi.org/10.1016/j.scitotenv.2012.06.013

Csavina, J., Landázuri, A., Wonaschütz, A., Rine, K., Rheinheimer, P., Barbaris, B., ... Betterton, E. A. (2011). Metal and Metalloid Contaminants in Atmospheric Aerosols from Mining Operations. Water, Air, \& Soil Pollution, 221(1-4), 145-157. https://doi.org/10.1007/s11270-011-0777-x.

Feldmann, C., \& Hamm, U. (2015). Consumers' perceptions and preferences for local food: A review. Food Quality and Preference, 40(PA), 152-164. https://doi.org/10.1016/j.foodqual.2014.09.014

Ferri, R., Hashim, D., Smith, D. R., Guazzetti, S., Donna, F., Ferretti, E., ... Lucchini, R. G. (2015). Metal contamination of home garden soils and cultivated vegetables in the province of Brescia, Italy: Implications for human exposure. Science of the Total Environment, 518-519, 507-517. https://doi.org/10.1016/j.scitotenv.2015.02.072

Freedman, D. A., Vaudrin, N., Schneider, C., Trapl, E., Ohri-vachaspati, P., Taggart, M., ... Flocke, S. (2016). Systematic Review of Factors Influencing Farmers' Market Use Overall and among Low-Income Populations. Journal of the Academy of Nutrition and Dietetics, 116(7), 1136-1155. https://doi.org/10.1016/j.jand.2016.02.010

Garcia, R.A., Taren, D., Teufel, N.I., (2000). Factors associated with the reproducibility of specific food items from the southwest food frequency questionnaire. Ecol. Food Nutr. 38, 549-561. doi:10.1080/03670244.2000.9991596 
Gaw, S. K., et al. (2008). "Uptake of $\Sigma$ DDT, Arsenic, Cadmium, Copper, and Lead by Lettuce and Radish Grown in Contaminated Horticultural Soils." Journal of Agricultural and Food Chemistry, vol. 56, no. 15, pp. 6584-6593., doi:10.1021/jf073327t.

Grebitus, C., Lusk, J. L., \& Nayga, R. M. (2013). Effect of distance of transportation on willingness to pay for food. Ecological Economics, 88, 67-75.

https://doi.org/10.1016/j.ecolecon.2013.01.006

Hu, F.B., Rimm, E., Smith-Warner, S.A., Feskanich, D., Stampfer, M.J., Ascherio, A., Sampson, L., Willett, W.C. (1999). Reproducibility and validity of dietary patterns assessed with a food-frequency questionnaire. Am. J. Clin. Nutr. 69, 243-9.

Johnson-kozlow, M., Matt, G.E., Rock, C.L., Rosa, R. De, Conway, T.L., Romero, R.A., (2011). Assessment of Dietary Intakes of Filipino-Americans: Implications for Food Frequency Questionnaire Design. J. Nutr. Educ. Behav. 43, 505-510.

doi:10.1016/j.jneb.2010.09.001

Lee, Y. Z., Suzuki, S., Kawada, T., Wang, J., Koyama, H., Rivai, I. F., \& Herawati, N. (1999). Content of cadmium in carrots compared with rice in Japan. Bulletin of Environmental Contamination and Toxicology. https://doi.org/10.1007/s001289901038

Li, Yu, et al. (2006). "Risk Assessment of Heavy Metals in Soils and Vegetables around Non-Ferrous Metals Mining and Smelting Sites, Baiyin, China." Journal of Environmental Sciences, vol. 18, no. 6, pp. 1124-1134., doi:10.1016/s10010742(06)60050-8.

Liu, P., Wang, C., Song, X., \& Wu, Y. (2010). Dietary intake of lead and cadmium by children and adults - Result calculated from dietary recall and available lead/cadmium level in food in comparison to result from food duplicate diet method. International Journal of Hygiene and Environmental Health, 213(6), 450-457. https://doi.org/10.1016/j.ijheh.2010.07.002

McCormack, L. A., Laska, M. N., Larson, N. I., \& Story, M. (2010). Review of the Nutritional Implications of Farmers' Markets and Community Gardens: A Call for Evaluation and Research Efforts. Journal of the American Dietetic Association, 110(3), 399-408. https://doi.org/10.1016/j.jada.2009.11.023

National Cancer Institute. (2010). National Institute of Health, Epidemiology and Genomics Research Program. Diet History Questionnaire, Version 2.0.

Newton, K., Amarasiriwardena, D., \& Xing, B. (2006). Distribution of soil arsenic species, lead and arsenic bound to humic acid molar mass fractions in a contaminated apple orchard. Environmental Pollution, 143(2), 197-205. 
Probst, Y., Tapsell, L., (2007). Over- and underreporting of energy intake by patients with metabolic syndrome using an automated dietary assessment website. Nutr. Diet. 64, 280-284. doi:10.1111/j.1747-0080.2007.00220.x.

Racine, E. F., Mumford, E. A., Laditka, S. B., \& Lowe, A. E. (2013). Understanding Characteristics of Families Who Buy Local Produce. Journal of Nutrition Education and Behavior, 45(1), 30-38. https://doi.org/10.1016/j.jneb.2012.04.011 Thompson, Frances E., \& Subar, Amy F. (2001). Dietary Assessment Methodology Chapter 1.In Nutrition in the Prevention and Treatment of Disease (pp. 3-30).

Ramirez-Andreotta, M. D., Brusseau, M. L., Artiola, J. F., \& Maier, R. M. (2013a). A greenhouse and field-based study to determine the accumulation of arsenic in common homegrown vegetables grown in mining-affected soils. Science of the Total Environment, 443, 299-306. https://doi.org/10.1016/j.scitotenv.2012.10.095

Ramirez-Andreotta, M. D., Brusseau, M. L., Beamer, P., \& Maier, R. M. (2013b). Home gardening near a mining site in an arsenic-endemic region of Arizona: Assessing arsenic exposure dose and risk via ingestion of home garden vegetables, soils, and water. Science of the Total Environment, 454-455, 373-382. https://doi.org/10.1016/j.scitotenv.2013.02.063

Ramirez-Andreotta, M. D., Tapper, A., Clough, D., Carrera, J. S., \& Sandhaus, S. (2019). Understanding the Intrinsic and Extrinsic Motivations Associated with Community Gardening to Improve Environmental Public Health Prevention and Intervention. International Journal of Environmental Research and Public Health, 16(3), 494. https://doi.org/10.3390/ijerph16030494

Shim, J.-S., Oh, K., Kim, H.C., (2014). Dietary assessment methods in epidemiologic studies. Epidemiol. Health e2014009. doi:10.4178/epih/e2014009

Smith, E., Juhasz, A. L., \& Weber, J. (2009). Arsenic uptake and speciation in vegetables grown under greenhouse conditions. Environmental Geochemistry and Health. https://doi.org/10.1007/s10653-008-9242-1

Thompson, F. E., Dixit-Joshi, S., Potischman, N., Dodd, K. W., Kirkpatrick, S. I., Kushi, L. H., ... Subar, A. F. (2015). Comparison of Interviewer-Administered and Automated Self-Administered 24-Hour Dietary Recalls in 3 Diverse Integrated Health Systems. American Journal of Epidemiology, 181(12), 970-978. https://doi.org/10.1093/aje/kwu467

Thompson, F. E., \& Subar, A. F. (2017). Dietary Assessment Methodology Chapter 1. In Nutrition in the Prevention and Treatment of Disease (pp. 3-30).

Thompson, F.E., Subar, A.F., Loria, C.M., Reedy, J.L., Baranowski, T., (2010). Need for Technological Innovation in Dietary Assessment. J. Am. Diet. Assoc. 110, 48-51. doi:10.1016/j.jada.2009.10.008 
U.S. Census Bureau. (2017). U.S. Census Bureau QuickFacts: Nevada County, California; California. Retrieved April 11, 2019, from

https://www.census.gov/quickfacts/fact/table/nevadacountycalifornia,ca/PST045218.

U.S. Department of Agriculture (USDA) (2018). What We Eat in America. NHANES 2015-2016, individuals 2 years and over (excluding breast-fed children), day 1 dietary intake data, weighted. Food Patterns Equivalents Database (FPED) 2015-2016. Available at: www.ars.usda.gov/nea/bhnrc/fsrg.

U.S. EPA. (2011). Exposure Factors Handbook 2011 Edition (Final Report). U.S. Environmental Protection Agency, Washington, DC, EPA/600/R-09/052F, 2011.

U.S. EPA. (2018b). Exposure Factors Handbook Chapter 9 (Update): Intake of Fruits and Vegetables. U.S. EPA Office of Research and Development, Washington, DC, EPA/600/R-18/098F.

Walton, J., (2015). Dietary Assessment Methodology for Nutritional Assessment. Top. Clin. Nutr. 30, 33-46. doi:10.1097/TIN.0000000000000018

Warren, G. P., Alloway, B. J., Lepp, N. W., Singh, B., Bochereau, F. J. M., \& Penny, C. (2003). Field trials to assess the uptake of arsenic by vegetables from contaminated soils and soil remediation with iron oxides. Science of the Total Environment, 311(1-3), 1933. https://doi.org/10.1016/S0048-9697(03)00096-2

Yu, G., Zheng, W., Wang, W., Dai, F., Zhang, Z., Yuan, Y., \& Wang, Q. (2017). Health risk assessment of Chinese consumers to Cadmium via dietary intake. Journal of Trace Elements in Medicine and Biology. https://doi.org/10.1016/j.jtemb.2017.07.003

Zhang, C., Wang, Y., Zhang, Z., Wang, D., Luo, C., Xu, F. (2015). Health Risk Assessment of Heavy Metals and As in Vegetable and Soil System in Chongqing, Southwest of China. Journal of Residuals Science and Technology, 12(4), 231-240. 


\title{
APPENDIX B
}

\section{Ingestion and Inhalation of Metal(loid)s Through Preschool Gardening: An Exposure and Risk Assessment in Legacy Mining Communities}

\author{
Iliana Manjón ${ }^{1}$, Annika Alexander-Ozinskas ${ }^{4}$, Joanne Hild ${ }^{4}$, Katy Janes ${ }^{5}$, Robert A. \\ Root $^{1}$, A. Eduardo Sáez ${ }^{3}$, Mónica D. Ramírez-Andreotta ${ }^{1,2 *}$
${ }^{1}$ Department of Soil, Water, and Environmental Science, University of Arizona, Tucson, AZ
${ }^{2} \mathrm{Mel}$ and Enid Zuckerman College of Public Health's Division of Community,
Environment \& Policy, University of Arizona, Tucson, AZ
${ }^{4}$ Sierra Streams Institute, Nevada City, CA
${ }^{5}$ California Department of Water Resources, Sacramento, CA \\ ${ }^{3}$ Department of Chemical and Environmental Engineering, University of Arizona, Tucson, AZ
}

Prepared for:

Science of the Total Environment

*Corresponding Author: mdramire@email.arizona.edu

University of Arizona

1177 E Fourth Street, Rm. 429, Tucson, AZ 85721

Phone: 520-621-0091; Fax: 520-621-1647 


\begin{abstract}
Children residing in legacy mining towns are potentially disproportionately exposed to metal(loid)s via ingestion (of food, water, and incidental soil), and dust inhalation, thus, increasing their risk of exposure when engaging in school or home gardening or playing outside in non-garden, playground soil. The purpose of this citizen-science study was to assess preschool children's potential metal(loid) exposure through these routes. Parents and teachers were trained to properly collect water, soil, and vegetable samples from their preschools throughout Nevada County, California. Arsenic (As), cadmium (Cd), and lead $(\mathrm{Pb})$ concentrations in garden irrigation sources did not exceed the U.S. EPA Safe Drinking Water Act and Lead and Copper Rule's maximum contaminant and action levels. In general, $\mathrm{As}$ and $\mathrm{Pb}$ concentration from garden and playground soil samples exceeded the US EPA Regional Screening Level (RSL), CalEPA's California Human Health Screening Level (CHHSL) and California Department of Toxic Substances Control Screening Level (DTSC-SL). In contrast, all Cd concentrations were below these recommended screening levels. Dust samples $(<10 \mu \mathrm{m}$ diameter) were generated from surface garden and playground soil collected at the preschools. Soil and dust samples were then analyzed by in-vitro bioaccessibility assays using synthetic lung and gastric fluids to estimate the bioaccessible fraction of $\mathrm{As}, \mathrm{Cd}$, and $\mathrm{Pb}$ in the body. Metal(loid) exposure via homegrown produce revealed that lettuce, carrot, and cabbage grown in the preschool gardens accumulated a higher concentration of metal(loid) than those store-bought nation-wide (U.S. FDA Total Diet Study, 2006-2013). None of the vegetables exceeded the respective recommendation maximum levels for $\mathrm{Cd}$ and $\mathrm{Pb}$ set by the World Health Organization Codex Alimentarius Commission. Lastly, a dietary assessment consisting of a 24-hour recall and food frequency questionnaire was administered to determine ingestion rates of foods shown to accumulate these contaminants. The results of this study suggest that consumption of preschool-grown foods and incidental soil ingestion were major contributors to preschool-aged children's exposure to $\mathrm{As}, \mathrm{Cd}$, and $\mathrm{Pb}$. This comprehensive environmental monitoring and exposure assessment that includes child-specific dietary data and the average daily doses of contaminants through ingestion of soil, water, and vegetable and inhalation of dust informs future risk assessment and public health interventions related to childhood exposure to these metal(loid)s.
\end{abstract}




\section{Introduction}

The impacts of contamination by active and legacy resource extraction sites are of increasing concern for neighboring communities. This is particularly worrisome for communities that rely on foods locally grown in community and school gardens. Active and legacy mining and smelting operations commonly release metal(loid)s such as arsenic (As) cadmium $(\mathrm{Cd})$, and lead $(\mathrm{Pb})$, which can be transported by wind and water erosion to nearby communities and contaminate groundwater via leaching (Csavina et al., 2011, and references therein). Nevada County, CA, is impacted with metal(loid) contamination from legacy Gold Rush mining which began in 1848. Historically, gold was dominantly mined by hydraulic mining of placer deposits (Alpers, 2017), and to date, more than 3,634 U.S. tons of gold have been extracted from the Sierra Nevada foothills (Solnit, 2006). The Sierra Nevada foothills area of Nevada County has a rich history of gold mining including the California Mother Lode zone containing hundreds of now abandoned mines (Smith, 1999). Consequently, this region has been shown to have significantly high concentrations of As in mine tailings (up to 5,000 $\mathrm{mg} \mathrm{kg}^{-1}$ ) left behind (Smith, 1999). These mine tailings were used for residential development, which led to health risks for the residents and workers in the area (Behrshing et al., 2009).

Toxic contamination of metal(loid)s including $\mathrm{As}, \mathrm{Cd}$, and $\mathrm{Pb}$ has persisted in the region's soil, surface water, and groundwater as a result of legacy gold mining. These metal(loid)s are of special concern as they are within the top 10 of the Agency for Toxic Substances and Disease Registry (ATSDR)'s 2017 Substance Priority List due to their frequent and likely exposure and potential toxicity (ATSDR, 2017). Arsenic is recognized as a human carcinogen by the International Agency for Research on Cancer (IARC) and U.S. Environmental Protection Agency (EPA), while $\mathrm{Cd}$ and $\mathrm{Pb}$ are classified as probable carcinogens by the U.S. EPA (U.S. EPA, 2018b; U.S. EPA, 2006a). Adverse health effects from an acute exposure to high levels of As include gastrointestinal, hepatic, renal, and cardiovascular damage, while chronic exposures have been shown to lead to severe peripheral neuropathy and multi-organ cancers (ATSDR, 2007a). Exposures to Cd have been associated with anemia and neurological impairments from acute and chronic exposures, respectively (ATSDR, 2008). High Pb levels pose a serious risk to children by causing neurobehavioral development delays (ATSDR, 2007b). These heavy metal(loid)s 
have also been shown to be endocrine-disrupting agents associated with the increase risk of breast cancers (Vaiserman, 2014). Children have an air and caloric intake that is 2 to 3 times greater than adults and undergo more rapid and complex body system development, which make them more susceptible to adverse health effects of environmental toxicants (Landrigan et al., 2011). Children residing in communities at-risk of pollution are principally exposed to metal(oid)s via incidental ingestion of dust and soil as a result of hand-to-mouth transfer (Huang et al., 1997; Beamer et al., 2012). In efforts to increase public health prevention and informal science education activities, more schools have incorporated gardening programs in their curriculum (Turner et al., 2016) potentially increasing the risk of exposure to these contaminants in the area. Furthermore, gardening has become a more prevalent hobby in the United States, providing families with essential fruits, vegetables, and herbs, but also presenting a potential dietary exposure if soil or irrigation water is contaminated or garden produce accumulates these metal(loids) (Bian et al., 2015; Ramirez-Andreotta et al., 2013a \& 2013b).

Plants with metal(loid)-accumulating capacity are known as accumulators, while those with increased capacity are known as hyperaccumulators (Ávila et al., 2016; Tangahu et al., 2011). This ability is useful in phytoremediation but can pose a threat when consumed regularly by children. Members of the Apiaceae (Stilwell et al., 2008), Brassicaceae and Asteraceae families accumulated more As (Ramirez-Andreotta et al., 2013a) and $\mathrm{Cd}$ in the edible portion of the plant than plants from other families. Further, it is suggested that members of the same plant family have the same metal(loid) up-taking properties (Ramirez-Andreotta et al., 2013a). Thus, members of these families are crucial to consider when assessing possible exposure to metal(loid)s by ingestion of garden plants.

Soil and dust can cause significant exposures to metal(loid)s if ingested or inhaled. Most human risk assessments do not consider the bioavailability of a metal(loid), which may over- or under-estimate exposure. The bioavailability of a metal(loid) is the absorbed fraction of the metal(loid) that enters systemic circulation and may reach target organs, typically determined by in-vivo animal models (U.S. EPA, 2007c). Bioaccessibility is the fraction of the total metal(loid) concentration released from the environmental matrix (e.g. dust, soil, food, water) into the biofluid and becomes available for absorption (Thomas et al., 2018; Roussel et al., 2010; Oomen et al., 2002). The bioavailability is therefore, 
influenced by the bioaccessibility of that metal(loid) since solubilization is required for crossing membranes in the body (U.S. EPA, 2007c). The bioaccessible fraction determined by in-vitro assays are a useful and inexpensive tool that represents the maximum amount of metal(loid) that can be absorbed (Oomen et al., 2002).

Given the possible association between metal(loid) exposures through gardening and adverse health effects, the present study was designed to evaluate a child's potential exposure to $\mathrm{As}, \mathrm{Cd}$, and $\mathrm{Pb}$ at preschools located in Nevada County, $\mathrm{CA}$. Building upon the traditional U.S. EPA exposure assessment guidance (U.S. EPA, 1992), this study employs site-specific analysis to predict a preschool-aged child's exposure to $\mathrm{As}, \mathrm{Cd}$, and $\mathrm{Pb}$ in a legacy mining community. Using a citizen-science approach, a child's dietary assessment was conducted in tandem with the collection of irrigation water, soil (garden and playground), dust, and preschool-grown plant samples. With site specific As, Cd, and $\mathrm{Pb}$ concentrations, a comprehensive exposure assessment was then completed to account for ingestion (locally grown food, soil, and water) and inhalation using gastric and lung fluid assays to evaluate bioaccessibility (Figure 1). 
Environmental Media

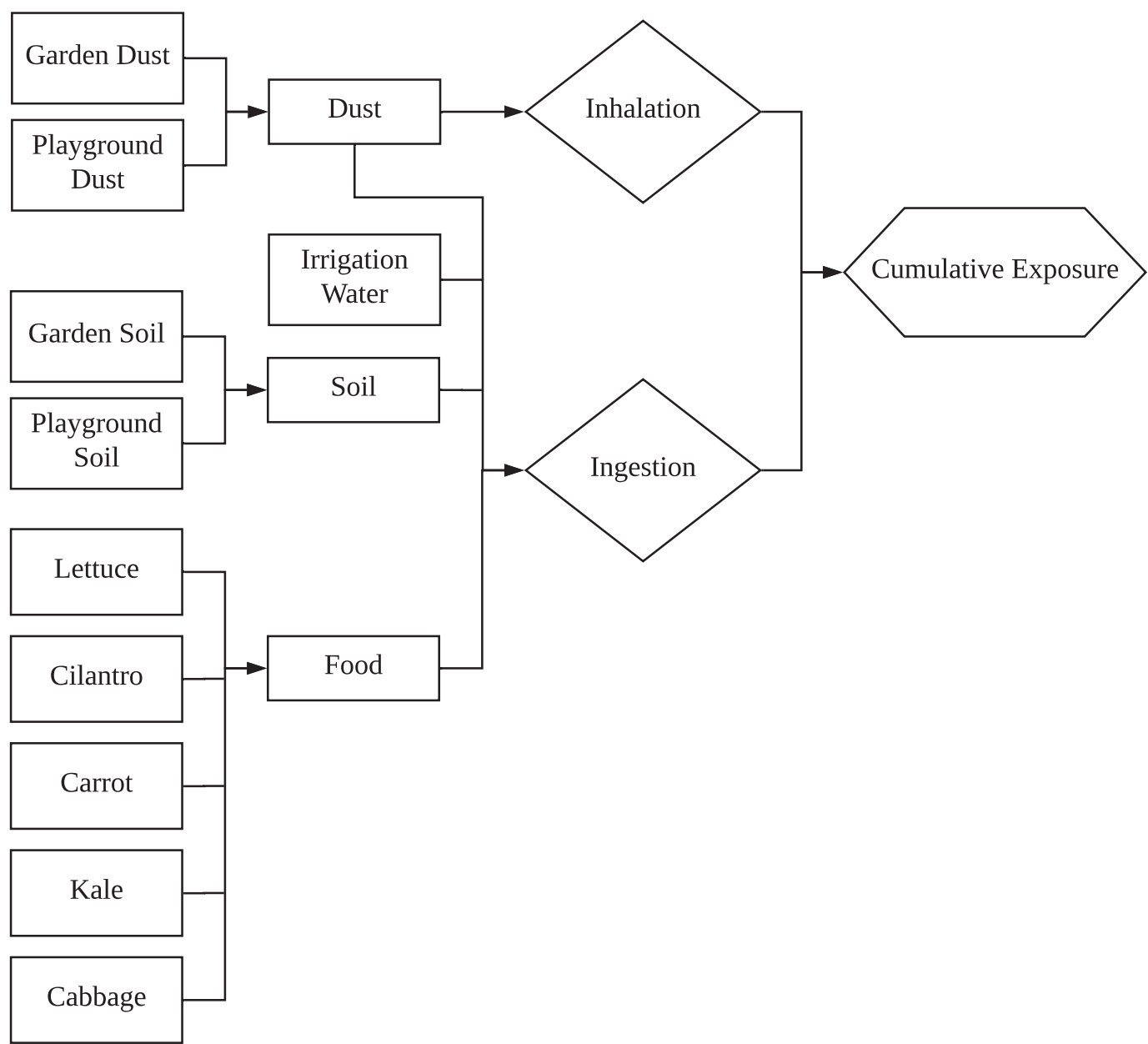

Figure 1. Schematic of a child's multi-route exposure considered in this study.

\section{Materials and Methods}

\subsection{Site description}

Due to previous and current research efforts conducted in the area by the Sierra Springs Institute, a non-governmental watershed monitoring, research, and restoration group based in Nevada City, CA and the Cancer Prevention Institute of California, a Community Advisory Board ( $\mathrm{CAB}$ ) was developed to inform and guide research efforts. The $\mathrm{CAB}$ was composed of families of preschool students, teachers, local farmers, public health workers, and other residents who wanted to ensure the area's preschool environment did not pose a risk to children. 
Four preschools throughout Grass Valley (95945) and Nevada City (95959), CA, were selected as sampling sites for Gardenroots: The Nevada County, CA Garden Project (referred to as Gardenroots hereafter). The two rural cities are located in the foothills of the Sierra Nevada mountain range in Northern California. As of 2010, Grass Valley comprised of 4.74 square miles and had 12,860 residents, while Nevada City has a population of less than 5,000 residents (U.S. Census Bureau, 2010).

The gardens at all four schools were established before 2015 and have been used exclusively for vegetable gardening. Site 1 (S1) and site 3 (S3) have grown produce for over eight years and 6-8 years, respectively. Sites 2 (S1) and 4 (S4) have been vegetable gardening for only 3-5 years. S1, S2, and S3 have previously used some of garden produce for school meals, and report that children take home produce from the school gardens at $\mathrm{S} 2$ and $\mathrm{S} 3$. The mean soil pHs at S1, S2, S3, and S4 gardens were 5.4, 5.8, 7.0, and 5.2, respectively. According to the U.S. Department of Agriculture Web Soil Survey, the dominant soil type for the Nevada County area is classified as a Josephine-mariposa complex composed of a gravelly loam within the first 12-in from the surface (USDA, 2018). 


\subsection{Dietary assessment and gardening description survey}

A dietary assessment including a 24-hour recall (24HR) (Appendix F) and food frequency questionnaire (FFQ) (Appendix E), as well as a gardening description survey was administered to school administrators and parents at each site. Each respondent was consented under the University of California, San Francisco Institutional Review Board (IRB). The site administrators' responses $(n=4)$ to the gardening description survey provided insight on possible contamination sources, child behavior, gardening activities, and time spent outside in the gardens. Parents' responses $(n=10)$ to the FFQ questions listed below were used to calculate ingestion rates of the preschool-grown foods used in the exposure assessment calculations (Table 6).

- In the last 12 months, did your child eat [food]?

- How often did your child eat [food]?

- What was your child's usual serving size of [food]?

\subsection{Environmental sampling}

In May 2018, Gardenroots participants $(\mathrm{n}=33)$ including school administrators, teachers, parents, and community members were trained by the research group on how to properly collect irrigation water, soil, and plant samples at each preschool. Participants were given a sample-collection kit, as well as an easy-to-follow instruction manual written in English and Spanish to facilitate sample collection (Appendix D). The sample-collection kit contained all the necessary materials for sample collection, documentation, and personal protection equipment. Given their own insight regarding the preschool's gardening practices and their students' regular play areas, the participants decided on specific sampling locations for soil and irrigation water sources. Irrigation water and soil samples were collected during the sample collection trainings in May 2018, while the plant samples were collected from July to October 2018.

\subsubsection{Water sampling, preparation, and analysis}

Participants collected one water sample from the irrigation source for the garden as well as a field blank at each preschool. The samples and field blanks $(n=8)$ were collected in trace metal-free $50 \mathrm{~mL}$ centrifuge tubes. To collect the field blank, a centrifuge tube was filled with nanopure water, and then transferred into a clean centrifuge tube next to the 
source of irrigation water where the sample was collected at each site. Samples and field blanks were refrigerated upon collection and promptly shipped on ice within two days to the University of Arizona (UA). Upon arrival at UA, the samples were analyzed for total metal(loid) concentration including $\mathrm{As}, \mathrm{Cd}$, and $\mathrm{Pb}$ by Inductively Coupled Plasma-Mass Spectrometry (ICP-MS) (Agilent 7700 ICP-MS, Santa Clara, CA) per U.S. EPA Method 6020B (SW-846) (U.S. EPA, 1994) at the Arizona Laboratory for Emerging Contaminants (ALEC). The ICP-MS instrument quantifiable detection limits are reported in Table 1.

Table 1. ICP-MS quantifiable detection limits for metal(loid)s.

\begin{tabular}{lll}
\hline Element & Instrument Detection Limit $(\mu \mathrm{g} / \mathrm{L})$ & Method Detection Limit $(\mu \mathrm{g} / \mathrm{g})$ \\
\hline $\mathrm{As}$ & $0.033 \& 0.0018^{\mathrm{b}}$ & $0.041 \& 0.0032^{\mathrm{b}}$ \\
$\mathrm{Cd}$ & 0.00064 & 0.0018 \\
$\mathrm{~Pb}$ & 0.00047 & 0.0016 \\
\hline
\end{tabular}

${ }^{a}$ Agilent 7700 ICP-MS

${ }^{\mathrm{b}}$ Specific for Agilent 8900 ICP-QQQ ICP-MS only

\subsubsection{Soil/garden amendment sampling, preparation, and analysis}

The research group and Gardenroots participants collected soil samples from the garden $(n=4-8)$ and playground (native, unamended, $n=3-4)$ areas at each preschool for a total of 38 soil samples. For each garden, participants were instructed to select six sampling spots within a grid pattern drawn in each garden bed. Participants then collected the top $15 \mathrm{~cm}$ of soil from each of the six spots and homogenized it within a five-gallon plastic bucket. From the homogenized bulk sample, up to four samples were separated into individual brown paper bags. For the playground soil samples, participants selected an area in the surrounding playground areas where children often play. When appropriate, wood chips and other ground cover elements were removed before collecting the samples. Participants were instructed to repeat the grid pattern and sampling instructions as stated above. All soil samples were immediately refrigerated and shipped on ice to UA within two days.

Similar to the garden and playground soil samples, participants and the research group collected a separate set of garden and playground soil samples at each preschool to be used for dust generation. For these garden samples, a scrape of approximately the top 2 
$\mathrm{cm}$ of the garden soil was collected and homogenized into a five-gallon plastic bucket. This was repeated for a larger area of the playground. These five-gallon plastic buckets $(n=8)$ were also immediately refrigerated and shipped on ice to UA within two days.

Samples of garden amendments presumed to be similar to what was originally applied when the gardens were first built were collected from the same local businesses (Table 2). The samples were collected separately to evaluate their individual contribution to metal(loid) concentrations in garden soils. Samples of an organic 'green waste' compost $(\mathrm{n}=3)$ and garden blend $(\mathrm{n}=3)$ amendment were collected. These amendments are presumed to be a similar mix that was added to the S3 and S2 gardens. Further, samples of the potting soil $(n=3)$ added to S1 were collected. Lastly, the local organic dairy compost that was added to each garden (after soil samples were collected) to aid in plant growth was collected. These garden amendment samples were promptly shipped to UA upon collection and stored in a laboratory refrigerator upon arrival before chemical analysis.

Table 2. Garden soil amendment description and sites to which they were presumably added to.

\begin{tabular}{lll}
\hline Garden Amendment & Description & Site \\
\hline Compost A & $\begin{array}{l}\text { Organic 'green waste' } \\
\text { compost }\end{array}$ & S2, S3 \\
\hline Potting soil & $\begin{array}{l}\text { GreenAl1® Natural \& } \\
\text { Organic Potting Soil } \\
\text { (Commercially sold) }\end{array}$ & S1 \\
\hline Garden blend & $\begin{array}{l}\text { Locally produced organic } \\
\text { dairy compost }\end{array}$ & S1, S2, S3, S4 \\
\hline Compost B & & \\
\hline
\end{tabular}

All garden and playground soil and amendment samples were first air dried under a hood for 24-96 hours, sieved to $\leq 2 \mathrm{~mm}$ diameter and then oven dried at $105{ }^{\circ} \mathrm{C}$ to a constant mass. Once dried, the garden and playground soil samples (excluding those used for dust generation) and the amendment samples were additionally sieved to $\leq 63 \mu \mathrm{m}$ diameter using a standard stainless-steel mesh sieve (W.S. Tyler ${ }^{\mathrm{TM}}$, ASTM E-11 standard No. 230). These garden and playground soil samples were also sieved to $75-106 \mu \mathrm{m}$ diameter using similar sieves. A subsample of the homogenized garden and playground 
soil samples collected for dust generation was separated and ball-milled (8000D Mixer/Mill-Dual High-Energy Ball Mill, SPEX Sample Prep, Metuchen, NJ) to approximately $\leq 100 \mu \mathrm{m}$ diameter for preliminary chemical analysis. All dried and sieved soil and amendment samples were microwave acid-digested using $\mathrm{HNO}_{3}$ (CEM Corporation, MARS 6, 2009) following US EPA Method 3051A (SW-846) (U.S. EPA, 2007a) and analyzed for total metal(loid) concentrations via ICP-MS (Agilent 7700 ICPMS, Santa Clara, CA) by the ALEC. The ICP-MS instrument quantifiable detection limits are reported in Table 1.

\subsubsection{Dust sample generation}

The laboratory dust generator used in this study was developed to produce a mass of several grams of dust samples from bulk soil and tailing samples (Gonzales et al., 2014). The dust generator is comprised of a $208 \mathrm{~L}$ steel drum with built-in baffles, which rotate to mix and resuspend the bulk soil sample. Clean air supplied by an air compressor flows at a rate of $28.3 \mathrm{~L} \mathrm{~min}^{-1}$ through a fixed $3.5 \mathrm{~cm}$ diameter PVC pipe threaded horizontally through the drum. The re-suspended particles within the drum flow through the pipe and enter a cyclone separator with a cut-point diameter of $10 \mu \mathrm{m}$ (model URG-2000-30 EA, URG Corp. Chapel Hill, NC). Subsamples of the $<10 \mu \mathrm{m}$ dust samples generated from this process were then microwave acid-digested and analyzed for total metal(loid) concentrations as previously described for soil samples. These dust samples were later used to determine the particle size distribution and the lung in-vitro bioaccessibility assay. The dust generated simulates the particle size and composition of windblown fine atmospheric dust (Gonzales et al, 2014 and Thomas et al., 2018 for theory details).

Atmospheric $\mathrm{PM}_{10}$ metal(loid) concentrations $\left(\mu \mathrm{g} \mathrm{m}^{-3}\right)$ were estimated using the measured concentration $\left(\mu \mathrm{g} \mathrm{g}^{-1}\right)$ in generated dust samples and the highest $\mathrm{PM}_{10}$ concentrations $\left(0.339 \mathrm{mg} \mathrm{m}^{-3}\right)$ measured in 2018 by a local U.S. EPA AirData Air Quality Monitor approximately $30 \mathrm{mi}$ away from the site locations (U.S. EPA, 2018a). This calculation was made to conservatively estimate the metal(loid) concentration $\left(C_{m a}\right)$ at the preschools using the following equation:

$$
C_{m a}\left(\mu g m^{-3}\right)=C_{P M 10}\left(m g m^{-3}\right) \times C_{m d}\left(\mu g g^{-1}\right) \times C F
$$


where $C_{m d}$ is the concentration of the metal(loid) measured in the generated dust samples $(<10 \mu \mathrm{m}), C F$ is the unit conversion factor of $10^{-3}$, and $C_{P M 10}$ is the highest recorded $\mathrm{PM}_{10}$ concentration measured by the U.S. EPA air monitor in 2018 (U.S. EPA, 2018a).

\subsubsection{Determination of particle size distribution}

The particle size distribution of the generated dust was determined using micrographs taken of dust samples by Environmental Scanning Electron Microscopy (ESEM) (Inspect S, FEI Company, Hillsboro, OR). Samples were prepared with a goldcoating and then visualized at 1,300 $\times$ and 2,500× magnification. Images of each sample at both magnifications were captured and the distribution was determined using the imaging software, ImageJ (Version 2.0.0-rc69/1.52i, 2018). Particle diameter using this method was extrapolated with the assumption that particles are spherical in shape with a twodimensional area of $A=\pi r^{2}$. A limitation to this analysis was the inability to distinguish between large particles and multiple small particles aggregated together. This analysis is outlined in Figure 2. 

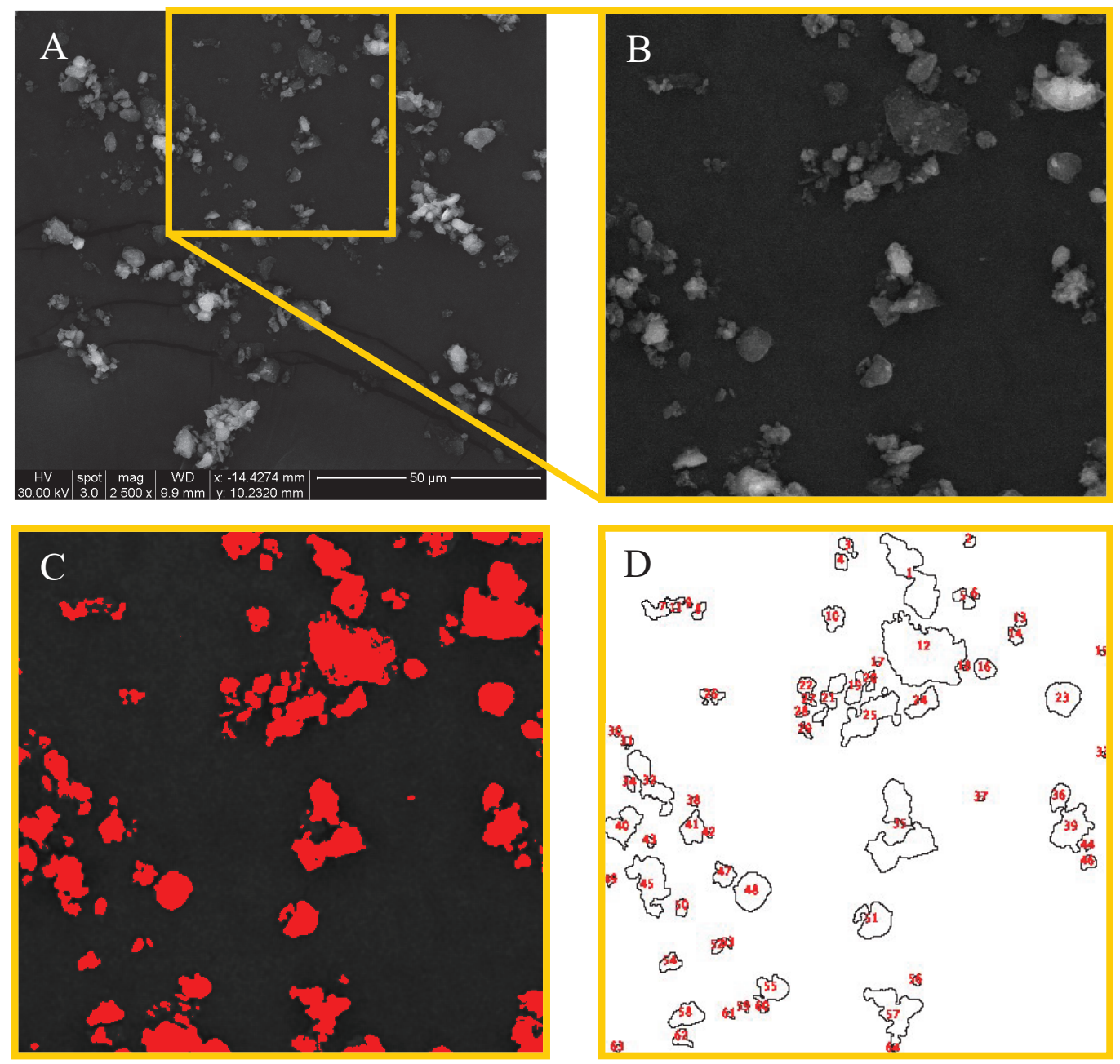

Figure 2. Process of determining particle size distribution by ImageJ. (A) ESEM image of S1 playground dust sample viewed at 2,500 $\times$ magnification. Yellow box indicates analyzed area. (B) Contrast and brightness adjustment for selected area. (C) Particle area analyzed. (D) Outlines of analyzed particles.

\subsubsection{Plant amendment sampling, preparation, and analysis}

A thorough literature review was conducted to select plants for the dietary assessment and to grow in each preschool garden (Appendix A). Similar to the criteria previously used in a Gardenroots greenhouse study (Ramirez-Andreotta et al., 2013a), the following criteria was used to select plants for this study:

- Shown to accumulate As and/or Cd in previous studies

- Commonly grown in the area 
- Regionally, culturally, ethnically, and age-appropriate for the target population

Based on these criteria, the following plants were sowed in each preschool garden between June and August 2018:

- Santo cilantro (also known as coriander) (Apiaceae Coriandrum sativum)

- Spearmint (Lamiaceae Mentha spicate)

- Lacinato kale (Brassicaceae Brassica oleracea 'Lacinato')

- Nantes organic carrot (Apiaceae Daucus carota)

- Early Jersey Wakefield cabbage (Brassicaceae Brassica oleracea)

- Ridgeline Romaine lettuce (Asteraceae Lactuca sativa)

The seeds were planted randomly throughout the gardens to account for variation and inconsistencies with shade, irrigation regime, and soil. A local farmer was contracted to tend to each garden and implement changes to the gardens and irrigation systems when necessary to aid plant growth. Due to low crop production, each garden was amended with 0.5 in (S1, S2, S3) to 1 in (S4) of an organic dairy compost. The plants were also replanted as needed using the same seeds and/or plant starts of the same cultivar.

Between July and October 2018, the research group and Gardenroots participants collected garden plant samples. They were instructed to collect three samples (replicates) of carrot, lettuce, and either cabbage or kale, and also mint or cilantro for a total of three samples per species. A visual description of what each plant sample should look like (e.g. how many carrots should be included in a single sample) was included in the instruction manual (Appendix D) to ensure enough plant material was collected per plant species. Participants were instructed to select portions of the plant that are representative of what the child would consume. Plant samples were placed in sterile sample bags (Whirl-Pak ${ }^{\circledR}$ or VWR ${ }^{\circledR}$ ) and refrigerated upon collection.

Once in the laboratory, the inedible portions of each plant sample were removed unless noted otherwise and only the edible portion of the plant was analyzed. In order to simulate the average consumer at their home, samples were washed for 30 seconds with deionized water. The decision to wash the plant samples in this manner was made by the Gardenroots participants. The samples were then oven-dried at $60^{\circ} \mathrm{C}$ in brown paper bags until they reached a constant mass. Dried samples were then finely grinded using a mortar 
and pestle or dedicated coffee grinder and shipped to UA for analysis. Due to inconsistencies in final dry weights for cilantro only, the fresh weight was calculated using the mean moisture content ratio of 0.8771 for parsley as reported by the U.S. EPA Exposure Factor Handbook (cilantro was not provided; U.S. EPA, 2018b).

Plant samples were then microwave acid-digested using $\mathrm{HNO}_{3}(\mathrm{CEM}$ Corporation, MARS 6, 2009) following U.S. EPA Method 3051 (SW-846) (U.S. EPA, 2007a) and analyzed for total metal(loid) concentrations via ICP-MS (Agilent 7700 ICP-MS, Santa Clara, CA). The ICP-MS instrument quantifiable detection limits are reported in Table 1.

The metal(loid) concentrations in plants were compared to recommended maximum levels set by the World Health Organization (WHO) Codex Alimentarius Commission (referred to as Codex hereafter) (Joint FAO/WHO Codex Alimentarius Commission, 2018). These internationally recommended maximum levels were established to protect consumer health and ensure food safety. The metal(loid) concentrations measured from the present study were also compared to mean concentrations reported in the U.S. Food and Drug Administration (U.S. FDA) Total Diet Study (Market Baskets 2006-2013) (U.S. FDA, 2014) to determine how store-bought produce compares to the produce grown at the preschools. In the Total Diet Study, mean concentrations calculated with samples less than the limit of detections are reported a value of zero (U.S. FDA, 2014). For these non-detects, a more conservative, modified average (MA) was calculated with the metal(loid) limit of detection (LOD) using following expression (Ramirez-Andreotta et al., 2013b; U.S. EPA, 2000): $M A=L O D / 2$. Similarly, metal(loid) concentrations for all samples in this study that were at or below the detection limit are also reported as $1 / 2$ the detection limit concentration. Lastly, a One-way Anova analysis and Tukey-Kramer Honest Significant Difference test was performed to compare the mean metal(loid) concentrations between plant types using JMP Pro Software version 13.0. For all comparisons, a probability of $\mathrm{p}<0.05$ was considered statistically significant.

\subsubsection{Bioconcentration factor $(B C F)$ calculation}

The bioconcentration factor (BCF) is the ratio of metal(loid) concentration (dry weight) in the plant to the concentration in garden soil $(75-106 \mu \mathrm{m})$, expressed as $B C F=$ $C_{\text {plant }} / C_{\text {soil }}$ (Ramirez-Andreotta et al, 2013a; Ávila et al., 2016; Alam et al., 2003). The $\mathrm{BCF}$ was calculated for each plant type grown in each preschool garden. 


\subsection{In-vitro bioaccessibility assay (IVBA)}

A validated in-vitro bioaccessibility assay (IVBA) for $\mathrm{As}, \mathrm{Cd}$, and $\mathrm{Pb}$ in soil was used to determine the bioaccessible fraction (BAF) of the ingested dose of metal(loid) that would become available to target organs (U.S. EPA, 2017b). Due to the low yield of dust samples and garden and playground soil within the $\leq 63 \mu \mathrm{m}$ diameter size fraction, $0.01 \mathrm{~g}$ of soil and dust samples to $1 \mathrm{~mL}$ of extraction fluid was used in the EPA Method 1340 (U.S. EPA, 2017b).

\subsubsection{Gastric in-vitro bioaccessibility assay}

The garden and playground soil samples (previously sieved to $\leq 63 \mu \mathrm{m}$ diameter) from each preschool that contained the highest concentration of $\mathrm{As}, \mathrm{Cd}$, and $\mathrm{Pb}$ were selected for the gastric IVBA. Replicates weighing $0.01 \pm 0.0038 \mathrm{~g}$ were prepared for these soil samples $(\mathrm{n}=20)$ and placed in black $1.5 \mathrm{~mL}$ polypropylene microcentrifuge tubes to prevent photocatalysis (Thomas et al., 2018). For the extraction fluid used in this assay, a synthetic gastric fluid composed of $0.4 \mathrm{M}$ glycine adjusted to $\mathrm{pH} 1.51-1.71$ using reagentgrade $\mathrm{HCl}$ was made. Within an anoxic chamber $\left(2 \% \mathrm{H}_{2(\mathrm{~g})}\right.$ and $\left.98 \% \mathrm{~N}_{2(\mathrm{~g})}\right)$, the soil sample was reacted with $1 \mathrm{~mL}$ of the extraction fluid and agitated in an end-over-end rotator inside of an incubator (Bioexpress Genemate Mini Incubator Shaker, UT) at $37{ }^{\circ} \mathrm{C}$ for $1 \mathrm{~h}$ as described by Thomas et al. (2018). After an hour of agitation, the samples were centrifuged at 2,700 RCF for $1 \mathrm{~min}$ and the supernatant was then filtered through an Acrodisc $\mathbb{R} 0.2 \mu \mathrm{m}$ metal-trace free hydrophilic polypropylene syringe filter to terminate the reaction. Lastly, $0.5 \mathrm{~g}$ of the filtered supernatant was weighed, and acid preserved using $9.5 \mathrm{~g}$ of $0.01 \mathrm{M}$ $\mathrm{HNO}_{3}$ until ICP-MS analysis (Agilent 8900 ICP-QQQ, Santa Clara, CA). The ICP-MS instrument quantifiable detection limits are reported in Table 1.

\subsubsection{Lung in-vitro bioaccessibility assay}

An IVBA simulating an inhalation exposure was conducted using the generated garden and playground dust samples. For this assay, a synthetic lung fluid composed of inorganic salts, surfactants, buffers, and humectant was used as described by Thomas et al. (2018). Under oxic conditions, the same modified standard operating procedure and preservation as the gastric IVBA was used. Metal(loid) concentrations were then measured by ICP-MS (Agilent 8900 ICP-QQQ, Santa Clara, CA). The ICP-MS instrument quantifiable detection limits are reported in Table 1. 


\subsubsection{Bioaccessible fraction (BAF) calculation}

The bioaccessible fraction (BAF) is the fraction of metal(loid) concentration extracted by the synthetic gastric and lung fluid from the soil and dust samples, respectively. The $\mathrm{BAF}$ for $\mathrm{As}, \mathrm{Cd}$, and $\mathrm{Pb}$ was calculated using the total metal(loid) concentrations measured in garden and playground soil $(<63 \mu \mathrm{m})\left(C_{s}\right)$ and dust $\left(C_{d}\right)$ samples and metal(loid) concentrations measured in the IVBA extracts $\left(C_{\text {ext }}\right)$. BAFs were calculated using the expression:

$$
B A F=\frac{C_{e x t} \times V_{e x t}}{C_{s, d} \times M_{s, d}} \times d f
$$

where $V_{\text {ext }}$ is the extraction solution volume; $M_{s}$ is the mass of soil sample used in the gastric IVBA; $M_{d}$ is the mass of dust sample used in the lung IVBA; and $d f$ is the dilution factor (U.S. EPA, 2017b).

\subsection{Exposure Assessment}

\subsubsection{Average daily dose and lifetime average daily dose calculations}

The estimated average daily dose (ADD, milligrams per kilogram of body weight per day) and lifetime average daily dose (LADD) of $\mathrm{As}, \mathrm{Cd}$, and $\mathrm{Pb}$ from ingested water, incidental soil, and consumption of plants grown in the gardens, as well as inhalation of dust was calculated using site-specific ingestion rates combined with environmental monitoring data. The $\mathrm{As}, \mathrm{Cd}$, and $\mathrm{Pb}$ concentration in plants $\left(C_{p}\right)$, soil $\left(C_{s}\right)$, dust $\left(C_{d}\right)$, and water $\left(C_{w}\right)$ was used to calculate the ADD for each age group using the expressions (Ramirez-Andreotta et al., 2013b; U.S. EPA. 2011):

$$
\begin{aligned}
A D D\left[m g \mathrm{~kg}^{-1} \mathrm{~d}^{-1}\right] & =\frac{C_{p, s, d, w} \times I R \times B A F \times C F \times E F \times E D}{B W \times A T-N C} \\
L A D D\left[m g \mathrm{~kg}^{-1} d^{-1}\right] & =\frac{C_{p, s, d, w} \times I R \times B A F \times C F \times E F \times E D}{B W \times A T-C}
\end{aligned}
$$

Where: $I R=$ ingestion rate; $B A F=$ bioaccessible fraction; $C F=$ conversion factor (only for soil and plant calculations); $E F=$ exposure frequency; $E D=$ exposure duration; $B W=$ average body weight (child); $A T-C=$ average time - cancer; and $A T-N C=$ average time non-cancer. Values used for these parameters for each child age group are presented in Tables 3-5. When not estimated from this study's FFQ and gardening description survey, 
values for these parameters were obtained from the U.S. EPA Children's Exposure Factors Handbook (U.S. EPA, 2008). The exposure frequency (EF) for incidental soil ingestion is defined as the frequency over which a child (of a defined age group) is exposed to the metal(loid) in question. Here, 181 days (26 weeks) (U.S. Department of Education, 2008) was used to account for the child's time at the preschool over one year. The ADD was modified to compare to values reported in the literature using the expression below as described by Ramirez-Andreotta et al. (2013b):

$$
A D D_{m}\left[\mu g d^{-1}\right]=A D D\left[m g k^{-1} d^{-1}\right] \times 1000 \times B W
$$

The cumulative ADD (CADD) and cumulative LADD (CLADD) describes the total exposure to $\mathrm{As}, \mathrm{Cd}$, or $\mathrm{Pb}$ by combined ingestion (of plant, soil, and water) and inhalation (of dust). The CADD and CLADD of each individual metal(loid) was calculated for each child age group using the expression below.

$$
\begin{gathered}
C A D D=\sum A D D\left[m g k g^{-1} d^{-1}\right] \\
C L A D D=\sum L A D D\left[m g k g^{-1} d^{-1}\right]
\end{gathered}
$$

\subsubsection{Site-specific ADD/LADD parameters}

Table 3. General parameters used in ADD and LADD calculations.

\begin{tabular}{lll}
\multicolumn{1}{c}{ Parameter } & Mean Value & \\
\hline EF $\left.(\mathrm{d} \mathrm{yr})^{-1}\right)$ & 181 & U.S. Department of Education (2008) \\
ED $(\mathrm{yr})$ & 1 & This study \\
AT-C $(\mathrm{yr})$ & 78 & U.S. EPA (2011) \\
AT-NC $(\mathrm{yr})$ & 1 & This study \\
BAF $_{\text {water, plant }}$ & 0.8 & Ramirez-Andreotta et al. (2013b) \\
\hline
\end{tabular}

Table 4. Mean metal(loid)-specific values for parameters used in ADD and LADD calculations.

\begin{tabular}{llll} 
& \multicolumn{3}{c}{ Element } \\
\cline { 2 - 4 } Parameter & \multicolumn{1}{c}{ As } & \multicolumn{1}{c}{$\mathrm{Cd}$} \\
\hline $\mathrm{C}_{\text {waater }}\left(\mathrm{mg} \mathrm{L}^{-1}\right)$ & $1.1 \times 10^{-4}$ & $2.50 \times 10^{-6}$ & $1.4 \times 10^{-4}$ \\
Cgarden_soil $\left.^{-4} \mathrm{mg} \mathrm{kg}^{-1}\right)$ & 6.9 & $3.1 \times 10^{-1}$ & $5.7 \times 10^{2}$ \\
C $_{\text {playground_soil }}\left(\mathrm{mg} \mathrm{kg}^{-1}\right)$ & 6.1 & $2.3 \times 10^{-1}$ & $1.5 \times 10^{2}$ \\
Cgarden_dust $_{\left(\mathrm{mg} \mathrm{m}^{-3}\right)}$ & $7.4 \times 10^{-6}$ & $1.7 \times 10^{-7}$ & $1.4 \times 10^{-5}$ \\
C $_{\text {playground_dust }}\left(\mathrm{mg} \mathrm{m}^{-3}\right)$ & $6.0 \times 10^{-6}$ & $1.0 \times 10^{-7}$ & $1.1 \times 10^{-5}$ \\
BAF $_{\text {soil }}$ & $9.3 \times 10^{-2}$ & $5.6 \times 10^{-1}$ & $1.2 \times 10^{-1}$ \\
$\mathrm{BAF}_{\text {dust }}$ & $1.9 \times 10^{-2}$ & $8.2 \times 10^{-2}$ & $8.0 \times 10^{-4}$ \\
\hline
\end{tabular}


Table 5. Age-specific values for parameters used in ADD and LADD calculations.

\begin{tabular}{|c|c|c|c|c|}
\hline \multirow[b]{2}{*}{ Parameter } & \multicolumn{3}{|c|}{ Exposure Age Group } & \multirow[b]{2}{*}{ Reference } \\
\hline & 1 to $<2 \mathrm{yrs}$ & 2 to $<3 \mathrm{yrs}$ & 3 to $<6 \mathrm{yrs}$ & \\
\hline BW (kg) & $11.4^{\mathrm{a}}$ & $13.8^{\mathrm{a}}$ & $18.6^{\mathrm{a}}$ & U.S. EPA (2011) \\
\hline $\operatorname{IR}_{\text {water }}\left(\mathrm{L} \mathrm{d}^{-1}\right)^{\mathrm{b}}$ & 0.146 & 0.205 & 0.208 & U.S. EPA (2019a) \\
\hline $\mathrm{IR}_{\text {soil }}\left(\mathrm{mg} \mathrm{d}^{-1}\right)$ & $40^{\mathrm{c}}$ & $30^{\mathrm{c}}$ & $30^{\mathrm{c}}$ & U.S. EPA (2017a) \\
\hline $\operatorname{IR}$ dust $\left(\mathrm{m}^{3} \mathrm{~d}^{-1}\right)$ & $8.0^{\mathrm{d}}$ & $9.5^{\mathrm{d}}$ & $10.9^{\mathrm{d}}$ & U.S. EPA (2008) \\
\hline $\mathrm{IR}_{\text {lettuce }}\left(\mathrm{mg} \mathrm{d}^{-1}\right)$ & $9.5 \times 10^{2}$ & $7.0 \times 10^{3}$ & $7.8 \times 10^{1}$ & This study \\
\hline $\mathrm{IR}_{\text {cilantro }}\left(\mathrm{mg} \mathrm{d}^{-1}\right)$ & $2.3 \times 10^{2}$ & $3.1 \times 10^{1}$ & 2.6 & \\
\hline $\mathrm{IR}_{\text {carrot }}\left(\mathrm{mg} \mathrm{d}^{-1}\right)$ & $3.4 \times 10^{3}$ & $1.5 \times 10^{4}$ & $2.3 \times 10^{3}$ & \\
\hline $\mathrm{IR}_{\text {kale }}\left(\mathrm{mg} \mathrm{d}^{-1}\right)$ & $3.4 \times 10^{2}$ & $1.7 \times 10^{2}$ & $1.7 \times 10^{2 \mathrm{e}}$ & \\
\hline $\operatorname{IR}_{\text {cabbage }}\left(\mathrm{mg} \mathrm{d}^{-1}\right)$ & $6.1 \times 10^{2}$ & $3.4 \times 10^{2}$ & $2.7 \times 10^{2}$ & \\
\hline
\end{tabular}

${ }^{a}$ Derived from NHANES (1999-2006) males and females combined.

${ }^{\mathrm{b}}$ Based on the 2-day average for water consumption (NHANES)

${ }^{c}$ Estimates of soil and dust were derived from the soil + dust values assuming $45 \%$ soil and $55 \%$ dust, rounded to one significant figure (used for EPA IEUBK model) (U.S. EPA, 2017a).

${ }^{\mathrm{d}}$ Long-term exposure (more than 30 days)

${ }^{\mathrm{e}}$ Ingestion rate of kale for 2 to $<3$ year-olds due to lack of data for children 3 to $<6$ years of age.

\subsection{Risk Characterization}

\subsubsection{Incremental excess lifetime cancer risk calculation}

The incremental excess lifetime cancer risk (IELCR) was calculated for each metal(loid) per exposure age group. The IELCR characterizes the risk of cancer from a lifetime exposure to carcinogens beyond one's natural risk. The IELCR from As exposures was calculated using the expression:

$$
I E L C R=L A D D \times C S F
$$

where the $C S F$ is the cancer slope factor for As, which is the upper bound increased risk of cancer from exposure to As over a lifetime (Ramirez-Andreotta et al., 2013b). The IELCR was calculated for ingestion of water, plants, (incidental) soil, and inhalation of dust using a CSF of $1.5\left(\mathrm{mg} \mathrm{kg}^{-1} \mathrm{~d}^{-1}\right)^{-1}$ (Table 6).

\subsubsection{Hazard quotient}

The cumulative hazard quotient (HQ) was calculated to characterize a child's cumulative risk of non-carcinogenic effects for each exposure age group per metal(loid). The HQ was calculated using the expression:

$$
H Q=\frac{C A D D}{R f D}
$$


where the reference dose (RfD) is the ratio extrapolated at which no-observable adverse effects are expected. When available, a child-specific RfD was used. The CalEPA and federal EPA recommended $\mathrm{RfDs}$ for $\mathrm{As}, \mathrm{Cd}$, and $\mathrm{Pb}$, used for this calculation are shown in Table 6. An HQ $\geq 1$ indicates no adverse health effects expected from an exposure.

\section{Table 6. Values used for risk characterization calculations.}

\begin{tabular}{ccc}
\hline Metal(loid) & $\begin{array}{c}\text { CSF } \\
{\left[\left(\mathrm{mg} \mathrm{kg}^{-1} \mathrm{~d}^{-1}\right)^{-1}\right]}\end{array}$ & $\begin{array}{c}\text { Oral RfD } \\
\left(\mathrm{mg} \mathrm{kg}^{-1} \mathrm{~d}^{-1}\right)\end{array}$ \\
\hline $\mathrm{As}$ & $1.5^{1,2}$ & $3 \times 10^{-4} \mathrm{c}$ \\
$\mathrm{Cd}$ & $\mathrm{NA}$ & $1.1 \times 10^{-5} \mathrm{a}, \mathrm{b}$ \\
$\mathrm{Pb}$ & $\mathrm{NA}$ & $\mathrm{NA}$ \\
\hline
\end{tabular}

${ }^{a}$ Child-specific reference dose estimated as the concentration at which continuous exposure will likely not result in noncancerous effects over a lifetime (CalEPA OEHHA, 2003)

${ }^{\mathrm{b}}$ CalEPA OEHHA Chemical Database (CalEPA OEHHA, 2003)

${ }^{c}$ U.S. EPA IRIS Database (U.S. EPA, 2006a)

\section{Results}

\subsection{Metal and metalloids in environmental media}

\subsubsection{Irrigation water}

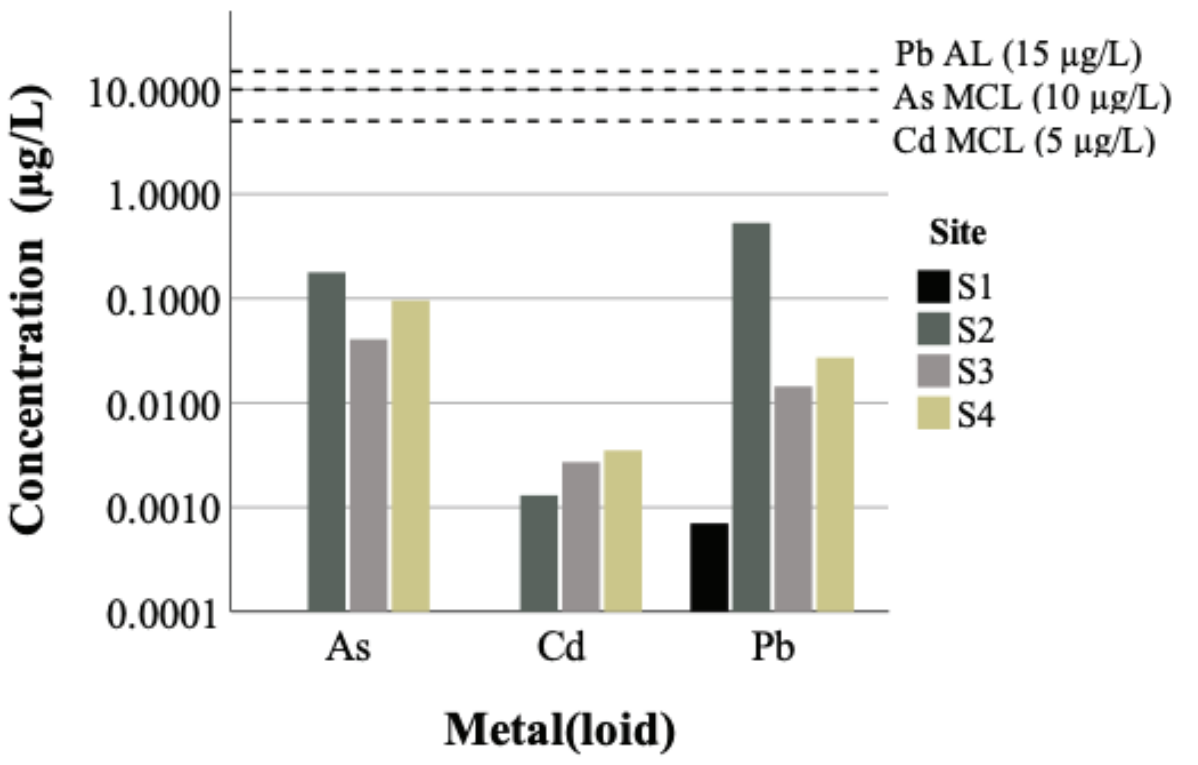

Figure 3. Garden irrigation water metal(loid) concentrations $\left(\mu g L^{-1}\right)$.

The total $\mathrm{As}, \mathrm{Cd}$, and $\mathrm{Pb}$ concentrations in irrigation water samples ranged from 0.041 to $0.18 \mu \mathrm{g} \mathrm{L}^{-1}, 0.0013$ to $0.0035 \mu \mathrm{g} \mathrm{L}^{-1}, 0.00066$ to $0.53 \mu \mathrm{g} \mathrm{L}^{-1}$, respectively. The sample taken at S2 had the highest concentration of As $\left(0.18 \mu \mathrm{g} \mathrm{L}^{-1}\right)$ and $\mathrm{Pb}\left(0.53 \mu \mathrm{g} \mathrm{L}^{-1}\right)$; however, these concentrations were two orders of magnitude below the U.S. EPA primary 
maximum contaminant level (MCL) of $10 \mu \mathrm{g} \mathrm{L}^{-1}$ for As and the Lead and Copper Rule action level (AL) of $15 \mu \mathrm{g} \mathrm{L}^{-1}$ for $\mathrm{Pb}$ for drinking water (Figure 3). Furthermore, the highest Cd concentration measured (S4) was three orders of magnitude less than the MCL of $5 \mu \mathrm{g}$ $\mathrm{L}^{-1}$ for $\mathrm{Cd}$. Tap water is currently the irrigation water source for all preschool gardens, as reported by all site administrators in the gardening description survey. To irrigate the gardens, water is collected from an outdoor water fountain at S1, and from a hose at S2, S3, and S4.

\subsubsection{Soil}

The metal(loid) concentrations for garden and playground soil samples sieved to $<$ $63 \mu \mathrm{m}$ are reported in Figure 4. Sections 3.1.2.1. to 3.1.2.3. summarize how the median concentrations of each metal(loid) compared to soil screening levels recommended by federal and California state agencies listed in Table 7. These screening levels are based on the carcinogenic effects of long-term exposures to metal(loid)s by multiple pathways with a target risk of $10^{-6}$ unless specified otherwise (U.S. EPA, 2019b; CalEPA DTSC 2018; OEHHA, 2010). 

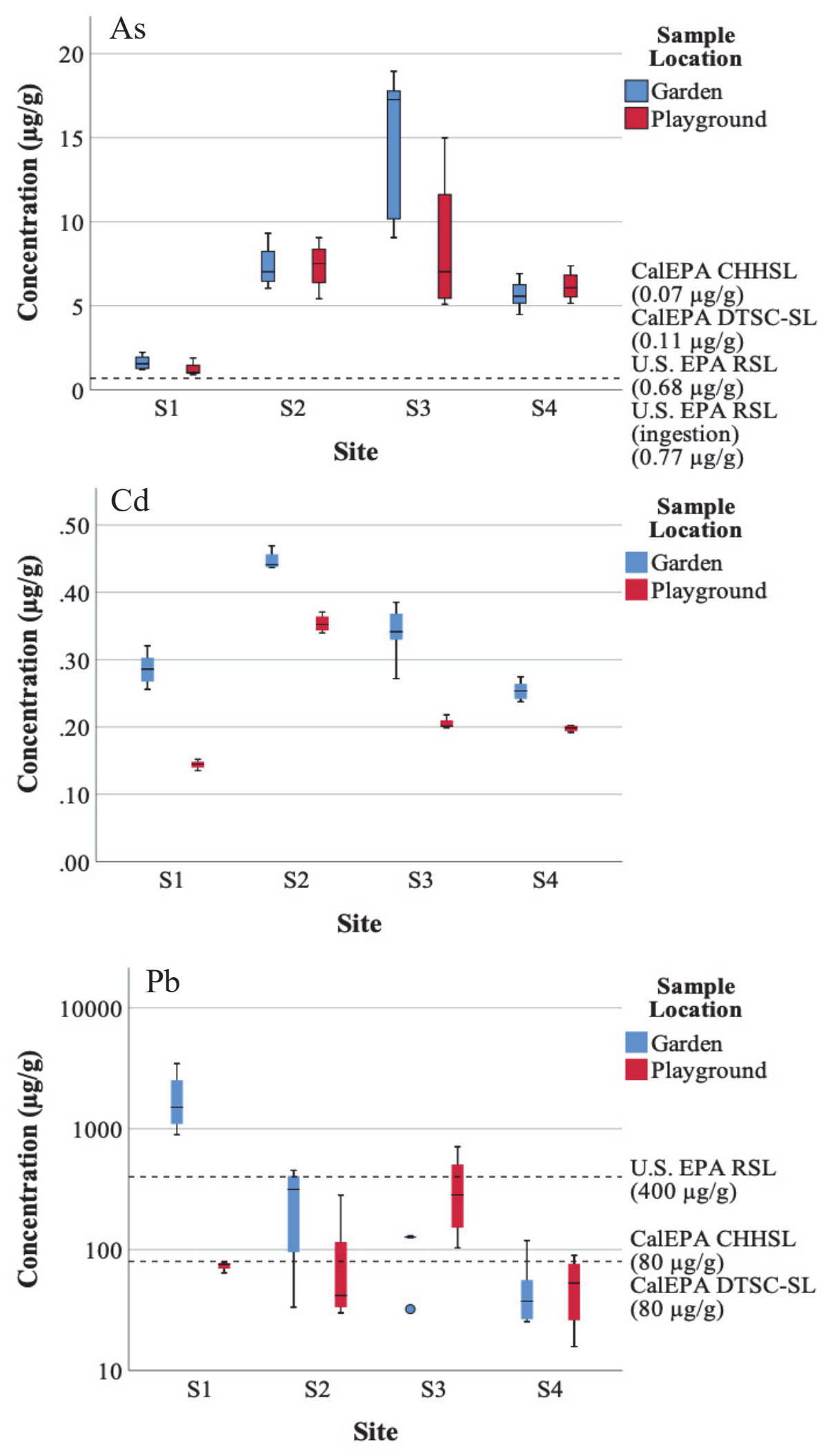

Figure 4. Median metal(loid) concentrations $\left(\mu g^{-1}\right)$ measured from garden and playground soil samples $(<63 \mu \mathrm{m})$. 


\begin{tabular}{ccccc}
\multicolumn{5}{c}{ Table 7. Federal and state recommended residential soil screening levels $\left(\mu g g^{-1}\right)$} \\
$\begin{array}{c}\text { Governing } \\
\text { Agency }\end{array}$ & As & $\mathrm{Cd}^{2}$ & $\mathrm{~Pb}$ \\
\hline CalEPA & CHHSL & $0.07(\mathrm{ca})$ & $1.7(\mathrm{ca})$ & $80(\mathrm{nc})^{1}$ \\
\hline CalEPA & DTSC-SL & $0.11(\mathrm{ca})$ & $\begin{array}{c}2,100(\mathrm{ca})^{3} \\
5.2(\mathrm{nc})\end{array}$ & $80(\mathrm{nc})$ \\
\hline U.S. EPA & EPA RSL & $0.68(\mathrm{ca})$ & $2,100(\mathrm{ca})$ & $400(\mathrm{ncc})$ \\
\hline U.S. EPA & $\begin{array}{c}\text { EPA RSL } \\
\text { (ingestion) }\end{array}$ & $0.77(\mathrm{ca})$ & $78(\mathrm{ncc})$ & \\
\hline U.S. EPA & $\begin{array}{c}\text { EPA RSL } \\
\text { (inhalation) }\end{array}$ & $890(\mathrm{ca})$ & $2,100(\mathrm{ca})$ & \\
\hline NR & $\begin{array}{c}4 \\
\text { Background levels }\end{array}$ & $\begin{array}{l}8.2^{5} \\
3.5^{6}\end{array}$ & $0.36^{6}$ & $23.9^{6}$
\end{tabular}

(ca) denotes that the risk-based screening level is based on carcinogenic effects (CSF). TR $=10^{-6}$

(nc) denotes that the risk-based screening level is based on non-carcinogenic chronic effects. $\mathrm{HI}=1$

(ncc) denotes that the risk-based screening level is based on non-carcinogenic chronic effects for children. $\mathrm{HI}=1$

${ }^{1} 95 \%$ upper confidence limit that is protective for children (not-risk based)

${ }^{2}$ From diet only

${ }^{3}$ U.S. EPA risk-based screening level recommended by DTSC

${ }^{4}$ Not regulated (NR)

${ }^{5}$ mean background concentration of native soil on California island not affected by legacy mining (Behrshing et al., 2009)

${ }^{6}$ Mean concentrations of 50 benchmark CA soils (Kearney Foundation of Soil Science, 1996)

\subsubsection{Arsenic}

Arsenic concentration in garden and playground soil collected from each school ranged from 1.2 to $19 \mu \mathrm{g} \mathrm{g}^{-1}$ and 0.90 and $15 \mu \mathrm{g} \mathrm{g}{ }^{-1}$, respectively (Figure 4). All As concentrations in soil samples exceeded the recommended California Human Health Screening Level (CHHSL) (0.07 $\left.\mu \mathrm{g} \mathrm{g}^{-1}\right)$, California Department of Toxic Substances Control Screening Level (DTSC-SL) of $0.11 \mu \mathrm{g} \mathrm{g}^{-1}$ and the U.S. EPA Regional Screening Level (RSL) of $0.68 \mu \mathrm{g} \mathrm{g}^{-1}$. Further, all soil samples exceeded the EPA RSL specific to exposures by ingestion $\left(0.77 \mu \mathrm{g} \mathrm{g}^{-1}\right)$. All garden amendment samples had median As concentrations that also exceeded these recommended screening levels. All median As concentrations in garden and playground samples and amendments were similar to CA background concentrations for As listed in Table 7 (Kearney Foundation of Soil Science, 1996).

\subsubsection{Cadmium}

Cadmium concentration in gardens and playgrounds ranged from 0.24 to $0.44 \mu \mathrm{g}$ $\mathrm{g}^{-1}$, and 0.14 to $0.37 \mu \mathrm{g} \mathrm{g}^{-1}$, respectively (Figure 4). All garden and playground soil samples 
taken from all sites did not exceed the corresponding CHHSL, DTSC-SL, and EPA RSLs for $\mathrm{Cd}$ listed in Table 7. The $\mathrm{Cd}$ concentrations in garden amendments also did not exceed these recommended levels. Median garden and playground samples and amendments from all sites were similar to CA Cd background levels listed in Table 7 (Kearney Foundation of Soil Science, 1996).

\subsubsection{Lead}

All garden soil samples $(n=6)$ from $\mathrm{S} 1$ exceeded all three recommended screening levels, with a median $\mathrm{Pb}$ concentration approximately 19 times higher than the California state screening levels (Figure 4). Likewise, the median $\mathrm{Pb}$ concentration in garden soil from $\mathrm{S} 2\left(3.2 \times 10^{2} \mu \mathrm{g} \mathrm{g}^{-1}\right)$ and garden and playground soil from S3 $\left(1.3 \times 10^{2} \mu \mathrm{g} \mathrm{g}^{-1}\right.$ for garden and $2.9 \times 10^{2} \mu \mathrm{g} \mathrm{g}^{-1}$ for playground) exceeded the CHHSL and DTSC-SL. All garden and playground soil samples exceeded background $\mathrm{Pb}$ levels found throughout $\mathrm{CA}$ listed in Table 7 (Kearney Foundation of Soil Science, 1996). Lead concentrations were much greater in soil samples than in the amendments. This suggests that the garden amendments did not have a significant contribution to the elevated $\mathrm{Pb}$ levels measured in the soil.

\subsubsection{Dust}

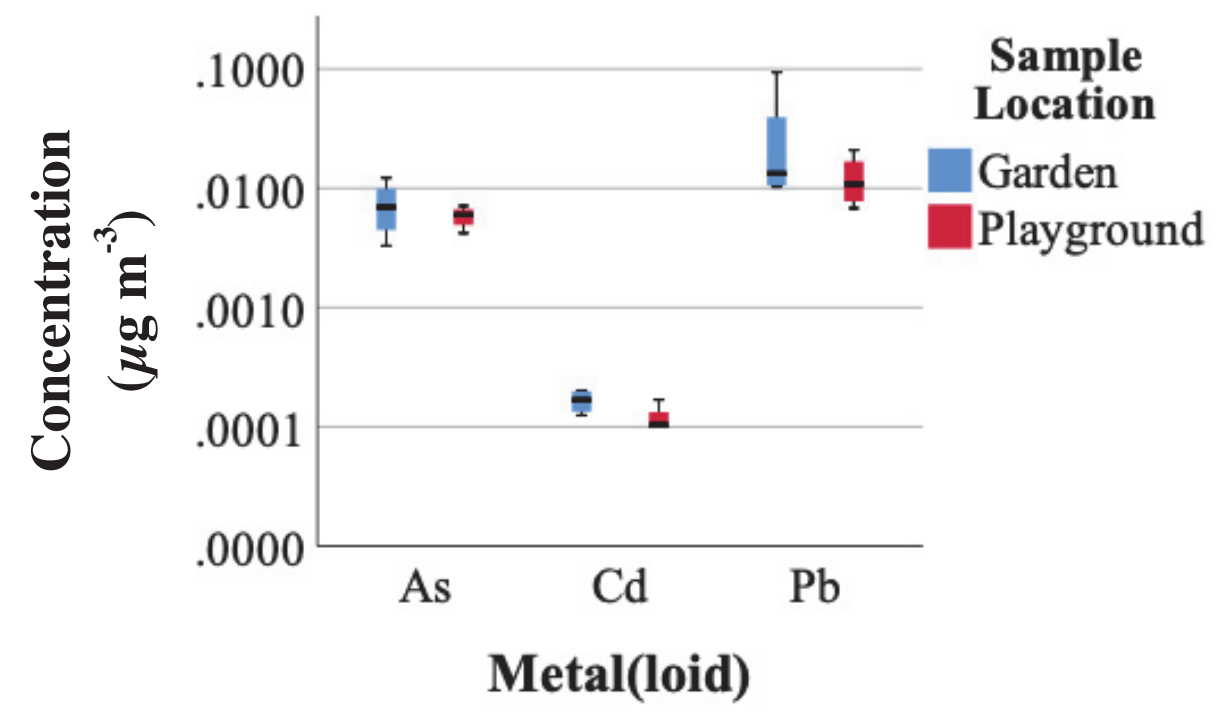

Figure 5. Atmospheric metal(loid) concentrations $\left(\mu \mathrm{g} \mathrm{m}^{-3}\right)$ estimated from garden and playground dust samples $(<10 \mu \mathrm{m})$. 
The metal(loid) concentration in dust $(<10 \mu \mathrm{m})$ samples produced from garden and playground surface soils are reported in Figure 5. The median $\mathrm{Pb}$ concentrations from garden and playground dust ( 0.14 and $0.011 \mu \mathrm{g} \mathrm{m}^{-3}$, respectively) were lower than the U.S. EPA National Ambient Air Quality Standard of $0.15 \mu \mathrm{g} \mathrm{m}^{-3}$ for Pb (U.S. EPA, 2006b). However, these concentrations were similar to concentrations in a smelter impacted site in Hayden, AZ of $0.023 \mu \mathrm{g} \mathrm{m}^{-3}$ reported by Csavina et al. (2011). Metal(loid) concentration in dust $(<10 \mu \mathrm{m})$ samples were used to determine ADD and LADD for exposure age group. There is currently no federal or state standard for As or Cd concentration.

The particle size distribution of generated dust samples was analyzed using ImageJ. The particle diameter ranged from 0.80 to $26 \mu \mathrm{m}$ and 0.41 to $17 \mu \mathrm{m}$, respectively. The percentage of particles with a diameter of $\leq 10 \mu \mathrm{m}$ was $95-98 \%$. The majority of particles were within the 0.40 to approximately $2.0 \mu \mathrm{m}$ size fraction. 


\subsubsection{Plants}

A

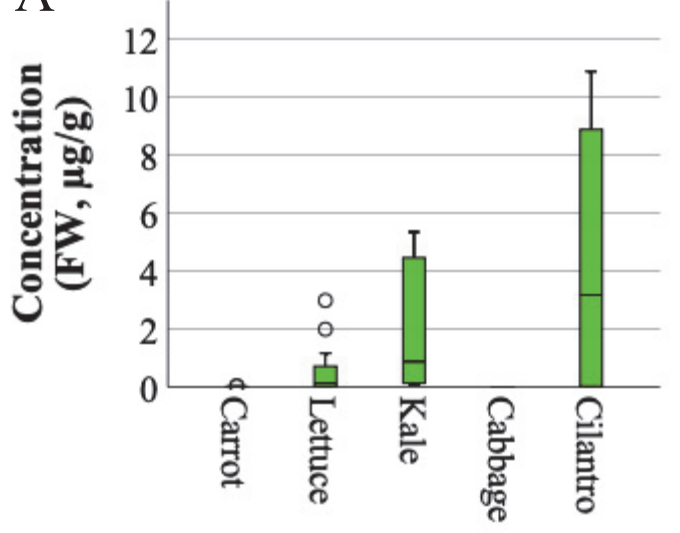

Preschool-grown plant

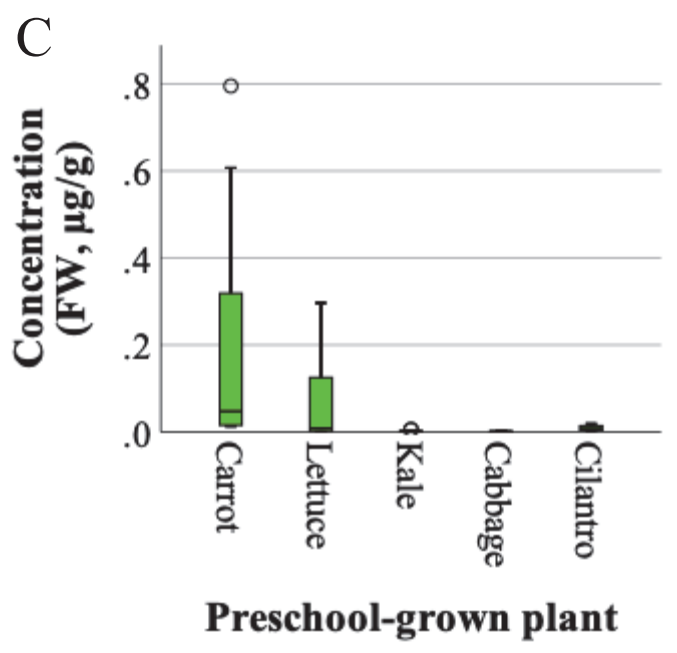

B

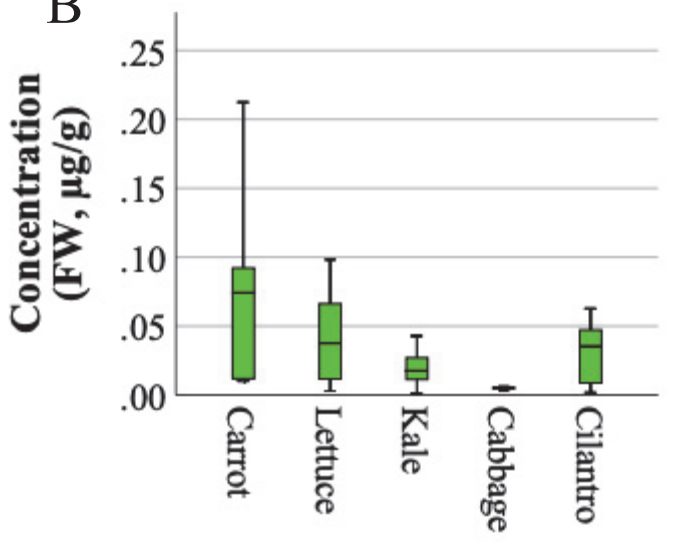

Preschool-grown plant

D

\begin{tabular}{c|c|c|c}
\hline Plant (Family) & $\mathrm{As}$ & $\mathrm{Cd}$ & $\mathrm{Pb}$ \\
\hline $\begin{array}{c}\text { Cabbage } \\
\text { (Brassicaceae) }\end{array}$ & $\mathrm{AB}$ & $\mathrm{AB}$ & $\mathrm{AB}$ \\
$\begin{array}{c}\text { Carrot } \\
\text { (Apiaceae) }\end{array}$ & $\mathrm{B}$ & $\mathrm{A}$ & $\mathrm{A}$ \\
$\begin{array}{c}\text { Cilantro } \\
\text { (Apiaceae) }\end{array}$ & $\mathrm{A}$ & $\mathrm{AB}$ & $\mathrm{B}$ \\
$\begin{array}{c}\text { Kale } \\
\text { (Brassicaceae) }\end{array}$ & $\mathrm{AB}$ & $\mathrm{B}$ & $\mathrm{B}$ \\
$\begin{array}{c}\text { Lettuce } \\
\text { (Asteraceae) }\end{array}$ & $\mathrm{B}$ & $\mathrm{AB}$ & $\mathrm{AB}$ \\
\hline
\end{tabular}

Figure 6. As (A), $C d(B)$, and $P b(C)$ concentration in preschool garden produce, and (D) significant difference among measured metal(loid) mean concentration $\left(F W, \mu g g^{-1}\right)$ by plant type per metal(loid)). Significant differences $(p<0.05)$ in mean metal(loid) concentrations are denoted by different letters by plant type.

Apiaceae plants (carrot and cilantro) had the greatest median concentrations across all metal(loid)s (Figure 6). Significant differences ( $\mathrm{p}$-value $<0.05$ ) in mean $\mathrm{As}, \mathrm{Cd}$, and $\mathrm{Pb}$ concentrations were observed between the different plant types shown in Figure 6. 
Table 8. Median metal(loid) concentrations (FW, $\mathrm{mg} \mathrm{kg}^{-1}$ ), and mean metal(loid) concentrations reported in the U.S. FDA Total Diet Study, and WHO Codex Recommended Maximum Levels ( $F W, \mathrm{mg} \mathrm{kg}^{-1}$ ).

\begin{tabular}{|c|c|c|c|c|}
\hline $\begin{array}{c}\text { Plant } \\
\text { (Family) }\end{array}$ & & As & $\mathrm{Cd}$ & $\mathrm{Pb}$ \\
\hline \multirow{3}{*}{$\begin{array}{c}\text { Lettuce } \\
\text { (Asteraceae) }\end{array}$} & $\operatorname{Median}(\mathrm{n}=12)^{\mathrm{b}}$ & $\begin{array}{c}0.14^{*} \\
(0.0014-3.0)\end{array}$ & $\begin{array}{c}0.04 \\
(0.0030-0.098)\end{array}$ & $\begin{array}{c}0.01 * \\
(0.0010-0.30)\end{array}$ \\
\hline & $\begin{array}{l}\text { U.S. FDA } \\
\text { (leaf, raw) }\end{array}$ & 0.002 & 0.066 & 0.005 \\
\hline & $\begin{array}{c}\text { Codex } \\
\text { (leafy vegetables) }\end{array}$ & N/A & 0.2 & 0.3 \\
\hline \multirow{3}{*}{$\begin{array}{l}\text { Cilantro } \\
\text { (Apiaceae) }\end{array}$} & Median $(\mathrm{n}=12)^{\mathrm{b}}$ & $\begin{array}{c}3.2 \\
(0.0025-11)\end{array}$ & $\begin{array}{c}0.035 \\
(0.0018-0.063)\end{array}$ & $\begin{array}{c}0.0071 \\
(0.0031-0.020)\end{array}$ \\
\hline & U.S. FDA & $\mathrm{N} / \mathrm{A}$ & $\mathrm{N} / \mathrm{A}$ & N/A \\
\hline & $\begin{array}{c}\text { Codex } \\
\text { (leafy vegetables) }\end{array}$ & N/A & 0.2 & 0.3 \\
\hline \multirow{3}{*}{$\begin{array}{c}\text { Carrot } \\
\text { (Apiaceae) }\end{array}$} & Median $(n=9)^{b}$ & $\begin{array}{c}0.0079^{*} \\
(0.0058- \\
0.038) \\
\end{array}$ & $\begin{array}{c}0.074^{*} \\
(0.010-0.21) \\
\end{array}$ & $\begin{array}{c}0.048^{*} \\
(0.013-0.80)\end{array}$ \\
\hline & $\begin{array}{c}\text { U.S. FDA } \\
\text { (fresh, peeled, boiled) }\end{array}$ & $0.005^{\mathrm{a}}$ & 0.019 & 0.002 \\
\hline & $\begin{array}{c}\text { Codex } \\
\text { (root and tuber } \\
\text { vegetables) }\end{array}$ & N/A & 0.1 & 0.1 \\
\hline \multirow{3}{*}{$\begin{array}{c}\text { Kale } \\
\text { (Brassicaceae) }\end{array}$} & Median $(n=9)^{b}$ & $\begin{array}{c}0.87 \\
(0.068-5.3) \\
\end{array}$ & $\begin{array}{c}0.018 \\
(0.0012-0.04)\end{array}$ & $\begin{array}{c}0.0017 \\
(0.0003-0.0064) \\
\end{array}$ \\
\hline & U.S. FDA & N/A & N/A & N/A \\
\hline & $\begin{array}{c}\text { Codex } \\
\text { (leafy vegetables) }\end{array}$ & N/A & 0.2 & 0.3 \\
\hline \multirow{3}{*}{$\begin{array}{c}\text { Cabbage } \\
(\text { Brassicaceae) }\end{array}$} & $\operatorname{Median}(\mathrm{n}=3)^{\mathrm{b}}$ & $0.0036^{* \mathrm{c}}$ & $\begin{array}{c}0.0051^{*} \\
(0.0037-0.0061)\end{array}$ & $\begin{array}{c}0.0013 \\
(0.0011-0.0015) \\
\end{array}$ \\
\hline & $\begin{array}{c}\text { U.S. FDA } \\
\text { (fresh, boiled) }\end{array}$ & $0.004^{\mathrm{a}}$ & 0.005 & $0.0025^{\mathrm{a}}$ \\
\hline & $\begin{array}{c}\text { Codex } \\
\text { (Brassica vegetables - } \\
\text { head cabbages) }\end{array}$ & N/A & 0.05 & 0.1 \\
\hline
\end{tabular}

* Denotes a measured median concentration larger than the respective mean reported by the U.S. FDA Total Diet Study (U.S. FDA, 2014).

${ }^{a}$ More conservative value calculated when a mean value of 0 is reported. This value is calculated as $1 / 2$ the detection limit (Ramirez-Andreotta et al., 2013b).

${ }^{\mathrm{b}}$ This study

${ }^{c}$ Values reported are $1 / 2$ the detection limit due to As concentrations of cabbage being at or below the detection limit (U.S. EPA, 2000).

The median metal(loid) concentrations of $\mathrm{As}, \mathrm{Cd}$, and $\mathrm{Pb}$ observed in the plant samples were compared to the U.S. Food and Drug Administration Total Diet Study (U.S. FDA, 2014) to determine how store-bought produce compares to the produce grown at the preschools. Preschool-grown carrots had a higher concentration of each of the measured metal(loid)s than those store-bought. Preschool-grown lettuce accumulated more As and 
$\mathrm{Pb}$ while cabbage accumulated more $\mathrm{As}$ and $\mathrm{Cd}$ than store-bought lettuce and cabbage, respectively. Trends of decreasing mean metal(loid) concentrations in plant families grown at the preschools decreased in the order of:

- As: Apiaceae > Brassicaceae > Asteraceae

- $\mathrm{Cd}$ : Apiaceae $>$ Asteraceae $>$ Brassicaceae

- $\mathrm{Pb}$ : Apiaceae $>$ Asteraceae $>$ Brassicaceae

Median $\mathrm{Cd}$ and $\mathrm{Pb}$ concentrations in preschool-grown plants were below the respective recommendation maximum level set by WHO Codex in Table 8 .

\subsubsection{Bioconcentration factor}

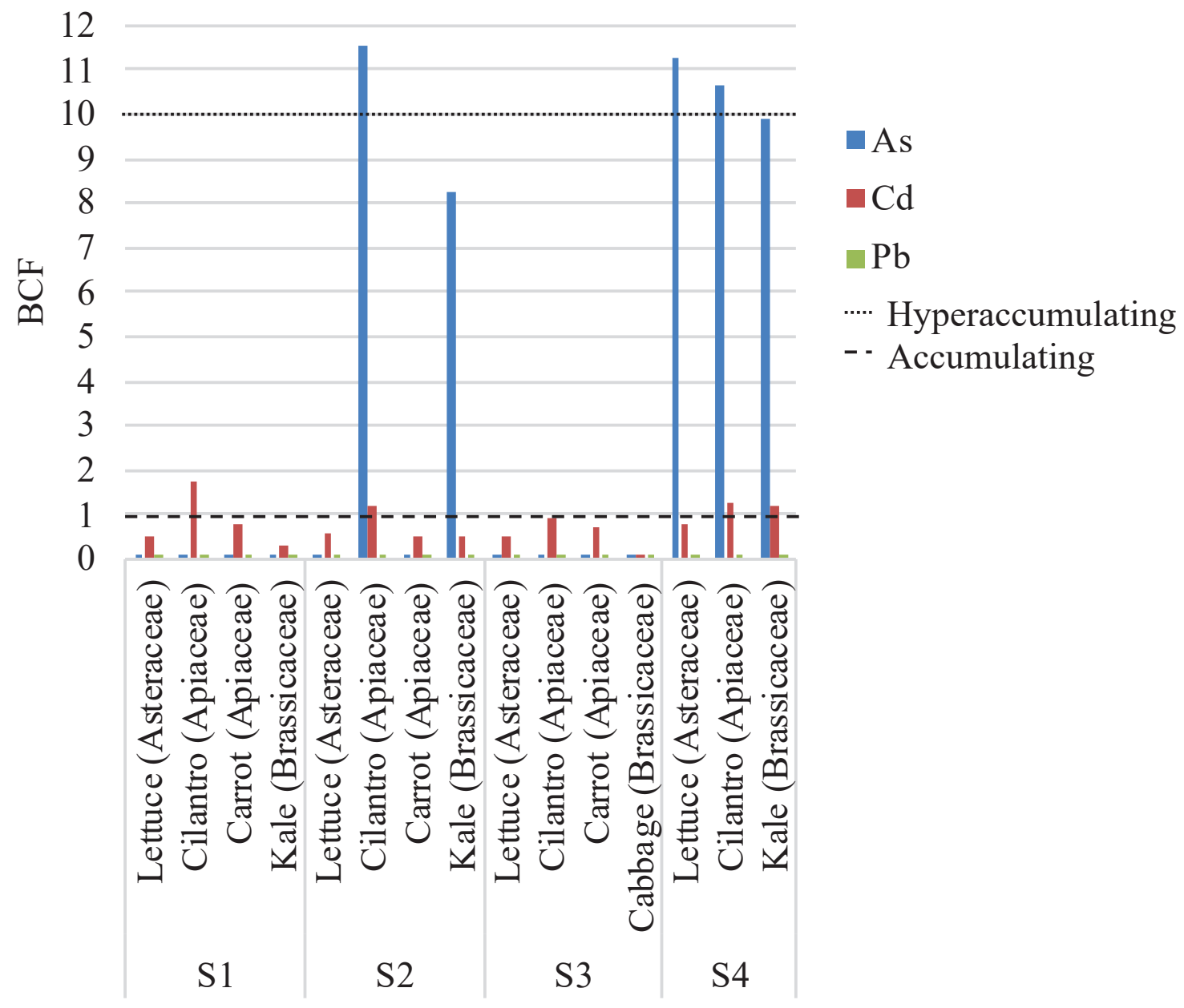

Figure 7. Site-specific median BCF of metal(loid) per plant type. 


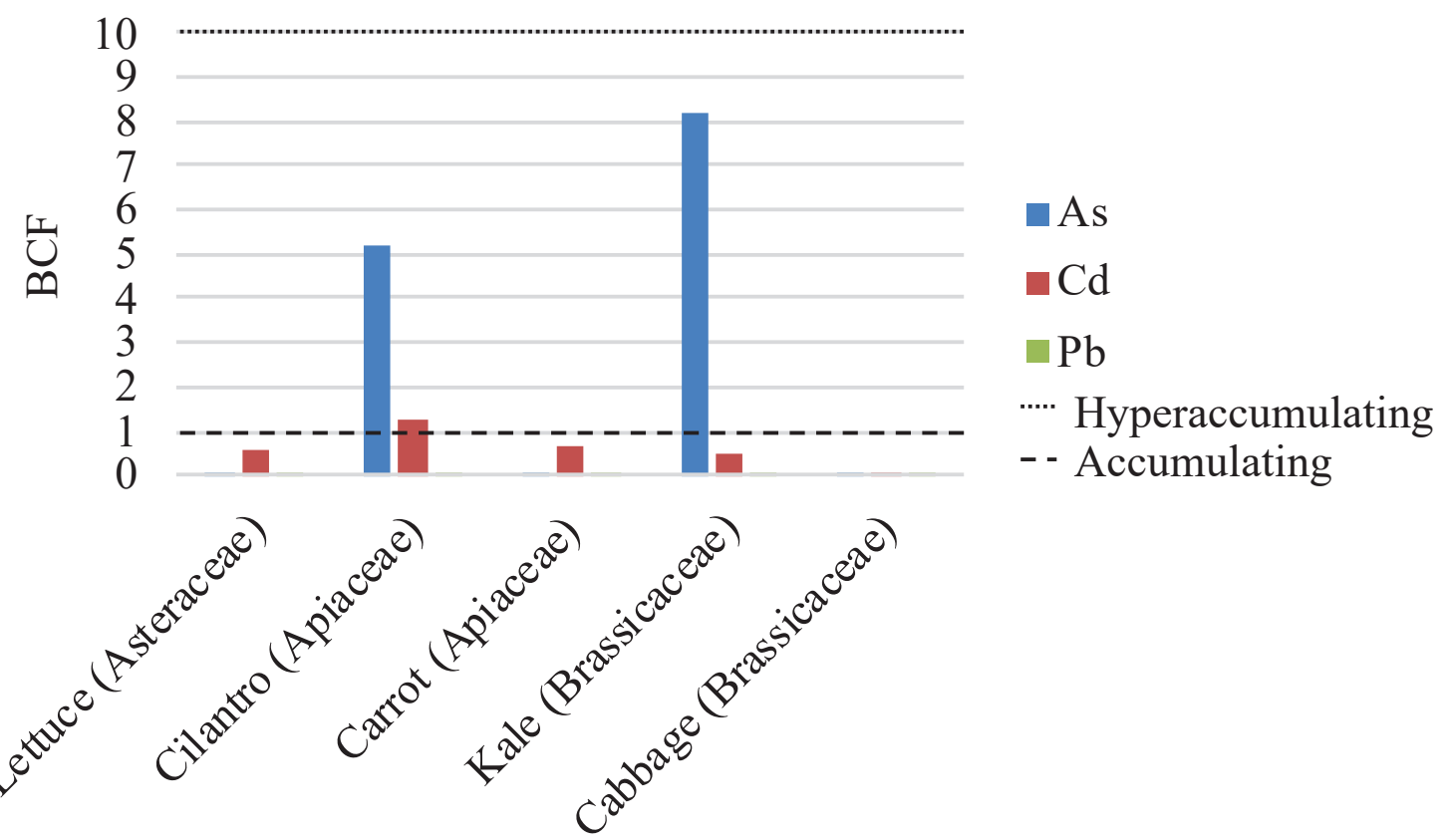

Figure 8. Median BCF of metal(loid) per plant type (across all sites).

The bioconcentration factor (BCF) of plants varied by site and metal(loid). The calculated BCF of each metal(loid) for each plant type per preschool school is shown (Figure 7). The following categories were used to identify metal accumulators and hyperaccumulators: $\mathrm{BCF}<1$ - no metal(loid) accumulation; $1 \leq \mathrm{BCF}<10-$ metal(loid) accumulation; and $\mathrm{BCF} \geq 10$ - metal(loid) hyperaccumulation (Ávila et al., 2016). All plants (lettuce, cilantro, and kale) at S4 hyperaccumulated As, and nearly all accumulated Cd. Further, S2 cilantro and kale hyperaccumulated and accumulated As, respectively. The $\mathrm{S} 1$ and $\mathrm{S} 2$ cilantro also accumulated $\mathrm{Cd}$. No plant accumulated or hyperaccumulated $\mathrm{Pb}$ (Figure 7). The median BCF was also calculated across all preschool locations to show a general accumulation trend across sites (Figure 8). In general, cilantro was an accumulator of As and $\mathrm{Cd}$, and kale only accumulated As. 
3.2. Bioaccessible fraction of $\mathrm{As}, \mathrm{Cd}, \mathrm{Pb}$
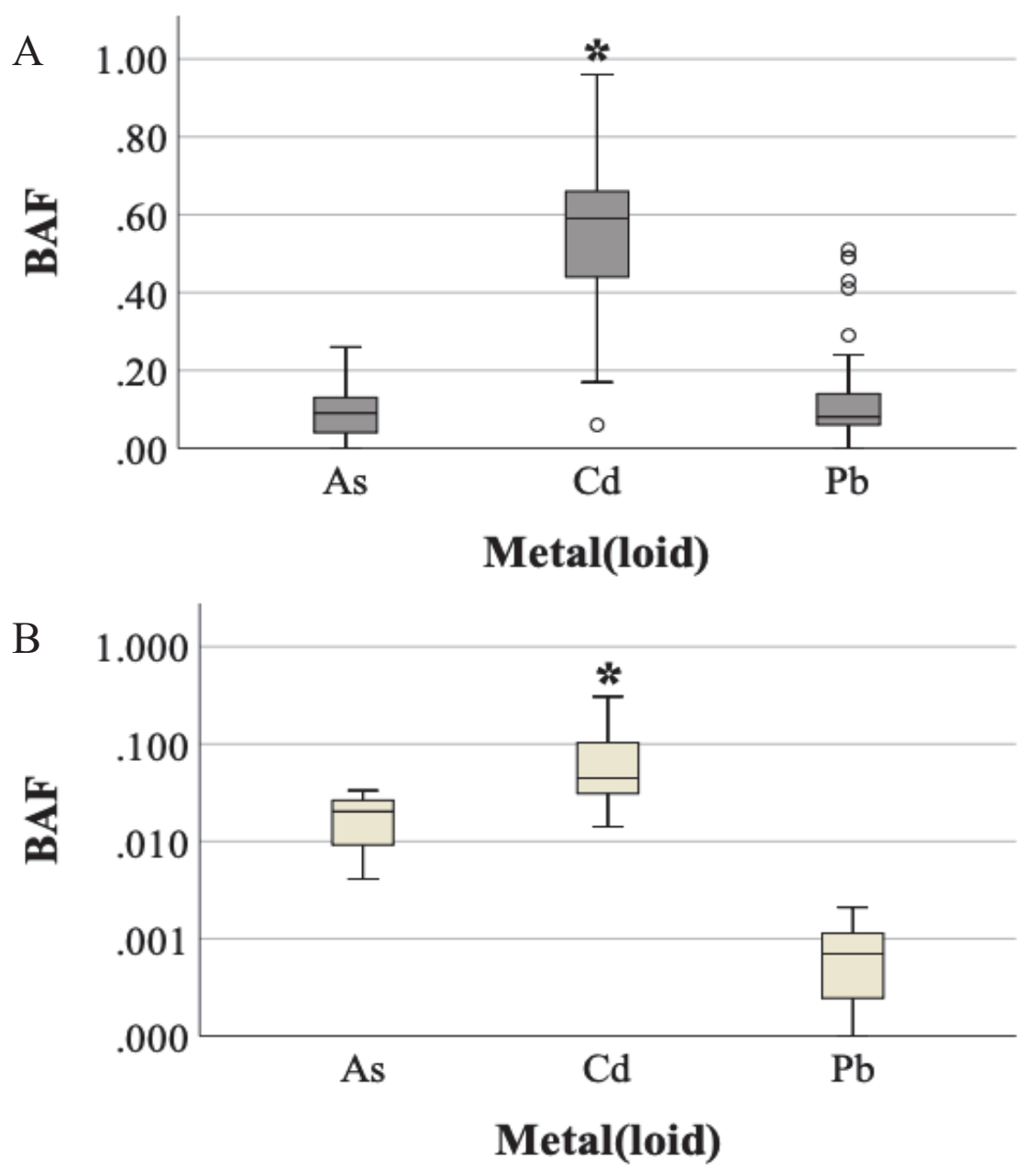

Figure 9. BAF of metal(loid) determined by gastric (A) and lung (B) IVBA. Asterisk signifies significant difference at p-value $<0.05$.

The gastric and lung BAF varied by metal(loid) and sample location (garden vs. playground). The BAF of $\mathrm{As}, \mathrm{Cd}$, and $\mathrm{Pb}$ determined by the gastric and lung IVBA are shown in Figure 9. When considering sample location, the median of $\mathrm{As}, \mathrm{Cd}$, and $\mathrm{Pb}$ extracted from by the synthetic gastric fluid were 12 and $7.4 \%, 62$ and 58\%, and 8.4 and $8.0 \%$, respectively for garden and playground soils. Generally, the BAF of $\mathrm{As}, \mathrm{Cd}$, and $\mathrm{Pb}$ determined by gastric IVBA were greater than those by lung IVBA. This is presumably due to the nature of the chemical properties of each IVBA extraction fluid. 


\subsection{Exposure Assessment}

\subsubsection{Cumulative exposure}

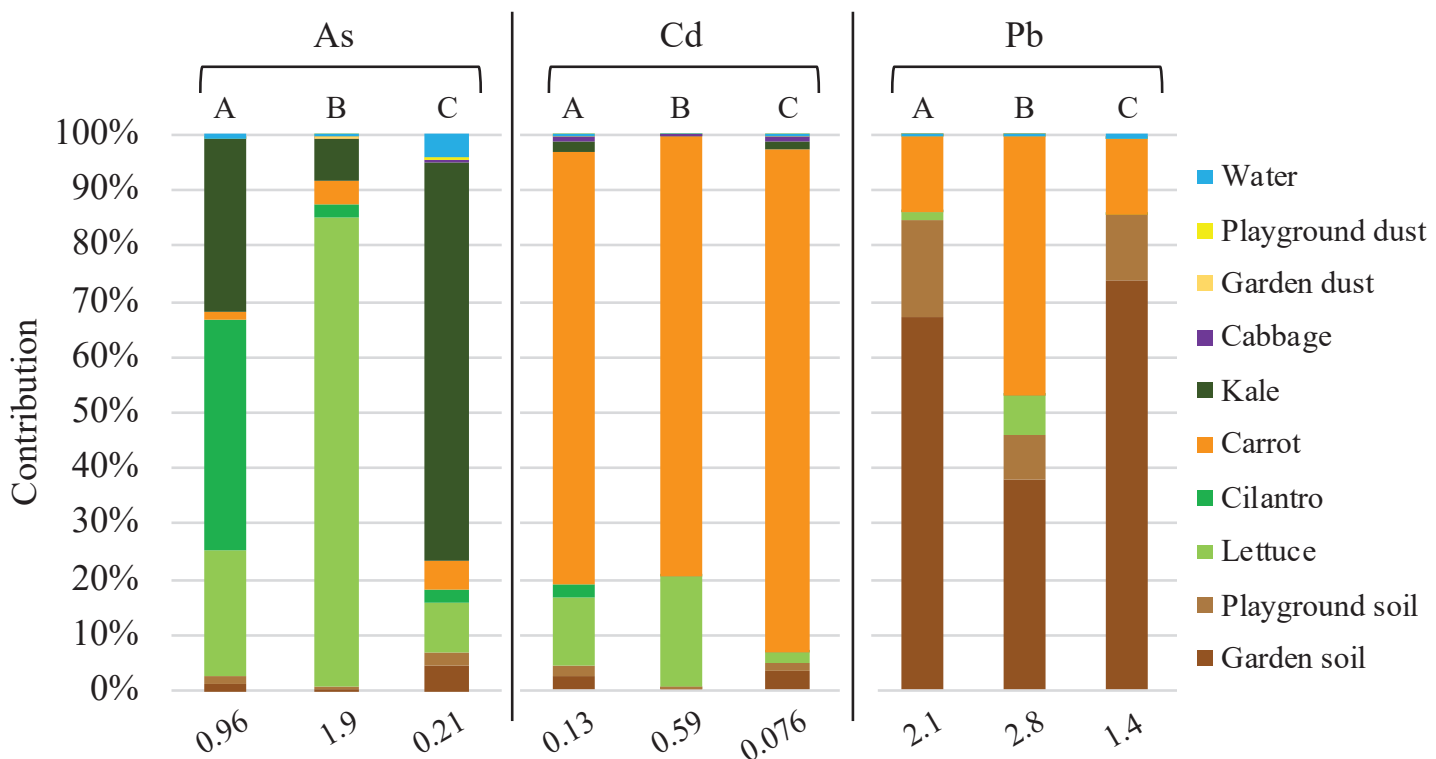

Total ADD of metal(loid) per age group $\left(\mu \mathrm{g} \mathrm{d}^{-1}\right)$

Figure 10. Percent contribution of exposure media to $A D D$ of $A s, C d$, and Pb for children of different exposure age groups: (A) 1 to $<2$ yrs, (B) 2 to $<3$ yrs, and (C) 3 to $<6$ yrs. The value below each bar is the cumulative exposure to $\mathrm{As}, \mathrm{Cd}$, and $\mathrm{Pb}\left(\mathrm{mg} \mathrm{kg}^{-1} \mathrm{~d}^{-1}\right)$ for a child of that age group.

The percent contribution of $\mathrm{As}, \mathrm{Cd}$, and $\mathrm{Pb}$ from different environmental media, for children of each exposure age group is shown in Figure 10. Consumption of preschoolgrown cilantro (41\%), lettuce (84\%), and kale (70\%) accounted for the highest percent contribution to the cumulative exposure to As for children aged 1 to $<2$ years, 2 to $<3$ years, and 3 to $<6$ years, respectively (Figure 10). Carrot contributed the most to a child's cumulative exposure to $\mathrm{Cd}$ for each age group: $78 \%, 79 \%$, and $90 \%$ for 1 to $<2$ years, 2 to $<3$ years, and 3 to $<6$ years, respectively. Carrot contributed the most (37\%) to a 2 to $<3$ year-old child's cumulative $\mathrm{Pb}$ exposure, however, incidental garden soil ingestion contributed the most $\mathrm{Pb}$ for children 1 to $<2(67 \%)$ years and 3 to $<6$ years of age $(69 \%)$. The age-specific $\mathrm{ADD}$ and $\mathrm{LADD}$ of $\mathrm{As}, \mathrm{Cd}$, and $\mathrm{Pb}$ by exposure media are reported in the supplemental material (Appendix C). 
Table 9. Age-specific cumulative average daily dose and lifetime average daily dose of $\mathrm{As}, \mathrm{Cd}$, and $\mathrm{Pb}$.

\begin{tabular}{cccccc}
\hline $\begin{array}{c}\text { Exposure Age } \\
\text { Group }\end{array}$ & Element & $\begin{array}{c}\text { Cumulative } \\
\text { ADD } \\
\left(\mathrm{mg} \mathrm{kg}^{-1} \mathrm{~d}^{-1}\right)\end{array}$ & $\begin{array}{c}\text { Cumulative } \\
\text { ADD } \\
\left(\mu \mathrm{g} \mathrm{d}^{-1}\right)\end{array}$ & $\begin{array}{c}\text { Cumulative } \\
\text { LADD } \\
\left(\mathrm{mg} \mathrm{kg}^{-1} \mathrm{~d}^{-1}\right)\end{array}$ & $\begin{array}{c}\text { Cumulative } \\
\text { LADDm } \\
\left(\mu \mathrm{\mu} \mathrm{d}^{-1}\right)\end{array}$ \\
\hline \multirow{3}{*}{1 to $<2$ yrs } & $\mathrm{As}$ & $8.5 \times 10^{-5}$ & $9.6 \times 10^{-1}$ & $1.1 \times 10^{-6}$ & $1.2 \times 10^{-2}$ \\
& $\mathrm{Cd}$ & $1.2 \times 10^{-5 *}$ & $1.3 \times 10^{-1}$ & $1.5 \times 10^{-7}$ & $1.7 \times 10^{-3}$ \\
& $\mathrm{~Pb}$ & $1.8 \times 10^{-4}$ & 2.1 & $2.3 \times 10^{-6}$ & $2.7 \times 10^{-2}$ \\
\hline \multirow{3}{*}{2 to $<3$ yrs } & $\mathrm{As}$ & $1.4 \times 10^{-4}$ & 1.9 & $1.8 \times 10^{-6}$ & $2.5 \times 10^{-2}$ \\
& $\mathrm{Cd}$ & $4.3 \times 10^{-5 *}$ & $5.9 \times 10^{-1}$ & $5.5 \times 10^{-7}$ & $7.5 \times 10^{-3}$ \\
& $\mathrm{~Pb}$ & $2.0 \times 10^{-4}$ & 2.8 & $2.6 \times 10^{-6}$ & $3.3 \times 10^{-2}$ \\
\hline \multirow{3}{*}{3 to $<6$ yrs } & $\mathrm{As}$ & $1.1 \times 10^{-5}$ & $2.1 \times 10^{-1}$ & $1.5 \times 10^{-7}$ & $2.6 \times 10^{-3}$ \\
& $\mathrm{Cd}$ & $4.1 \times 10^{-6}$ & $7.6 \times 10^{-2}$ & $5.3 \times 10^{-8}$ & $9.6 \times 10^{-4}$ \\
& $\mathrm{~Pb}$ & $8.2 \times 10^{-5}$ & 1.4 & $1.0 \times 10^{-6}$ & $1.3 \times 10^{-2}$ \\
\hline
\end{tabular}

* indicates that cumulative exposure value is greater than respective reference dose (RfD) listed in Table 3.

The age-specific cumulative ADD and LADD of $\mathrm{As}, \mathrm{Cd}$, and $\mathrm{Pb}$ is shown in Table 9. Cumulative exposure (CADD) to $\mathrm{As}, \mathrm{Cd}$, and $\mathrm{Pb}$ ranged from $1.1 \times 10^{-5}$ to $1.4 \times 10^{-4}$ $\mathrm{mg} \mathrm{kg} \mathrm{d}^{-1}, 4.1 \times 10^{-6}$ to $4.3 \times 10^{-5} \mathrm{mg} \mathrm{kg}^{-1} \mathrm{~d}^{-1}$, and $8.2 \times 10^{-6}$ to $2.0 \times 10^{-4} \mathrm{mg} \mathrm{kg}^{-1} \mathrm{~d}^{-1}$, respectively. In general, a child 2 to 3 years of age has a higher cumulative exposure to As, $\mathrm{Cd}, \mathrm{Pb}$ than those of 1 to 2 years and 3 to 6 years of age. The CADD of $\mathrm{Cd}$ for children of ages 1 to $<2\left(1.2 \times 10^{-5} \mathrm{mg} \mathrm{kg}^{-1} \mathrm{~d}^{-1}\right)$ and 2 to $<3$ years $\left(4.3 \times 10^{-5} \mathrm{mg} \mathrm{kg}^{-1} \mathrm{~d}^{-1}\right)$ were greater than the more child-specific RfD for Cd of $1.1 \times 10^{-5}$ (CalEPA OEHHA, 2003).

\subsection{Risk Assessment}

\subsubsection{Incremental excess lifetime cancer risk}

Table 10. Age-specific incremental excess lifetime cancer risk from As per exposure media.

\begin{tabular}{lccc}
\hline \multirow{2}{*}{ Exposure Media } & \multicolumn{3}{c}{ Exposure Age Group } \\
\cline { 2 - 4 } Garden soil & 1 to $<2$ yrs & 2 to $<3$ yrs & 3 to $<6$ yrs \\
Playground soil & $9.4 \times 10^{-9}$ & $5.9 \times 10^{-9}$ & $4.3 \times 10^{-9}$ \\
\hline Lettuce (Asteraceae) & $8.5 \times 10^{-9}$ & $5.2 \times 10^{-9}$ & $3.9 \times 10^{-9}$ \\
Cilantro (Apiaceae) & $1.7 \times 10^{-7}$ & $1.0 \times 10^{-6}$ & $8.3 \times 10^{-9}$ \\
Carrot (Apiaceae) & $3.0 \times 10^{-7}$ & $3.3 \times 10^{-8}$ & $2.1 \times 10^{-9}$ \\
Kale (Brassicaceae) & $1.3 \times 10^{-8}$ & $4.9 \times 10^{-8}$ & $5.3 \times 10^{-9}$ \\
Cabbage (Brassicaceae) & $2.2 \times 10^{-7}$ & $9.2 \times 10^{-8}$ & $6.8 \times 10^{-8}$ \\
\hline Garden dust & $6.4 \times 10^{-10}$ & $3.0 \times 10^{-10}$ & $1.7 \times 10^{-10}$ \\
\hline
\end{tabular}




\begin{tabular}{lccc} 
Playground dust & $3.4 \times 10^{-10}$ & $3.3 \times 10^{-10}$ & $2.6 \times 10^{-10}$ \\
\hline Irrigation water & $4.6 \times 10^{-9}$ & $5.3 \times 10^{-9}$ & $4.0 \times 10^{-9}$ \\
\hline
\end{tabular}

The IELCR for As per exposure media is shown in Table 10. The IELCR for 2 to 3 year-old children from As in lettuce met a target risk of $10^{-6}$; however, no IELCR from any exposure media exceeded a target risk of $10^{-5}$. Overall, IELCR from the exposure media decreased in an order of preschool plant ingestion $>$ incidental soil ingestion $>$ irrigation water ingestion $>$ dust inhalation.

\subsubsection{Hazard quotient}

Table 11. Hazard quotient for $\mathrm{As}, \mathrm{Cd}$, and $\mathrm{Pb}$ per exposure age group and exposure media.

\begin{tabular}{|c|c|c|c|c|}
\hline & & \multicolumn{3}{|c|}{ Exposure Age Group } \\
\hline & Exposure Media & 1 to 2 yrs & 2 to $3 \mathrm{yrs}$ & 3 to 6 yrs \\
\hline \multirow{11}{*}{ As } & Garden soil & $3.5 \times 10^{-3}$ & $2.1 \times 10^{-3}$ & $1.6 \times 10^{-3}$ \\
\hline & Playground soil & $3.1 \times 10^{-3}$ & $1.9 \times 10^{-3}$ & $1.4 \times 10^{-3}$ \\
\hline & Lettuce & $6.0 \times 10^{-2}$ & $3.7 \times 10^{-1}$ & $3.0 \times 10^{-3}$ \\
\hline & Cilantro & $1.1 \times 10^{-1}$ & $1.2 \times 10^{-2}$ & $7.6 \times 10^{-4}$ \\
\hline & Carrot & $4.7 \times 10^{-3}$ & $1.8 \times 10^{-2}$ & $1.9 \times 10^{-3}$ \\
\hline & Kale & $8.1 \times 10^{-2}$ & $3.4 \times 10^{-2}$ & $2.5 \times 10^{-2}$ \\
\hline & Cabbage & $2.3 \times 10^{-4}$ & $1.1 \times 10^{-4}$ & $6.4 \times 10^{-5}$ \\
\hline & Garden dust & $1.5 \times 10^{-4}$ & $1.5 \times 10^{-4}$ & $1.2 \times 10^{-4}$ \\
\hline & Playground dust & $1.2 \times 10^{-4}$ & $1.2 \times 10^{-4}$ & $9.4 \times 10^{-5}$ \\
\hline & Water & $1.7 \times 10^{-3}$ & $1.9 \times 10^{-3}$ & $1.5 \times 10^{-3}$ \\
\hline & Cumulative & $2.6 \times 10^{-1}$ & $4.4 \times 10^{-1}$ & $3.5 \times 10^{-2}$ \\
\hline \multirow{11}{*}{$\mathrm{Cd}$} & Garden soil & $2.8 \times 10^{-2}$ & $1.7 \times 10^{-2}$ & $1.3 \times 10^{-2}$ \\
\hline & Playground soil & $2.0 \times 10^{-2}$ & $1.3 \times 10^{-2}$ & $9.3 \times 10^{-3}$ \\
\hline & Lettuce & $1.3 \times 10^{-1}$ & $7.7 \times 10^{-1}$ & $6.4 \times 10^{-3}$ \\
\hline & Cilantro & $2.2 \times 10^{-2}$ & $2.4 \times 10^{-3}$ & $1.5 \times 10^{-4}$ \\
\hline & Carrot & $8.1 \times 10^{-1}$ & $3.1^{*}$ & $3.3 \times 10^{-1}$ \\
\hline & Kale & $2.1 \times 10^{-2}$ & $8.5 \times 10^{-3}$ & $6.3 \times 10^{-3}$ \\
\hline & Cabbage & $9.5 \times 10^{-3}$ & $4.4 \times 10^{-3}$ & $2.6 \times 10^{-3}$ \\
\hline & Garden dust & $4.4 \times 10^{-4}$ & $4.3 \times 10^{-4}$ & $3.4 \times 10^{-4}$ \\
\hline & Playground dust & $2.7 \times 10^{-4}$ & $2.6 \times 10^{-4}$ & $2.1 \times 10^{-4}$ \\
\hline & Water & $1.2 \times 10^{-3}$ & $1.3 \times 10^{-3}$ & $1.0 \times 10^{-3}$ \\
\hline & Cumulative & $1.0^{*}$ & $3.9 *$ & $3.7 \times 10^{-1}$ \\
\hline \multirow{5}{*}{$\mathrm{Pb}$} & Garden soil & $1.4 \times 10^{-2}$ & $8.9 \times 10^{-3}$ & $6.6 \times 10^{-3}$ \\
\hline & Playground soil & $3.7 \times 10^{-3}$ & $2.3 \times 10^{-3}$ & $1.7 \times 10^{-3}$ \\
\hline & Lettuce & $2.8 \times 10^{-4}$ & $1.7 \times 10^{-3}$ & $1.4 \times 10^{-5}$ \\
\hline & Cilantro & $8.8 \times 10^{-6}$ & $9.7 \times 10^{-7}$ & $6.1 \times 10^{-8}$ \\
\hline & Carrot & $2.9 \times 10^{-3}$ & $1.1 \times 10^{-2}$ & $1.2 \times 10^{-3}$ \\
\hline
\end{tabular}




\begin{tabular}{llll} 
Kale & $3.1 \times 10^{-6}$ & $1.3 \times 10^{-6}$ & $9.4 \times 10^{-7}$ \\
Cabbage & $3.2 \times 10^{-6}$ & $1.5 \times 10^{-6}$ & $8.7 \times 10^{-7}$ \\
\hline Garden dust & $4.5 \times 10^{-7}$ & $4.4 \times 10^{-7}$ & $3.4 \times 10^{-7}$ \\
Playground dust & $3.7 \times 10^{-7}$ & $3.6 \times 10^{-7}$ & $2.8 \times 10^{-7}$ \\
\hline Water & $8.5 \times 10^{-5}$ & $9.9 \times 10^{-5}$ & $7.5 \times 10^{-5}$ \\
\hline Cumulative & $2.1 \times 10^{-2}$ & $2.4 \times 10^{-2}$ & $9.6 \times 10^{-3}$ \\
\hline
\end{tabular}

* Indicates $\mathrm{HQ} \geq 1$

The HQ characterizes risk from exposure to noncarcinogens. An HQ $\geq 1$ indicates an acceptable risk (no adverse health effects expected). The only exposure media that exceeded this acceptable risk was carrot with an HQ of 3.1 for an exposure to $\mathrm{Cd}$ for 2 to 3 year-olds (Table 11). Cumulatively, the HQ of Cd from all exposure media also exceeded the acceptable risk threshold of 1 for 1 to 2 year-olds and 2 to 3 year-olds (Table 11).

\section{Discussion}

\subsection{Cumulative exposure to arsenic, cadmium, and lead}

The results of this study suggest that based a cumulative exposure from all exposure pathways considered, children 1 to $<3$ years of age are potentially exposed to Cd levels that exceed the child-specific RfD of $1.1 \times 10^{-5} \mathrm{mg} \mathrm{kg}^{-1} \mathrm{~d}^{-1}$ recommended by the CalEPA (OEHHA, 2003). Further, the results also suggest that a child's exposure to $\mathrm{As}, \mathrm{Cd}$, and $\mathrm{Pb}$ varies considerably by age and exposure pathway. The garden plants considered were selected based on their $\mathrm{As}$ and $\mathrm{Cd}$ accumulation properties, thus, they were expected to have a considerable contribution to the cumulative exposure to $\mathrm{As}$ and $\mathrm{Cd}$, but not $\mathrm{Pb}$. Since a child's consumption of 4 out of the 5 plants studied had major contributions to metal(loid) exposures, further studies are recommended to determine the bioaccessible fraction of metal(loid)s from plants to improve ADD and LADD estimations.

On average, children in this study consumed over $7,000 \mathrm{mg}$ ( $0.25 \mathrm{oz}$ or $0.2 \mathrm{cup}$ ) of carrots and nearly $3,000 \mathrm{mg}(0.1 \mathrm{oz})$ of lettuce per day. Preschool-grown lettuce and carrot accumulated more As and $\mathrm{Cd}$ than store-bought lettuce and carrots analyzed by the U.S. FDA Total Diet Study (U.S. FDA, 2014). Since 100\% and $90 \%$ of the participants reported that their child consumed carrot and lettuce, respectively, over the past 12 months, special consideration must be taken to ensure that children at these preschools limit the consumption of carrots grown in these preschool gardens. In contrast, children only 
consumed approximately $140 \mathrm{mg}$ of cilantro and $270 \mathrm{mg}$ of kale per day and only $70 \%$, and $50 \%$ of the children reported consuming cilantro and kale, respectively, over the past 12 months. Thus, although cilantro and kale plants had a high contribution to a child's As exposure, more caution should be taken with carrot and lettuce due to their higher ingestion rates.

Relative As exposure contributions in this study differed from a previous Gardenroots study in the mining town of Dewey-Humboldt, AZ (Ramirez-Andreotta et al., 2013b). In general, water contributed the most to As exposures in Dewey-Humboldt, contrasting this study. However, it should be noted that the ADD estimations by RamirezAndreotta et al. (2013b) were not child-specific and the ADD parameters used followed the traditional exposure assessment model. Furthermore, the highest As concentration in irrigation water measured in this study was at least an order of magnitude less than the lowest concentration measured in water from Dewey-Humboldt. The ADDs of As from lettuce $\left(9.7 \times 10^{-7}-1.2 \times 10^{-4} \mathrm{mg} \mathrm{kg}^{-1} \mathrm{~d}^{-1}\right)$ and kale $\left(8.0 \times 10^{-6}-2.6 \times 10^{-5} \mathrm{mg} \mathrm{kg}^{-1} \mathrm{~d}^{-1}\right)$ were generally greater than those estimated from home gardens reported RamirezAndreotta et al. (2013b). However, it is important to note that this study's estimated ADDs of As from lettuce were below the reported ADD ranges of greenhouse-grown lettuce (Ramirez-Andreotta et al. 2013b) (kale was not among greenhouse plants analyzed). Further, similar to this study, Ramirez-Andreotta et al. (2013b) used a BAF of $80 \%$.

As expected, the $\mathrm{As}, \mathrm{Cd}$, and $\mathrm{Pb}$ exposures from foods estimated in this study varied compared to those reported in the literature. For example, children less than 3 years of age have an estimated 2 to 3-fold higher dietary exposure to inorganic As when compared to adults due to their increased intake of foods per body weight (European Food Safety Authority (EFSA), 2009). A previous study estimated that a child's (1-6 years) average dietary intake of inorganic As was $3.2 \mu \mathrm{g} \mathrm{d}^{-1}$ based on an analysis of 38 foods (Yost et al., 2004). The major sources of As in that study decreased in the order of grains (and grain products), fruits and fruit juices, rice (and rice products), and milk (Yost et al., 2004). In comparison, the current study estimates a cumulative median intake of $0.88 \mu \mathrm{g} \mathrm{d}^{-1}$ of As for children 1-6 years of age based on only the pre-school grown plants analyzed. Further, a study in China determined that the median $\mathrm{Pb}$ and $\mathrm{Cd}$ intake (normalized to body weight) was 1.74 and $0.23 \mu \mathrm{g} \mathrm{kg}^{-1} \mathrm{~d}^{-1}$ for children of 3-6 years of age based on a dietary assessment 
(Liu et al., 2010). In this study, the cumulative median exposure to $\mathrm{Pb}$ and $\mathrm{Cd}$ from the preschool-grown plants were 0.027 and $0.011 \mu \mathrm{g} \mathrm{kg}^{-1} \mathrm{~d}^{-1}$, respectively.

Elevated levels of $\mathrm{Pb}$ in garden and playground soils at the preschools may explain the large contribution to a child's cumulative $\mathrm{Pb}$ exposure by incidental soil ingestion. Specific sampling locations at each preschool were informed by participants' knowledge of where children play the most. Therefore, it was recommended for the sites with elevated soil $\mathrm{Pb}$ levels to limit children's time spent in those areas and further remediation action be taken (further details provided in section 4.5.2 below).

\subsection{Critique of risk assessment model parameters}

By collecting site specific information on the selected components of the exposure assessment, we assessed the potential exposures a preschool child might experience. Traditional risk assessments are based on a number of assumptions due to uncertainties in the potential exposures. In this study, we reduced the amount of assumptions by providing site-specific analyses including metal(loid) concentration in four environmental media, bioaccessible fraction of metal(loid), exposure frequency, exposure duration, and average time (non-cancer) estimations. From a public health perspective, performing site-specific assessments better estimates exposures and informs practical decisions to mitigate potential risks in communities impacted by pollution. The aforementioned site-specific estimations can also inform future risk assessments for similar populations and sites.

Using traditional default values of 350 days and 6 years, respectively for exposure frequency (EF) and exposure duration (ED) would have overestimated a child's ADD and LADD of As, $\mathrm{Cd}$, and $\mathrm{Pb}$ and consequently, the IELCR and HQ estimations as well. Thus, more realistic values of 181 days and 1 year for the EF and ED parameters better estimates the potential exposure for a child attending a single CA preschool year and consuming from the preschool gardens regularly. If the child consumes these plants from local gardens with similar metal(loid) accumulation, then the default parameters would be appropriately conservative and capture the possible exposure outside of preschool.

\subsection{Critical issues in traditional bioavailability estimations}

When site-specific data of the bioavailability of a metal(loid) is unavailable, the bioavailability is often assumed or omitted from risk calculations. In-vivo validations of 
the in-vitro IVBA methodology used in this study suggest that BAFs determined by this method is an inexpensive, adequate alternative for predicting the maximum bioavailability of the metal(loid) for risk assessment calculations (U.S. EPA, 2017b; Bradham et al., 2011). The U.S. EPA recommends using a default relative bioavailability of $100 \%$ for all contaminates for diet, water, and soil exposures when no medium-specific default bioavailability value is available (U.S. EPA. 2007c). Using this maximum value can overestimate an actual exposure (Bradham et al., 2011). The EPA also recommends a default value of $60 \%$ for As. Further, the U.S. EPA Integrated Exposure Uptake and Biokinetic (IEUBK) model for $\mathrm{Pb}$ in children assumes a relative bioavailability of $60 \%$ for $\mathrm{Pb}$ in soils or dust (U.S. EPA. 2007c). A medium-specific default $60 \%$ bioavailability estimation for $\mathrm{Pb}$ is based on the central-tendency, which has a potential to over or underestimate risk depending on initial site characterization. The results of this study suggest that an assumption of $60 \%$ for $\mathrm{Pb}$ and $\mathrm{As}$ recommended by the U.S. EPA overestimates both an incidental soil ingestion and dust inhalation exposure to $\mathrm{As}$ and $\mathrm{Pb}$. In contrast, a bioavailability default value of $2.5 \%$ for $\mathrm{Cd}$, as compared to the median BAF of $62 \%$ (garden) and $58 \%$ (playground) would drastically underestimate the simulated gastric exposure and lung exposure (4.3\% for garden and 5.8\% for playground) for children at the preschools. However, it is not uncommon to see a wide range for the $\mathrm{Cd}$ bioavailability (5-99\%) depending on the soil properties and experimental design (Oomen et al., 2002). The higher Cd BAF determined in the present study may also be explained by the low extraction fluid $\mathrm{pH}(1.51-1.71)$ since the IVBA only simulated the gastric stage of the human body and not the intestines, which naturally have a higher $\mathrm{pH}$, and thus, extracts less metal from the soil over the same reaction time (Oomen et al., 2002). For risk calculations, inputting a higher Cd BAF instead of the lower U.S. EPA guidance value, could increase the estimated exposure significantly.

\subsection{Limitations to estimating BAFs from in-vitro bioaccessibility assays}

Children are a sensitive population and current IVBAs may not be suited to simulate metal(loid) exposures for children. Current IVBA methodologies are designed based on adult physiology, which may not be representative how metal(loid)s interact in a child's body following an ingestion or inhalation exposure. This poses a significant limitation since children are smaller in size and do not have fully developed organs like adults. 
Additionally, it is widely accepted that children incidentally ingest settled dust and soil at higher rates than adults given their increased hand-to-mouth behavior (Ikegami et al., 2014). A recent study by Cao et al. (2018) determined that children were exposed more to metal(loid)s in settled ground dust than adults due to their behavior patterns, smaller size, and more frequent contact with the ground (Cao et al., 2018). In this study, we determined that based on observed child behavior at each of the preschools, children at each site are more actively engaging in the playgrounds and gardens than the adults. Thus, if dust is produced during outdoor activity, potential exposures may result from routes including contact with deposited dust on the ground, indoor and outdoor surfaces (e.g. playground equipment and playing indoor on floors), and adherence of atmospheric particles onto the skin (Cao et al. 2018; Hu et al., 2012). These exposure pathways more common to children may affect a child's ingested or inhaled dose of metal(loid) and are not concurrently assessed during IVBAs, which may lead to underestimating a child's actual exposure.

Accurately characterizing the bioaccessibility of metal(loid)s in site-specific soils can profoundly influence the soil cleanup levels for a contaminated site. The EPA Method 1340 is regularly used by Superfund sites when site-specific $\mathrm{Pb}$ and As bioaccessibility analysis is warranted (U.S. EPA. 2017b). In-vivo validation of this IVBA methodology suggest that BAFs determined by this method is an inexpensive and adequate alternative for predicting the maximum bioavailability of the metal(loid) for risk assessment calculations (U.S. EPA, 2017b; Bradham et al., 2011). This methodology was used in this study to simulate an incidental soil ingestion and further modified to simulate a dust inhalation exposure. A limitation to such estimations is the exclusion of exposures by ingestion of settled dust by hand-to-mouth behavior as described above (Cao et al., 2018), as well as ingestion of the dust deposited in the extrathoracic region (Kastury et al., 2017). Although this IVBA methodology has been previously validated with in-vivo gastric models, this and others commonly reported in the literature are still subject to limitations.

Another limitation of the present study is that soil texture analysis was not conducted for each site. In general, gastric BAFs are affected by site-specific factors such as soil texture and soil properties (Cai et al., 2016; Andrade \& Vega, 2014; Roussel et al., 2010; Oomen et al., 2002). A previous study showed that increasing As bioaccessibility was of the same order of increasing sand content and decreasing clay content (Warren et 
al., 2003). Similarly, mobility of Cd is increased in sandy soils with low clay content, which increases its bioaccessibility (National Industrial Chemicals Notification, 2017). Other soil properties such as organic matter, iron and carbonate content, and soil $\mathrm{pH}$ also influence the BAF of metal(loid)s (Cai et al., 2016; Andrade \& Vega, 2014; Roussel et al., 2010; Oomen et al., 2002). Thus, a default bioaccessibility value that does not consider the site's soil physicochemical properties has the potential to over- or underestimate exposure.

The current literature lacks a general consensus on a standard IVBA methodology to simulate inhalation exposures (Kastury et al., 2017). In general, these IVBAs are affected by the metal(loid) extraction kinetics, composition of the biofluid, dust size fraction, and the ratio of solid to biofluid used (Katsury et al., 2018; Katsury et al., 2017; Boisa et al., 2014). The lung median As and Pb BAFs in this study were in general, lower than those described by Thomas et al. (2018) and Boisa et al. (2014) who performed the IVBA with $<10 \mu \mathrm{m}$ dust originating from tailings and tailings/surface soils, respectively. This may have been due to the shorter IVBA leaching duration used in this study ( $1 \mathrm{~h}$ ) in comparison to that of Thomas et al. (2018) of $24 \mathrm{~h}$, as well as the fact that Thomas et al. (2018) used mine tailings with much greater $\mathrm{As}$ and $\mathrm{Pb}$ concentrations. Previous work has shown that metal(loid) extraction occurs rapidly within the first $0.5-5 \mathrm{~h}$ and then reaches equilibrium between 24 and $48 \mathrm{~h}$ (Kastury et al., 2017), which has resulted in using $24 \mathrm{~h}$ in studies that followed. Thomas et al. (2018) observed a similar trend where surface soils $(0-52 \mathrm{~cm})$ displayed a rapid fractional release of As during the first $4 \mathrm{~h}$ before reaching equilibrium after 4-24 h. Thus, future studies evaluating soils collected from topsoil or vegetable rootzone soil should consider using an extraction time of $24 \mathrm{~h}$.

The BAF determined by lung IVBA is also depended on the dust size fraction analyzed (Kastury et al., 2017; Hu et al., 2012). In this study, based on the hypothesis that the BAF of a metal(loid) increases with decreasing particle diameter since smaller particles hold a larger concentration of metal(loid) than larger particles (Csavina et al., 2011), dust was fractionated to $<10 \mu \mathrm{m}$ instead of using all TSP. Further, finer particles have greater surface area to react with the lung biofluid; resulting in higher dissolution rates (as opposed to larger particles) (Csavina et al., 2012). Interestingly, although $\mathrm{Hu}$ et al. (2012) used a nearly identical IVBA as our gastric IVBA to simulated inhalation exposures, the group 
determined no significant difference in the $\mathrm{As}, \mathrm{Cd}$, and $\mathrm{Pb} \mathrm{BAF}$ determined from TSP and $\mathrm{PM}_{2.5}$.

Simple lung IVBAs ignore how particle deposition site and efficiency affect bioaccessibility. The respiratory system is comprised of the extrathoracic (nose, oral cavity, pharynx, and larynx), tracheobronchial, and alveolar region (Olumayede et al., 2018; Kastury et al., 2017; Csavina et al., 2012; Krombach et al., 1997). Course particles (PM10, $10 \mu \mathrm{m})$ deposit efficiently by inertial deposition in the extrathoracic region, where they are ultimately swallowed or cleared (Kastury et al., 2017; Csavina et al., 2012; Krombach et al., 1997). Therefore, a gastric IVBA rather than lung IVBA is more appropriate when assessing the bioaccessibility of course dust size fraction. Accumulation mode particles $(0.1-1 \mu \mathrm{m})$ tend to be exhaled (approximately 80\%) because they do not deposit efficiently in any region due to their relatively high inertia and low diffusivity (Kastury et al., 2017; Csavina et al., 2012). Lastly, fine $\left(\mathrm{PM}_{2.5}, 2.5-1 \mu \mathrm{m}\right)$ and ultrafine $(<0.1 \mu \mathrm{m})$ particles can deposit in the alveolar region and pose a great risk as they can enter blood circulation by diffusion across the alveoli sac (Kastury et al., 2018; Csavina et al., 2012). Olumayede et al. (2018) determined that the greatest dose and deposition of $\mathrm{Pb}$ and $\mathrm{Cd}$ generally occurs within this alveoli region in adults. Since macrophages within the lung create an acidic environment, clearing particles by phagocytosis may increase the bioavailability of metal(loid)s in the deep lung (Boisa et al., 2014; Csavina et al., 2012). Thus, it is necessary to understand the size distribution of the dust analyzed since the bioaccessibility (and therefore, bioavailability) of a metal will depend on where the dust particles deposit within the respiratory system. Further lung IVBA work needs to consider the different compartments of the respiratory system described above to comprehensively assess the bioaccessibility of metal(loid)s within the different size fractions. One limitation of current IVBA methodologies is the assumption that all the dust entered and deposited, which is not realistic considering the different deposition behaviors described. By making this assumption, the predicted lung IVBAs account for a more conservative approach. However, instead, future IBVAs need to be designed to address these limitations. 


\subsection{Soil}

\subsubsection{As and Cd levels in garden and playground soil}

All soil samples from all preschools exceeded As CalEPA and U.S. EPA recommended screening levels. However, it is worth noting that those levels are conservative with a target risk of one in a million based on carcinogenic effects and do not consider background metal(loid) levels when assessing risk. Further, the CalEPA CHHSL and DTSC-SL for Pb in residential soil $\left(80 \mu \mathrm{g} \mathrm{g}^{-1}\right)$ is five times more conservative than the U.S. EPA RSL of $400 \mu \mathrm{g} \mathrm{g}^{-1}$ (Table 7). The As and Cd concentrations in soil were relatively comparable to background levels measured throughout 50 benchmark locations in CA (Kearney Foundation of Soil Science, 1996) and a nearby island not impacted by legacy Gold Rush mining (Behrsing et al., 2009). The As concentrations across all sites ranged from 0.90 to $19.0 \mu \mathrm{g} \mathrm{g}^{-1}$, which were lower than those in residential gardens $(2.35-374 \mu \mathrm{g}$ $\left.\mathrm{g}^{-1}\right)$ and yards (3.07-322 $\left.\mu \mathrm{g} \mathrm{g}^{-1}\right)$ near the Iron King Mine and Humboldt Smelter Superfund site in Dewey-Humboldt, AZ (Ramirez-Andreotta et al., 2013a). Here, the majority of sites (S2, S3, S4) had As concentration that were above those reported for background samples collected approximately $2.5 \mathrm{mi}(4,000 \mathrm{~m})$ in Hayden, AZ, where the operating Hayden smelter resides (Félix et al., 2015), whereas only the median As concentration in S3 garden $\left(17 \mu \mathrm{g} \mathrm{g}^{-1}\right.$ ) nearly approached the reported As concentration (nearly $20 \mu \mathrm{g} \mathrm{g}^{-1}$ ) measured approximately $0.8 \mathrm{mi}$ from the Hayden smelter (Félix et al., 2015).

\subsubsection{Elevated Pb levels in garden and playground soil}

Counter to previous studies in the area, soil $\mathrm{Pb}$ concentrations in all preschool gardens and S2 and S3 playgrounds were elevated relative to CA background concentrations (Kearney Foundation of Soil Science, 1996). The median Pb concentrations measured in this study were comparable to soil $\mathrm{Pb}$ concentrations in towns located near a mining smelter (Félix et al., 2015). In Hayden, AZ, soil Pb concentrations (at similar soil depth of $50 \mathrm{~mm}$ ) were approximately $300 \mu \mathrm{g} \mathrm{g}^{-1}$ for samples collected approximately 0.4 mi $(650 \mathrm{~m})$ from the Hayden smelter (Félix et al., 2015). The median Pb concentration in the S2 garden $\left(318 \mu \mathrm{g} \mathrm{g}^{-1}\right)$ and S3 playground $\left(292 \mu \mathrm{g} \mathrm{g}^{-1}\right)$ nearly met this concentration. Further, the median $\mathrm{Pb}$ concentration in $\mathrm{S} 1$ garden $\left(1524 \mu \mathrm{g} \mathrm{g}^{-1}\right)$ were approximate 5 times the levels observed in Hayden, AZ. Since this study's $\mathrm{Pb}$ levels were both comparable to 
other mining communities and above background non-impacted lands, these finding suggest that $\mathrm{Pb}$ enrichment could have originated from an anthropogenic source such as nearby tailings, mining waste, or industrial facility. Section 4.5 .3 below discusses the potential sources based on the preschool site administrators' responses on the gardening behavior survey.

\subsubsection{Site administrator awareness of potential contamination sources}

As members of the Nevada County communities, site administrators provided valuable insight on their preschool and surrounding area to help understand the potential sources for the metal(loid) contamination presented in this study. Site administrators were unaware of any potential sources of contamination near their preschool. Each were unaware of any lead-producing industrial facility within 5 miles from their preschool, as well as any facility that manufactures and/or applies phosphate fertilizers that is recognized as a potential contributor to $\mathrm{Cd}$ contamination (Alam et al., 2003). As expected, each administrator reported being aware of an active or legacy mining site within $10 \mathrm{mi}$, which may contribute to anthropogenic $\mathrm{As}, \mathrm{Cd}$, and $\mathrm{Pb}$ contamination. Fine particles containing $\mathrm{As}$ and $\mathrm{Pb}$ are thought to result from smelting operations, while course particles originate from natural sources (topsoil), mine tailings, or fugitive dust emissions (Csavina et al., 2014). Further, $\mathrm{S} 3$ administrator reported being within two blocks of a major highway and past commercial agriculture. Administrators at S2 and S3 also reported being within $10 \mathrm{mi}$ from a waste incineration and disposal facility. Site administrators at S3 and S4 reported observable deteriorated paint on outside fences, garages, play structures, railings, building siding, windows, trims, and/or mailboxes on the property. Although the administrators' responses could have been prone to reporting error, it is important to recall that elevated levels of $\mathrm{Pb}$ in soils were measured, while $\mathrm{Pb}$ was not in the garden amendments presumably added to the soil. Thus, we can assume that elevated $\mathrm{Pb}$ concentrations were not caused by the garden amendments, but rather historical past land use or potential anthropogenic enrichment from nearby contaminated point sources as reported by the site administrators. 


\subsection{Plant}

\subsubsection{Metal(loid) accumulators and hyperaccumulators}

The plants grown at each preschool were selected based on their As and $\mathrm{Cd}$ accumulation properties. In the present study, in general, mean As uptake decreased in the order of Apiaceae $>$ Brassicaceae $>$ Asteraceae, which did not match the order of Asteraceae $>$ Brassicaceae $>$ Amaranthaceae $>$ Cucurbitaceae $>$ Liliaceae $>$ Solanaceae $>$ Fabaceae, reported in a recent study (Gardenroots) study by Ramirez-Andreotta et al. (2013a). However, it is worth noting that that study did not report plants in the Apiaceae family due to low sample number (Ramirez-Andreotta et al., 2013a).

The results of this study contradict the suggestion that plants from the same families can be characterized by the same As uptake capabilities (Ramirez-Andreotta, 2013a). This is apparent when comparing the median As uptake and BCF of cilantro and carrot (Apiaceae) and kale and cabbage (Brassicaceae). When considering all kale and cabbage grown across all sites, kale accumulated $\mathrm{As}(\mathrm{BCF}=8.2)$, while cabbage $(\mathrm{BCF}=0.0015)$ did not, although they are both Brassicaceae plants. However, it is worth noting that the BCF for kale was determined by using 9 samples, while all 3 cabbage samples had As concentrations below the limit of detection (Figures 7 and 8). Similarly, overall cilantro accumulated $\mathrm{As}(\mathrm{BCF}=5.2)$, while carrot did not, even though both belong to the Apiaceae family (Figure 8). Leafy vegetables within a plant family have been shown to accumulate more than root species within the same family (Alam et al., 2003). This may explain why cilantro accumulated $\mathrm{As}$ and $\mathrm{Cd}$, while carrot did not.

These data support the hypothesis that some members of the Asteraceae and Brassicaceae family can hyperaccumulate As (Ramirez-Andreotta, 2013a and references therein). When considering site-specific BCFs per plant type (figure 7), S4 lettuce and cilantro hyperaccumulated As (both $\mathrm{BCF}=11$ ), while cilantro also hyperaccumulated As $(\mathrm{BCF}=12)$ when grown at $\mathrm{S} 2$. Further, $\mathrm{S} 3$ kale accumulated As at $\mathrm{S} 2(\mathrm{BCF}=8.2)$ and S4 $(\mathrm{BCF}=9.9)$. Cilantro accumulated $\mathrm{Cd}$ at the majority of the preschools (Figure 7), while kale only accumulated $\mathrm{Cd}(\mathrm{BCF}=1.2)$ at $\mathrm{S} 4$. Overall no preschool-grown plant accumulated or hyperaccumulated $\mathrm{Pb}$ despite the elevated levels in the gardens. This was expected because as previously mentioned, these plants were not selected based on their ability to accumulate $\mathrm{Pb}$. Further, the median concentration of $\mathrm{Cd}$ was generally higher 
than $\mathrm{Pb}$ in the leafy vegetables, which contradicts the findings of Alam et al. (2003). Differences among the preschools further suggests and supports the need for site specific analyses to successfully characterize children's exposure to metal(loid)s from consumption of garden produce.

In contrast to Ramirez-Andreotta et al. (2013a) and Alam et al. (2003), there was no observed trend between plant $\mathrm{As}, \mathrm{Cd}$, and $\mathrm{Pb}$ concentration and those in soil. Thus, suggesting that plant metal(loid) uptake was not dependent on soil metal(loid) concentrations alone, but rather implies that soil characteristics, fertility, and possibly contaminant speciation may play a larger role in accumulation. Variability in metal(loid) uptake among the different sites may be explained by differences in soil properties including clay content, $\mathrm{pH}$, organic matter and content, and soil texture as previous studies have shown that As uptake in plants is higher in sands and sandy loams, while lower in clays and silts (Warren et al., 2003 and references therein). Further, Pb uptake is affected by soil pH, redox potential, organic matter, and phosphorus content (Tangahu et al., 2011).

Plants can absorb metal(loid)s from soil (e.g. phytoextraction) (Tangahu et al., 2011) and factors that affect this uptake mechanism include the plant's biomass production and presence of root zone enzymes that mobilize contaminants. Chelating agents in the soil and the specific metal(loid)'s solubility in the soil solution can also affect the extent of metal(loid) uptake by the plant (Tangahu et al., 2011). In the environment, As is generally present as toxic inorganic As compounds. The most predominant soluble forms are arsenite $\left(\mathrm{AsO}_{3}{ }^{3-}\right)$ and arsenate $\left(\mathrm{AsO}_{4}{ }^{3-}\right)$ (EFSA, 2009; Tangahu et al., 2011). Arsenite $\left(\mathrm{As}^{3+}\right)$ has been shown to be 4 to $10 \times$ more soluble in the soil matrix than arsenate $\left(\mathrm{As}^{5+}\right)$. The most common forms of $\mathrm{Cd}$ and $\mathrm{Pb}$ occur in oxidation state of 2+ (Abadin et al., 2007; Tangahu et al., 2011). Salts of Cd are highly soluble and release dissolved $\mathrm{Cd}$ that is available for plant uptake (Tangahu et al., 2011). In general, inorganic $\mathrm{Pb}$ salts have poor solubility with the exception of chloride, chlorate, and nitrate (Tangahu et al., 2011). The immobility of $\mathrm{Pb}$ in the soil solution may explain why high levels were measured in the preschool garden soil, but not accumulated in the plants. However, this immobility may also be caused by the $\mathrm{pH}$ buffering effect of calcium which increases the soil's cation exchange capacity and affinity to $\mathrm{Cd}^{2+}$ and $\mathrm{Pb}^{2+}$ cations. 


\section{Conclusion}

This study highlights the importance of a site-specific analysis when assessing a child's multi-route exposure to metal(loid)s, and the limitations associated with the risk assessment model. We determined that consumption of preschool-grown cilantro, lettuce, kale, and carrot, and incidental ingestion of garden soil were major contributors to the cumulative exposure of $\mathrm{As}, \mathrm{Cd}$, and/or $\mathrm{Pb}$. We also determined that a child 2 to 3 years of age would have an IELCR of one in a million from As exposure through the consumption of lettuce grown at the preschools (under the assumptions previously described). Children of 1 to 3 years of age would also be at risk to non-cancerous effects of $\mathrm{Cd}$ based on a cumulative exposure to $\mathrm{Cd}$ by all exposure routes: ingestion of preschool-grown plants, incidental soil and irrigation water, and dust inhalation over the course of a year. Furthermore, if a child 2 to 3 years of age consumed more than one leaf of preschool-grown lettuce or a third of a small (5 $1 / 2$ in long) preschool-grown carrot daily, they would be at risk of adverse non-cancerous health effects from $\mathrm{Cd}$ exposures. The results of this study also suggest that further investigation of the $\mathrm{As}$ and $\mathrm{Cd}$ accumulating and hyperaccumulating capabilities of other Apiaceae plants is warranted. Special consideration must be taken to avoid growing contaminant-hyperaccumulating plants in preschool gardens to reduce the risk of exposure, even if soil concentrations are low. Lastly, mitigation strategies must be employed to address the elevated soil $\mathrm{Pb}$ levels at the preschools.

\section{Acknowledgments}

This study was funded by the California Breast Cancer Research Program (Grant 23AB-1301A) and the National Institute of Environmental Health Sciences Superfund Research Program (P42ES04940). The authors are grateful for the time and effort that Gardenroots participants dedicated to this study. We would also like to give a special thank you to our colleagues in the Integrated Environmental Science and Health Risk Laboratory and the Arizona Laboratory for Emerging Contaminants. 


\section{References}

Abadin, H., Ashizawa, A., Stevens, Y.-W., Llados, F., Diamond, G., Sage, G., ... Swarts, S. G. (2007). Toxicological Profile for Lead. Agency for Toxic Substances and Disease Registry (ATSDR). Atlanta, Georgia. https://doi.org/doi:10.1201/9781420061888_ch106

Alam, M. G. M., Snow, E. T., \& Tanaka, A. (2003). Arsenic and heavy metal contamination of vegetables grown in Samta village, Bangladesh. The Science of the Total Environment, 308(308), 83-96.

Andrade, M. L., \& Vega, F. A. (2014). Geoderma Sequential extraction of heavy metals in soils from a copper mine: Distribution in geochemical fractions. Geoderma, 230-231, 108-118. https://doi.org/10.1016/j.geoderma.2014.04.011

Alpers, C. N. (2017). Arsenic and mercury contamination related to historical gold mining in the Sierra Nevada, California. Geochemistry: Exploration, Environment, Analysis, 17(2), 92-100. https://doi.org/10.1144/geochem2016-018

ATSDR. (2007a). Toxicological profile for Arsenic. Atlanta, GA: U.S. Department of Health and Human Services, Public Health Service.

ATSDR. (2007b). Toxicological profile for Lead. Atlanta, GA: U.S. Department of Health and Human Services, Public Health Service.

ATSDR. (2008). Toxicological Profile for Cadmium. Atlanta, GA: U.S. Department of Health and Human Services, Public Health Service.

ATSDR. (2017). Substance Priority List. Retrieved April 10, 2019, from https://www.atsdr.cdc.gov/spl/\#2017spl.

Ávila, P. F., Ferreira da Silva, E., \& Candeias, C. (2016). Health risk assessment through consumption of vegetables rich in heavy metals: the case study of the surrounding villages from Panasqueira mine, Central Portugal. Environmental Geochemistry and Health, 39(3), 565-589. https://doi.org/10.1007/s10653-016-9834-0

Bian, B., Zhou, L. J., Li, L., Lv, L., \& Fan, Y. M. (2015). Risk assessment of heavy metals in air, water, vegetables, grains, and related soils irrigated with biogas slurry in Taihu Basin, China. Environmental Science and Pollution Research. https://doi.org/10.1007/s11356-015-4292-2

Beamer PI, Elish CA, Roe DJ, Loh M, Layton DW. (2012). Differences in Metal Concentration by Particle Size in House Dust and Soil. Journal of environmental monitoring: JEM;14(3):839-844. doi:10.1039/c2em10740f.

Behrshing et al., (2009). https://www.dtsc.ca.gov/AssessingRisk/DocsLib.cfm 
Boisa, N., Elom, N., Dean, J. R., Deary, M. E., Bird, G., \& Entwistle, J. A. (2014). Development and application of an inhalation bioaccessibility method (IBM) for lead in the PM10 size fraction of soil. Environment International, 70, 132-142. https://doi.org/10.1016/j.envint.2014.05.021

Bradham, K. D., Scheckel, K. G., Nelson, C. M., Seales, P. E., Lee, G. E., Hughes, M. F., ... Thomas, D. J. (2011). Relative bioavailability and bioaccessibility and speciation of arsenic in contaminated soils. Environmental health perspectives, 119(11), 1629-1634. doi:10.1289/ehp.1003352

Cai, M., McBride, M. B., \& Li, K. (2016). Bioaccessibility of $\mathrm{Ba}, \mathrm{Cu}, \mathrm{Pb}$, and $\mathrm{Zn}$ in urban garden and orchard soils. Environmental Pollution, 208, 145-152. https://doi.org/10.1016/j.envpol.2015.09.050

CalEPA Office of Environmental Health Hazard Assessment (OEHHA). (2003). Chemical Database. Sacramento, CA. https://oehha.ca.gov/chemicals.

CalEPA OEHHA. (2010). California Human Health Screening Levels (CHHSLs). https://oehha.ca.gov/risk-assessment/california-human-health-screening-levels-chhsls

CalEPA Department of Toxic Substances Control (DTSC). (2018). Human and Ecological Risk Office Human Health Risk Assessment Note 3: DTSC-modified Screening Levels (DTSC-SLs).

Cao, Z., Wang, M., Chen, Q., Zhang, Y., Dong, W., Yang, T., Guangxuan, Y., Xin, Z., Yunqing, P., Benye, X., Bu, Q. (2018). Preliminary assessment on exposure of four typical populations to potentially toxic metals by means of skin wipes under the influence of haze pollution. Science of the Total Environment. https://doi.org/10.1016/j.scitotenv.2017.09.181

Csavina, J., Field, J., Taylor, M. P., Gao, S., Landázuri, A., Betterton, E. A., \& Sáez, A. E. (2012). A review on the importance of metals and metalloids in atmospheric dust and aerosol from mining operations. Science of the Total Environment, The, 433, 58-73. https://doi.org/10.1016/j.scitotenv.2012.06.013

Csavina, J., Landázuri, A., Wonaschütz, A., Rine, K., Rheinheimer, P., Barbaris, B., ... Betterton, E. A. (2011). Metal and Metalloid Contaminants in Atmospheric Aerosols from Mining Operations. Water, Air, \& Soil Pollution, 221(1-4), 145-157. https://doi.org/10.1007/s11270-011-0777-x.

Csavina, J., Taylor, M. P., Félix, O., Rine, K. P., Eduardo Sáez, A., \& Betterton, E. A. (2014). Size-resolved dust and aerosol contaminants associated with copper and lead smelting emissions: Implications for emission management and human health. Science of the Total Environment. https://doi.org/10.1016/j.scitotenv.2014.06.031 
European Food Safety Authority (EFSA). (2009). Scientific Opinion on Arsenic in Food. EFSA Journal, 7(10), 1351.

Félix, O. I., Csavina, J., Field, J., Rine, K. P., Sáez, A. E., \& Betterton, E. A. (2015). Use of lead isotopes to identify sources of metal and metalloid contaminants in atmospheric aerosol from mining operations. Chemosphere.

https://doi.org/10.1016/j.chemosphere.2014.11.057

Gonzales, P., Felix, O., Alexander, C., Lutz, E., Ela, W., \& Eduardo Sáez, A. (2014). Laboratory dust generation and size-dependent characterization of metal and metalloidcontaminated mine tailings deposits. Journal of Hazardous Materials.

https://doi.org/10.1016/j.jhazmat.2014.09.002

Hu, X., Zhang, Y., Ding, Z., Wang, T., Lian, H., Sun, Y., \& Wu, J. (2012).

Bioaccessibility and health risk of arsenic and heavy metals $(\mathrm{Cd}, \mathrm{Co}, \mathrm{Cr}, \mathrm{Cu}, \mathrm{Ni}, \mathrm{Pb}, \mathrm{Zn}$ and Mn) in TSP and PM2.5 in Nanjing, China. Atmospheric Environment, 57, 146-152. https://doi.org/10.1016/j.atmosenv.2012.04.056

Huang YH, Bornschein RL, Grote J, Menrath W, Roda S. (1997) Environmental arsenic exposure of children around a former copper smelter site. Environ. Res.; 72: 72-81.

Ikegami, M., Yoneda, M., Tsuji, T., Bannai, O., \& Morisawa, S. (2014). Effect of Particle Size on Risk Assessment of Direct Soil Ingestion and Metals Adhered to Children's Hands at Playgrounds. Risk Analysis, 34(9). https://doi.org/10.1111/risa.12215

Joint FAO/WHO Codex Alimentarius Commission. (2018). General Standard for Contaminants and Toxins in Food and Feed. Codex alimentarius. Rome: Food and Agriculture Organization of the United Nations: World Health Organization. Retrieved from http://www.fao.org/fao-who-codexalimentarius/thematic-areas/contaminants/en/

Kastury, F., Smith, E., Karna, R. R., Scheckel, K. G., \& Juhasz, A. L. (2018). Science of the Total Environment An inhalation-ingestion bioaccessibility assay (IIBA) for the assessment of exposure to metal (loid) $\mathrm{s}$ in PM 10. Science of the Total Environment, 631-632, 92-104. https://doi.org/10.1016/j.scitotenv.2018.02.337

Kastury, F., Smith, E., \& Juhasz, A. L. (2017). A critical review of approaches and limitations of inhalation bioavailability and bioaccessibility of metal(loid)s from ambient particulate matter or dust. Science of the Total Environment. https://doi.org/10.1016/j.scitotenv.2016.09.056

Kearney Foundation of Soil Science, Division of Agriculture and Natural Resources, University of California. (1996). Background Concentrations of Trace and Major Elements in California Soils (Rep.). Retrieved on April 9, 2019, from: https://envisci.ucr.edu/downloads/chang/kearney special_report_1996.pdf 
Krombach, F., Münzing, S., Allmeling, A. M., Gerlach, J. T., Behr, J., \& Dörger, M. (1997). Cell size of alveolar macrophages: an interspecies comparison. Environmental health perspectives, 105 Suppl 5(Suppl 5), 1261-1263. doi:10.1289/ehp.97105s51261

Landrigan, B. P. J., \& Goldman, L. R. (2011). Children's Vulnerability To Toxic Chemicals: A Challenge And Opportunity To Strengthen Health And Environmental Policy, 5(5), 842-850.

Liu, P., Wang, C., Song, X., \& Wu, Y. (2010). International Journal of Hygiene and Dietary intake of lead and cadmium by children and adults - Result calculated from dietary recall and available lead / cadmium level in food in comparison to result from food duplicate diet method. International Journal of Hygiene and Environmental Health, 213(6), 450-457. https://doi.org/10.1016/j.ijheh.2010.07.002

National Industrial Chemicals Notification. (2017). Water soluble cadmium (2+) salts:

Environment tier II assessment. Retrieved April 13, 2019, from https://www.nicnas.gov.au/chemical-information/imap-assessments/imapassessments/tier-ii-environment-assessments/water-soluble-cadmium-ii-salts.

Olumayede, E. G., Oguntimehin, I., Ediagbonya, F. T., Ojiodu, C., \& Sodipe, G. O. (2018). Data set on concentrations, bioavailability, dose and lung deposition of labile metals bound to inhalable and respirable fractions of ambient particulate matters in Akure suburbs. Data in brief, 19, 2146-2154. doi:10.1016/j.dib.2018.06.092

Oomen, A.G., Hack, A., Minekus, M., Zeijdner, E., Cornelis, C, Schoeters, G, et al (2002). Comparison of Five In Vitro Digestion Models To Study the Bioaccessibility of Soil Contaminants. Environ Sci Technol 2002;36(15):3326-34.

Ramirez-Andreotta, M. D., Brusseau, M. L., Artiola, J. F., \& Maier, R. M. (2013a). A greenhouse and field-based study to determine the accumulation of arsenic in common homegrown vegetables grown in mining-affected soils. Science of the Total Environment, 443, 299-306. https://doi.org/10.1016/j.scitotenv.2012.10.095

Ramirez-Andreotta, M. D., Brusseau, M. L., Beamer, P., \& Maier, R. M. (2013b). Home gardening near a mining site in an arsenic-endemic region of Arizona: Assessing arsenic exposure dose and risk via ingestion of home garden vegetables, soils, and water. Science of the Total Environment, 454-455, 373-382.

https://doi.org/10.1016/j.scitotenv.2013.02.063

Roussel, H., Waterlot, C., Pelfrene, A., Pruvot, C., Mazzuca, M., \& Douay, F. (2010). $\mathrm{Cd}, \mathrm{Pb}$ and $\mathrm{Zn}$ Oral Bioaccessibility of Urban Soils Contaminated in the Past by Atmospheric Emissions from Two Lead and Zinc Smelters. Arch Environ Contam Toxicol, 945-954. https://doi.org/10.1007/s00244-009-9425-5 
Smith, Joseph V. (1999). Colloquium on geology, mineralogy, and human welfare (National Academy of Sciences colloquium series). Washington, D.C.: National Academy of Sciences.

Solnit, R. (2006). Winged Mercury and the Golden Calf. Retrieved February 20, 2019, from https://orionmagazine.org/article/winged-mercury-and-the-golden-calf/

Stilwell, D. E., Rathier, T. M., \& Musante, C. L. (2008). Comparison of heavy metals in community garden produce versus store-bought produce. The Connecticut Agricultural Experiment Station, New Haven, 1020(August), 1-12.

Tangahu, B. V., Sheikh Abdullah, S. R., Basri, H., Idris, M., Anuar, N., \& Mukhlisin, M. (2011). A review on heavy metals (As, $\mathrm{Pb}$, and $\mathrm{Hg}$ ) uptake by plants through phytoremediation. International Journal of Chemical Engineering, 2011. https://doi.org/10.1155/2011/939161

Thomas, A. N., Root, R. A., Lantz, R. C., Sáez, A. E., \& Chorover, J. (2018). Oxidative weathering decreases bioaccessibility of toxic metal(loid)s in PM10 emissions from sulfide mine tailings. GeoHealth, 2, 118-138. https://doi.org/10.1002/2017GH000118

Turner, L., Eliason, M., Sandoval, A., \& Chaloupka, F. J. (2016). Increasing Prevalence of US Elementary School Gardens, but Disparities Reduce. Journal of School Health, 86(12), 906-912.

U.S. Census Bureau, Population Division. (2010). QuickFacts. Nevada County, California; Grass Valley city, California. Retrieved from:

https://www.census.gov/quickfacts/fact/table/nevadacountycalifornia,grassvalleycitycalif ornia/PST045218

U.S. Department of Education. (2008). National Center for Education Statistics, Schools and Staffing Survey (SASS), "Public School Data File," 2007-08. Retrieved from: https://nces.ed.gov/surveys/sass/tables/sass0708 035 s1s.asp

U.S. Food and Drug Administration (FDA). (2014). Total Diet Study Elements Results Summary Statistics - Market Baskets 2006 through 2013. College Park, MD. Retrieved from https://www.fda.gov/food/science-research-food/total-diet-study

U.S. EPA (1992). Guidelines for Exposure Assessment (Vol.57). Washington, DC. Retrieved from https://www.epa.gov/sites/production/files/201411/documents/guidelines_exp_assessment.pdf

U.S. EPA. (1994). "Method 200.8: Determination of Trace Elements in Waters and Wastes by Inductively Coupled Plasma-Mass Spectrometry," Revision 5.4. Cincinnati, $\mathrm{OH}$. 
U.S. EPA (2000). Assigning Values to Non-Detected/Non-Quantified Pesticide Residues in Human Health Food Exposure Assessments. Washington, DC.

U.S. EPA. (2006a). Integrated Risk Information System (IRIS). Office of Research and Development, National Center for Environmental Assessment. Washington, DC. http://www.epa.gov/iris/.

U.S. EPA (2006b). National Ambient Air Quality Standards for Lead; Final Rule. Washington, D.C.: GPO. Web. Retrieved on 8 April. 2019.

U.S. EPA. (2007a). "Method 3051A (SW-846): Microwave Assisted Acid Digestion of Sediments, Sludges, and Oils," Revision 1. Washington, DC.

U.S. EPA. (2007b). "Method 3015A (SW-846): Microwave Assisted Acid Digestion of Aqueous Samples and Extracts," Revision 1. Washington, DC.

U.S. EPA. (2007c). "Guidance for Evaluating the Oral Bioavailability of Metals in Soils for Use in Human Health Risk Assessment.” Washington, DC.

U.S. EPA. (2008). Child-Specific Exposure Factors Handbook (Final Report). U.S. Environmental Protection Agency, Washington, DC, EPA/600/R-06/096F, 2008.

U.S. EPA. (2011). Exposure Factors Handbook 2011 Edition (Final Report). U.S. Environmental Protection Agency, Washington, DC, EPA/600/R-09/052F, 2011.

U.S. EPA. (2017a). Exposure Factors Handbook Chapter 5 (Update): Soil and Dust Ingestion. U.S. EPA Office of Research and Development, Washington, DC, EPA/600/R17/384F, 2017.

U.S. EPA. (2017b). "Standard Operating Procedure for an In Vitro Bioaccessibility Assay for Lead and Arsenic in Soil." Washington, DC.

U.S. EPA. (2018a). AirData Air Quality Monitors. [Air Quality System database] available at https://epa.maps.arcgis.com/apps/webappviewer/index.html?id=5f239fd3e $72 \mathrm{f} 424 \mathrm{f} 98 \mathrm{ef} 3 \mathrm{~d}$

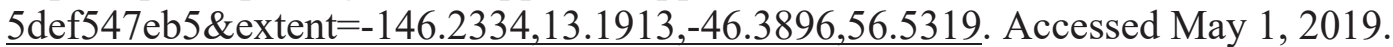

U.S. EPA. (2018b). Exposure Factors Handbook Chapter 9 (Update): Intake of Fruits and Vegetables. U.S. EPA Office of Research and Development, Washington, DC, EPA/600/R-18/098F.

U.S. EPA. (2019a). Exposure Factors Handbook Chapter 3 (Update): Ingestion of Water and Other Select Liquids. U.S. EPA Office of Research and Development, Washington, DC. 
U.S. EPA. (2019b). Regional Screening Levels for Chemical Contaminants at Superfund Sites. Washington, DC.

United States Department of Agriculture (USDA), Natural Resources Conservation Service. (2018). Web Soil Survey. Soil Survey Area: Nevada County Area, California, Survey Area Data: Version 11, Sep 12, 2018. Accessed at: http://websoilsurvey.nrcs.usda.gov

Vaiserman A. (2014). Early-life Exposure to Endocrine Disrupting Chemicals and Laterlife Health Outcomes: An Epigenetic Bridge? Aging and disease, 5(6), 419-429.

doi:10.14336/AD.2014.0500419

Warren, G. P., Alloway, B. J., Lepp, N. W., Singh, B., Bochereau, F. J. M., \& Penny, C. (2003). Field trials to assess the uptake of arsenic by vegetables from contaminated soils and soil remediation with iron oxides. Science of the Total Environment, 311(1-3), 1933. https://doi.org/10.1016/S0048-9697(03)00096-2

Yost, L. J., Tao, S. H., Egan, S. K., Barraj, L. M., Smith, K. M., Tsuji, J. S., ... Rachman, N. J. (2004). Estimation of dietary intake of inorganic arsenic in U.S. children. Human and Ecological Risk Assessment. https://doi.org/10.1080/10807030490452151 
APPENDIX C

Supplementary Data 


\section{Age-specific $\mathrm{ADD}$ and LADD of $\mathrm{As}, \mathrm{Cd}$, and $\mathrm{Pb}$ by Exposure Media}

Table 1. Age-specific average daily dose (ADD) and lifetime average daily dose (LADD) of metal(loid)s from ingestion of irrigation water across all sites.

\begin{tabular}{cccccc}
\hline $\begin{array}{c}\text { Exposure Age } \\
\text { Group }\end{array}$ & Element & $\begin{array}{c}\mathrm{ADD} \\
\left(\mathrm{mg} \mathrm{kg}^{-1} \mathrm{~d}^{-1}\right)\end{array}$ & $\begin{array}{c}\mathrm{ADD} \\
\left(\mu \mathrm{g} \mathrm{d}^{-1}\right)\end{array}$ & $\begin{array}{c}\mathrm{LADD} \\
\left(\mathrm{mg} \mathrm{kg}^{-1} \mathrm{~d}^{-1}\right)\end{array}$ & $\begin{array}{c}\text { LADDm } \\
\left(\mu \mathrm{g} \mathrm{d}^{-1}\right)\end{array}$ \\
\hline \multirow{3}{*}{1 to $<2$ yrs } & $\mathrm{As}$ & $5.3 \mathrm{E}-07$ & $6.1 \mathrm{E}-03$ & $6.8 \mathrm{E}-09$ & $7.8 \mathrm{E}-05$ \\
& $\mathrm{Cd}$ & $1.3 \mathrm{E}-08$ & $1.4 \mathrm{E}-04$ & $1.6 \mathrm{E}-10$ & $1.9 \mathrm{E}-06$ \\
& $\mathrm{~Pb}$ & $7.3 \mathrm{E}-07$ & $8.3 \mathrm{E}-03$ & $9.3 \mathrm{E}-09$ & $1.1 \mathrm{E}-04$ \\
\hline \multirow{3}{*}{2 to $<3$ yrs } & $\mathrm{As}$ & $6.2 \mathrm{E}-07$ & $8.5 \mathrm{E}-03$ & $7.9 \mathrm{E}-09$ & $9.0 \mathrm{E}-05$ \\
& $\mathrm{Cd}$ & $1.5 \mathrm{E}-08$ & $2.0 \mathrm{E}-04$ & $1.9 \mathrm{E}-10$ & $2.2 \mathrm{E}-06$ \\
& $\mathrm{~Pb}$ & $8.4 \mathrm{E}-07$ & $1.2 \mathrm{E}-02$ & $1.1 \mathrm{E}-08$ & $1.2 \mathrm{E}-04$ \\
\hline \multirow{3}{*}{3 to $<6$ yrs } & $\mathrm{As}$ & $4.7 \mathrm{E}-07$ & $8.7 \mathrm{E}-03$ & $6.0 \mathrm{E}-09$ & $6.8 \mathrm{E}-05$ \\
& $\mathrm{Cd}$ & $1.1 \mathrm{E}-08$ & $2.1 \mathrm{E}-04$ & $1.4 \mathrm{E}-10$ & $1.6 \mathrm{E}-06$ \\
& $\mathrm{~Pb}$ & $6.3 \mathrm{E}-07$ & $1.2 \mathrm{E}-02$ & $8.1 \mathrm{E}-09$ & $9.3 \mathrm{E}-05$ \\
\hline
\end{tabular}

Table 2. Age-specific average daily dose $(A D D)$ and lifetime average daily dose (LADD) of metal(loid)s from incidental soil $(<63 \mu \mathrm{m})$ ingestion across all sites.

\begin{tabular}{|c|c|c|c|c|c|c|}
\hline $\begin{array}{l}\text { Sample } \\
\text { location }\end{array}$ & $\begin{array}{c}\text { Exposure } \\
\text { Age } \\
\text { Group }\end{array}$ & Element & $\begin{array}{c}\mathrm{ADD} \\
\left(\mathrm{mg} \mathrm{kg}^{-1} \mathrm{~d}^{-1}\right)\end{array}$ & $\begin{array}{l}\mathrm{ADD}_{\mathrm{m}} \\
\left(\mu \mathrm{g} \mathrm{d}^{-1}\right)\end{array}$ & $\begin{array}{c}\text { LADD } \\
\left(\mathrm{mg} \mathrm{kg}^{-1} \mathrm{~d}^{-1}\right)\end{array}$ & $\begin{array}{l}\mathrm{LADD}_{\mathrm{m}} \\
\left(\mu \mathrm{g} \mathrm{d}^{-1}\right)\end{array}$ \\
\hline \multirow{9}{*}{ Garden } & \multirow{3}{*}{1 to $<2 \mathrm{yrs}$} & As & $1.1 \mathrm{E}-06$ & $1.3 \mathrm{E}-02$ & $1.4 \mathrm{E}-08$ & $1.6 \mathrm{E}-04$ \\
\hline & & $\mathrm{Cd}$ & $3.1 \mathrm{E}-07$ & $3.5 \mathrm{E}-03$ & 3.9E-09 & $4.5 \mathrm{E}-05$ \\
\hline & & $\mathrm{Pb}$ & $1.2 \mathrm{E}-04$ & 1.4 & $1.6 \mathrm{E}-06$ & $1.8 \mathrm{E}-02$ \\
\hline & \multirow{3}{*}{2 to $<3 \mathrm{yrs}$} & As & $6.8 \mathrm{E}-07$ & $9.5 \mathrm{E}-03$ & $8.8 \mathrm{E}-09$ & $1.0 \mathrm{E}-04$ \\
\hline & & $\mathrm{Cd}$ & $1.9 \mathrm{E}-07$ & $2.6 \mathrm{E}-03$ & 2.4E-09 & $2.8 \mathrm{E}-05$ \\
\hline & & $\mathrm{Pb}$ & 7.5E-05 & 1.0 & $9.7 \mathrm{E}-07$ & $1.1 \mathrm{E}-02$ \\
\hline & \multirow{3}{*}{3 to $<6$ yrs } & As & $5.1 \mathrm{E}-07$ & $9.5 \mathrm{E}-03$ & $6.5 \mathrm{E}-09$ & 7.4E-05 \\
\hline & & $\mathrm{Cd}$ & $1.4 \mathrm{E}-07$ & $2.6 \mathrm{E}-03$ & $1.8 \mathrm{E}-09$ & $2.1 \mathrm{E}-05$ \\
\hline & & $\mathrm{Pb}$ & $5.6 \mathrm{E}-05$ & 1.0 & $7.2 \mathrm{E}-07$ & $8.2 \mathrm{E}-03$ \\
\hline \multirow{9}{*}{ Playground } & \multirow{3}{*}{1 to $<2 \mathrm{yrs}$} & As & $9.9 \mathrm{E}-07$ & $1.1 \mathrm{E}-02$ & $1.3 \mathrm{E}-08$ & $1.4 \mathrm{E}-04$ \\
\hline & & $\mathrm{Cd}$ & $2.2 \mathrm{E}-07$ & $2.6 \mathrm{E}-03$ & $2.9 \mathrm{E}-09$ & $3.3 \mathrm{E}-05$ \\
\hline & & $\mathrm{Pb}$ & $3.2 \mathrm{E}-05$ & $3.6 \mathrm{E}-01$ & 4.1E-07 & 4.6E-03 \\
\hline & \multirow{3}{*}{2 to $<3 \mathrm{yrs}$} & As & $6.1 \mathrm{E}-07$ & $7.0 \mathrm{E}-03$ & 7.9E-09 & $9.0 \mathrm{E}-05$ \\
\hline & & $\mathrm{Cd}$ & $1.4 \mathrm{E}-07$ & $1.6 \mathrm{E}-03$ & $1.8 \mathrm{E}-09$ & $2.0 \mathrm{E}-05$ \\
\hline & & $\mathrm{Pb}$ & $2.0 \mathrm{E}-05$ & $2.2 \mathrm{E}-01$ & $2.5 \mathrm{E}-07$ & $2.9 \mathrm{E}-03$ \\
\hline & \multirow{3}{*}{3 to $<6 \mathrm{yrs}$} & As & 4.6E-07 & $5.2 \mathrm{E}-03$ & $5.8 \mathrm{E}-09$ & $6.7 \mathrm{E}-05$ \\
\hline & & $\mathrm{Cd}$ & $1.0 \mathrm{E}-07$ & $1.2 \mathrm{E}-03$ & $1.3 \mathrm{E}-09$ & $1.5 \mathrm{E}-05$ \\
\hline & & $\mathrm{Pb}$ & $1.5 \mathrm{E}-05$ & $1.7 \mathrm{E}-01$ & $1.9 \mathrm{E}-07$ & $2.1 \mathrm{E}-03$ \\
\hline
\end{tabular}


Table 3. Age-specific average daily dose (ADD) and lifetime average daily dose (LADD) of metal(loid)s from preschool garden plants across all sites.

\begin{tabular}{|c|c|c|c|c|c|c|}
\hline $\begin{array}{c}\text { Exposure } \\
\text { Age } \\
\text { Group } \\
\end{array}$ & Plant & Element & $\frac{\mathrm{ADD}}{\left(\mathrm{mg} \mathrm{kg}^{-1} \mathrm{~d}^{-1}\right)}$ & $\begin{array}{l}\mathrm{ADD}_{\mathrm{m}} \\
\left(\mu \mathrm{g} \mathrm{d}^{-1}\right)\end{array}$ & $\begin{array}{c}\text { LADD } \\
\left(\mathrm{mg} \mathrm{kg}^{-1} \mathrm{~d}^{-1}\right)\end{array}$ & $\begin{array}{r}\mathrm{LADD}_{\mathrm{m}} \\
\left(\mu \mathrm{g} \mathrm{d}^{-1}\right)\end{array}$ \\
\hline \multirow{15}{*}{$\begin{array}{c}1 \text { to }<2 \\
\text { yrs }\end{array}$} & \multirow{3}{*}{$\begin{array}{c}\text { Lettuce } \\
\text { (Asteraceae) }\end{array}$} & As & $1.9 \mathrm{E}-05$ & $2.2 \mathrm{E}-01$ & $2.5 \mathrm{E}-07$ & $2.8 \mathrm{E}-03$ \\
\hline & & $\mathrm{Cd}$ & $1.4 \mathrm{E}-06$ & $1.6 \mathrm{E}-02$ & $1.8 \mathrm{E}-08$ & $2.0 \mathrm{E}-04$ \\
\hline & & $\mathrm{Pb}$ & $2.4 \mathrm{E}-06$ & $2.7 \mathrm{E}-02$ & $3.0 \mathrm{E}-08$ & 3.4E-04 \\
\hline & \multirow{3}{*}{$\begin{array}{l}\text { Cilantro } \\
\text { (Apiaceae) }\end{array}$} & As & $3.5 \mathrm{E}-05$ & $4.0 \mathrm{E}-01$ & $4.5 \mathrm{E}-07$ & $5.1 \mathrm{E}-03$ \\
\hline & & $\mathrm{Cd}$ & $2.4 \mathrm{E}-07$ & $2.8 \mathrm{E}-03$ & 3.1E-09 & 3.6E-05 \\
\hline & & $\mathrm{Pb}$ & 7.5E-08 & $8.5 \mathrm{E}-04$ & $9.6 \mathrm{E}-10$ & $1.1 \mathrm{E}-05$ \\
\hline & \multirow{3}{*}{$\begin{array}{c}\text { Carrot } \\
\text { (Apiaceae) }\end{array}$} & As & $1.5 \mathrm{E}-06$ & $1.7 \mathrm{E}-02$ & $1.9 \mathrm{E}-08$ & $2.2 \mathrm{E}-04$ \\
\hline & & $\mathrm{Cd}$ & $8.9 \mathrm{E}-06$ & $1.0 \mathrm{E}-01$ & $1.1 \mathrm{E}-07$ & $1.3 \mathrm{E}-03$ \\
\hline & & $\mathrm{Pb}$ & $2.5 \mathrm{E}-05$ & $2.8 \mathrm{E}-01$ & $3.2 \mathrm{E}-07$ & 3.6E-03 \\
\hline & \multirow{3}{*}{$\begin{array}{c}\text { Kale } \\
\text { (Brassicaceae) }\end{array}$} & As & $2.6 \mathrm{E}-05$ & $3.0 \mathrm{E}-01$ & $3.3 \mathrm{E}-07$ & $3.8 \mathrm{E}-03$ \\
\hline & & $\mathrm{Cd}$ & 2.3E-07 & $2.6 \mathrm{E}-03$ & 2.9E-09 & 3.3E-05 \\
\hline & & $\mathrm{Pb}$ & $2.6 \mathrm{E}-08$ & $3.0 \mathrm{E}-04$ & $3.4 \mathrm{E}-10$ & $3.8 \mathrm{E}-06$ \\
\hline & \multirow{3}{*}{$\begin{array}{c}\text { Cabbage } \\
\text { (Brassicaceae) }\end{array}$} & As & 7.5E-08 & $8.6 \mathrm{E}-04$ & $9.6 \mathrm{E}-10$ & $1.1 \mathrm{E}-05$ \\
\hline & & $\mathrm{Cd}$ & $1.0 \mathrm{E}-07$ & $1.2 \mathrm{E}-03$ & $1.3 \mathrm{E}-09$ & $1.5 \mathrm{E}-05$ \\
\hline & & $\mathrm{Pb}$ & 2.7E-08 & $3.1 \mathrm{E}-04$ & $3.5 \mathrm{E}-10$ & 4.0E-06 \\
\hline \multirow{15}{*}{$\begin{array}{c}2 \text { to }<3 \\
\text { yrs }\end{array}$} & \multirow{3}{*}{$\begin{array}{c}\text { Lettuce } \\
\text { (Asteraceae) }\end{array}$} & As & $1.2 \mathrm{E}-04$ & 1.6 & $1.5 \mathrm{E}-06$ & $2.1 \mathrm{E}-02$ \\
\hline & & $\mathrm{Cd}$ & $8.5 \mathrm{E}-06$ & $1.2 \mathrm{E}-01$ & $1.1 \mathrm{E}-07$ & $1.5 \mathrm{E}-03$ \\
\hline & & $\mathrm{Pb}$ & $1.4 \mathrm{E}-05$ & $2.0 \mathrm{E}-01$ & $1.8 \mathrm{E}-07$ & $2.5 \mathrm{E}-03$ \\
\hline & \multirow{3}{*}{$\begin{array}{l}\text { Cilantro } \\
\text { (Apiaceae) }\end{array}$} & As & $3.8 \mathrm{E}-06$ & $5.3 \mathrm{E}-02$ & 4.9E-08 & $6.8 \mathrm{E}-04$ \\
\hline & & $\mathrm{Cd}$ & 2.7E-08 & 3.7E-04 & $3.4 \mathrm{E}-10$ & 4.8E-06 \\
\hline & & $\mathrm{Pb}$ & $8.2 \mathrm{E}-09$ & $1.1 \mathrm{E}-04$ & $1.1 \mathrm{E}-10$ & $1.5 \mathrm{E}-06$ \\
\hline & \multirow{3}{*}{$\begin{array}{c}\text { Carrot } \\
\text { (Apiaceae) }\end{array}$} & As & 5.7E-06 & $7.8 \mathrm{E}-02$ & 7.3E-08 & $1.0 \mathrm{E}-03$ \\
\hline & & $\mathrm{Cd}$ & 3.4E-05 & $4.6 \mathrm{E}-01$ & 4.3E-07 & $6.0 \mathrm{E}-03$ \\
\hline & & $\mathrm{Pb}$ & $9.3 \mathrm{E}-05$ & 1.3 & $1.2 \mathrm{E}-06$ & $1.6 \mathrm{E}-02$ \\
\hline & \multirow{3}{*}{$\begin{array}{c}\text { Kale } \\
\text { (Brassicaceae) }\end{array}$} & As & $1.1 \mathrm{E}-05$ & $1.5 \mathrm{E}-01$ & $1.4 \mathrm{E}-07$ & $1.9 \mathrm{E}-03$ \\
\hline & & $\mathrm{Cd}$ & $9.4 \mathrm{E}-08$ & $1.3 \mathrm{E}-03$ & $1.2 \mathrm{E}-09$ & $1.7 \mathrm{E}-05$ \\
\hline & & $\mathrm{Pb}$ & $1.1 \mathrm{E}-08$ & $1.5 \mathrm{E}-04$ & $1.4 \mathrm{E}-10$ & $1.9 \mathrm{E}-06$ \\
\hline & \multirow{3}{*}{$\begin{array}{c}\text { Cabbage } \\
\text { (Brassicaceae) }\end{array}$} & As & $3.5 \mathrm{E}-08$ & $4.8 \mathrm{E}-04$ & $4.5 \mathrm{E}-10$ & $6.2 \mathrm{E}-06$ \\
\hline & & $\mathrm{Cd}$ & 4.8E-08 & $6.7 \mathrm{E}-04$ & $6.2 \mathrm{E}-10$ & 8.6E-06 \\
\hline & & $\mathrm{Pb}$ & $1.3 \mathrm{E}-08$ & $1.7 \mathrm{E}-04$ & $1.6 \mathrm{E}-10$ & 2.2E-06 \\
\hline \multirow{9}{*}{$\begin{array}{c}3 \text { to }<6 \\
\text { yrs }\end{array}$} & \multirow{3}{*}{$\begin{array}{c}\text { Lettuce } \\
\text { (Asteraceae) }\end{array}$} & As & 9.7E-07 & $1.8 \mathrm{E}-02$ & $1.2 \mathrm{E}-08$ & 2.3E-04 \\
\hline & & $\mathrm{Cd}$ & 7.0E-08 & $1.3 \mathrm{E}-03$ & $9.0 \mathrm{E}-10$ & $1.7 \mathrm{E}-05$ \\
\hline & & $\mathrm{Pb}$ & $1.2 \mathrm{E}-07$ & $2.2 \mathrm{E}-03$ & $1.5 \mathrm{E}-09$ & 2.8E-05 \\
\hline & \multirow{3}{*}{$\begin{array}{l}\text { Cilantro } \\
\text { (Apiaceae) }\end{array}$} & As & $2.4 \mathrm{E}-07$ & $4.5 \mathrm{E}-03$ & 3.1E-09 & $5.8 \mathrm{E}-05$ \\
\hline & & $\mathrm{Cd}$ & $1.7 \mathrm{E}-09$ & $3.1 \mathrm{E}-05$ & $2.2 \mathrm{E}-11$ & 4.0E-07 \\
\hline & & $\mathrm{Pb}$ & $5.2 \mathrm{E}-10$ & $9.6 \mathrm{E}-06$ & $6.6 \mathrm{E}-12$ & $1.2 \mathrm{E}-07$ \\
\hline & \multirow{3}{*}{$\begin{array}{c}\text { Carrot } \\
\text { (Apiaceae) }\end{array}$} & As & $6.2 \mathrm{E}-07$ & $1.2 \mathrm{E}-02$ & 7.9E-09 & $1.5 \mathrm{E}-04$ \\
\hline & & $\mathrm{Cd}$ & $3.7 \mathrm{E}-06$ & $6.8 \mathrm{E}-02$ & 4.7E-08 & $8.8 \mathrm{E}-04$ \\
\hline & & $\mathrm{Pb}$ & $1.0 \mathrm{E}-05$ & $1.9 \mathrm{E}-01$ & $1.3 \mathrm{E}-07$ & 2.4E-03 \\
\hline
\end{tabular}




\begin{tabular}{cccccc}
\hline Kale & $\mathrm{As}$ & $8.0 \mathrm{E}-06$ & $1.5 \mathrm{E}-01$ & $1.0 \mathrm{E}-07$ & $1.9 \mathrm{E}-03$ \\
$($ Brassicaceae $)$ & $\mathrm{Cd}$ & $6.9 \mathrm{E}-08$ & $1.3 \mathrm{E}-03$ & $8.9 \mathrm{E}-10$ & $1.7 \mathrm{E}-05$ \\
& $\mathrm{~Pb}$ & $8.0 \mathrm{E}-09$ & $1.5 \mathrm{E}-04$ & $1.0 \mathrm{E}-10$ & $1.9 \mathrm{E}-06$ \\
\hline \multirow{2}{*}{ Cabbage } & $\mathrm{As}$ & $2.0 \mathrm{E}-08$ & $3.8 \mathrm{E}-04$ & $2.6 \mathrm{E}-10$ & $4.8 \mathrm{E}-06$ \\
(Brassicaceae) & $\mathrm{Cd}$ & $2.8 \mathrm{E}-08$ & $5.3 \mathrm{E}-04$ & $3.6 \mathrm{E}-10$ & $6.7 \mathrm{E}-06$ \\
& $\mathrm{~Pb}$ & $7.4 \mathrm{E}-09$ & $1.4 \mathrm{E}-04$ & $9.5 \mathrm{E}-11$ & $1.8 \mathrm{E}-06$ \\
\hline
\end{tabular}

Table 4. Age-specific average daily dose (ADD) and lifetime average daily dose (LADD) of metal(loid)s from inhalation of dust $(<10 \mu \mathrm{m})$ across all sites.

\begin{tabular}{|c|c|c|c|c|c|c|}
\hline $\begin{array}{l}\text { Sample } \\
\text { location }\end{array}$ & $\begin{array}{l}\text { Exposure } \\
\text { Age } \\
\text { Group }\end{array}$ & Element & $\begin{array}{c}\mathrm{ADD} \\
\left(\mathrm{mg} \mathrm{kg}^{-1} \mathrm{~d}^{-1}\right)\end{array}$ & $\begin{array}{l}\mathrm{ADD}_{\mathrm{m}} \\
\left(\mu \mathrm{g} \mathrm{d}^{-1}\right)\end{array}$ & $\begin{array}{c}\text { LADD } \\
\left(\mathrm{mg} \mathrm{kg}^{-1} \mathrm{~d}^{-1}\right)\end{array}$ & $\begin{array}{r}\mathrm{LADD}_{\mathrm{m}} \\
\left(\mu \mathrm{g} \mathrm{d}^{-1}\right)\end{array}$ \\
\hline \multirow{9}{*}{ Garden } & \multirow{3}{*}{1 to $<2 \mathrm{yrs}$} & As & $4.8 \mathrm{E}-08$ & $5.5 \mathrm{E}-04$ & $6.2 \mathrm{E}-10$ & 7.1E-06 \\
\hline & & $\mathrm{Cd}$ & 4.9E-09 & $5.6 \mathrm{E}-05$ & $6.2 \mathrm{E}-11$ & 7.1E-07 \\
\hline & & $\mathrm{Pb}$ & $3.8 \mathrm{E}-09$ & $4.3 \mathrm{E}-05$ & $4.9 \mathrm{E}-11$ & $5.6 \mathrm{E}-07$ \\
\hline & \multirow{3}{*}{2 to $<3 \mathrm{yrs}$} & As & 4.7E-08 & $6.6 \mathrm{E}-04$ & $6.1 \mathrm{E}-10$ & $6.9 \mathrm{E}-06$ \\
\hline & & $\mathrm{Cd}$ & 4.8E-09 & $6.6 \mathrm{E}-05$ & $6.1 \mathrm{E}-11$ & 7.0E-07 \\
\hline & & $\mathrm{Pb}$ & 3.7E-09 & $5.2 \mathrm{E}-05$ & $4.8 \mathrm{E}-11$ & 5.5E-07 \\
\hline & \multirow{3}{*}{3 to $<6 \mathrm{yrs}$} & As & $3.7 \mathrm{E}-08$ & $6.9 \mathrm{E}-04$ & $4.8 \mathrm{E}-10$ & $5.4 \mathrm{E}-06$ \\
\hline & & $\mathrm{Cd}$ & 3.7E-09 & $6.9 \mathrm{E}-05$ & $4.8 \mathrm{E}-11$ & $5.5 \mathrm{E}-07$ \\
\hline & & $\mathrm{Pb}$ & $2.9 \mathrm{E}-09$ & $5.4 \mathrm{E}-05$ & 3.7E-11 & 4.3E-07 \\
\hline \multirow{9}{*}{$\begin{array}{c}\text { Playgroun } \\
\mathrm{d}\end{array}$} & \multirow{3}{*}{1 to $<2 \mathrm{yrs}$} & As & 3.9E-08 & 4.5E-04 & $5.0 \mathrm{E}-10$ & $5.8 \mathrm{E}-06$ \\
\hline & & $\mathrm{Cd}$ & $3.0 \mathrm{E}-09$ & $3.4 \mathrm{E}-05$ & $3.8 \mathrm{E}-11$ & 4.3E-07 \\
\hline & & $\mathrm{Pb}$ & $3.1 \mathrm{E}-09$ & $3.5 \mathrm{E}-05$ & $4.0 \mathrm{E}-11$ & 4.5E-07 \\
\hline & \multirow{3}{*}{2 to $<3 \mathrm{yrs}$} & As & 3.9E-08 & 4.4E-04 & $5.0 \mathrm{E}-10$ & $5.6 \mathrm{E}-06$ \\
\hline & & $\mathrm{Cd}$ & $2.9 \mathrm{E}-09$ & $3.3 \mathrm{E}-05$ & 3.7E-11 & 4.2E-07 \\
\hline & & $\mathrm{Pb}$ & $3.1 \mathrm{E}-09$ & $3.5 \mathrm{E}-05$ & $3.9 \mathrm{E}-11$ & 4.5E-07 \\
\hline & \multirow{3}{*}{3 to $<6 \mathrm{yrs}$} & As & $3.0 \mathrm{E}-08$ & $3.4 \mathrm{E}-04$ & $3.9 \mathrm{E}-10$ & 4.4E-06 \\
\hline & & $\mathrm{Cd}$ & 2.3E-09 & $2.6 \mathrm{E}-05$ & $2.9 \mathrm{E}-11$ & 3.3E-07 \\
\hline & & $\mathrm{Pb}$ & 2.4E-09 & $2.7 \mathrm{E}-05$ & $3.1 \mathrm{E}-11$ & $3.5 \mathrm{E}-07$ \\
\hline
\end{tabular}


Results for Chromium, Zinc, Nickel, Mercury

Table 5. ICP-MS quantifiable detection limits for $\mathrm{Cr}, \mathrm{Zn}, \mathrm{Ni}$.

\begin{tabular}{lll}
\hline Element & Instrument Detection Limit ${ }^{\mathrm{a}}(\mu \mathrm{g} / \mathrm{L})$ & Method Detection Limit $(\mu \mathrm{g} / \mathrm{g})$ \\
\hline $\mathrm{Cr}$ & 0.0151 & 0.063 \\
$\mathrm{Zn}$ & 0.006 & 0.020 \\
$\mathrm{Ni}$ & 0.0066 & 0.054 \\
\hline
\end{tabular}

${ }^{a}$ Agilent 7700 ICP-MS

Table 6. Garden irrigation water $\mathrm{Cr}, \mathrm{Zn}$, Ni concentrations $\left(\mu \mathrm{g}^{-1}\right)$.

\begin{tabular}{cccc}
\hline Site & $\mathrm{Cr}\left(\mu \mathrm{g} \mathrm{L}^{-1}\right)$ & $\mathrm{Ni}\left(\mu \mathrm{g} \mathrm{L}^{-1}\right)$ & $\mathrm{Zn}\left(\mu \mathrm{g} \mathrm{L}^{-1}\right)$ \\
\hline $\mathrm{S} 1(\mathrm{n}=1)$ & $--^{*}$ & 0.0117 & 0.2464 \\
$\mathrm{~S} 2(\mathrm{n}=1)$ & 0.0526 & 0.1010 & 7.2324 \\
$\mathrm{~S} 3(\mathrm{n}=1)$ & 0.0406 & 0.0735 & 1.3010 \\
$\mathrm{~S} 4(\mathrm{n}=1)$ & 0.0926 & 0.1347 & 3.7915 \\
\hline
\end{tabular}

* Contaminated sample (field blank was greater than actual sample)

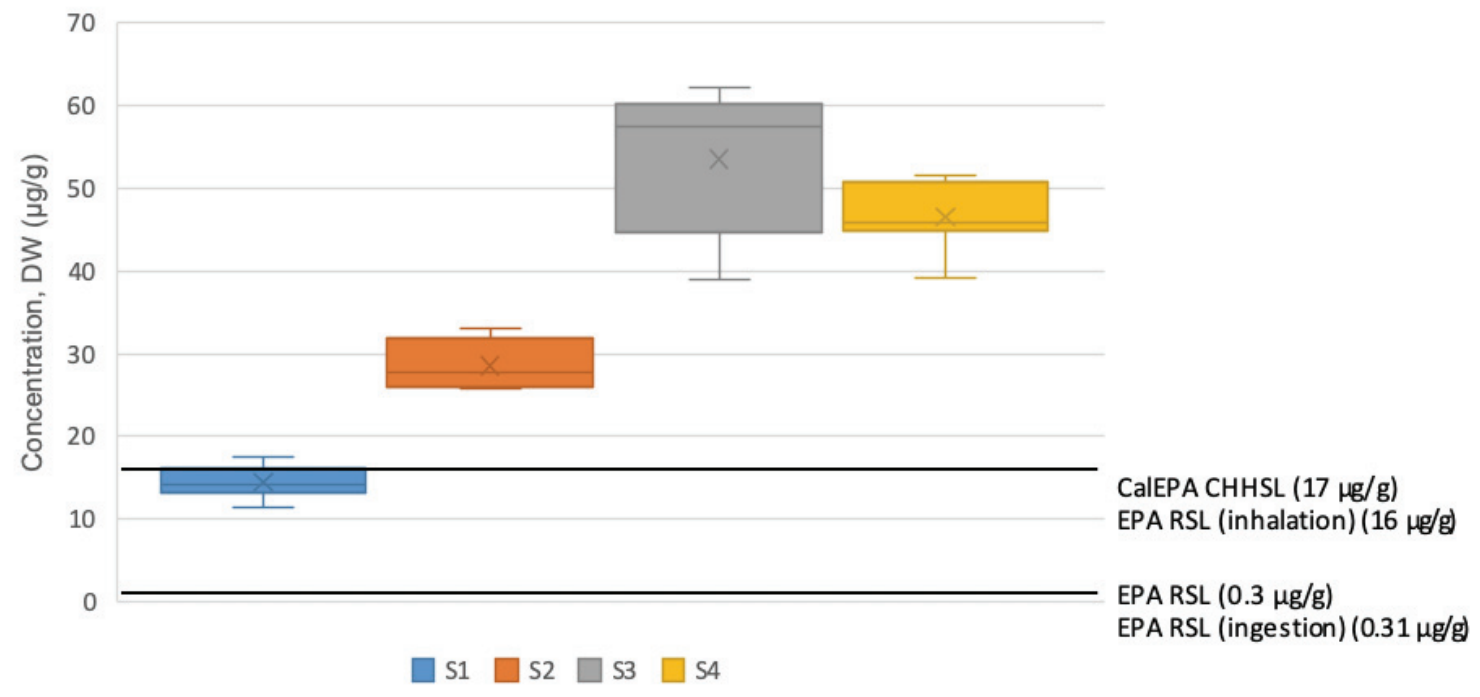

Figure 1. Cr concentration in garden soil $\left(\mu g g^{-1}\right)$. 


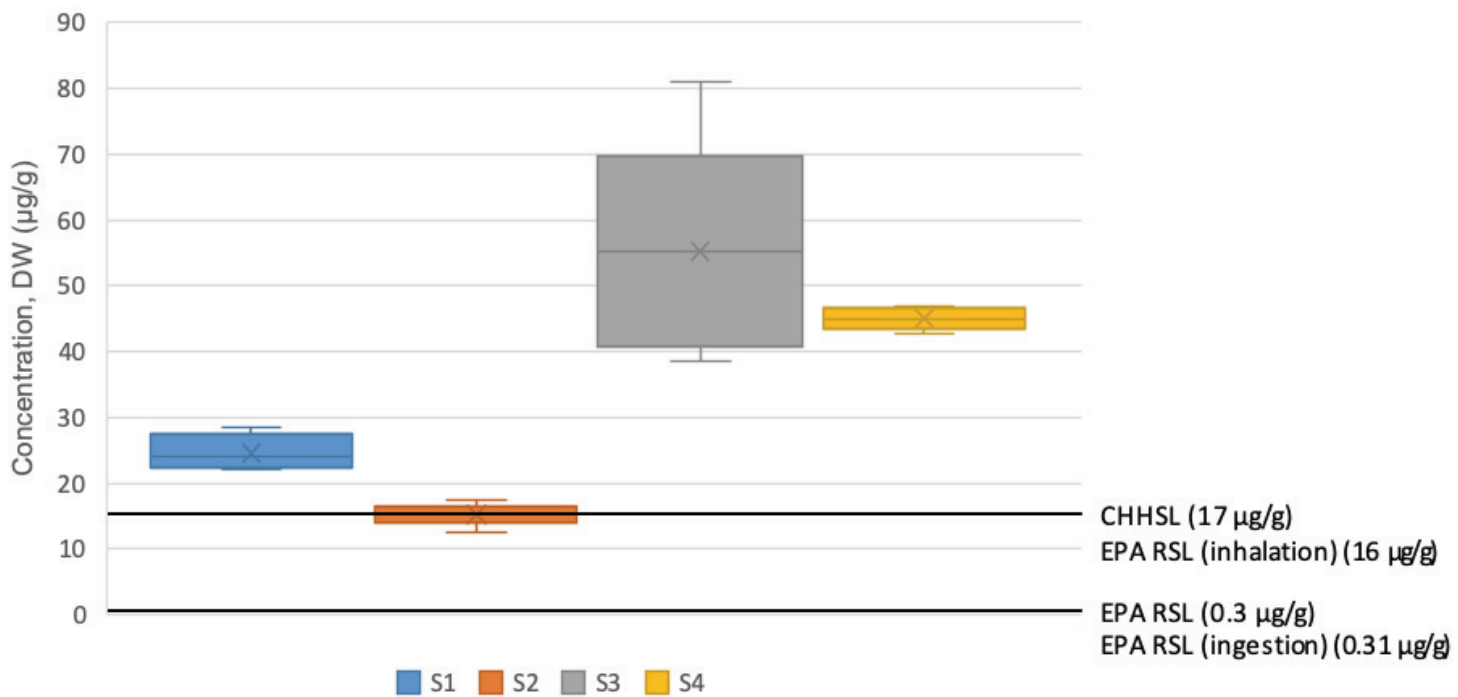

Figure 2. Cr concentration in playground soil $\left(\mu g g^{-1}\right)$.

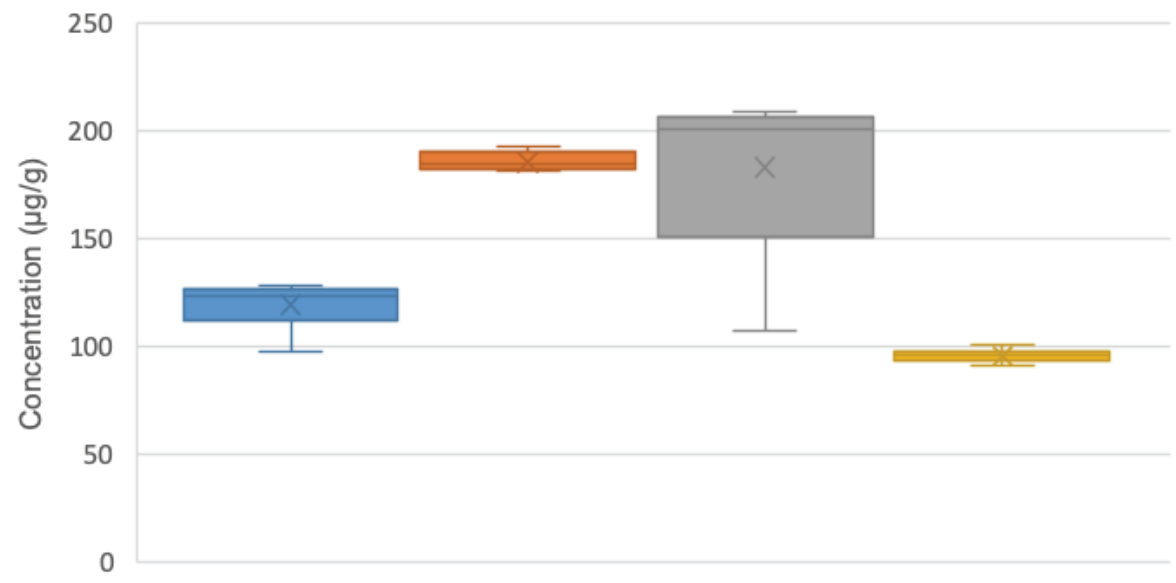

S1 $\square$ S2 $\square$ s3 $\square$ S4

Figure 3. Zn concentration in garden soil $\left(\mu g g^{-1}\right)$. 


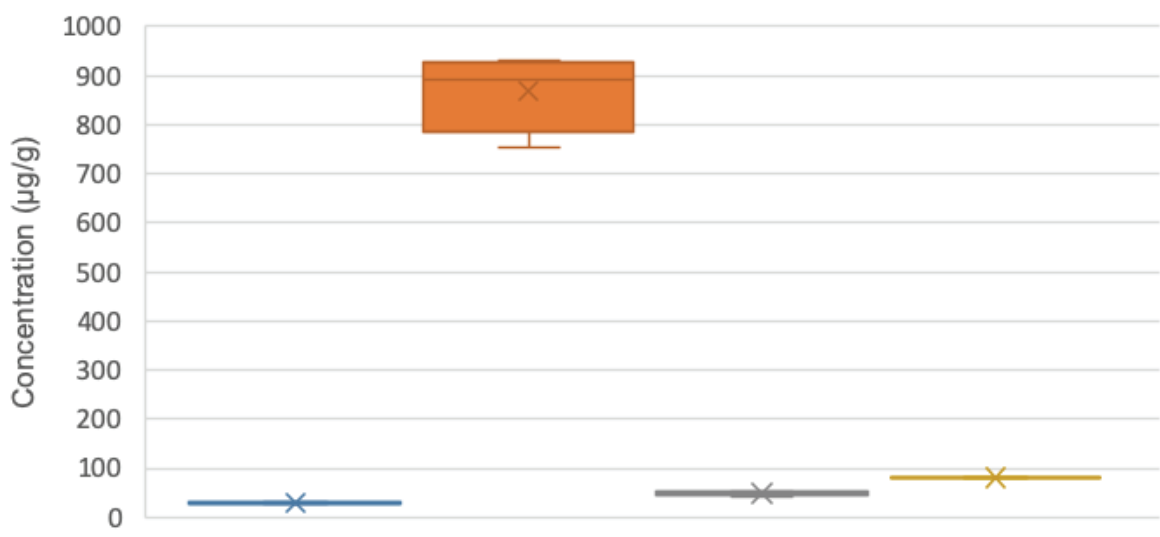

S1 $\square$ S2 $\square$ S3 $\square$ S4

Figure 4. Zn concentration in playground soil $\left(\mu g g^{-1}\right)$.

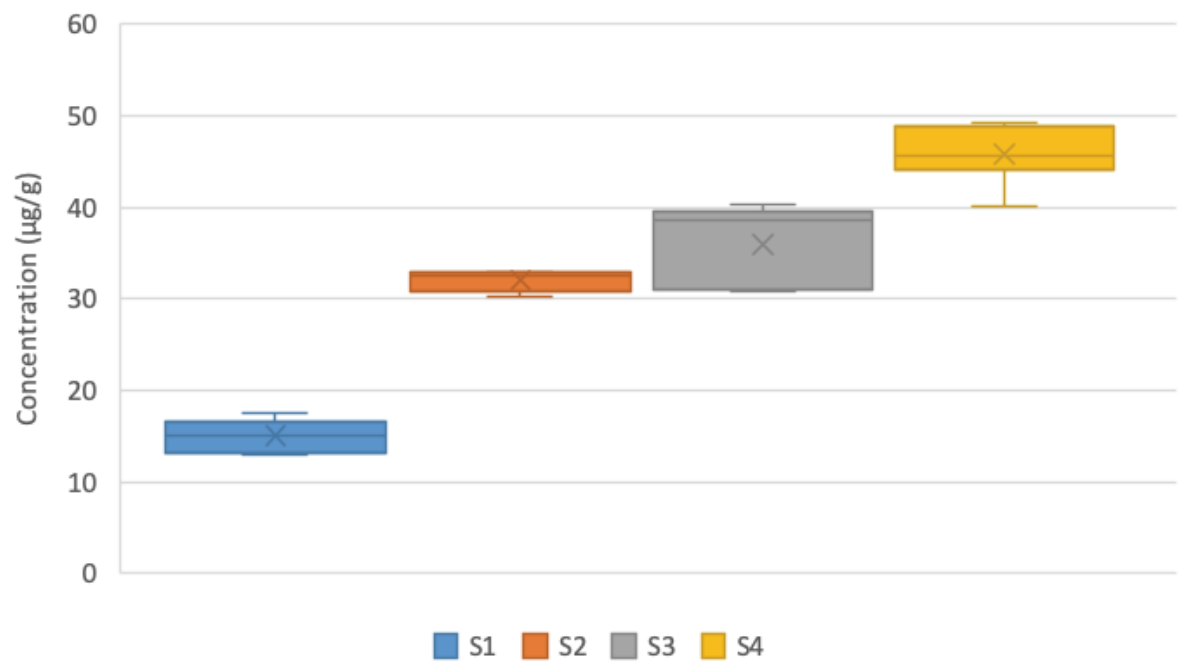

Figure 5. Ni concentration in garden soil $\left(\mu g g^{-1}\right)$. 


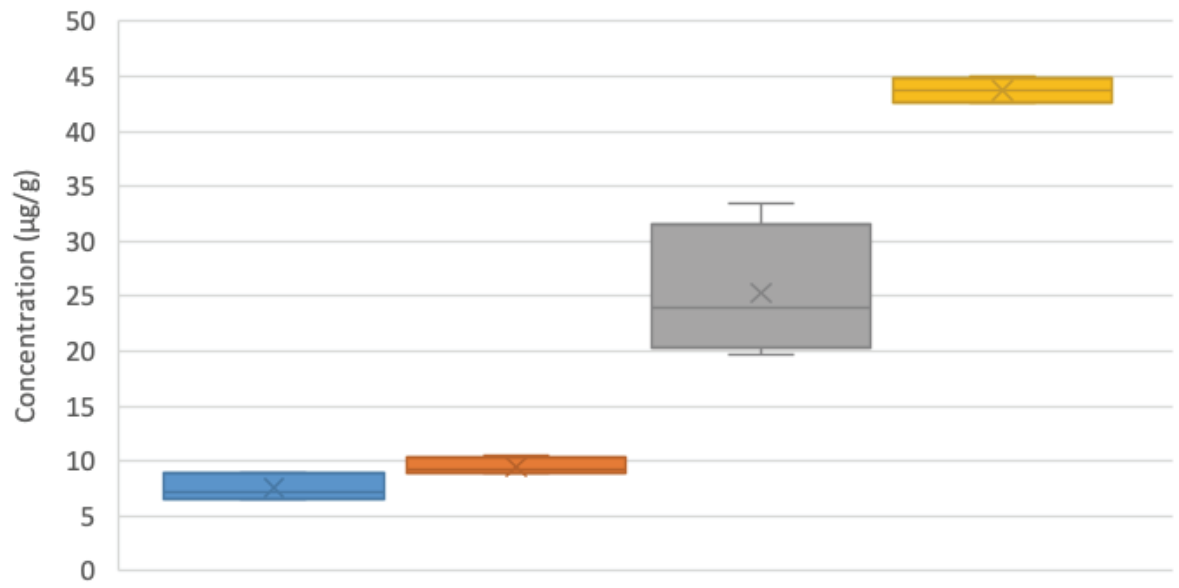

S1 $\square$ S2 $\square$ S3 $\square$ S4

Figure 6. Ni concentration in playground soil $\left(\mu g g^{-1}\right)$.

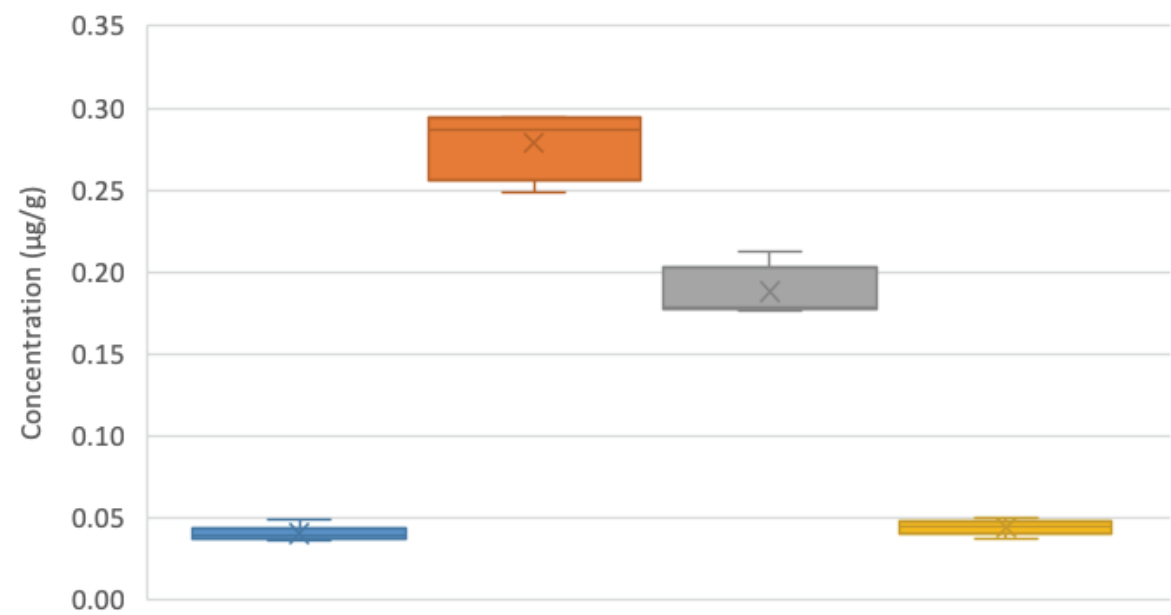

$\square$ S1 $\square$ S2 $\square$ S3 $\square$ S4

Figure 7. Hg concentration in garden soil $\left(\mu g g^{-1}\right)$. 


\subsection{5}

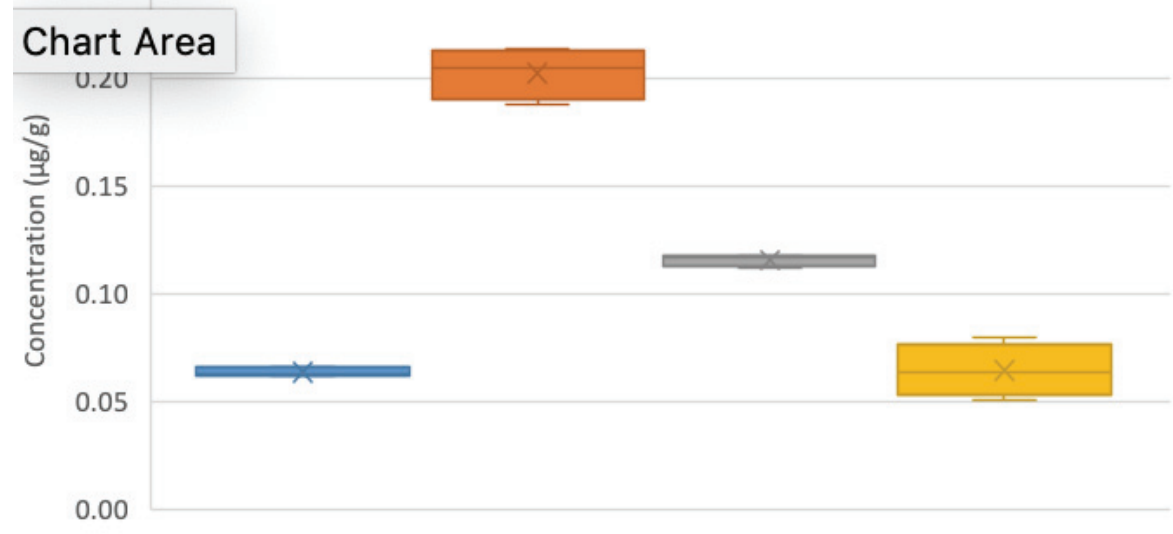

S1 $\square$ S2 $\square$ S3 $\square$ S4

Figure 8. Hg concentration in playground soil $\left(\mu g g^{-1}\right)$.

Table 7. Federal and state recommended soil screening levels for $\mathrm{Cr}, \mathrm{Ni}, \mathrm{Zn}$, and $H g\left(\mu g g^{-1}\right)$.

\begin{tabular}{cccccc}
\hline $\begin{array}{c}\text { Governing } \\
\text { Agency }\end{array}$ & & $\mathrm{Cr}(\mathrm{VI})$ & $\mathrm{Ni}$ & $\mathrm{Zn}$ & $\mathrm{Hg}^{1}$ \\
\hline CalEPA & CHHSL & $17(\mathrm{ca})$ & $1,600(\mathrm{nc})$ & $23,000(\mathrm{nc})$ & $18(\mathrm{nc})$ \\
\hline CalEPA & DTSC-SL & & $\begin{array}{c}1,500(\mathrm{ca})^{2} \\
490(\mathrm{nc})\end{array}$ & & $1.0(\mathrm{nc})$ \\
\hline U.S. EPA & EPA RSL & $0.3(\mathrm{ca})$ & & $23,000(\mathrm{ncc})$ & $11(\mathrm{ncc})$ \\
\hline U.S. EPA & $\begin{array}{c}\text { EPA RSL } \\
\text { (ingestion) }\end{array}$ & $0.31(\mathrm{ca})$ & & $23,000(\mathrm{ncc})$ & \\
\hline U.S. EPA & $\begin{array}{c}\text { EPA RSL } \\
\text { (inhalation) }\end{array}$ & $16(\mathrm{ca})$ & & & $11(\mathrm{ncc})$ \\
\hline NR $^{6}$ & $\begin{array}{c}\text { Background } \\
\text { levels }\end{array}$ & $\begin{array}{c}566^{3,4,5} \\
122^{5}\end{array}$ & $\begin{array}{c}1,929^{3,5} \\
57^{5}\end{array}$ & $149^{5}$ & $0.26^{5}$ \\
\hline
\end{tabular}

(ca) denotes that the risk-based screening level is based on carcinogenic effects (CSF). TR $=10^{-6}$

(nc) denotes that the risk-based screening level is based on non-carcinogenic chronic effects. $\mathrm{HI}=1$

(ncc) denotes that the risk-based screening level is based on non-carcinogenic chronic effects for children. HI $=1$

${ }^{1}$ Elemental mercury

${ }^{2}$ U.S. EPA risk-based screening level recommended by DTSC

${ }^{3} 95^{\text {th }}$ upper confidence limit on the arithmetic mean

${ }^{4}$ Total chromium

${ }^{5}$ Mean of 50 benchmark CA soils (Kearney Foundation of Soil Science, 1996)

${ }^{6}$ Not regulated (NR) 
Table 8. Median Cr, Zn, Ni concentrations $\left(\mu \mathrm{g} \mathrm{g}^{-1}\right)$ measured from garden and playground dust samples $(<10 \mu \mathrm{m})$.

\begin{tabular}{cccc}
\hline & Sample Location & $\begin{array}{c}\text { Concentration }\left(\mu \mathrm{g} \mathrm{g}^{-1}\right) \\
(\mathrm{n}=8)\end{array}$ & $\begin{array}{c}\text { Concentration }\left(\mu \mathrm{g} / \mathrm{m}^{3}\right) \\
(\mathrm{n}=8)\end{array}$ \\
\hline \multirow{2}{*}{$\mathrm{Cr}$} & Garden & $70.96(16.89-95.15)$ & $0.0263(0.0063-0.0352)$ \\
& Playground & $53.65(26.58-68.83)$ & $0.0199(0.0098-0.0255)$ \\
\hline \multirow{2}{*}{$\mathrm{Zn}$} & Garden & $262.0(158.7-342.9)$ & $0.0970(0.0588-0.1270)$ \\
& Playground & $129.2(108.4-2628)$ & $0.0478(0.0401-0.9735)$ \\
\hline \multirow{2}{*}{$\mathrm{Ni}$} & Garden & $57.20(13.24-78.22)$ & $0.0212(0.0049-0.0290)$ \\
& Playground & $31.03(14.84-65.44)$ & $0.0115(0.0055-0.0242)$ \\
\hline
\end{tabular}

Table 9. Median $\mathrm{Zn}$ and Ni concentrations ( $F W, \mathrm{mg} \mathrm{kg}^{-1}$ ), and mean metal(loid) concentrations reported in the USFDA Total Diet Study, and WHO Codex Recommended Maximum Levels ( $F W, \mathrm{mg} \mathrm{kg}^{-1}$ ).

\begin{tabular}{|c|c|c|c|}
\hline $\begin{array}{l}\text { Plant (Plant } \\
\text { Family) }\end{array}$ & & $\mathrm{Zn}$ & $\mathrm{Ni}$ \\
\hline \multirow{2}{*}{$\begin{array}{c}\text { Lettuce } \\
(\text { Asteraceae })\end{array}$} & $\operatorname{Median}(\mathrm{n}=12)^{\mathrm{a}}$ & $13.95 *(1.162-38.74)$ & $0.1291 *(0.0083-0.9559)$ \\
\hline & USFDA (leaf, raw) & 2.00 & 0.062 \\
\hline \multirow{2}{*}{$\begin{array}{c}\text { Cilantro } \\
\text { (Apiaceae) }\end{array}$} & Median $(\mathrm{n}=12)^{\mathrm{a}}$ & $7.429(6.303-13.15)$ & $0.0992(0.0554-0.1698)$ \\
\hline & USFDA & N/A & $\mathrm{N} / \mathrm{A}$ \\
\hline \multirow{2}{*}{$\begin{array}{c}\text { Carrot } \\
\text { (Apiaceae) }\end{array}$} & $\operatorname{Median}(\mathrm{n}=9)^{\mathrm{a}}$ & $14.13 *(2.716-29.96)$ & $0.2313 *(0.0198-0.3404)$ \\
\hline & $\begin{array}{c}\text { USFDA } \\
\text { (fresh, peeled, boiled) }\end{array}$ & 1.8 & 0.047 \\
\hline \multirow{2}{*}{$\begin{array}{c}\text { Kale } \\
\text { (Brassicaceae } \\
\text { ) }\end{array}$} & $\operatorname{Median}(\mathrm{n}=9)^{\mathrm{a}}$ & $4.527(0.4328-17.23)$ & $0.0428(0.0048-0.4377)$ \\
\hline & USFDA & $\mathrm{N} / \mathrm{A}$ & N/A \\
\hline \multirow{2}{*}{$\begin{array}{c}\text { Cabbage } \\
\text { (Brassicaceae } \\
\text { ) }\end{array}$} & Median $(\mathrm{n}=3)^{\mathrm{a}}$ & $5.107 *(4.681-5.222)$ & $0.0949 *(0.0885-0.0951)$ \\
\hline & USFDA (fresh, boiled) & 0.88 & 0.016 \\
\hline
\end{tabular}

* Denotes a measured median concentration larger than the respective mean reported by the USFDA Total Diet Study.

${ }^{a}$ This study 
Table 10. Site-specific median BCF of Zn and Ni per plant type.

\begin{tabular}{ccccc}
\hline Site & Plant & No. samples & $\mathrm{Zn}$ & $\mathrm{Ni}$ \\
\hline S1 & Lettuce (Asteraceae) & 3 & 0.4341 & 0.0343 \\
& Cilantro (Apiaceae) & 3 & 0.7986 & 0.0657 \\
& Carrot (Apiaceae) & 3 & 0.3529 & 0.0476 \\
& Kale (Brassicaceae) & 3 & 0.3460 & 0.0679 \\
\hline S2 & Lettuce (Asteraceae) & 3 & 0.4009 & 0.0289 \\
& Cilantro (Apiaceae) & 3 & 0.4805 & 0.0197 \\
& Carrot (Apiaceae) & 3 & 0.2433 & 0.0139 \\
& Kale (Brassicaceae) & 3 & 0.3426 & 0.0219 \\
\hline S3 & Lettuce (Asteraceae) & 3 & 0.4313 & 0.0501 \\
& Cilantro (Apiaceae) & 3 & 0.3208 & 0.0221 \\
& Carrot (Apiaceae) & 3 & 0.4595 & 0.0257 \\
& Cabbage (Brassicaceae) & 3 & 0.1653 & 0.0162 \\
\hline S4 & Lettuce (Asteraceae) & 3 & 0.8110 & 0.0084 \\
& Cilantro (Apiaceae) & 3 & 0.7663 & 0.0302 \\
& Kale (Brassicaceae) & 3 & 0.7130 & 0.0140 \\
\hline
\end{tabular}

* indicates metal(loid) accumulator $(1 \leq \mathrm{BCF}<10)$

$* *$ indicates metal(loid) hyperaccumulator $(\mathrm{BFC} \geq 10)$

Table 11. Median BCF of Zn and Ni per plant type (across all sites).

\begin{tabular}{cccc}
\hline Plant & No. samples & $\mathrm{Zn}$ & $\mathrm{Ni}$ \\
\hline $\begin{array}{c}\text { Lettuce } \\
\text { (Asteraceae) }\end{array}$ & 12 & 0.4327 & 0.0320 \\
Cilantro (Apiaceae) & 12 & 0.4857 & 0.0271 \\
Carrot (Apiaceae) & 9 & 0.3529 & 0.0257 \\
Kale (Brassicaceae) & 9 & 0.3623 & 0.0228 \\
$\begin{array}{c}\text { Cabbage } \\
\text { (Brassicaceae) }\end{array}$ & 3 & 0.1653 & 0.0162 \\
\hline
\end{tabular}

* indicates metal(loid) accumulator $(1 \leq \mathrm{BCF}<10)$

$* *$ indicates metal(loid) hyperaccumulator $(\mathrm{BFC} \geq 10)$ 


\section{APPENDIX D}

Sample Collection Instructions Manual (English/Spanish) 

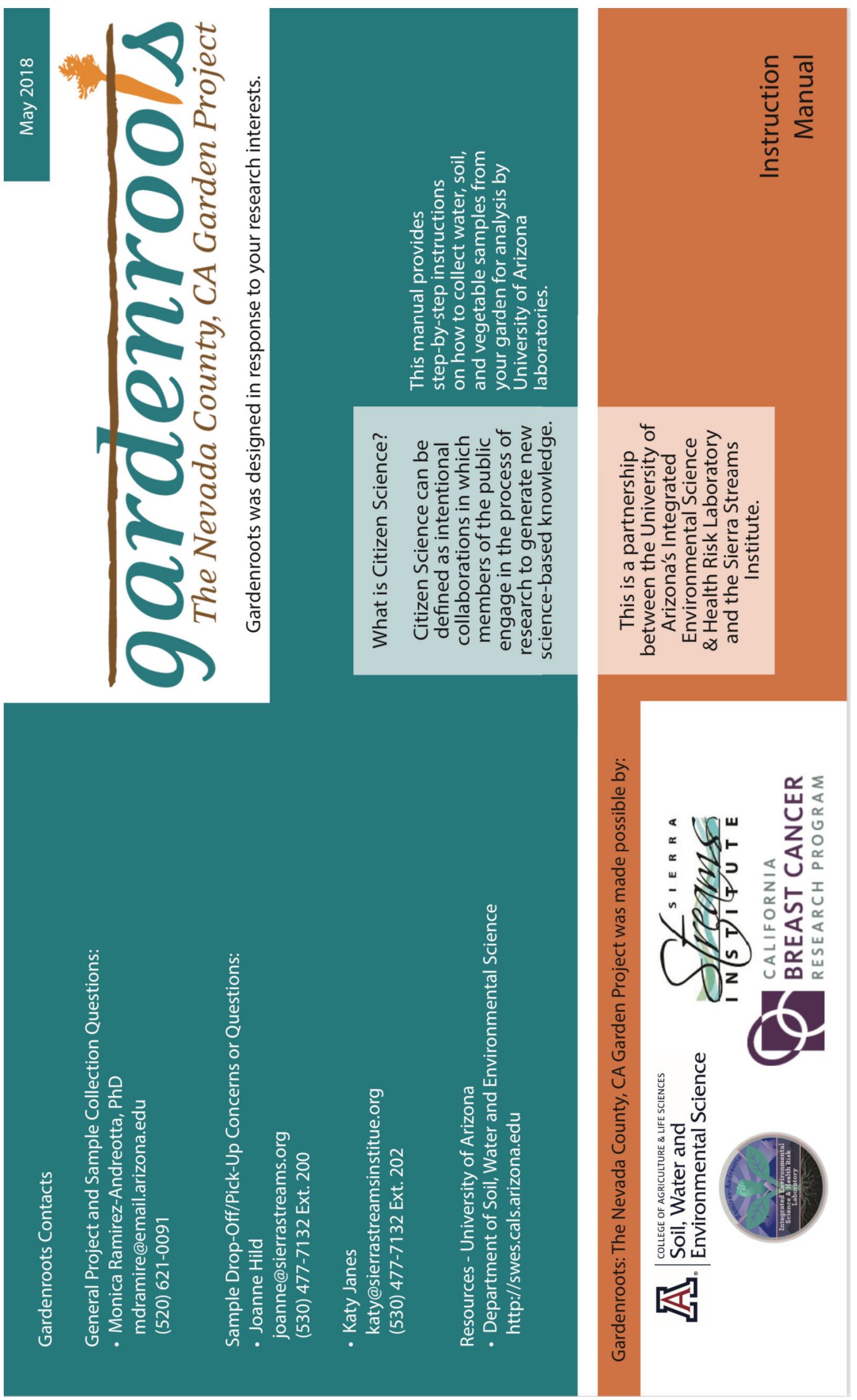


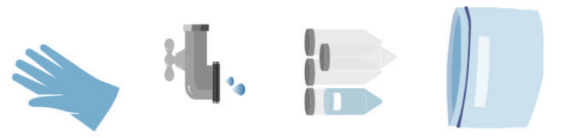

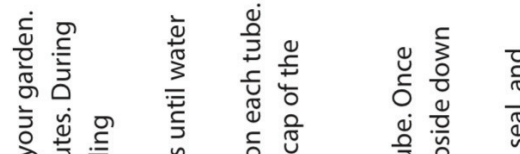

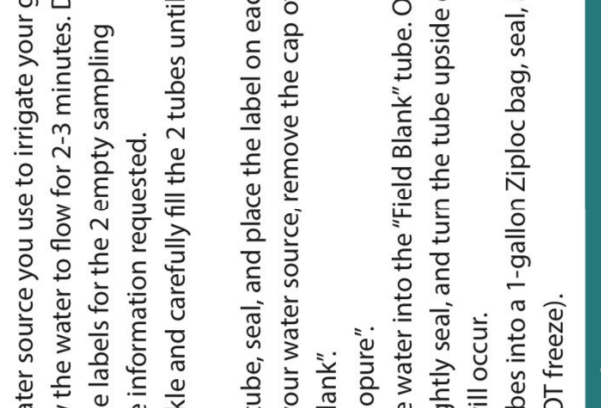

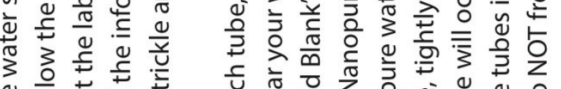

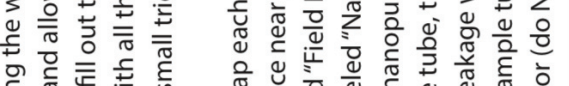

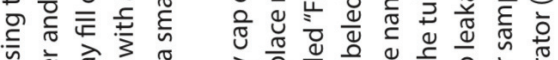

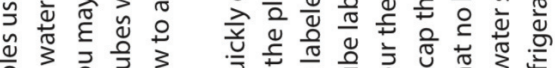

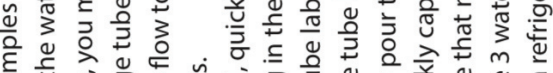

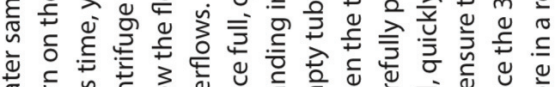

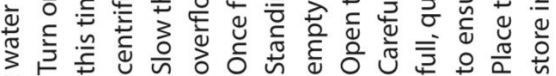
产 .
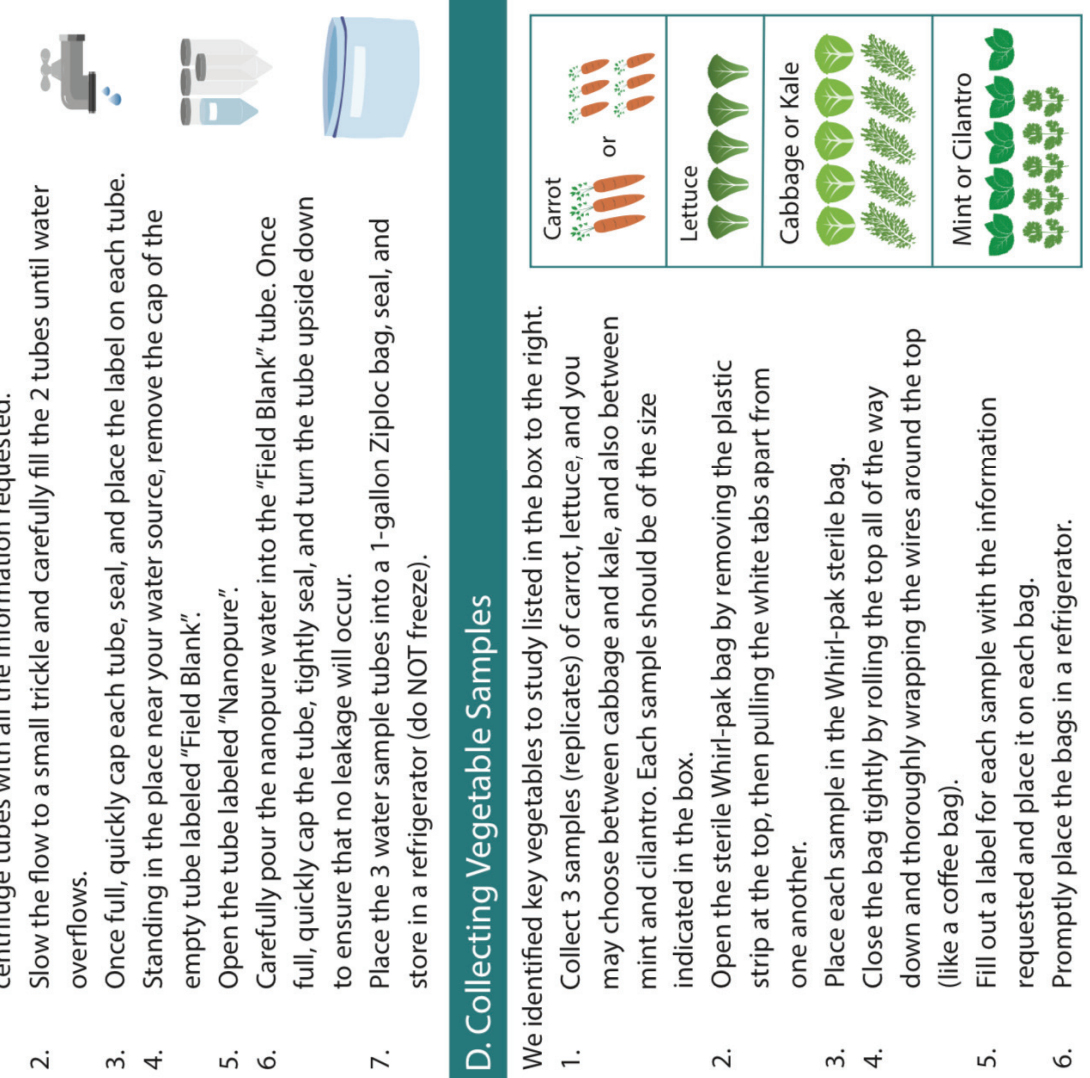

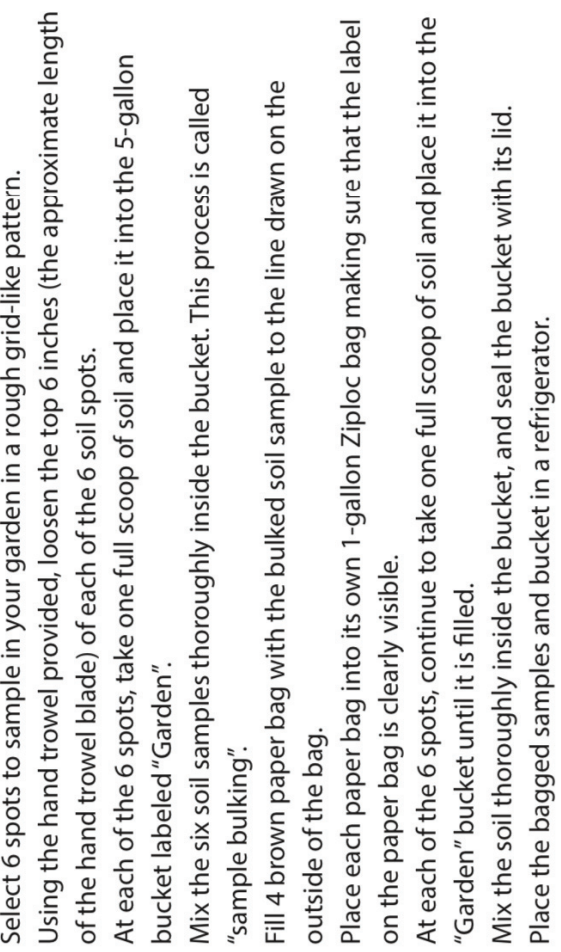
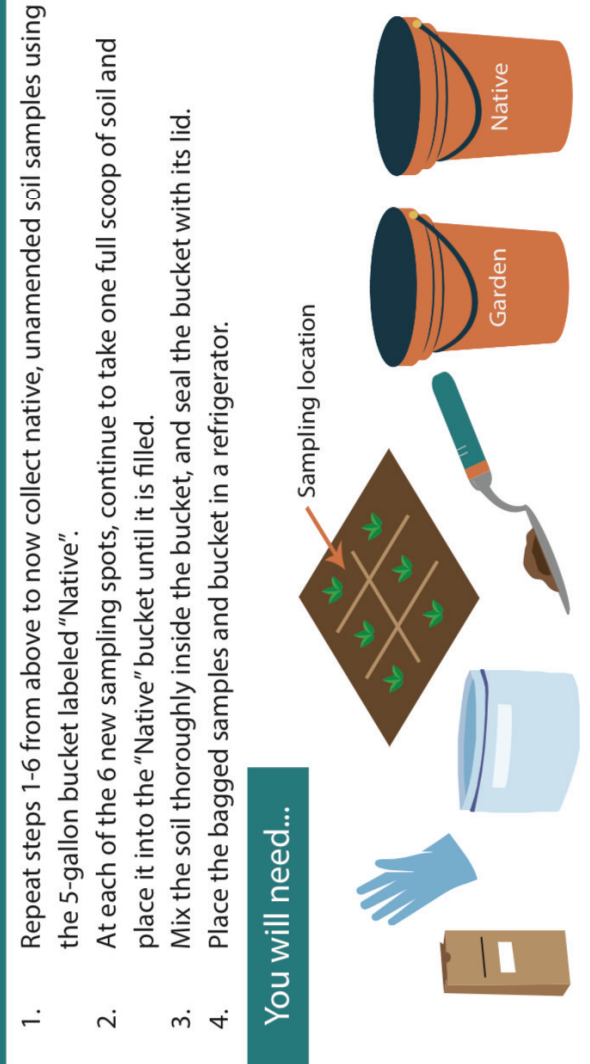

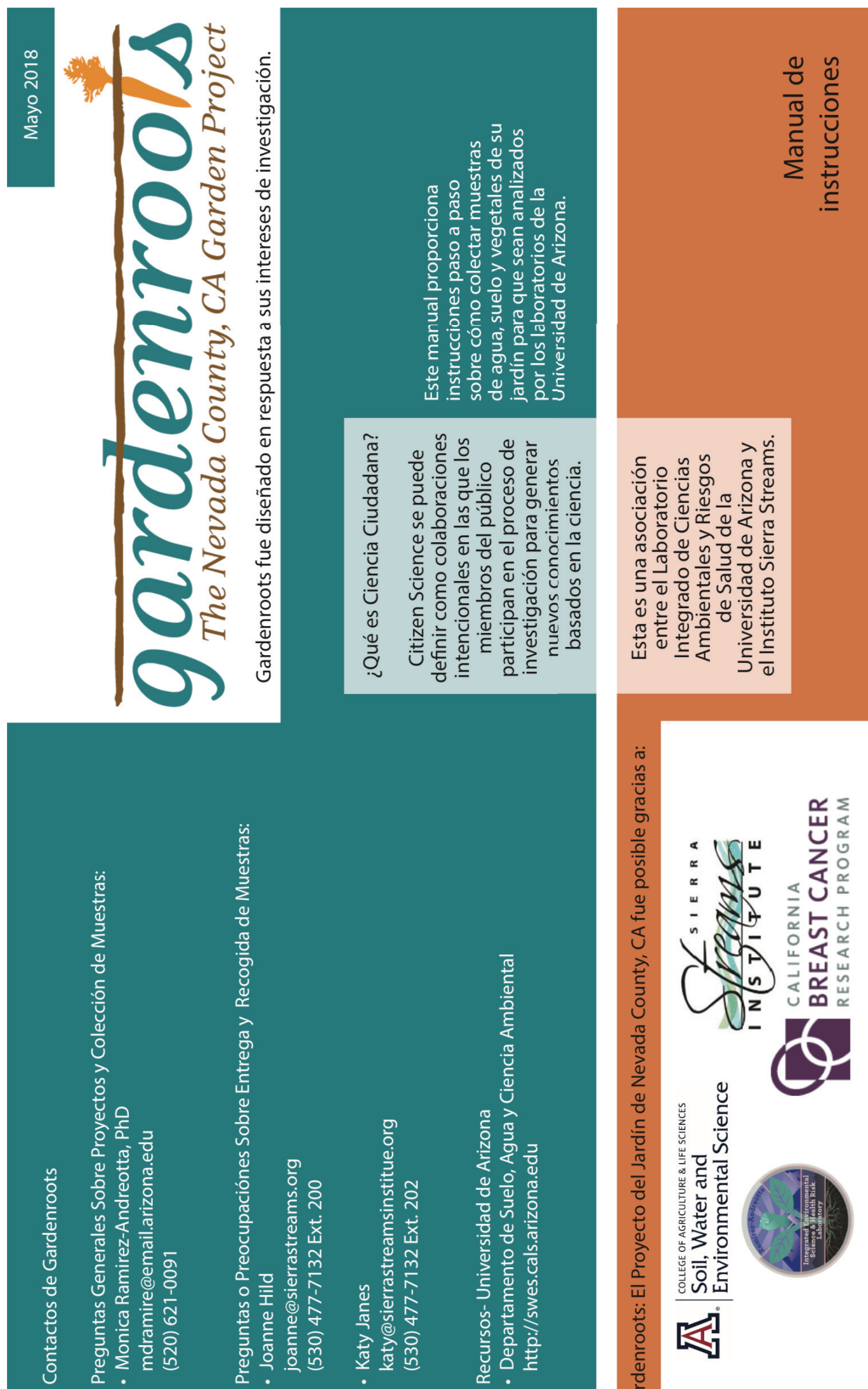

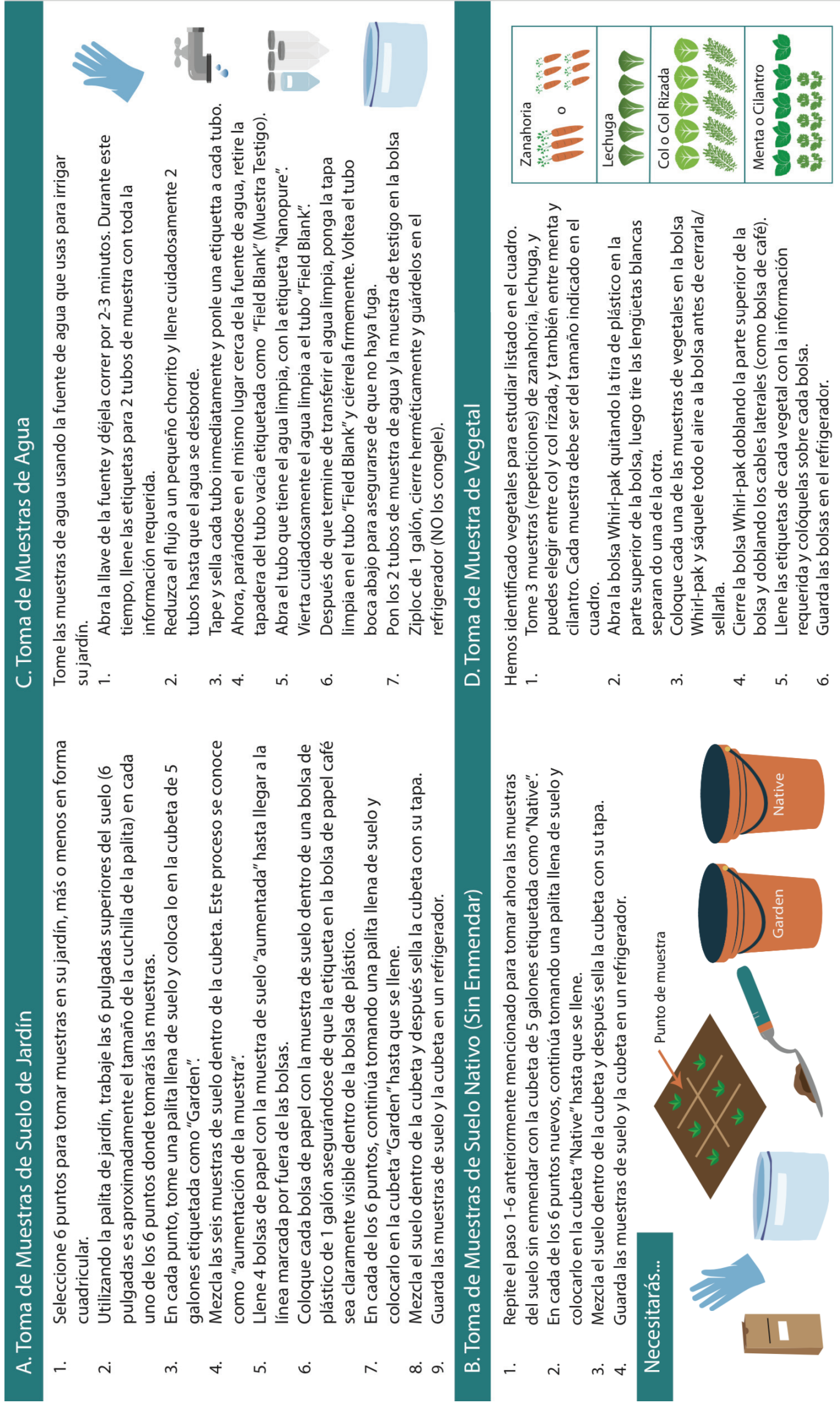
APPENDIXE

\section{Food Frequency Questionnaire (English/Spanish)}




\section{TA THE UNIVERSITY OF ARIZONA.}

English

\section{Consent Form}

Please enter the following:

Child's Preschool Name

Last 4 digits of your phone number

Consent to Participate in Research for Parent/Caregiver

Study Title: Gardenroots: The Nevada City, CA Garden Project

Sponsored By: California Breast Cancer Research Program - University of CA

Principal Investigators: Monica Ramirez-Andreotta, MPA, PhD (University of Arizona), Joanne Hild, MS (Sierra Streams Institute), Peggy Reynolds, PhD (University of California, San Francisco)

This is a consent form for research participation. It contains important information about the human research part of the study and what to expect if you decide to participate.

Why is this study being done?

The goals of this human research are to determine:

1) what the outcomes are of research projects that involve members of the public in some or all steps of the scientific method,

2) how to successfully report environmental monitoring data back to communities to address environmental health concerns,

3) participants' gardening practices in preschools, and/or

4) what and how much locally grown food is consumed by the family and preschool children. 
As part of this study, you will be asked to complete all or just some of the activities listed below:

1) Survey about your child's participation in gardening behavior and consumption patterns

2) Participation in environmental sampling of water, soil, dust and produce from your child's preschool garden

3) A food frequency questionnaire and 24 hour dietary recall

\section{How long will I be in the study?}

1) The survey about your child's participation in gardening activities will take about 20 minutes.

2) Your participation in environmental sampling in your child's preschool garden will involve a training session of 1-2 hours and approximately 30 minutes collecting garden samples.

3) The food frequency questionnaire and 24-hour dietary recall take an average of one hour.

\section{How many people will take part in this study?}

Gardenroots in CA will work with up to 30 families.

\section{Can I stop being in the study?}

Your participation is voluntary. You may refuse to participate in this study, or to participate in any of the aspects of this study. If you decide to take part in the study, you may leave the study at any time. No matter what decision you make, there will be no penalty to you and you will not lose any of your usual benefits. Your decision will not affect your future relationship with The University of Arizona, Sierra Streams Institute or the University of California, San Francisco.

What risks, side effects or discomforts can I anticipate from being in the study? There is no expected research-related injury (i.e. physical, psychological, social or otherwise) associated with the human research component of the study.

\section{What benefits can I expect from being in the study?}

There are no direct benefits from participation. You may or may not benefit as a result of participating in the human research portion of the study. However, the knowledge gained by this study related to citizen science, environmental health, environmental communication, and individual gardening practices may inform future research studies and community activities and protect human health.

\section{What other choices do I have if I do not take part in the study?}

You may choose not to participate in this study without penalty or loss of benefits to which you are otherwise entitled. If you decide you do not want to participate in the human research, you may still participate in the citizen science environmental monitoring portion of the project.

\section{What are the costs of taking part in this study?}

Participant - You may have to pay for gas to travel to drop off environmental samples. You may 
also have to drive to attend community gatherings and data sharing events. This is the only anticipated cost that you may incur through the participation in the research.

\section{Will I be paid for taking part in this study?}

No, you will not be paid for your participation.

\section{Will my study-related information be kept confidential?}

Efforts will be made to keep your study-related information confidential. However, there may be circumstances where this information must be released. For example, personal information regarding your participation in this study may be disclosed if required by state law. In this study, any record that includes your name, phone number, street address or email address will be kept in locked filing cabinets and access to these records will be restricted to researchers involved in the study. You will not be identified in any articles or reports written about this project. Data will be retained for future research under IRB review.

Also, your records may be reviewed by the following groups:

The University of Arizona Institutional Review Board

California Breast Cancer Research Program - University of CA

\section{Who can answer my questions about the study?}

For questions, concerns, or complaints about the study you may contact any of the study investigators:

Monica Ramirez-Andreotta by phone at 520-621-0091 or by email, mdramire@email.arizona.edu.

Joanne Hild by phone at 530-265-6090 or by email, joannehild@sierrastreamsinstitute.org Peggy Reynolds by phone at 510-608-5180 or by email, Peggy.Reynolds@ucsf.edu

If you wish to ask questions about the study or your rights as a research participant to someone other than the researchers or if you wish to voice any problems or concerns you may have about the study, please call the office of the UCSF Institutional Review Board at 415-476-1814.

Institutional Review Boards responsible for human subjects research at The University of Arizona and the University of California, San Francisco reviewed this research project and found it to be acceptable, according to applicable state and federal regulations and University policies designed to protect the rights and welfare of participants in research.

\section{Signing the consent form}

I have read (or someone has read to me) this form, and I am aware that I am being asked to participate in a research study. I have had the opportunity to ask questions and have had them answered to my satisfaction. I voluntarily agree to participate in this study. 
I am not giving up any legal rights by signing this form. I will be given a copy of this 118 form.

\section{Printed name of participant}

\section{Signature of participant}

\section{clear}

\section{Date (MM/DD/YYYY)}

\section{Time (XX:XX AM or PM)}

May we contact you again in the future? The data you provide might lead to new research questions.
Yes
No 
What is the best way to contact you in the future?

$\checkmark$ Email

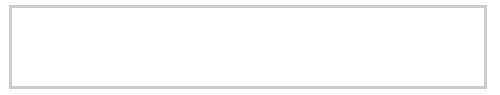

Phone

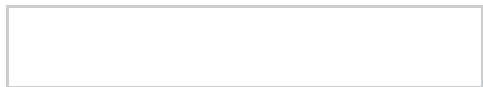

Mail

\section{Demographics pt 1}

How many preschool-aged children live at home?

In this study, we are interested in the consumption patterns of your preschool-aged children. If you have more than 1 child in preschool, please answer all the following questions in this food frequency questionnaire for one of them specifically.

How old is the child that will be represented by this FFQ?

Child's school

How would you describe your child's gender? 
Which of the following groups does your child MOST identify with? (choose all that apply)

African-American, Black

American Indian, Native American, or Alaskan Native

Asian, Asian-American

Caribbean Islander

Latino or Hispanic

Middle Eastern or Arab

$\checkmark$ Native Hawaiian or Other Pacific Islander

$\checkmark$ White, Caucasian, European American

$\square$ Other (please specify)

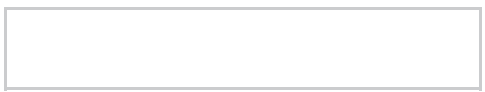

What is your home zip code?

What languages do you speak?

Primary

Secondary

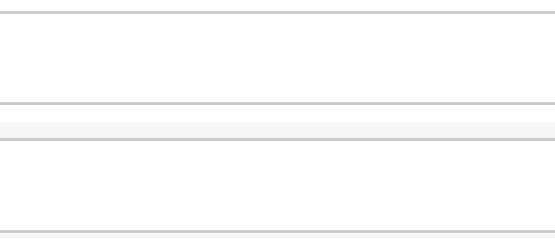

What is the highest level of education you have completed (check one)

Preschool/Kindergarten

Elementary/Primary School

Middle/Junior High School 
High/Secondary School

Some College (less than four years)

Trade/Technical School/Training Program

College Degree (Bachelor)

Post-Graduate Degree (Master/PhD, MD, JD, etc)

Prefer not to respond

Go to the column that has the number of persons that live in your household. Select the number in the column that represents less than or equal to your total household income.

\begin{tabular}{|l|c|c|c|c|c|c|c|c|}
\hline $\begin{array}{l}\text { \# of persons } \\
\text { in household } \\
\text { (\# de } \\
\text { personas en } \\
\text { casa) }\end{array}$ & $\mathbf{1}$ & $\mathbf{2}$ & $\mathbf{3}$ & $\mathbf{4}$ & $\mathbf{5}$ & $\mathbf{6}$ & $\mathbf{7}$ & $\mathbf{8 +}$ \\
\hline $\begin{array}{l}\text { Income } \\
\text { (Ingreso) (\$) }\end{array}$ & 15,250 & 17,400 & 20,780 & 25,100 & 29,420 & 33,740 & 38,060 & 42,380 \\
\cline { 2 - 9 } & 25,400 & 29,000 & 32,650 & 36,250 & 39,150 & 42,050 & 44,950 & 47,850 \\
\cline { 2 - 8 } & 40,600 & 46,400 & 52,200 & 58,000 & 62,650 & 67,300 & 71,950 & 76,600 \\
\cline { 2 - 8 } & $\begin{array}{c}\text { Above } \\
\text { (Más de) }\end{array}$ & $\begin{array}{c}\text { Above } \\
\text { (Más de) }\end{array}$ & $\begin{array}{c}\text { Above } \\
\text { (Más de) }\end{array}$ & $\begin{array}{c}\text { Above } \\
\text { (Más de) }\end{array}$ & $\begin{array}{c}\text { Above } \\
\text { (Más de) }\end{array}$ & $\begin{array}{c}\text { Above } \\
\text { (Más de) }\end{array}$ & $\begin{array}{c}\text { Above } \\
\text { (Más de) }\end{array}$ & $\begin{array}{c}\text { Above } \\
\text { (Más de) }\end{array}$ \\
\hline
\end{tabular}

\section{Demographics pt 2}

Do you prefer to buy your foods from local sources?

Yes

No

What is your motivation for buying locally?

Perceived health benefits

Concern for product source

Environmental consciousness

Perception of lower cost (discounts, bartering, deal-making)

Food assistance benefits accepted 
Freshness and quality of produce

Product variety

Clean and safe

Convenient location

$\checkmark$ Camaraderie

Farmer-consumer relationship

Support local economy, farmers

$\checkmark$ Others

What is your motivation for NOT buying locally?

Markets do not fit into lifestyle or routine

$\checkmark$ Unfamiliarity with experience

$\square$ Perception of higher cost (not competitive with other stores)

$\square$ Food assistance benefits NOT accepted

$\checkmark$ Cash only

$\square$ Inconvenient hours and season of operation

$\square$ Lack of food variety

$\square$ Discomfort with market design/outdoor shopping venues

$\square$ Inconvenient location

$\square$ Have own garden/farm

$\square$ Exclusionary social space

$\checkmark$ Lack of racial, ethnic diversity (language barriers)

$\square$ Lack of cultural and ethnically diverse produce

$\square$ Others

\section{Demographics pt 3}


Approximately what percent of your child's yearly consumption of corn, grains, oats, 123 and rice were from the following sources? (sum of percentages must equal 100)

\begin{tabular}{l|l|} 
& \multicolumn{2}{|c}{ Percentage } \\
\hline Home Grown & \\
Locally Grown/Food & \\
Market & \\
Store (Organically & \\
grown) & \\
Store (Conventionally & \\
grown) &
\end{tabular}

Approximately what percent of your child's yearly consumption of fruits and vegetables were from the following sources? (sum of percentages must equal 100)

\begin{tabular}{l|l|} 
& \multicolumn{2}{|c|}{ Percentage } \\
\hline Home Grown & \\
Locally Grown/Food & \\
Market & \\
Store (Organically & \\
grown) & \\
Store (Conventionally & \\
grown)
\end{tabular}

Approximately what percent of your child's yearly consumption of meat (fish, poultry, beef, pork, etc) were from the following sources? (sum of percentages must equal 100)

\begin{tabular}{l|l|} 
& \multicolumn{2}{|c}{ Percentage } \\
\hline Home & \\
Local Farm & \\
Store (Organically \\
farmed)
\end{tabular}


Store (Conventionally

farmed)

\section{Asteraceae}

In the last 12 months, did your child eat garden lettuce?
Yes
No

How often did your child eat garden lettuce?
1-6 times per year
7-11 times per year
1 time per month
2-3 times per month
1 time per week
2 times per week
3-4 times per week
5-6 times per week
1 time per day
2 or more times per day

What was your child's usual serving size of garden lettuce?

$\square$ Dash or pinch (size of a pea)

1 teaspoon (size of a dice)

1 tablespoon (size of a poker chip)

1 ounce (volume in a shot glass)

$\square 1 / 4$ cup (size of a golf ball) 
$1 / 2$ cup (size of a tennis ball)

$3 / 4$ cup (volume in a tea cup)

$\square 1$ cup (size of a baseball)

In the last 12 months, was the source ever from a home or local garden?
Yes
No

In the last 12 months, did your child eat romaine lettuce?
Yes
No

How often did your child eat romaine lettuce?
1-6 times per year
7-11 times per year
1 time per month
2-3 times per month
1 time per week
2 times per week
3-4 times per week
5-6 times per week
1 time per day
2 or more times per day

What was your child's usual serving size of romaine lettuce?

Dash or pinch (size of a pea) 
1 teaspoon (size of a dice)

1 tablespoon (size of a poker chip)

1 ounce (volume in a shot glass)

$\square 1 / 4$ cup (size of a golf ball)

$1 / 2$ cup (size of a tennis ball)

3/4 cup (volume in a tea cup)

$\checkmark 1$ cup (size of a baseball)

In the last 12 months, was the source ever from a home or local garden?

Yes

No

\section{Brassicaceae}

In the last 12 months, did your child eat radish?

Yes

No

How often did your child eat radish?

1-6 times per year

7-11 times per year

1 time per month

2-3 times per month

1 time per week

2 times per week

3-4 times per week

5-6 times per week 
1 time per day

2 or more times per day

What was your child's usual serving size of radish?

Dash or pinch (size of a pea)

$\square 1$ teaspoon (size of a dice)

$\square 1$ tablespoon (size of a poker chip)

$\square 1$ ounce (volume in a shot glass)

$\square 1 / 4$ cup (size of a golf ball)

$1 / 2$ cup (size of a tennis ball)

3/4 cup (volume in a tea cup)

$\square 1$ cup (size of a baseball)

In the last 12 months, was the source ever from a home or local garden?
Yes
No

In the last 12 months, did your child eat kale?
Yes
No

How often did your child eat kale?
1-6 times per year
7-11 times per year
1 time per month
2-3 times per month 
1 time per week

2 times per week

3-4 times per week

5-6 times per week

1 time per day

2 or more times per day

What was your child's usual serving size of kale?

Dash or pinch (size of a pea)

1 teaspoon (size of a dice)

1 tablespoon (size of a poker chip)

$\square 1$ ounce (volume in a shot glass)

$\square 1 / 4$ cup (size of a golf ball)

$\square 1 / 2$ cup (size of a tennis ball)

$\square 3 / 4$ cup (volume in a tea cup)

$\square 1$ cup (size of a baseball)

In the last 12 months, was the source ever from a home or local garden?

Yes

No

In the last 12 months, did your child eat broccoli?

Yes

No

How often did your child eat broccoli? 
1-6 times per year

7-11 times per year

1 time per month

2-3 times per month

1 time per week

2 times per week

3-4 times per week

5-6 times per week

1 time per day

2 or more times per day

What was your child's usual serving size of broccoli?

$\square$ Dash or pinch (size of a pea)

$\square 1$ teaspoon (size of a dice)

$\square 1$ tablespoon (size of a poker chip)

$\square 1$ ounce (volume in a shot glass)

$\square 1 / 4$ cup (size of a golf ball)

$\square 1 / 2$ cup (size of a tennis ball)

$3 / 4$ cup (volume in a tea cup)

1 cup (size of a baseball)

In the last 12 months, was the source ever from a home or local garden?

Yes

No

In the last 12 months, did your child eat cabbage? 
No

How often did your child eat cabbage?

1-6 times per year

7-11 times per year

1 time per month

2-3 times per month

1 time per week

2 times per week

3-4 times per week

5-6 times per week

1 time per day

2 or more times per day

What was your child's usual serving size of cabbage?

Dash or pinch (size of a pea)

$\square 1$ teaspoon (size of a dice)

$\checkmark 1$ tablespoon (size of a poker chip)

$\square 1$ ounce (volume in a shot glass)

$\square 1 / 4$ cup (size of a golf ball)

$\square 1 / 2$ cup (size of a tennis ball)

3/4 cup (volume in a tea cup)

1 cup (size of a baseball)

In the last 12 months, was the source ever from a home or local garden? 
No

In the last 12 months, did your child eat papaya?
Yes

No

How often did your child eat papaya?

1-6 times per year

7-11 times per year

1 time per month

2-3 times per month

1 time per week

2 times per week

3-4 times per week

5-6 times per week

1 time per day

2 or more times per day

What was your child's usual serving size of papaya?

Dash or pinch (size of a pea)

1 teaspoon (size of a dice)

1 tablespoon (size of a poker chip)

$\square 1$ ounce (volume in a shot glass)

$\square 1 / 4$ cup (size of a golf ball)

$1 / 2$ cup (size of a tennis ball) 
$3 / 4$ cup (volume in a tea cup)

1 cup (size of a baseball)

In the last 12 months, was the source ever from a home or local garden?
Yes
No

In the last 12 months, did your child eat turnip?

How often did your child eat turnip?
1-6 times per year
7-11 times per year
1 time per month
2-3 times per month
1 time per week
2 times per week
3-4 times per week
5-6 times per week
1 time per day
2 or more times per day

What was your child's usual serving size of turnip?

$\square$ Dash or pinch (size of a pea)

$\square 1$ teaspoon (size of a dice) 
1 tablespoon (size of a poker chip)

1 ounce (volume in a shot glass)

$1 / 4$ cup (size of a golf ball)

$1 / 2$ cup (size of a tennis ball)

3/4 cup (volume in a tea cup)

1 cup (size of a baseball)

In the last 12 months, was the source ever from a home or local garden?
Yes
No

In the last 12 months, did your child eat cauliflower?
Yes
No

How often did your child eat cauliflower?

1-6 times per year

7-11 times per year

1 time per month

2-3 times per month

1 time per week

2 times per week

3-4 times per week

5-6 times per week

1 time per day

2 or more times per day 
What was your child's usual serving size of cauliflower?

Dash or pinch (size of a pea)

1 teaspoon (size of a dice)

1 tablespoon (size of a poker chip)

1 ounce (volume in a shot glass)

$1 / 4$ cup (size of a golf ball)

$\square 1 / 2$ cup (size of a tennis ball)

$\square 3 / 4$ cup (volume in a tea cup)

1 cup (size of a baseball)

In the last 12 months, was the source ever from a home or local garden?

Yes

No

In the last 12 months, did your child eat arugula?

Yes

No

How often did your child eat arugula?
1-6 times per year
7-11 times per year
1 time per month
2-3 times per month
1 time per week
2 times per week 
3-4 times per week

5-6 times per week

1 time per day

2 or more times per day

What was your child's usual serving size of arugula?

Dash or pinch (size of a pea)

$\checkmark 1$ teaspoon (size of a dice)

$\square 1$ tablespoon (size of a poker chip)

$\square 1$ ounce (volume in a shot glass)

$\square 1 / 4$ cup (size of a golf ball)

- $1 / 2$ cup (size of a tennis ball)

$\square 3 / 4$ cup (volume in a tea cup)

1 cup (size of a baseball)

In the last 12 months, was the source ever from a home or local garden?

Yes

No

In the last 12 months, did your child eat Brussels sprouts?

Yes

No

How often did your child eat Brussels sprouts?

1-6 times per year

7-11 times per year 
1 time per month

2-3 times per month

1 time per week

2 times per week

3-4 times per week

5-6 times per week

1 time per day

2 or more times per day

What was your child's usual serving size of Brussels sprouts?

Dash or pinch (size of a pea)

1 teaspoon (size of a dice)

1 tablespoon (size of a poker chip)

$\checkmark 1$ ounce (volume in a shot glass)

$\square 1 / 4 \operatorname{cup}$ (size of a golf ball)

$\square 1 / 2$ cup (size of a tennis ball)

$\square 3 / 4$ cup (volume in a tea cup)

$\checkmark 1$ cup (size of a baseball)

In the last 12 months, was the source ever from a home or local garden?
Yes
No

\section{Amaranthaceae}

In the last 12 months, did your child eat spinach? 
How often did your child eat spinach?

1-6 times per year

7-11 times per year

1 time per month

2-3 times per month

1 time per week

2 times per week

3-4 times per week

5-6 times per week

1 time per day

2 or more times per day

What was your child's usual serving size of spinach?

Dash or pinch (size of a pea)

$\square 1$ teaspoon (size of a dice)

$\checkmark 1$ tablespoon (size of a poker chip)

$\square 1$ ounce (volume in a shot glass)

$1 / 4$ cup (size of a golf ball)

$\square 1 / 2$ cup (size of a tennis ball)

$3 / 4$ cup (volume in a tea cup)

$\checkmark 1$ cup (size of a baseball)

In the last 12 months, was the source ever from a home or local garden? 
In the last 12 months, did your child eat Swiss chard?
Yes
No

How often did your child eat Swiss chard?
1-6 times per year
7-11 times per year
1 time per month
2-3 times per month
1 time per week
2 times per week
3-4 times per week
5-6 times per week
1 time per day
2 or more times per day

What was your child's usual serving size of Swiss chard?

Dash or pinch (size of a pea)

$\checkmark 1$ teaspoon (size of a dice)

1 tablespoon (size of a poker chip)

1 ounce (volume in a shot glass)

$\square 1 / 4$ cup (size of a golf ball)

$1 / 2$ cup (size of a tennis ball)

$3 / 4$ cup (volume in a tea cup) 
In the last 12 months, was the source ever from a home or local garden?

Yes

No

\section{Cucurbitaceae}

In the last 12 months, did your child eat pumpkin?

Yes

No

How often did your child eat pumpkin?

1-6 times per year

7-11 times per year

1 time per month

2-3 times per month

1 time per week

2 times per week

3-4 times per week

5-6 times per week

1 time per day

2 or more times per day

What was your child's usual serving size of pumpkin?

Dash or pinch (size of a pea) 
1 teaspoon (size of a dice)

1 tablespoon (size of a poker chip)

$\square 1$ ounce (volume in a shot glass)

$\square 1 / 4$ cup (size of a golf ball)

$\square 1 / 2$ cup (size of a tennis ball)

3/4 cup (volume in a tea cup)

$\square 1$ cup (size of a baseball)

In the last 12 months, was the source ever from a home or local garden?
Yes
No

In the last 12 months, did your child eat squash?
Yes
No

How often did your child eat squash?

1-6 times per year

7-11 times per year

1 time per month

2-3 times per month

1 time per week

2 times per week

3-4 times per week

5-6 times per week

1 time per day 
What was your child's usual serving size of squash?

$\checkmark$ Dash or pinch (size of a pea)

$\square 1$ teaspoon (size of a dice)

$\square 1$ tablespoon (size of a poker chip)

$\square 1$ ounce (volume in a shot glass)

$\square 1 / 4$ cup (size of a golf ball)

$\square 1 / 2$ cup (size of a tennis ball)

3/4 cup (volume in a tea cup)

$\checkmark 1$ cup (size of a baseball)

In the last 12 months, was the source ever from a home or local garden?

Yes

No

In the last 12 months, did your child eat cucumber?

Yes

No

How often did your child eat cucumber?

1-6 times per year

7-11 times per year

1 time per month

2-3 times per month

1 time per week 
2 times per week

3-4 times per week

5-6 times per week

1 time per day

2 or more times per day

What was your child's usual serving size of cucumber?

Dash or pinch (size of a pea)

$\checkmark 1$ teaspoon (size of a dice)

$\checkmark 1$ tablespoon (size of a poker chip)

$\square 1$ ounce (volume in a shot glass)

$\square 1 / 4$ cup (size of a golf ball)

$\square 1 / 2$ cup (size of a tennis ball)

$\checkmark 3 / 4$ cup (volume in a tea cup)

1 cup (size of a baseball)

In the last 12 months, was the source ever from a home or local garden?

Yes

No

In the last 12 months, did your child eat melon?

Yes

No

How often did your child eat melon? 
7-11 times per year

1 time per month

2-3 times per month

1 time per week

2 times per week

3-4 times per week

5-6 times per week

1 time per day

2 or more times per day

What was your child's usual serving size of melon?

Dash or pinch (size of a pea)

$\square 1$ teaspoon (size of a dice)

$\square 1$ tablespoon (size of a poker chip)

$\square 1$ ounce (volume in a shot glass)

$\square 1 / 4$ cup (size of a golf ball)

$1 / 2$ cup (size of a tennis ball)

$3 / 4$ cup (volume in a tea cup)

$\square 1$ cup (size of a baseball)

In the last 12 months, was the source ever from a home or local garden?

Yes

No

In the last 12 months, did your child eat zucchini? 
No

How often did your child eat zucchini?

1-6 times per year

7-11 times per year

1 time per month

2-3 times per month

1 time per week

2 times per week

3-4 times per week

5-6 times per week

1 time per day

2 or more times per day

What was your child's usual serving size of zucchini?

Dash or pinch (size of a pea)

$\square 1$ teaspoon (size of a dice)

$\checkmark 1$ tablespoon (size of a poker chip)

$\square 1$ ounce (volume in a shot glass)

$\square 1 / 4$ cup (size of a golf ball)

$1 / 2$ cup (size of a tennis ball)

$\checkmark 3 / 4$ cup (volume in a tea cup)

1 cup (size of a baseball)

In the last 12 months, was the source ever from a home or local garden? 


\section{Liliaceae}

In the last 12 months, did your child eat garlic?
Yes
No

How often did your child eat garlic?
1-6 times per year
7-11 times per year
1 times per month
2-3 times per month
1 time per week
2 times per week
3-4 times per week
5-6 times per week
1 time per day
2 or more times per day

What was your child's usual serving size of garlic?
1 tablespoon
$1 / 2$ tablespoon
1 teaspoon
$1 / 2$ teaspoon
$1 / 4$ teaspoon 
In the last 12 months, was the source ever from a home or local garden?
Yes
No

In the last 12 months, did your child eat onions?
Yes
No

How often did your child eat onions?
1-6 times per year
7-11 times per year
1 time per month
2-3 times per month
1 time per week
2 times per week
3-4 times per week
5-6 times per week
1 time per day
2 or more times per day

What was your child's usual serving size of onions?

Dash or pinch (size of a pea)

$\square 1$ teaspoon (size of a dice)

$\square 1$ tablespoon (size of a poker chip) 
1 ounce (volume in a shot glass)

$1 / 4$ cup (size of a golf ball)

$1 / 2$ cup (size of a tennis ball)

$3 / 4$ cup (volume in a tea cup)

$\checkmark 1$ cup (size of a baseball)

In the last 12 months, was the source ever from a home or local garden?

Yes

No

\section{Solanaceae}

In the last 12 months, did your child eat Irish potatoes (aka Lady Rosetta)?

Yes

No

How often did your child eat Irish potatoes?

1-6 times per year

7-11 times per year

1 time per month

2-3 times per month

1 time per week

2 times per week

3-4 times per week

5-6 times per week

1 time per day

2 or more times per day 
What was your child's usual serving size of Irish potatoes?

Dash or pinch (size of a pea)

$\square 1$ teaspoon (size of a dice)

$\square 1$ tablespoon (size of a poker chip)

$\square 1$ ounce (volume in a shot glass)

$\square 1 / 4 \operatorname{cup}$ (size of a golf ball)

$\square 1 / 2$ cup (size of a tennis ball)

3/4 cup (volume in a tea cup)

$\checkmark 1$ cup (size of a baseball)

In the last 12 months, was the source ever from a home or local garden?
Yes
No

In the last 12 months, did your child eat tomatoes?
Yes
No

How often did your child eat tomatoes?
1-6 times per year
7-11 times per year
1 time per month
2-3 times per month
1 time per week
2 times per week 
3-4 times per week

5-6 times per week

1 time per day

2 or more times per day

What was your child's usual serving size of tomatoes?

$\square$ Dash or pinch (size of a pea)

$\checkmark 1$ teaspoon (size of a dice)

$\checkmark 1$ tablespoon (size of a poker chip)

$\square 1$ ounce (volume in a shot glass)

$\square 1 / 4$ cup (size of a golf ball)

$\square 1 / 2$ cup (size of a tennis ball)

$\square 3 / 4$ cup (volume in a tea cup)

1 cup (size of a baseball)

In the last 12 months, was the source ever from a home or local garden?

Yes

No

In the last 12 months, did your child eat eggplant?

Yes

No

How often did your child eat eggplant? 
7-11 times per year

1 time a month

2-3 times per month

1 time per week

2 times per week

3-4 times per week

5-6 times per week

1 time per day

2 or more times per day

What was your child's usual serving size of eggplant?

Dash or pinch (size of a pea)

$\square 1$ teaspoon (size of a dice)

1 tablespoon (size of a poker chip)

$\square 1$ ounce (volume in a shot glass)

$\square 1 / 4$ cup (size of a golf ball)

$1 / 2$ cup (size of a tennis ball)

3/4 cup (volume in a tea cup)

1 cup (size of a baseball)

In the last 12 months, was the source ever from a home or local garden?

Yes

No

In the last 12 months, did your child eat sweet peppers? 
How often did your child eat sweet peppers?
1-6 times per year
7-11 times per year
1 times per month
2-3 times per month
1 time per week
2 times per week
3-4 times per week
5-6 times per week
1 time per day
2 or more times per day

What was your child's usual serving size of sweet peppers?

Dash or pinch (size of a pea)

$\checkmark 1$ teaspoon (size of a dice)

$\square 1$ tablespoon (size of a poker chip)

$\square 1$ ounce (volume in a shot glass)

$\square 1 / 4$ cup (size of a golf ball)

$\checkmark 1 / 2$ cup (size of a tennis ball)

3/4 cup (volume in a tea cup)

$\square 1$ cup (size of a baseball)

In the last 12 months, was the source ever from a home or local garden? 


\section{Apiaceae}

In the last 12 months, did your child eat carrots?

Yes

No

How often did your child eat carrots?

1-6 times per year

7-11 times per year

1 time per month

2-3 times per month

1 time per week

2 times per week

3-4 times per week

5-6 times per week

1 time per day

2 times or more per day

What was your child's usual serving size of carrots?

Dash or pinch (size of a pea)

$\square 1$ teaspoon (size of a dice)

$\square 1$ tablespoon (size of a poker chip)

$\square 1$ ounce (volume in a shot glass)

$\square 1 / 4$ cup (size of a golf ball)

$\square 1 / 2$ cup (size of a tennis ball) 
1 cup (size of a baseball)

In the last 12 months, was the source ever from a home or local garden?
Yes
No

In the last 12 months, did your child eat celery?
Yes
No

How often did your child eat celery?
1-6 times per year
7-11 times per year
1 time per month
2-3 times per month
1 time per week
2 times per week
3-4 times per week
5-6 times per week
1 time per day
2 or more times per day

What was your child's usual serving size of celery?

$\checkmark$ Dash or pinch (size of a pea)

$\square 1$ teaspoon (size of a dice) 
1 tablespoon (size of a poker chip)

1 ounce (volume in a shot glass)

$1 / 4$ cup (size of a golf ball)

$1 / 2$ cup (size of a tennis ball)

$3 / 4$ cup (volume in a tea cup)

1 cup (size of a baseball)

In the last 12 months, was the source ever from a home or local garden?
Yes
No

In the last 12 months, did your child eat fresh coriander (aka cilantro)?
Yes
No

How often did your child eat fresh coriander?

1-6 times per year

7-11 times per year

1 time per month

2-3 times per month

1 time per week

2 times per week

3-4 times per week

5-6 times per week

1 time per day

2 times or more per day 
What was your child's usual serving size of fresh coriander?

\section{3 leafs with stems ( 3 hojas con tallo)}

6 leafs with stems (6 hojas con tallo)

9 leafs with stems ( 9 hojas con tallo)

12 leafs with stems ( 12 hojas con tallo)

15 leafs with stems ( 15 hojas con tallo)

In the last 12 months, was the source ever from a home or local garden?

Yes

No

\section{Fabaceae}

In the last 12 months, did your child eat kidney beans?
Yes
No

How often did your child eat kidney beans?

1-6 times per year

7-11 times per year

1 time per month

2-3 times per month

1 time per week

2 times per week 
3-4 times per week

5-6 times per week

1 time per day

2 or more times per day

What was your child's usual serving size of kidney beans?

Dash or pinch (size of a pea)

$\checkmark 1$ teaspoon (size of a dice)

$\checkmark 1$ tablespoon (size of a poker chip)

$\square 1$ ounce (volume in a shot glass)

$\square 1 / 4$ cup (size of a golf ball)

- $1 / 2$ cup (size of a tennis ball)

$\square 3 / 4$ cup (volume in a tea cup)

1 cup (size of a baseball)

In the last 12 months, was the source ever from a home or local garden?

Yes

No

In the last 12 months, did your child eat green beans?
Yes
No

How often did your child eat green beans?

1-6 times per year

7-11 times per year 
1 time per month

2-3 times per month

1 time per week

2 times per week

3-4 times per week

5-6 times per week

1 time per day

2 or more times per day

What was your child's usual serving size of green beans?

Dash or pinch (size of a pea)

1 teaspoon (size of a dice)

1 tablespoon (size of a poker chip)

1 ounce (volume in a shot glass)

$\square 1 / 4$ cup (size of a golf ball)

$1 / 2$ cup (size of a tennis ball)

$\square 3 / 4$ cup (volume in a tea cup)

$\square 1$ cup (size of a baseball)

In the last 12 months, was the source ever from a home or local garden?
Yes
No

In the last 12 months, did your child eat bush beans?

Yes

No 
How often did your child eat bush beans?

1-6 times per year

7-11 times per year

1 time per month

2-3 times per month

1 time per week

2 times per week

3-4 times per week

5-6 times per week

1 time per day

2 or more times per day

What was your child's usual serving size of bush beans?

$\square$ Dash or pinch (size of a pea)

$\square 1$ teaspoon (size of a dice)

$\square 1$ tablespoon (size of a poker chip)

$\square 1$ ounce (volume in a shot glass)

$\square 1 / 4$ cup (size of a golf ball)

$\square 1 / 2$ cup (size of a tennis ball)

3/4 cup (volume in a tea cup)

$\checkmark 1$ cup (size of a baseball)

In the last 12 months, was the source ever from a home or local garden?

Yes

No 
In the last 12 months, did your child eat peas?

How often did your child eat peas?

1-6 times per year

7-11 times per year

1 time per month

2-3 times per month

1 time per week

2 times per week

3-4 times per week

5-6 times per week

1 time per day

2 or more times per day

What was your child's usual serving size of peas?

Dash or pinch (size of a pea)

$\square 1$ teaspoon (size of a dice)

$\checkmark 1$ tablespoon (size of a poker chip)

$\square 1$ ounce (volume in a shot glass)

$\square 1 / 4$ cup (size of a golf ball)

$\square 1 / 2$ cup (size of a tennis ball)

$\square 3 / 4$ cup (volume in a tea cup)

$\checkmark 1$ cup (size of a baseball) 
In the last 12 months, was the source ever from a home or local garden?

Yes

No

In the last 12 months, did your child eat lima beans?

Yes

No

How often did your child eat lima beans?

1-6 times per year

7-11 times per year

1 time per month

2-3 times per month

1 time per week

2 times per week

3-4 times per week

5-6 times per week

1 time per day

2 or more times per day

What was your child's usual serving size of lima beans?

Dash or pinch (size of a pea)

$\checkmark 1$ teaspoon (size of a dice)

$\square 1$ tablespoon (size of a poker chip)

1 ounce (volume in a shot glass) 
$1 / 4$ cup (size of a golf ball)

$\square 1 / 2$ cup (size of a tennis ball)

$\checkmark 3 / 4$ cup (volume in a tea cup)

$\square 1$ cup (size of a baseball)

In the last 12 months, was the source ever from a home or local garden?

Yes

No

In the last 12 months, did your child eat lentils?

Yes

No

How often did your child eat lentils?

1-6 times per year

7-11 times per year

1 time per month

2-3 times per month

1 time per week

2 times per week

3-4 times per week

5-6 times per week

1 time per day

2 or more times per day

What was your child's usual serving size of lentils? 
Dash or pinch (size of a pea)

$\square 1$ teaspoon (size of a dice)

$\square 1$ tablespoon (size of a poker chip)

$\square 1$ ounce (volume in a shot glass)

$\square 1 / 4$ cup (size of a golf ball)

$\square 1 / 2$ cup (size of a tennis ball)

$3 / 4$ cup (volume in a tea cup)

1 cup (size of a baseball)

In the last 12 months, was the source ever from a home or local garden?
Yes
No

In the last 12 months, did your child eat soy beans?
Yes
No

How often did your child eat soy beans?
1-6 times per year
7-11 times per year
1 time per month
2-3 times per month
1 time per week
2 times per week
3-4 times per week
5-6 times per week 
2 or more times per day

What was your child's usual serving size of soy beans?

$\square$ Dash or pinch (size of a pea)

1 teaspoon (size of a dice)

$\checkmark 1$ tablespoon (size of a poker chip)

$\square 1$ ounce (volume in a shot glass)

$\square 1 / 4$ cup (size of a golf ball)

$\square 1 / 2$ cup (size of a tennis ball)

$3 / 4$ cup (volume in a tea cup)

1 cup (size of a baseball)

In the last 12 months, was the source ever from a home or local garden?

Yes

No

\section{Lamiaceae}

In the last 12 months, did your child eat fresh basil?

Yes

No

How often did your child eat fresh basil?

1-6 times per year

7-11 times per year 
1 time per month

2-3 times per month

1 time per week

2 times per week

3-4 times per week

5-6 times per week

1 time per day

2 or more times per day

What was your child's usual serving size of fresh basil?

1 leaf (1hoja)

\section{2 leaves ( 2 hojas)}

\section{3 leaves (3 hojas)}

4 leaves (4 hojas)

5 leaves (5 hojas)

In the last 12 months, was the source ever from a home or local garden?

Yes

No 
In the last 12 months, did your child eat fresh mint?

How often did your child eat fresh mint?
1-6 times per year
7-11 times per year
1 time per month
2-3 times per month
1 time per week
2 times per week
3-4 times per week
5-6 times per week
1 time per day
2 times or more per day

What was your child's usual serving size of mint?

\section{1 leaf (1hoja)}

\section{2 leaves ( 2 hojas)}

\section{3 leaves (3 hojas)}

4 leaves (4 hojas)

5 leaves ( 5 hojas)

In the last 12 months, was the source ever from a home or local garden? 


\section{Malvaceae}

In the last 12 months, did your child eat okra?
Yes
No

How often did your child eat okra?
1-6 times per year
7-11 times per year
1 time per month
2-3 times per month
1 time per week
2-3 times per week
3-4 times per week
5-6 times per week
1 time per day
2 or more times per day

What was your child's usual serving size of okra?

Dash or pinch (size of a pea)

$\square 1$ teaspoon (size of a dice)

$\checkmark 1$ tablespoon (size of a poker chip)

$\square 1$ ounce (volume in a shot glass)

$\square 1 / 4$ cup (size of a golf ball) 
$1 / 2$ cup (size of a tennis ball)

3/4 cup (volume in a tea cup)

1 cup (size of a baseball)

In the last 12 months, was the source ever from a home or local garden?
Yes
No

\section{Rosaceae}

In the last 12 months, did your child eat apples?
Yes
No

How often did your child eat apples?
1-6 times per year
7-11 times per year
1 time per month
2-3 times per month
1 time per week
2 times per week
3-4 times per week
5-6 times per week
1 time per day
2 or more times per day

What was your child's usual serving size of apples? 
Dash or pinch (size of a pea)

$\checkmark 1$ teaspoon (size of a dice)

$\checkmark 1$ tablespoon (size of a poker chip)

$\square 1$ ounce (volume in a shot glass)

$1 / 4$ cup (size of a golf ball)

$1 / 2$ cup (size of a tennis ball)

$3 / 4$ cup (volume in a tea cup)

1 cup (size of a baseball)

In the last 12 months, was the source ever from home or grown locally?
Yes

No

In the last 12 months, did your child eat strawberries?
Yes
No

How often did your child eat strawberries?
1-6 times per year
7-11 times per year
1 time per month
2-3 times per month
1 time per week
2 times per week
3-4 times per week
5-6 times per week 
2 or more times per day

What was your child's usual serving size of strawberries?

$\checkmark$ Dash or pinch (size of a pea)

$\checkmark 1$ teaspoon (size of a dice)

$\square 1$ tablespoon (size of a poker chip)

$\square 1$ ounce (volume in a shot glass)

$\square 1 / 4$ cup (size of a golf ball)

$\square 1 / 2$ cup (size of a tennis ball)

3/4 cup (volume in a tea cup)

1 cup (size of a baseball)

In the last 12 months, was the source ever from a home or local garden?

Yes

No

\section{Convolvulaceae}

In the last 12 months, did your child eat sweet potatoes?

Yes

No

How often did your child eat sweet potatoes?

1-6 times per year

7-11 times per year 
1 time per month

2-3 times per month

1 time per week

2 times per week

3-4 times per week

5-6 times per week

1 time per day

2 or more times per day

What was your child's usual serving size of sweet potatoes?

Dash or pinch (size of a pea)

1 teaspoon (size of a dice)

$\checkmark 1$ tablespoon (size of a poker chip)

$\checkmark 1$ ounce (volume in a shot glass)

$\square 1 / 4$ cup (size of a golf ball)

$\square 1 / 2$ cup (size of a tennis ball)

3/4 cup (volume in a tea cup)

$\square 1 \mathrm{cup}$ (size of a baseball)

In the last 12 months, was the source ever from a home or local garden?

Yes

No

\section{Poaceae}

In the last 12 months, did your child eat corn? 
How often did your child eat corn?
1-6 times per year
7-11 times per year
1 time per month
2-3 times per month
1 time per week
2 times per week
3-4 times per week
5-6 times per week
1 time per day
2 or more times per day

What was your child's usual serving size of corn?

Dash or pinch (size of a pea)

$\square 1$ teaspoon (size of a dice)

$\square 1$ tablespoon (size of a poker chip)

$\square 1$ ounce (volume in a shot glass)

$\square 1 / 4 \operatorname{cup}$ (size of a golf ball)

$\checkmark 1 / 2$ cup (size of a tennis ball)

$\checkmark 3 / 4$ cup (volume in a tea cup)

$\square 1$ cup (size of a baseball)

In the last 12 months, was the source ever grown at home or locally? 
In the last 12 months, did your child eat rice?
Yes
No

How often did your child eat rice?
1-6 times per year
7-11 times per year
1 time per month
2-3 times per month
1 time per week
2 times per week
3-4 times per week
5-6 times per week
1 time per year
2 or more times per year

What was your child's usual serving size of rice?

Dash or pinch (size of a pea)

$\checkmark 1$ teaspoon (size of a dice)

1 tablespoon (size of a poker chip)

$\square 1$ ounce (volume in a shot glass)

$\square 1 / 4 \operatorname{cup}$ (size of a golf ball)

$1 / 2$ cup (size of a tennis ball)

$3 / 4$ cup (volume in a tea cup) 
In the last 12 months, was the source ever grown at home or locally?
Yes
No

In the last 12 months, did your child eat rice-based products (for example: rice cereal)

Yes

No

Please list and describe the rice-based products your child consumed.

How often did your child eat rice-based products?
1-6 times per year
7-11 times per year
1 time per month
2-3 times per month
1 time per week
2 times per week
3-4 times per week
5-6 times per week
1 time per day
2 or more times per day 
What was your child's usual serving size of rice-based products?

Dash or pinch (size of a pea)

$\checkmark 1$ teaspoon (size of a dice)

1 tablespoon (size of a poker chip)

1 ounce (volume in a shot glass)

$\checkmark 1 / 4$ cup (size of a golf ball)

$\checkmark 1 / 2$ cup (size of a tennis ball)

$3 / 4$ cup (volume in a tea cup)

1 cup (size of a baseball)

In the last 12 months, was the source ever grown at home or locally?

Yes

No

In the last 12 months, did your child eat gluten-free products that contain the following:

Quinoa

$\square$ Brown rice

Wild rice

$\square$ Buckwheat

$\checkmark$ Sorghum

Tapioca

Millet

Amaranth

Teff

Arrowroot 
What was your child's usual serving size of gluten-free products?

Dash or pinch (size of a pea)

$\square 1$ teaspoon (size of a dice)

1 tablespoon (size of a poker chip)

$\square 1$ ounce (volume in a shot glass)

$\square 1 / 4$ cup (size of a golf ball)

$\square 1 / 2$ cup (size of a tennis ball)

$3 / 4$ cup (volume in a tea cup)

$\square 1$ cup (size of a baseball)

In the last 12 months, was the source ever grown at home or locally?

Yes

No

In the last 12 months, did your child eat whole wheat?

Yes

No

How often did your child eat whole wheat?

1-6 times per year

7-11 times per year

1 time per month

2-3 times per month

1 time per week 
2 times per week

3-4 times per week

5-6 times per week

1 time per day

2 or more times per day

What was your child's usual serving size of whole wheat?

Dash or pinch (size of a pea)

$\checkmark 1$ teaspoon (size of a dice)

$\checkmark 1$ tablespoon (size of a poker chip)

$\square 1$ ounce (volume in a shot glass)

$\square 1 / 4$ cup (size of a golf ball)

$\square 1 / 2$ cup (size of a tennis ball)

$\checkmark 3 / 4$ cup (volume in a tea cup)

1 cup (size of a baseball)

In the last 12 months, was the source ever grown at home or locally?

Yes

No

In the last 12 months, did your child eat oats?

Yes

No

How often did your child eat oats? 
7-11 times per year

1 time per month

2-3 times per month

1 time per week

2 times per week

3-4 times per week

5-6 times per week

1 time per day

2 or more times per day

What was your child's usual serving size of oats?

Dash or pinch (size of a pea)

$\square 1$ teaspoon (size of a dice)

$\square 1$ tablespoon (size of a poker chip)

$\square 1$ ounce (volume in a shot glass)

$\square 1 / 4$ cup (size of a golf ball)

$1 / 2$ cup (size of a tennis ball)

3/4 cup (volume in a tea cup)

$\square 1$ cup (size of a baseball)

In the last 12 months, was the source ever grown at home or locally?

Yes

No

\section{Selfish and seafood}


In the last 12 months, did your child eat shellfish (scallops, clams, oysters, mussels, crab, lobster)?

Yes

No

How often did your child eat shellfish (scallops, clams, oysters, mussels, crab, lobster)?

1-6 times per year

7-11 times per year

1 time per month

2-3 times per month

1 time per week

2 times per week

3-4 times per week

5-6 times per week

1 time per day

2 or more times per day

What was your child's usual serving size of shellfish (scallops, clams, oysters, mussels, crab, lobster)?

Dash or pinch (size of a pea)

$\checkmark 1$ teaspoon (size of a dice)

1 tablespoon (size of a poker chip)

1 ounce (volume in a shot glass)

$1 / 4$ cup (size of a golf ball)

$1 / 2$ cup (size of a tennis ball)

$3 / 4$ cup (volume in a tea cup) 
In the last 12 months, was the source locally caught?
Yes
No

In the last 12 months, did your child eat seaweed/kelp?
Yes
No

How often did your child eat seaweed/kelp?
1-6 times per year
7-11 times per year
1 time per month
2-3 times per month
1 time per week
2 times per week
3-4 times per week
5-6 times per week
1 time per day
2 or more times per day

What was your child's usual serving size of seaweed/kelp?

Dash or pinch (size of a pea)

$\square 1$ teaspoon (size of a dice)

$\checkmark 1$ tablespoon (size of a poker chip) 
1 ounce (volume in a shot glass)

$1 / 4$ cup (size of a golf ball)

$1 / 2$ cup (size of a tennis ball)

3/4 cup (volume in a tea cup)

$\square 1$ cup (size of a baseball)

In the last 12 months, was the source locally caught?

Yes

No

\section{Baby food}

In the last 12 months, did your child eat organic baby food?

Yes

No

How often did your child eat organic baby food?
1-6 times per year
7-11 times per year
1 time per month
2-3 times per month
1 time per week
2 times per week
3-4 times per week
5-6 times per week
1 time per day
2 or more times per day 
What was your child's usual serving size of organic baby food?

$1 / 4$ cup $=2$ ounces

$1 / 2$ cup $=4$ ounces

$3 / 4$ cup $=6$ ounces

1 cup $=8$ ounces

$11 / 4$ cups $=10$ ounces

$11 / 2$ cups $=12$ ounces

$13 / 4$ cups $=14$ ounces

2 cups $=16$ ounces

In the last 12 months, were the source of ingredients for your child's baby food from your home or local garden?

Yes

No

\section{Apple Juice}

In the last 12 months, did your child drink apple juice?

Yes

No

How often did your child drink apple juice?

NEVER

1 time per month or less

2-3 times per month 
1-2 times per week

3-4 times per week

5-6 times per week

1 time per day

2-3 times per day

4-5 times per day

6 or more times per day

What was your child's usual serving size of apple juice?

$1 / 4$ cup $=2$ ounces

$1 / 2$ cup $=4$ ounces

$3 / 4$ cup $=6$ ounces

1 cup $=8$ ounces

$11 / 4$ cups $=10$ ounces

$11 / 2$ cups $=12$ ounces

$13 / 4$ cups $=14$ ounces

2 cups $=16$ ounces

\section{Water}

Over the past 12 months, how often did your child drink tap water?

NEVER

1 time per month or less

2-3 times per month

1-2 times per week

3-4 times per week

5-6 times per week

1 time per day 
2-3 times per day

4-5 times per day

6 or more times per day

What was your child's usual serving size of water?

$1 / 4$ cup $=2$ ounces

$1 / 2$ cup $=4$ ounces

$3 / 4$ cup $=6$ ounces

1 cup $=8$ ounces

$11 / 4$ cups $=10$ ounces

$11 / 2$ cups $=12$ ounces

$13 / 4$ cups $=14$ ounces

2 cups $=16$ ounces

Over the past 12 months, when your child drank tap water, what was the main source?

Community drinking fountain

$\checkmark$ A well or rain water

$\square$ A river

$\square$ I don't know

$\bigcirc$ Other

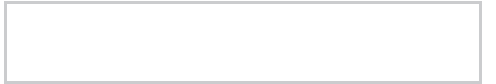

Over the past 12 months, how often did your child drink bottled water?

NEVER

1 time per month or less 
2-3 times per month

1-2 times per week

3-4 times per week

5-6 times per week

1 time per day

2-3 times per day

4-5 times per day

6 or more times per day

\section{End of Survey Questions}

How easy was this food frequency questionnaire to complete?

$\begin{array}{cccccc}\text { Extremely } & \text { Moderately } & \text { Neither easy } & \text { Slightly } & \text { Moderately } & \text { Extremely } \\ \text { easy } & \text { easy } & \text { Slightly easy nor difficult } & \text { difficult } & \text { difficult } & \text { difficult }\end{array}$

How likely are you to participate in future dietary assessments?

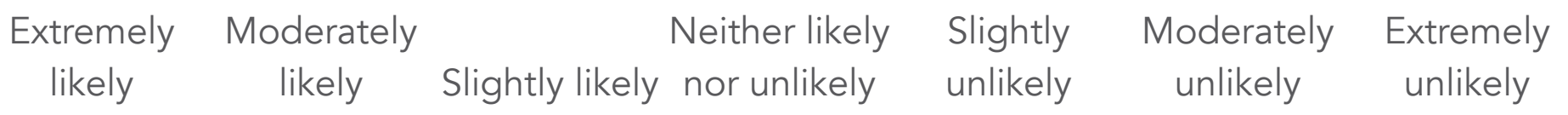




\section{AT THE UNIVERSITY \\ $\llbracket \checkmark$ OF ARIZONA。}

Español

\section{Consent Form}

Por favor, escribe lo siguiente:

Nombre de la escuela de su hijo

Últimos 4 dígitos de su número de teléfono

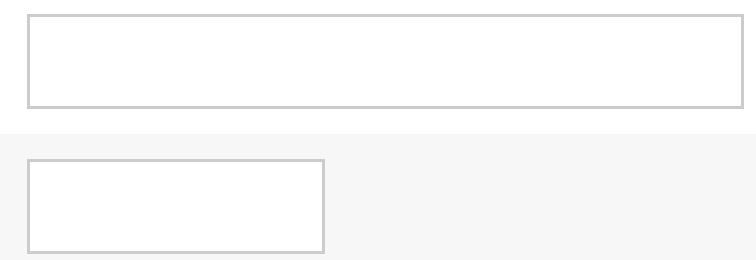

Consentimiento para participar en la investigación - Padre / Cuidador

Título del estudio: The Nevada City, CA Garden Project Sponsored By: California Breast Cancer Research Program - University of CA

Investigadora principal: Monica Ramirez-Andreotta, MPA, PhD (University of Arizona), Joanne Hild, MS (Sierra Streams Institute), Peggy Reynolds, PhD (University of California, San Francisco)

Este es un formulario de consentimiento para la participación en la investigación. Contiene información importante sobre la parte de investigación humana del estudio e información sobre qué es lo que puede esperar si decide participar en el estudio.

\section{¿Por qué se está haciendo este estudio?}

Los objetivos de esta investigación humana son determinar: 1) cuáles son los resultados de los proyectos de investigación que involucran a miembros del público en algunos o todos los pasos del método científico, 2) cómo informar con éxito los datos de monitoreo ambiental a las comunidades para abordar los problemas de salud ambiental, 3) cuales son las prácticas de 
jardinería de los participantes en preescolares, y / o 4) qué y cuánta comida cultivada 186 localmente es consumida por la familia y los niños preescolares.

\section{¿Qué pasará si participo en este estudio?}

Como parte de este estudio, se le pedirá que complete todas o solo algunas de las actividades enumeradas a continuación:

1) Encuesta sobre la participación de su hijo en el comportamiento de jardinería y en los patrones

de consumo.

2) Participación en el muestreo ambiental de agua, suelo, polvo y productos del jardín/huerta preescolar de su hijo

3) Un cuestionario de frecuencia de alimentos y dietario o diario alimenticio de 24 horas.

\section{¿Qué pasará si participo en este estudio?}

Como parte de este estudio, se le pedirá que complete todas o solo algunas de las actividades enumeradas a continuación:

1) Encuesta sobre la participación de su hijo en el jardín o huerta y en los patrones de consumo.

2) Participación en el muestreo ambiental de agua, suelo, polvo y productos del jardín o huerta

preescolar de su hijo

3) Un cuestionario de frecuencia de alimentos y dietario o diario alimenticio de 24 horas.

\section{¿Cuánto tiempo estaré en el estudio?}

1) La encuesta sobre la participación de su hijo en actividades de jardinería tomará aproximadamente 20 minutos.

2) Su participación en el muestreo ambiental del jardín/huerta preescolar de su hijo implicará una sesión de capacitación de 1 a 2 horas y aproximadamente y 30 minutos de recolección de muestras del jardín/huerta.

3) El cuestionario de frecuencia de alimentos y dietario o diario alimenticio toman un promedio de una hora.

\section{¿Cuántas personas participarán en este estudio?}

Gardenroots en California trabajará con hasta 30 familias.

\section{¿Puedo dejar de estar en el estudio?}

Su participación es voluntaria. Puede negarse a participar en este estudio o a participar en cualquiera de los aspectos de este estudio. Si decide participar en el estudio, puede dejar el estudio en cualquier momento. No importa la decisión que tome, no habrá ninguna sanción para usted y no perderá ninguno de sus beneficios habituales. Su decisión no afectará su relación futura con la Universidad de Arizona, Sierra Streams Institute o la Universidad de 


\section{¿Qué riesgos, efectos secundarios o molestias puedo anticipar al participar en el estudio?}

No se espera ningún daño relacionado con la investigación (es decir, físico, psicológico, social o de otro tipo) asociado con el componente de investigación humana del estudio.

\section{¿Qué beneficios puedo esperar de estar en el estudio?}

No hay beneficios directos de la participación. Puede o no puede beneficiarse como resultado de participar en la parte de investigación humana del estudio. Sin embargo, el conocimiento adquirido por este estudio relacionado con la ciencia ciudadana, la salud ambiental, la comunicación ambiental y las prácticas individuales de jardinería puede informar los estudios de investigación futuros y las actividades de la comunidad y proteger la salud humana.

\section{¿Qué otras opciones tengo si no participo en el estudio?}

Puede elegir no participar en este estudio sin penalización o pérdida de beneficios a los que tiene derecho. Si decide que no desea participar en la investigación humana, aún puede participar en la parte de monitoreo ambiental del proyecto de ciencia ciudadana.

\section{¿Cuáles son los costos de participar en este estudio?}

Participante: Es posible que tenga que pagar por la gasolina utilizada durante el transporte a la entrega de muestras ambientales. También es posible que deba conducir para asistir a reuniones de la comunidad y eventos de intercambio de datos. Este es el único costo anticipado en el que puede incurrir a través de la participación en la investigación.

\section{¿Me pagarán por participar en este estudio?}

No, no se le pagará por su participación.

\section{¿Se mantendrá confidencial mi información relacionada con el estudio?}

Se harán esfuerzos para mantener la confidencialidad de su información relacionada con el estudio. Sin embargo, puede haber circunstancias en las que esta información deba ser divulgada. Por ejemplo, la información personal con respecto a su participación en este estudio puede ser divulgada si así lo requiere la ley estatal. En este estudio, cualquier registro que incluya su nombre, número de teléfono, dirección postal o dirección de correo electrónico se guardará en archivadores cerrados con llave y el acceso a estos registros estará restringido a los investigadores involucrados en el estudio. No se le identificará en ningún artículo o informe escrito sobre este proyecto. Los datos se conservarán para futuras investigaciones bajo la revisión de IRB (Junta de Revisión Institucional).

Además, sus registros pueden ser revisados por los siguientes grupos: 


\section{¿Quién puede responder mis preguntas sobre el estudio?}

Para preguntas, inquietudes o quejas sobre el estudio, puede comunicarse con cualquiera de los investigadores del estudio:

Monica Ramirez-Andreotta por teléfono al 520-621-

0091 o email, dramire@email.arizona.edu

Joanne Hild por teléfono 530-265-6090 o email, joannehild@sierrastreamsinstitute.org Peggy Reynolds por teléfono 510-608-5180 o email, Peggy.Reynolds@ucsf.edu

Si desea hacer preguntas sobre el estudio o sobre sus derechos como participante de una investigación a otra persona que no sea el investigador o si desea expresar cualquier problema o inquietud que pueda tener sobre el estudio, llame a la oficina de la Junta de Revisión Institucional de UCSF al 415-476-1814.

Las Juntas de Revisión Institucional responsables de la investigación de sujetos humanos en la Universidad de Arizona y la Universidad de California en San Francisco revisaron este proyecto de investigación y lo encontraron aceptable, de acuerdo con las regulaciones estatales y federales aplicables y las políticas universitarias diseñadas para proteger los derechos y el bienestar de los Participantes en la investigación.

\section{Firmando el formulario de consentimiento}

He leído (o alguien me ha leído) este formulario, y soy consciente de que me piden participar en un estudio de investigación. He tenido la oportunidad de hacer preguntas y he recibido respuestas satisfactorias. Estoy de acuerdo en participar en este estudio voluntariamente. No estoy renunciando a ningún derecho legal al firmar este formulario. Me darán una copia de este formulario.

\section{Nombre de participante}

\section{Firma del participante}


borrar

\section{Fecha (MM / DD / YYYY)}

\section{Hora (XX: XX AM o PM)}

¿Podemos estar en contacto con usted en el futuro? Su respuestas pueden conducir nuevas preguntas de investigación.

Sí

No

¿Cuál es la mejor manera de contactarte en el futuro?

$\square$ Correo electrónico

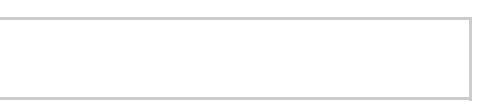

$\square$ Teléfono

\section{Demographics pt 1}


¿Cuántos niños de edad preescolar viven en casa?

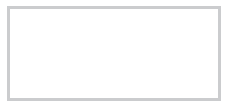

En este estudio, estamos interesados en los patrones de consumo de sus niños en edad preescolar.

Si tienes más de 1 hijo en preescolar, responde a las siguientes preguntas en este cuestionario de frecuencia de alimentos para uno de ellos.

Cuántos años tiene tu hijo?

La escuela de su hijo

¿Cómo describiría el género de su hijo?

¿Con cuál de los siguientes grupos se identifica su hijo? (elija todo lo que corresponda)

Afroamericano, negro

Indio americano, nativo americano o nativo de Alaska

Asiático, asiático-americano

$\checkmark$ Isleño del caribe

$\square$ Latino o hispano 
Oriente medio o árabe

$\square$ Nativo de Hawai u otra isla del Pacífico

$\square$ Blanco, caucásico, europeo americano

$\bigcirc$ Otros (especifica)

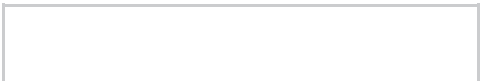

¿Cuál es el código postal de tu casa?

¿Qué idiomas hablas usted?

Primario

Secundario

¿Cuál es el nivel más alto de educación que has completado (marque uno)?

Preescolar / Kindergarten

Primaria / primaria

Secundaria / secundaria

Escuela secundaria / secundaria

Un poco de universidad (menos de cuatro años)

Escuela comercial / técnica / programa de entrenamiento

Título universitario (Licenciatura)

Posgrado (Masteria / PhD, MD, JD, etc.)

Prefiero no responder 
¿Cuantas personas viven en su casa? Seleccione el número en la columna que represente menos o igual al ingreso total de su casa.

\begin{tabular}{|l|c|c|c|c|c|c|c|c|}
\hline $\begin{array}{l}\text { \# of persons } \\
\text { in household } \\
\text { (\# de } \\
\text { personas en } \\
\text { casa) }\end{array}$ & $\mathbf{1}$ & $\mathbf{2}$ & $\mathbf{3}$ & $\mathbf{4}$ & $\mathbf{5}$ & $\mathbf{6}$ & $\mathbf{7}$ & $\mathbf{8 +}$ \\
\hline $\begin{array}{l}\text { Income } \\
\text { (Ingreso) (\$) }\end{array}$ & 15,250 & 17,400 & 20,780 & 25,100 & 29,420 & 33,740 & 38,060 & 42,380 \\
\cline { 2 - 9 } & 25,400 & 29,000 & 32,650 & 36,250 & 39,150 & 42,050 & 44,950 & 47,850 \\
\cline { 2 - 8 } & 40,600 & 46,400 & 52,200 & 58,000 & 62,650 & 67,300 & 71,950 & 76,600 \\
\cline { 2 - 8 } & $\begin{array}{c}\text { Above } \\
\text { (Más de) }\end{array}$ & $\begin{array}{c}\text { Above } \\
\text { (Más de) }\end{array}$ & $\begin{array}{c}\text { Above } \\
\text { (Más de) }\end{array}$ & $\begin{array}{c}\text { Above } \\
\text { (Más de) }\end{array}$ & $\begin{array}{c}\text { Above } \\
\text { (Más de) }\end{array}$ & $\begin{array}{c}\text { Above } \\
\text { (Más de) }\end{array}$ & $\begin{array}{c}\text { Above } \\
\text { (Más de) }\end{array}$ & $\begin{array}{c}\text { Above } \\
\text { (Más de) }\end{array}$ \\
\hline
\end{tabular}

\section{Demographics pt 2}

¿Prefieres comprar sus vegetales de mercados de agricultores locales?

Sí

No

¿Cuál es tu motivación para comprar localmente?

Beneficios de salud percibidos

Preocupación por la origen del producto

Conciencia ambiental

Percepción de menor costo (descuentos, trueque, tratos)

Beneficios de asistencia alimental aceptados

Frescura y calidad del producto

Variedad de producto

Limpio y seguro

Ubicacion conveniente

Camaradería

Relación de agricultor-consumidor

Apoyar la economía local o los agricultores 
¿Cuál es tu motivación para NO comprar localmente?

Los mercados no encajan en el estilo de vida o la rutina

Desconocimiento con la experiencia

Percepción de mayor costo (no competitivo con otras tiendas)

No se aceptan beneficios de asistencia alimental

Solamente efectivo

Horas incómodas y temporada de operación

Falta de variedad de comida

Malestia con el diseño del mercado / lugares de compras al aire libre

Ubicación incómoda

Tienes su propio jardín / granja

Espacio social excluyente

Falta de diversidad racial, étnica (barreras del idioma)

Falta de productos culturales y étnicamente diversos

$\square$ Otros

\section{Demographics pt 3}

Aproximadamente, ¿qué porcentaje del consumo anual de maíz, granos, avena y arroz de su hijo vino de las siguientes orígenes? (la suma de los porcentajes debe ser igual a 100)

\begin{tabular}{l|r} 
& Porcentaje \\
\hline Casa & $\square$ \\
\hline
\end{tabular}

Cultivado localmente 
agricultores

Tienda (cultivada

orgánicamente)

Tienda (cultivada

convencionalmente)

¿Aproximadamente qué porcentaje del consumo anual de frutas y verduras de su hijo vino de las siguientes orígenes? (la suma de los porcentajes debe ser igual a 100)

\begin{tabular}{l|l} 
& \multicolumn{2}{|c|}{ Porcentaje } \\
\hline Casa & \\
Cultivado localmente \\
/ Mercado de \\
alimentos \\
Tienda (cultivada \\
orgánicamente) \\
Tienda (cultivada \\
convencionalmente)
\end{tabular}

¿Aproximadamente qué porcentaje del consumo anual de carne de su hijo (pescado, pollo, carne de res, cerdo, etc.) vino de las siguientes orígenes? (la suma de los porcentajes debe ser igual a 100)

\begin{tabular}{l|l|} 
& \multicolumn{2}{|c|}{ Porcentaj } \\
\hline Casa & \\
Granja local & \\
Tienda (cultivada & \\
orgánicamente) & \\
Tienda (cultivada \\
convencionalmente)
\end{tabular}


En los últimos 12 meses, ¿comió lechuga su hijo?
Sí
No

¿Con qué frecuencia comió lechuga su hijo?
1-6 veces al año
7-11 veces al año
1 vez por mes
2-3 veces al mes
1 vez por semana
2 veces por semana
3-4 veces por semana
$5-6$ veces por semana
1 vez por día
2 o más veces al día

¿Cuál fue el tamaño de porción habitual de lechuga de su hijo?

Dash o pellizco (tamaño de un guisante)

1 cucharadita (tamaño de un dado)

$\checkmark 1$ cucharada (tamaño de una ficha de póker)

$\square 1$ onza (volumen de un vasito para tragos)

1/4 de taza (tamaño de una pelota de golf)

$\square 1 / 2$ de taza (tamaño de una pelota de tenis)

3/4 de taza (volumen en una taza de té) 
En los últimos 12 meses, ¿alguna vez originó de un casa o jardín local?
Sí
No

En los últimos 12 meses, ¿comió su hijo lechuga romana?
Sí
No

¿Con qué frecuencia comió su hijo lechuga romana?
1-6 veces al año
7-11 veces al año
1 vez por mes
2-3 veces al mes
1 vez por semana
2 veces por semana
3-4 veces por semana
5-6 veces por semana
1 vez por día
2 o más veces al día

¿Cuál fue el tamaño de porción habitual de lechuga romana de su hijo?

Dash o pellizco (tamaño de un guisante)

$\square 1$ cucharadita (tamaño de un dado)

$\square 1$ cucharada (tamaño de una ficha de póker) 
1 onza (volumen de un vasito para tragos)

$1 / 4$ de taza (tamaño de una pelota de golf)

$1 / 2$ de taza (tamaño de una pelota de tenis)

$3 / 4$ de taza (volumen en una taza de té)

1 taza (tamaño de una pelota de béisbol)

En los últimos 12 meses, ¿alguna vez originó de un casa o jardín local?

Sí

No

\section{Brassicaceae}

En los últimos 12 meses, ¿comió rábano su hijo?

¿Con qué frecuencia comió rábano su hijo?
1-6 veces al año
7-11 veces al año
1 vez por mes
2-3 veces al mes
1 vez por semana
2 veces por semana
3-4 veces por semana
5-6 veces por semana
1 vez por día
2 o más veces al día 
¿Cuál fue el tamaño de porción habitual de rábano de su hijo?

Dash o pellizco (tamaño de un guisante)

1 cucharadita (tamaño de un dado)

$\square 1$ cucharada (tamaño de una ficha de póker)

1 onza (volumen de un vasito para tragos)

$\square 1 / 4$ de taza (tamaño de una pelota de golf)

$\square 1 / 2$ de taza (tamaño de una pelota de tenis)

$\checkmark 3 / 4$ de taza (volumen en una taza de té)

1 taza (tamaño de una pelota de béisbol)

En los últimos 12 meses, ¿alguna vez originó de un casa o jardín local?

Sí

No

En los últimos 12 meses, ¿comió col rizada su hijo?

Sí

No

¿Con qué frecuencia comió col rizada su hijo?

1-6 veces al año

7-11 veces al año

1 vez por mes

2-3 veces al mes

1 vez por semana

2 veces por semana 
3-4 veces por semana

5-6 veces por semana

1 vez por día

2 o más veces al día

¿Cuál fue el tamaño de porción habitual de col rizada de su hijo?

Dash o pellizco (tamaño de un guisante)

$\square 1$ cucharadita (tamaño de un dado)

$\square 1$ cucharada (tamaño de una ficha de póker)

$\square 1$ onza (volumen de un vasito para tragos)

1/4 de taza (tamaño de una pelota de golf)

$1 / 2$ de taza (tamaño de una pelota de tenis)

$\checkmark 3 / 4$ de taza (volumen en una taza de té)

1 taza (tamaño de una pelota de béisbol)

En los últimos 12 meses, ¿alguna vez originó de un casa o jardín local?

Sí

No

En los últimos 12 meses, ¿comió brócoli su hijo?

Sí

No

¿Con qué frecuencia comió brócoli su hijo?

1-6 veces al año 
7-11 veces al año

1 vez por mes

2-3 veces al mes

1 vez por semana

2 veces por semana

3-4 veces por semana

5-6 veces por semana

1 vez por día

2 o más veces al día

¿Cuál fue el tamaño de porción habitual de brócoli de su hijo?

Dash o pellizco (tamaño de un guisante)

1 cucharadita (tamaño de un dado)

$\square$ cucharada (tamaño de una ficha de póker)

$\square 1$ onza (volumen de un vasito para tragos)

1/4 de taza (tamaño de una pelota de golf)

$\square 1 / 2$ de taza (tamaño de una pelota de tenis)

$\square$ 3/4 de taza (volumen en una taza de té)

1 taza (tamaño de una pelota de béisbol)

En los últimos 12 meses, ¿alguna vez originó de un casa o jardín local?

Sí

No

En los últimos 12 meses, ¿comió repollo su hijo? 
¿Con qué frecuencia comió repollo su hijo?

1-6 veces al año

7-11 veces al año

1 vez por mes

2-3 veces al mes

1 vez por semana

2 veces por semana

3-4 veces por semana

5-6 veces por semana

1 vez por día

2 o más veces al día

¿Cuál fue el tamaño de porción habitual de repollo de su hijo?

Dash o pellizco (tamaño de un guisante)

$\checkmark 1$ cucharadita (tamaño de un dado)

$\square 1$ cucharada (tamaño de una ficha de póker)

$\checkmark 1$ onza (volumen de un vasito para tragos)

$\square$ 1/4 de taza (tamaño de una pelota de golf)

$1 / 2$ de taza (tamaño de una pelota de tenis)

3/4 de taza (volumen en una taza de té)

1 taza (tamaño de una pelota de béisbol)

En los últimos 12 meses, ¿alguna vez originó de un casa o jardín local? 
En los últimos 12 meses, ¿comió papaya su hijo?
Sí
No

¿Con qué frecuencia comió papaya su hijo?
1-6 veces al año
7-11 veces al año
1 vez por mes
2-3 veces al mes
1 vez por semana
2 veces por semana
3-4 veces por semana
5-6 veces por semana
1 vez por día
2 o más veces al día

¿Cuál fue el tamaño de porción habitual de papaya de su hijo?

$\checkmark$ Dash o pellizco (tamaño de un guisante)

$\square 1$ cucharadita (tamaño de un dado)

1 cucharada (tamaño de una ficha de póker)

1 onza (volumen de un vasito para tragos)

1/4 de taza (tamaño de una pelota de golf)

$1 / 2$ de taza (tamaño de una pelota de tenis)

3/4 de taza (volumen en una taza de té) 
En los últimos 12 meses, ¿alguna vez originó de un casa o jardín local?
Sí
No

En los últimos 12 meses, ¿comió nabo su hijo?

Sí

No

¿Con qué frecuencia comió nabo su hijo?

1-6 veces al año

7-11 veces al año

1 vez por mes

2-3 veces al mes

1 vez por semana

2 veces por semana

3-4 veces por semana

5-6 veces por semana

1 vez por día

2 o más veces al día

¿Cuál fue el tamaño de porción habitual de nabo de su hijo?

Dash o pellizco (tamaño de un guisante)

$\square 1$ cucharadita (tamaño de un dado)

$\square 1$ cucharada (tamaño de una ficha de póker) 
1 onza (volumen de un vasito para tragos)

$1 / 4$ de taza (tamaño de una pelota de golf)

$1 / 2$ de taza (tamaño de una pelota de tenis)

$\square$ 3/4 de taza (volumen en una taza de té)

1 taza (tamaño de una pelota de béisbol)

En los últimos 12 meses, ¿alguna vez originó de un casa o jardín local?

Sí

No

En los últimos 12 meses, ¿comió coliflor su hijo?

Sí

No

¿Con qué frecuencia comió coliflor su hijo?

1-6 veces al año

7-11 veces al año

1 vez por mes

2-3 veces al mes

1 vez por semana

2 veces por semana

3-4 veces por semana

5-6 veces por semana

1 vez por día

2 o más veces por semana 
$\checkmark$ Dash o pellizco (tamaño de un guisante)

$\square 1$ cucharadita (tamaño de un dado)

$\checkmark 1$ cucharada (tamaño de una ficha de póker)

1 onza (volumen de un vasito para tragos)

$1 / 4$ de taza (tamaño de una pelota de golf)

$1 / 2$ de taza (tamaño de una pelota de tenis)

3/4 de taza (volumen en una taza de té)

1 taza (tamaño de una pelota de béisbol)

En los últimos 12 meses, ¿alguna vez originó de un casa o jardín local?

Sí

No

En los últimos 12 meses, ¿comió rúcula su hijo?

Sí

No

¿Con qué frecuencia comió rúcula su hijo?

1-6 veces al año

7-11 veces al año

1 vez por mes

2-3 veces al mes

1 vez por semana

2 veces por semana

3-4 veces por semana 
1 vez por día

2 o más veces al día

¿Cuál fue el tamaño de porción habitual de rúcula de su hijo?

Dash o pellizco (tamaño de un guisante)

1 cucharadita (tamaño de un dado)

$\square 1$ cucharada (tamaño de una ficha de póker)

1 onza (volumen de un vasito para tragos)

$1 / 4$ de taza (tamaño de una pelota de golf)

$1 / 2$ de taza (tamaño de una pelota de tenis)

3/4 de taza (volumen en una taza de té)

1 taza (tamaño de una pelota de béisbol)

En los últimos 12 meses, ¿alguna vez originó de un casa o jardín local?

Sí

No

En los últimos 12 meses, ¿comió coles de Bruselas su hijo?

Sí

No

¿Con qué frecuencia comió coles de Bruselas su hijo?

1-6 veces al año

7-11 veces al año

1 vez por mes 
2-3 veces al mes

1 vez por semana

2 veces por semana

3-4 veces por semana

5-6 veces por semana

1 vez por día

2 o más veces al día

¿Cuál fue el tamaño de porción habitual de coles de Bruselas de su hijo?

Dash o pellizco (tamaño de un guisante)

$\square 1$ cucharadita (tamaño de un dado)

1 cucharada (tamaño de una ficha de póker)

1 onza (volumen de un vasito para tragos)

$1 / 4$ de taza (tamaño de una pelota de golf)

$1 / 2$ de taza (tamaño de una pelota de tenis)

$3 / 4$ de taza (volumen en una taza de té)

$\checkmark 1$ taza (tamaño de una pelota de béisbol)

En los últimos 12 meses, ¿alguna vez originó de un casa o jardín local?

Sí

No

\section{Amaranthaceae}

En los últimos 12 meses, ¿comió espinacas su hijo?

Sí

No 
¿Con qué frecuencia comió espinacas su hijo?
1-6 veces al año
7-11 veces al año
1 vez por mes
2-3 veces al mes
1 vez por semana
2 veces por semana
3-4 veces por semana
5-6 veces por semana
1 vez por día
2 o más veces al día

¿Cuál fue el tamaño de porción habitual de espinacas de su hijo?

Dash o pellizco (tamaño de un guisante)

$\square 1$ cucharadita (tamaño de un dado)

$\square 1$ cucharada (tamaño de una ficha de póker)

$\square 1$ onza (volumen de un vasito para tragos)

$\square$ 1/4 de taza (tamaño de una pelota de golf)

$\square 1 / 2$ de taza (tamaño de una pelota de tenis)

$\square$ 3/4 de taza (volumen en una taza de té)

$\checkmark 1$ taza (tamaño de una pelota de béisbol)

En los últimos 12 meses, ¿alguna vez originó de un casa o jardín local?
Sí
No 
En los últimos 12 meses, ¿comió acelga suiza su hijo?

Sí

No

¿Con qué frecuencia comió acelga suiza su hijo?

1-6 veces por año

7-11 veces por año

1 vez por mes

2-3 veces al mes

1 vez por semana

2 veces por semana

3-4 veces por semana

5-6 veces por semana

1 vez por día

2 o más veces al día

¿Cuál fue el tamaño de porción habitual de acelga suiza de su hijo?

Dash o pellizco (tamaño de un guisante)

$\square 1$ cucharadita (tamaño de un dado)

$\square 1$ cucharada (tamaño de una ficha de póker)

$\square 1$ onza (volumen de un vasito para tragos)

$\square$ 1/4 de taza (tamaño de una pelota de golf)

$\checkmark 1 / 2$ de taza (tamaño de una pelota de tenis)

3/4 de taza (volumen en una taza de té)

1 taza (tamaño de una pelota de béisbol) 
En los últimos 12 meses, ¿alguna vez originó de un casa o jardín local?

Sí

No

\section{Cucurbitaceae}

En los últimos 12 meses, ¿comió calabaza su hijo?

Sí

No

¿Con qué frecuencia comió calabaza su hijo?

1-6 veces al año

7-11 veces al año

1 vez por mes

2-3 veces al mes

1 vez por semana

2 veces por semana

3-4 veces por semana

5-6 veces por semana

1 veces por día

2 o más veces al día

¿Cuál fue el tamaño de porción habitual de calabaza de su hijo?

Dash o pellizco (tamaño de un guisante)

1 cucharadita (tamaño de un dado)

1 cucharada (tamaño de una ficha de póker)

1 onza (volumen de un vasito para tragos) 
$1 / 4$ de taza (tamaño de una pelota de golf)

1 $1 / 2$ de taza (tamaño de una pelota de tenis)

3/4 de taza (volumen en una taza de té)

$\checkmark 1$ taza (tamaño de una pelota de béisbol)

En los últimos 12 meses, ¿alguna vez originó de un casa o jardín local?

Sí

No

En los últimos 12 meses, ¿comió zapallo su hijo?

Sí

No

¿Con qué frecuencia comió zapallo su hijo?

1-6 veces al año

7-11 veces al año

1 vez por mes

2-3 veces al mes

1 vez por semana

2 veces por semana

3-4 veces por semana

5-6 veces por semana

1 vez por día

2 o más veces al día

¿Cuál fue el tamaño de porción habitual de zapallo de su hijo? 
Dash o pellizco (tamaño de un guisante)

$\square 1$ cucharadita (tamaño de un dado)

1 cucharada (tamaño de una ficha de póker)

1 onza (volumen de un vasito para tragos)

$1 / 4$ de taza (tamaño de una pelota de golf)

$1 / 2$ de taza (tamaño de una pelota de tenis)

3/4 de taza (volumen en una taza de té)

1 taza (tamaño de una pelota de béisbol)

En los últimos 12 meses, ¿alguna vez originó de un casa o jardín local?

Sí

No

En los últimos 12 meses, ¿comió pepino su hijo?

Sí

No

¿Con qué frecuencia comió pepino su hijo?

1-6 veces al año

7-11 veces al año

1 vez por mes

2-3 veces al mes

1 vez por semana

2 veces por semana

3-4 veces por semana

5-6 veces por semana 
2 o más veces al día

¿Cuál fue el tamaño de porción habitual de pepino de su hijo?

Dash o pellizco (tamaño de un guisante)

1 cucharadita (tamaño de un dado)

$\square 1$ cucharada (tamaño de una ficha de póker)

$\square$ onza (volumen de un vasito para tragos)

$1 / 4$ de taza (tamaño de una pelota de golf)

$\square 1 / 2$ de taza (tamaño de una pelota de tenis)

3/4 de taza (volumen en una taza de té)

1 taza (tamaño de una pelota de béisbol)

En los últimos 12 meses, ¿alguna vez originó de un casa o jardín local?

Sí

No

En los últimos 12 meses, ¿comió melón su hijo?

Sí

No

¿Con qué frecuencia comió melón su hijo?

1-6 veces al año

7-11 veces al año

1 vez por mes

2-3 veces por mes 
1 vez por semana

2 veces por semana

3-4 veces por semana

5-6 veces por semana

1 vez por día

2 o más veces al día

¿Cuál fue el tamaño de porción habitual de melón de su hijo?

Dash o pellizco (tamaño de un guisante)

$\square 1$ cucharadita (tamaño de un dado)

$\square 1$ cucharada (tamaño de una ficha de póker)

1 onza (volumen de un vasito para tragos)

$1 / 4$ de taza (tamaño de una pelota de golf)

$1 / 2$ de taza (tamaño de una pelota de tenis)

3/4 de taza (volumen en una taza de té)

1 taza (tamaño de una pelota de béisbol)

En los últimos 12 meses, ¿alguna vez originó de un casa o jardín local?

Sí

No

En los últimos 12 meses, ¿comió calabacín su hijo?

Sí

No

¿Con qué frecuencia comió calabacín su hijo? 
1-6 veces al año

7-11 veces al año

1 vez por mes

2-3 veces al mes

1 vez por semana

2 veces por semana

3-4 veces por semana

5-6 veces por semana

1 vez por día

2 o más veces al día

¿Cuál fue el tamaño de porción habitual de calabacín de su hijo?

$\checkmark$ Dash o pellizco (tamaño de un guisante)

$\square 1$ cucharadita (tamaño de un dado)

$\square 1$ cucharada (tamaño de una ficha de póker)

$\square 1$ onza (volumen de un vasito para tragos)

$1 / 4$ de taza (tamaño de una pelota de golf)

$1 / 2$ de taza (tamaño de una pelota de tenis)

$3 / 4$ de taza (volumen en una taza de té)

1 taza (tamaño de una pelota de béisbol)

En los últimos 12 meses, ¿alguna vez originó de un casa o jardín local?

Sí

No

\section{Liliaceae}


En los últimos 12 meses, ¿comió ajo su hijo?

Sí

No

¿Con qué frecuencia comió ajo su hijo?

$1-6$ veces al año

7-11 veces al año

1 veces por mes

2-3 veces al mes

1 vez por semana

2 veces por semana

3-4 veces por semana

5-6 veces por semana

1 vez por día

2 o más veces al día

¿Cuál fue el tamaño de porción habitual de ajo para su hijo?

1 cucharada

$1 / 2$ cucharada

1 cucharadita

$1 / 2$ cucharadita

$1 / 4$ cucharadita

1/8 cucharadita

En los últimos 12 meses, ¿alguna vez originó de un casa o jardín local? 
No

En los últimos 12 meses, ¿comió cebolla su hijo?

Sí

No

¿Con qué frecuencia comió cebollas su hijo?

1-6 veces al año

7-11 veces al año

1 vez por mes

2-3 veces al mes

1 vez por semana

2 veces por semana

3-4 veces por semana

5-6 veces por semana

1 vez por día

2 o más veces al día

¿Cuál fue el tamaño de porción habitual de cebolla de su hijo?

Dash o pellizco (tamaño de un guisante)

1 cucharadita (tamaño de un dado)

1 cucharada (tamaño de una ficha de póker)

$\square 1$ onza (volumen de un vasito para tragos)

$1 / 4$ de taza (tamaño de una pelota de golf)

$1 / 2$ de taza (tamaño de una pelota de tenis) 
1 taza (tamaño de una pelota de béisbol)

En los últimos 12 meses, ¿alguna vez originó de un casa o jardín local?
Sí
No

\section{Solanaceae}

En los últimos 12 meses, ¿comió su hijo papas irlandesas?

Sí

No

¿Con qué frecuencia comió papas irlandesas su hijo?

1-6 veces al año

7-11 veces al año

1 vez por mes

2-3 veces al mes

1 vez por semana

2 veces por semana

3-4 veces por semana

5-6 veces por semana

1 vez por día

2 o más veces al día

¿Cuál fue el tamaño de porción habitual de papas irlandesas de su hijo? 
Dash o pellizco (tamaño de un guisante)

1 cucharadita (tamaño de un dado)

1 cucharada (tamaño de una ficha de póker)

$\square 1$ onza (volumen de un vasito para tragos)

$1 / 4$ de taza (tamaño de una pelota de golf)

$1 / 2$ de taza (tamaño de una pelota de tenis)

$\square$ 3/4 de taza (volumen en una taza de té)

$\checkmark 1$ taza (tamaño de una pelota de béisbol)

En los últimos 12 meses, ¿alguna vez originó de un casa o jardín local?

Sí

No

En los últimos 12 meses, ¿comió tomates su hijo?

Sí

No

¿Con qué frecuencia comió tomates su hijo?

1-6 veces al año

7-11 veces al año

1 vez por mes

2-3 veces al mes

1 vez por semana

2 veces por semana

3-4 veces por semana

5-6 veces por semana 
1 vez por día

2 o más veces al día

¿Cuál fue el tamaño de porción habitual de tomate de su hijo?

Dash o pellizco (tamaño de un guisante)

1 cucharadita (tamaño de un dado)

$\square 1$ cucharada (tamaño de una ficha de póker)

$\square$ onza (volumen de un vasito para tragos)

$\square 1 / 4$ de taza (tamaño de una pelota de golf)

$\square 1 / 2$ de taza (tamaño de una pelota de tenis)

3/4 de taza (volumen en una taza de té)

1 taza (tamaño de una pelota de béisbol)

En los últimos 12 meses, ¿alguna vez originó de un casa o jardín local?

Sí

No

En los últimos 12 meses, ¿comió berenjena su hijo?

Sí

No

¿Con qué frecuencia comió berenjena su hijo?

1-6 veces al año

7-11 veces al año

1 vez al mes

2-3 veces al mes 
1 vez por semana

2 veces por semana

3-4 veces por semana

5-6 veces por semana

1 vez por día

2 o más veces al día

¿Cuál fue el tamaño de porción habitual de berenjena de su hijo?

Dash o pellizco (tamaño de un guisante)

$\square 1$ cucharadita (tamaño de un dado)

$\checkmark 1$ cucharada (tamaño de una ficha de póker)

$\square 1$ onza (volumen de un vasito para tragos)

1/4 de taza (tamaño de una pelota de golf)

$1 / 2$ de taza (tamaño de una pelota de tenis)

$3 / 4$ de taza (volumen en una taza de té)

1 taza (tamaño de una pelota de béisbol)

En los últimos 12 meses, ¿alguna vez originó de un casa o jardín local?

Sí

No

En los últimos 12 meses, ¿comió pimientos dulces su hijo?

Sí

No

¿Con qué frecuencia comió pimientos dulces su hijo? 
1-6 veces al año

7-11 veces al año

1 veces por mes

2-3 veces al mes

1 vez por semana

2 veces por semana

3-4 veces por semana

5-6 veces por semana

1 vez por día

2 o más veces al día

¿Cuál fue el tamaño de porción habitual de pimientos dulces de su hijo?

$\checkmark$ Dash o pellizco (tamaño de un guisante)

$\square 1$ cucharadita (tamaño de un dado)

$\square 1$ cucharada (tamaño de una ficha de póker)

1 onza (volumen de un vasito para tragos)

$1 / 4$ de taza (tamaño de una pelota de golf)

$1 / 2$ de taza (tamaño de una pelota de tenis)

3/4 de taza (volumen en una taza de té)

1 taza (tamaño de una pelota de béisbol)

En los últimos 12 meses, ¿alguna vez originó de un casa o jardín local?

Sí

No

\section{Apiaceae}


En los últimos 12 meses, ¿comió zanahorias su hijo?

Sí

No

¿Con qué frecuencia comió zanahorias su hijo?

1-6 veces al año

7-11 veces al año

1 vez por mes

2-3 veces al mes

1 vez por semana

2 veces por semana

3-4 veces por semana

5-6 veces por semana

1 vez por día

2 veces o más por día

¿Cuál fue el tamaño de porción habitual de zanahorias de su hijo?

Dash o pellizco (tamaño de un guisante)

1 cucharadita (tamaño de un dado)

$\checkmark 1$ cucharada (tamaño de una ficha de póker)

$\square 1$ onza (volumen de un vasito para tragos)

$1 / 4$ de taza (tamaño de una pelota de golf)

$\square 1 / 2$ de taza (tamaño de una pelota de tenis)

$\square$ 3/4 de taza (volumen en una taza de té)

1 taza (tamaño de una pelota de béisbol) 
En los últimos 12 meses, ¿alguna vez originó de un casa o jardín local?

Sí

No

En los últimos 12 meses, ¿comió apio su hijo?

Sí

No

¿Con qué frecuencia comió apio su hijo?

1-6 veces al año

7-11 veces al año

1 vez por mes

2-3 veces al mes

1 vez por semana

2 veces por semana

3-4 veces por semana

5-6 veces por semana

1 vez por día

2 o más veces al día

¿Cuál fue el tamaño de porción habitual de apio de su hijo?

Dash o pellizco (tamaño de un guisante)

$\square 1$ cucharadita (tamaño de un dado)

$\square 1$ cucharada (tamaño de una ficha de póker)

1 onza (volumen de un vasito para tragos) 
$1 / 4$ de taza (tamaño de una pelota de golf)

$1 / 2$ de taza (tamaño de una pelota de tenis)

3/4 de taza (volumen en una taza de té)

1 taza (tamaño de una pelota de béisbol)

En los últimos 12 meses, ¿alguna vez originó de un casa o jardín local?

Sí

No

En los últimos 12 meses, ¿comió cilantro fresco su hijo?

Sí

No

¿Con qué frecuencia comió cilantro fresco su hijo?

1-6 veces al año

7-11 veces al año

1 vez por mes

2-3 veces al mes

1 vez por semana

2 veces por semana

3-4 veces por semana

5-6 veces por semana

1 vez por día

2 veces o más por día

¿Cuál fue el tamaño de porción habitual de cilantro fresco de su hijo? 
3 leafs with stems ( 3 hojas con tallo)

6 leafs with stems ( 6 hojas con tallo)

9 leafs with stems (9 hojas con tallo)

12 leafs with stems ( 12 hojas con tallo)

15 leafs with stems ( 15 hojas con tallo)

En los últimos 12 meses, ¿alguna vez originó de un casa o jardín local?

Sí

No

Fabaceae

En los últimos 12 meses, ¿comió frijoles rojos su hijo?

Sí

No

¿Con qué frecuencia comió frijoles rojos su hijo?

1-6 veces al año

7-11 veces al año

1 vez por mes

2-3 veces al mes

1 vez por semana

2 veces por semana

3-4 veces por semana

5-6 veces por semana 
2 o más veces al día

¿Cuál fue el tamaño de porción habitual de frijoles rojos de su hijo?

Dash o pellizco (tamaño de un guisante)

1 cucharadita (tamaño de un dado)

$\square 1$ cucharada (tamaño de una ficha de póker)

$\square$ onza (volumen de un vasito para tragos)

$1 / 4$ de taza (tamaño de una pelota de golf)

$\square 1 / 2$ de taza (tamaño de una pelota de tenis)

3/4 de taza (volumen en una taza de té)

1 taza (tamaño de una pelota de béisbol)

En los últimos 12 meses, ¿alguna vez originó de un casa o jardín local?

Sí

No

En los últimos 12 meses, ¿comió ejotes verdes su hijo?

Sí

No

¿Con qué frecuencia comió ejotes verdes su hijo?

1-6 veces al año

7-11 veces al año

1 vez por mes

2-3 veces al mes 
1 vez por semana

2 veces por semana

3-4 veces por semana

5-6 veces por semana

1 vez por día

2 o más veces al día

¿Cuál fue el tamaño de porción habitual de ejotes verdes de su hijo?

Dash o pellizco (tamaño de un guisante)

$\square 1$ cucharadita (tamaño de un dado)

$\checkmark 1$ cucharada (tamaño de una ficha de póker)

1 onza (volumen de un vasito para tragos)

1/4 de taza (tamaño de una pelota de golf)

$1 / 2$ de taza (tamaño de una pelota de tenis)

$3 / 4$ de taza (volumen en una taza de té)

1 taza (tamaño de una pelota de béisbol)

En los últimos 12 meses, ¿alguna vez originó de un casa o jardín local?

Sí

No

En los últimos 12 meses, ¿comió habichuelas su hijo?

Sí

No

¿Con qué frecuencia comió habichuelas su hijo? 
1-6 veces al año

7-11 veces al año

1 vez por mes

2-3 veces al mes

1 vez por semana

2 veces por semana

3-4 veces por semana

5-6 veces por semana

1 vez por día

2 o más veces al día

¿Cuál fue el tamaño de porción habitual de habichuelas de su hijo?

$\checkmark$ Dash o pellizco (tamaño de un guisante)

$\square 1$ cucharadita (tamaño de un dado)

$\square 1$ cucharada (tamaño de una ficha de póker)

1 onza (volumen de un vasito para tragos)

1/4 de taza (tamaño de una pelota de golf)

$1 / 2$ de taza (tamaño de una pelota de tenis)

3/4 de taza (volumen en una taza de té)

1 taza (tamaño de una pelota de béisbol)

En los últimos 12 meses, ¿alguna vez originó de un casa o jardín local?

Sí

No

En los últimos 12 meses, ¿comió chícharos su hijo? 
No

¿Con qué frecuencia comió chícharos su hijo?

1-6 veces al año

7-11 veces al año

1 vez por mes

2-3 veces al mes

1 vez por semana

2 veces por semana

3-4 veces por semana

5-6 veces por semana

1 vez por día

2 o más veces al día

¿Cuál fue el tamaño de porción habitual de chícharos de su hijo?

Dash o pellizco (tamaño de un guisante)

1 cucharadita (tamaño de un dado)

1 cucharada (tamaño de una ficha de póker)

1 onza (volumen de un vasito para tragos)

$1 / 4$ de taza (tamaño de una pelota de golf)

$1 / 2$ de taza (tamaño de una pelota de tenis)

$\square$ 3/4 de taza (volumen en una taza de té)

- 1 taza (tamaño de una pelota de béisbol)

En los últimos 12 meses, ¿alguna vez originó de un casa o jardín local? 
No

En los últimos 12 meses, ¿comió habas su hijo?

Sí

No

¿Con qué frecuencia comió habas su hijo?

1-6 veces al año

7-11 veces al año

1 vez por mes

2-3 veces al mes

1 vez por semana

2 veces por semana

3-4 veces por semana

5-6 veces por semana

1 vez por día

2 o más veces al día

¿Cuál fue el tamaño de porción habitual de habas de su hijo?

Dash o pellizco (tamaño de un guisante)

1 cucharadita (tamaño de un dado)

1 cucharada (tamaño de una ficha de póker)

1 onza (volumen de un vasito para tragos)

$1 / 4$ de taza (tamaño de una pelota de golf)

$1 / 2$ de taza (tamaño de una pelota de tenis) 
1 taza (tamaño de una pelota de béisbol)

En los últimos 12 meses, ¿alguna vez originó de un casa o jardín local?

Sí

No

En los últimos 12 meses, ¿comió lentejas su hijo?

Sí

No

¿Con qué frecuencia comió lentejas su hijo?

1-6 veces al año

7-11 veces al año

1 vez por mes

2-3 veces al mes

1 vez por semana

2 veces por semana

3-4 veces por semana

5-6 veces por semana

1 vez por día

2 o más veces al día

¿Cuál fue el tamaño de porción habitual de lentejas de su hijo?

Dash o pellizco (tamaño de un guisante)

$\square 1$ cucharadita (tamaño de un dado) 
1 cucharada (tamaño de una ficha de póker)

1 onza (volumen de un vasito para tragos)

$1 / 4$ de taza (tamaño de una pelota de golf)

$1 / 2$ de taza (tamaño de una pelota de tenis)

$3 / 4$ de taza (volumen en una taza de té)

$\checkmark 1$ taza (tamaño de una pelota de béisbol)

En los últimos 12 meses, ¿alguna vez originó de un casa o jardín local?

Sí

No

En los últimos 12 meses, ¿comió frijoles de soya su hijo?

Sí

No

¿Con qué frecuencia comió frijoles de soya su hijo?

1-6 veces al año

7-11 veces al año

1 vez por mes

2-3 veces al mes

1 vez por semana

2 veces por semana

3-4 veces por semana

5-6 veces por semana

1 vez por día

2 o más veces al día 
¿Cuál fue el tamaño de porción habitual de frijoles de soya de su hijo?

Dash o pellizco (tamaño de un guisante)

1 cucharadita (tamaño de un dado)

1 cucharada (tamaño de una ficha de póker)

$\square 1$ onza (volumen de un vasito para tragos)

$1 / 4$ de taza (tamaño de una pelota de golf)

$1 / 2$ de taza (tamaño de una pelota de tenis)

$\square 3 / 4$ de taza (volumen en una taza de té)

1 taza (tamaño de una pelota de béisbol)

En los últimos 12 meses, ¿alguna vez originó de un casa o jardín local?

Sí

No

\section{Lamiaceae}

En los últimos 12 meses, ¿comió albahaca fresca su hijo?

Sí

No

¿Con qué frecuencia comió albahaca fresca su hijo?

1-6 veces al año

7-11 veces al año

1 vez por mes

2-3 veces al mes

1 vez por semana 
3-4 veces por semana

5-6 veces por semana

1 veces por día

2 o más veces al día

¿Cuál fue el tamaño de porción habitual de albahaca fresca de su hijo?

\section{1 leaf (1hoja)}

\section{2 leaves ( 2 hojas)}

\section{3 leaves ( 3 hojas)}

\section{4 leaves ( 4 hojas)}

\section{5 leaves (5 hojas)}

En los últimos 12 meses, ¿alguna vez originó de un casa o jardín local?
Sí
No

En los últimos 12 meses, ¿comió menta fresca su hijo?

Sí

No 
¿Con qué frecuencia comió menta fresca su hijo?
1-6 veces al año
7-11 veces al año
1 vez por mes
2-3 veces al mes
1 vez por semana
2 veces por semana
3-4 veces por semana
5-6 veces por semana
1 vez por día
2 veces o más por día

¿Cuál era la porción habitual de menta de su hijo?

\section{1 leaf (1hoja)}

\section{2 leaves ( 2 hojas)}

\section{3 leaves ( 3 hojas)}

\section{4 leaves ( 4 hojas)}

5 leaves ( 5 hojas)

En los últimos 12 meses, ¿alguna vez originó de un casa o jardín local?

Sí

No 
En los últimos 12 meses, ¿comió okra su hijo?

Sí

No

¿Con qué frecuencia comió okra su hijo?

1-6 veces al año

7-11 veces al año

1 vez por mes

2-3 veces al mes

1 vez por semana

2-3 veces por semana

3-4 veces por semana

5-6 veces por semana

1 vez por día

2 o más veces al día

¿Cuál fue el tamaño de porción habitual de okra de su hijo?

$\square$ Dash o pellizco (tamaño de un guisante)

$\square 1$ cucharadita (tamaño de un dado)

$\square 1$ cucharada (tamaño de una ficha de póker)

$\square 1$ onza (volumen de un vasito para tragos)

1/4 de taza (tamaño de una pelota de golf)

$\square 1 / 2$ de taza (tamaño de una pelota de tenis)

$\square$ 3/4 de taza (volumen en una taza de té)

$\square 1$ taza (tamaño de una pelota de béisbol) 
En los últimos 12 meses, ¿alguna vez originó de un casa o jardín local?

Sí

No

\section{Rosaceae}

En los últimos 12 meses, ¿comió manzanas su hijo?
Sí
No

¿Con qué frecuencia comió manzanas su hijo?
1-6 veces al año
7-11 veces al año
1 vez por mes
2-3 veces al mes
1 vez por semana
2 veces por semana
3-4 veces por semana
5-6 veces por semana
1 vez por día
2 o más veces al día

¿Cuál fue el tamaño de porción habitual de manzanas de su hijo?
Dash o pellizco (tamaño de un guisante)
1 cucharadita (tamaño de un dado)
$\checkmark 1$ cucharada (tamaño de una ficha de póker)
$\square 1$ onza (volumen de un vasito para tragos) 
$1 / 4$ de taza (tamaño de una pelota de golf)

1 $1 / 2$ de taza (tamaño de una pelota de tenis)

$\square$ 3/4 de taza (volumen en una taza de té)

1 taza (tamaño de una pelota de béisbol)

En los últimos 12 meses, ¿alguna vez originó de casa o lugar local?

Sí

No

En los últimos 12 meses, ¿comió fresas su hijo?

Sí

No

¿Con qué frecuencia comió fresas su hijo?

1-6 veces al año

7-11 veces al año

1 vez por mes

2-3 veces al mes

1 vez por semana

2 veces por semana

3-4 veces por semana

5-6 veces por semana

1 vez por día

2 o más veces al día

¿Cuál fue el tamaño de porción habitual de fresas de su hijo? 
Dash o pellizco (tamaño de un guisante)

1 cucharadita (tamaño de un dado)

$\square 1$ cucharada (tamaño de una ficha de póker)

$\square 1$ onza (volumen de un vasito para tragos)

$1 / 4$ de taza (tamaño de una pelota de golf)

$1 / 2$ de taza (tamaño de una pelota de tenis)

$3 / 4$ de taza (volumen en una taza de té)

1 taza (tamaño de una pelota de béisbol)

En los últimos 12 meses, ¿alguna vez originó de un casa o jardín local?

Sí

No

\section{Convolvulaceae}

En los últimos 12 meses, ¿comió batatas su hijo?

Sí

No

¿Con qué frecuencia comió batatas su hijo?

1-6 veces al año

6-7 veces al año

1 vez por mes

2-3 veces al mes

1 vez por semana

2 veces por semana

3-4 veces por semana 
5-6 veces por semana

1 vez por día

2 o más veces al día

¿Cuál fue el tamaño de porción habitual de batatas de su hijo?

Dash o pellizco (tamaño de un guisante)

1 cucharadita (tamaño de un dado)

$\square 1$ cucharada (tamaño de una ficha de póker)

1 onza (volumen de un vasito para tragos)

$1 / 4$ de taza (tamaño de una pelota de golf)

$1 / 2$ de taza (tamaño de una pelota de tenis)

3/4 de taza (volumen en una taza de té)

1 taza (tamaño de una pelota de béisbol)

En los últimos 12 meses, ¿alguna vez originó de un casa o jardín local?

Sí

No

\section{Poaceae}

En los últimos 12 meses, ¿comió maíz su hijo?

Sí

No

¿Con qué frecuencia comió maíz su hijo?

1-6 veces al año 
7-11 veces al año

1 vez por mes

2-3 veces al mes

1 vez por semana

2 veces por semana

3-4 veces por semana

5-6 veces por semana

1 vez por día

2 o más veces al día

¿Cuál fue el tamaño de porción habitual de maíz de su hijo?

Dash o pellizco (tamaño de un guisante)

1 cucharadita (tamaño de un dado)

$\checkmark 1$ cucharada (tamaño de una ficha de póker)

$\square 1$ onza (volumen de un vasito para tragos)

$1 / 4$ de taza (tamaño de una pelota de golf)

$\square 1 / 2$ de taza (tamaño de una pelota de tenis)

$\square$ 3/4 de taza (volumen en una taza de té)

1 taza (tamaño de una pelota de béisbol)

En los últimos 12 meses, ¿alguna vez originó de casa o lugar local?

Sí

No

En los últimos 12 meses, ¿comió arroz su hijo? 
¿Con qué frecuencia comió arroz su hijo?

1-6 veces al año

7-11 veces al año

1 vez por mes

2-3 veces al mes

1 vez por semana

2 veces por semana

3-4 veces por semana

5-6 veces por semana

1 vez por año

2 o más veces al año

¿Cuál fue el tamaño de porción habitual de arroz de su hijo?

Dash o pellizco (tamaño de un guisante)

1 cucharadita (tamaño de un dado)

$\square 1$ cucharada (tamaño de una ficha de póker)

$\checkmark 1$ onza (volumen de un vasito para tragos)

$\square$ 1/4 de taza (tamaño de una pelota de golf)

$1 / 2$ de taza (tamaño de una pelota de tenis)

3/4 de taza (volumen en una taza de té)

1 taza (tamaño de una pelota de béisbol)

En los últimos 12 meses, ¿alguna vez originó de casa o lugar local? 
En los últimos 12 meses, ¿comió su hijo productos de arroz (por ejemplo: cereal de arroz)?

Sí

No

Describe los productos de arroz que su hijo consumió.

¿Con qué frecuencia comió productos de arroz su hijo?

1-6 veces al año

7-11 veces al año

1 vez por mes

2-3 veces al mes

1 vez por semana

2 veces por semana

3-4 veces por semana

5-6 veces por semana

1 vez por día

2 o más veces al día

¿Cuál fue el tamaño de porción habitual de productos de arroz de su hijo?

$\checkmark$ Dash o pellizco (tamaño de un guisante)

$\checkmark 1$ cucharadita (tamaño de un dado) 
1 cucharada (tamaño de una ficha de póker)

1 onza (volumen de un vasito para tragos)

1/4 de taza (tamaño de una pelota de golf)

$1 / 2$ de taza (tamaño de una pelota de tenis)

$\square$ 3/4 de taza (volumen en una taza de té)

$\checkmark 1$ taza (tamaño de una pelota de béisbol)

En los últimos 12 meses, ¿alguna vez originó de casa o lugar local?

Sí

No

En los últimos 12 meses, ¿comió su hijo productos sin gluten que contienen lo siguiente:

Quinoa

Arroz integral

Arroz salvaje

Alforfón

Sorgo

Tapioca

Mijo

Amaranto

Teff

Arrurruz

$\square$ No

¿Cuál fue el tamaño de porción habitual de productos sin gluten de su hijo? 
Dash o pellizco (tamaño de un guisante)

1 cucharadita (tamaño de un dado)

1 cucharada (tamaño de una ficha de póker)

1 onza (volumen de un vasito para tragos)

$1 / 4$ de taza (tamaño de una pelota de golf)

$1 / 2$ de taza (tamaño de una pelota de tenis)

$\square$ 3/4 de taza (volumen en una taza de té)

$\checkmark 1$ taza (tamaño de una pelota de béisbol)

En los últimos 12 meses, ¿alguna vez originó de casa o lugar local?

Sí

No

En los últimos 12 meses, ¿comió trigo integral su hijo?

Sí

No

¿Con qué frecuencia comió trigo integral su hijo?

1-6 veces al año

7-11 veces al año

1 vez por mes

2-3 veces al mes

1 vez por semana

2 veces por semana

3-4 veces por semana

5-6 veces por semana 
1 vez por día

2 o más veces al día

¿Cuál fue el tamaño de porción habitual de trigo integral de su hijo?

Dash o pellizco (tamaño de un guisante)

1 cucharadita (tamaño de un dado)

$\square 1$ cucharada (tamaño de una ficha de póker)

$\square 1$ onza (volumen de un vasito para tragos)

$1 / 4$ de taza (tamaño de una pelota de golf)

$1 / 2$ de taza (tamaño de una pelota de tenis)

3/4 de taza (volumen en una taza de té)

1 taza (tamaño de una pelota de béisbol)

En los últimos 12 meses, ¿alguna vez originó de casa o lugar local?

Sí

No

En los últimos 12 meses, ¿comió avena su hijo?

Sí

No

¿Con qué frecuencia comió avena su hijo?

1-6 veces al año

7-11 veces al año

1 vez por mes

2-3 veces al mes 
1 vez por semana

2 veces por semana

3-4 veces por semana

5-6 veces por semana

1 vez por día

2 o más veces al día

¿Cuál fue el tamaño de porción habitual de avena de su hijo?

Dash o pellizco (tamaño de un guisante)

$\square 1$ cucharadita (tamaño de un dado)

$\square 1$ cucharada (tamaño de una ficha de póker)

1 onza (volumen de un vasito para tragos)

$\square$ 1/4 de taza (tamaño de una pelota de golf)

$1 / 2$ de taza (tamaño de una pelota de tenis)

3/4 de taza (volumen en una taza de té)

1 taza (tamaño de una pelota de béisbol)

En los últimos 12 meses, ¿alguna vez originó de casa o lugar local?

Sí

No

\section{Selfish and seafood}

En los últimos 12 meses, ¿comió mariscos su hijo (vieiras, almejas, ostras, mejillones, cangrejo, langosta)?

S Sí

No 
¿Con qué frecuencia comió mariscos su hijo (vieiras, almejas, ostras, mejillones, cangrejo, langosta)?
1-6 veces por año
7-11 veces por año
1 vez por mes
2-3 veces por mes
1 vez por semana
2 veces por semana
3-4 veces por semana
5-6 veces por semana
1 vez al día
2 o más veces al día

¿Cuál fue el tamaño de porción habitual de mariscos de su hijo?

Dash o pellizco (tamaño de un guisante)

$\checkmark 1$ cucharadita (tamaño de un dado)

$\checkmark 1$ cucharada (tamaño de una ficha de póker)

1 onza (volumen de un vasito para tragos)

$1 / 4$ de taza (tamaño de una pelota de golf)

$1 / 2$ de taza (tamaño de una pelota de tenis)

3/4 de taza (volumen en una taza de té)

$\square 1$ taza (tamaño de una pelota de béisbol)

En los últimos 12 meses, ¿el origen fue capturada localmente?

Sí

No 
En los últimos 12 meses, ¿comió algas marinas su hijo?

Sí

No

¿Con qué frecuencia comió algas marinas su hijo?

1-6 veces por año

7-11 veces por año

1 vez por mes

2-3 veces por mes

1 vez por semana

2 veces por semana

3-4 veces por semana

5-6 veces por semana

1 vez al día

2 o más veces al día

¿Cuál fue el tamaño de porción habitual de algas marinas de su hijo?

Dash o pellizco (tamaño de un guisante)

1 cucharadita (tamaño de un dado)

1 cucharada (tamaño de una ficha de póker)

$\square 1$ onza (volumen de un vasito para tragos)

$\square 1 / 4$ de taza (tamaño de una pelota de golf)

$\square 1 / 2$ de taza (tamaño de una pelota de tenis)

$\square$ 3/4 de taza (volumen en una taza de té)

$\checkmark 1$ taza (tamaño de una pelota de béisbol) 
En los últimos 12 meses, ¿el origen fue capturada localmente?

Sí

No

\section{Baby food}

En los últimos 12 meses, ¿comió su hijo comida orgánica para bebés?

Sí

No

¿Con qué frecuencia comió comida orgánica para bebés?
1-6 veces al año
7-11 veces al año
1 vez por mes
2-3 veces al mes
1 vez por semana
2 veces por semana
3-4 veces por semana
5-6 veces por semana
1 vez al día
2 o más veces al día

¿Cuál era el tamaño de porción habitual de comida orgánica para bebés de su hijo?
$1 / 4$ taza $=2$ onzas
$1 / 2$ taza $=4$ onzas
$3 / 4$ taza $=6$ onzas 
1 taza $=8$ onzas

$11 / 4$ tazas $=10$ onzas

$11 / 2$ tazas $=12$ onzas

$13 / 4$ tazas $=14$ onzas

2 tazas $=16$ onzas

En los últimos 12 meses, ¿el origen de los ingredientes para la comida para bebés de su hijo fue de su casa o algún jardín local?

Sí

No

\section{Apple Juice}

En los últimos 12 meses, ¿tomó jugo de manzana su hijo?

Sí

No

¿Con qué frecuencia tomó jugo de manzana su hijo?

NUNCA

1 vez por mes o menos

2-3 veces por mes

1-2 veces por semana

3-4 veces por semana

5-6 veces por semana

1 vez por día

2-3 veces por día 
6 o más veces al día

¿Cuál era el tamaño de porción habitual de jugo de manzana de su hijo?

$1 / 4$ taza $=2$ onzas

$1 / 2$ taza $=4$ onzas

$3 / 4$ taza $=6$ onzas

1 taza $=8$ onzas

$11 / 4$ tazas $=10$ onzas

$11 / 2$ tazas $=12$ onzas

$13 / 4$ tazas $=14$ onzas

2 tazas $=16$ onzas

\section{Water}

En los últimos 12 meses, ¿con qué frecuencia bebió agua del grifo su hijo?

NUNCA

1 vez por mes o menos

2-3 veces al mes

1-2 veces por semana

3-4 veces por semana

5-6 veces por semana

1 vez por día

2-3 veces al día

4-5 veces al día

6 o más veces al día 
¿Cuál era el tamaño de porción habitual de agua del grifo de su hijo?
$1 / 4$ taza $=2$ onzas
$1 / 2$ taza $=4$ onzas
$3 / 4$ taza $=6$ onzas
1 taza $=8$ onzas
$11 / 4$ tazas $=10$ onzas
$11 / 2$ tazas $=12$ onzas
$13 / 4$ tazas $=14$ onzas
2 tazas $=16$ onzas

En los últimos 12 meses, cuando su hijo bebió agua del grifo, ¿cuál fue el origen principal?

$\square$ fuente de agua de la comunidad

$\square$ Un pozo o agua de lluvia

$\square$ Un rio

$\square$ No lo sé

$\square$ Otro

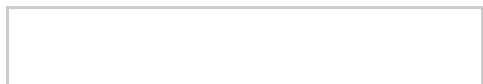

En los últimos 12 meses, ¿con qué frecuencia bebió agua embotellada su hijo?

NUNCA

1 vez por mes o menos

2-3 veces al mes

1-2 veces por semana

3-4 veces por semana

5-6 veces por semana

1 vez por día 
2-3 veces al día

4-5 veces al día

6 o más veces al día

\section{End of Survey Questions}

¿Qué fácil fue completar este cuestionario de frecuencia de alimentos?

ExtremadamenteModeradamente Un poco Ni fácil Un poco ModeradamenteExtremadamente facil fácil facil ni difícil dificil dificil difícil

¿Qué tan probable es que participes en futuras evaluaciones dietéticas?

$\mathrm{Ni}$

extremadamenteModeradamente Poco probable niLigeramenteModeradamenteExtremadamer probable probable probableimprobable improbable improbable improbable 
APPENDIX F

24-Hour Recall (English/Spanish) 

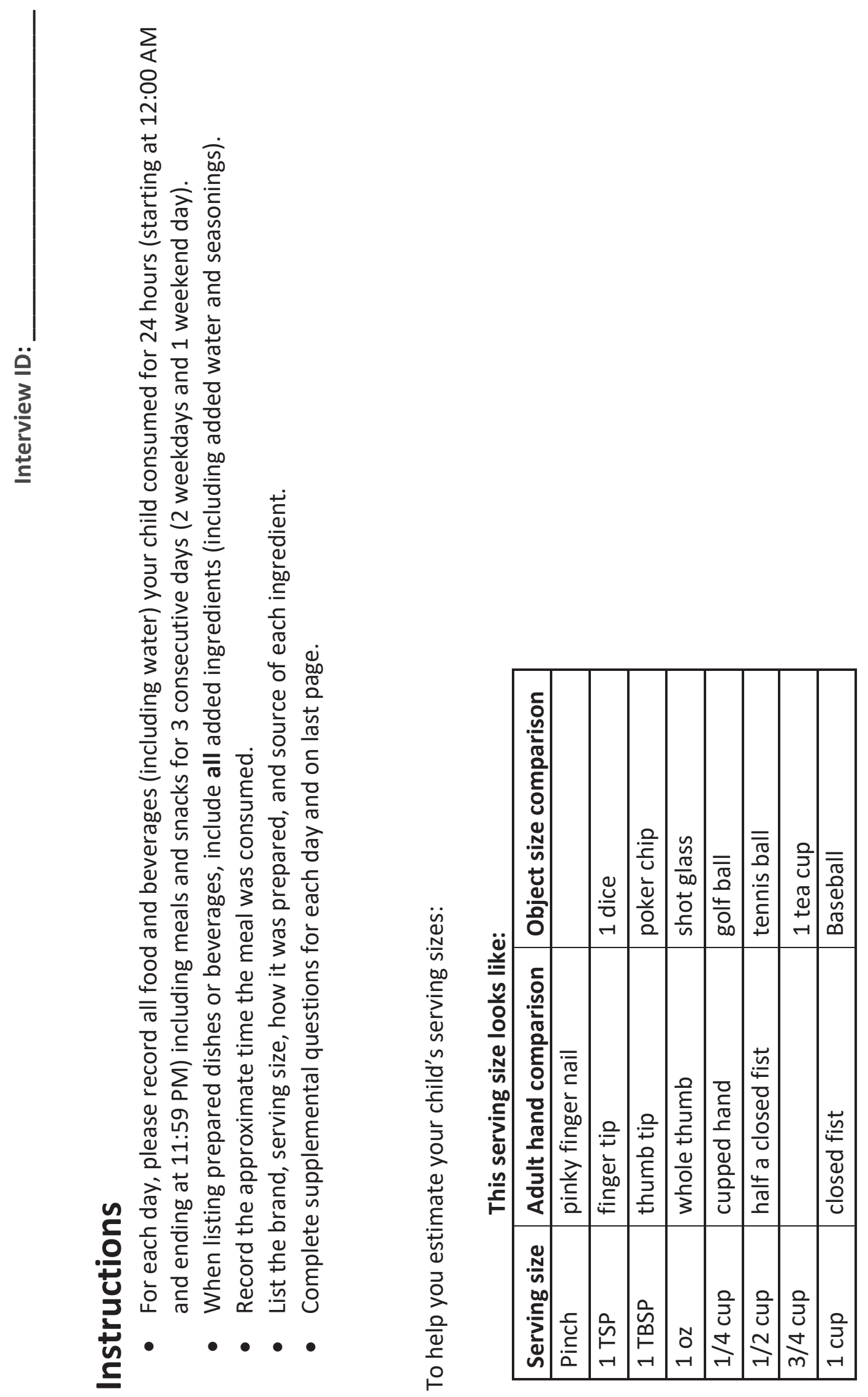


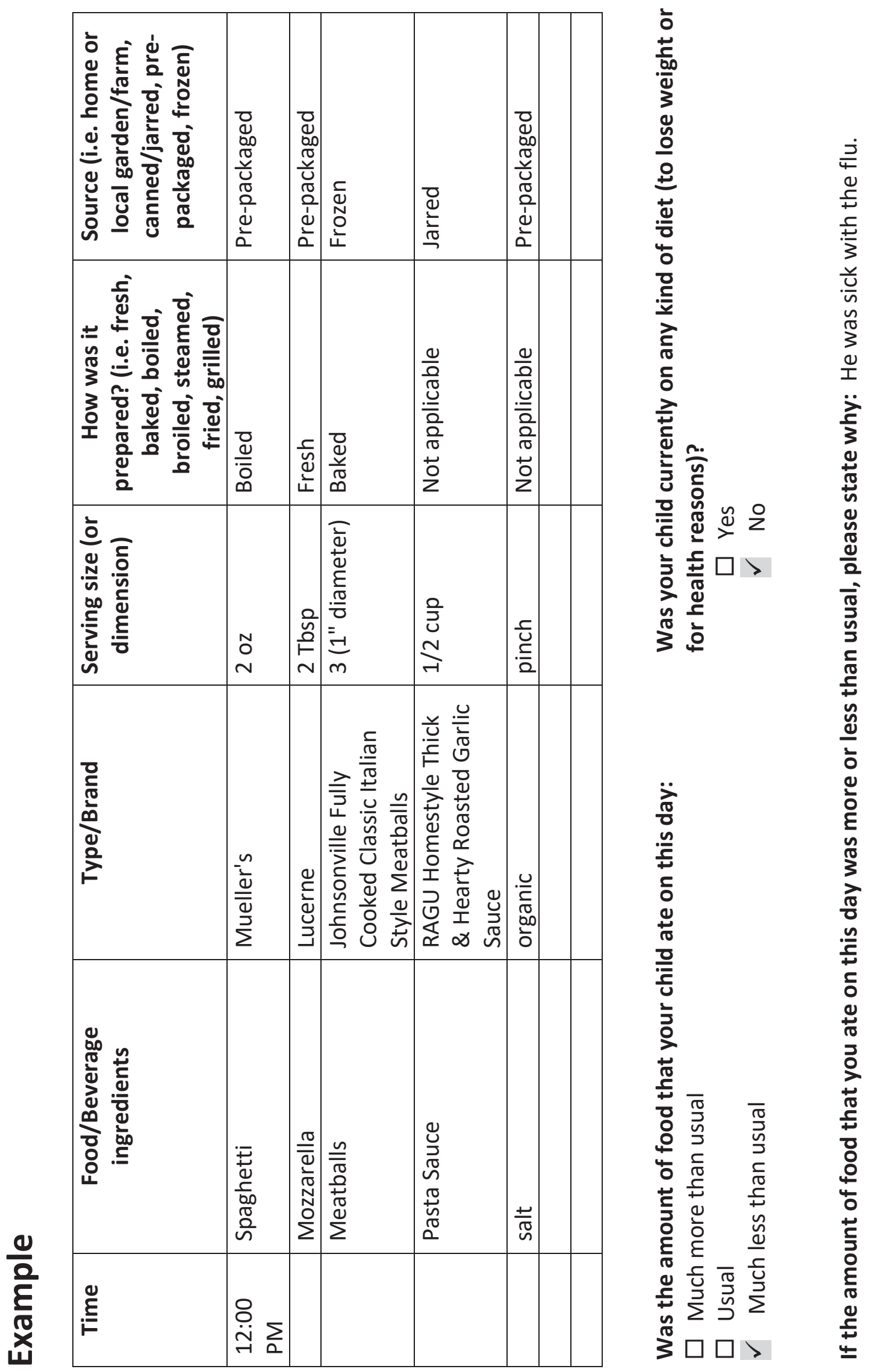




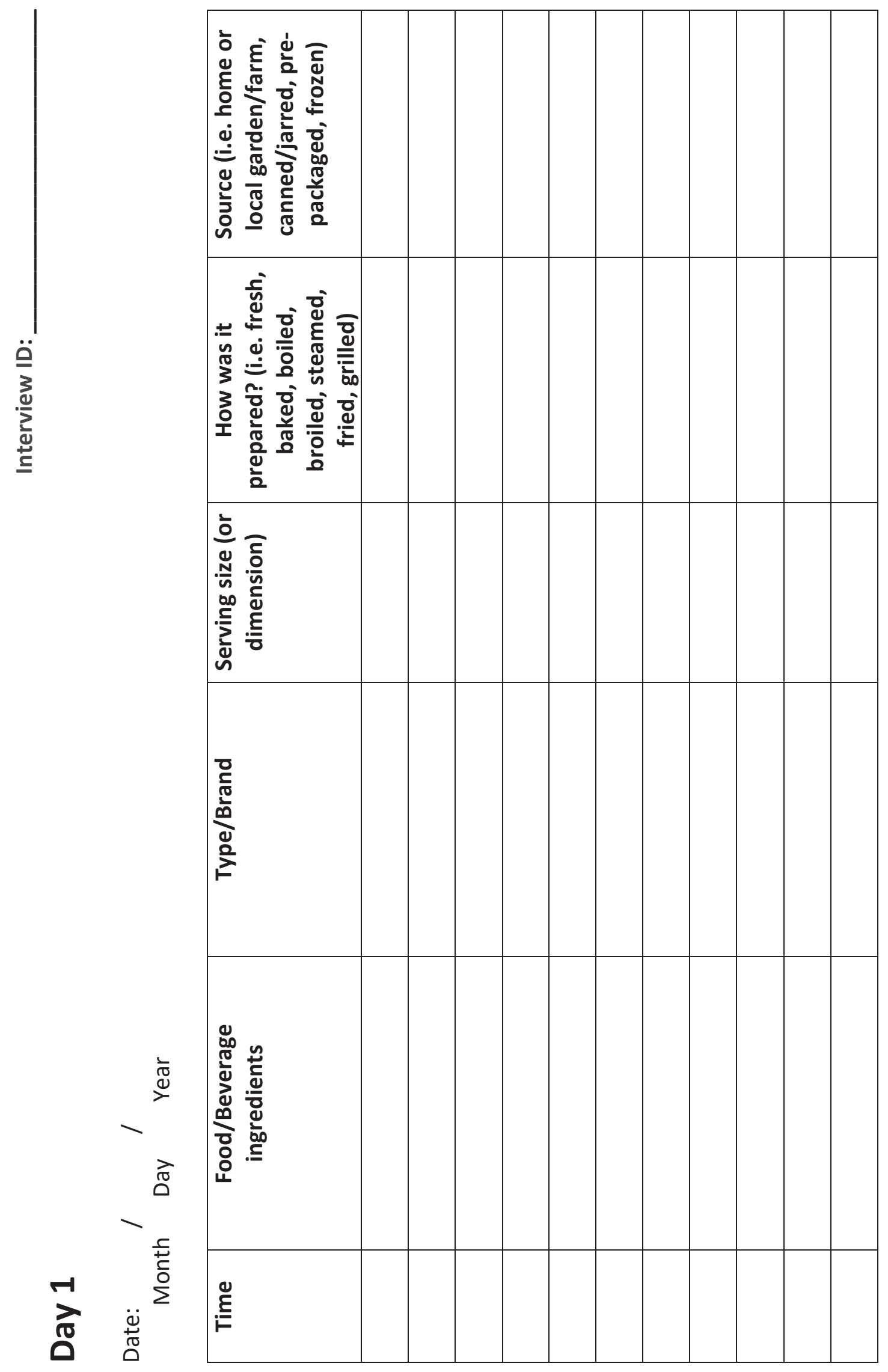



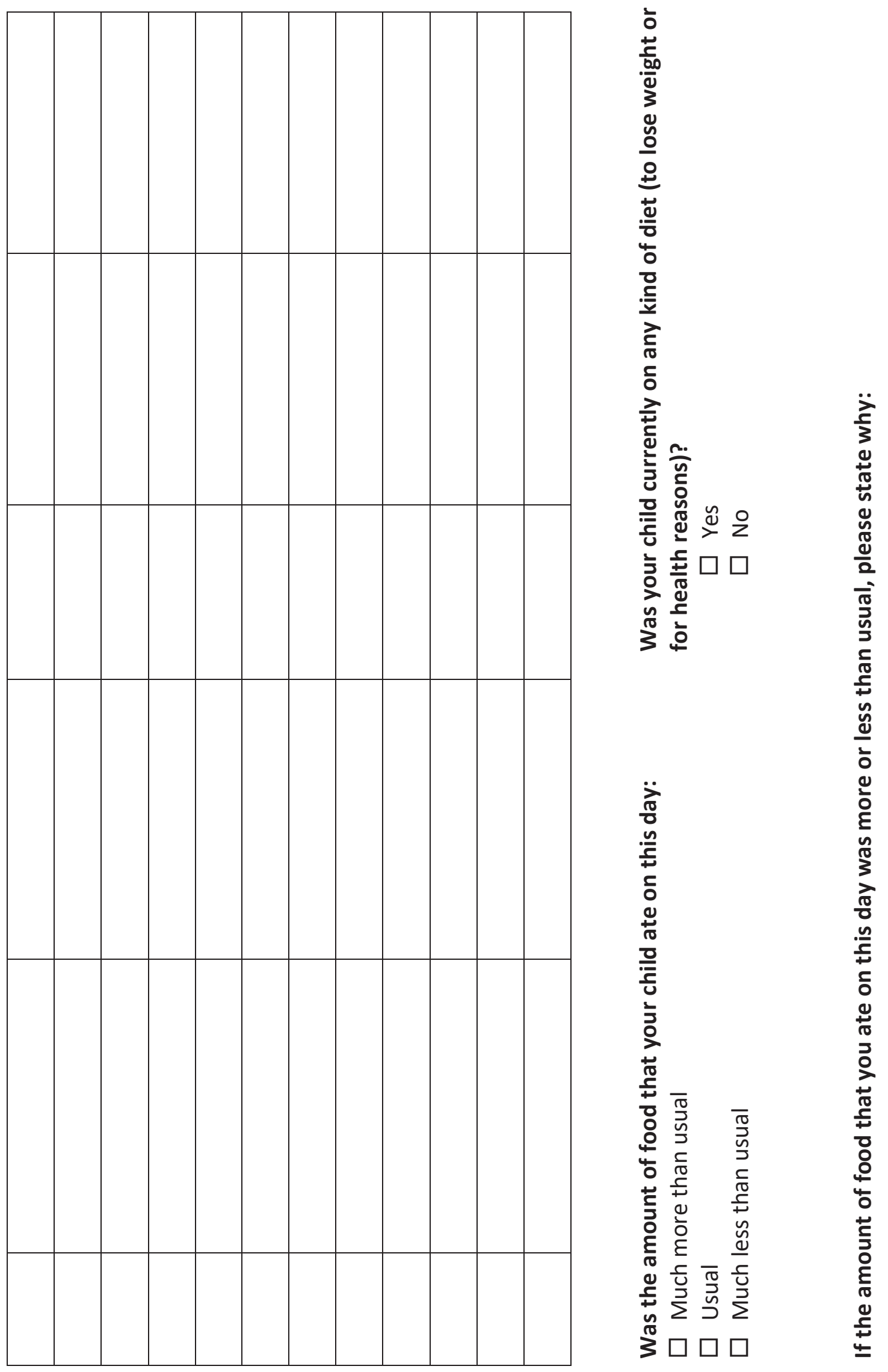


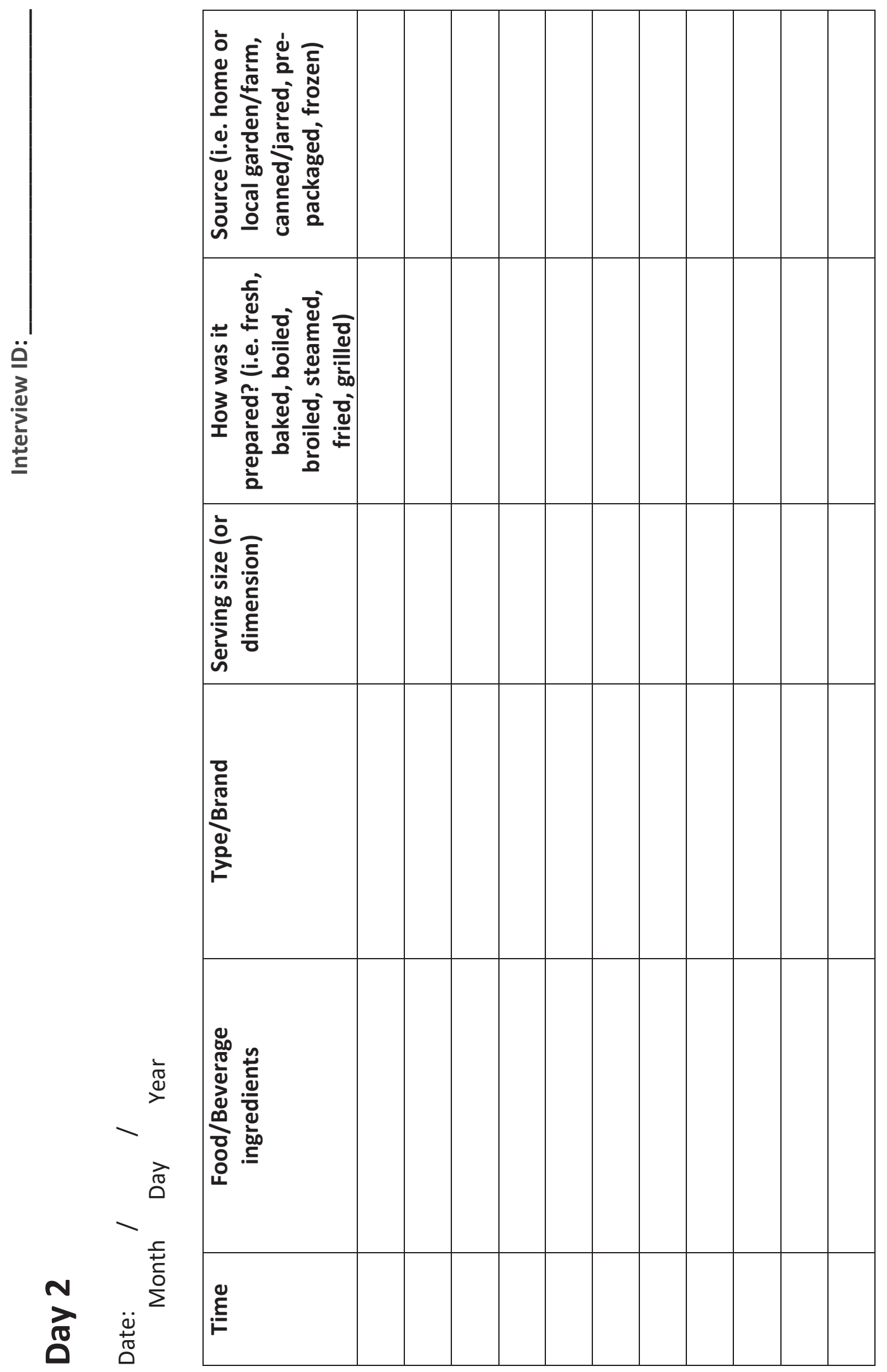



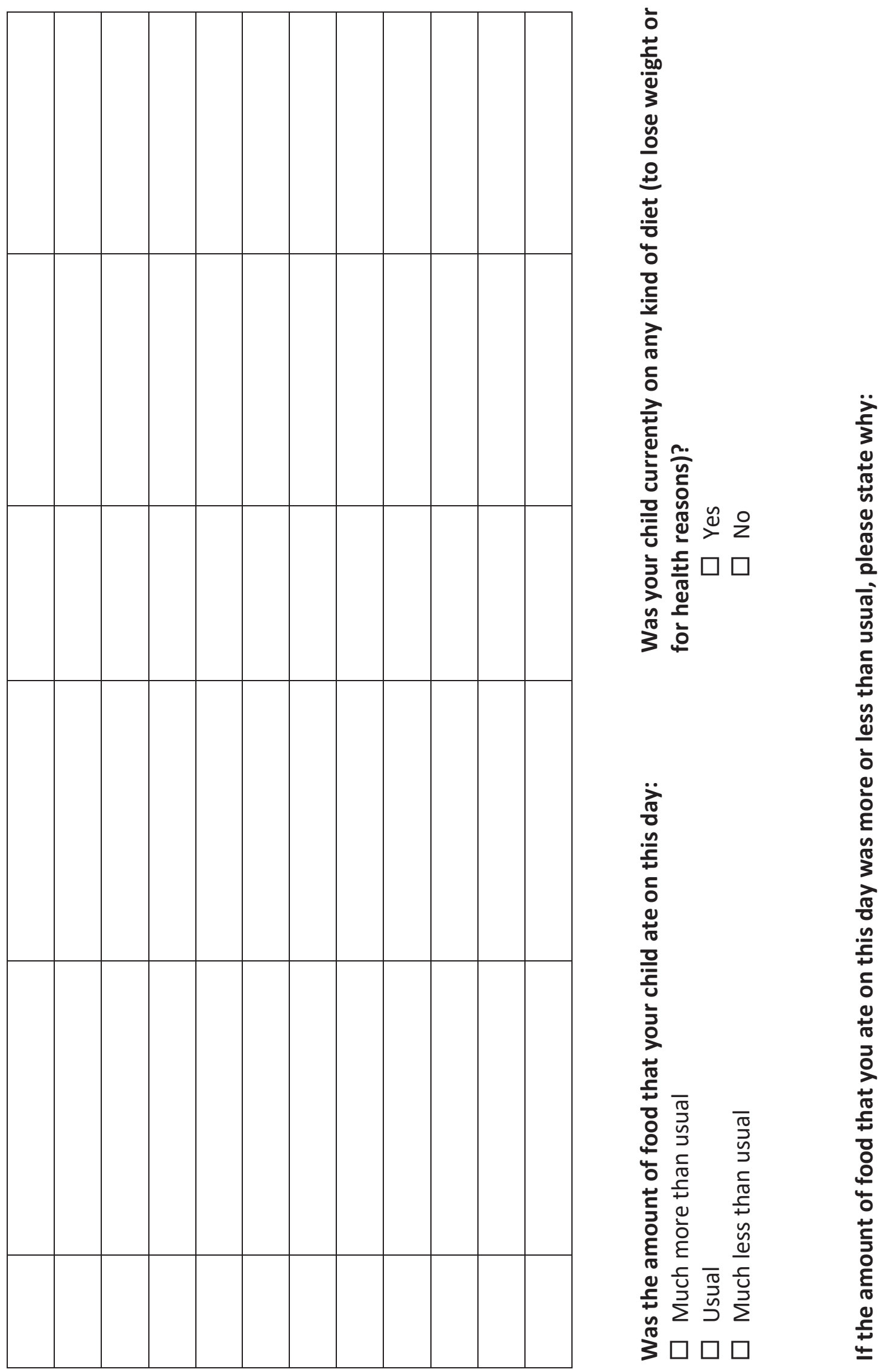


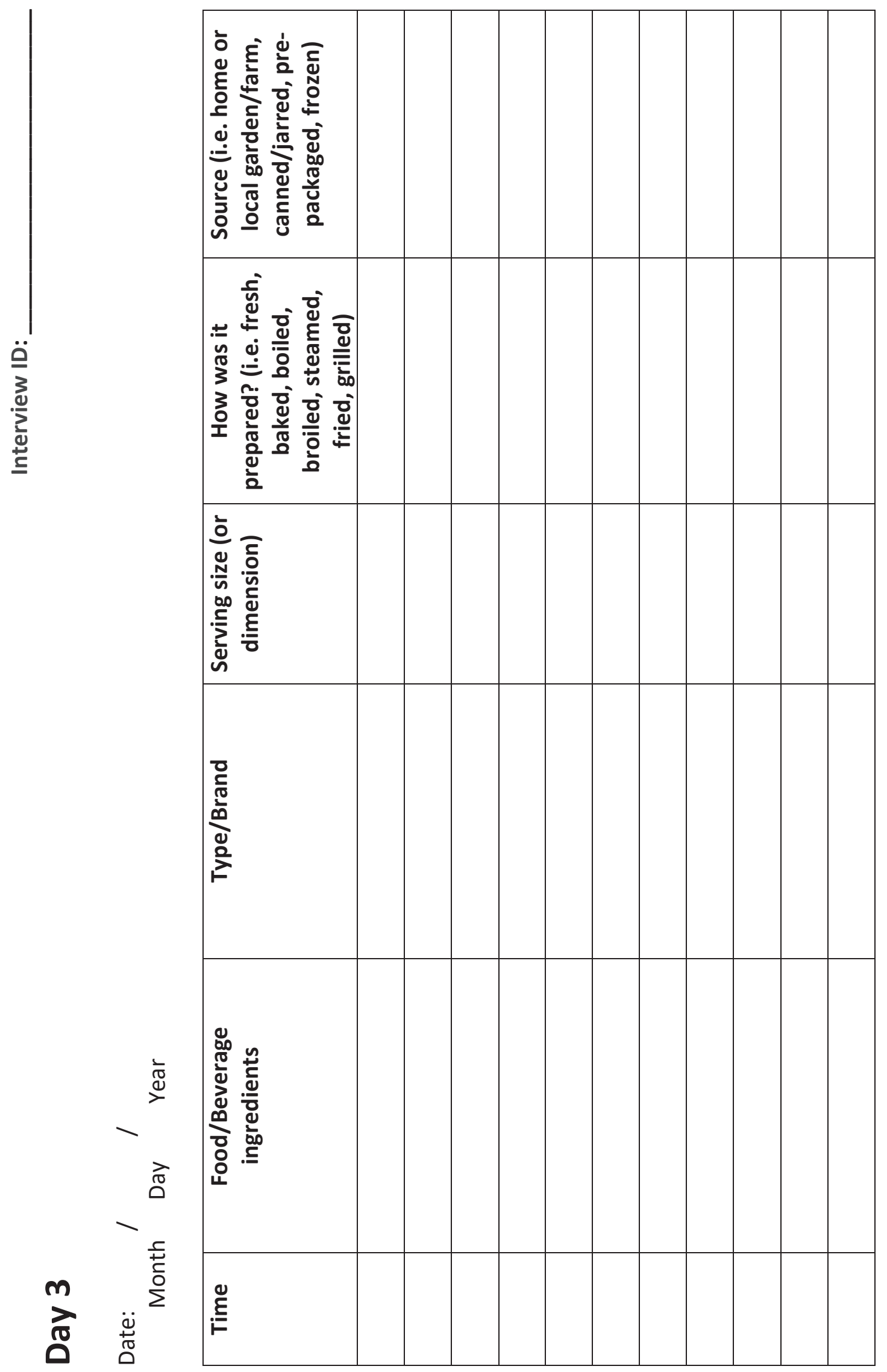



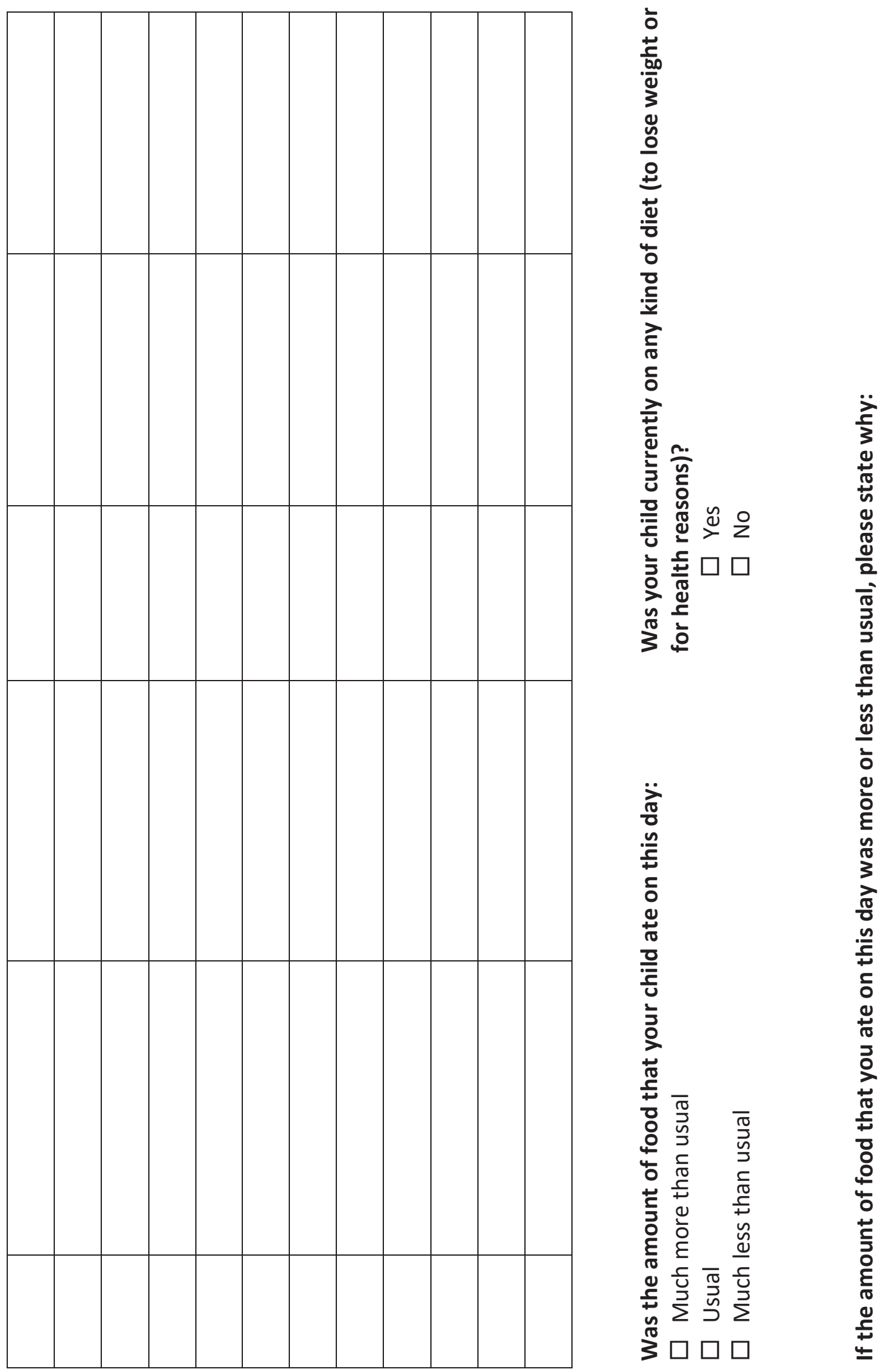


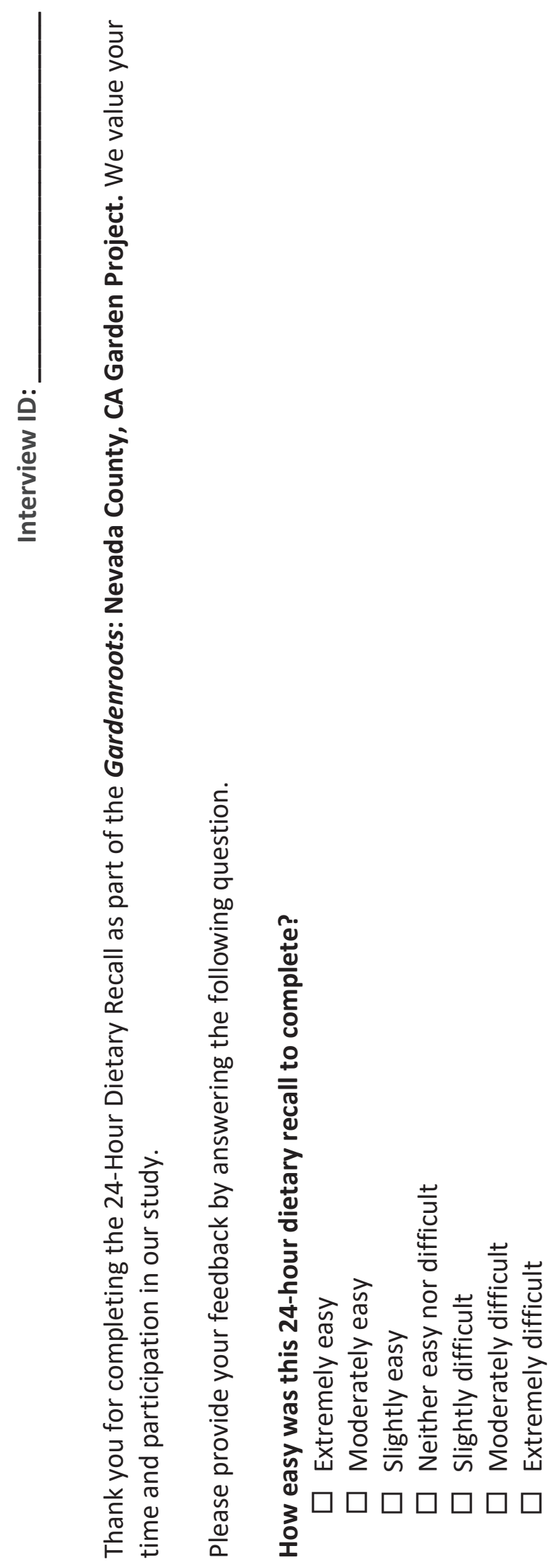




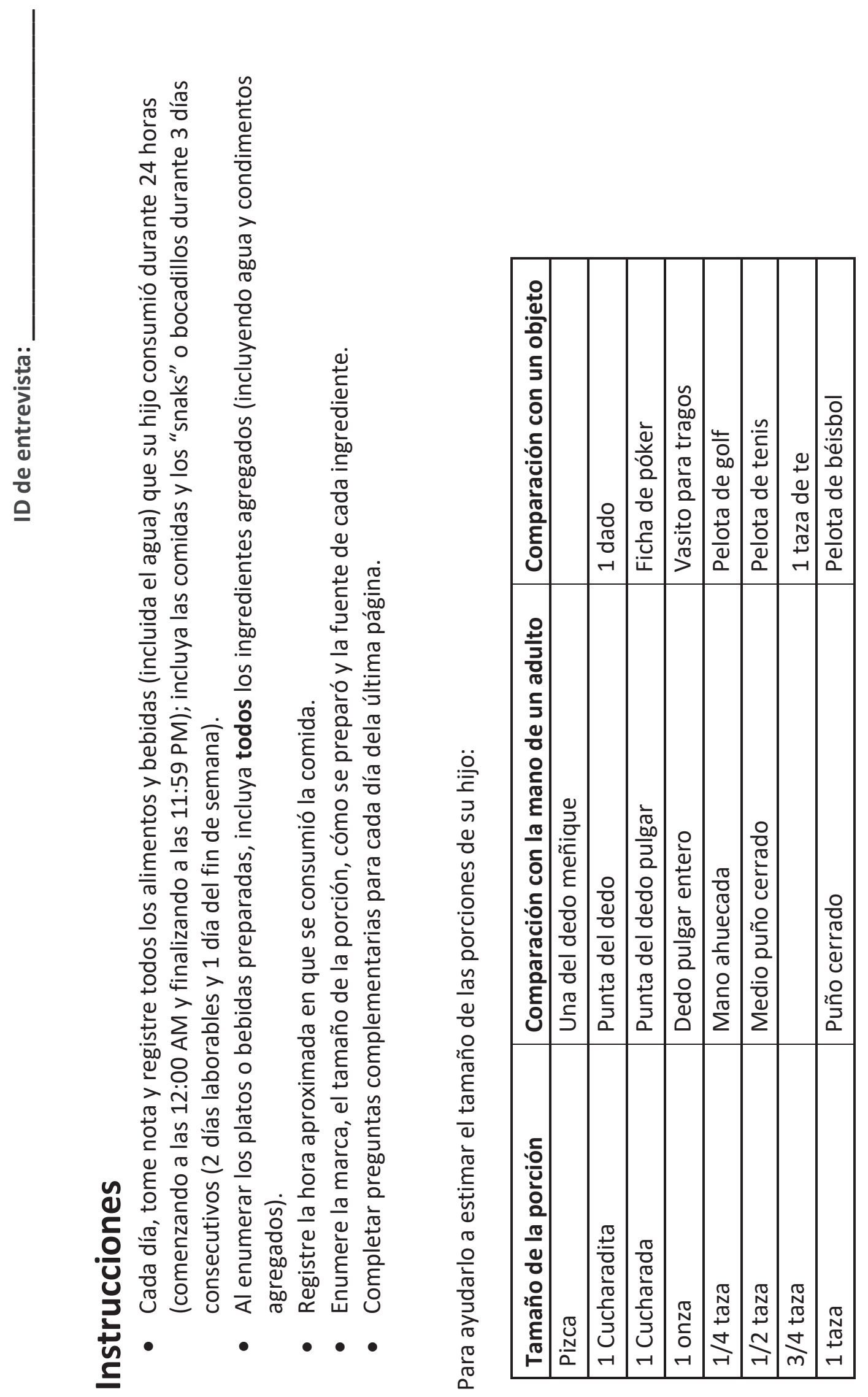



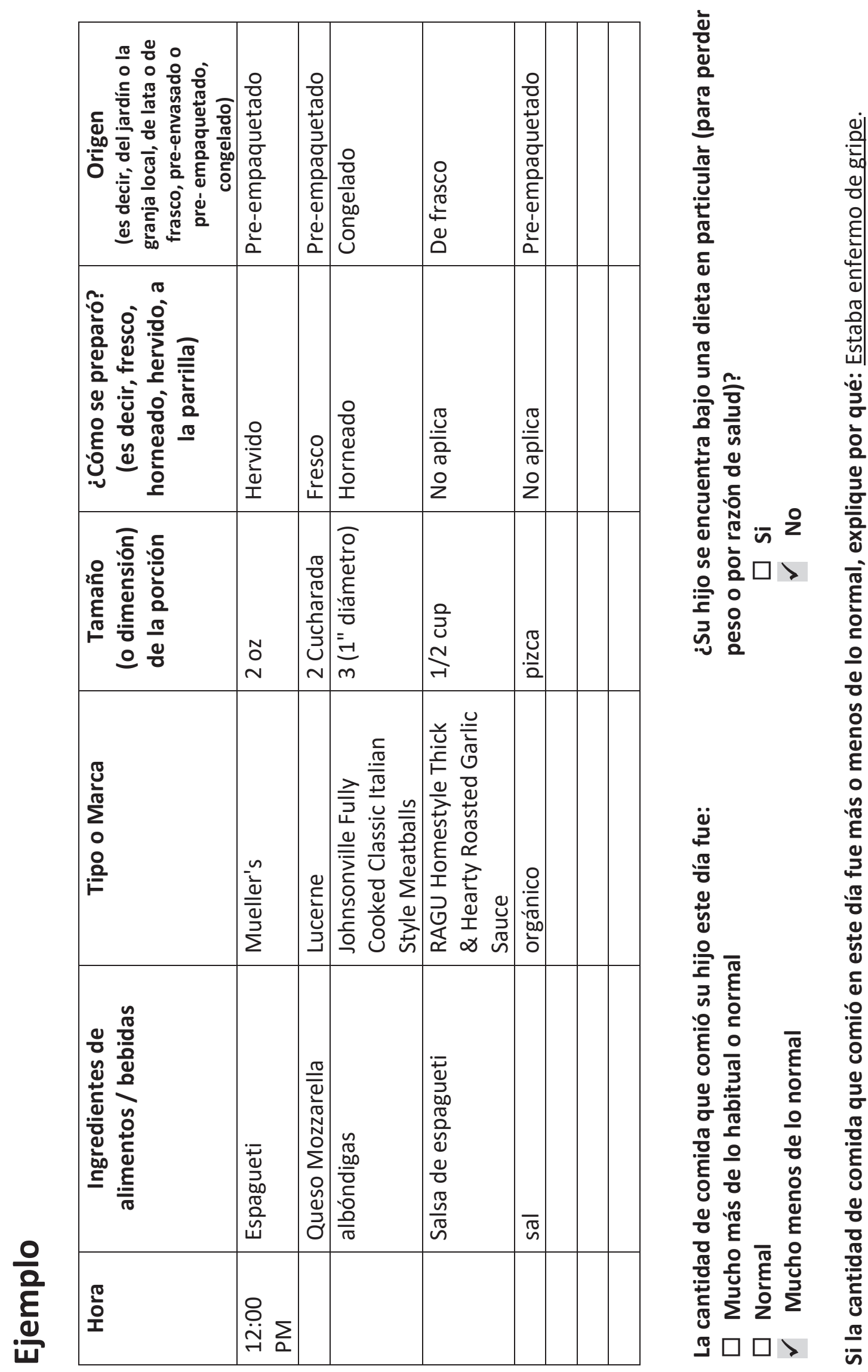

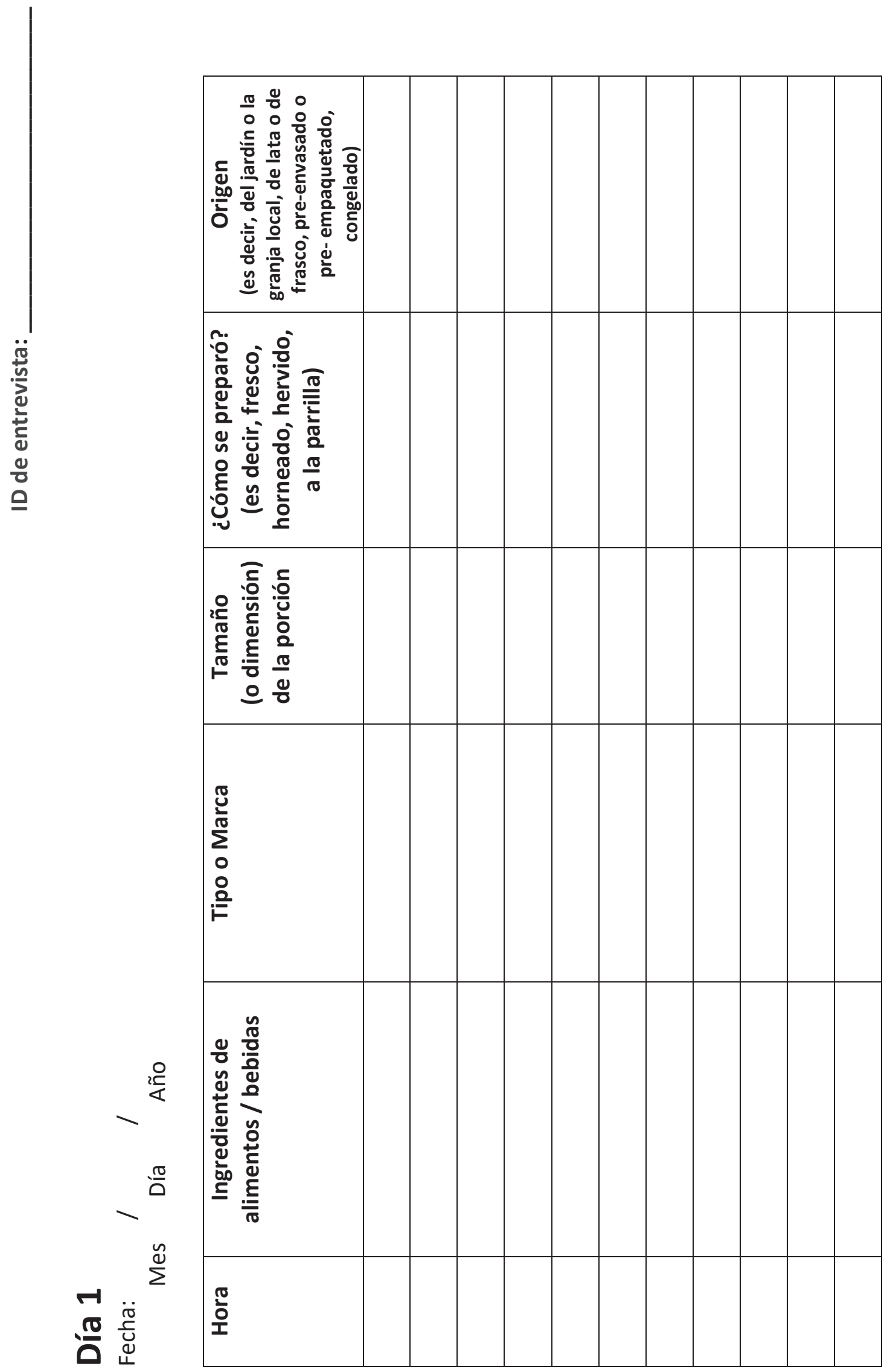


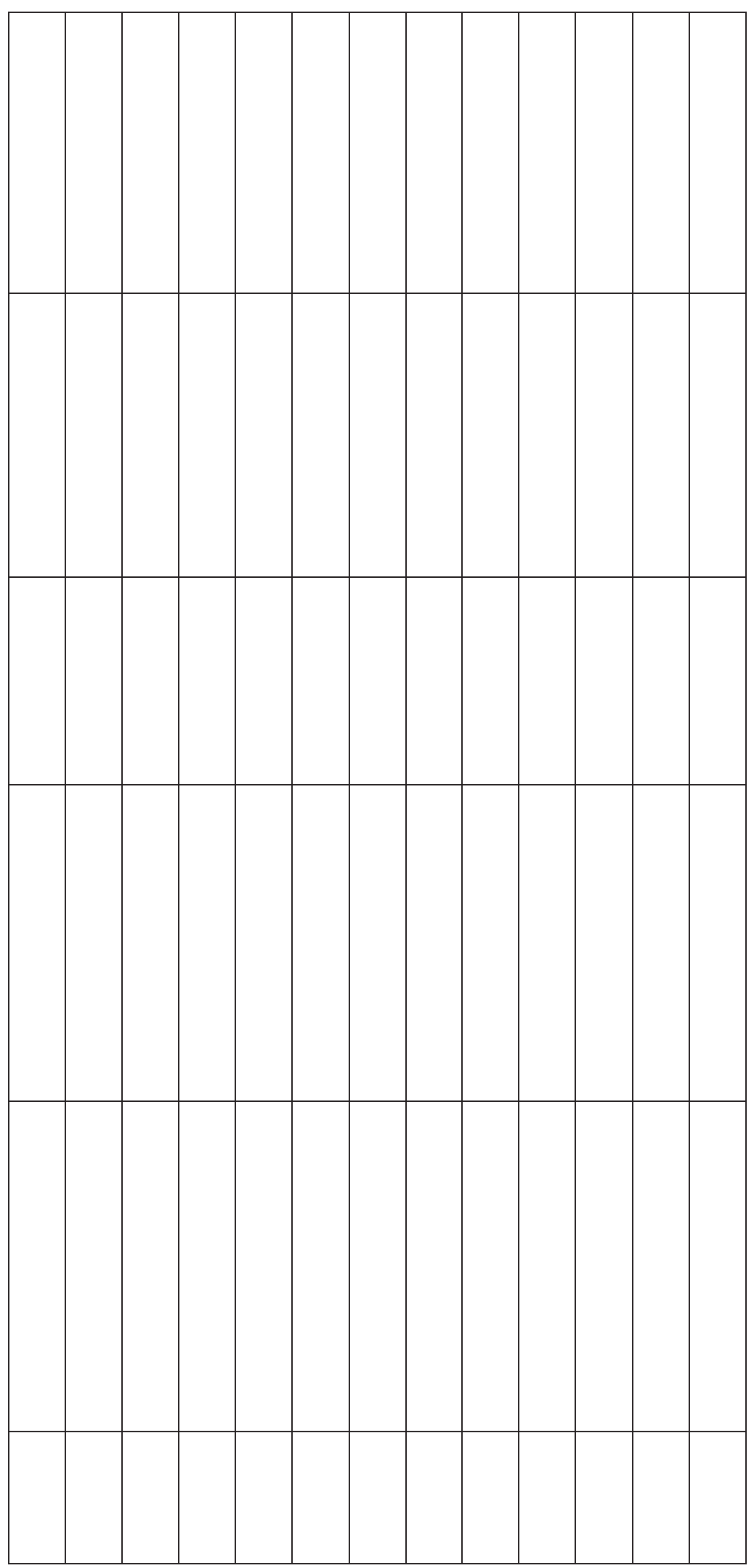

ปั

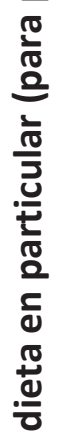

옥

응 홍

กั

뉸

ปิ

ฮ ญ

ڤ

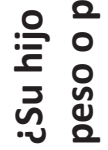

in 2

¿ $\square$ 离

ํㅗㄹ

:을 줄

ज

व

ํํㅇำ

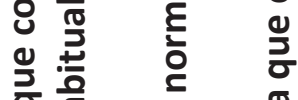

등

중으 으 응 을

트 응

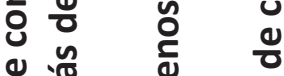

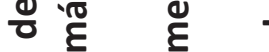

중 응

은 돌 동 놀

ত $\Sigma \mathbf{z}$

ฮ $\square \square \square$

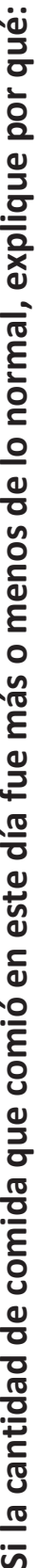



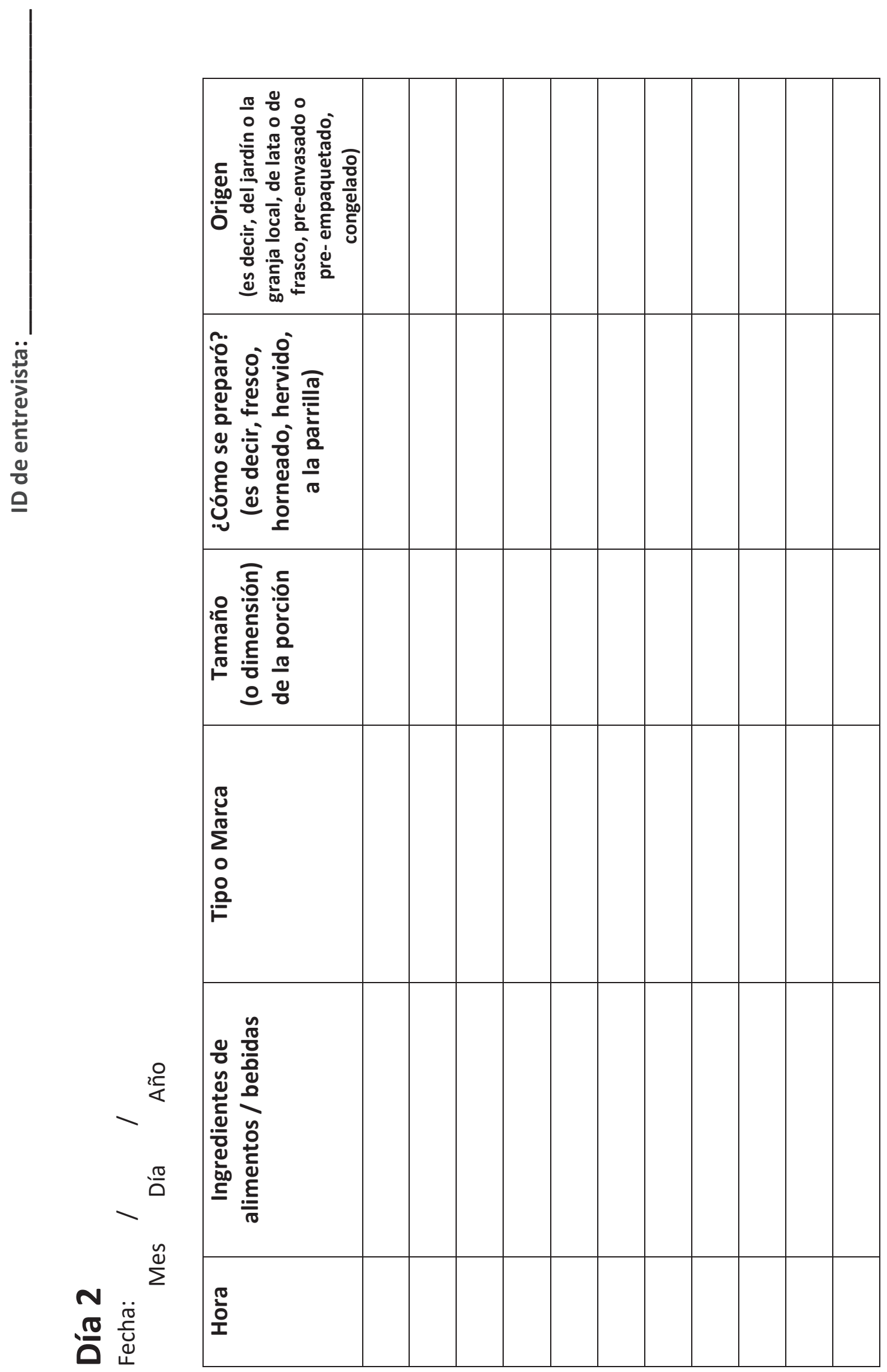


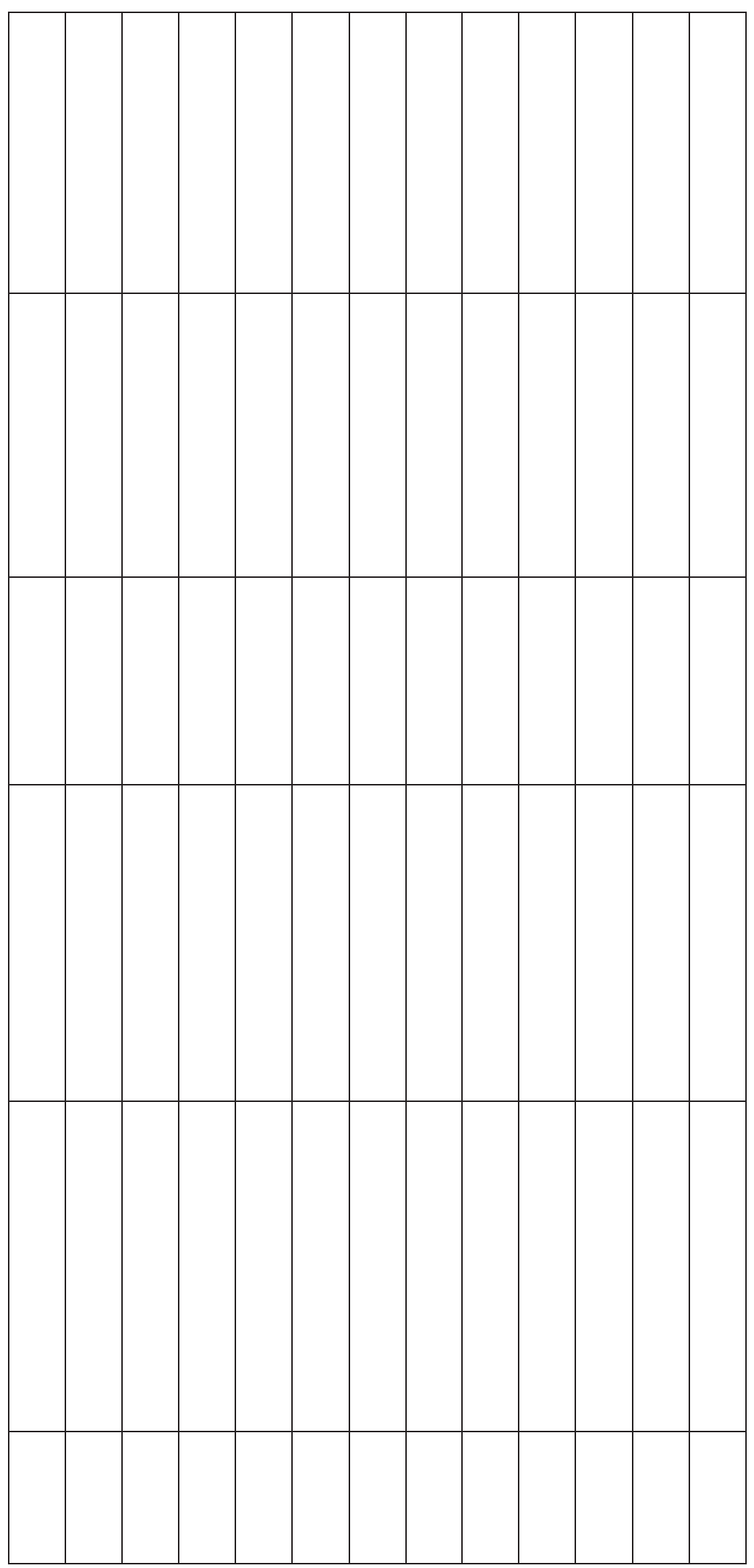

ปั

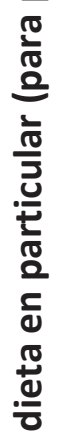

독

응

ำ

는

ปิ

ปั

ज 2

乡 ㅎㅁ

:을 음

जั ๕

ن

:을 중

ज ह

잉

응

중

을 흥

옹

을

ㅇํㅇ 잉

ป ำ

융

은 돌 동

突 党

ग $\square \square \square$

is 

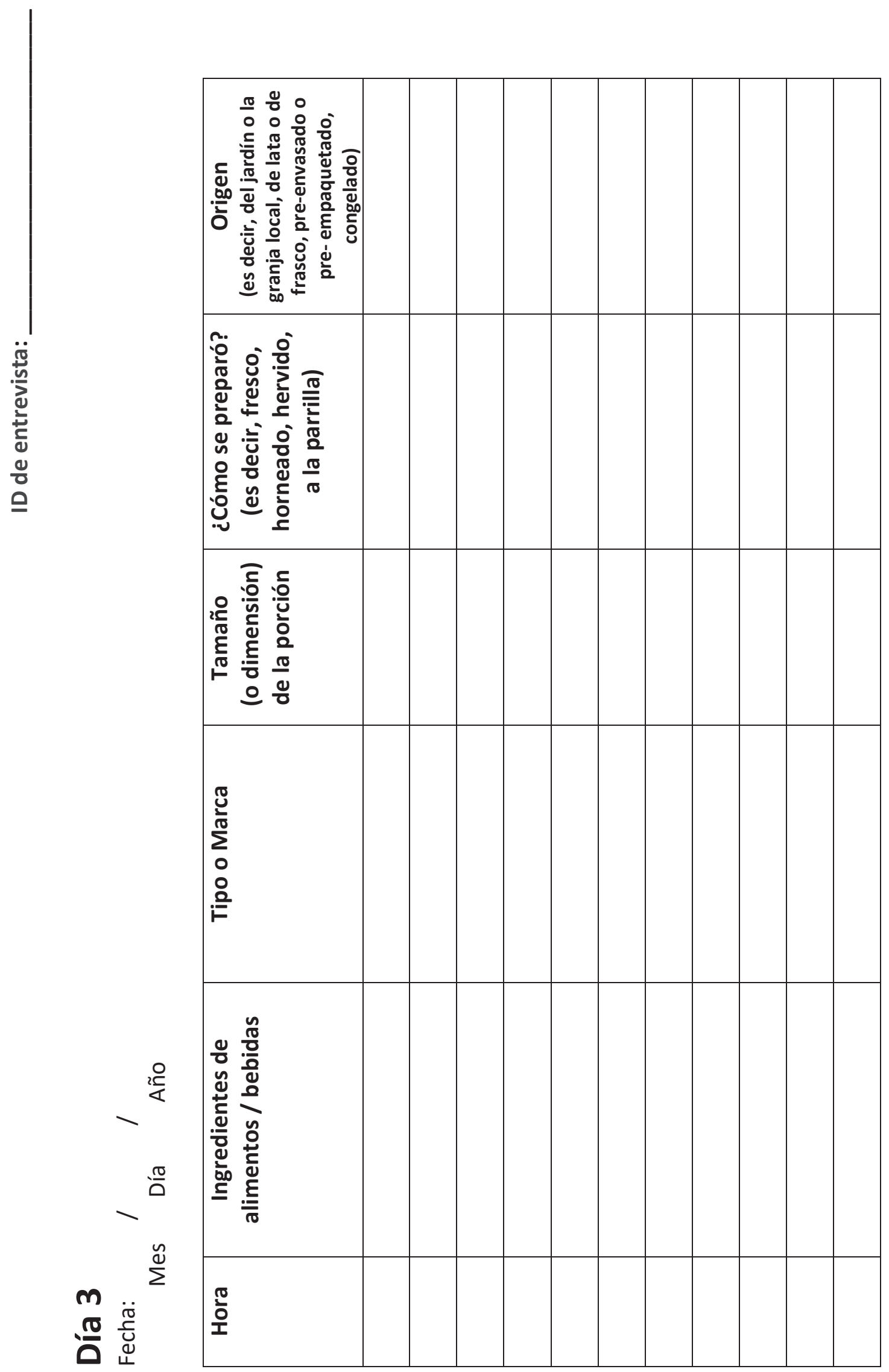


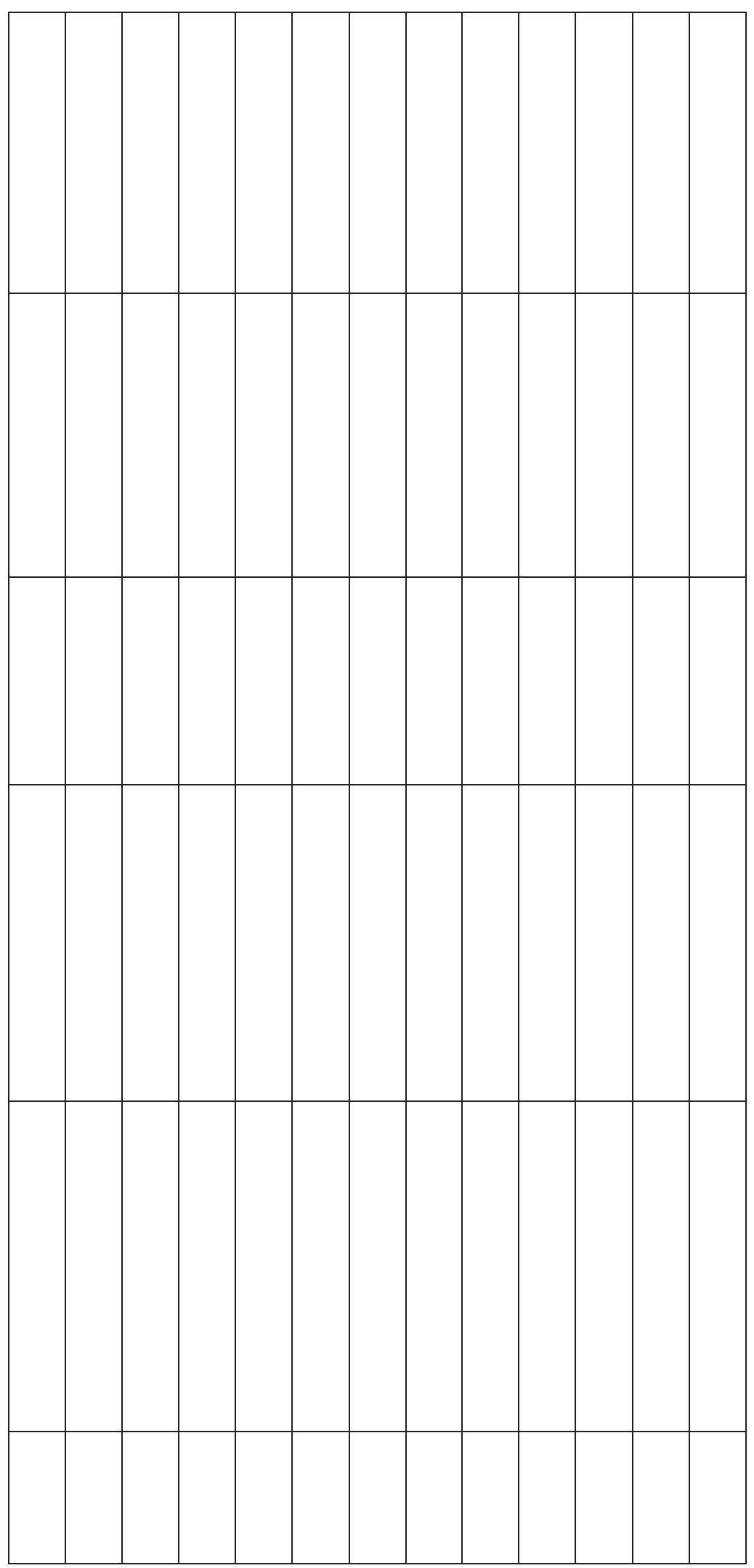

ปั

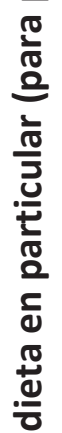

옥

응 홍

กั

뉸

ปิ

ฮ ญ

乡 ᄒ̀口

:올

जู ๕

$\underset{\frac{0}{2}}{\frac{\pi}{2}}$

:을

ज ह

-

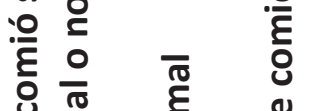

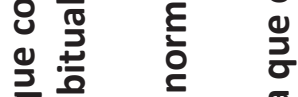

등

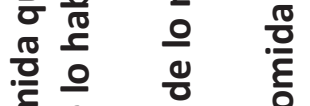

흥 음

ㅇํ ڤั บิ

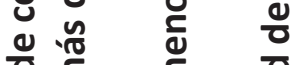

ठ ह

융 옹 웅

은 늘 돈 널

음

త $\square \square \square$ ज 


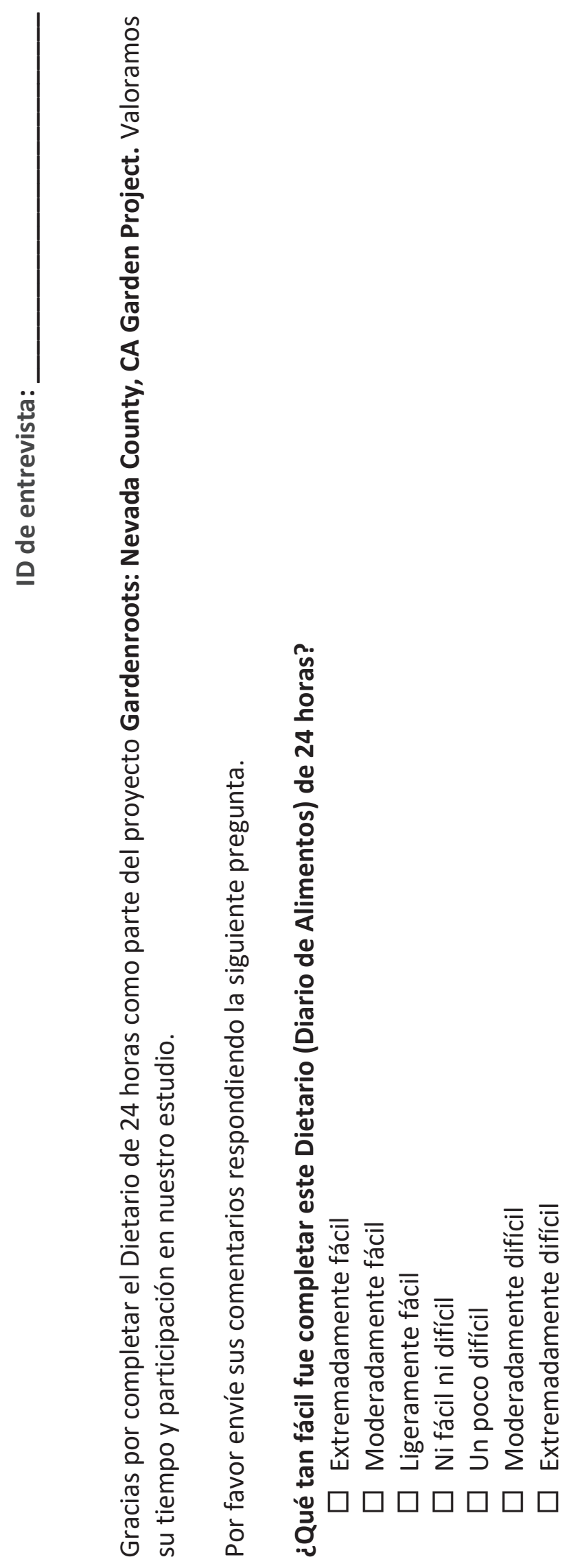




\section{APPENDIX G}

\section{Dust Generator Operating Procedure}




\section{PURPOSE}

This standard operating procedure outlines how to operate the dust generator to generate and fractionate particulate matter. Details regarding theory is described by Gonzales et al. (2014) and Thomas et al. (2018). This procedure is applicable to mine tailings or residential soil.

\section{SAMPLE HANDLING}

Prior to working with the dust generator, all students must be cleared by the UA Occupational Health Medical Surveillance Program and respirator-fit tested by UA Risk Management Services. The respirator must be worn when cleaning and working with the dust generator. Samples may be collected and stored in plastic, 5-gal buckets with a lid. Samples must be oven-dried to $105^{\circ} \mathrm{C}$ and sieved to $<2 \mathrm{~mm}$ before being placed in the dust generator.

\section{MATERIALS}

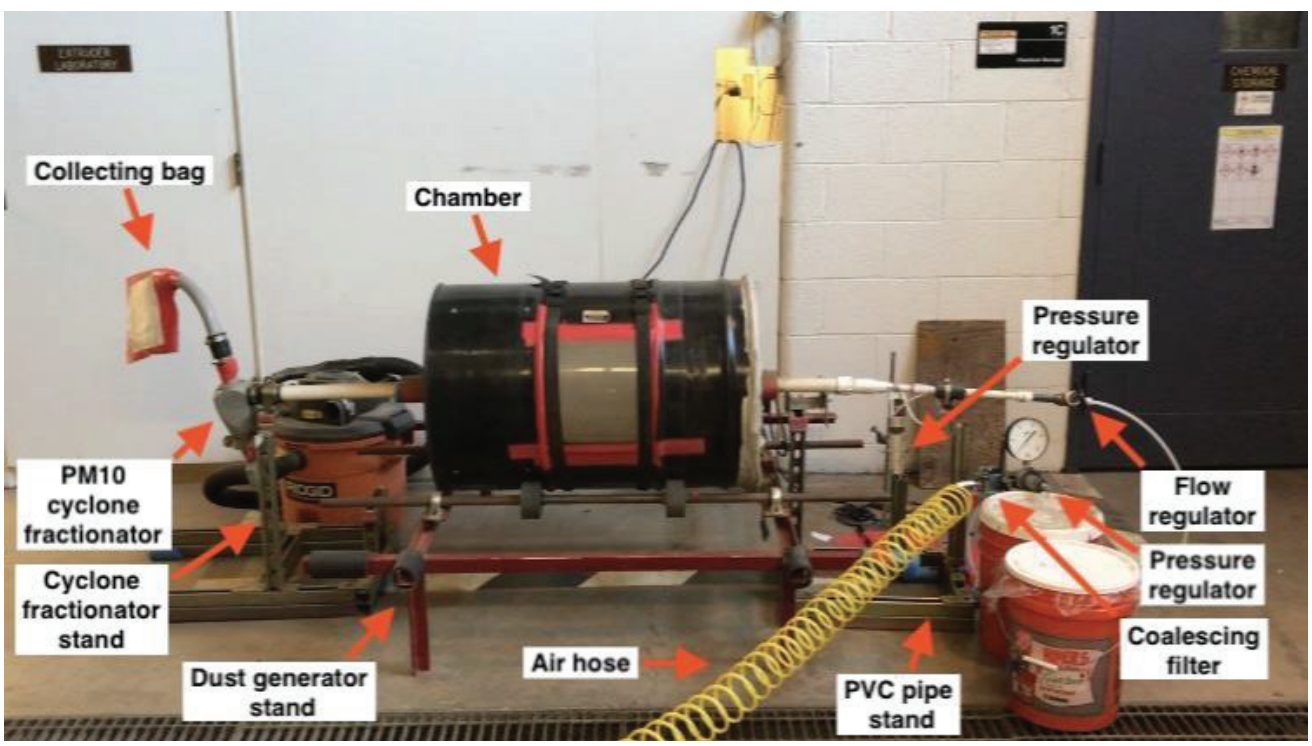

Figure 1. Overview of dust generator parts.

Equipment and supplies

- Person protection equipment

- Half facepiece reusable respirator $\left(3 \mathrm{M}^{\mathrm{TM}}\right.$ Half Facepiece Reusable Respirator 7000 Series)

- (2) NIOSH-approved particulate cartridges for respirator (3M $\mathrm{M}^{\mathrm{TM}} 7093$, 
P100 Particulate Filter)

- Lab coat

- Eye protection

- Gloves

- Dust generator parts

○ Dust generator chamber

- 208-L steel drum

- two belts (secured on outside of chamber)

- Plexiglas window

- $3.5-\mathrm{cm}$ diameter PVC pipe (threaded through drum)

- Stand for chamber

- 4-in rubber wheels

- Sing-speed motor

○ Fractionator

- $\mathrm{PM}_{10}$ cyclone separator (model URG-2000-30 EA, URG Corp. Chapel Hill, NC)

$\circ$ Air-flow regulation instruments

- Coalescing filter

- Pressure regulator

- Flow regulator

- U-tube manometer with tubing

- Collecting chamber

- Ziploc ${ }^{\circledR}$ sandwich bags (6 1/2 x 5 7/8-in)

- Labeling tape

- Vacuum filter bag (Universal vacuum bag fits Bissell ${ }^{\circ}$ Style: 1/4 7 PART No. 440002693)

- Air compressor (Speedaire model 3JR80, Acklands-Grainger Inc. Richmond Hill, Canada)

- $1 / 4$ in x $25 \mathrm{ft}$ air hose

- Materials for stability

○ (1) Hose clamps

- (2) $11 / 4$ x $11 / 4$-in rubber PVC coupling fittings with hose clamps

- PVC pipe stand

- Cyclone fractionator stand

- Materials to reduce fugitive dust emission

$\circ$ Foam pipe insulation (fits 1 1/2-in pipe)

- Swiffer ${ }^{\circledR}$ Dusters ${ }^{\mathrm{TM}}$ Refills

○ Duct tape

- Cleaning supplies

- HEPA wet/dry vacuum cleaner 
- Trash bags

- Waste bucket

- $70 \%$ ethanol solution

- 15 x 17-in Kimwipes (model S-8116, Kimberly-Clark Inc. Irving, TX) 


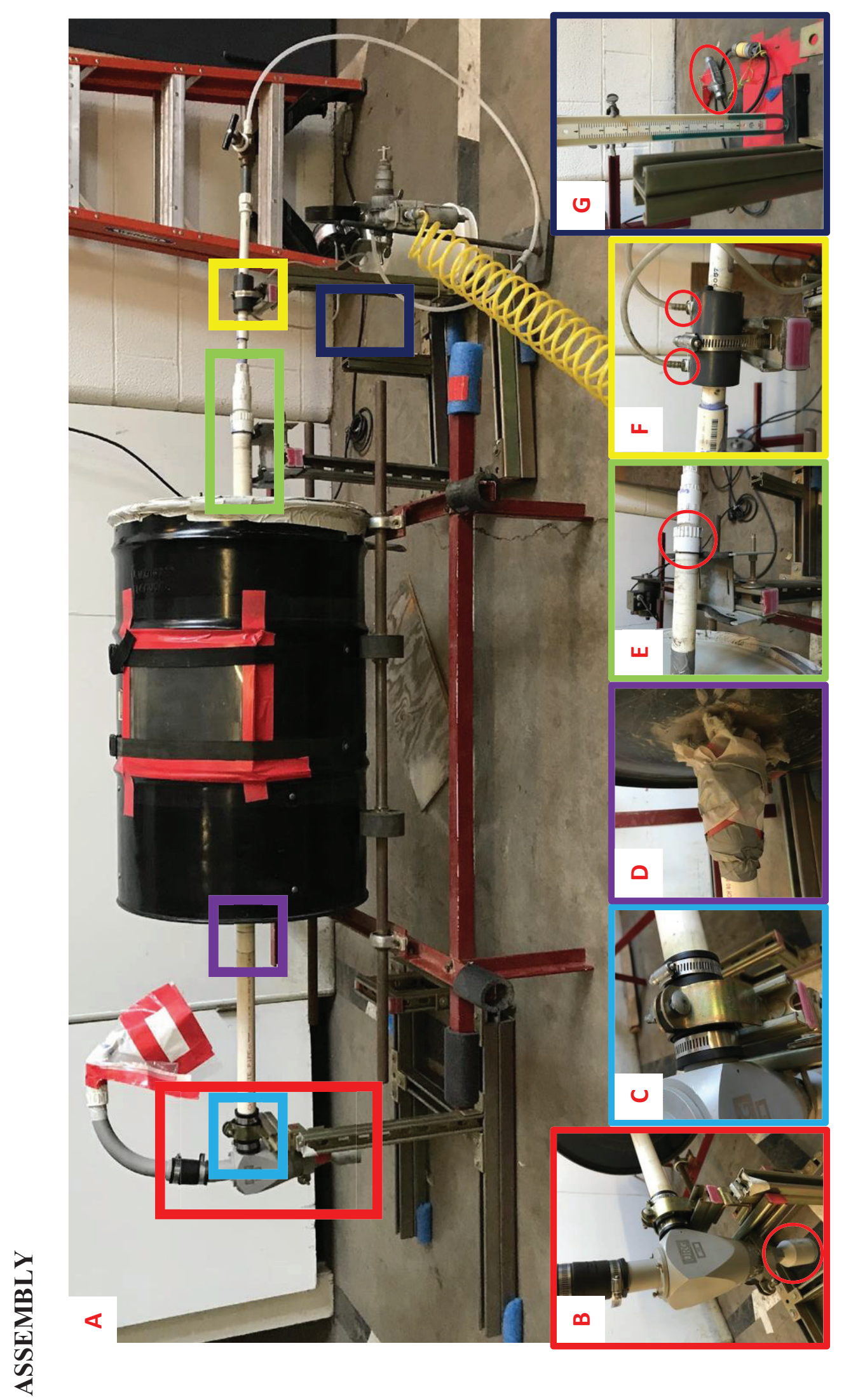

उे)

Iิ

ن

$\frac{1}{2}: \frac{5}{2}$

₹

ช

₹

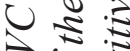

a 50

ป ะ

오용

요요

요요

ป ซ

कह

旁

ㅎํㅇ

ป $\frac{2}{3} \frac{\sqrt{3}}{3}$

.

₹

क 0

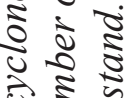

टे ह

원

रิ

बी डे गे

$\therefore \approx$

웡ㅇำ

2) $\frac{2}{2}$

ป क ड

$\infty \div$

ป

ว.

$\frac{0}{\frac{1}{0}} \frac{0}{0}$

के 5

ป ฐ

$\approx 20$

ชิ

3 bे

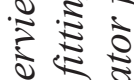

$>005$

0.5.

छิ :

i 8

ป के ईี

这造 


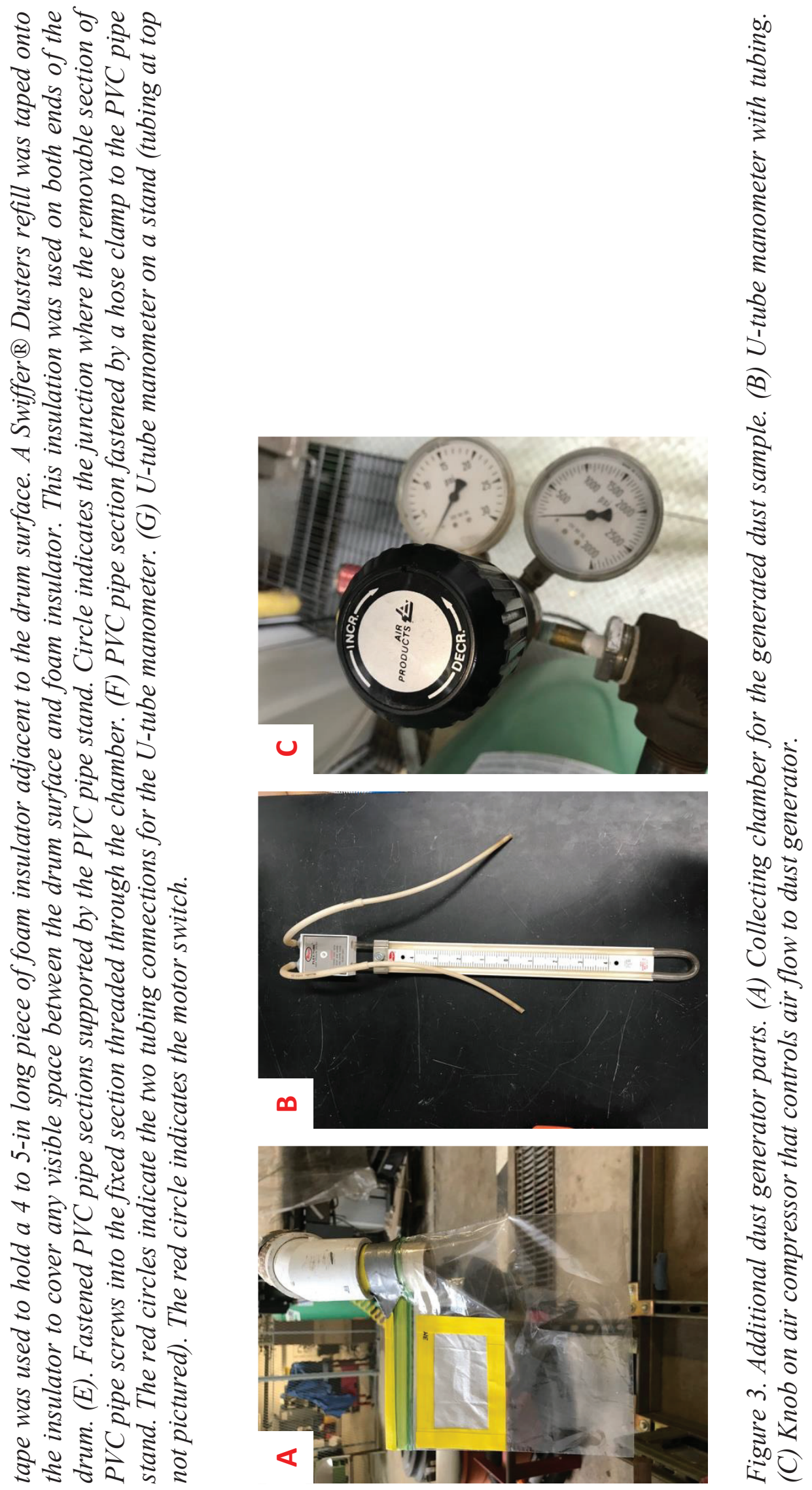




\section{PROCEDURE}

A. Making the collection chamber

1. Cut out a 2-in x 3-in widow on the top left corner of the Ziploc ${ }^{\circledR}$ bag.

2. Cut a rectangular piece from the vacuum filter bag slightly larger than the window.

3. Tape the rectangular filter to the inside of the bag using the labeling tape, then seal the filter from the outside of the bag using the labeling tape.

4. Repeat steps 1-3 for each sample.

B. Cleaning before and after each sample

1. Seal a trash bag around the window opening of the drum with duct tape.

2. Rotate the drum to dump the soil sample into the bag.

3. Wait approximately 10 minutes for the sample to settle within the trash bag.

4. Remove the trash bag and discard the sample in accordance with proper waste disposal procedure.

5. Detach the threaded PVC pipe from the removable pipe section (at the junction shown in Figure 2(E)), the rubber couple fitting (Figure 2(B)), and the cyclone stand clamp (Figure 2(C)).

6. Tilt the threaded PVC pipe and drum vertically in the air to remove any residual sample within the pipe into a waste bucket.

7. Vacuum any remaining sample inside the drum using the HEPA wet/dry vacuum cleaner.

8. Vacuum any dust settled on the dust generator parts and around the work area.

9. Wipe clean the inside and outside of the drum using the $70 \%$ ethanol solution and Kimwipes $^{\mathrm{TM}}$.

10. Remove the cyclone fractionator and PVC arm from the dust generator.

11. Remove the bottom collection chamber from the cyclone fractionator (Figure 2(B)).

12. Transfer the dust collected in this chamber $(>10-\mu \mathrm{m})$ into a proper sample storage container and label accordingly.

13. Run DI water through the cyclone fractionator and PVC arm to remove adhered dust. 
14. Once the cyclone fractionator and PVC arm are dried, wipe the inside and outside of each with the $70 \%$ ethanol solution and Kimwipes ${ }^{\mathrm{TM}}$.

C. Generating dust

1. Once the dust generator is assembled and cleaned thoroughly, transfer 5 to $8-\mathrm{kg}$ of the dry, sieved soil sample into the chamber through the window.

2. Cover the window opening with the plexiglass and seal all sides with duct tape. Then, fasten the plexiglass to the drum by tightening the belts over it.

3. Tape the collection bag to the top end of the PVC arm as shown in Figure 3(A).

4. Add approximately 6-in of DI water and coloring dye to U-tube manometer.

5. Attach the two tubes on the U-tube manometer to the connections shown in Figure 2(F).

6. Connect the air hose to the air compressor.

7. Turn on the air compressor and allow the pressure in the tank to reach 100-125 PSI. Note: the air compressor will automatically shut off when the pressure in the tank reaches approximately 130 psi.

8. Once the tank pressure has reached 100-125 psi, turn off the air compressor and twist the knob (Figure 3(C)) to increase the pressure being released from 0 to 5-6 psi.

9. Check the difference in inches of water on the U-tube manometer. If the difference is not between 4-5 in, continue to twist the knob on the air compressor to increase the pressure released into the system until the difference is within this range. Optimal dust generation occurs at 5 psi and 5 inches of water (Gonzales et al., 2014).

10. Check the pressure within the air compressor tank and on the pressure gauge closest to the chamber, and the difference in inches of water on the U-tube manometer every 30 min. Adjust the pressure released accordingly to maintain the desired range of difference in inches of water.

11. Turn on the motor by flipping the switch shown in Figure $2(\mathrm{H})$. To keep the chamber rotating while in use, secure the flipped switch with duct tape.

12. Allow the dust generator to run for 4-8 hours or until adequate amount of dust sample is produced. 
13. Remove the sample collection chamber from the PVC pipe arm and carefully extract the dust sample from the inside of the bag and properly label.

14. Complete the cleaning procedure outlined above before moving on to the next soil sample.

\section{REFERENCES}

Gonzales, P., Felix, O., Alexander, C., Lutz, E., Ela, W., \& Eduardo Sáez, A. (2014). Laboratory dust generation and size-dependent characterization of metal and metalloid-contaminated mine tailings deposits. Journal of Hazardous Materials. https://doi.org/10.1016/j.jhazmat.2014.09.002

Thomas, A. N., Root, R. A., Lantz, R. C., Sáez, A. E., \& Chorover, J. (2018). Oxidative weathering decreases bioac- cessibility of toxic metal(loid)s in PM10 emissions from sulfide mine tailings. GeoHealth, 2, 118-138. https://doi.org/10.1002/2017GH000118 
APPENDIX H

Data Sharing Material (Drafts) 


\section{Thank you!}

Dear Parent,

We did it! I would like to give a special thanks to all Nevada County Gardenroots participants for your efforts, motivation, and patience throughout this research project. We appreciate the time you have invested in participating in this project. Altogether, over 33 community members were trained, and 38 soil, 8 dust, 12 water, and 45 plant samples were prepared and analyzed.

This collaborative study was conducted by a team of researchers from the Sierra Streams Institute (a regional nonprofit watershed science organization in Nevada City, CA), the University of Arizona, and the University of CA-San Francisco. This study was funded by the California Breast Cancer Research Program.

By learning about your child's diet and the environmental quality of your community, we were able to identify environmental health research gaps and ways to improve the quality of preschool gardens. This packet shows the test results of the exposure assessment done for multiple preschools including the one your child attends. These results are highlighted and compared to state and federal regulatory standards and/or reference values when available. In this package, we have included the following:

1. Project overview

2. Important terms that you will see throughout the results

3. General information on selected contaminants of concern

4. A guide to reading the results

5. Preschool vegetable, soil, irrigation water, and dust results

6. Child's cumulative exposure results

7. References for further information on environmental quality and guidelines

Sincerely,

Mónica Ramírez-Andreotta, Assistant Professor

University of Arizona

1177 E Fourth Street, Rm. 429, Tucson, AZ 85721

Phone: 520-621-0091 Fax: 520-621-1647

Joanne Hild

Executive Director, River Scientist

Sierra Streams Institute 13075 Woolman Lane

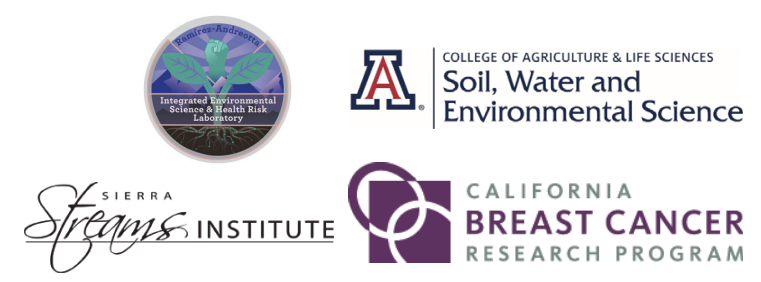

Nevada City, CA 95959 (530) 477- 7132 Ext. 200

www.sierrastreamsinstitute.org

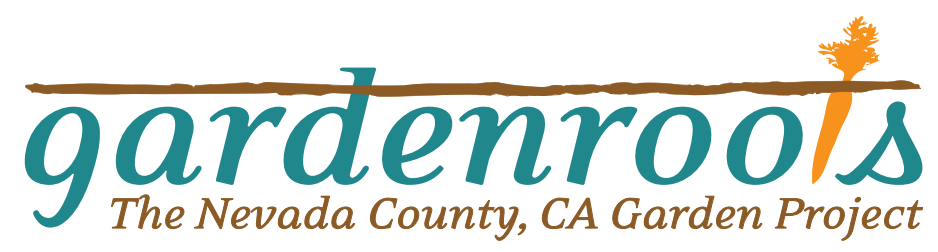




\section{Project Description}

Based on community member's concerns regarding environmental quality, Gardenroots: The Nevada City, CA Garden Project was developed. Gardenroots is an environmental monitoring and children's exposure assessment project designed to better understand potential child exposure to arsenic, cadmium, and lead. Seeing gardens as hubs for environmental health research and education, Gardenroots is trying to understand the state of environmental quality in rural communities. Results from this study are helping to determine whether people are exposed to metal contaminants through gardening and crop ingestion.

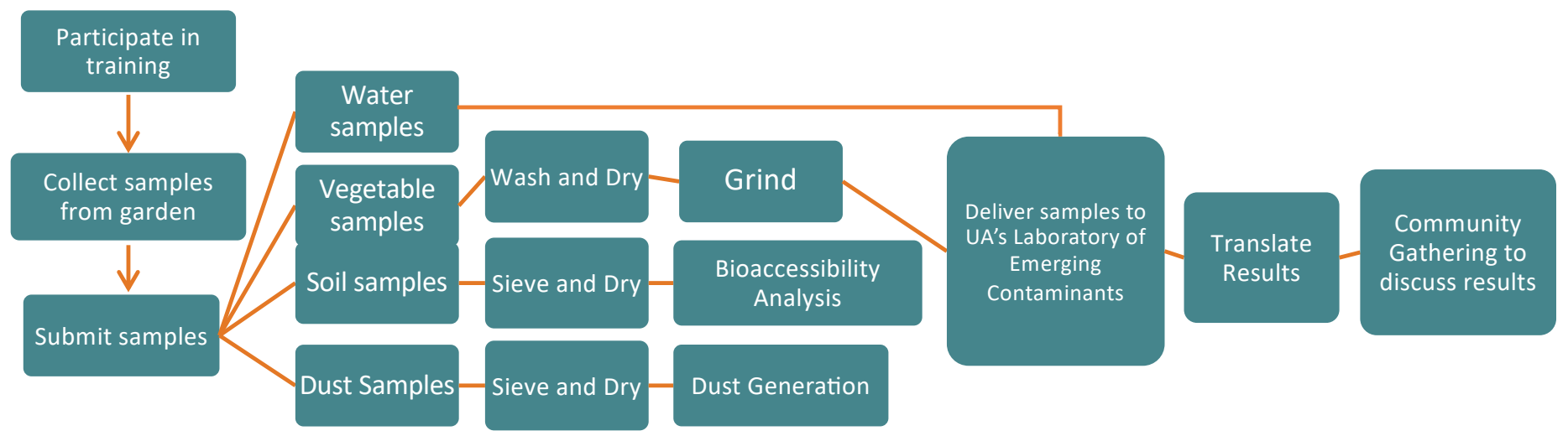

\section{Data may be subject to revisions.}

The results have been internally reviewed, but have not undergone external peer review and may be subjected to minor changes.

Metals occur naturally in the environment.

While we can measure the level of a metal in certain substances, like water or soil, it is difficult to know the original source of the metal. For example, arsenic may be found in soil in many parts of the state because it also naturally occurs in these regions.

It is important to note that, elements such as arsenic occur naturally in soil and it is impossible to grow plants completely free of these and other trace elements like lead and cadmium.

Please refer to the recommended gardening best practices handouts for ways to reduce levels of harmful chemicals in your garden plot and in your vegetables.

Single exposure measurements are "snapshots in time".

We are measuring metal concentrations at a single point in time. Measuring metal concentrations with a single sampling does not establish what the exposures were in the past or what they may be in the future.

For more information about the study and safe gardening practices, please visit the Gardenroots website: http://www.gardenroots.arizona.edu/ 


\section{Important Terms}

Below is a set of terms that you will see throughout your results:

Action Level (AL) - The U.S. Environment Protection Agency (U.S. EPA) regulates lead under the Lead and Copper Rule. This rule describes the water treatment requirements needed to control plumbing corrosion that may contaminate drinking water. If the water concentration of lead is above the action level, this means actions are required to correct the water system to meet this regulation.

Concentration - The amount of a chemical in a given mass of water, soil, or plant tissue. This is written as $\mu \mathrm{g} / \mathrm{L}$ (micrograms per liter), $\mu \mathrm{g} / \mathrm{m}^{3}$ (micrograms per cubic meter), or $\mu \mathrm{g} / \mathrm{g}$ (micrograms per gram).

Guideline - A non-enforceable, but recommended maximum concentration of a chemical.

MCL (Maximum Contaminant Level) - The MCL is the maximum amount of a contaminant allowed in drinking water so that it is still safe to drink over many years. This level is set by the US Environmental Protection Agency.

Median - The value at the midpoint (middle value) of the range of values.

National Ambient Air Quality Standard (NAAQS) - These are standards established by the U.S. EPA to protect human health. The standard for lead defines the maximum allowable concentration of lead in a cubic squared meter of outdoor air. This standard is current set to $0.15 \mu \mathrm{g} / \mathrm{m}^{3}$.

Percentile - A number where a certain percentage of scores fall below that number. For example, if you know that your score is in the 90th percentile, that means you scored better than $90 \%$ of people who took the test.

$\mu \mathrm{g} / \mathrm{g}$ (Micrograms per Gram) - A measure of how many micrograms of a substance (such as a metal) are in a gram of a solid (such as soil). This measure is also referred to as parts per million (ppm).

$\mu \mathrm{g} / \mathrm{L}$ (Micrograms per Liter) - A measure of how many micrograms (one-thousandth of a milligram) of a substance (such as a metal) are in a liter of liquid (such as water). This measure is also referred to as parts per billion (ppb). For perspective, $1 \mu \mathrm{g} / \mathrm{L}$ or $\mathrm{ppb}$ is the equivalent to a drop of ink in a backyard swimming pool.

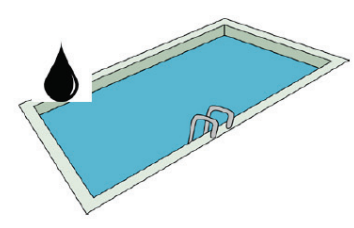

\begin{tabular}{|c|c|c|}
\hline $\begin{array}{c}\text { Micrograms per liter } \\
(\mu \mathrm{g} / \mathrm{L})\end{array}$ & $\begin{array}{c}\text { Parts per billion } \\
(\mathrm{ppb})\end{array}$ & $1 / 1,000,000,000$ \\
\hline
\end{tabular}




\section{Important Terms (con't)}

$\mu \mathrm{g} / \mathrm{m}^{3}$ (Micrograms per Cubic Meter) - A measure of how many micrograms of a substance (such as a metal) are in a cubic meter of a air.

Reference Dose (RfD) - Estimate of a daily intake of a chemical that is not likely to result in any significant negative health effects (including sensitive populations like children and elderly). It may be referred to as the acceptable daily intake.

Standards - The standards are enforceable and regulatory values, developed either by federal agencies or by the state of Arizona for water providers/utilities. They are different from advisories (see definition on previous page) and guidelines.

\section{Soil Screening Levels}

- U.S. EPA Regional Screening Level (RSL) - Risk-based concentrations of contaminant in soils that are calculated using what we know about the exposure to a contaminant and what the U.S. EPA knows about the toxicity of the chemical. U.S. EPA considers these screening levels as initial cleanup goals, when applicable. They are not national cleanup standards, and are based on different target risks.

- CalEPA California Human Health Screening Levels (CHHSLs) - Risk-based concentrations of contaminants in soils that are specific to California. Screening levels for lead are not risk-based screening levels, but rather the average $\mathrm{Pb}$ concentration in residential soil that would be protective of children and women of child-bearing ages. These values are more conservative than the U.S EPA RSLS.

- CalEPA California Department of Toxic Substances Control Screening Levels (DTSC-SL) - Riskbased recommended screening levels that are derived using DTSC-modified exposure and toxicity factors for contaminants in soil. These values are also more conservative than the U.S EPA RSLs. 


\section{Arsenic (As)}

\section{Contaminant Name: Arsenic (As)}

Contaminant Type: Metalloid

\section{What is Arsenic?}

Arsenic naturally exists in the Earth's crust and can be found in sediments, soils, and groundwater. Arsenic may also be released into the environment via mining, ore smelting, and industrial use of the element.

\section{What happens to arsenic when it enters the environment?}

In the environment, people can be exposed to arsenic in two chemical forms:

- Inorganic: Varying amounts of this poisonous (toxic) form can be found naturally in geologic materials (soils, rocks, aquifer materials) and in ground and surface water, which may also be impacted by mining and industrial wastes and arsenical pesticides).

- Organic (arsenic compounds that contain carbon): Varying amounts of this non-poisonous (lowtoxicity) form can be found in sources such as animals, plants, fish and seafood. Fish and shellfish can accumulate arsenic; most of this arsenic is in an organic form called arsenobetaine that is much less harmful.

\section{How can arsenic affect my health?}

Severe (acute) arsenic poisoning can cause vomiting, abdominal pain, and diarrhea. This can be followed by numbness and tingling of the extremities, muscle cramping, and death in extreme cases. Ingesting or breathing low levels of inorganic arsenic for a long time (chronic) can cause non-cancer health effects, like a darkening of the skin and the appearance of small "warts" on the palms, soles, and torso. Other non- cancer health effects linked to long- term ingestion of arsenic include developmental effects, diabetes, pulmonary disease, and cardiovascular disease. Ingestion of inorganic arsenic can increase the risk of skin cancer and cancer in the liver, bladder, and lungs. Inhalation of inorganic arsenic can cause increased risk of lung cancer.

\section{Where can I get more information on Arsenic?}

Agency for Toxic Substances and Disease Registry. ToxFAQsTM for Arsenic. Last Updated on March 12, 2015. You can access this information at: https://www.atsdr.cdc.gov/toxfaqs/tf.asp?id=19\&tid=3 


\title{
Cadmium (Cd)
}

\author{
Contaminant Name: Cadmium (Cd) \\ Contaminant Type: Heavy metal
}

\section{What is cadmium?}

Cadmium is found in the Earth's crust. Most cadmium used in the U.S. is extracted as a byproduct during the production of other metals such as zinc, lead, or copper. Cadmium is also recovered from used batteries. Cadmium is used for the following: batteries, pigments, coatings and platings, stabilizers for plastics, photovoltaic (solar power materials) devices, and other uses.

\section{What happens to cadmium when it enters the environment?}

Cadmium is emitted to soil, water, and air by metal mining and refining, manufacture and application of phosphate fertilizers, fossil fuel combustion, and waste incineration and disposal. Generally, cadmium binds strongly to organic matter where it can stay in soil and be taken up by plant life, eventually entering the food supply.

\section{How can cadmium affect my health?}

Cigarette smoking is a major exposure route to cadmium. Tobacco may have been grown in contaminated soils, or pesticides/fungicides or additives were applied during the growing and manufacturing process.

Exposure to cadmium can occur through breathing contaminated workplace air, drinking contaminated water, or living near industrial facilities that release cadmium into the air. Eating food or drinking water with very high levels severely irritates the stomach, leading to vomiting and diarrhea. Long-term exposure to lower levels of cadmium in air, food, or water leads to a buildup of cadmium in the kidneys and possible kidney disease. Other long-term effects include lung damage and fragile bones. Low levels of cadmium are found in all foods (highest levels are found in shellfish, liver, and kidney meats). In the U.S., for nonsmokers the primary source of cadmium exposure is from the food supply. Breathing high levels of cadmium can severely damage the lungs. Cadmium and cadmium compounds are known to cause cancer in humans.

\section{Where can I get more information on Cadmium?}

Agency for Toxic Substances and Disease Registry. ToxFAQsTM for Cadmium. Last Updated on March 12, 2015. You can access this information at: https://www.atsdr.cdc.gov/toxfags/tf.asp?id=47\&tid=15 


\section{Lead $(\mathrm{Pb})$}

Contaminant Name: Lead (Pb)

Contaminant Type: Heavy Metal

\section{What is lead?}

Lead is a metal in the Earth's crust that is normally found with other metals such as zinc, silver, and copper. Lead has many uses including manufacturing of paints, batteries, and fishing weights. Leadbased solder, which had been used to connect copper water pipes, was banned in the 1980s, but may still be a source of lead in drinking water in older homes. In the United States, lead was used as a gasoline additive, but was banned beginning in 1973 and eliminated by 1996.

\section{What happens to lead when it enters the environment?}

Lead itself does not break down, but lead compounds are changed by sunlight, air, and water. When lead is released to the air, it may travel long distances before settling to the ground. Once lead falls onto soil, it usually sticks to soil particles. Ingestion (soil, food, water) is the main route of exposure in humans.

Children are most impacted by lead exposure because they often put their hands and/or toys in their mouths. Pregnant women can also expose their unborn child to lead via ingestion. Adults can be exposed via lifestyle choices (e.g., cigarette smoking) or through their occupation (e.g., plumbing, soldering, manufacturing plants, construction/remodeling companies, smelters, and auto repair shops). There are other sources of potential lead exposure which include: paints, glazed clay pots, wine, food, leaded glass (crystal), stained glass, dyes, and home remedies (e.g., azarcon or greta used to treat digestive illness).

\section{How can lead affect my health?}

Lead can affect almost every organ and system in your body, both in adults and children. Exposure to lead can seriously harm a child's health. It can damage the brain and nervous system, slow growth and development, cause learning, behavior, hearing, and speech problems. It causes lower IQ, decreased ability to pay attention, and underperformance in school. Lead exposure also causes small increases in blood pressure, particularly in middle-aged and older people and can cause anemia. In pregnant women, high levels of exposure to lead may cause miscarriage. High-level exposure in men can damage the organs responsible for sperm production.

\section{Where can I get more information on Lead?}

Agency for Toxic Substances and Disease Registry. ToxFAQsTM for Lead. Last Updated on August 24, 2016. You can access this information at: https://www.atsdr.cdc.gov/toxfaqs/tf.asp?id=93\&tid=22 


\section{A Guide to Reading the Results}

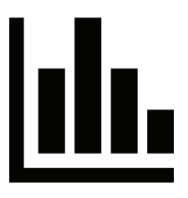

\section{Guide for reading soil, plant, water, and dust results}

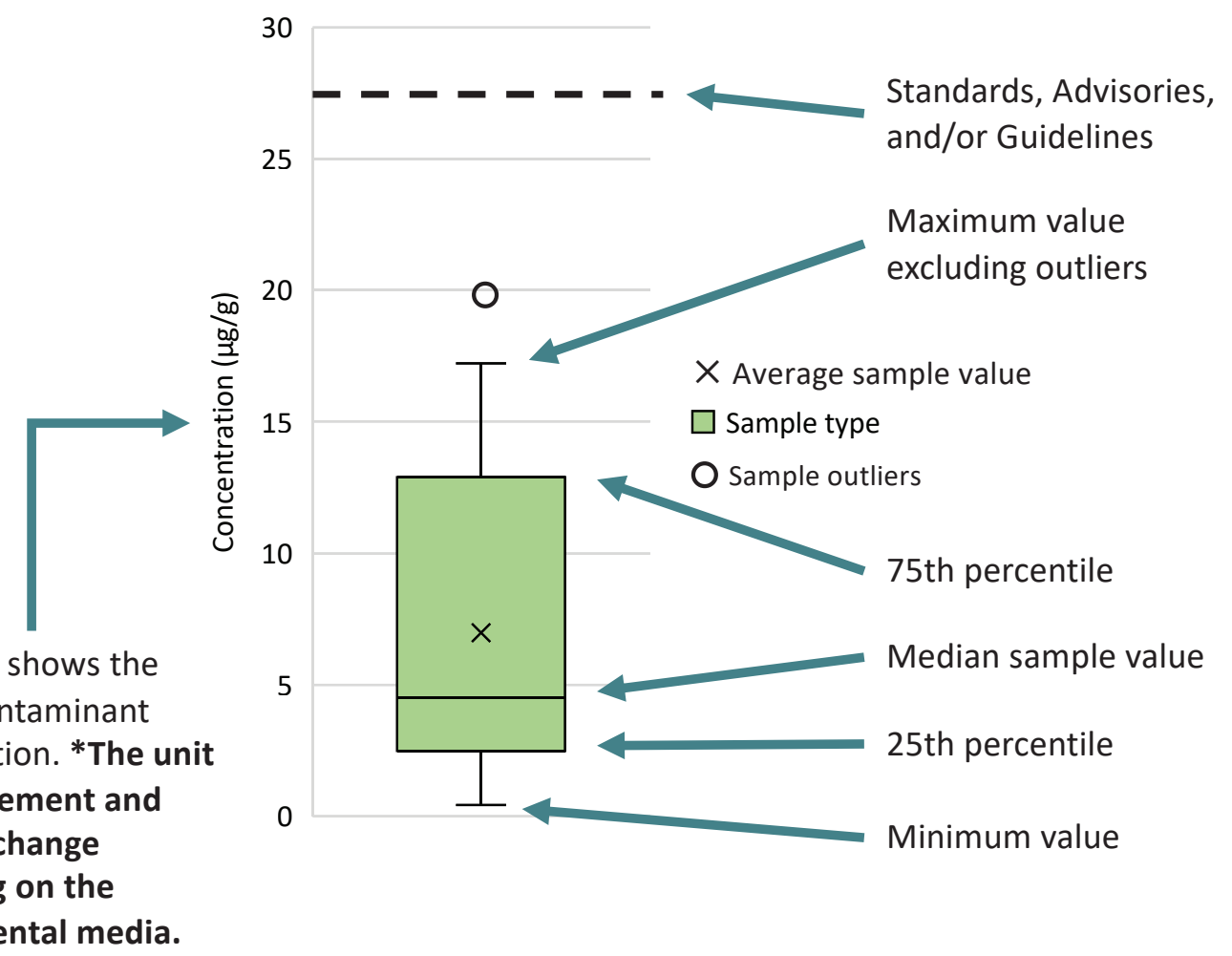

The Y-Axis shows the level of contaminant concentration. *The unit of measurement and scale will change depending on the environmental media.

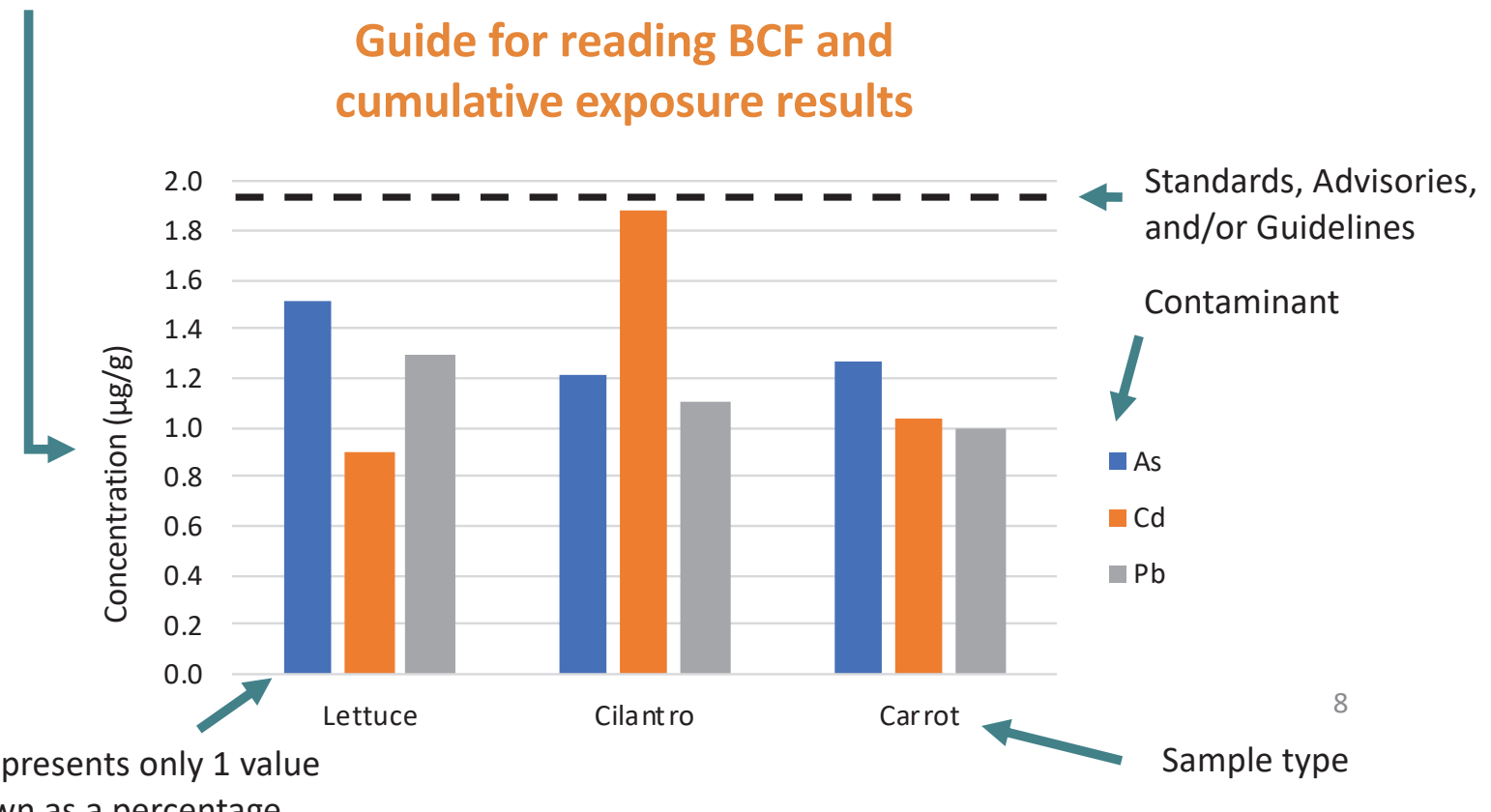

Each bar represents only 1 value unless shown as a percentage out of $100 \%$ on the Y-Axis 


\section{Vegetable Results}

Below are the measured arsenic, cadmium, and lead concentrations in vegetables that were collected at each preschool.

\section{Concentration in Garden Vegetables}
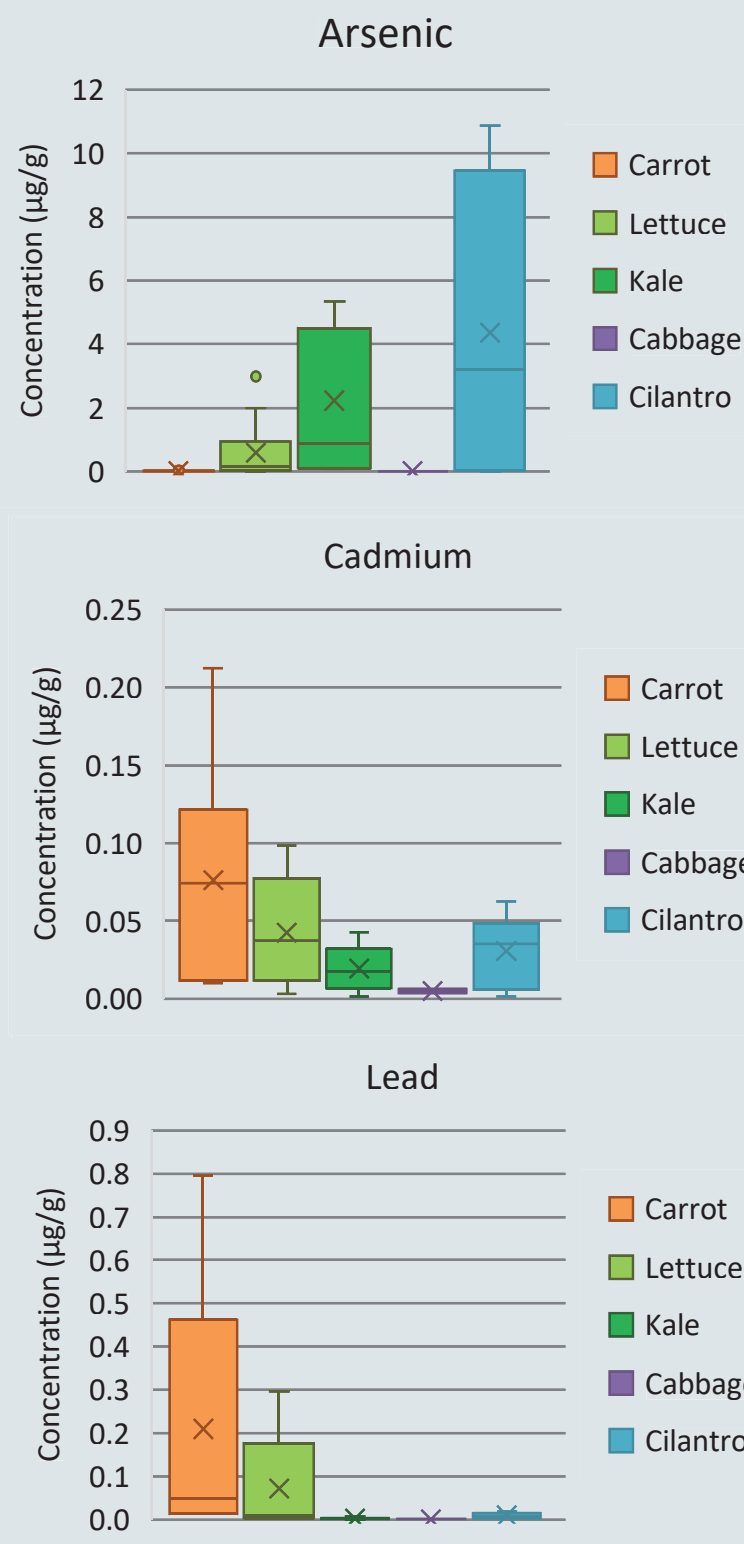

We found that Apaiaceae plants (carrot and cilantro) had the greatest median concentrations.

\section{Plant Bioconcentration Factor}

The plant bioconcentration factor (BCF) is the ratio of the metal concentration in the edible portion in the vegetable (dry weight) and the metal concentration in the soil.

$$
B C F=\frac{\text { Contaminant concentration in plant }}{\text { Contaminant concentration in garden soil }}
$$

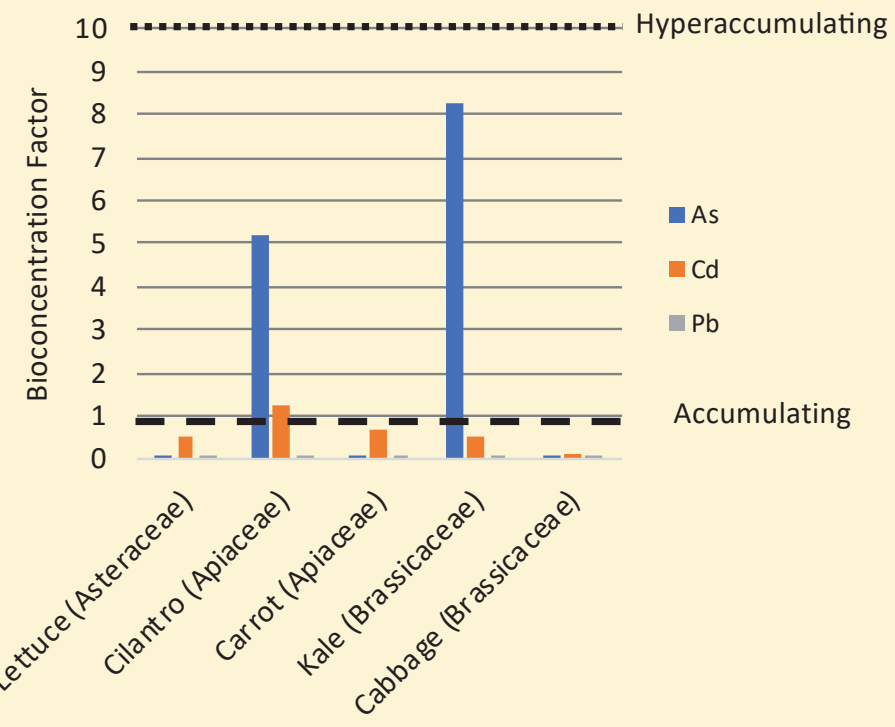

The results suggested that cilantro and kale accumulated more As than other plants, while only cilantro accumulated $\mathbf{C d}$. Certain members of the Asteraceae and Brassicaceae families have been previously identified as hyperaccumulator plants, meaning they may have a genetic and physiological capacity to accumulate high amounts of metals.

With this evidence, it is recommended that Nevada County, CA home gardeners limit the use of vegetables from the Apiaceae and Brassicaceae plant families. 


\section{Soil Results}

Below are the measured arsenic, cadmium, and lead concentrations in soil samples that were collected at each preschool.

Arsenic Concentration in Garden and

Playground Soil

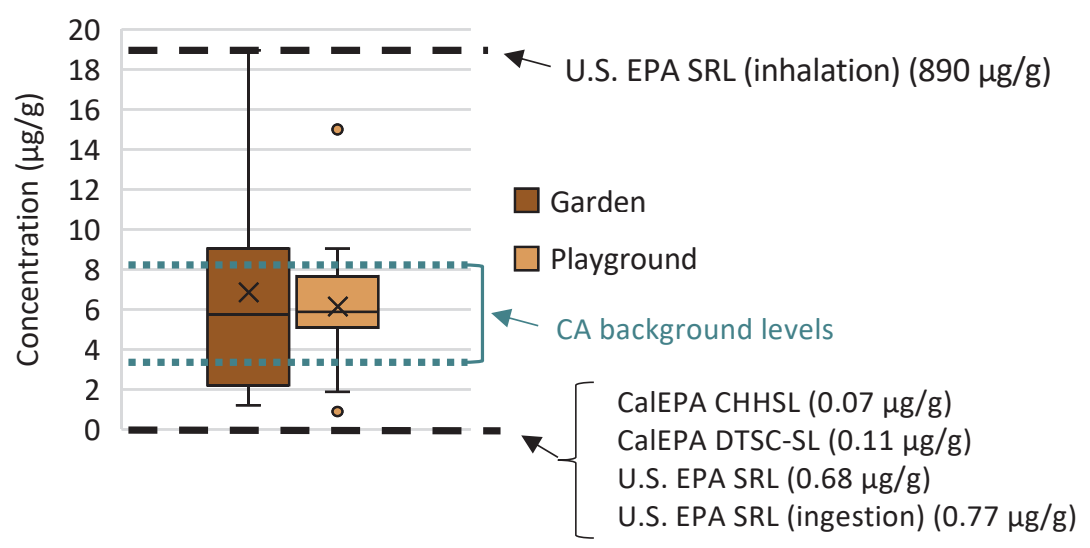

Soil samples exceeded the recommended conservative state and federal soil screening levels for As.

Please note! The measured As concentrations in garden and playground soil were generally similar to CA background As levels. This may suggest, that in general, these levels are not due to human activity or historical land use.

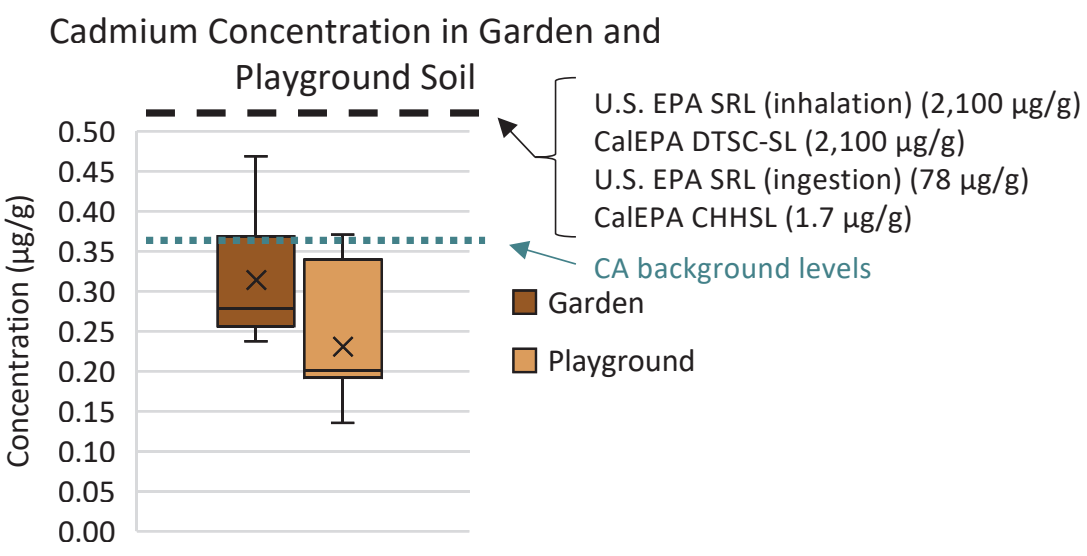

In general, soil samples did not exceeded the recommended conservative state and federal soil screening levels for $\mathrm{Cd}$.

Like As, the measured Cd concentrations in garden and playground soil were similar or below $\mathrm{CA}$ background $\mathrm{Cd}$ levels. This may suggest, that in general, these levels are not due to human activity or historical land use.
Lead Concentration in Garden and Playground Soil

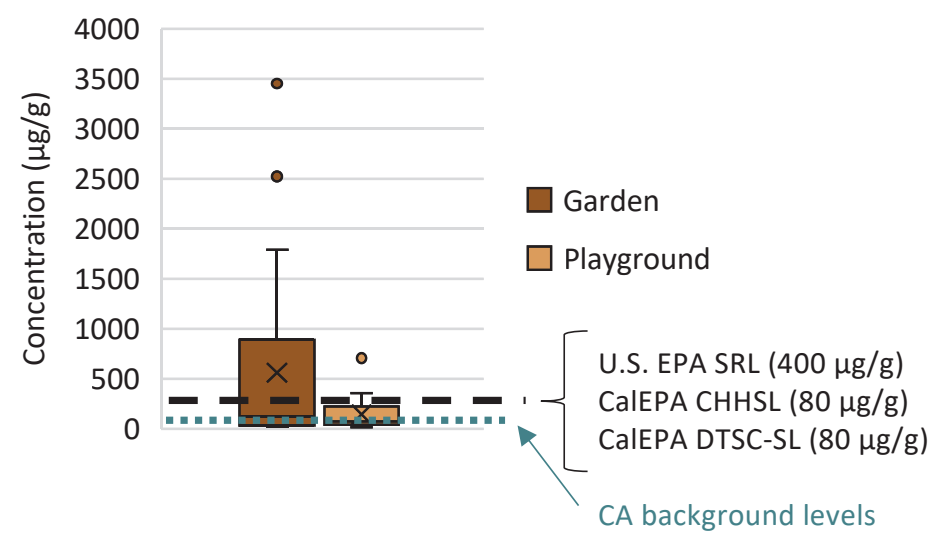

Garden soil samples did exceeded the recommended conservative state and federal soil screening levels for $\mathrm{Pb}$.

Unlike $\mathrm{As}$ and $\mathrm{Cd}$, the measured $\mathrm{Pb}$ concentrations in garden and playground soil were overall above CA background $\mathrm{Pb}$ levels. This suggests that in general, the elevated $\mathrm{Pb}$ concentrations in preschool garden and playground soils are possibly caused by human activity. 


\section{Water \& Dust Results}

Below are the measured arsenic, cadmium, and lead concentrations in garden irrigation water and dust results from the samples collected at each preschool.

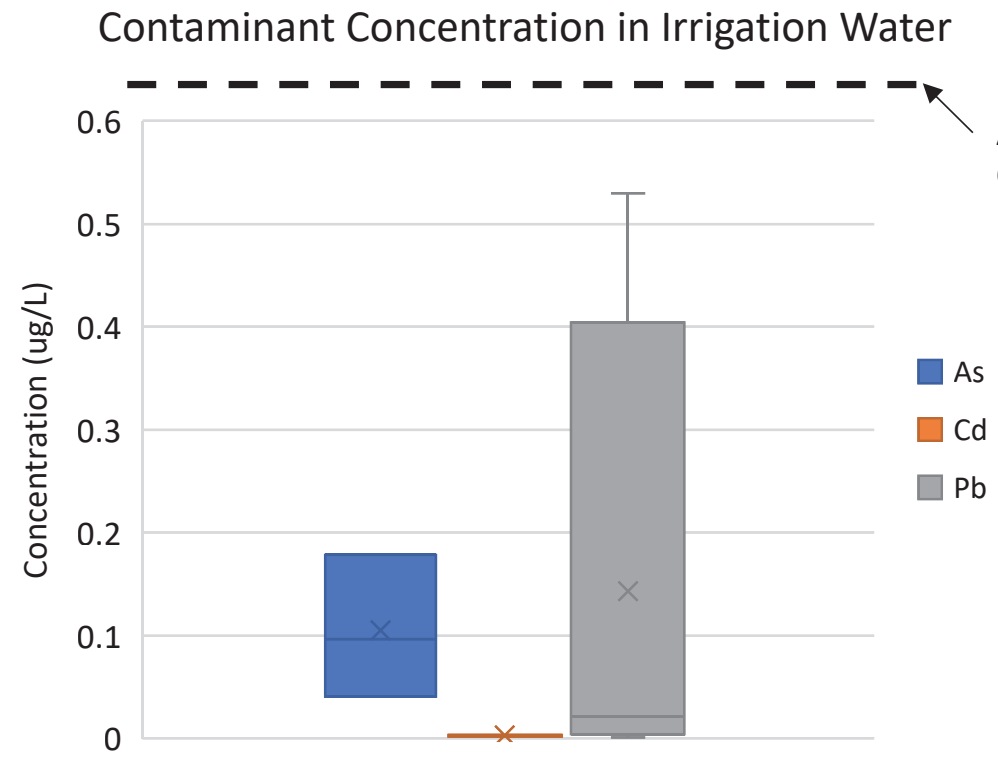

$\mathrm{Pb}$ Action level (AL) (15 ug/L)

As MCL (10 ug/L)

$\mathrm{Cd} \mathrm{MCL}(5 \mathrm{ug} / \mathrm{L})$

The Maximum Contaminant Level

(MCL) is the maximum amount of a regulated contaminant allowable in drinking water. The U.S. EPA sets standards for drinking water that all public water providers must meet.

As, $\mathrm{Cd}$, or $\mathrm{Pb}$ concentrations did not meet or exceed the MCL.

The median $\mathrm{Pb}$ concentration from garden and playground dust in this study were below to the U.S. EPA's National Ambient Air Quality Standard (NAAQS) of $0.15 \mu \mathrm{g} / \mathrm{m}^{3}$ for $\mathrm{Pb}$.

There is currently no federal or state outdoor air standard for As or $\mathrm{Cd}$ concentration available for comparison.

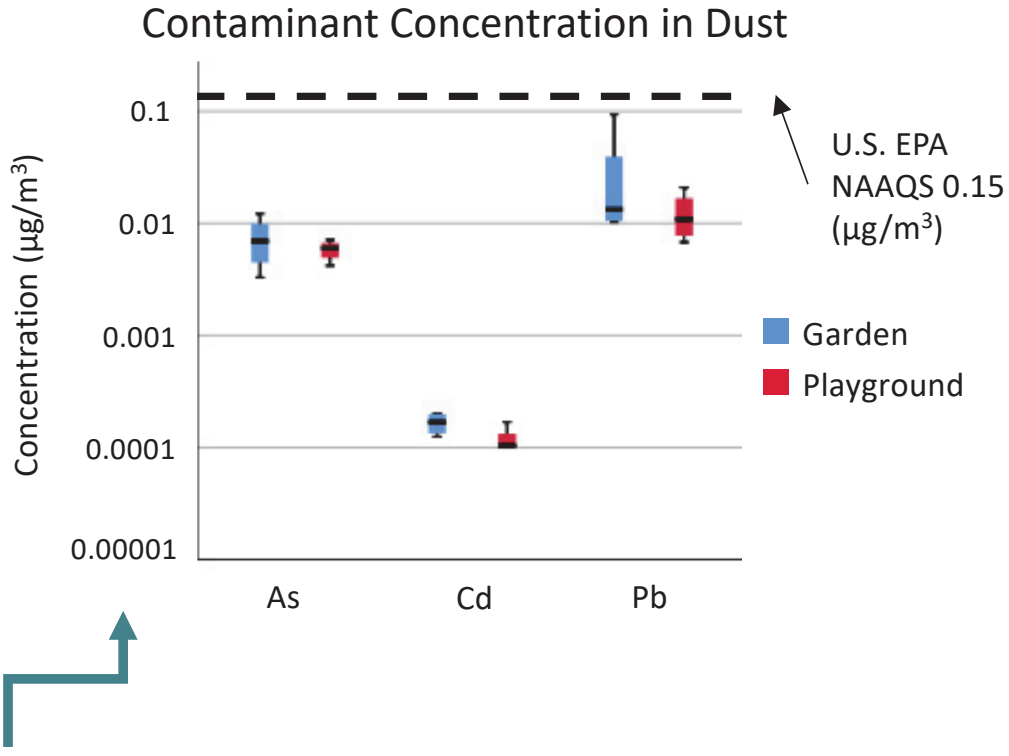

Please note! This Y-axis has a logarithmic scale.

This means that the $Y$-axis increases by a power of 10 . Logarithmic scales are useful to show a large range in values. 


\section{What is an Exposure Assessment?}

An exposure assessment aims to answer the following questions: How much of a contaminant is present in the environment? Are we exposed? If so, how and how much are we exposed to?

In this study we estimated a preschool child's daily dose of $\mathrm{As}, \mathrm{Cd}$, and $\mathrm{Pb}$ from playing and gardening. To do this we used the equation below and the following assumptions:

- Intake rate for the vegetable, water, dust, or soil (incidental) a child would be consuming daily

- Body weight (11.4 to $18.6 \mathrm{~kg}=25$ to $40 \mathrm{lbs}$ )

- Life span equal to 78 years

- Eating that vegetable, drinking the water, incidentally ingesting soil, and inhaling dust for 181 days out of the year (average school year) for 1 year while attending the preschool

- Bioaccessibility of As, Cd, and Pb once it's in your body

Child-specific estimated values are highlighted in the orange boxes.

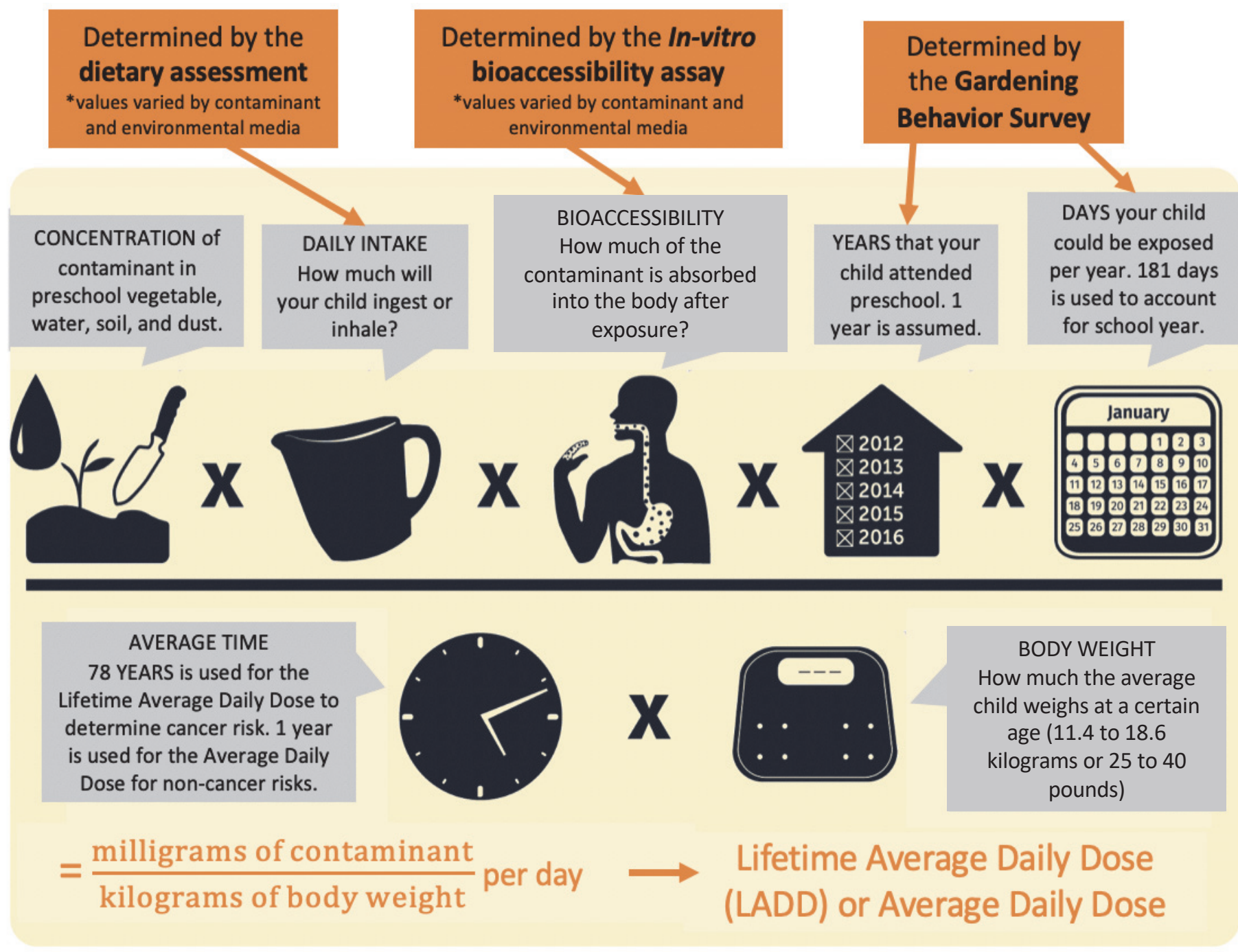




\section{Estimated Exposure (Daily Intake) to Arsenic, Cadmium, and Lead from Vegetables, Soil, Water, and Dust}

A child's cumulative exposure to $\mathrm{As}, \mathrm{Cd}$, and $\mathrm{Pb}$ was estimated for each age group. We determined how much (percentage) each potential exposure route contributed to a child's daily intake (calculated on page 12).

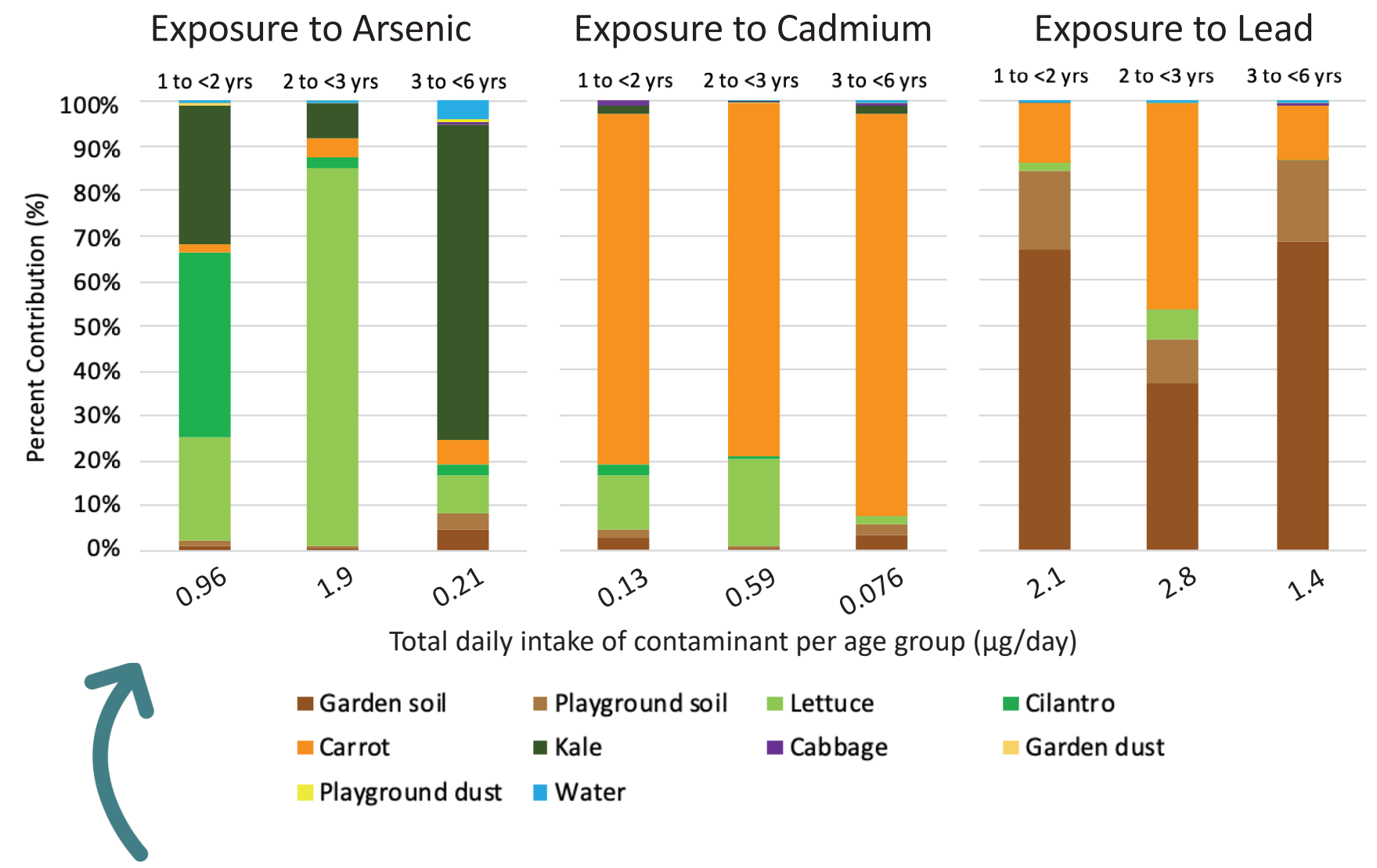

The estimated daily intake of arsenic from all measured exposure routes (vegetables, soil - garden and playground, water, and dust) DID NOT exceed the U.S. EPA's reference dose for arsenic.

Please note! The estimated daily intake of cadmium for 1 to 3 year old children DID exceed CalEPA's child-specific reference dose for cadmium. 


\section{How much can we eat from the preschool garden?} It is your choice to decide what target risk you want to use to make decisions about how many cups per week to consume from the garden.

We calculated how much of each vegetable your child would have to consume weekly to reach a target excess lifetime cancer risk from arsenic exposure. This target excess risk is in addition to our already existing cancer risk from living our normal lives. These intakes were calculated using the median arsenic concentrations in vegetables across all preschools and the same assumptions described on page 12.

\begin{tabular}{|c|c|c|c|}
\hline \multicolumn{3}{|c|}{$\begin{array}{c}\text { Cups per week that your child can eat based } \\
\text { on different target risks }\end{array}$} & \multirow[t]{2}{*}{$\begin{array}{l}\text { USDA recommended } \\
\text { amounts for 2-3 year } \\
\text { old (cups/week) }\end{array}$} \\
\hline $\begin{array}{l}\text { Target risk of } \\
1 / 1,000,000\end{array}$ & $\begin{array}{c}\text { Target risk of } \\
1 / 100,000\end{array}$ & $\begin{array}{c}\text { Target risk of } \\
1 / 10,000\end{array}$ & \\
\hline \multicolumn{3}{|c|}{ Carrot } & Carrot \\
\hline 11.5 & 115 & 1158 & 2.5 \\
\hline \multicolumn{3}{|c|}{ Lettuce } & Lettuce \\
\hline 2 & 21 & 219 & 1.5 \\
\hline \multicolumn{3}{|c|}{ Kale } & Kale \\
\hline 0.1 & 1 & 10 & 0.5 \\
\hline \multicolumn{3}{|c|}{ Cilantro } & Cilantro \\
\hline 0.2 & 2 & 21 & $\begin{array}{c}\text { No recommendation } \\
\text { available }\end{array}$ \\
\hline
\end{tabular}

\section{Please Note!}

- There are uncertainties associated with this estimation.

- For example, a child will be eating the vegetable for 181 days a year for his/her entire lifetime (78 years).

- This is unlikely due to limited vegetable growing seasons and changes in garden productivity.

- Therefore, the calculated risks are conservative, and the actual risk values would most likely be smaller.

$1 / 1,000,000=1$-in-a-million

$1 / 100,000=1$-in-a-hundred-thousand

$1 / 10,000=1$-in-ten-thousand 


\section{References for More Information}

\section{Vegetable}

- U.S. Department of Agriculture (USDA)

- http://www.choosemyplate.gov/food-groups/vegetables amount table.html

- U.S. Environmental Protection Agency (U.S. EPA) - Exposure Factors Handbook

- http://cfpub.epa.gov/ncea/risk/recordisplay.cfm?deid=236252

- U.S. Food and Drug Administration

- http://www.fda.gov/Food/FoodSafety/FoodContaminantsAdulteration/TotalDietStudy

- USDA - What's In The Foods You Eat Search Tool

- $\quad$ http://www.ars.usda.gov/Services/docs.htm?docid=17032

Soil

- CalEPA California Human Health Screening Levels (CHHSLs)

- $\quad$ https://oehha.ca.gov/risk-assessment/california-human-health-screening-levels-chhsls

- CalEPA California Department of Toxic Substances Control Screening Levels (DTSC-SL)

- $\quad$ https://www.dtsc.ca.gov/assessingrisk/humanrisk2.cfm

- University of Arizona Superfund Research Program (UA SRP) - Community Information Sheets

- $\quad$ https://www.superfund.arizona.edu/info-material/information-sheets

- U.S. EPA - Soil Screening Guidance

- $\quad$ http://www.epa.gov/superfund/health/conmedia/soil/index.htm

\section{Water}

- Agency for Toxic Substances and Disease Registry

- http://www.atsdr.cdc.gov/

- UA SRP - Water Booklets

- https://superfund.arizona.edu/info-material/water-booklets-and-videos

- U.S. EPA - Drinking Water Contaminants - Standards and Regulations

- http://water.epa.gov/drink/contaminants/index.cfm

\section{Dust}

- U.S. EPA - Lead National Ambient Air Quality Standard

- https://www.epa.gov/criteria-air-pollutants/naaqs-table 


\section{¡Muchas gracias!}

Estimado padre de familia,

¡Lo hicimos! Me gustaría dar un agradecimiento especial a todos los participantes de Nevada County Gardenroots por sus esfuerzos, motivación y paciencia durante este proyecto de investigación. Agradecemos el tiempo que ha invertido en participar en este proyecto. En total, entrenamos a 33 miembros de la comunidad que recibieron capacitación, y se prepararon y analizaron 38 muestras de suelo, 8 de polvo, 12 de agua y 45 de vegetales.

Este estudio de colaboración fue realizado por un equipo de investigadores del Instituto Sierra Streams (una organización regional sin fines de lucro de ciencia de cuencas hidrográficas en Nevada City, CA), la Universidad de Arizona y la Universidad de California en San Francisco. Este estudio fue financiado por el Programa de Investigación del Cáncer de Mama de California.

Al conocer la dieta de su hijo y la calidad ambiental de su comunidad, pudimos identificar las brechas en la investigación de salud ambiental y las formas de mejorar la calidad de los jardines preescolares. Este paquete muestra los resultados de la evaluación de exposición realizada para varios centros preescolares, incluido el que asiste su hijo. Comparamos los resultados con los estándares regulatorios estatales y federales y / o valores de referencia cuando están disponibles. En este paquete, hemos incluido lo siguiente:

1. Descripción del proyecto

2. Términos importantes que verás a lo largo de los resultados

3. Información general sobre contaminantes seleccionados de interés

4. Una guía para leer los resultados

5. Resultados de vegetales, suelo, agua de riego y polvo

6. Resultados de la exposición acumulativa del niño

7. Referencias para más información sobre calidad ambiental y lineamientos

Sinceramente,

Mónica Ramírez-Andreotta, Profesor Asastente Universidad de Arizona

1177 E $4^{\text {th }}$ St., Rm. 429, Tucson, AZ 85721

Teléfono: 520-621-0091 Fax: 520-621-1647

Joanne Hild

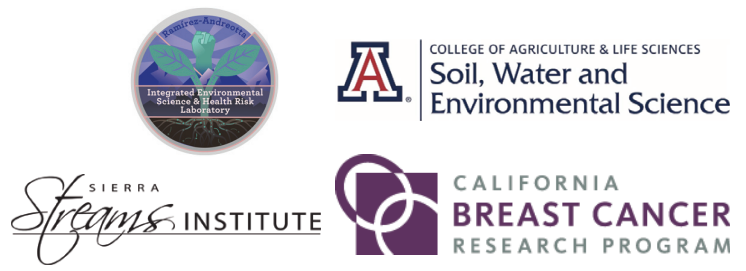

Director Ejecutivo, Científico del río

Instituto de Sierra Streams

13075 Woolman Ln.

Nevada City, CA 95959 (530) 477- 7132 Ext. 200

www.sierrastreamsinstitute.org

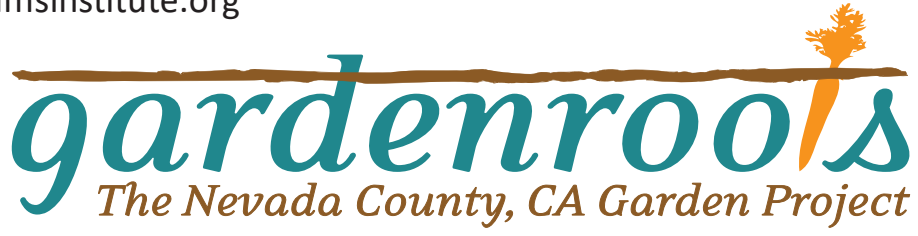




\section{Descripción del proyecto}

Basado en las preocupaciones de los miembros de la comunidad con respecto a la calidad ambiental, se desarrolló Gardenroots: The Nevada City, CA Garden Project. Gardenroots es un proyecto de monitoreo ambiental y de evaluación de la exposición infantil diseñado para comprender mejor la posible exposición del niño al arsénico, el cadmio y el plomo. Al ver a los jardines como centros de investigación y educación para la salud ambiental, Gardenroots está tratando de comprender el estado de la calidad ambiental en las comunidades rurales. Los resultados de este estudio ayudan a determinar si las personas están expuestas a contaminantes metálicos a través de la jardinería y la ingestión de cultivos.

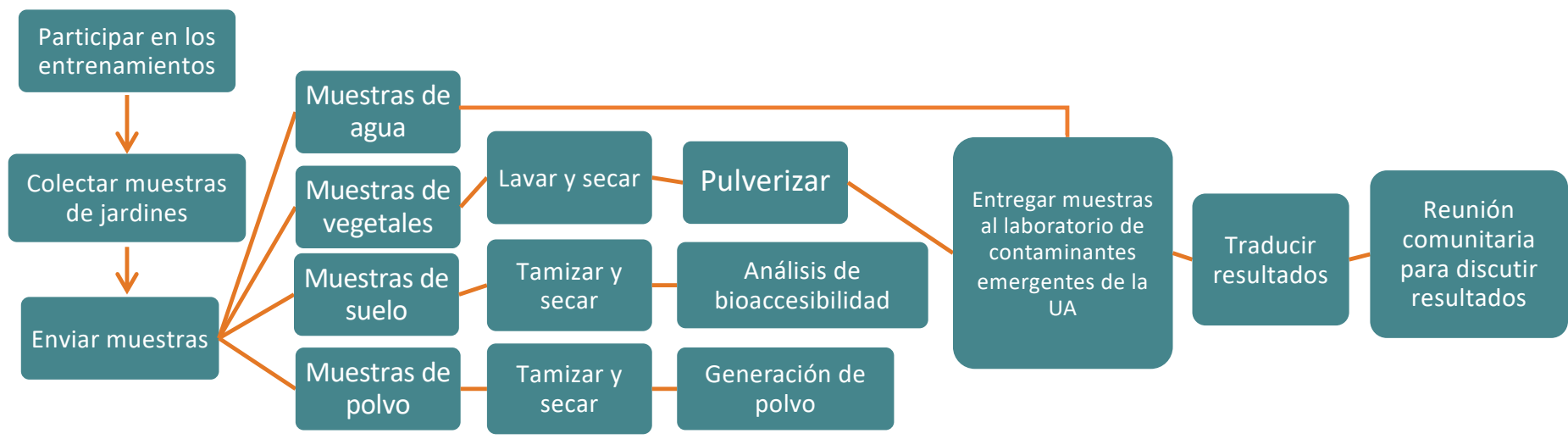

Los datos pueden estar sujetos a revisiones.

Los resultados han sido revisados internamente, pero no han sido revisados por pares externos y pueden estar sujetos a cambios menores.

Los metales se producen naturalmente en el medio ambiente.

Podemos medir el nivel de un metal en ciertas sustancias, como el agua o el suelo, pero es difícil saber la fuente original del metal. Por ejemplo, el arsénico se puede encontrar en el suelo en muchas partes del estado porque también ocurre naturalmente en estas regiones.

Es importante tener en cuenta que, como el arsénico, se producen naturalmente en el suelo y es imposible cultivar plantas completamente libres de estos y otros oligoelementos como el plomo y el cadmio.

Consulte los folletos de prácticas de jardinería recomendadas para encontrar formas de reducir los niveles de químicos dañinos en su jardín y en sus vegetales.

Las mediciones de una sola exposición son "instantáneas en el tiempo".

Estamos midiendo las concentraciones de metales en un solo punto en el tiempo. La medición de las concentraciones de metales con un solo muestreo no establece cuáles fueron las exposiciones en el pasado ni cuáles podrían ser en el futuro.

Para obtener más información sobre el estudio y las prácticas seguras de jardinería, visite el sitio web de Gardenroots: http://www.gardenroots.arizona.edu/ 


\section{Términos importantes}

A continuación se muestra un conjunto de términos que se pueden ver en sus resultados:

Nivel de acción (AL): La Agencia de Protección del Medio Ambiente de los Estados Unidos (U.S. EPA) Regula el plomo según la Regla de Plomo y Cobre. Esta regla describe los requisitos de tratamiento de agua necesarios para controlar la corrosión de las tuberías que pueden contaminar el agua potable. Si la concentración de plomo en el agua está por encima del nivel de acción, esto significa que se requieren acciones para corregir el sistema de agua para cumplir con esta regulación.

Concentración: La cantidad de un producto químico en una masa determinada de agua, suelo o tejido vegetal. Esto se escribe como $\mu \mathrm{g} / \mathrm{L}$ (microgramos por litro), $\mu \mathrm{g} / \mathrm{m}^{3}$ (microgramos por metro cúbico) o $\mu \mathrm{g} / \mathrm{g}$ (microgramos por gramo).

MCL (Nivel máximo de contaminantes): El MCL es la cantidad máxima de un contaminante permitido en el agua potable, por lo que aún es seguro beberla durante muchos años. Este nivel es establecido por la Agencia de Protección Ambiental de los Estados Unidos.

Nivel mediana: El valor en el punto medio (valor medio) del rango de valores.

Estándar Nacional de Calidad del Aire Ambiental (NAAQS): Estos son estándares establecidos por la EPA de los EE. UU. Para proteger la salud humana. El estándar para el plomo define la concentración máxima permitida de plomo en un metro cuadrado cúbico de aire exterior. Este estándar tiene un ajuste de corriente de $0.15 \mu \mathrm{g} / \mathrm{m}^{3}$.

Percentil: Un número en el que un cierto porcentaje de puntajes cae por debajo de ese número. Por ejemplo, si sabe que su puntaje está en el percentil 90, eso significa que obtuvo un puntaje mejor que el $90 \%$ de las personas que tomaron la prueba.

$\mu \mathrm{g} / \mathrm{L}$ (microgramos por litro): una medida de la cantidad de microgramos de una sustancia (como un metal, o un producto químico) en un litro de líquido (como el agua). Esta medida también puede denominarse partes por billón (ppb) o 0,0000001\%. Para comparación, 1 mg/L o ppb es el equivalente a una gota de tinta en una piscina de 15,000 galones de una casa.

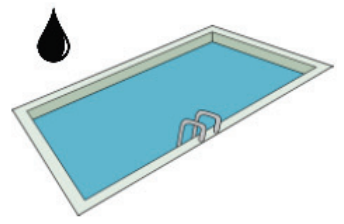

\begin{tabular}{|c|c|c|}
\hline $\begin{array}{c}\text { Microgramos por Litro } \\
(\mu \mathrm{g} / \mathrm{L})\end{array}$ & $\begin{array}{c}\text { Partes por Billón } \\
(\mathrm{ppb})\end{array}$ & $1 / 1,000,000,000$ \\
\hline
\end{tabular}




\section{Términos importantes}

$\mu \mathrm{g} / \mathrm{m}^{3} \mathrm{o} \mu \mathrm{g} / \mathrm{cu} \mathrm{m}$ (microgramos por metro cúbico): Una medida de cuántos microgramos de una sustancia (como un metal) hay en un metro cúbico de aire.

Dosis de referencia $(\mathrm{RfD})$ : Estimación de la ingesta diaria de un producto químico que no es probable que produzca efectos negativos significativos para la salud (incluidas las poblaciones sensibles, como niños y ancianos). Puede ser referido como la ingesta diaria aceptable.

Estándares: Los estándares notificados en este folleto son valores ejecutables y regulatorios, establecidos por agencias federales o por el estado de California. Son diferentes de las advertencias o los avisos y de las pautas o directrices.

Niveles de cribado del suelo

- Nivel de selección regional de la EPA de los EE. UU. (U.S. EPA RSL): Concentraciones de contaminantes basadas en el riesgo en los suelos que se calculan utilizando lo que sabemos sobre la exposición a un contaminante y lo que la EPA de los EE. UU. conoce sobre la toxicidad del producto químico. La EPA de EE. UU. considera estos niveles de detección como objetivos iniciales de limpieza, cuando corresponda. No son estándares nacionales de limpieza, y se basan en diferentes riesgos objetivo.

- CalEPA California Human Health Screening Levels (CalEPA CHHSLs): Concentraciones de contaminantes basadas en el riesgo en suelos que son específicos de California. Los niveles de detección del plomo no son niveles de detección basados en el riesgo, sino la concentración promedio de $\mathrm{Pb}$ en el suelo residencial que protegería a los niños y mujeres en edad fértil. Estos valores son más conservadores que los EE. UU. EPA RSL.

- CalEPA California Departamento de Niveles de Detección de Control de Sustancias Tóxicas (CalEPA DTSC-SL): Niveles de detección recomendados basados en el riesgo que se derivan de la exposición modificada con DTSC y factores de toxicidad para contaminantes en el suelo. Estos valores también son más conservadores que los EE. UU. EPA RSL. 


\section{Arsénico (As)}

Nombre del Contaminante: Arsénico (As)

Tipo de Contaminante: Metaloide

\section{¿Qué es el arsénico?}

El arsénico existe naturalmente en la corteza terrestre y se puede encontrar en sedimentos, suelos y aguas subterráneas. El arsénico también puede liberarse al medio ambiente a través de la minería, la fundición de mineral y el uso industrial del elemento.

\section{¿Qué le sucede al arsénico cuando entra al medio ambiente?}

En el medio ambiente, las personas pueden estar expuestas al arsénico en dos formas químicas:

- Inorgánico: Se pueden encontrar naturalmente cantidades variables de esta forma venenosa (formas tóxicas) en los materiales geológicos (suelos, rocas, materiales de acuíferos) y en aguas subterráneas y superficiales, que también pueden verse afectadas por residuos mineros e industriales y plaguicidas arsenicales.

- Orgánicos (compuestos de arsénico que contienen carbono): Se pueden encontrar cantidades variables de esta forma no tóxica (baja toxicidad) en fuentes como animales, plantas, pescados y mariscos. Los pescados y mariscos pueden acumular arsénico; la mayor parte de este arsénico se encuentra en una forma orgánica llamada arsenobetaína que es mucho menos dañina.

\section{¿Cómo puede el arsénico afectar mi salud?}

La intoxicación grave (aguda) por arsénico puede causar vómitos, dolor abdominal y diarrea. Esto puede ser seguido por adormecimiento y hormigueo de las extremidades, calambres musculares y muerte en casos extremos. Ingerir o respirar niveles bajos de arsénico inorgánico durante un tiempo prolongado (crónico) puede causar efectos no relacionados con la salud, como el oscurecimiento de la piel y la aparición de pequeñas "verrugas" en las palmas de las manos, las plantas de los pies y el torso. Otros efectos no concernientes con el cáncer relacionado con la ingestión a largo plazo de arsénico incluyen efectos sobre el desarrollo, diabetes, enfermedad pulmonar y enfermedad cardiovascular. La ingestión de arsénico inorgánico puede aumentar el riesgo de cáncer de piel y cáncer en el hígado, la vejiga y los pulmones. La inhalación de arsénico inorgánico puede aumentar el riesgo de cáncer de pulmón.

\section{¿Dónde puedo obtener más información sobre el arsénico?}

Agencia de Sustancias Tóxicas y Registro de Enfermedades. ToxFAQsTM para el arsénico. Última actualización el 12 de marzo de 2015. Puede acceder a esta información en:

\section{https://www.atsdr.cdc.gov/toxfaqs/tf.asp?id=19\&tid=3}




\section{Cadmium (Cd)}

Nombre del contaminante: Cadmio (Cd)

Tipo de contaminante: Heavy Metal

\section{¿Qué es el cadmio?}

El cadmio se encuentra en la corteza terrestre. La mayoría del cadmio utilizado en los Estados Unidos se extrae como un subproducto durante la producción de otros metales como el zinc, el plomo o el cobre. El cadmio también se recupera de las baterías usadas. El cadmio se utiliza para lo siguiente: baterías, pigmentos, recubrimientos y revestimientos, estabilizadores para plásticos, dispositivos fotovoltaicos (materiales de energía solar) y otros usos.

\section{¿Qué le sucede al cadmio cuando entra al medio ambiente?}

El cadmio se libera al suelo, el agua y el aire mediante la extracción y refinación de metales, la fabricación y aplicación de fertilizantes con fosfato, la combustión de combustibles fósiles y la incineración y eliminación de desechos. En general, el cadmio se une fuertemente a la materia orgánica, donde puede permanecer en el suelo y ser absorbido por la vida vegetal, entrando eventualmente en el suministro de alimentos.

\section{¿Cómo puede afectar el cadmio mi salud?}

Fumar cigarrillos es una ruta importante de exposición al cadmio. El tabaco puede haber sido cultivado en suelos contaminados, o se aplicaron pesticidas / fungicidas o aditivos durante el proceso de cultivo y fabricación. La exposición al cadmio puede ocurrir al respirar el aire del lugar de trabajo contaminado, beber agua contaminada o vivir cerca de instalaciones industriales que liberan el cadmio en el aire. Comer alimentos o tomar agua con niveles muy altos irrita gravemente el estómago y provoca vómitos y diarrea. La exposición a largo plazo a niveles más bajos de cadmio en el aire, los alimentos o el agua conduce a una acumulación de cadmio en los riñones y a una posible enfermedad renal. Otros efectos a largo plazo incluyen daño pulmonar y huesos frágiles. Los niveles bajos de cadmio se encuentran en todos los alimentos (los niveles más altos se encuentran en los mariscos, el hígado y las carnes renales). En los EE. UU., Para los no fumadores, la fuente principal de exposición al cadmio es el suministro de alimentos. Respirar altos niveles de cadmio puede dañar gravemente los pulmones. Se sabe que el cadmio y los compuestos de cadmio causan cáncer en los humanos.

\section{¿Dónde puedo obtener más información sobre el cadmio?}

Agencia de Sustancias Tóxicas y Registro de Enfermedades. ToxFAQsTM para Cadmio. Última actualización el 12 de marzo de 2015. Puede acceder a esta información en: https://www.atsdr.cdc.gov/toxfags/tf.asp?id=47\&tid=15 


\section{Lead $(\mathrm{Pb})$}

Nombre del contaminante: Plomo (Pb)

Tipo de contaminante: Metal Pesado

\section{¿Qué es el plomo?}

El plomo es un metal en la corteza terrestre que normalmente se encuentra con otros metales como el zinc, la plata y el cobre. El plomo tiene muchos usos, incluyendo la fabricación de pinturas, baterías y pesas. La soldadura con base de plomo, que se había utilizado para conectar tuberías de cobre de agua, se prohibió en la década de 1980, pero aún puede ser una fuente de plomo en el agua potable en las casas más antiguas. En los E.E.U.U., el plomo se usaba como aditivo de la gasolina, pero se prohibió a partir de 1973 y se eliminó en 1996.

¿Qué pasa con el plomo cuando entra en el ambiente?

Las mujeres embarazadas también pueden exponer a su hijo por nacer al plomo a través de la ingestión. Los adultos pueden estar expuestos a través de las opciones de diversos estilos de vida o por medio de su ocupación (plomería, soldadura, plantas de fabricación, empresas de construcción / remodelación, fundiciones y talleres de automóviles). Otras fuentes de exposición potencial al plomo que incluyen: pinturas, vasijas de arcilla vidriada, vino, alimentos, vidrio con plomo, vitrales, tintes y remedios caseros (azarcón o greta para tratar enfermedades digestivas).

\section{¿Cómo puede el plomo afectar mi salud?}

El plomo puede afectar a casi todos los órganos y sistemas de su cuerpo, tanto en adultos como en niños. La exposición al plomo puede dañar seriamente la salud de un niño. Puede dañar el cerebro y el sistema nervioso, retrasar el crecimiento y el desarrollo, causar problemas de aprendizaje, comportamiento, audición y habla. Provoca un menor coeficiente intelectual, una menor capacidad para prestar atención y un bajo rendimiento en la escuela. La exposición al plomo también causa pequeños aumentos de la presión arterial, especialmente en personas de mediana edad y mayores de edad, y puede causar anemia. En mujeres embarazadas, los altos niveles de exposición al plomo pueden causar un aborto espontáneo. La exposición de alto nivel en los hombres puede dañar los órganos responsables de la producción de esperma.

¿Dónde puedo obtener más información sobre el plomo?

Agencia de Sustancias Tóxicas y Registro de Enfermedades. ToxFAQsTM para plomo. Última actualización el 24 de agosto de 2016. Puede acceder a esta información en: https://www.atsdr.cdc.gov/toxfaqs/tf.asp?id=93\&tid=22 


\section{Una guía para leer los resultados}
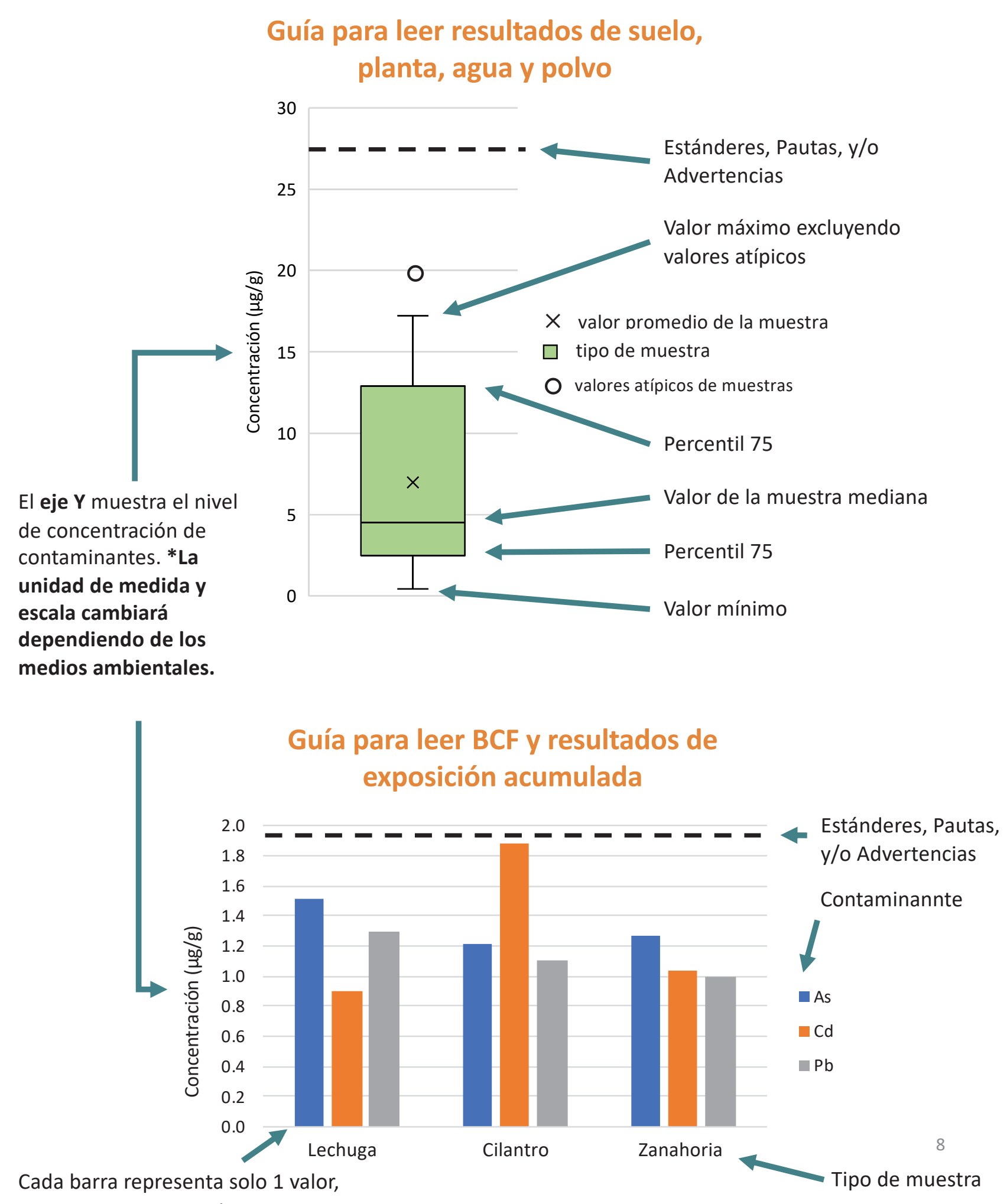

Cada barra representa solo 1 valor a menos que se muestre como un porcentaje del $100 \%$ en el eje $Y$ 


\section{Resultados de vegetales}

A continuación se describen las concentraciones medidas de arsénico, cadmio y plomo en los vegetales que se recolectaron en cada preescolar.

\section{Concentración en vegetales de jardín}
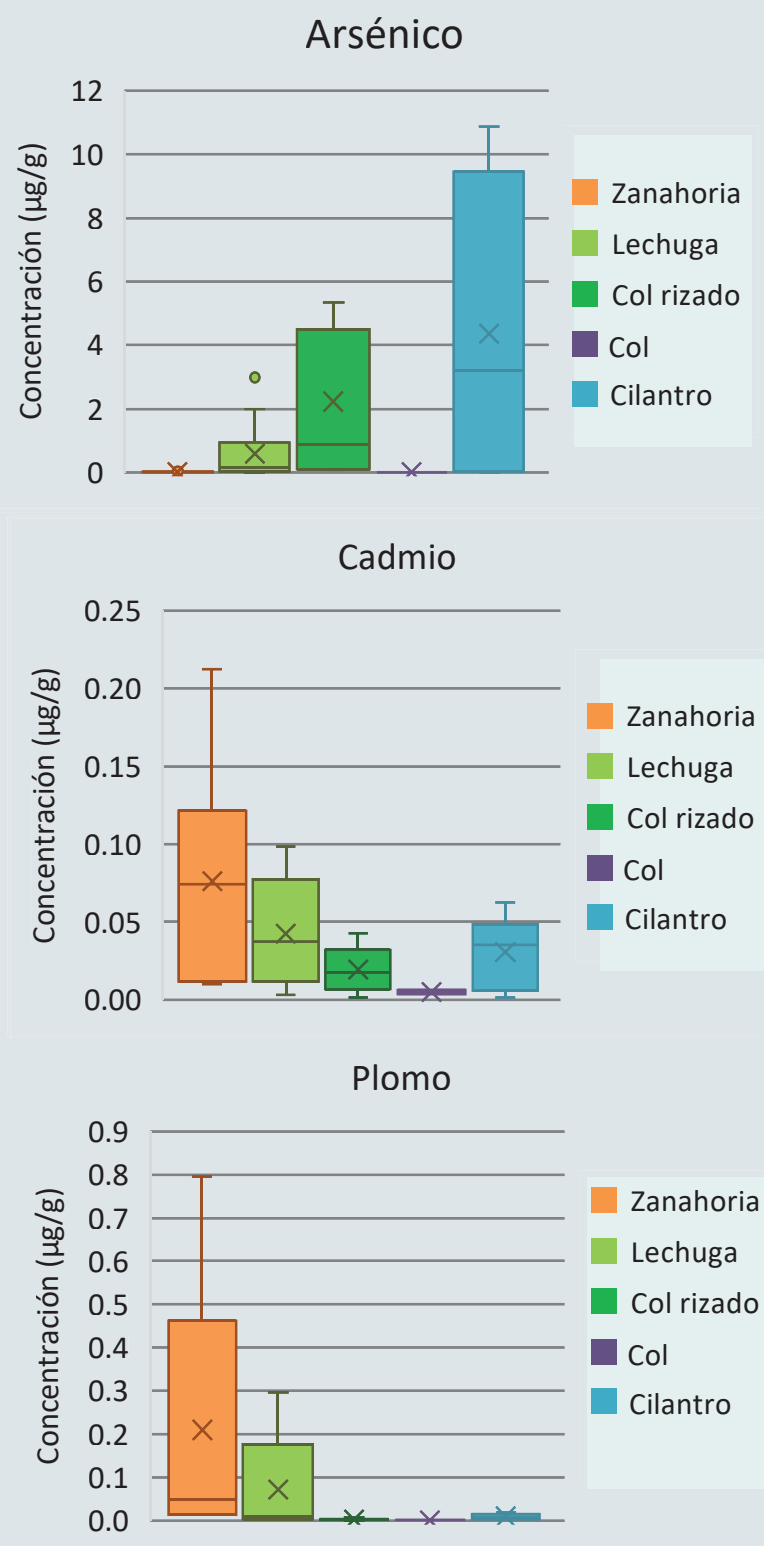

Encontramos que las plantas de Apaiaceae (zanahoria y cilantro) tuvieron las concentraciones medias más altas.

\section{Factor de bioconcentración de la planta}

El factor de bioconcentración de la planta (BCF) es la proporción de la concentración de metal en la porción comestible en el vegetal (peso seco) y la concentración de metal en el suelo.

$B C F=\frac{\text { Concentración de contaminante en la planta }}{\text { Concentración de contaminante en suelo de jardín }}$

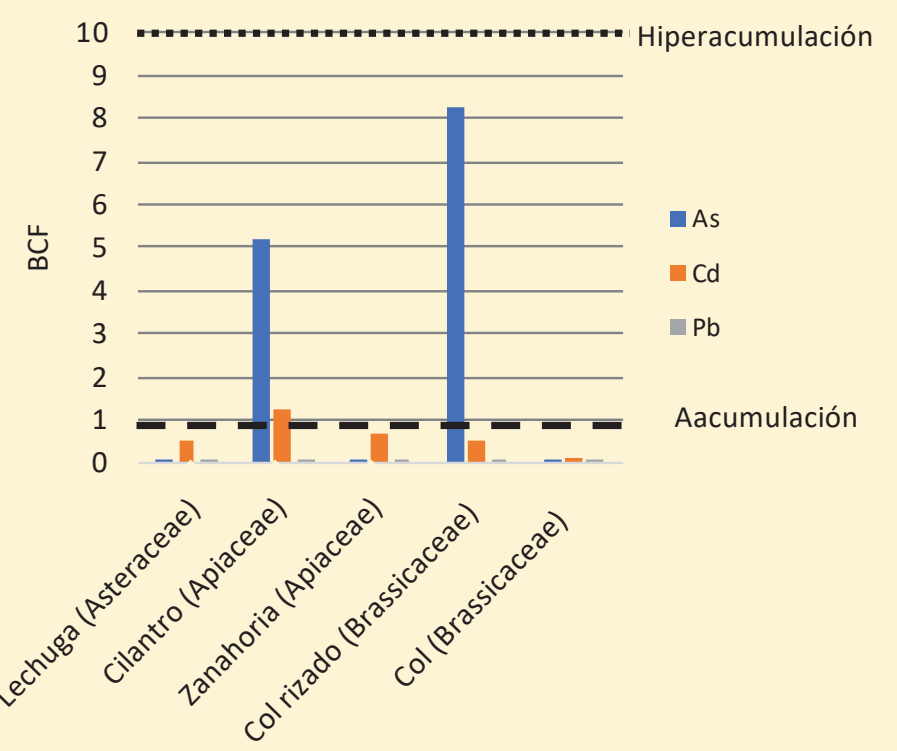

Los resultados sugirieron que el cilantro y la col rizada acumularon más As que otras plantas, mientras que solo el cilantro acumuló $\mathbf{C d}$. Ciertos miembros de las familias Asteraceae y Brassicaceae han sido identificados previamente como plantas hiperacumuladoras, lo que significa que pueden tener una capacidad genética y fisiológica para acumular altas cantidades de metales.

Con esta evidencia, se recomienda que los jardineros domésticos limiten el uso de vegetales de las familias de plantas Apiaceae y Brassicaceae. 


\section{Resultados del suelo}

A continuación se muestran las concentraciones de arsénico, cadmio y plomo en las muestras de suelo que se recolectaron en cada preescolar.

\section{Concentración de arsénico en}

suelos de jardines y patio de recreo

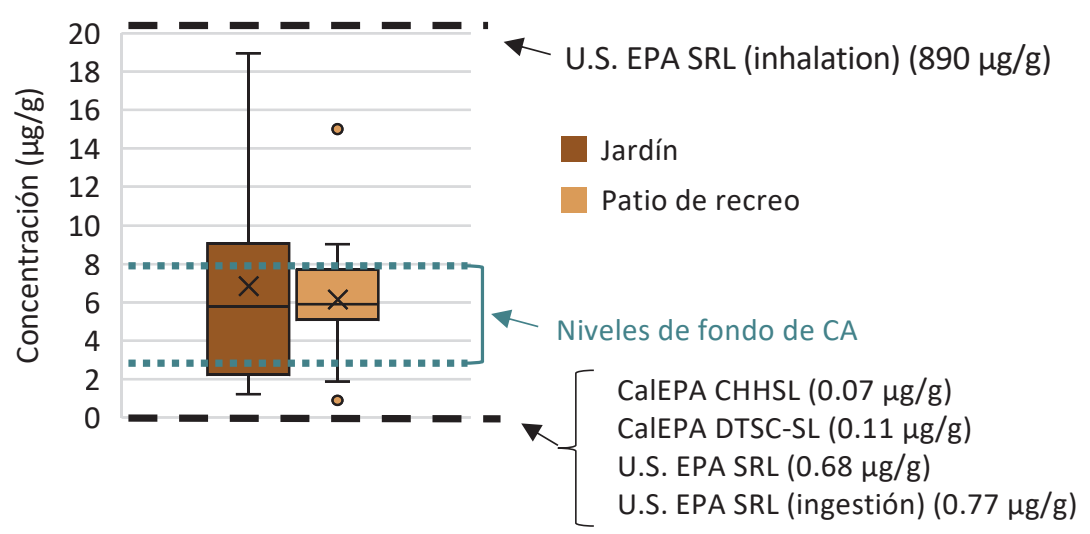

Las muestras de suelo excedieron los niveles de evaluación de suelos federales y estatales conservadores recomendados para As.

¡Tenga en cuenta! Las concentraciones medidas de As en el suelo del jardín y del patio de recreo en general fueron similares a los niveles de As de fondo de CA. Esto puede sugerir que, en general, estos niveles no se deben a la actividad humana o al uso histórico de la tierra.

\section{Concentración de cadmio en suelos}

\section{de jardines y patio de recreo}

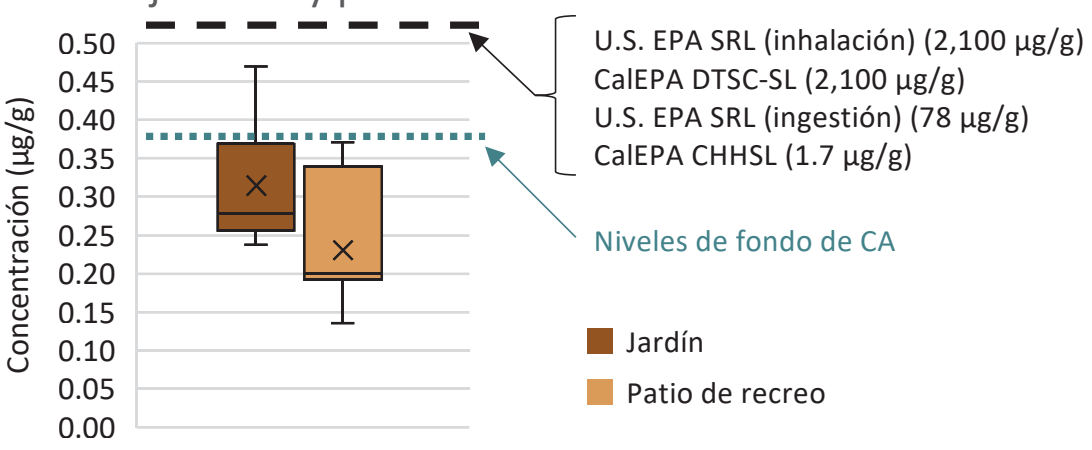

En general, las muestras de suelo no excedieron los niveles de detección de suelo federales y estatales recomendados para $\mathrm{Cd}$.

Como en As, las concentraciones de Cd medidas en el suelo del jardín y del patio de recreo fueron similares o inferiores a los niveles de $\mathrm{Cd}$ de fondo de CA. Esto puede sugerir que, en general, estos niveles no se deben a la actividad humana o al uso histórico de la tierra.

\section{Concentración de plomo en suelos} de jardines y parques infantiles

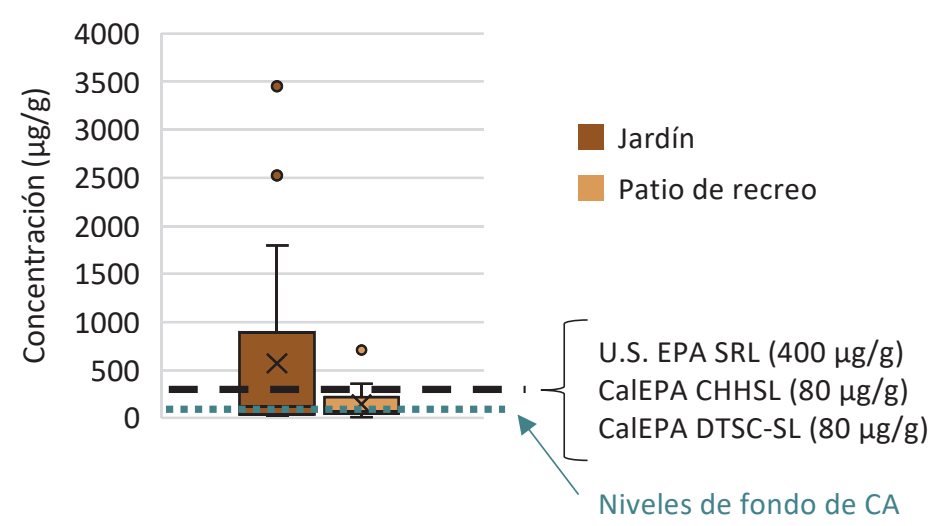

Las muestras de suelo de jardín superaron los niveles de detección de suelo federales y estatales recomendados para $\mathrm{Pb}$.

A diferencia de $\mathrm{As}$ y $\mathrm{Cd}$, las concentraciones de $\mathrm{Pb}$ medidas en el suelo del jardín y del patio de recreo fueron en general superiores a los niveles de $\mathrm{Pb}$ de fondo de CA. Esto sugiere que, en general, las concentraciones elevadas de $\mathrm{Pb}$ en los jardines de los jardines preescolares y los terrenos de juego posiblemente sean causados por la actividad humana. 


\section{Resultados de agua y polvo}

A continuación se muestran las concentraciones de arsénico, cadmio y plomo medidas en los resultados de agua y polvo de riego de jardines de las muestras recolectadas en cada preescolar.

Concentración de contaminantes en el agua de riego

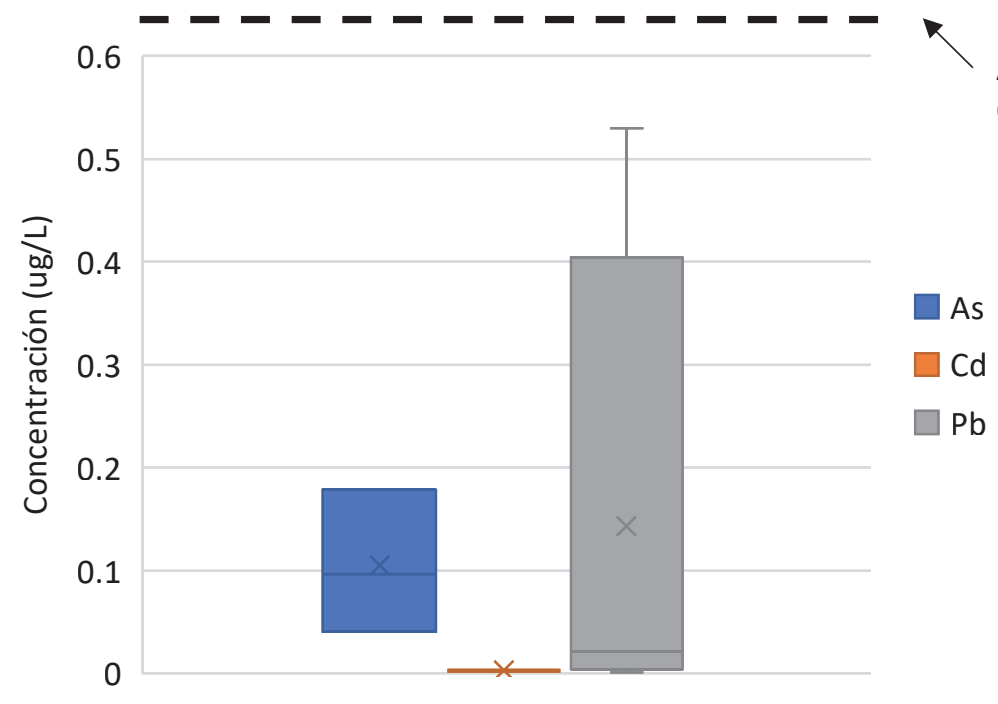

$\mathrm{Pb}$ Nivel de acción (AL) (15ug/L)

As MCL (10 ug/L)

$\mathrm{Cd} \mathrm{MCL}(5 \mathrm{ug} / \mathrm{L})$

\section{El Nivel Máximo de Contaminante}

(MCL) es la cantidad máxima de un contaminante regulado permitido en el agua potable. La EPA de los EE. UU. Establece normas para el agua potable que todos los proveedores públicos de agua deben cumplir.

Las concentraciones de $\mathrm{As}, \mathrm{Cd}$ o $\mathrm{Pb}$ no alcanzaron o superaron el MCL.

La concentración media de $\mathrm{Pb}$ del polvo del jardín y del patio de recreo en este estudio fue inferior al Estándar Nacional de Calidad del Aire Ambiental (NAAQS) de los EE. UU. EPA de $0,15 \mu \mathrm{g} / \mathrm{m}^{3}$ para $\mathrm{Pb}$.

Actualmente no existe un estándar federal o estatal de aire exterior para la concentración de As o Cd disponible para comparación.
Concentración de contaminantes en el polvo

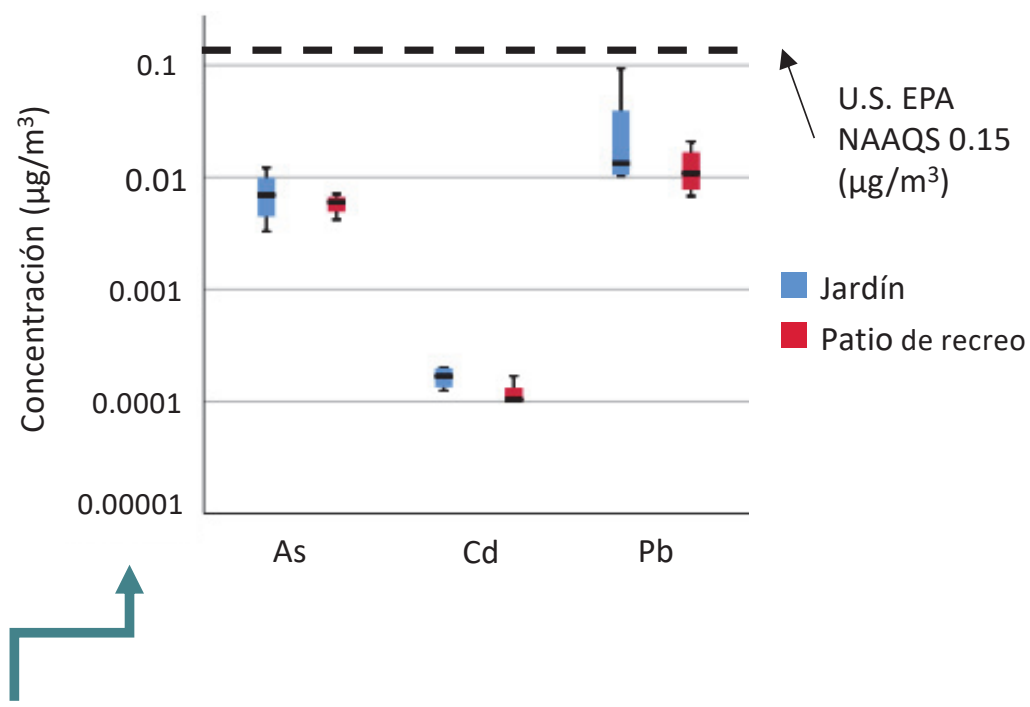

¡Tenga en cuenta! Este eje $\mathrm{Y}$ tiene una escala logarítmica. Esto significa que el eje $\mathrm{Y}$ aumenta con una potencia de 10. Las escalas logarítmicas son útiles para mostrar un amplio rango de valores. 


\section{¿Qué es una evaluación de exposición?}

Una evaluación de exposición responde las siguientes preguntas: ¿Qué cantidad de contaminante está presente en el medio ambiente? ¿Estamos expuestos? Si es así, ¿cómo y cuánto estamos expuestos?

En este estudio, estimamos la dosis diaria de $\mathrm{As}, \mathrm{Cd}$ y $\mathrm{Pb}$ de un niño en edad preescolar por juego y jardinería. Para hacer esto usamos la siguiente ecuación y los siguientes supuestos:

- La cantidad de ingestion de vegetales, agua, polvo o tierra (incidental) que un niño consumiría diariamente

- Peso corporal (11.4 a $18.6 \mathrm{~kg}=25$ a $40 \mathrm{lbs})$

- Vida útil igual a 78 años

- Comer esa verdura, beber el agua, ingerir incidentalmente tierra e inhalar polvo durante 181 días al año (año escolar promedio) durante 1 año

- Bioaccesibilidad de As, Cd y Pb en su cuerpo

Los valores estimados específicos del niño se resaltan en los cuadros de color naranja.

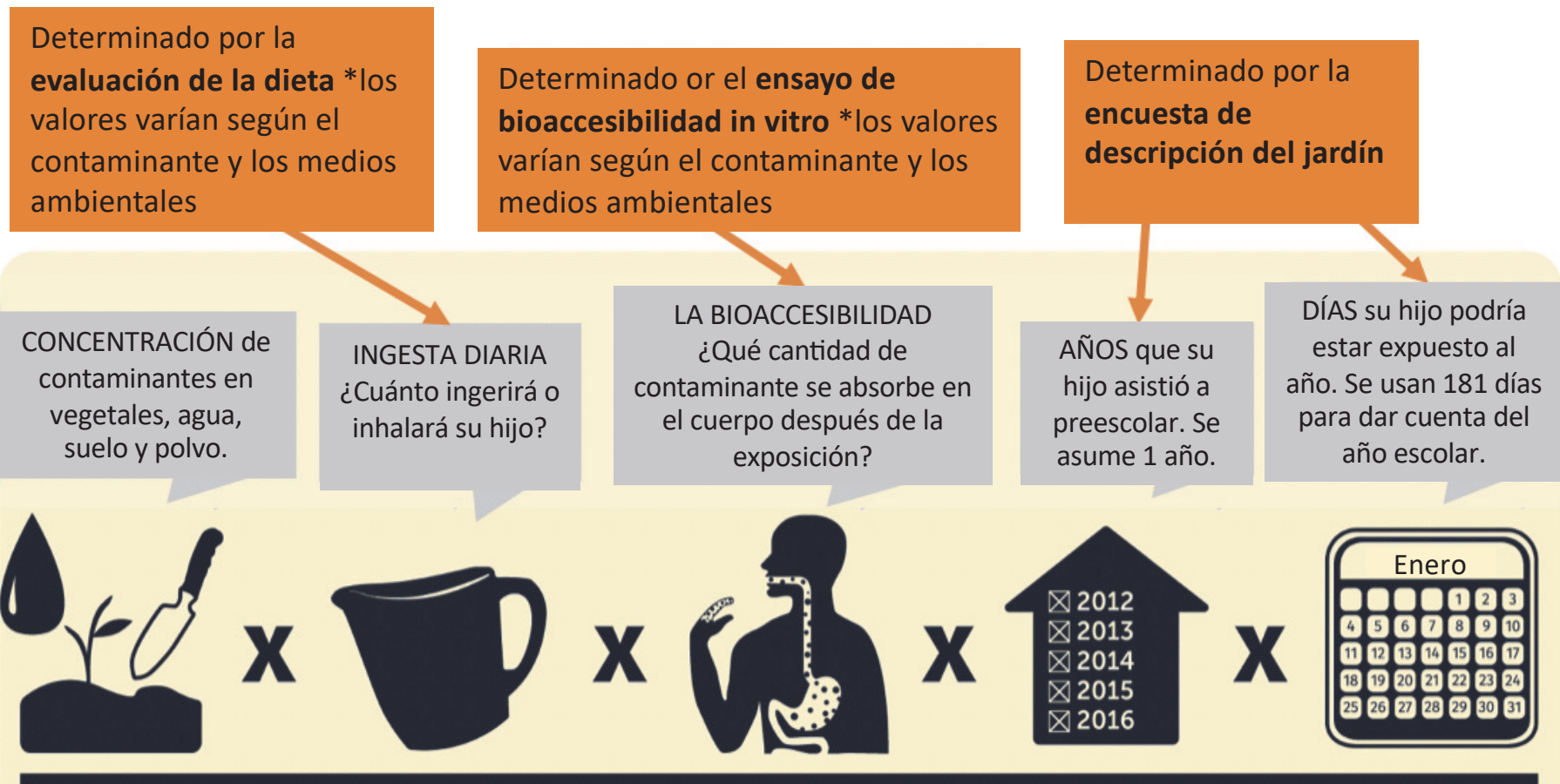

TIEMPO PROMEDIO

78 años se usan para la Dosis

Diaria Promedio Por Vida para determinar el riesgo de cáncer. Se utiliza 1 año para la Dosis Diaria Promedio para los riesgos no relacionados con el cáncer.
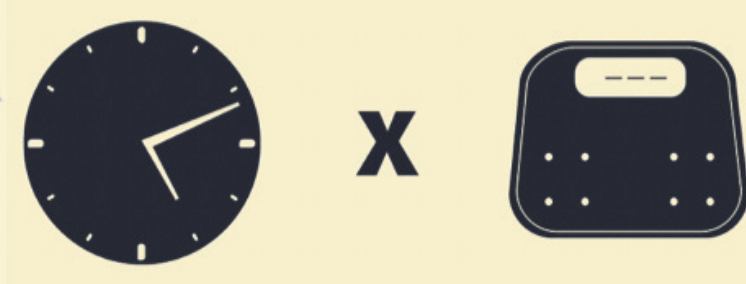

PESO CORPORAL

Cuánto pesa un niño promedio a cierta edad (11.4 a 18.6 kilogramos o 25 a 40 libras)

$$
=\frac{\text { miligramos de contaminante }}{\text { kilogramos de contaminante }}
$$




\section{Exposición estimada (ingesta} diaria) de arsénico, cadmio y plomo de vegetales, suelo, agua y polvo

La exposición acumulada de un niño a As, $\mathrm{Cd}$ y Pb se estimó para cada grupo de edad. Determinamos cuánto (porcentaje) contribuyó cada ruta de exposición potencial a la dosis diaria de un niño (calculada en la página 12).

\section{Exposición al arsénico}

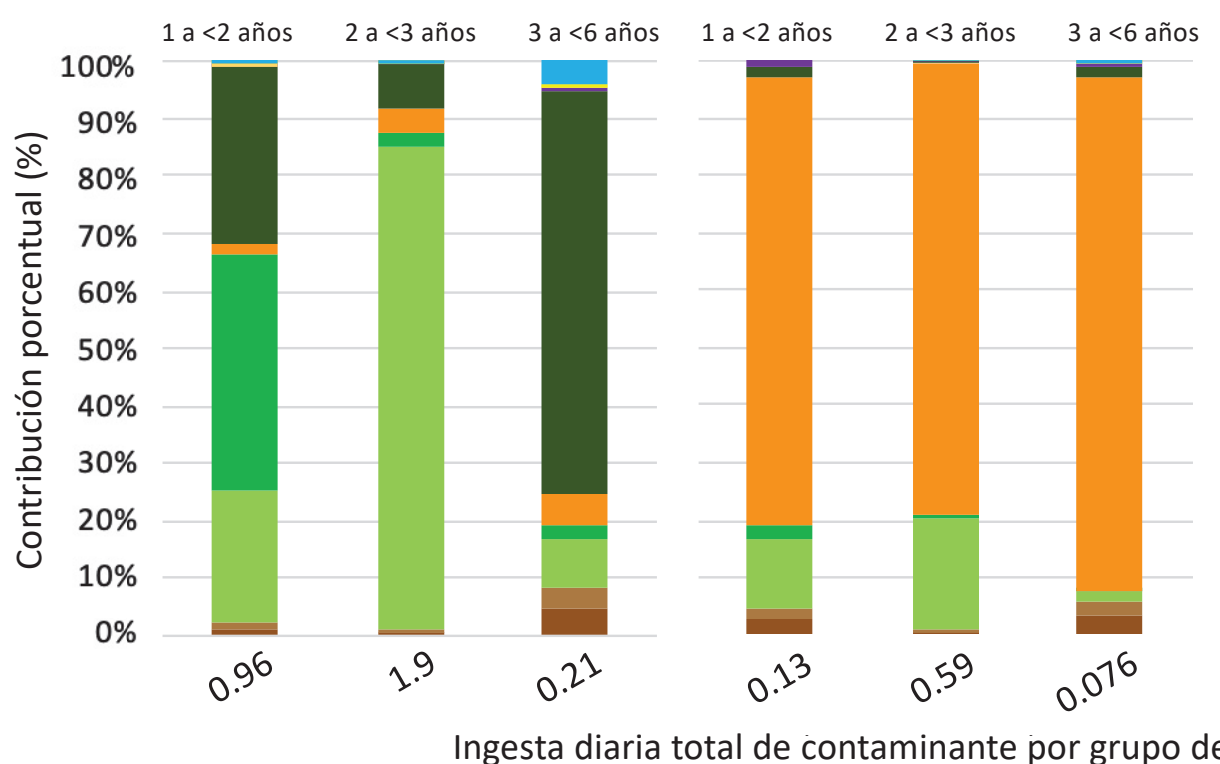

\section{Exposición al cadmio}

Exposición al plomo

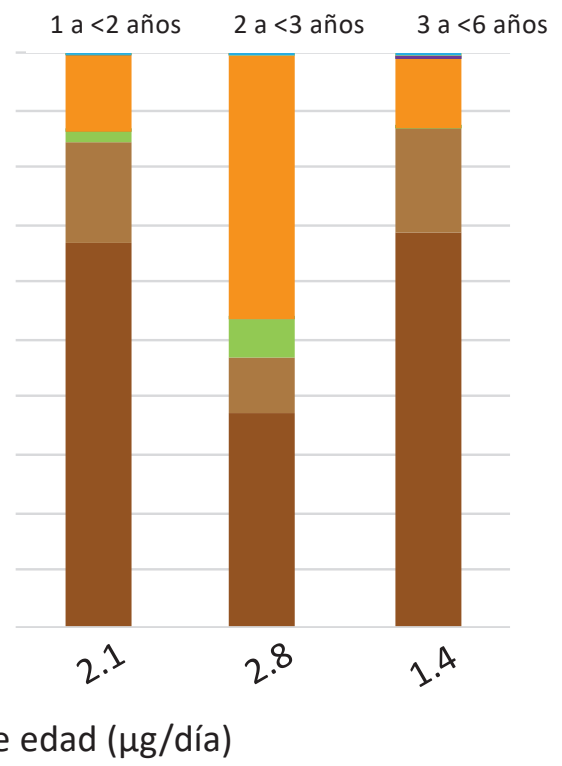

Ingesta diaria total de contaminante por grupo de edad ( $\mu \mathrm{g} /$ día)

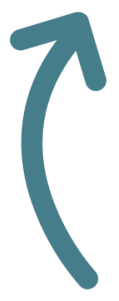

La ingesta diaria estimada de arsénico de todas las rutas de exposición medidos (vegetales, suelo - jardín y patio de recreo, agua y polvo) no excedieron la dosis de referencia de la EPA de EE.UU. para el arsénico.

¡Tenga en cuenta! La ingesta diaria estimada de cadmio para niños de 1 a 3 años excedidó la dosis de referencia específica para niños de CalEPA para el cadmio. 


\section{¿Cuánto podemos comer del jardín preescolar?}

Es su decisión decidir qué riesgo objetivo desea utilizar para tomar decisiones sobre cuántas tazas por semana su niño va a consumir del jardín.

Calculamos la cantidad de cada verdura que su hijo tendría que consumir semanalmente para alcanzar un exceso de riesgo objetivo de cáncer de por vida debido a la exposición al arsénico. Este exceso de riesgo objetivo es adicional a nuestro riesgo de cáncer ya existente al vivir nuestras vidas normales. Estas ingestas se calcularon utilizando las concentraciones medias de arsénico en vegetales en todos los centros preescolares y las mismas suposiciones en la página 12.

\begin{tabular}{|c|c|c|c|}
\hline \multicolumn{3}{|c|}{$\begin{array}{l}\text { Copas por semana que su hijo puede comer en base } \\
\text { en diferentes riesgos }\end{array}$} & \multirow[t]{2}{*}{$\begin{array}{l}\text { USDA cantidades } \\
\text { recomendadas para } \\
\text { niños de 2-3 años } \\
\text { (tazas/semana) }\end{array}$} \\
\hline $\begin{array}{c}\text { Riesgo objective de } \\
1 / 1,000,000\end{array}$ & $\begin{array}{c}\text { Riesgo objective de } \\
1 / 1,000,000\end{array}$ & $\begin{array}{c}\text { Riesgo objetivo de } \\
1 / 10,000\end{array}$ & \\
\hline \multicolumn{3}{|c|}{ Zanahoria } & Zanahoria \\
\hline 11.5 & 115 & 1158 & 2.5 \\
\hline \multicolumn{3}{|c|}{ Lechuga } & Lechuga \\
\hline 2 & 21 & 219 & 1.5 \\
\hline \multicolumn{3}{|c|}{ Col rizada } & Col rizada \\
\hline 0.1 & 1 & 10 & 0.5 \\
\hline \multicolumn{3}{|c|}{ Cilantro } & Cilantro \\
\hline 0.2 & 2 & 21 & $\begin{array}{l}\text { Ninguna } \\
\text { recomendación } \\
\text { disponible }\end{array}$ \\
\hline
\end{tabular}

\section{¡Tenga en cuenta!}

- Hay incertidumbres asociadas con esta estimación.

- Por ejemplo, un niño estará comiendo la verdura durante 181 días al año durante toda su vida (78 años).

- Esto es poco probable debido a las temporadas de cultivo de hortalizas limitadas y los cambios en la productividad del jardín.

- Por lo tanto, los riesgos calculados son conservadores, y los valores de riesgo reales serían probablemente más pequeños.

$1 / 1,000,000=1$ en un millón

$1 / 100,000=1$ en cien mil

$1 / 10,000=1$ en diez mil 


\section{Referencias para más \& información}

\section{Vegetal}

- Departamento de Agricultura de los Estados Unidos (USDA)

- $\quad$ http://www.choosemyplate.gov/food-groups/vegetables amount table.html

- Agencia de Protección Ambiental de los Estados Unidos (US EPA) - Manual de Factores de Exposición

- $\quad$ http://cfpub.epa.gov/ncea/risk/recordisplay.cfm?deid=236252

- Administración de Drogas y Alimentos de los Estados Unidos (USDA)

- $\quad$ http://www.fda.gov/Food/FoodSafety/FoodContaminantsAdulteration/TotalDietStudy

- USDA - ¿Qué está en la comida que comes? Herramienta de búsqueda

- $\quad$ http://www.ars.usda.gov/Services/docs.htm?docid=17032

\section{Suelo}

- CalEPA Niveles de evaluación de la salud humana de CalEPA California (CHHSLs)

- $\quad$ https://oehha.ca.gov/risk-assessment/california-human-health-screening-levels-chhsls

- CalEPA California Departamento de Niveles de Detección de Control de Sustancias Tóxicas (DTSC-SL)

- $\quad$ https://www.dtsc.ca.gov/assessingrisk/humanrisk2.cfm

- Programa de investigación Superfund (UA SRP) de la Universidad de Arizona - Hojas de información comunitaria

- $\quad$ https://www.superfund.arizona.edu/info-material/information-sheets

- $\quad$ EPA de EE.UU. - Guía de cribado del suelo

- $\quad$ http://www.epa.gov/superfund/health/conmedia/soil/index.htm

Agua

- Agencia de Sustancias Tóxicas y Registro de Enfermedades

- http://www.atsdr.cdc.gov/

- UA SRP - Cuadernos de agua

- https://superfund.arizona.edu/info-material/water-booklets-and-videos

- EPA de EE. UU. - Contaminantes del agua potable - Normas y regulaciones

- http://water.epa.gov/drink/contaminants/index.cfm

\section{Polvo}

- EPA de los EE. UU. - Estándar nacional de calidad del aire ambiental líder

- https://www.epa.gov/criteria-air-pollutants/naaqs-table 


\section{Thank you!}

Dear School Administrator,

We did it! I would like to give a special thanks to all Nevada County Gardenroots participants for your efforts, motivation, and patience throughout this research project. We appreciate the time you have invested in participating in this project. Altogether, over 33 community members were trained, and 38 soil, 8 dust, 12 water, and 45 plant samples were prepared and analyzed.

This collaborative study was conducted by a team of researchers from the Sierra Streams Institute (a regional nonprofit watershed science organization in Nevada City, CA), University of Arizona, and University of CA-San Francisco. This study was funded by the California Breast Cancer Research Program.

By learning about your students' diet and the environmental quality of your community, we were able to identify environmental health research gaps and ways to improve the quality of preschool gardens. This packet shows the test results of the exposure and risk assessment done for your preschool. Your results are highlighted and compared to state and federal regulatory standards and/or reference values when available. In this package, we have included the following:

1. Project overview

2. Important terms that you will see throughout the results

3. General information on selected contaminants of concern

4. A guide to reading the results

5. Preschool vegetable, soil, irrigation water, and dust results

6. Child's cumulative exposure

7. References for further information on environmental quality and guidelines

Sincerely,

Mónica Ramírez-Andreotta, Assistant Professor

University of Arizona

1177 E Fourth Street, Rm. 429, Tucson, AZ 85721

Phone: 520-621-0091 Fax: 520-621-1647

Joanne Hild

Executive Director, River Scientist

Sierra Streams Institute 13075 Woolman Lane

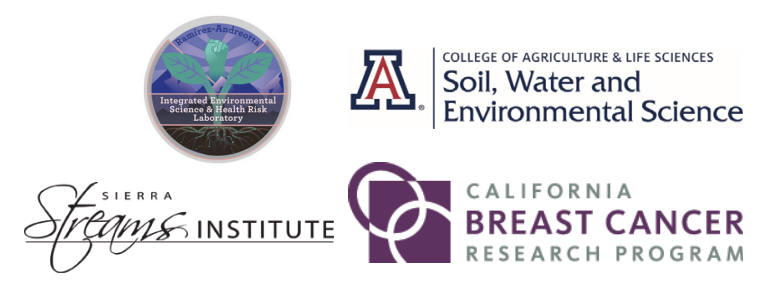

Nevada City, CA 95959 (530) 477- 7132 Ext. 200

www.sierrastreamsinstitute.org

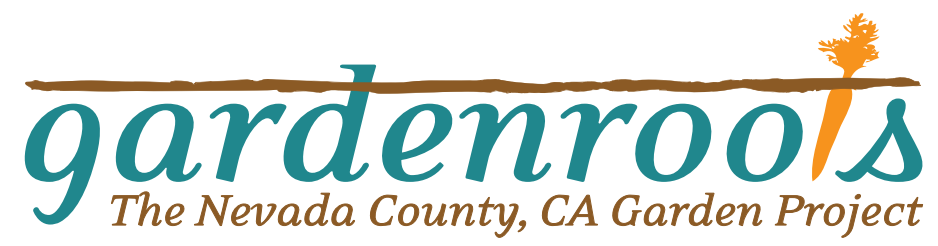




\section{Project Description}

Based on community member's concerns regarding environmental quality, Gardenroots: The Nevada City, CA Garden Project was developed. Gardenroots is an environmental monitoring and children's exposure assessment project designed to better understand potential child exposure to arsenic and cadmium. Seeing gardens as hubs for environmental health research and education, Gardenroots is trying to understand the state of environmental quality in rural communities. Results from this study are helping to determine whether people are exposed to metal contaminants through gardening and crop ingestion.

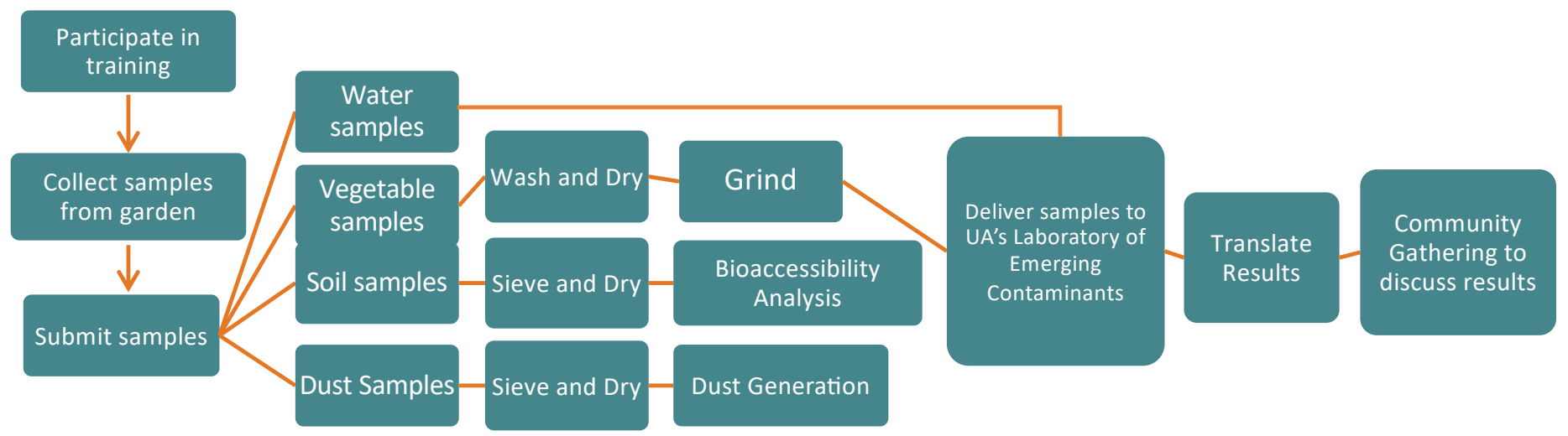

Data may be subject to revisions.

The results have been internally reviewed, but have not undergone external peer review and may be subjected to minor changes.

Metals occur naturally in the environment.

While we can measure the level of a metal in certain substances, like water or soil, it is difficult to know the original source of the metal. For example, arsenic may be found in soil in many parts of the state because it also naturally occurs in these regions.

It is important to note that, elements such as arsenic occur naturally in soil and it is impossible to grow plants completely free of these and other trace elements like lead and cadmium.

Please refer to the recommended gardening best practices handouts for ways to reduce levels of harmful chemicals in your garden plot and in your vegetables.

Single exposure measurements are "snapshots in time".

We are measuring metal concentrations at a single point in time. Measuring metal concentrations with a single sampling does not establish what the exposures were in the past or what they may be in the future.

For more information about the study and safe gardening practices, please visit the Gardenroots website: http://www.gardenroots.arizona.edu/ 


\section{Important Terms}

Below is a set of terms that you will see throughout your results:

Action Level (AL) - The U.S. Environment Protection Agency (U.S. EPA) regulates lead under the Lead and Copper Rule. This rule describes the water treatment requirements needed to control plumbing corrosion that may contaminate drinking water. If the water concentration of lead is above the action level, this means actions are required to correct the water system to meet this regulation.

Concentration - The amount of a chemical in a given mass of water, soil, or plant tissue. This is written as $\mu \mathrm{g} / \mathrm{L}$ (micrograms per liter), $\mu \mathrm{g} / \mathrm{m}^{3}$ (micrograms per cubic meter), or $\mu \mathrm{g} / \mathrm{g}$ (micrograms per gram).

Guideline - A non-enforceable, but recommended maximum concentration of a chemical.

MCL (Maximum Contaminant Level) - The MCL is the maximum amount of a contaminant allowed in drinking water so that it is still safe to drink over many years. This level is set by the US Environmental Protection Agency.

Median - The value at the midpoint (middle value) of the range of values.

National Ambient Air Quality Standard (NAAQS) - These are standards established by the U.S. EPA to protect human health. The standard for lead defines the maximum allowable concentration of lead in a cubic squared meter of outdoor air. This standard is current set to $0.15 \mu \mathrm{g} / \mathrm{m}^{3}$.

Percentile - A number where a certain percentage of scores fall below that number. For example, if you know that your score is in the 90th percentile, that means you scored better than $90 \%$ of people who took the test.

$\mu \mathrm{g} / \mathrm{g}$ (Micrograms per Gram) - A measure of how many micrograms of a substance (such as a metal) are in a gram of a solid (such as soil). This measure is also referred to as parts per million (ppm).

$\mu \mathrm{g} / \mathrm{L}$ (Micrograms per Liter) - A measure of how many micrograms (one-thousandth of a milligram) of a substance (such as a metal) are in a liter of liquid (such as water). This measure is also referred to as parts per billion (ppb). For perspective, $1 \mu \mathrm{g} / \mathrm{L}$ or $\mathrm{ppb}$ is the equivalent to a drop of ink in a backyard swimming pool.

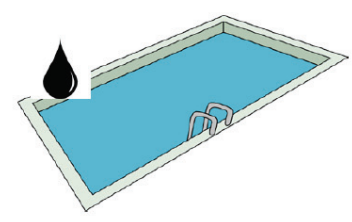

\begin{tabular}{|c|c|c|}
\hline $\begin{array}{c}\text { Micrograms per liter } \\
(\mu \mathrm{g} / \mathrm{L})\end{array}$ & $\begin{array}{c}\text { Parts per billion } \\
(\mathrm{ppb})\end{array}$ & $1 / 1,000,000,000$ \\
\hline
\end{tabular}




\section{Important Terms (con't)}

$\mu \mathrm{g} / \mathrm{m}^{3}$ (Micrograms per Cubic Meter) - A measure of how many micrograms of a substance (such as a metal) are in a cubic meter of a air.

Reference Dose (RfD) - Estimate of a daily intake of a chemical that is not likely to result in any significant negative health effects (including sensitive populations like children and elderly). It may be referred to as the acceptable daily intake.

Standards - The standards are enforceable and regulatory values, developed either by federal agencies or by the state of Arizona for water providers/utilities. They are different from advisories (see definition on previous page) and guidelines.

\section{Soil Screening Levels}

- U.S. EPA Regional Screening Level (RSL) - Risk-based concentrations of contaminant in soils that are calculated using what we know about the exposure to a contaminant and what the U.S. EPA knows about the toxicity of the chemical. U.S. EPA considers these screening levels as initial cleanup goals, when applicable. They are not national cleanup standards, and are based on different target risks.

- CalEPA California Human Health Screening Levels (CHHSLs) - Risk-based concentrations of contaminants in soils that are specific to California. Screening levels for lead are not risk-based screening levels, but rather the average $\mathrm{Pb}$ concentration in residential soil that would be protective of children and women of child-bearing ages. These values are more conservative than the U.S EPA RSLS.

- CalEPA California Department of Toxic Substances Control Screening Levels (DTSC-SL) - Riskbased recommended screening levels that are derived using DTSC-modified exposure and toxicity factors for contaminants in soil. These values are also more conservative than the U.S EPA RSLs. 


\section{Arsenic (As)}

\section{Contaminant Name: Arsenic (As)}

Contaminant Type: Metalloid

\section{What is Arsenic?}

Arsenic naturally exists in the Earth's crust and can be found in sediments, soils, and groundwater. Arsenic may also be released into the environment via mining, ore smelting, and industrial use of the element.

\section{What happens to arsenic when it enters the environment?}

In the environment, people can be exposed to arsenic in two chemical forms:

- Inorganic: Varying amounts of this poisonous (toxic) form can be found naturally in geologic materials (soils, rocks, aquifer materials) and in ground and surface water, which may also be impacted by mining and industrial wastes and arsenical pesticides).

- Organic (arsenic compounds that contain carbon): Varying amounts of this non-poisonous (lowtoxicity) form can be found in sources such as animals, plants, fish and seafood. Fish and shellfish can accumulate arsenic; most of this arsenic is in an organic form called arsenobetaine that is much less harmful.

\section{How can arsenic affect my health?}

Severe (acute) arsenic poisoning can cause vomiting, abdominal pain, and diarrhea. This can be followed by numbness and tingling of the extremities, muscle cramping, and death in extreme cases. Ingesting or breathing low levels of inorganic arsenic for a long time (chronic) can cause non-cancer health effects, like a darkening of the skin and the appearance of small "warts" on the palms, soles, and torso. Other non- cancer health effects linked to long- term ingestion of arsenic include developmental effects, diabetes, pulmonary disease, and cardiovascular disease. Ingestion of inorganic arsenic can increase the risk of skin cancer and cancer in the liver, bladder, and lungs. Inhalation of inorganic arsenic can cause increased risk of lung cancer.

\section{Where can I get more information on Arsenic?}

Agency for Toxic Substances and Disease Registry. ToxFAQsTM for Arsenic. Last Updated on March 12, 2015. You can access this information at: https://www.atsdr.cdc.gov/toxfaqs/tf.asp?id=19\&tid=3 


\title{
Cadmium (Cd)
}

\author{
Contaminant Name: Cadmium (Cd) \\ Contaminant Type: Heavy metal
}

\section{What is cadmium?}

Cadmium is found in the Earth's crust. Most cadmium used in the U.S. is extracted as a byproduct during the production of other metals such as zinc, lead, or copper. Cadmium is also recovered from used batteries. Cadmium is used for the following: batteries, pigments, coatings and platings, stabilizers for plastics, photovoltaic (solar power materials) devices, and other uses.

\section{What happens to cadmium when it enters the environment?}

Cadmium is emitted to soil, water, and air by metal mining and refining, manufacture and application of phosphate fertilizers, fossil fuel combustion, and waste incineration and disposal. Generally, cadmium binds strongly to organic matter where it can stay in soil and be taken up by plant life, eventually entering the food supply.

\section{How can cadmium affect my health?}

Cigarette smoking is a major exposure route to cadmium. Tobacco may have been grown in contaminated soils, or pesticides/fungicides or additives were applied during the growing and manufacturing process.

Exposure to cadmium can occur through breathing contaminated workplace air, drinking contaminated water, or living near industrial facilities that release cadmium into the air. Eating food or drinking water with very high levels severely irritates the stomach, leading to vomiting and diarrhea. Long-term exposure to lower levels of cadmium in air, food, or water leads to a buildup of cadmium in the kidneys and possible kidney disease. Other long-term effects include lung damage and fragile bones. Low levels of cadmium are found in all foods (highest levels are found in shellfish, liver, and kidney meats). In the U.S., for nonsmokers the primary source of cadmium exposure is from the food supply. Breathing high levels of cadmium can severely damage the lungs. Cadmium and cadmium compounds are known to cause cancer in humans.

\section{Where can I get more information on Cadmium?}

Agency for Toxic Substances and Disease Registry. ToxFAQsTM for Cadmium. Last Updated on March 12, 2015. You can access this information at: https://www.atsdr.cdc.gov/toxfaqs/tf.asp?id=47\&tid=15 


\title{
Lead $(\mathrm{Pb})$
}

\author{
Contaminant Name: Lead (Pb) \\ Contaminant Type: Heavy Metal
}

\section{What is lead?}

Lead is a metal in the Earth's crust that

is normally found with other metals such as zinc, silver, and copper. Lead has many uses including manufacturing of paints, batteries, and fishing weights. Lead- based solder, which had been used to connect copper water pipes, was banned in the 1980s, but may still be a source of lead in drinking water in older homes. In the United States, lead was used as a gasoline additive, but was banned beginning in 1973 and eliminated by 1996.

\section{What happens to lead when it enters the environment?}

Lead itself does not break down, but lead compounds are changed by sunlight, air, and water. When lead is released to the air, it may travel long distances before settling to the ground. Once lead falls onto soil, it usually sticks to soil particles. Ingestion (soil, food, water) is the main route of exposure in humans.

Children are most impacted by lead exposure because they often put their hands and/or toys in their mouths. Pregnant women can also expose their unborn child to lead via ingestion. Adults can be exposed via lifestyle choices (e.g., cigarette smoking) or through their occupation (e.g., plumbing, soldering, manufacturing plants, construction/remodeling companies, smelters, and auto repair shops). There are other sources of potential lead exposure which include: paints, glazed clay pots, wine, food, leaded glass (crystal), stained glass, dyes, and home remedies (e.g., azarcon or greta used to treat digestive illness).

\section{How can lead affect my health?}

Lead can affect almost every organ and system in your body, both in adults and children. Exposure to lead can seriously harm a child's health. It can damage the brain and nervous system, slow growth and development, cause learning, behavior, hearing, and speech problems. It causes lower IQ, decreased ability to pay attention, and underperformance in school. Lead exposure also causes small increases in blood pressure, particularly in middle-aged and older people and can cause anemia. In pregnant women, high levels of exposure to lead may cause miscarriage. High-level exposure in men can damage the organs responsible for sperm production.

\section{Where can I get more information on Lead?}

Agency for Toxic Substances and Disease Registry. ToxFAQsTM for Lead. Last Updated on August 24, 2016. You can access this information at: https://www.atsdr.cdc.gov/toxfaqs/tf.asp?id=93\&tid=22 


\section{A Guide to Reading the Results}

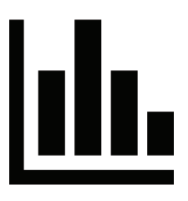

\section{Guide for reading soil, plant, water, and dust results}

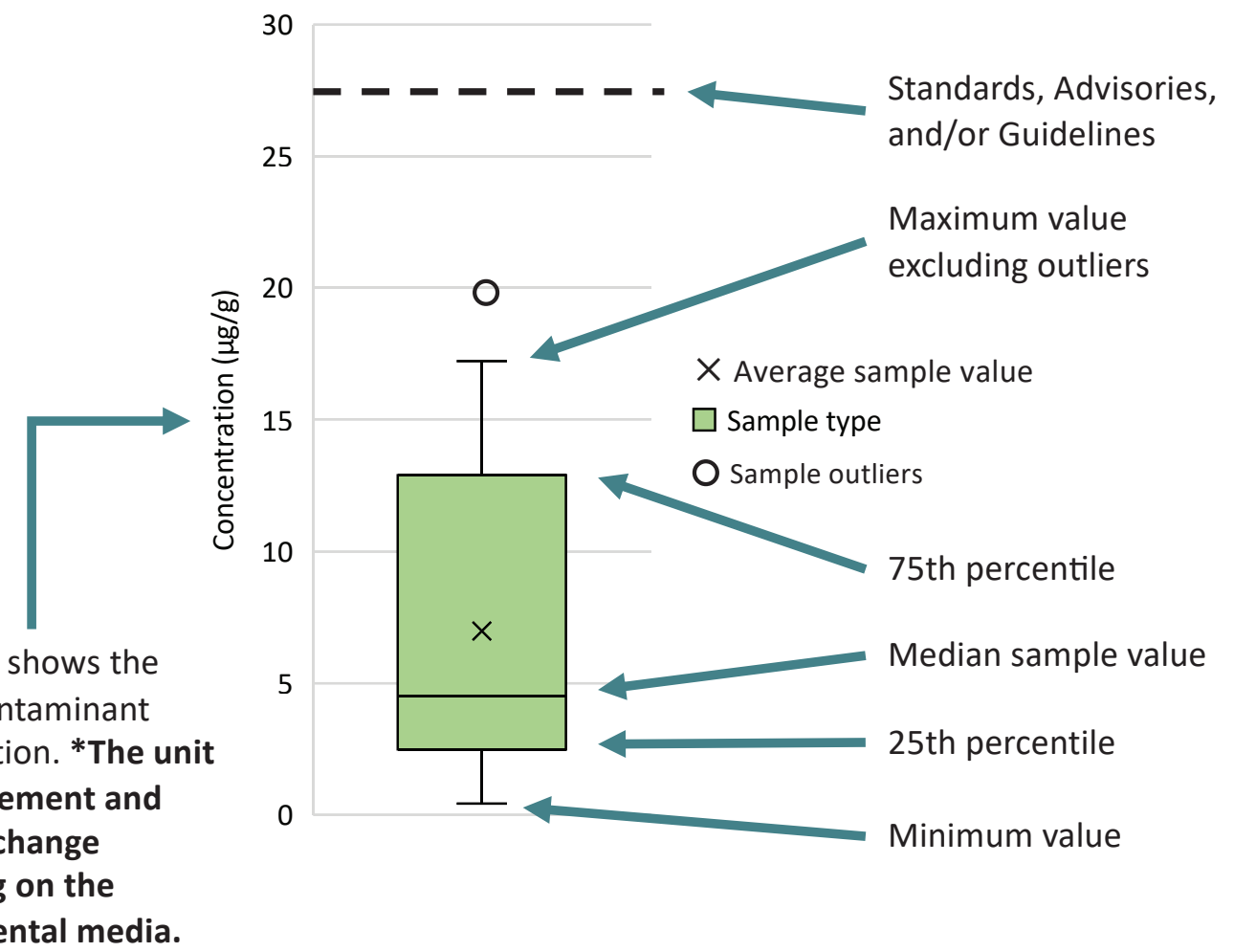

The Y-Axis shows the level of contaminant concentration. *The unit of measurement and scale will change depending on the environmental media.

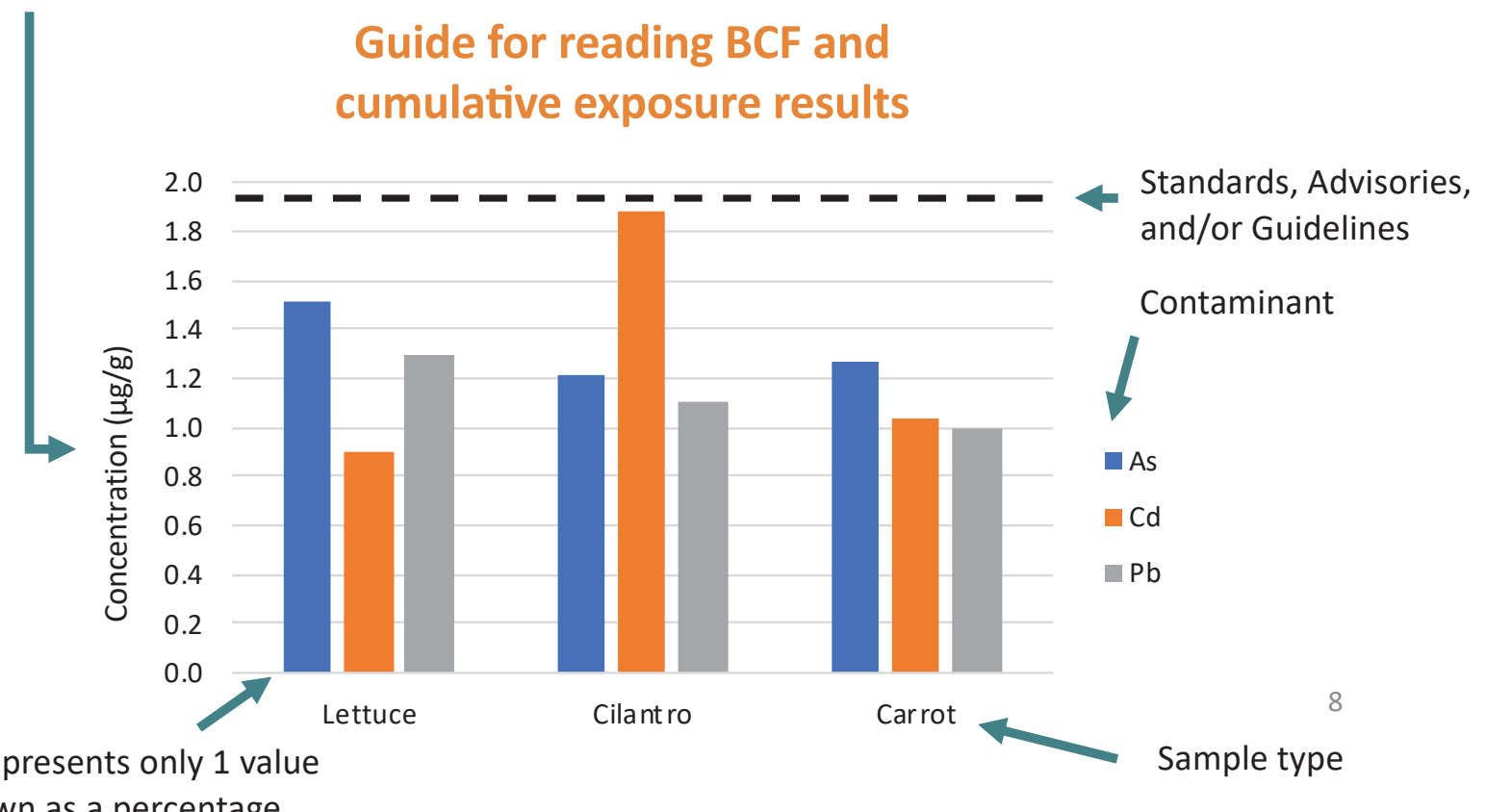

Each bar represents only 1 value unless shown as a percentage out of $100 \%$ on the Y-Axis 


\section{Vegetable Results}

Below are the measured arsenic, cadmium, and lead concentrations in vegetables that were collected at your preschool.

\section{Concentration in Garden Vegetables}
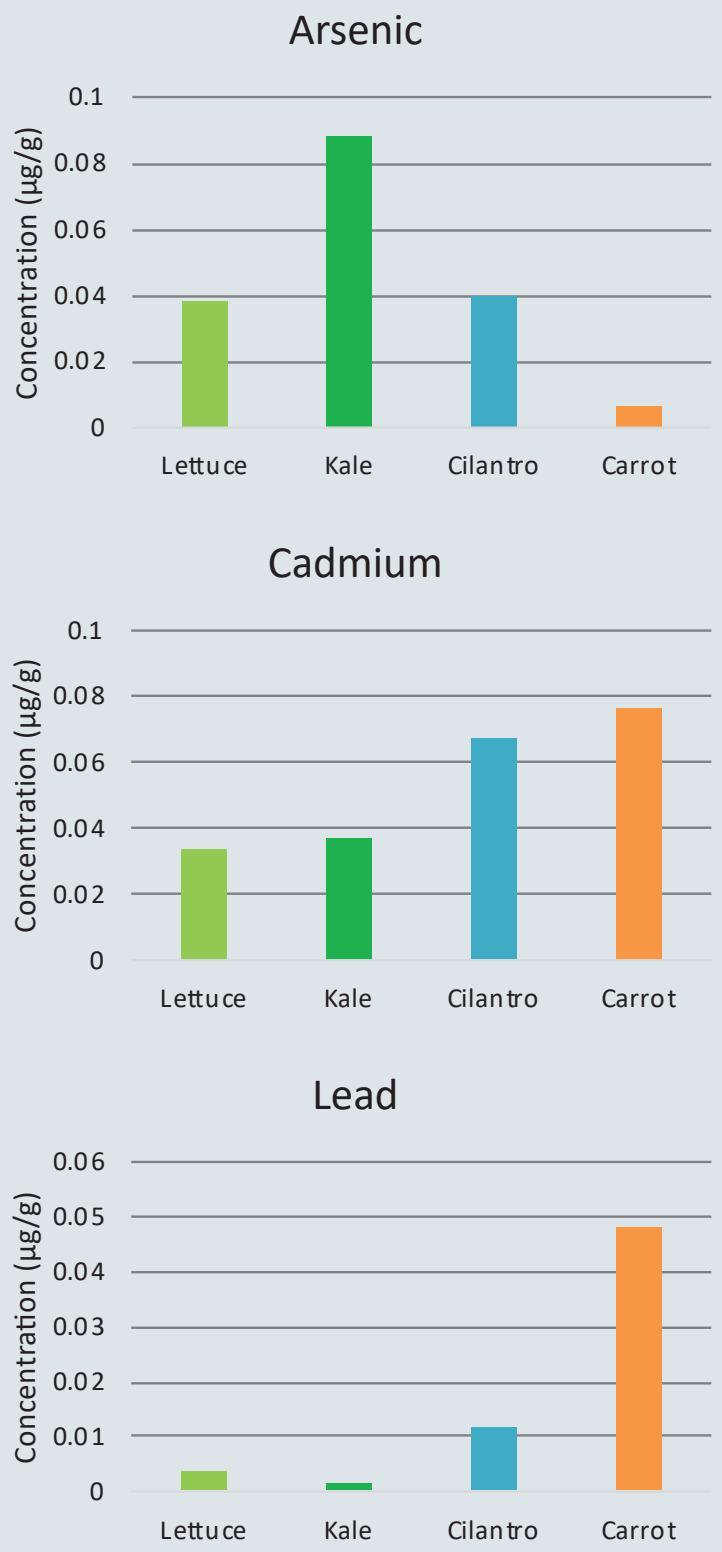

We found that Apaiaceae plants (carrot and cilantro) had the greatest median concentrations of $\mathrm{Cd}$ anf $\mathrm{Pb}$, while kale had the greatest median concentration of As.

\section{Plant Bioconcentration Factor}

The plant bioconcentration factor (BCF) is the ratio of the metal concentration in the edible portion in the vegetable (dry weight) and the metal concentration in the soil.

$$
B C F=\frac{\text { Contaminant concentration in plant }}{\text { Contaminant concentration in garden soil }}
$$

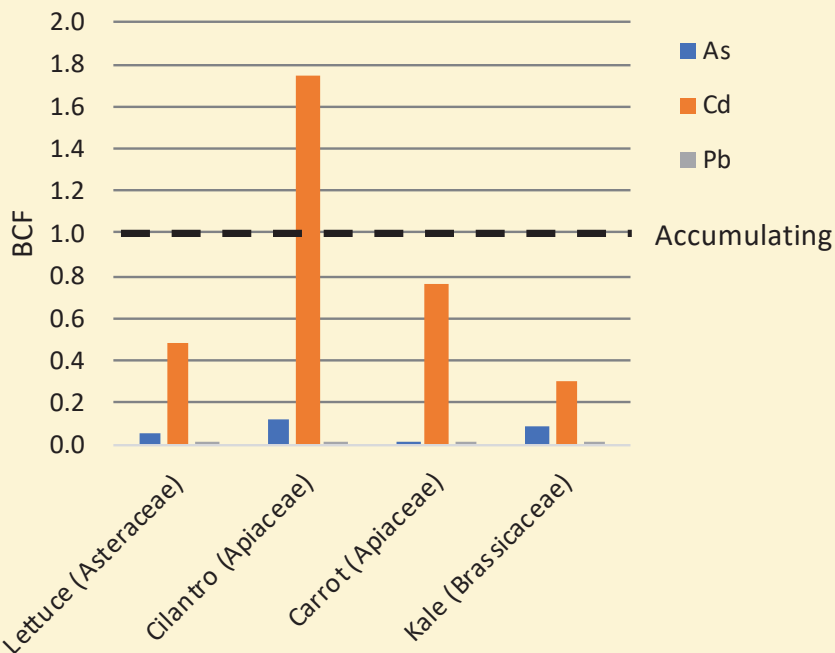

The results suggested that cilantro accumulated more Cd than did other plants. Certain members of the Asteraceae and Brassicaceae families have been previously identified as hyperaccumulator plants, meaning they may have a genetic and physiological capacity to accumulate high amounts of metals (BCF > 10).

With this evidence, it is recommended that Nevada County, CA gardeners limit the use of vegetables from the Apiaceae plant families. 


\section{Soil Results}

Below are the measured arsenic, cadmium, and lead concentrations in soil samples that were collected at your preschool.

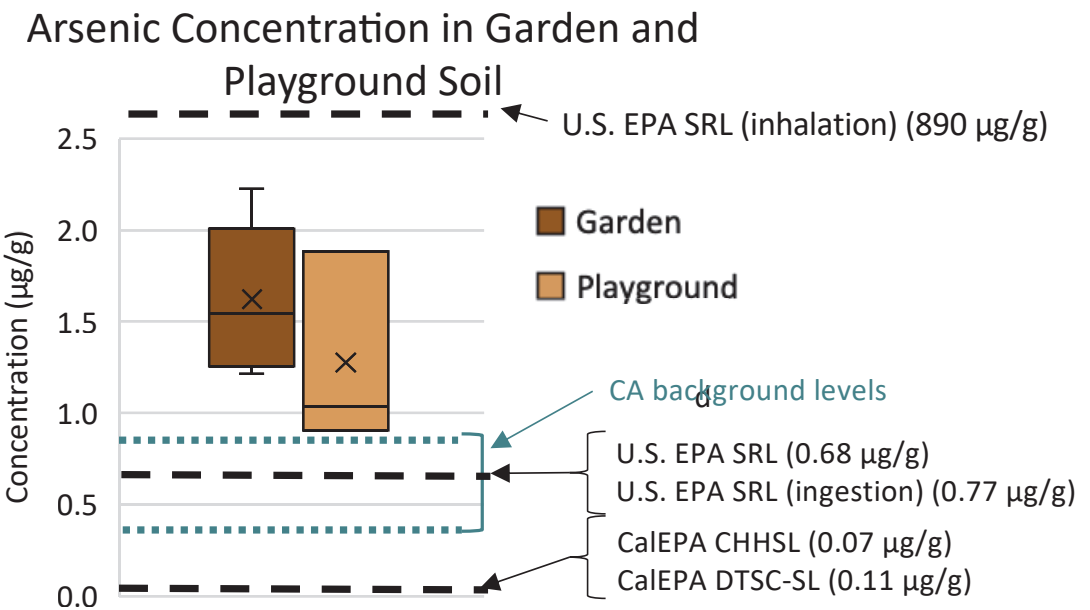

Garden soil samples exceeded the recommended conservative state and federal soil screening levels for As.

The measured As concentrations in garden and playground soil were generally above the CA background As levels. This suggests that in general, the elevated As concentrations in preschool garden and playground soils are possibly caused by human activity.

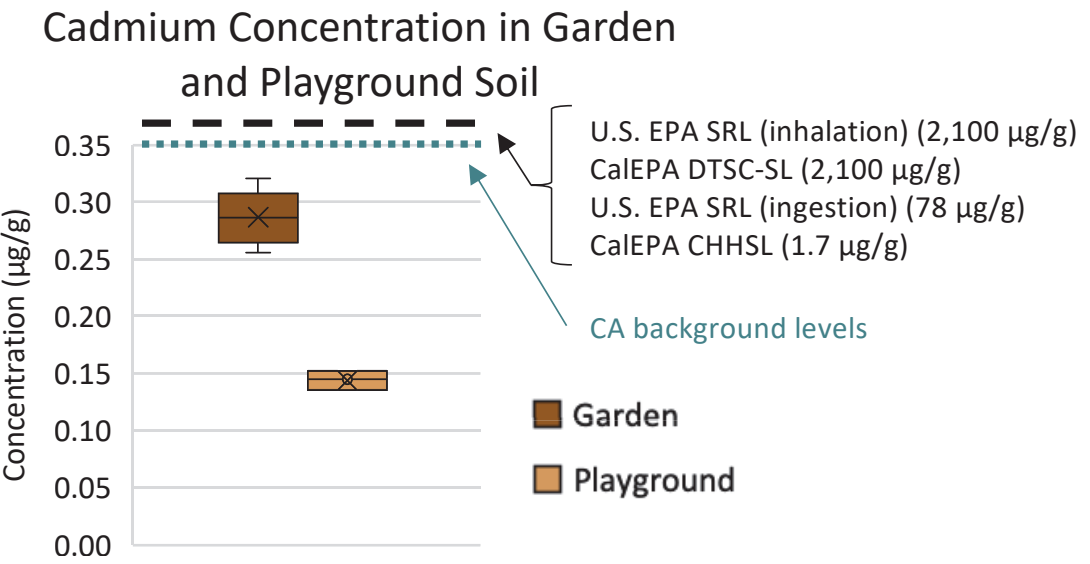

Garden soil samples did not exceeded the recommended conservative state and federal soil screening levels for $\mathrm{Cd}$.

The measured $\mathrm{Cd}$ concentrations in garden and playground soil were below CA background $\mathrm{Cd}$ levels. This suggests that in general, these levels are also not caused by human activity or historical land use.

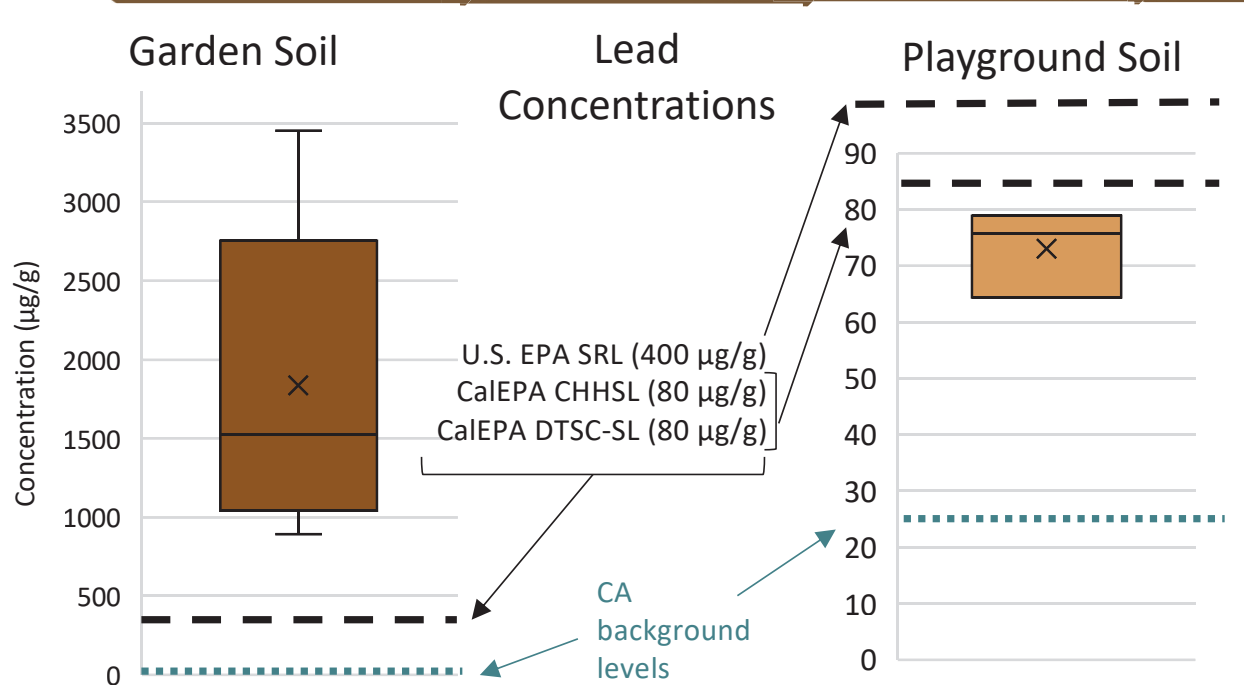

Garden soil samples exceeded the recommended conservative state and federal soil screening levels for $\mathrm{Pb}$.

Similar to As, the measured $\mathrm{Pb}$ concentrations in garden and playground soil were above CA background $\mathrm{Pb}$ levels. This suggests that in general, the elevated $\mathrm{Pb}$ concentrations in preschool garden and playground soils are possibly caused by human activity. 


\section{Water \& Dust Results}

Below are the measured arsenic, cadmium, and lead concentrations in garden irrigation water and dust results from the samples collected at your preschool.

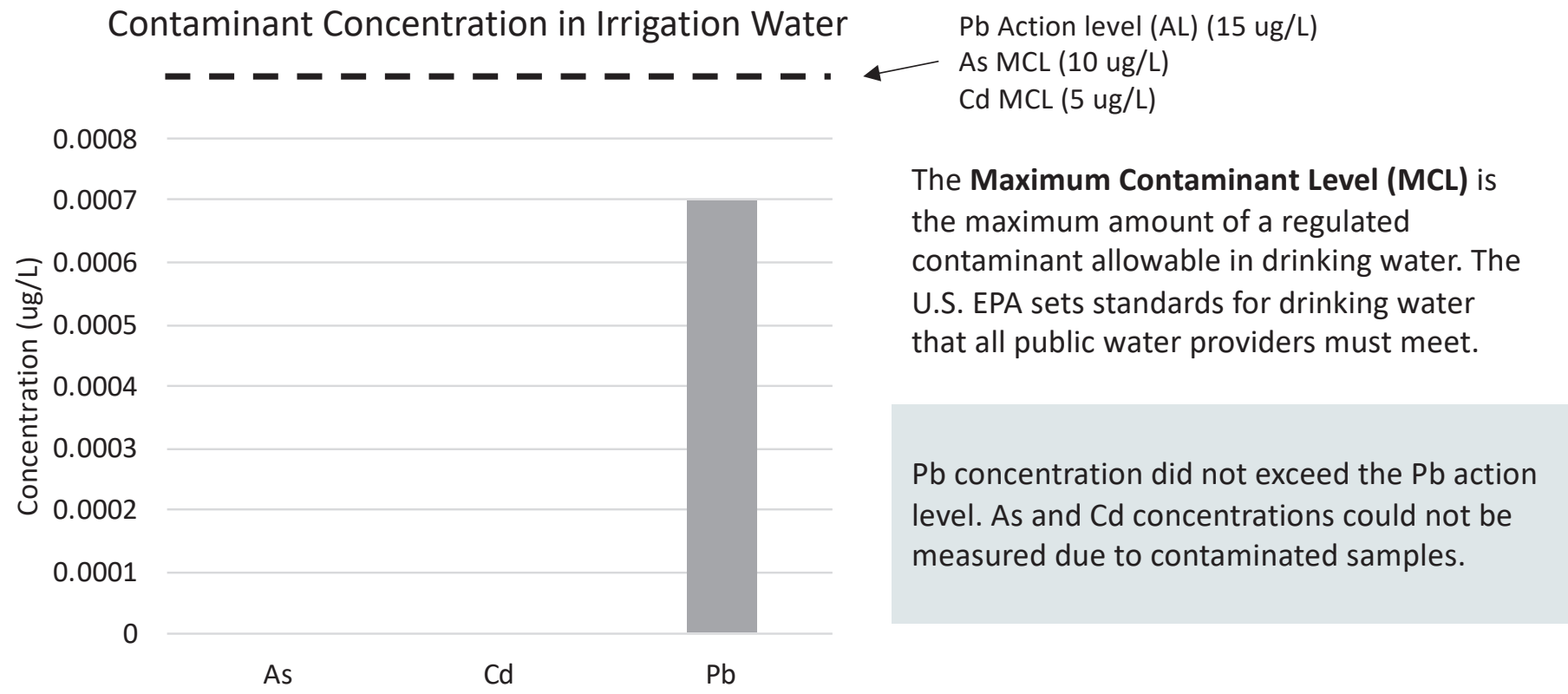

The median $\mathrm{Pb}$ concentration from garden and playground dust in this study were below the U.S. EPA's National Ambient Air Quality Standard (NAAQS) of $0.15 \mathrm{\mu g} / \mathrm{m}^{3}$ for $\mathrm{Pb}$.

There is currently no federal or state outdoor air standard for As or $\mathrm{Cd}$ concentration available for comparison.

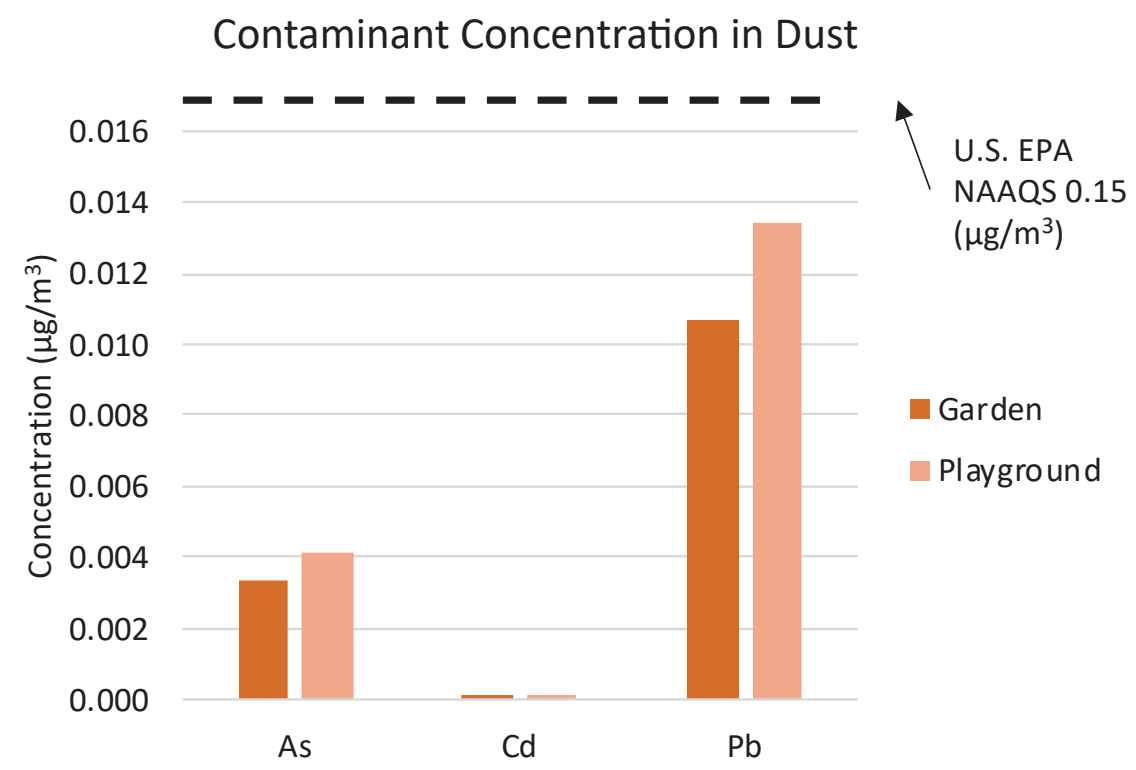




\section{What is an Exposure Assessment?}

An exposure assessment aims to answer the following questions: How much of a contaminant is present in the environment? Are we exposed? If so, how and how much are we exposed to?

In this study we estimated a preschool child's daily dose of $\mathrm{As}, \mathrm{Cd}$, and $\mathrm{Pb}$ from playing and gardening. To do this we used the equation below and the following assumptions:

- Intake rate for the vegetable, water, dust, or soil (incidental) a child would be consuming daily

- Body weight (11.4 to $18.6 \mathrm{~kg}=25$ to $40 \mathrm{lbs}$ )

- Life span equal to 78 years

- Eating that vegetable, drinking the water, incidentally ingesting soil, and inhaling dust for 181 days out of the year (average school year) for 1 year while attending the preschool

- Bioaccessibility of As, Cd, and Pb once it's in your body

Child-specific estimated values are highlighted in the orange boxes.

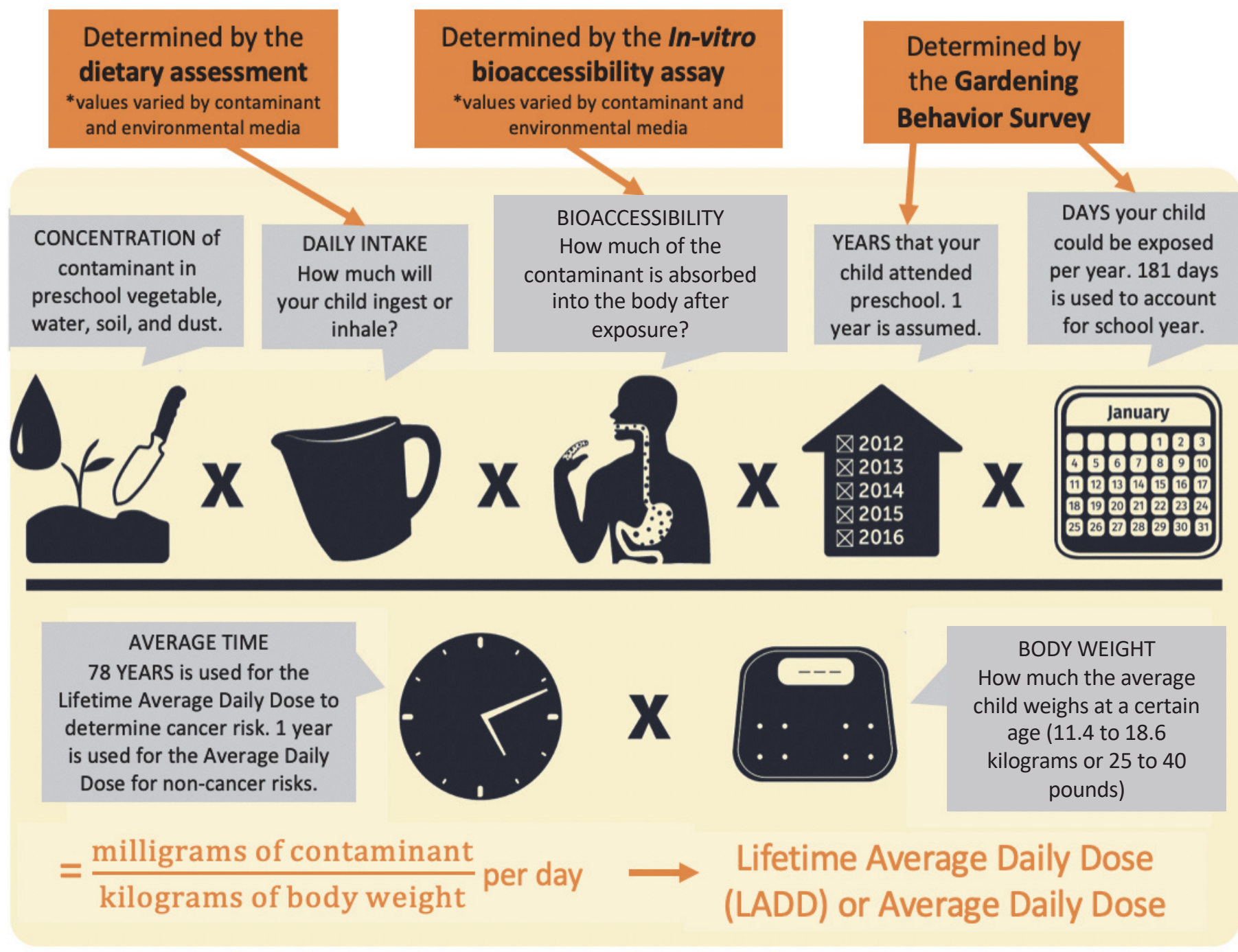




\section{Estimated Exposure (Daily Intake) to Arsenic, Cadmium, and Lead from Vegetables, Soil, Water, and Dust}

A child's cumulative exposure to $\mathrm{As}, \mathrm{Cd}$, and $\mathrm{Pb}$ was estimated for each age group. We determined how much (percentage) each potential exposure route contributed to a child's daily intake (calculated on page 12).

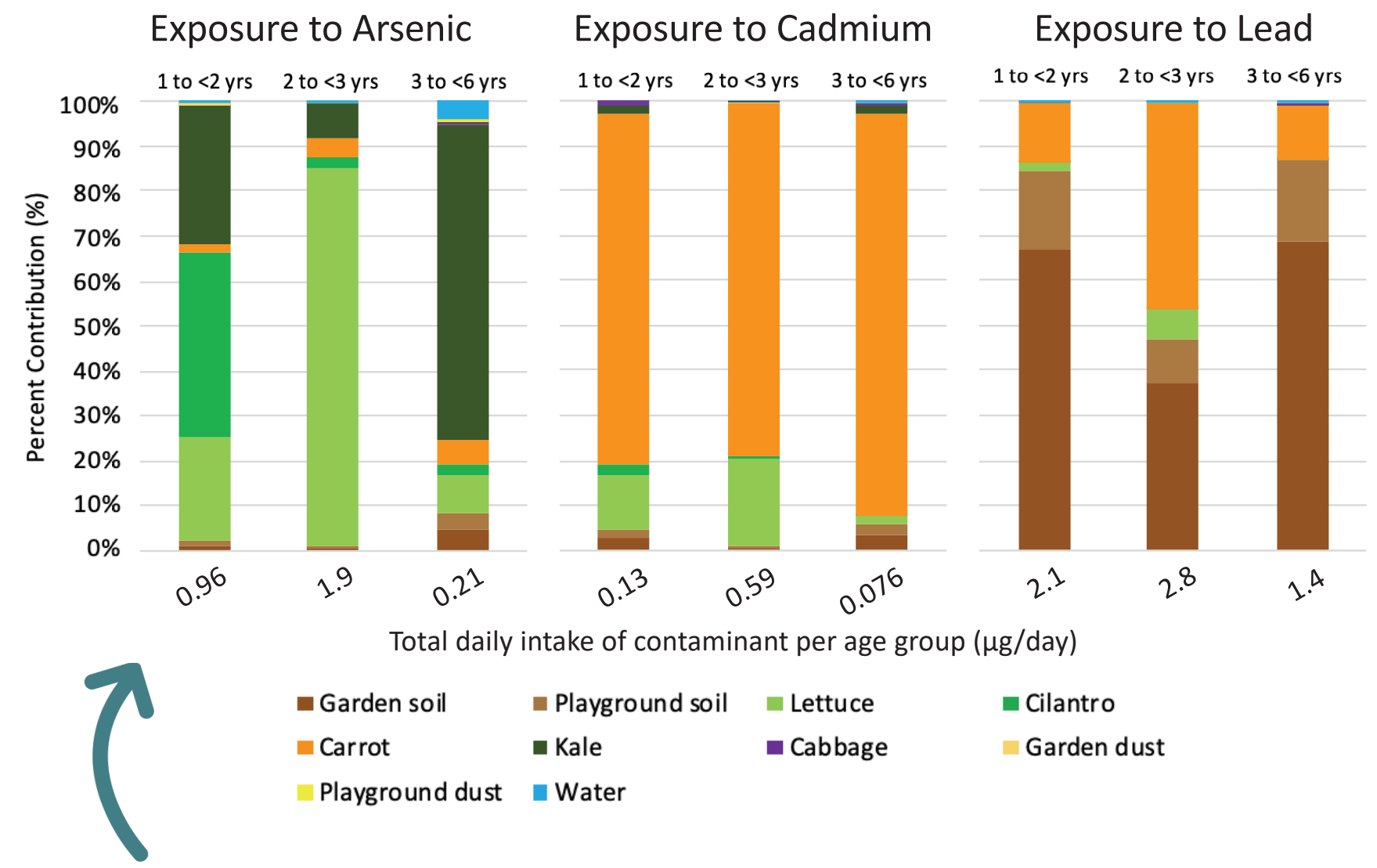

The estimated daily intake of arsenic from all measured exposure routes (vegetables, soil - garden and playground, water, and dust) DID NOT exceed the U.S. EPA's reference dose for arsenic.

Please note! The estimated daily intake of cadmium for 1 to 3 year old children DID exceed CalEPA's child-specific reference dose for cadmium. 


\section{How much can we eat from the preschool garden?} It is your choice to decide what target risk you want to use to make decisions about how many cups per week to consume from the garden.

We calculated how much of each vegetable your child would have to consume weekly to reach a target excess lifetime cancer risk from arsenic exposure. This target excess risk is in addition to our already existing cancer risk from living our normal lives. These intakes were calculated using the median arsenic concentrations in vegetables across all preschools and the same assumptions described on page 12.

\begin{tabular}{|c|c|c|c|}
\hline \multicolumn{3}{|c|}{$\begin{array}{c}\text { Cups per week that your child can eat based } \\
\text { on different target risks }\end{array}$} & \multirow[t]{2}{*}{$\begin{array}{l}\text { USDA recommended } \\
\text { amounts for 2-3 year } \\
\text { old (cups/week) }\end{array}$} \\
\hline $\begin{array}{l}\text { Target risk of } \\
1 / 1,000,000\end{array}$ & $\begin{array}{c}\text { Target risk of } \\
1 / 100,000\end{array}$ & $\begin{array}{c}\text { Target risk of } \\
1 / 10,000\end{array}$ & \\
\hline \multicolumn{3}{|c|}{ Carrot } & Carrot \\
\hline 11.5 & 115 & 1158 & 2.5 \\
\hline \multicolumn{3}{|c|}{ Lettuce } & Lettuce \\
\hline 2 & 21 & 219 & 1.5 \\
\hline \multicolumn{3}{|c|}{ Kale } & Kale \\
\hline 0.1 & 1 & 10 & 0.5 \\
\hline \multicolumn{3}{|c|}{ Cilantro } & Cilantro \\
\hline 0.2 & 2 & 21 & $\begin{array}{c}\text { No recommendation } \\
\text { available }\end{array}$ \\
\hline
\end{tabular}

\section{Please Note!}

- There are uncertainties associated with this estimation.

- For example, a child will be eating the vegetable for 181 days a year for his/her entire lifetime (78 years).

- This is unlikely due to limited vegetable growing seasons and changes in garden productivity.

- Therefore, the calculated risks are conservative, and the actual risk values would most likely be smaller.

$1 / 1,000,000=1$-in-a-million

$1 / 100,000=1$-in-a-hundred-thousand

$1 / 10,000=1$-in-ten-thousand 


\section{References for More}

\section{Information}

\section{Vegetable}

- U.S. Department of Agriculture (USDA)

- http://www.choosemyplate.gov/food-groups/vegetables amount table.html

- U.S. Environmental Protection Agency (U.S. EPA) - Exposure Factors Handbook

- $\quad$ http://cfpub.epa.gov/ncea/risk/recordisplay.cfm?deid=236252

- U.S. Food and Drug Administration

- $\quad$ http://www.fda.gov/Food/FoodSafety/FoodContaminantsAdulteration/TotalDietStudy

- USDA - What's In The Foods You Eat Search Tool

- $\quad$ http://www.ars.usda.gov/Services/docs.htm?docid=17032

Soil

- CalEPA California Human Health Screening Levels (CHHSLs)

- $\quad$ https://oehha.ca.gov/risk-assessment/california-human-health-screening-levels-chhsls

- CalEPA California Department of Toxic Substances Control Screening Levels (DTSC-SL)

- $\quad$ https://www.dtsc.ca.gov/assessingrisk/humanrisk2.cfm

- University of Arizona Superfund Research Program (UA SRP) - Community Information Sheets

- $\quad$ https://www.superfund.arizona.edu/info-material/information-sheets

- U.S. EPA - Soil Screening Guidance

- $\quad$ http://www.epa.gov/superfund/health/conmedia/soil/index.htm

\section{Water}

- Agency for Toxic Substances and Disease Registry

- http://www.atsdr.cdc.gov/

- UA SRP - Water Booklets

- https://superfund.arizona.edu/info-material/water-booklets-and-videos

- U.S. EPA - Drinking Water Contaminants - Standards and Regulations

- http://water.epa.gov/drink/contaminants/index.cfm

\section{Dust}

- U.S. EPA - Lead National Ambient Air Quality Standard

- https://www.epa.gov/criteria-air-pollutants/naaqs-table 


\section{Thank you!}

Dear School Administrator,

We did it! I would like to give a special thanks to all Nevada County Gardenroots participants for your efforts, motivation, and patience throughout this research project. We appreciate the time you have invested in participating in this project. Altogether, over 33 community members were trained, and 38 soil, 8 dust, 12 water, and 45 plant samples were prepared and analyzed.

This collaborative study was conducted by a team of researchers from the Sierra Streams Institute (a regional nonprofit watershed science organization in Nevada City, CA), University of Arizona, and University of CA-San Francisco. This study was funded by the California Breast Cancer Research Program.

By learning about your students' diet and the environmental quality of your community, we were able to identify environmental health research gaps and ways to improve the quality of preschool gardens. This packet shows the test results of the exposure and risk assessment done for your preschool. Your results are highlighted and compared to state and federal regulatory standards and/or reference values when available. In this package, we have included the following:

1. Project overview

2. Important terms that you will see throughout the results

3. General information on selected contaminants of concern

4. A guide to reading the results

5. Preschool vegetable, soil, irrigation water, and dust results

6. Child's cumulative exposure

7. References for further information on environmental quality and guidelines

Sincerely,

Mónica Ramírez-Andreotta, Assistant Professor

University of Arizona

1177 E Fourth Street, Rm. 429, Tucson, AZ 85721

Phone: 520-621-0091 Fax: 520-621-1647

Joanne Hild

Executive Director, River Scientist

Sierra Streams Institute 13075 Woolman Lane

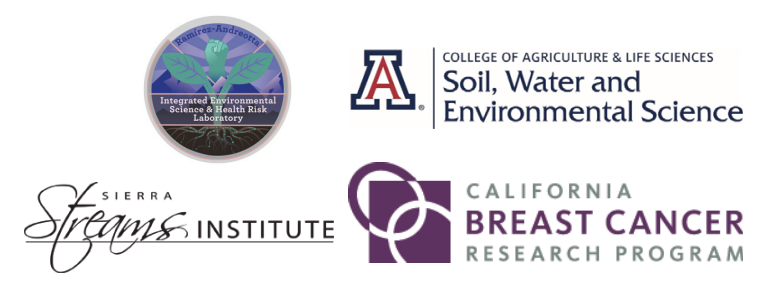

Nevada City, CA 95959 (530) 477- 7132 Ext. 200

www.sierrastreamsinstitute.org

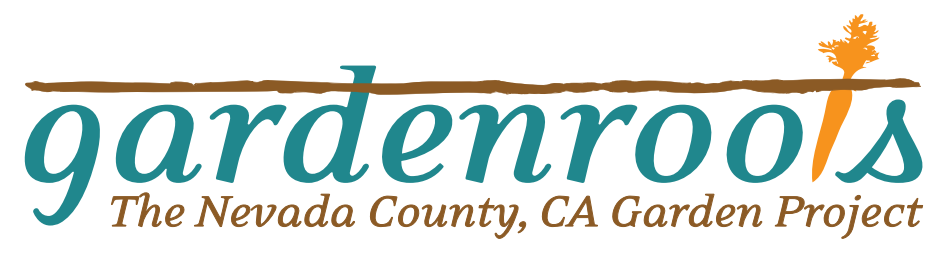




\section{Project Description}

Based on community member's concerns regarding environmental quality, Gardenroots: The Nevada City, CA Garden Project was developed. Gardenroots is an environmental monitoring and children's exposure assessment project designed to better understand potential child exposure to arsenic and cadmium. Seeing gardens as hubs for environmental health research and education, Gardenroots is trying to understand the state of environmental quality in rural communities. Results from this study are helping to determine whether people are exposed to metal contaminants through gardening and crop ingestion.

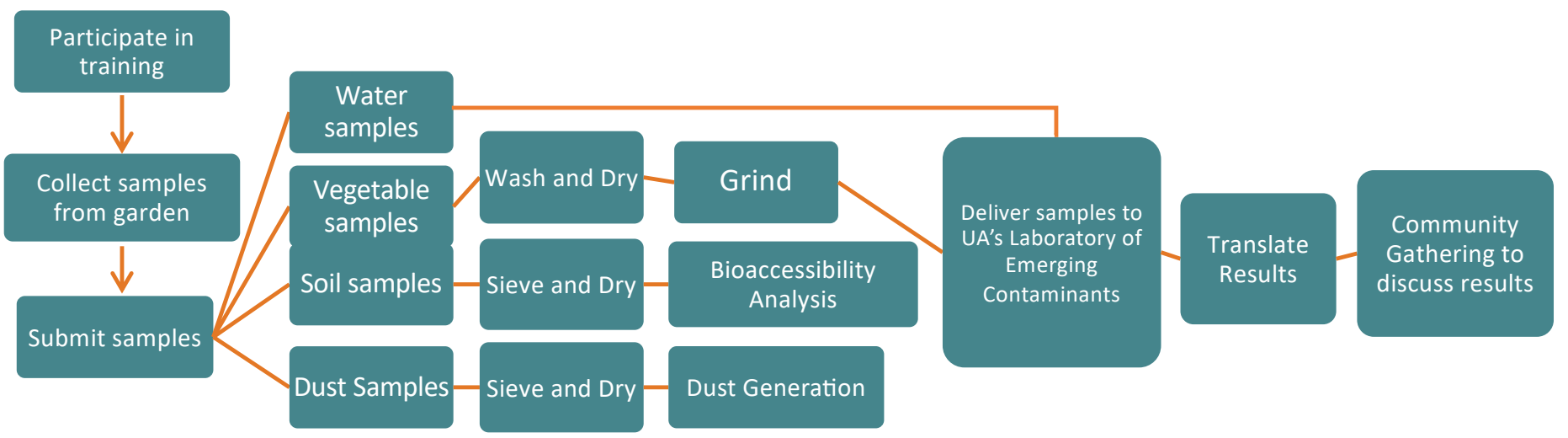

\section{Data may be subject to revisions.}

The results have been internally reviewed, but have not undergone external peer review and may be subjected to minor changes.

Metals occur naturally in the environment.

While we can measure the level of a metal in certain substances, like water or soil, it is difficult to know the original source of the metal. For example, arsenic may be found in soil in many parts of the state because it also naturally occurs in these regions.

It is important to note that, elements such as arsenic occur naturally in soil and it is impossible to grow plants completely free of these and other trace elements like lead and cadmium.

Please refer to the recommended gardening best practices handouts for ways to reduce levels of harmful chemicals in your garden plot and in your vegetables.

Single exposure measurements are "snapshots in time".

We are measuring metal concentrations at a single point in time. Measuring metal concentrations with a single sampling does not establish what the exposures were in the past or what they may be in the future.

For more information about the study and safe gardening practices, please visit the Gardenroots website: http://www.gardenroots.arizona.edu/ 


\section{Important Terms}

Below is a set of terms that you will see throughout your results:

Action Level (AL) - The U.S. Environment Protection Agency (U.S. EPA) regulates lead under the Lead and Copper Rule. This rule describes the water treatment requirements needed to control plumbing corrosion that may contaminate drinking water. If the water concentration of lead is above the action level, this means actions are required to correct the water system to meet this regulation.

Concentration - The amount of a chemical in a given mass of water, soil, or plant tissue. This is written as $\mu \mathrm{g} / \mathrm{L}$ (micrograms per liter), $\mu \mathrm{g} / \mathrm{m}^{3}$ (micrograms per cubic meter), or $\mu \mathrm{g} / \mathrm{g}$ (micrograms per gram).

Guideline - A non-enforceable, but recommended maximum concentration of a chemical.

MCL (Maximum Contaminant Level) - The MCL is the maximum amount of a contaminant allowed in drinking water so that it is still safe to drink over many years. This level is set by the US Environmental Protection Agency.

Median - The value at the midpoint (middle value) of the range of values.

National Ambient Air Quality Standard (NAAQS) - These are standards established by the U.S. EPA to protect human health. The standard for lead defines the maximum allowable concentration of lead in a cubic squared meter of outdoor air. This standard is current set to $0.15 \mu \mathrm{g} / \mathrm{m}^{3}$.

Percentile - A number where a certain percentage of scores fall below that number. For example, if you know that your score is in the 90th percentile, that means you scored better than $90 \%$ of people who took the test.

$\mu \mathrm{g} / \mathrm{g}$ (Micrograms per Gram) - A measure of how many micrograms of a substance (such as a metal) are in a gram of a solid (such as soil). This measure is also referred to as parts per million (ppm).

$\mu \mathrm{g} / \mathrm{L}$ (Micrograms per Liter) - A measure of how many micrograms (one-thousandth of a milligram) of a substance (such as a metal) are in a liter of liquid (such as water). This measure is also referred to as parts per billion (ppb). For perspective, $1 \mu \mathrm{g} / \mathrm{L}$ or $\mathrm{ppb}$ is the equivalent to a drop of ink in a backyard swimming pool.

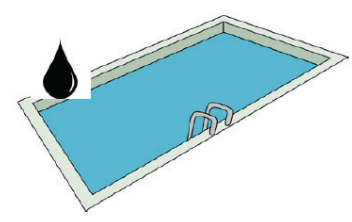

\begin{tabular}{|c|c|c|}
\hline $\begin{array}{c}\text { Micrograms per liter } \\
(\mu \mathrm{g} / \mathrm{L})\end{array}$ & $\begin{array}{c}\text { Parts per billion } \\
(\mathrm{ppb})\end{array}$ & $1 / 1,000,000,000$ \\
\hline
\end{tabular}




\section{Important Terms (con't)}

$\mu \mathrm{g} / \mathrm{m}^{3}$ (Micrograms per Cubic Meter) - A measure of how many micrograms of a substance (such as a metal) are in a cubic meter of a air.

Reference Dose (RfD) - Estimate of a daily intake of a chemical that is not likely to result in any significant negative health effects (including sensitive populations like children and elderly). It may be referred to as the acceptable daily intake.

Standards - The standards are enforceable and regulatory values, developed either by federal agencies or by the state of Arizona for water providers/utilities. They are different from advisories (see definition on previous page) and guidelines.

\section{Soil Screening Levels}

- U.S. EPA Regional Screening Level (RSL) - Risk-based concentrations of contaminant in soils that are calculated using what we know about the exposure to a contaminant and what the U.S. EPA knows about the toxicity of the chemical. U.S. EPA considers these screening levels as initial cleanup goals, when applicable. They are not national cleanup standards, and are based on different target risks.

- CalEPA California Human Health Screening Levels (CHHSLs) - Risk-based concentrations of contaminants in soils that are specific to California. Screening levels for lead are not risk-based screening levels, but rather the average $\mathrm{Pb}$ concentration in residential soil that would be protective of children and women of child-bearing ages. These values are more conservative than the U.S EPA RSLS.

- CalEPA California Department of Toxic Substances Control Screening Levels (DTSC-SL) - Riskbased recommended screening levels that are derived using DTSC-modified exposure and toxicity factors for contaminants in soil. These values are also more conservative than the U.S EPA RSLs. 


\section{Arsenic (As)}

\section{Contaminant Name: Arsenic (As) \\ Contaminant Type: Metalloid}

\section{What is Arsenic?}

Arsenic naturally exists in the Earth's crust and can be found in sediments, soils, and groundwater. Arsenic may also be released into the environment via mining, ore smelting, and industrial use of the element.

\section{What happens to arsenic when it enters the environment?}

In the environment, people can be exposed to arsenic in two chemical forms:

- Inorganic: Varying amounts of this poisonous (toxic) form can be found naturally in geologic materials (soils, rocks, aquifer materials) and in ground and surface water, which may also be impacted by mining and industrial wastes and arsenical pesticides).

- Organic (arsenic compounds that contain carbon): Varying amounts of this non-poisonous (lowtoxicity) form can be found in sources such as animals, plants, fish and seafood. Fish and shellfish can accumulate arsenic; most of this arsenic is in an organic form called arsenobetaine that is much less harmful.

\section{How can arsenic affect my health?}

Severe (acute) arsenic poisoning can cause vomiting, abdominal pain, and diarrhea. This can be followed by numbness and tingling of the extremities, muscle cramping, and death in extreme cases. Ingesting or breathing low levels of inorganic arsenic for a long time (chronic) can cause non-cancer health effects, like a darkening of the skin and the appearance of small "warts" on the palms, soles, and torso. Other non- cancer health effects linked to long- term ingestion of arsenic include developmental effects, diabetes, pulmonary disease, and cardiovascular disease. Ingestion of inorganic arsenic can increase the risk of skin cancer and cancer in the liver, bladder, and lungs. Inhalation of inorganic arsenic can cause increased risk of lung cancer.

\section{Where can I get more information on Arsenic?}

Agency for Toxic Substances and Disease Registry. ToxFAQsTM for Arsenic. Last Updated on March 12, 2015. You can access this information at: https://www.atsdr.cdc.gov/toxfaqs/tf.asp?id=19\&tid=3 


\title{
Cadmium (Cd)
}

\author{
Contaminant Name: Cadmium (Cd) \\ Contaminant Type: Heavy metal
}

\section{What is cadmium?}

Cadmium is found in the Earth's crust. Most cadmium used in the U.S. is extracted as a byproduct during the production of other metals such as zinc, lead, or copper. Cadmium is also recovered from used batteries. Cadmium is used for the following: batteries, pigments, coatings and platings, stabilizers for plastics, photovoltaic (solar power materials) devices, and other uses.

\section{What happens to cadmium when it enters the environment?}

Cadmium is emitted to soil, water, and air by metal mining and refining, manufacture and application of phosphate fertilizers, fossil fuel combustion, and waste incineration and disposal. Generally, cadmium binds strongly to organic matter where it can stay in soil and be taken up by plant life, eventually entering the food supply.

\section{How can cadmium affect my health?}

Cigarette smoking is a major exposure route to cadmium. Tobacco may have been grown in contaminated soils, or pesticides/fungicides or additives were applied during the growing and manufacturing process.

Exposure to cadmium can occur through breathing contaminated workplace air, drinking contaminated water, or living near industrial facilities that release cadmium into the air. Eating food or drinking water with very high levels severely irritates the stomach, leading to vomiting and diarrhea. Long-term exposure to lower levels of cadmium in air, food, or water leads to a buildup of cadmium in the kidneys and possible kidney disease. Other long-term effects include lung damage and fragile bones. Low levels of cadmium are found in all foods (highest levels are found in shellfish, liver, and kidney meats). In the U.S., for nonsmokers the primary source of cadmium exposure is from the food supply. Breathing high levels of cadmium can severely damage the lungs. Cadmium and cadmium compounds are known to cause cancer in humans.

\section{Where can I get more information on Cadmium?}

Agency for Toxic Substances and Disease Registry. ToxFAQsTM for Cadmium. Last Updated on March

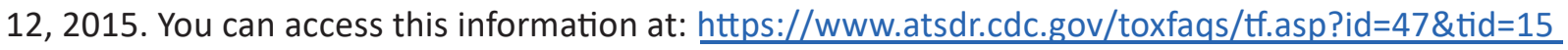




\title{
Lead $(\mathrm{Pb})$
}

\author{
Contaminant Name: Lead (Pb) \\ Contaminant Type: Heavy Metal
}

\section{What is lead?}

Lead is a metal in the Earth's crust that

is normally found with other metals such as zinc, silver, and copper. Lead has many uses including manufacturing of paints, batteries, and fishing weights. Lead- based solder, which had been used to connect copper water pipes, was banned in the 1980s, but may still be a source of lead in drinking water in older homes. In the United States, lead was used as a gasoline additive, but was banned beginning in 1973 and eliminated by 1996.

\section{What happens to lead when it enters the environment?}

Lead itself does not break down, but lead compounds are changed by sunlight, air, and water. When lead is released to the air, it may travel long distances before settling to the ground. Once lead falls onto soil, it usually sticks to soil particles. Ingestion (soil, food, water) is the main route of exposure in humans.

Children are most impacted by lead exposure because they often put their hands and/or toys in their mouths. Pregnant women can also expose their unborn child to lead via ingestion. Adults can be exposed via lifestyle choices (e.g., cigarette smoking) or through their occupation (e.g., plumbing, soldering, manufacturing plants, construction/remodeling companies, smelters, and auto repair shops). There are other sources of potential lead exposure which include: paints, glazed clay pots, wine, food, leaded glass (crystal), stained glass, dyes, and home remedies (e.g., azarcon or greta used to treat digestive illness).

\section{How can lead affect my health?}

Lead can affect almost every organ and system in your body, both in adults and children. Exposure to lead can seriously harm a child's health. It can damage the brain and nervous system, slow growth and development, cause learning, behavior, hearing, and speech problems. It causes lower IQ, decreased ability to pay attention, and underperformance in school. Lead exposure also causes small increases in blood pressure, particularly in middle-aged and older people and can cause anemia. In pregnant women, high levels of exposure to lead may cause miscarriage. High-level exposure in men can damage the organs responsible for sperm production.

\section{Where can I get more information on Lead?}

Agency for Toxic Substances and Disease Registry. ToxFAQsTM for Lead. Last Updated on August 24, 2016. You can access this information at: https://www.atsdr.cdc.gov/toxfaqs/tf.asp?id=93\&tid=22 


\section{A Guide to Reading the Results}

\section{Guide for reading soil, plant, water, and dust results}

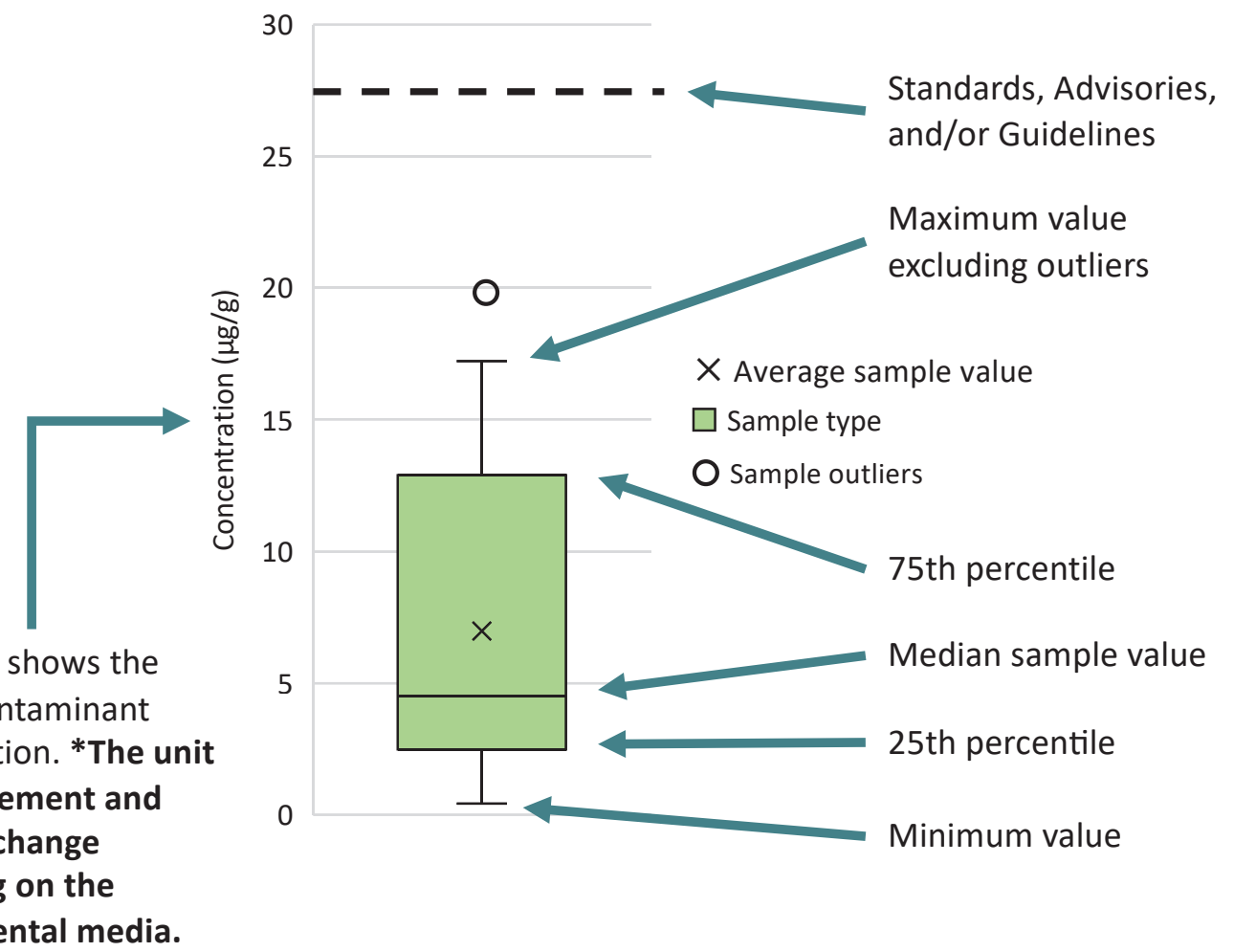

The Y-Axis shows the level of contaminant concentration. *The unit of measurement and scale will change depending on the environmental media.

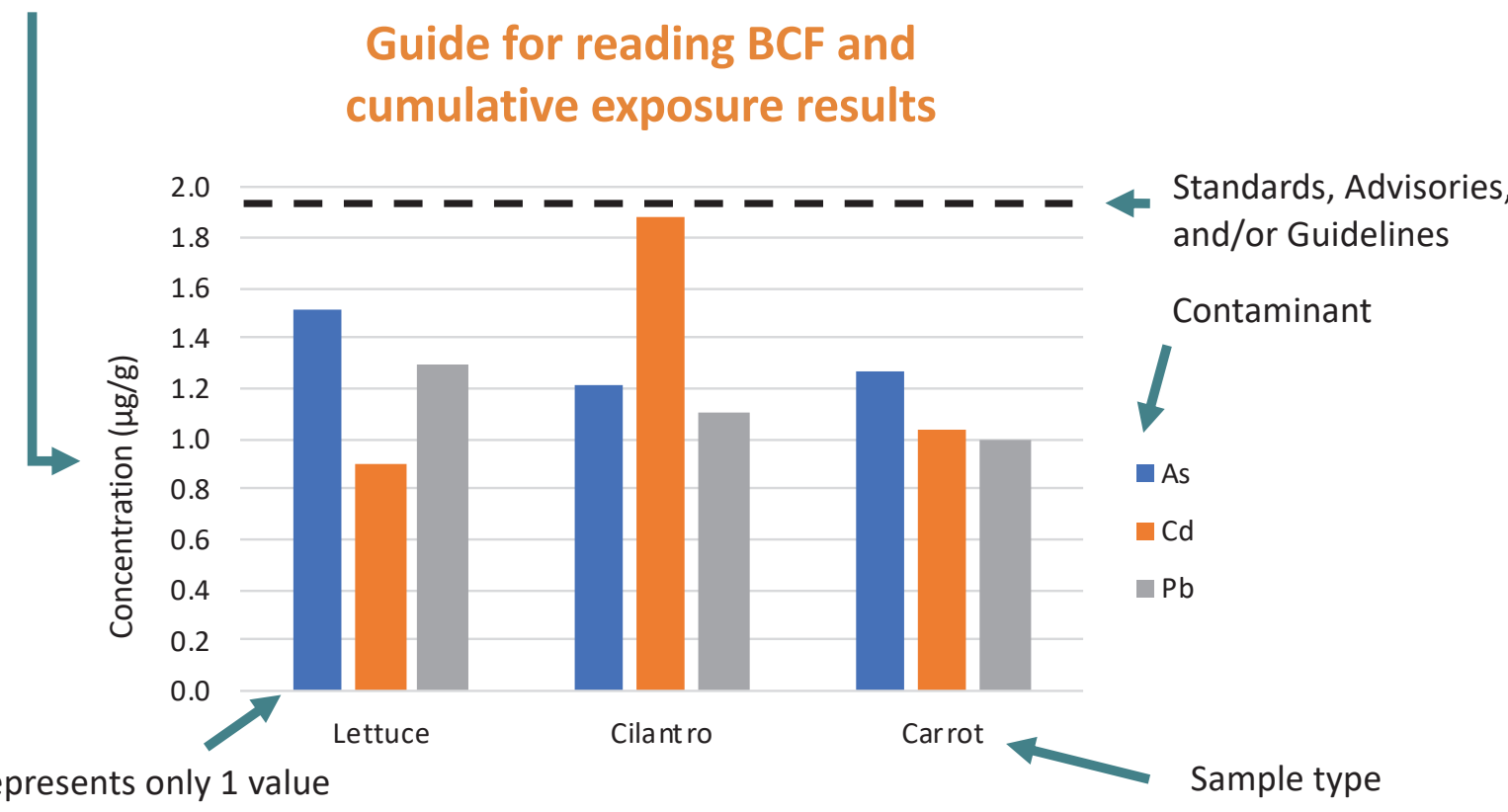

Each bar represents only 1 value unless shown as a percentage out of $100 \%$ on the Y-Axis 


\section{Vegetable Results}

Below are the measured arsenic, cadmium, and lead concentrations in vegetables that were collected at your preschool.

\section{Concentration in Garden Vegetables}
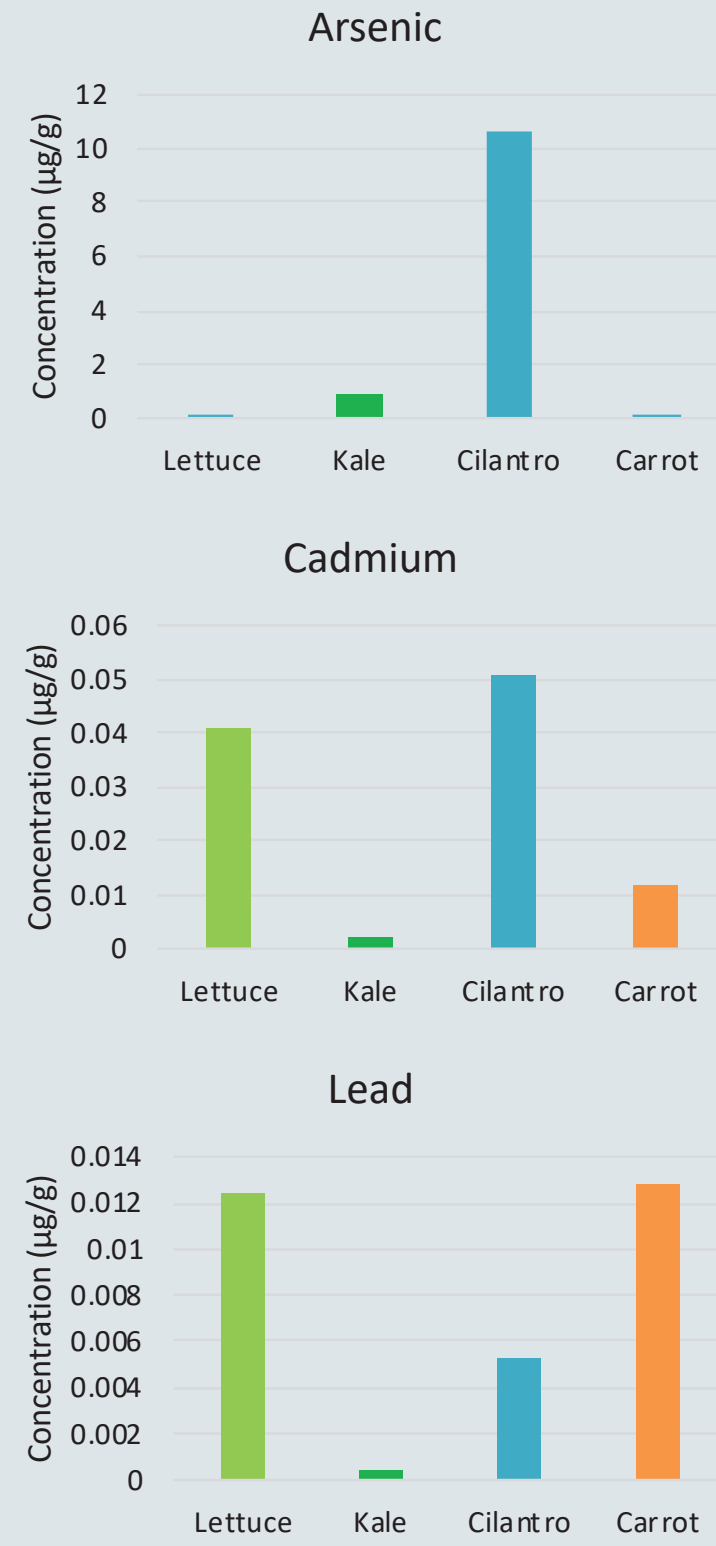

We found that in general, Asteracaea (lettuce) and Apaiaceae plants (carrot and cilantro) had the greatest median concentrations of $\mathrm{As}, \mathrm{Cd}$, and $\mathrm{Pb}$.

\section{Plant Bioconcentration Factor}

The plant bioconcentration factor (BCF) is the ratio of the metal concentration in the edible portion in the vegetable (dry weight) and the metal concentration in the soil.

$$
B C F=\frac{\text { Contaminant concentration in plant }}{\text { Contaminant concentration in garden soil }}
$$
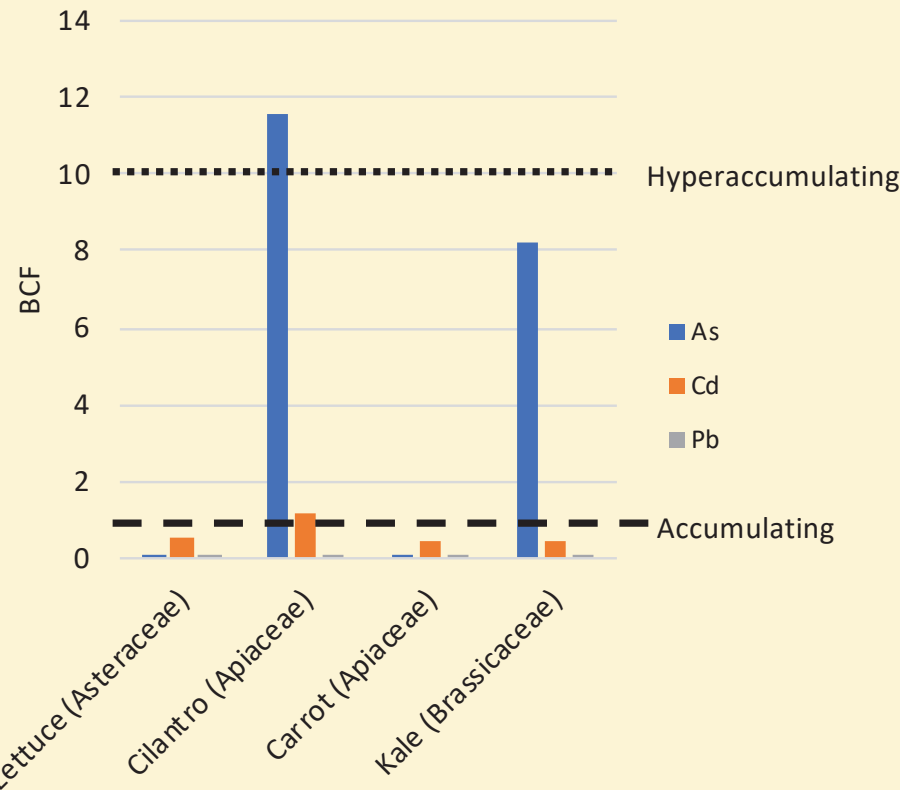

Certain members of the Asteraceae and Brassicaceae families have been previously identified as hyperaccumulator plants, meaning they may have a genetic and physiological capacity to accumulate high amounts of metals (BCF > 10). We found that preschoolgrown cilantro hyperaccumulated As, while kale was only an accumulator of As. Cilantro also accumulated Cd.

With this evidence, it is recommended that Nevada County, CA gardeners limit the use of vegetables from the Apiaceae and Brassicaceae plant families. 


\section{Soil Results}

Below are the measured arsenic, cadmium, and lead concentrations in soil samples that were collected at your preschool.

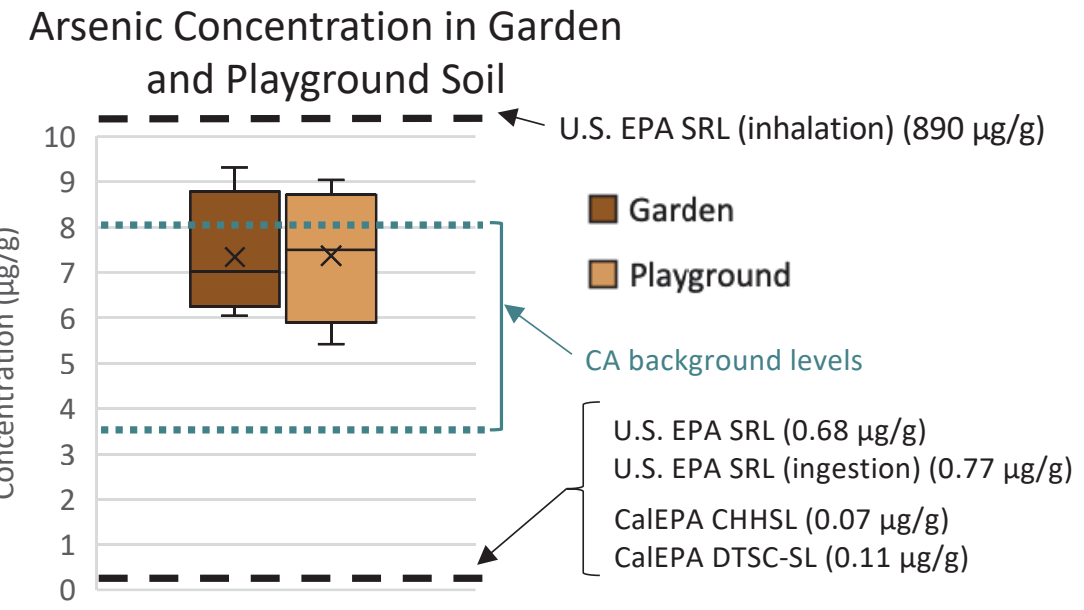

Garden soil samples exceeded the recommended conservative state and federal soil screening levels for As.

The measured As concentrations in garden and playground soil were generally similar to the $C A$ background As levels. This suggests that in general, these levels are not caused by human activity or historical land use.

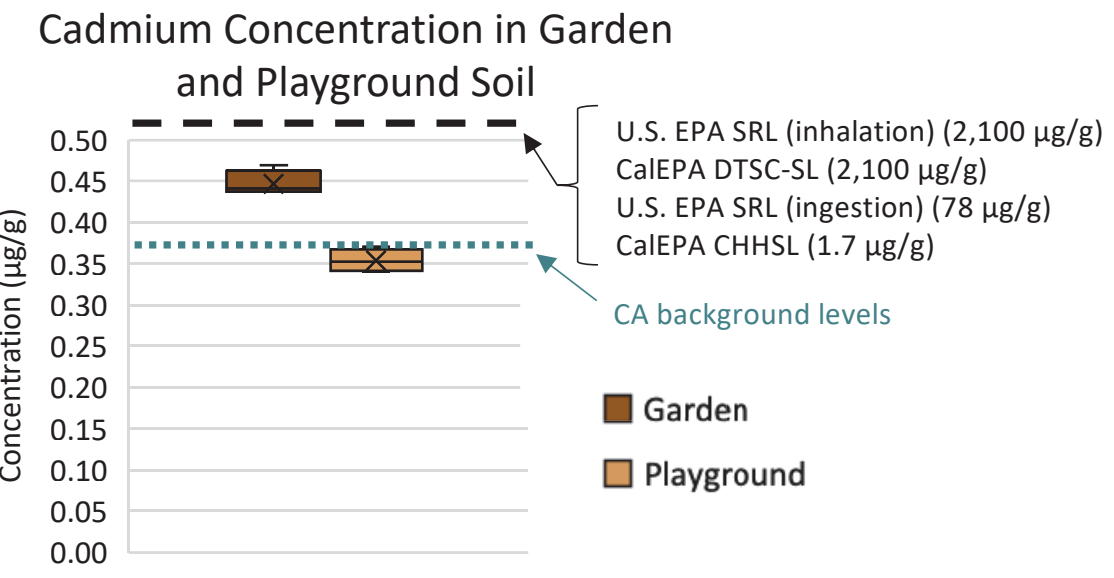

Garden soil samples did not exceeded the recommended conservative state and federal soil screening levels for $\mathrm{Cd}$.

In general, the measured $\mathrm{Cd}$ concentrations in the garden and playground soil were similar to CA background $\mathrm{Cd}$ levels. This suggests that in general, these levels are also not caused by human activity or historical land use.

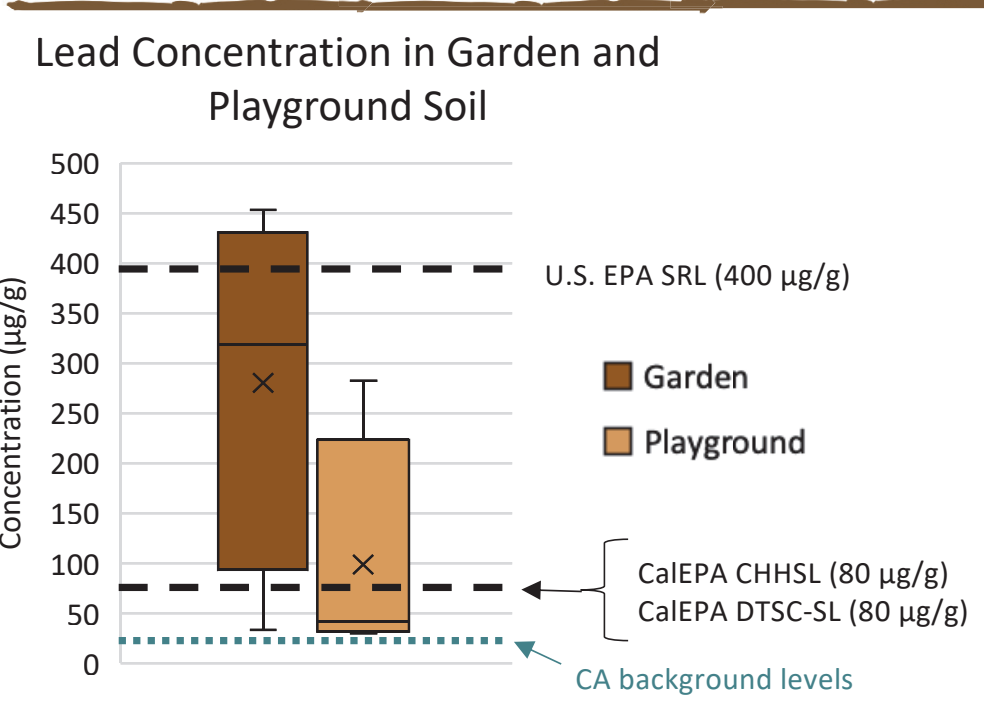

Garden soil samples exceeded the recommended conservative state and federal soil screening levels for $\mathrm{Pb}$. Playground soils also exceeded the conservative state screening levels.

The measured $\mathrm{Pb}$ concentrations in garden and playground soil were above $\mathrm{CA}$ background $\mathrm{Pb}$ levels. This suggests that in general, the elevated $\mathrm{Pb}$ concentrations in preschool garden and playground soils are possibly caused by human activity. 


\section{Water \& Dust Results}

Below are the measured arsenic, cadmium, and lead concentrations in garden irrigation water and dust results from the samples collected at your preschool.

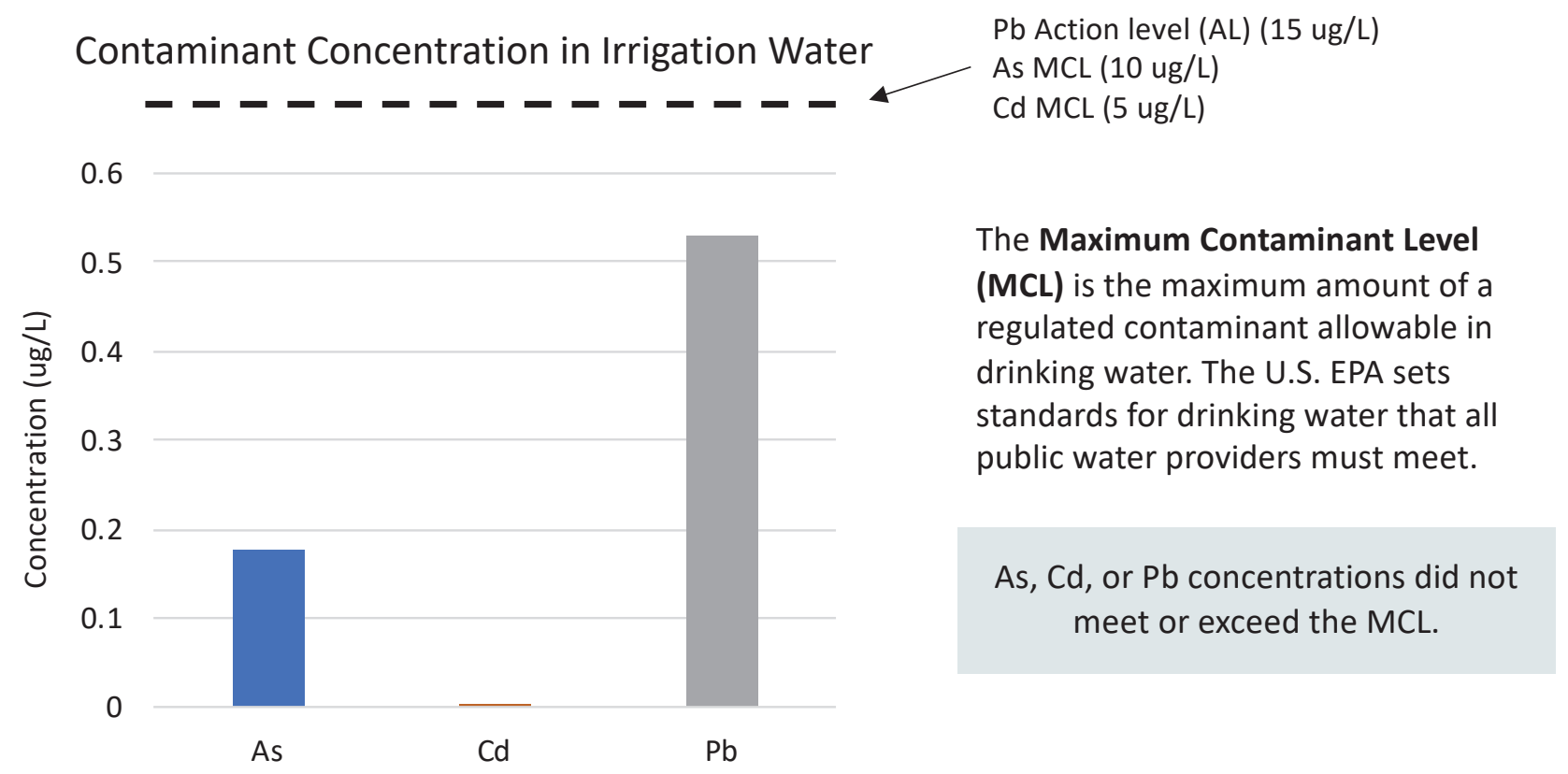

The median $\mathrm{Pb}$ concentration from garden and playground dust in this study were below the U.S. EPA's National Ambient Air Quality Standard (NAAQS) of $0.15 \mu \mathrm{g} / \mathrm{m}^{3}$ for $\mathrm{Pb}$.

There is currently no federal or state outdoor air standard for As or $\mathrm{Cd}$ concentration available for comparison.
Contaminant Concentration in Dust

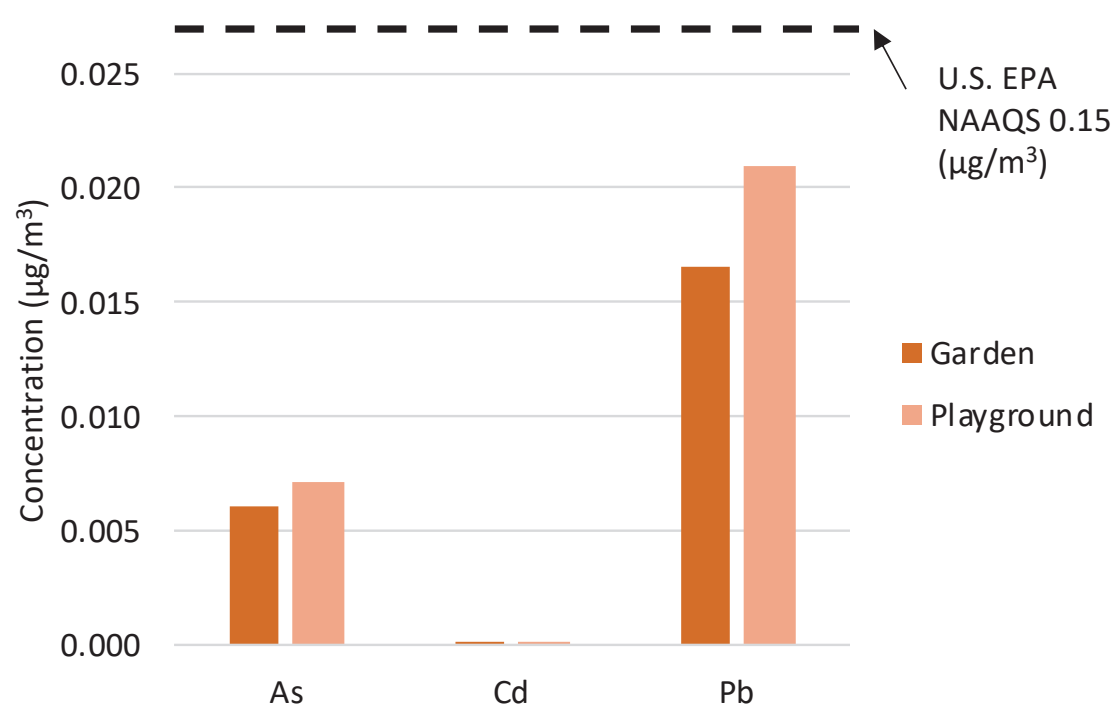




\section{What is an Exposure Assessment?}

An exposure assessment aims to answer the following questions: How much of a contaminant is present in the environment? Are we exposed? If so, how and how much are we exposed to?

In this study we estimated a preschool child's daily dose of $\mathrm{As}, \mathrm{Cd}$, and $\mathrm{Pb}$ from playing and gardening. To do this we used the equation below and the following assumptions:

- Intake rate for the vegetable, water, dust, or soil (incidental) a child would be consuming daily

- Body weight (11.4 to $18.6 \mathrm{~kg}=25$ to $40 \mathrm{lbs}$ )

- Life span equal to 78 years

- Eating that vegetable, drinking the water, incidentally ingesting soil, and inhaling dust for 181 days out of the year (average school year) for 1 year while attending the preschool

- Bioaccessibility of As, Cd, and Pb once it's in your body

Child-specific estimated values are highlighted in the orange boxes.

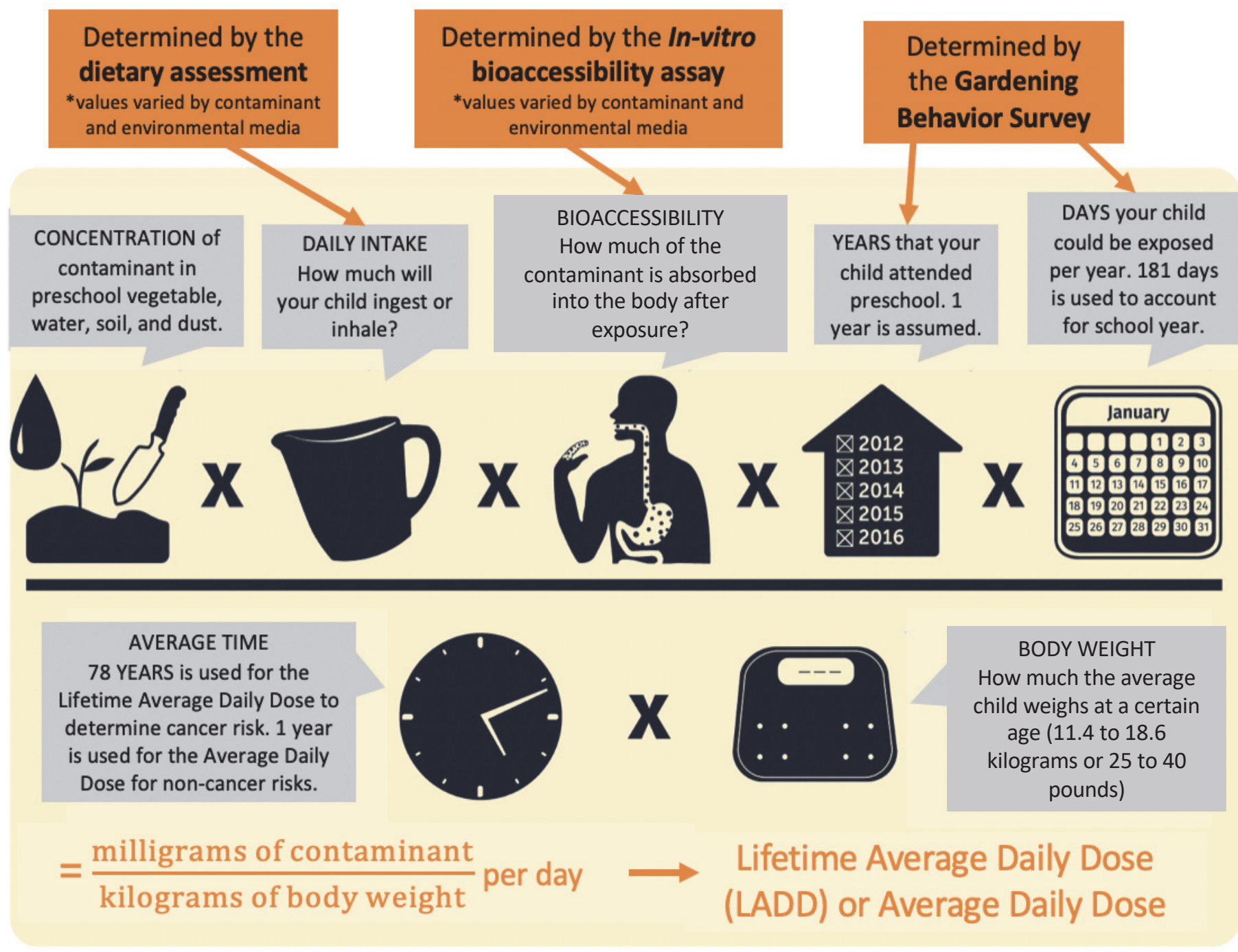




\section{Estimated Exposure (Daily Intake) to Arsenic, Cadmium, and Lead from Vegetables, Soil, Water, and Dust}

A child's cumulative exposure to $\mathrm{As}, \mathrm{Cd}$, and $\mathrm{Pb}$ was estimated for each age group. We determined how much (percentage) each potential exposure route contributed to a child's daily intake (calculated on page 12).

Exposure to Arsenic

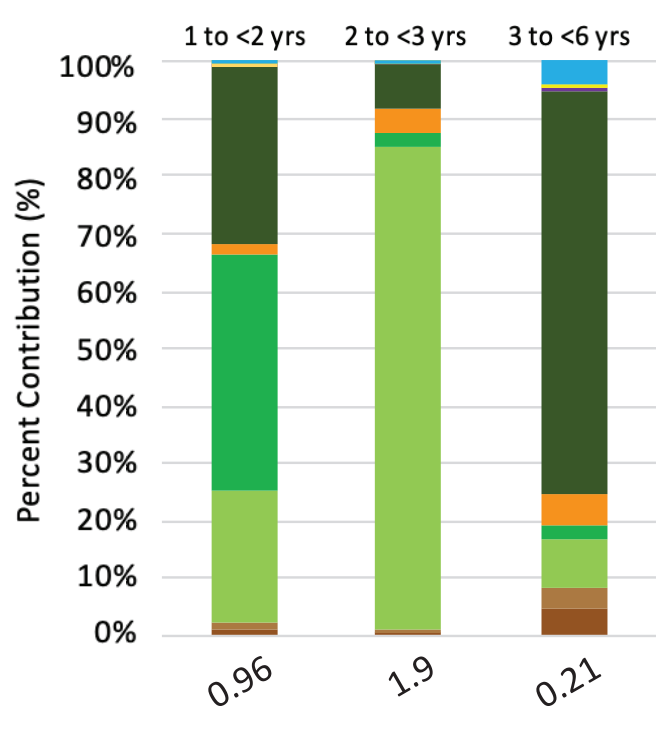

Exposure to Cadmium

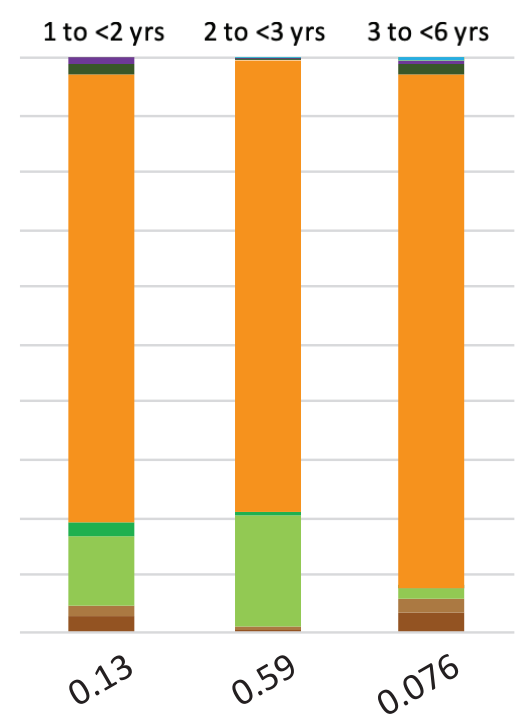

Exposure to Lead

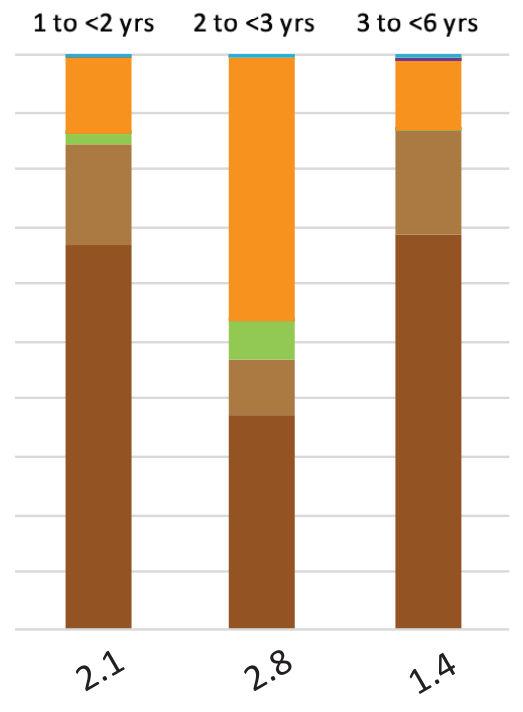

Total daily intake of contaminant per age group ( $\mu \mathrm{g} /$ day)

\begin{tabular}{|c|c|c|c|}
\hline $\begin{array}{l}\text { Garden soil } \\
\text { Carrot }\end{array}$ & - Playground soil & Lettuce & $\begin{array}{l}\text { Cilantro } \\
\text { Garden dust }\end{array}$ \\
\hline Playground dust & Water & & \\
\hline
\end{tabular}

The estimated daily intake of arsenic from all measured exposure routes (vegetables, soil - garden and playground, water, and dust) DID NOT exceed the U.S. EPA's reference dose for arsenic.

Please note! The estimated daily intake of cadmium for 1 to 3 year old children DID exceed CaIEPA's child-specific reference dose for cadmium. 


\section{How much can we eat from the preschool garden?} It is your choice to decide what target risk you want to use to make decisions about how many cups per week to consume from the garden.

We calculated how much of each vegetable your child would have to consume weekly to reach a target excess lifetime cancer risk from arsenic exposure. This target excess risk is in addition to our already existing cancer risk from living our normal lives. These intakes were calculated using the median arsenic concentrations in vegetables across all preschools and the same assumptions described on page 12.

\begin{tabular}{|c|c|c|c|}
\hline \multicolumn{3}{|c|}{$\begin{array}{l}\text { Cups per week that your child can eat based } \\
\text { on different target risks }\end{array}$} & \multirow[t]{2}{*}{$\begin{array}{l}\text { USDA recommended } \\
\text { amounts for 2-3 year } \\
\text { old (cups/week) }\end{array}$} \\
\hline $\begin{array}{l}\text { Target risk of } \\
1 / 1,000,000\end{array}$ & $\begin{array}{c}\text { Target risk of } \\
1 / 100,000\end{array}$ & $\begin{array}{c}\text { Target risk of } \\
1 / 10,000\end{array}$ & \\
\hline \multicolumn{3}{|c|}{ Carrot } & Carrot \\
\hline 11.5 & 115 & 1158 & 2.5 \\
\hline \multicolumn{3}{|c|}{ Lettuce } & Lettuce \\
\hline 2 & 21 & 219 & 1.5 \\
\hline \multicolumn{3}{|c|}{ Kale } & Kale \\
\hline 0.1 & 1 & 10 & 0.5 \\
\hline \multicolumn{3}{|c|}{ Cilantro } & Cilantro \\
\hline 0.2 & 2 & 21 & $\begin{array}{c}\text { No recommendation } \\
\text { available }\end{array}$ \\
\hline
\end{tabular}

\section{Please Note!}

- There are uncertainties associated with this estimation.

- For example, a child will be eating the vegetable for 181 days a year for his/her entire lifetime (78 years).

- This is unlikely due to limited vegetable growing seasons and changes in garden productivity.

- Therefore, the calculated risks are conservative, and the actual risk values would most likely be smaller.

$1 / 1,000,000=1$-in-a-million

$1 / 100,000=1$-in-a-hundred-thousand

$1 / 10,000=1$-in-ten-thousand 


\section{References for More}

\section{Information}

\section{Vegetable}

- U.S. Department of Agriculture (USDA)

- http://www.choosemyplate.gov/food-groups/vegetables amount table.html

- U.S. Environmental Protection Agency (U.S. EPA) - Exposure Factors Handbook

- $\quad$ http://cfpub.epa.gov/ncea/risk/recordisplay.cfm?deid=236252

- U.S. Food and Drug Administration

- http://www.fda.gov/Food/FoodSafety/FoodContaminantsAdulteration/TotalDietStudy

- USDA - What's In The Foods You Eat Search Tool

- $\quad$ http://www.ars.usda.gov/Services/docs.htm?docid=17032

Soil

- CalEPA California Human Health Screening Levels (CHHSLs)

- $\quad$ https://oehha.ca.gov/risk-assessment/california-human-health-screening-levels-chhsls

- CalEPA California Department of Toxic Substances Control Screening Levels (DTSC-SL)

- $\quad$ https://www.dtsc.ca.gov/assessingrisk/humanrisk2.cfm

- University of Arizona Superfund Research Program (UA SRP) - Community Information Sheets

- $\quad$ https://www.superfund.arizona.edu/info-material/information-sheets

- U.S. EPA - Soil Screening Guidance

- $\quad$ http://www.epa.gov/superfund/health/conmedia/soil/index.htm

\section{Water}

- Agency for Toxic Substances and Disease Registry

- http://www.atsdr.cdc.gov/

- UA SRP - Water Booklets

- https://superfund.arizona.edu/info-material/water-booklets-and-videos

- U.S. EPA - Drinking Water Contaminants - Standards and Regulations

- http://water.epa.gov/drink/contaminants/index.cfm

\section{Dust}

- U.S. EPA - Lead National Ambient Air Quality Standard

- https://www.epa.gov/criteria-air-pollutants/naaqs-table 


\section{Thank you!}

Dear School Administrator,

We did it! I would like to give a special thanks to all Nevada County Gardenroots participants for your efforts, motivation, and patience throughout this research project. We appreciate the time you have invested in participating in this project. Altogether, over 33 community members were trained, and 38 soil, 8 dust, 12 water, and 45 plant samples were prepared and analyzed.

This collaborative study was conducted by a team of researchers from the Sierra Streams Institute (a regional nonprofit watershed science organization in Nevada City, CA), University of Arizona, and University of CA-San Francisco. This study was funded by the California Breast Cancer Research Program.

By learning about your students' diet and the environmental quality of your community, we were able to identify environmental health research gaps and ways to improve the quality of preschool gardens. This packet shows the test results of the exposure and risk assessment done for your preschool. Your results are highlighted and compared to state and federal regulatory standards and/or reference values when available. In this package, we have included the following:

1. Project overview

2. Important terms that you will see throughout the results

3. General information on selected contaminants of concern

4. A guide to reading the results

5. Preschool vegetable, soil, irrigation water, and dust results

6. Child's cumulative exposure

7. References for further information on environmental quality and guidelines

Sincerely,

Mónica Ramírez-Andreotta Assistant Professor

University of Arizona

1177 E Fourth Street, Rm. 429, Tucson, AZ 85721

Phone: 520-621-0091 Fax: 520-621-1647

Joanne Hild

Executive Director, River Scientist

Sierra Streams Institute 13075 Woolman Lane

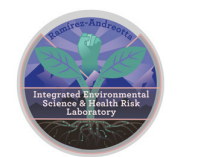

7 COllege of agriculture \& Ufe sciencis

A1 Soil, Water and

Environmental Science

Nevada City, CA 95959 (530) 477- 7132 Ext. 200

www.sierrastreamsinstitute.org

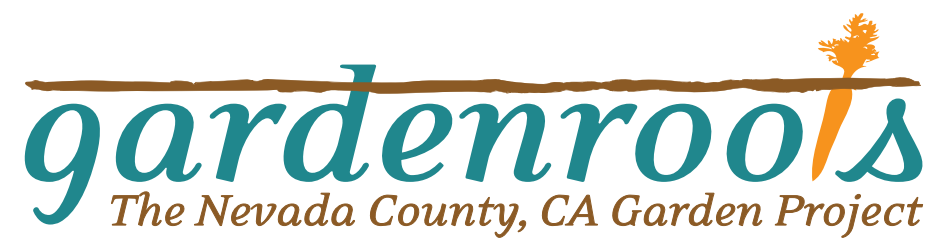




\section{Project Description}

Based on community member's concerns regarding environmental quality, Gardenroots: The Nevada City, CA Garden Project was developed. Gardenroots is an environmental monitoring and children's exposure assessment project designed to better understand potential child exposure to arsenic and cadmium. Seeing gardens as hubs for environmental health research and education, Gardenroots is trying to understand the state of environmental quality in rural communities. Results from this study are helping to determine whether people are exposed to metal contaminants through gardening and crop ingestion.

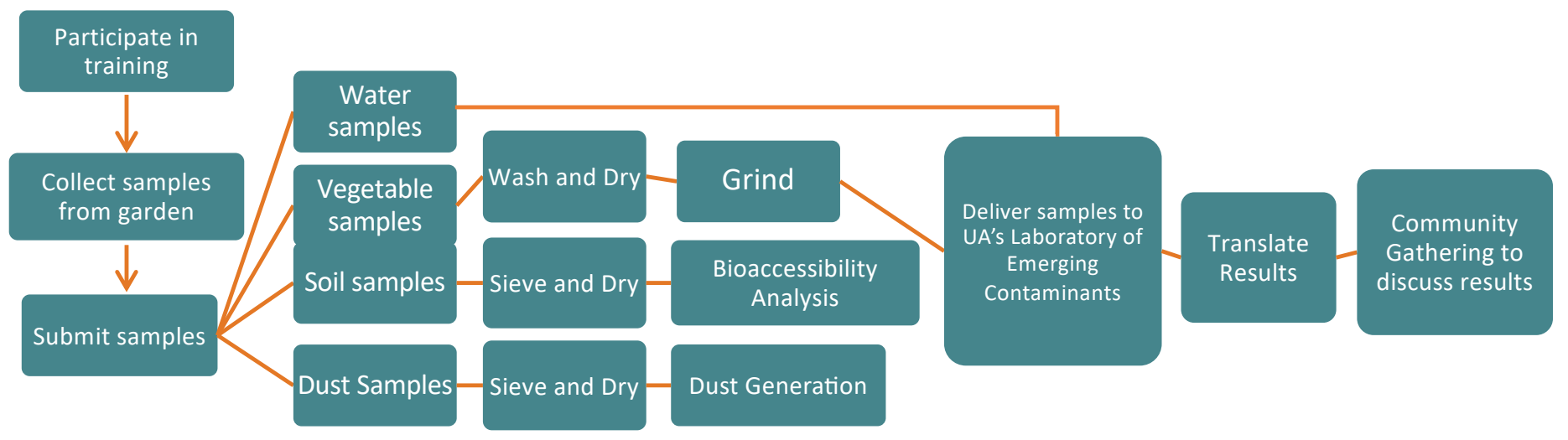

Data may be subject to revisions.

The results have been internally reviewed, but have not undergone external peer review and may be subjected to minor changes.

Metals occur naturally in the environment.

While we can measure the level of a metal in certain substances, like water or soil, it is difficult to know the original source of the metal. For example, arsenic may be found in soil in many parts of the state because it also naturally occurs in these regions.

It is important to note that, elements such as arsenic occur naturally in soil and it is impossible to grow plants completely free of these and other trace elements like lead and cadmium.

Please refer to the recommended gardening best practices handouts for ways to reduce levels of harmful chemicals in your garden plot and in your vegetables.

Single exposure measurements are "snapshots in time".

We are measuring metal concentrations at a single point in time. Measuring metal concentrations with a single sampling does not establish what the exposures were in the past or what they may be in the future.

For more information about the study and safe gardening practices, please visit the Gardenroots website: http://www.gardenroots.arizona.edu/ 


\section{Important Terms}

Below is a set of terms that you will see throughout your results:

Action Level (AL) - The U.S. Environment Protection Agency (U.S. EPA) regulates lead under the Lead and Copper Rule. This rule describes the water treatment requirements needed to control plumbing corrosion that may contaminate drinking water. If the water concentration of lead is above the action level, this means actions are required to correct the water system to meet this regulation.

Concentration - The amount of a chemical in a given mass of water, soil, or plant tissue. This is written as $\mu \mathrm{g} / \mathrm{L}$ (micrograms per liter), $\mu \mathrm{g} / \mathrm{m}^{3}$ (micrograms per cubic meter), or $\mu \mathrm{g} / \mathrm{g}$ (micrograms per gram).

Guideline - A non-enforceable, but recommended maximum concentration of a chemical.

MCL (Maximum Contaminant Level) - The MCL is the maximum amount of a contaminant allowed in drinking water so that it is still safe to drink over many years. This level is set by the US Environmental Protection Agency.

Median - The value at the midpoint (middle value) of the range of values.

National Ambient Air Quality Standard (NAAQS) - These are standards established by the U.S. EPA to protect human health. The standard for lead defines the maximum allowable concentration of lead in a cubic squared meter of outdoor air. This standard is current set to $0.15 \mu \mathrm{g} / \mathrm{m}^{3}$.

Percentile - A number where a certain percentage of scores fall below that number. For example, if you know that your score is in the 90th percentile, that means you scored better than $90 \%$ of people who took the test.

$\mu \mathrm{g} / \mathrm{g}$ (Micrograms per Gram) - A measure of how many micrograms of a substance (such as a metal) are in a gram of a solid (such as soil). This measure is also referred to as parts per million (ppm).

$\mu \mathrm{g} / \mathrm{L}$ (Micrograms per Liter) - A measure of how many micrograms (one-thousandth of a milligram) of a substance (such as a metal) are in a liter of liquid (such as water). This measure is also referred to as parts per billion (ppb). For perspective, $1 \mu \mathrm{g} / \mathrm{L}$ or $\mathrm{ppb}$ is the equivalent to a drop of ink in a backyard swimming pool.

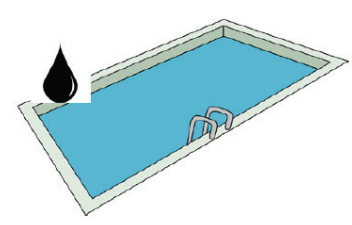

\begin{tabular}{|c|c|c|}
\hline $\begin{array}{c}\text { Micrograms per liter } \\
(\mu \mathrm{g} / \mathrm{L})\end{array}$ & $\begin{array}{c}\text { Parts per billion } \\
(\mathrm{ppb})\end{array}$ & $1 / 1,000,000,000$ \\
\hline
\end{tabular}




\section{Important Terms (con't)}

$\mu \mathrm{g} / \mathrm{m}^{3}$ (Micrograms per Cubic Meter) - A measure of how many micrograms of a substance (such as a metal) are in a cubic meter of a air.

Reference Dose (RfD) - Estimate of a daily intake of a chemical that is not likely to result in any significant negative health effects (including sensitive populations like children and elderly). It may be referred to as the acceptable daily intake.

Standards - The standards are enforceable and regulatory values, developed either by federal agencies or by the state of Arizona for water providers/utilities. They are different from advisories (see definition on previous page) and guidelines.

\section{Soil Screening Levels}

- U.S. EPA Regional Screening Level (RSL) - Risk-based concentrations of contaminant in soils that are calculated using what we know about the exposure to a contaminant and what the U.S. EPA knows about the toxicity of the chemical. U.S. EPA considers these screening levels as initial cleanup goals, when applicable. They are not national cleanup standards, and are based on different target risks.

- CalEPA California Human Health Screening Levels (CHHSLs) - Risk-based concentrations of contaminants in soils that are specific to California. Screening levels for lead are not risk-based screening levels, but rather the average $\mathrm{Pb}$ concentration in residential soil that would be protective of children and women of child-bearing ages. These values are more conservative than the U.S EPA RSLS.

- CalEPA California Department of Toxic Substances Control Screening Levels (DTSC-SL) - Riskbased recommended screening levels that are derived using DTSC-modified exposure and toxicity factors for contaminants in soil. These values are also more conservative than the U.S EPA RSLs. 


\section{Arsenic (As)}

\section{Contaminant Name: Arsenic (As) \\ Contaminant Type: Metalloid}

\section{What is Arsenic?}

Arsenic naturally exists in the Earth's crust and can be found in sediments, soils, and groundwater. Arsenic may also be released into the environment via mining, ore smelting, and industrial use of the element.

\section{What happens to arsenic when it enters the environment?}

In the environment, people can be exposed to arsenic in two chemical forms:

- Inorganic: Varying amounts of this poisonous (toxic) form can be found naturally in geologic materials (soils, rocks, aquifer materials) and in ground and surface water, which may also be impacted by mining and industrial wastes and arsenical pesticides).

- Organic (arsenic compounds that contain carbon): Varying amounts of this non-poisonous (lowtoxicity) form can be found in sources such as animals, plants, fish and seafood. Fish and shellfish can accumulate arsenic; most of this arsenic is in an organic form called arsenobetaine that is much less harmful.

\section{How can arsenic affect my health?}

Severe (acute) arsenic poisoning can cause vomiting, abdominal pain, and diarrhea. This can be followed by numbness and tingling of the extremities, muscle cramping, and death in extreme cases. Ingesting or breathing low levels of inorganic arsenic for a long time (chronic) can cause non-cancer health effects, like a darkening of the skin and the appearance of small "warts" on the palms, soles, and torso. Other non- cancer health effects linked to long- term ingestion of arsenic include developmental effects, diabetes, pulmonary disease, and cardiovascular disease. Ingestion of inorganic arsenic can increase the risk of skin cancer and cancer in the liver, bladder, and lungs. Inhalation of inorganic arsenic can cause increased risk of lung cancer.

\section{Where can I get more information on Arsenic?}

Agency for Toxic Substances and Disease Registry. ToxFAQsTM for Arsenic. Last Updated on March 12, 2015. You can access this information at: https://www.atsdr.cdc.gov/toxfaqs/tf.asp?id=19\&tid=3 


\title{
Cadmium (Cd)
}

\author{
Contaminant Name: Cadmium (Cd) \\ Contaminant Type: Heavy metal
}

\section{What is cadmium?}

Cadmium is found in the Earth's crust. Most cadmium used in the U.S. is extracted as a byproduct during the production of other metals such as zinc, lead, or copper. Cadmium is also recovered from used batteries. Cadmium is used for the following: batteries, pigments, coatings and platings, stabilizers for plastics, photovoltaic (solar power materials) devices, and other uses.

\section{What happens to cadmium when it enters the environment?}

Cadmium is emitted to soil, water, and air by metal mining and refining, manufacture and application of phosphate fertilizers, fossil fuel combustion, and waste incineration and disposal. Generally, cadmium binds strongly to organic matter where it can stay in soil and be taken up by plant life, eventually entering the food supply.

\section{How can cadmium affect my health?}

Cigarette smoking is a major exposure route to cadmium. Tobacco may have been grown in contaminated soils, or pesticides/fungicides or additives were applied during the growing and manufacturing process.

Exposure to cadmium can occur through breathing contaminated workplace air, drinking contaminated water, or living near industrial facilities that release cadmium into the air. Eating food or drinking water with very high levels severely irritates the stomach, leading to vomiting and diarrhea. Long-term exposure to lower levels of cadmium in air, food, or water leads to a buildup of cadmium in the kidneys and possible kidney disease. Other long-term effects include lung damage and fragile bones. Low levels of cadmium are found in all foods (highest levels are found in shellfish, liver, and kidney meats). In the U.S., for nonsmokers the primary source of cadmium exposure is from the food supply. Breathing high levels of cadmium can severely damage the lungs. Cadmium and cadmium compounds are known to cause cancer in humans.

\section{Where can I get more information on Cadmium?}

Agency for Toxic Substances and Disease Registry. ToxFAQsTM for Cadmium. Last Updated on March 12, 2015. You can access this information at: https://www.atsdr.cdc.gov/toxfags/tf.asp?id=47\&tid=15 


\title{
Lead $(\mathrm{Pb})$
}

\author{
Contaminant Name: Lead (Pb) \\ Contaminant Type: Heavy Metal
}

\section{What is lead?}

Lead is a metal in the Earth's crust that

is normally found with other metals such as zinc, silver, and copper. Lead has many uses including manufacturing of paints, batteries, and fishing weights. Lead- based solder, which had been used to connect copper water pipes, was banned in the 1980s, but may still be a source of lead in drinking water in older homes. In the United States, lead was used as a gasoline additive, but was banned beginning in 1973 and eliminated by 1996.

\section{What happens to lead when it enters the environment?}

Lead itself does not break down, but lead compounds are changed by sunlight, air, and water. When lead is released to the air, it may travel long distances before settling to the ground. Once lead falls onto soil, it usually sticks to soil particles. Ingestion (soil, food, water) is the main route of exposure in humans.

Children are most impacted by lead exposure because they often put their hands and/or toys in their mouths. Pregnant women can also expose their unborn child to lead via ingestion. Adults can be exposed via lifestyle choices (e.g., cigarette smoking) or through their occupation (e.g., plumbing, soldering, manufacturing plants, construction/remodeling companies, smelters, and auto repair shops). There are other sources of potential lead exposure which include: paints, glazed clay pots, wine, food, leaded glass (crystal), stained glass, dyes, and home remedies (e.g., azarcon or greta used to treat digestive illness).

\section{How can lead affect my health?}

Lead can affect almost every organ and system in your body, both in adults and children. Exposure to lead can seriously harm a child's health. It can damage the brain and nervous system, slow growth and development, cause learning, behavior, hearing, and speech problems. It causes lower IQ, decreased ability to pay attention, and underperformance in school. Lead exposure also causes small increases in blood pressure, particularly in middle-aged and older people and can cause anemia. In pregnant women, high levels of exposure to lead may cause miscarriage. High-level exposure in men can damage the organs responsible for sperm production.

\section{Where can I get more information on Lead?}

Agency for Toxic Substances and Disease Registry. ToxFAQsTM for Lead. Last Updated on August 24, 2016. You can access this information at: https://www.atsdr.cdc.gov/toxfaqs/tf.asp?id=93\&tid=22 


\section{A Guide to Reading the Results}

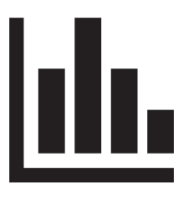

\section{Guide for reading soil, plant, water, and dust results}

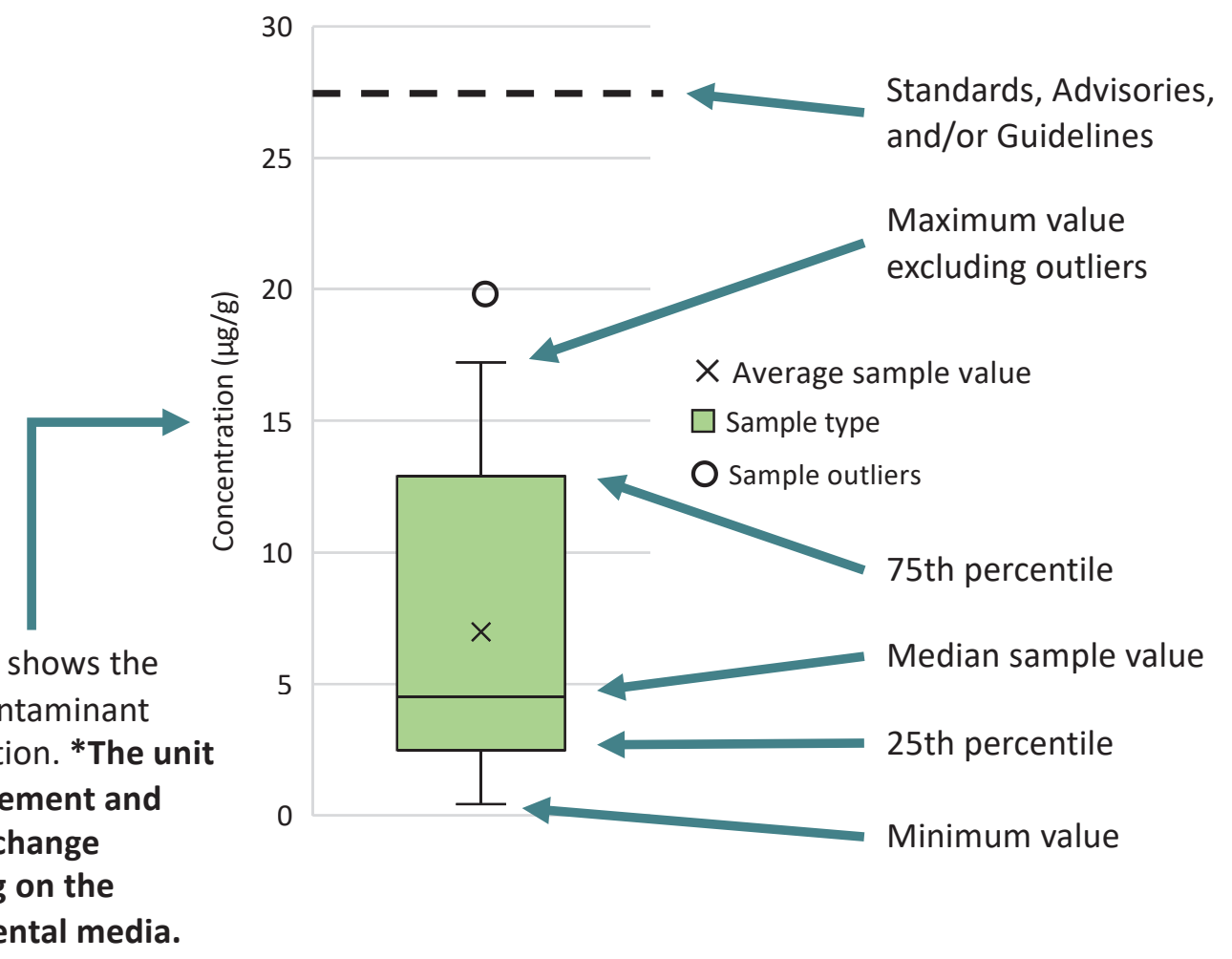

The Y-Axis shows the level of contaminant concentration. *The unit of measurement and scale will change depending on the environmental media.

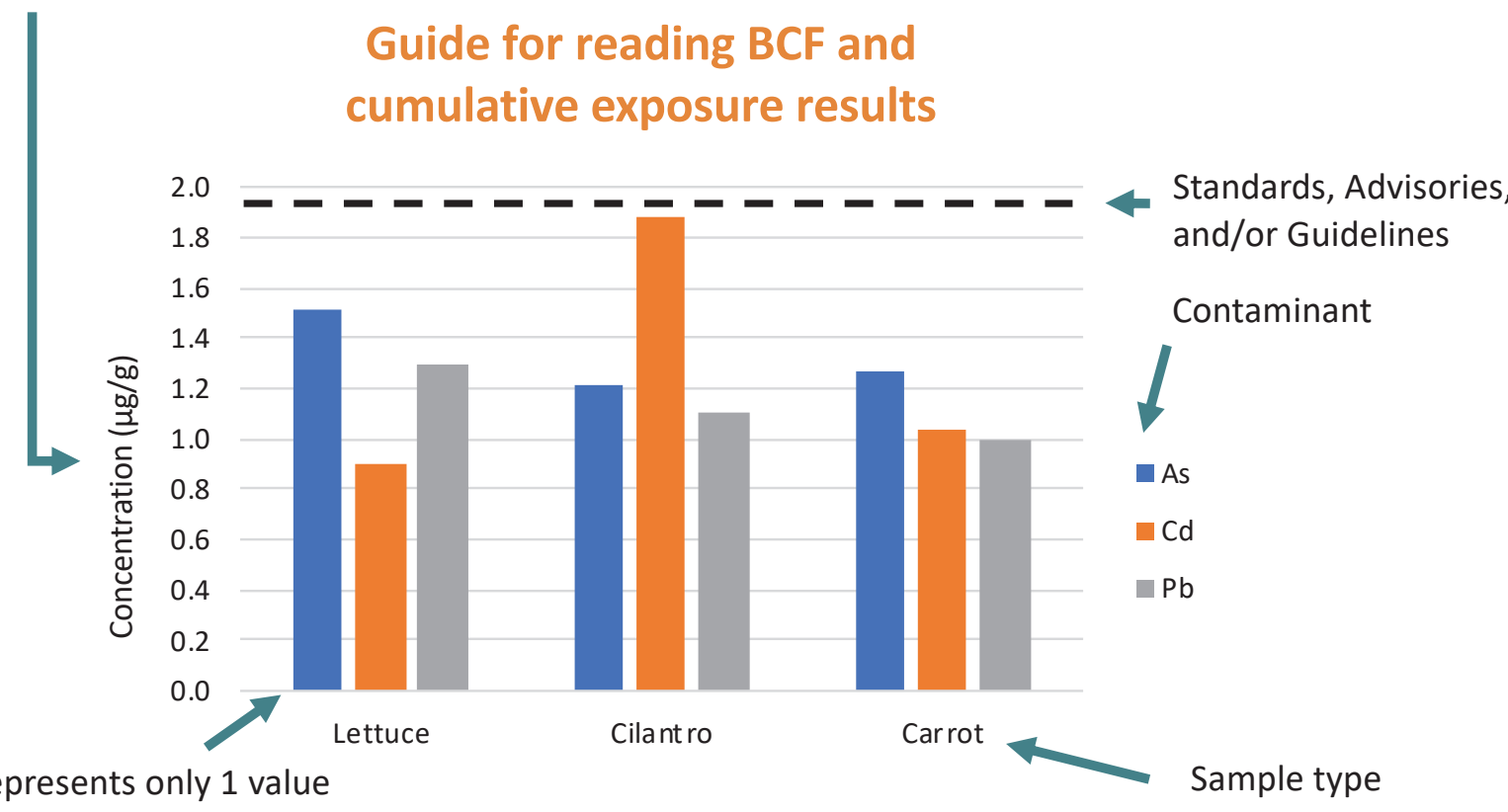

Each bar represents only 1 value unless shown as a percentage out of $100 \%$ on the Y-Axis 


\section{Vegetable Results}

Below are the measured arsenic, cadmium, and lead concentrations in vegetables that were collected at your preschool.

\section{Concentration in Garden Vegetables}
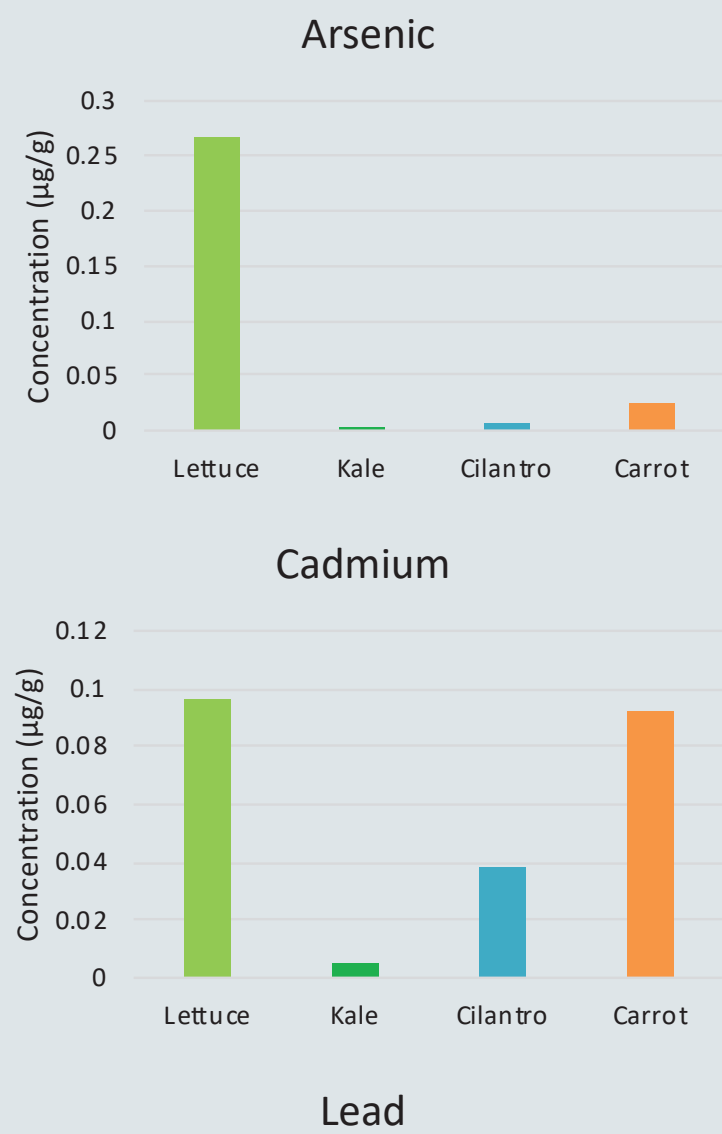

0.7

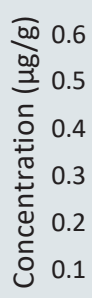

0

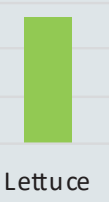

$\overline{\text { Kale }}$

Cilantro

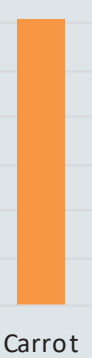

We found that in general, Asteracaea (lettuce) and Apaiaceae plants (carrot and cilantro) had the greatest median concentrations of $\mathrm{As}, \mathrm{Cd}$, and $\mathrm{Pb}$.

\section{Plant Bioconcentration Factor}

The plant bioconcentration factor (BCF) is the ratio of the metal concentration in the edible portion in the vegetable (dry weight) and the metal concentration in the soil.

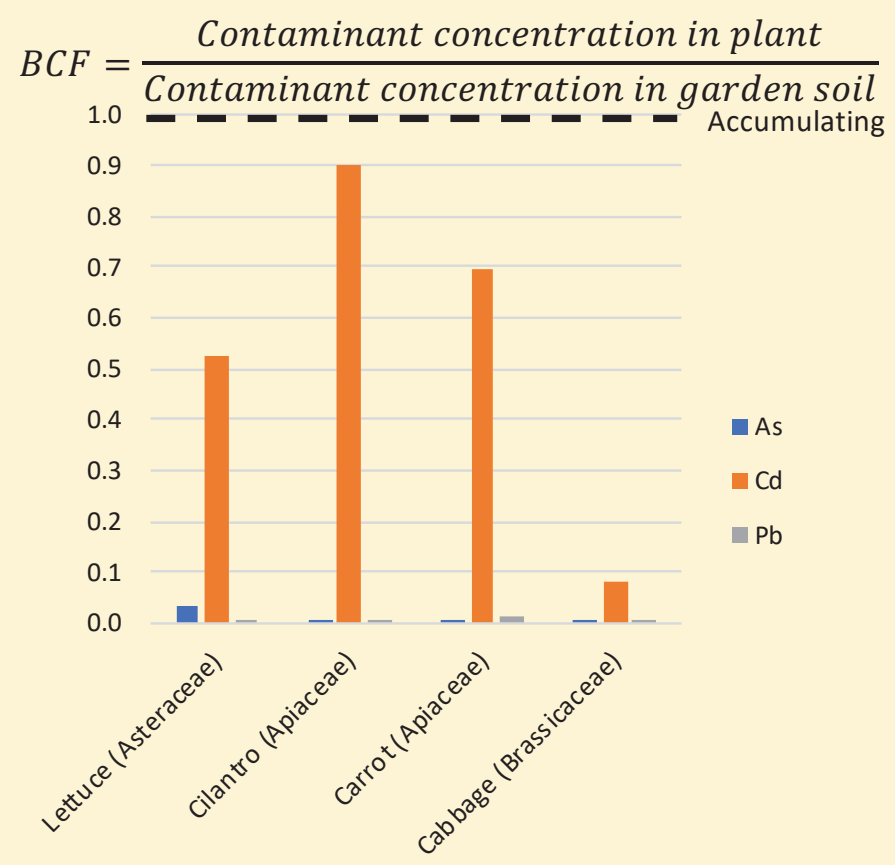

Certain members of the Asteraceae and Brassicaceae families have been previously identified as hyperaccumulator plants, meaning they may have a genetic and physiological capacity to accumulate high amounts of metals (BCF > 10). We found that none of the preschool-grown vegetables accumulated or hyperaccumulated $\mathrm{As}, \mathrm{Cd}$, or $\mathrm{Pb}$. Although, we can see that all vegetables did uptake more $\mathrm{Cd}$ than $\mathrm{As}$ and $\mathrm{Pb}$.

Since Apiaceae plants did nearly accumulate $\mathrm{Cd}$, it is recommended that Nevada County, CA gardeners limit the use of vegetables from the Apiaceae plant family. 


\section{Soil Results}

Below are the measured arsenic, cadmium, and lead concentrations in soil samples that were collected at your preschool.

\section{Arsenic Concentration in Garden} and Playground Soil

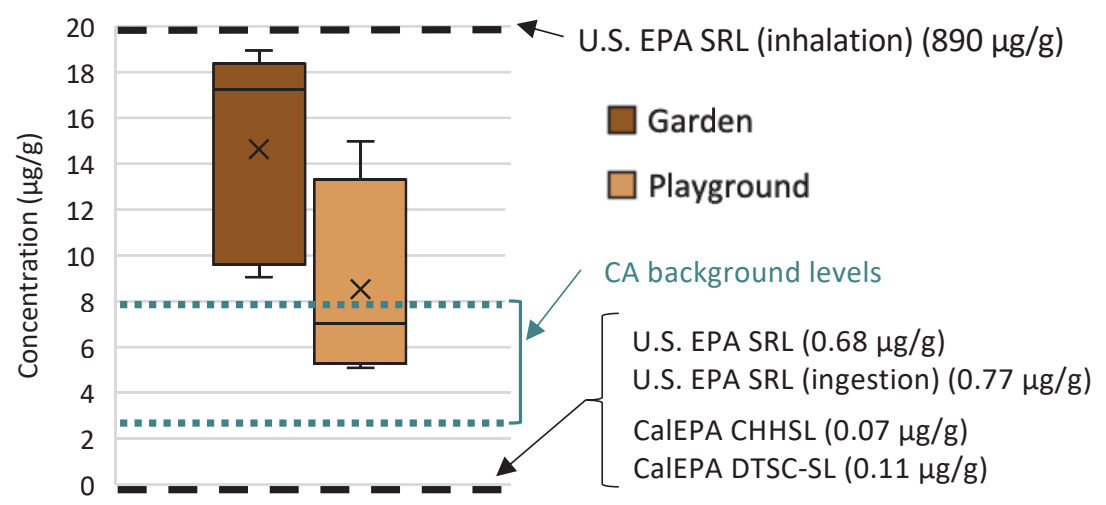

Garden soil samples exceeded the recommended conservative state and federal soil screening levels for As.

The measured As concentrations in garden and playground soil were generally similar to or above the CA background As levels. This suggests that in general, these levels could be caused by human activity.

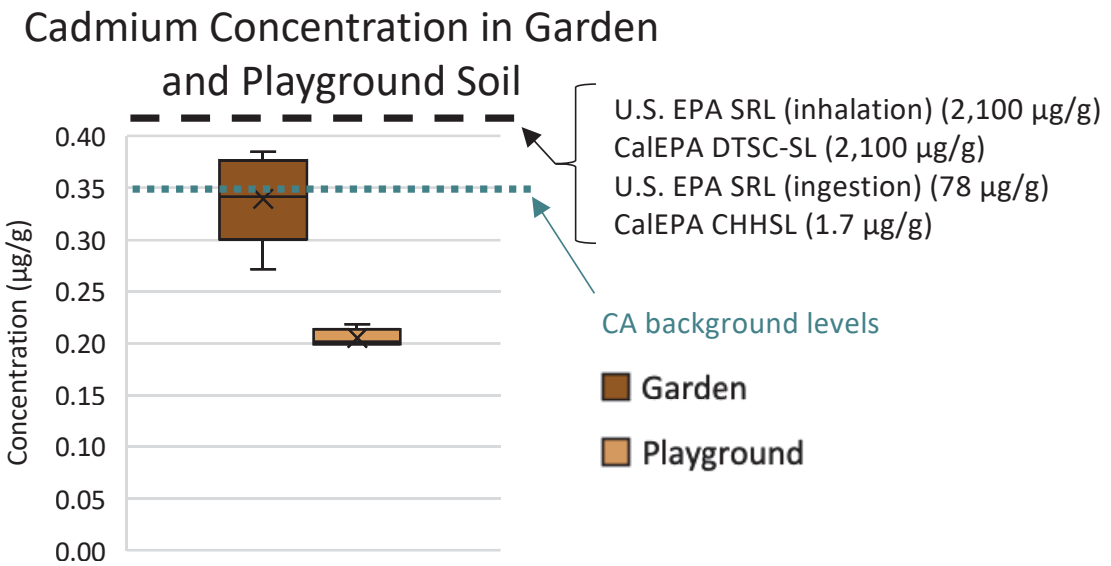

Garden soil samples did not exceeded the recommended conservative state and federal soil screening levels for $\mathrm{Cd}$.

In general, the measured $\mathrm{Cd}$ concentrations in the garden and playground soil were similar to or below CA background Cd levels. This suggests that in general, these levels are also not caused by human activity or historical land use.
Lead Concentration in Garden and

\section{Playground Soil}

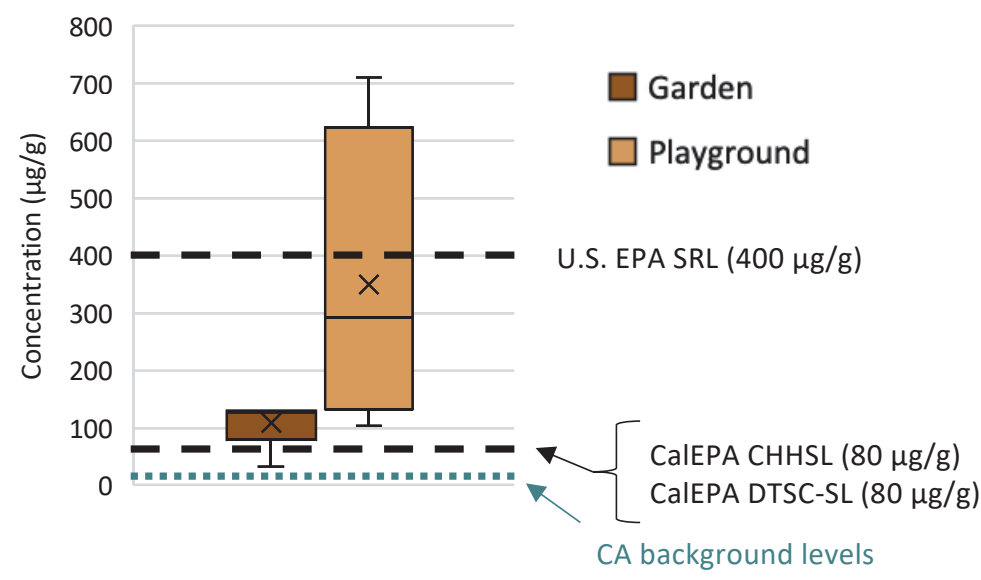

Garden soil samples exceeded the recommended conservative state and federal soil screening levels for $\mathbf{P b}$. Playground soils also exceeded the conservative state screening levels.

The measured $\mathrm{Pb}$ concentrations in garden and playground soil were above $\mathrm{CA}$ background $\mathrm{Pb}$ levels. This suggests that in general, the elevated $\mathrm{Pb}$ concentrations in preschool garden and playground soils are possibly caused by human activity 


\section{Water \& Dust Results}

Below are the measured arsenic, cadmium, and lead concentrations in garden irrigation water and dust results from the samples collected at your preschool.

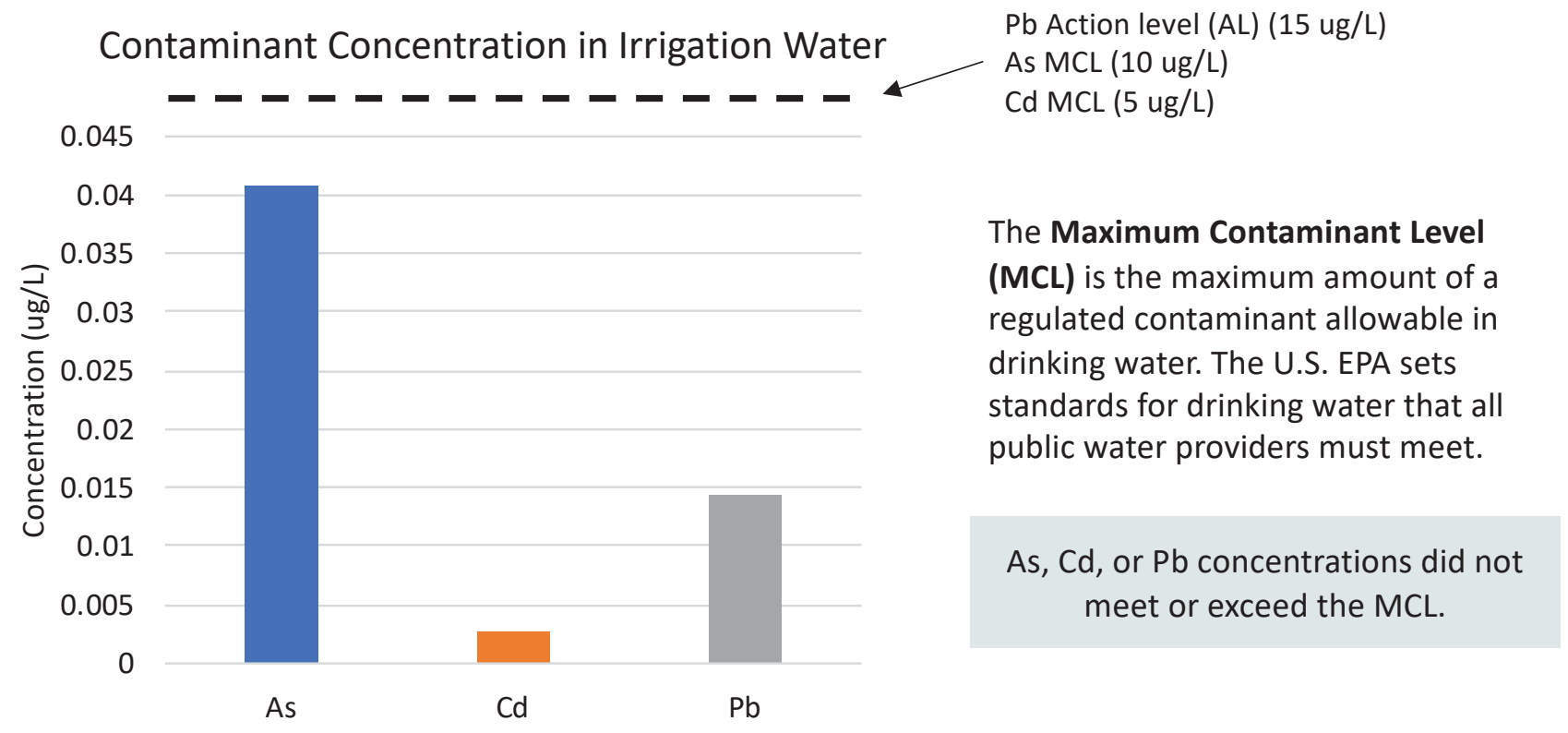

The median $\mathrm{Pb}$ concentration from garden and playground dust at this preschool were below to the U.S. EPA's National Ambient Air Quality Standard (NAAQS) of 0.15 $\mu \mathrm{g} / \mathrm{m}^{3}$

There is currently no federal or state outdoor air standard for As or $\mathrm{Cd}$ concentration available for comparison.
Contaminant Concentration in Dust

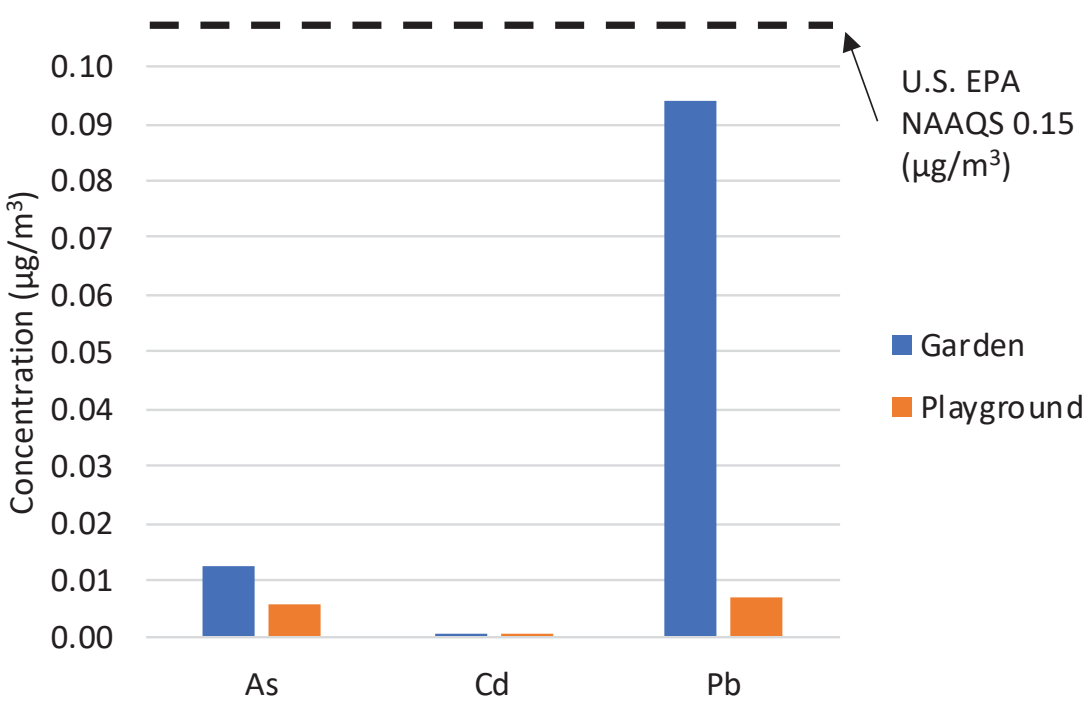




\section{What is an Exposure Assessment?}

An exposure assessment aims to answer the following questions: How much of a contaminant is present in the environment? Are we exposed? If so, how and how much are we exposed to?

In this study we estimated a preschool child's daily dose of $\mathrm{As}, \mathrm{Cd}$, and $\mathrm{Pb}$ from playing and gardening. To do this we used the equation below and the following assumptions:

- Intake rate for the vegetable, water, dust, or soil (incidental) a child would be consuming daily

- Body weight (11.4 to $18.6 \mathrm{~kg}=25$ to $40 \mathrm{lbs}$ )

- Life span equal to 78 years

- Eating that vegetable, drinking the water, incidentally ingesting soil, and inhaling dust for 181 days out of the year (average school year) for 1 year while attending the preschool

- Bioaccessibility of As, Cd, and Pb once it's in your body

Child-specific estimated values are highlighted in the orange boxes.

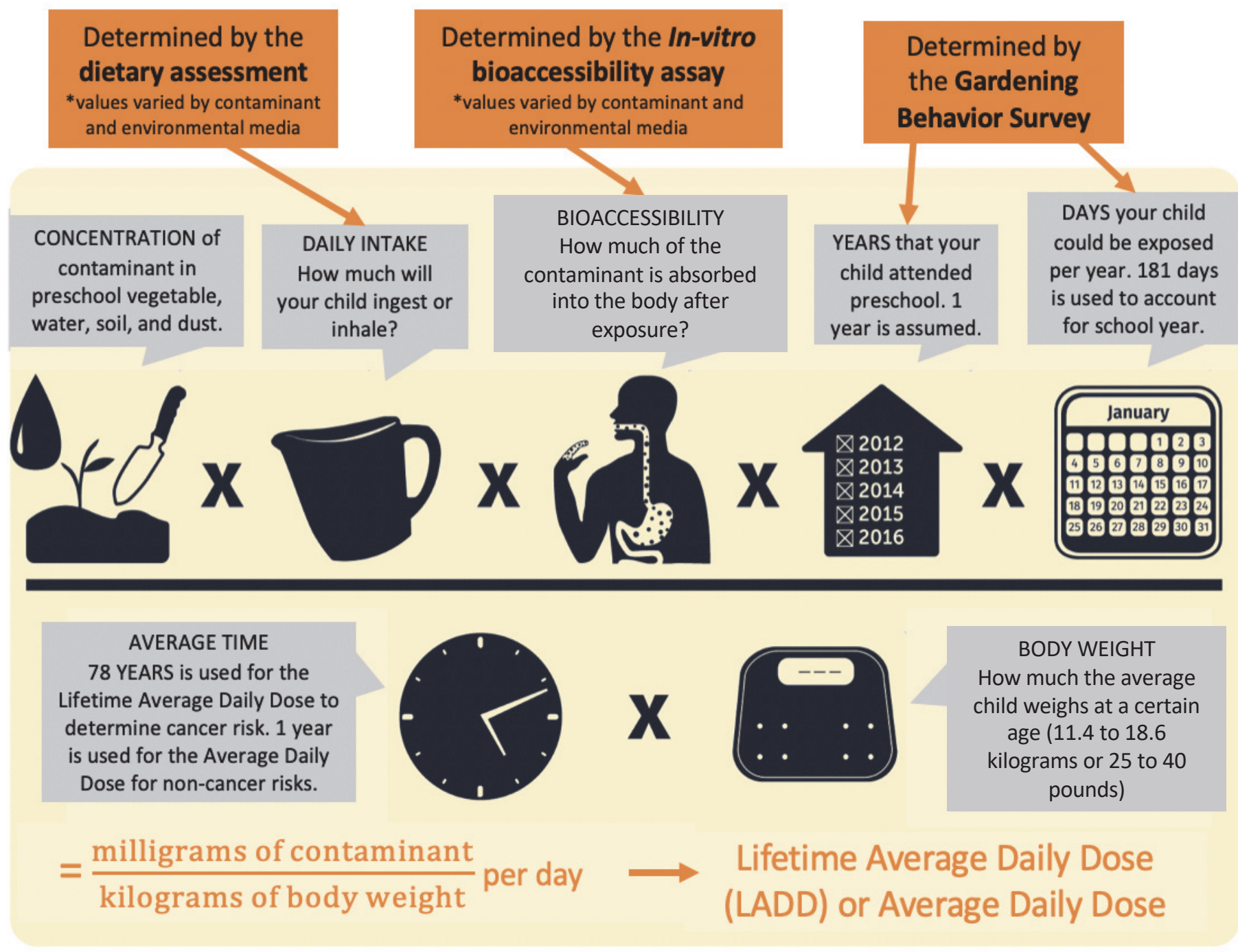




\section{Estimated Exposure (Daily Intake) to Arsenic, Cadmium, and Lead from Vegetables, Soil, Water, and Dust}

A child's cumulative exposure to $\mathrm{As}, \mathrm{Cd}$, and $\mathrm{Pb}$ was estimated for each age group. We determined how much (percentage) each potential exposure route contributed to a child's daily intake (calculated on page 12).

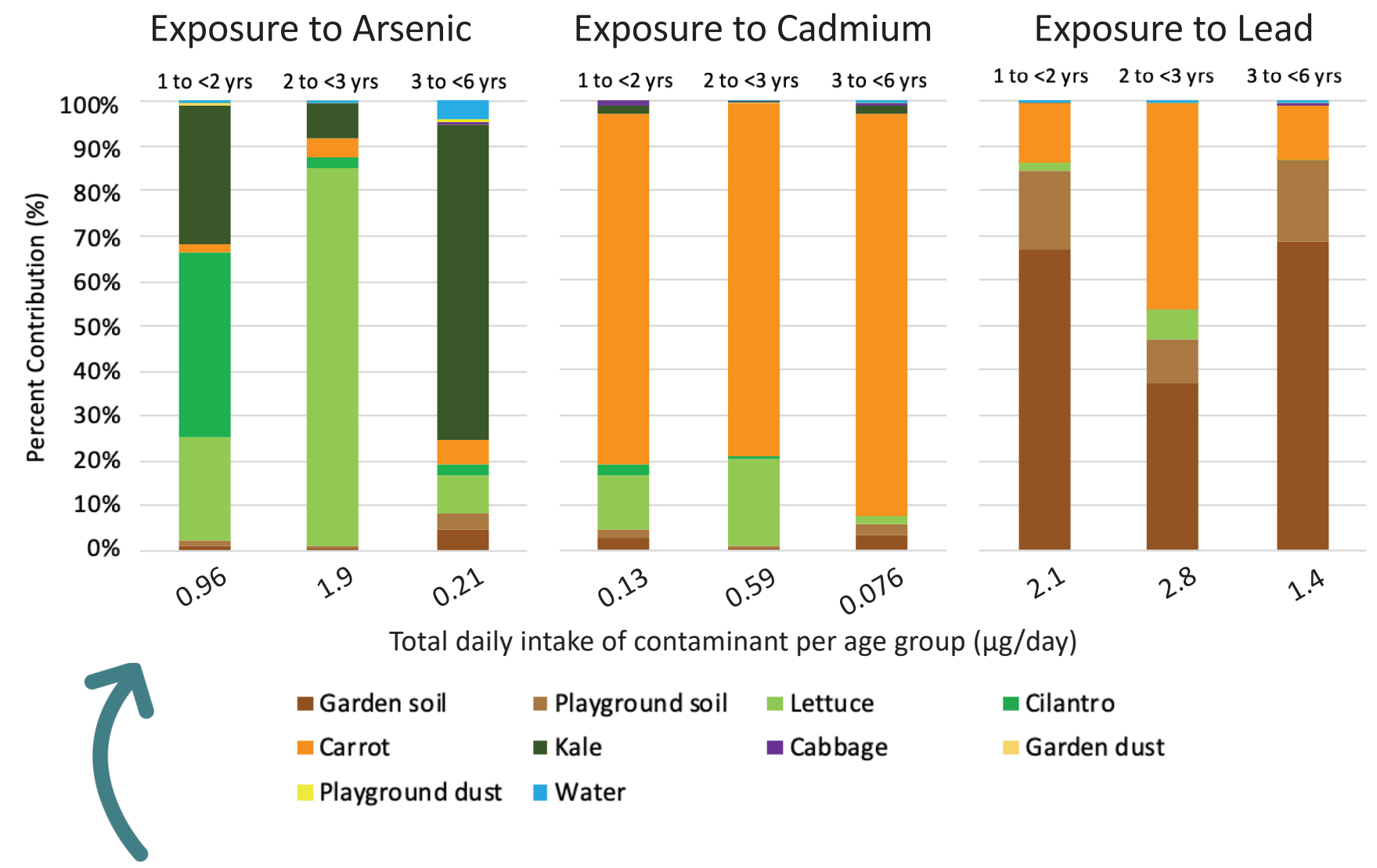

The estimated daily intake of arsenic from all measured exposure routes (vegetables, soil - garden and playground, water, and dust) DID NOT exceed the U.S. EPA's reference dose for arsenic.

Please note! The estimated daily intake of cadmium for 1 to 3 year old children DID exceed CalEPA's child-specific reference dose for cadmium. 


\section{How much can we eat from the preschool garden?}

It is your choice to decide what target risk you want to use to make decisions about how many cups per week to consume from the garden.

We calculated how much of each vegetable your child would have to consume weekly to reach a target excess lifetime cancer risk from arsenic exposure. This target excess risk is in addition to our already existing cancer risk from living our normal lives. These intakes were calculated using the median arsenic concentrations in vegetables across all preschools and the same assumptions described on page 12.

\begin{tabular}{|c|c|c|c|}
\hline \multicolumn{3}{|c|}{$\begin{array}{c}\text { Cups per week that your child can eat based } \\
\text { on different target risks }\end{array}$} & \multirow[t]{2}{*}{$\begin{array}{l}\text { USDA recommended } \\
\text { amounts for 2-3 year } \\
\text { old (cups/week) }\end{array}$} \\
\hline $\begin{array}{l}\text { Target risk of } \\
1 / 1,000,000\end{array}$ & $\begin{array}{c}\text { Target risk of } \\
1 / 100,000\end{array}$ & $\begin{array}{c}\text { Target risk of } \\
1 / 10,000\end{array}$ & \\
\hline \multicolumn{3}{|c|}{ Carrot } & Carrot \\
\hline 11.5 & 115 & 1158 & 2.5 \\
\hline \multicolumn{3}{|c|}{ Lettuce } & Lettuce \\
\hline 2 & 21 & 219 & 1.5 \\
\hline \multicolumn{3}{|c|}{ Kale } & Kale \\
\hline 0.1 & 1 & 10 & 0.5 \\
\hline \multicolumn{3}{|c|}{ Cilantro } & Cilantro \\
\hline 0.2 & 2 & 21 & $\begin{array}{c}\text { No recommendation } \\
\text { available }\end{array}$ \\
\hline
\end{tabular}

\section{Please Note!}

- There are uncertainties associated with this estimation.

- For example, a child will be eating the vegetable for 181 days a year for his/her entire lifetime (78 years).

- This is unlikely due to limited vegetable growing seasons and changes in garden productivity.

- Therefore, the calculated risks are conservative, and the actual risk values would most likely be smaller.

$1 / 1,000,000=1$-in-a-million

$1 / 100,000=1$-in-a-hundred-thousand

$1 / 10,000=1$-in-ten-thousand 


\section{References for More}

\section{Information}

\section{Vegetable}

- U.S. Department of Agriculture (USDA)

- http://www.choosemyplate.gov/food-groups/vegetables amount table.html

- U.S. Environmental Protection Agency (U.S. EPA) - Exposure Factors Handbook

- $\quad$ http://cfpub.epa.gov/ncea/risk/recordisplay.cfm?deid=236252

- U.S. Food and Drug Administration

- $\quad$ http://www.fda.gov/Food/FoodSafety/FoodContaminantsAdulteration/TotalDietStudy

- USDA - What's In The Foods You Eat Search Tool

- $\quad$ http://www.ars.usda.gov/Services/docs.htm?docid=17032

Soil

- CalEPA California Human Health Screening Levels (CHHSLs)

- $\quad$ https://oehha.ca.gov/risk-assessment/california-human-health-screening-levels-chhsls

- CalEPA California Department of Toxic Substances Control Screening Levels (DTSC-SL)

- $\quad$ https://www.dtsc.ca.gov/assessingrisk/humanrisk2.cfm

- University of Arizona Superfund Research Program (UA SRP) - Community Information Sheets

- $\quad$ https://www.superfund.arizona.edu/info-material/information-sheets

- U.S. EPA - Soil Screening Guidance

- $\quad$ http://www.epa.gov/superfund/health/conmedia/soil/index.htm

\section{Water}

- Agency for Toxic Substances and Disease Registry

- http://www.atsdr.cdc.gov/

- UA SRP - Water Booklets

- https://superfund.arizona.edu/info-material/water-booklets-and-videos

- U.S. EPA - Drinking Water Contaminants - Standards and Regulations

- http://water.epa.gov/drink/contaminants/index.cfm

\section{Dust}

- U.S. EPA - Lead National Ambient Air Quality Standard

- https://www.epa.gov/criteria-air-pollutants/naaqs-table 


\section{Thank you!}

Dear School Administrator,

We did it! I would like to give a special thanks to all Nevada County Gardenroots participants for your efforts, motivation, and patience throughout this research project. We appreciate the time you have invested in participating in this project. Altogether, over 33 community members were trained, and 38 soil, 8 dust, 12 water, and 45 plant samples were prepared and analyzed.

This collaborative study was conducted by a team of researchers from the Sierra Streams Institute (a regional nonprofit watershed science organization in Nevada City, CA), University of Arizona, and University of CA-San Francisco. This study was funded by the California Breast Cancer Research Program.

By learning about your students' diet and the environmental quality of your community, we were able to identify environmental health research gaps and ways to improve the quality of preschool gardens. This packet shows the test results of the exposure and risk assessment done for your preschool. Your results are highlighted and compared to state and federal regulatory standards and/or reference values when available. In this package, we have included the following:

1. Project overview

2. Important terms that you will see throughout the results

3. General information on selected contaminants of concern

4. A guide to reading the results

5. Preschool vegetable, soil, irrigation water, and dust results

6. Child's cumulative exposure

7. References for further information on environmental quality and guidelines

Sincerely,

Mónica Ramírez-Andreotta, Assistant Professor

University of Arizona

1177 E Fourth Street, Rm. 429, Tucson, AZ 85721

Phone: 520-621-0091 Fax: 520-621-1647

Joanne Hild

Executive Director, River Scientist

Sierra Streams Institute 13075 Woolman Lane

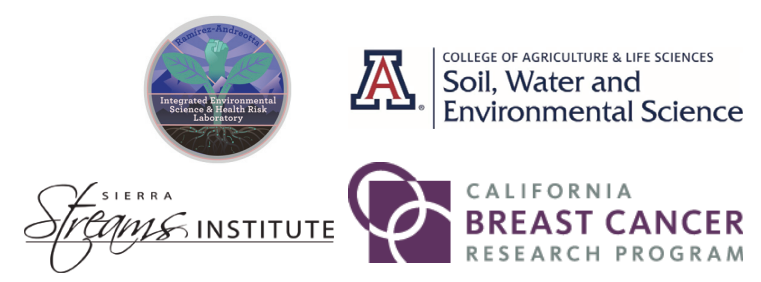

Nevada City, CA 95959 (530) 477- 7132 Ext. 200

www.sierrastreamsinstitute.org

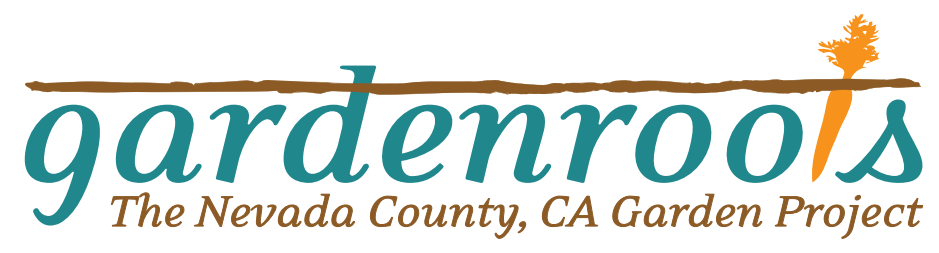




\section{Project Description}

Based on community member's concerns regarding environmental quality, Gardenroots: The Nevada City, CA Garden Project was developed. Gardenroots is an environmental monitoring and children's exposure assessment project designed to better understand potential child exposure to arsenic and cadmium. Seeing gardens as hubs for environmental health research and education, Gardenroots is trying to understand the state of environmental quality in rural communities. Results from this study are helping to determine whether people are exposed to metal contaminants through gardening and crop ingestion.

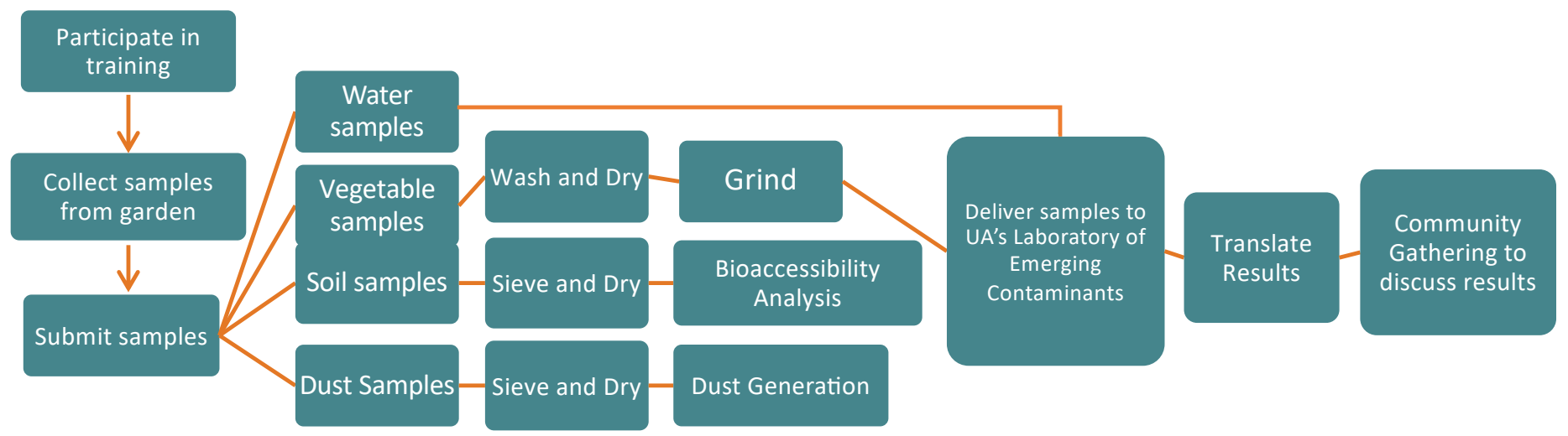

Data may be subject to revisions.

The results have been internally reviewed, but have not undergone external peer review and may be subjected to minor changes.

Metals occur naturally in the environment.

While we can measure the level of a metal in certain substances, like water or soil, it is difficult to know the original source of the metal. For example, arsenic may be found in soil in many parts of the state because it also naturally occurs in these regions.

It is important to note that, elements such as arsenic occur naturally in soil and it is impossible to grow plants completely free of these and other trace elements like lead and cadmium.

Please refer to the recommended gardening best practices handouts for ways to reduce levels of harmful chemicals in your garden plot and in your vegetables.

Single exposure measurements are "snapshots in time".

We are measuring metal concentrations at a single point in time. Measuring metal concentrations with a single sampling does not establish what the exposures were in the past or what they may be in the future.

For more information about the study and safe gardening practices, please visit the Gardenroots website: http://www.gardenroots.arizona.edu/ 


\section{Important Terms}

Below is a set of terms that you will see throughout your results:

Action Level (AL) - The U.S. Environment Protection Agency (U.S. EPA) regulates lead under the Lead and Copper Rule. This rule describes the water treatment requirements needed to control plumbing corrosion that may contaminate drinking water. If the water concentration of lead is above the action level, this means actions are required to correct the water system to meet this regulation.

Concentration - The amount of a chemical in a given mass of water, soil, or plant tissue. This is written as $\mu \mathrm{g} / \mathrm{L}$ (micrograms per liter), $\mu \mathrm{g} / \mathrm{m}^{3}$ (micrograms per cubic meter), or $\mu \mathrm{g} / \mathrm{g}$ (micrograms per gram).

Guideline - A non-enforceable, but recommended maximum concentration of a chemical.

MCL (Maximum Contaminant Level) - The MCL is the maximum amount of a contaminant allowed in drinking water so that it is still safe to drink over many years. This level is set by the US Environmental Protection Agency.

Median - The value at the midpoint (middle value) of the range of values.

National Ambient Air Quality Standard (NAAQS) - These are standards established by the U.S. EPA to protect human health. The standard for lead defines the maximum allowable concentration of lead in a cubic squared meter of outdoor air. This standard is current set to $0.15 \mu \mathrm{g} / \mathrm{m}^{3}$.

Percentile - A number where a certain percentage of scores fall below that number. For example, if you know that your score is in the 90th percentile, that means you scored better than $90 \%$ of people who took the test.

$\mu \mathrm{g} / \mathrm{g}$ (Micrograms per Gram) - A measure of how many micrograms of a substance (such as a metal) are in a gram of a solid (such as soil). This measure is also referred to as parts per million (ppm).

$\mu \mathrm{g} / \mathrm{L}$ (Micrograms per Liter) - A measure of how many micrograms (one-thousandth of a milligram) of a substance (such as a metal) are in a liter of liquid (such as water). This measure is also referred to as parts per billion (ppb). For perspective, $1 \mu \mathrm{g} / \mathrm{L}$ or $\mathrm{ppb}$ is the equivalent to a drop of ink in a backyard swimming pool.

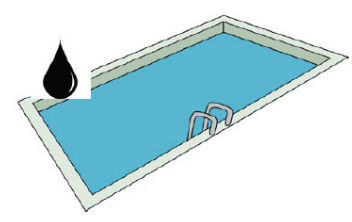

\begin{tabular}{|c|c|c|}
\hline $\begin{array}{c}\text { Micrograms per liter } \\
(\mu \mathrm{g} / \mathrm{L})\end{array}$ & $\begin{array}{c}\text { Parts per billion } \\
(\mathrm{ppb})\end{array}$ & $1 / 1,000,000,000$ \\
\hline
\end{tabular}




\section{Important Terms (con't)}

$\mu \mathrm{g} / \mathrm{m}^{3}$ (Micrograms per Cubic Meter) - A measure of how many micrograms of a substance (such as a metal) are in a cubic meter of a air.

Reference Dose (RfD) - Estimate of a daily intake of a chemical that is not likely to result in any significant negative health effects (including sensitive populations like children and elderly). It may be referred to as the acceptable daily intake.

Standards - The standards are enforceable and regulatory values, developed either by federal agencies or by the state of Arizona for water providers/utilities. They are different from advisories (see definition on previous page) and guidelines.

\section{Soil Screening Levels}

- U.S. EPA Regional Screening Level (RSL) - Risk-based concentrations of contaminant in soils that are calculated using what we know about the exposure to a contaminant and what the U.S. EPA knows about the toxicity of the chemical. U.S. EPA considers these screening levels as initial cleanup goals, when applicable. They are not national cleanup standards, and are based on different target risks.

- CalEPA California Human Health Screening Levels (CHHSLs) - Risk-based concentrations of contaminants in soils that are specific to California. Screening levels for lead are not risk-based screening levels, but rather the average $\mathrm{Pb}$ concentration in residential soil that would be protective of children and women of child-bearing ages. These values are more conservative than the U.S EPA RSLS.

- CalEPA California Department of Toxic Substances Control Screening Levels (DTSC-SL) - Riskbased recommended screening levels that are derived using DTSC-modified exposure and toxicity factors for contaminants in soil. These values are also more conservative than the U.S EPA RSLs. 


\section{Arsenic (As)}

\section{Contaminant Name: Arsenic (As)}

Contaminant Type: Metalloid

\section{What is Arsenic?}

Arsenic naturally exists in the Earth's crust and can be found in sediments, soils, and groundwater. Arsenic may also be released into the environment via mining, ore smelting, and industrial use of the element.

\section{What happens to arsenic when it enters the environment?}

In the environment, people can be exposed to arsenic in two chemical forms:

- Inorganic: Varying amounts of this poisonous (toxic) form can be found naturally in geologic materials (soils, rocks, aquifer materials) and in ground and surface water, which may also be impacted by mining and industrial wastes and arsenical pesticides).

- Organic (arsenic compounds that contain carbon): Varying amounts of this non-poisonous (lowtoxicity) form can be found in sources such as animals, plants, fish and seafood. Fish and shellfish can accumulate arsenic; most of this arsenic is in an organic form called arsenobetaine that is much less harmful.

\section{How can arsenic affect my health?}

Severe (acute) arsenic poisoning can cause vomiting, abdominal pain, and diarrhea. This can be followed by numbness and tingling of the extremities, muscle cramping, and death in extreme cases. Ingesting or breathing low levels of inorganic arsenic for a long time (chronic) can cause non-cancer health effects, like a darkening of the skin and the appearance of small "warts" on the palms, soles, and torso. Other non- cancer health effects linked to long- term ingestion of arsenic include developmental effects, diabetes, pulmonary disease, and cardiovascular disease. Ingestion of inorganic arsenic can increase the risk of skin cancer and cancer in the liver, bladder, and lungs. Inhalation of inorganic arsenic can cause increased risk of lung cancer.

\section{Where can I get more information on Arsenic?}

Agency for Toxic Substances and Disease Registry. ToxFAQsTM for Arsenic. Last Updated on March 12, 2015. You can access this information at: https://www.atsdr.cdc.gov/toxfaqs/tf.asp?id=19\&tid=3 


\title{
Cadmium (Cd)
}

\author{
Contaminant Name: Cadmium (Cd) \\ Contaminant Type: Heavy metal
}

\section{What is cadmium?}

Cadmium is found in the Earth's crust. Most cadmium used in the U.S. is extracted as a byproduct during the production of other metals such as zinc, lead, or copper. Cadmium is also recovered from used batteries. Cadmium is used for the following: batteries, pigments, coatings and platings, stabilizers for plastics, photovoltaic (solar power materials) devices, and other uses.

\section{What happens to cadmium when it enters the environment?}

Cadmium is emitted to soil, water, and air by metal mining and refining, manufacture and application of phosphate fertilizers, fossil fuel combustion, and waste incineration and disposal. Generally, cadmium binds strongly to organic matter where it can stay in soil and be taken up by plant life, eventually entering the food supply.

\section{How can cadmium affect my health?}

Cigarette smoking is a major exposure route to cadmium. Tobacco may have been grown in contaminated soils, or pesticides/fungicides or additives were applied during the growing and manufacturing process.

Exposure to cadmium can occur through breathing contaminated workplace air, drinking contaminated water, or living near industrial facilities that release cadmium into the air. Eating food or drinking water with very high levels severely irritates the stomach, leading to vomiting and diarrhea. Long-term exposure to lower levels of cadmium in air, food, or water leads to a buildup of cadmium in the kidneys and possible kidney disease. Other long-term effects include lung damage and fragile bones. Low levels of cadmium are found in all foods (highest levels are found in shellfish, liver, and kidney meats). In the U.S., for nonsmokers the primary source of cadmium exposure is from the food supply. Breathing high levels of cadmium can severely damage the lungs. Cadmium and cadmium compounds are known to cause cancer in humans.

\section{Where can I get more information on Cadmium?}

Agency for Toxic Substances and Disease Registry. ToxFAQsTM for Cadmium. Last Updated on March 12, 2015. You can access this information at: https://www.atsdr.cdc.gov/toxfags/tf.asp?id=47\&tid=15 


\title{
Lead $(\mathrm{Pb})$
}

\author{
Contaminant Name: Lead (Pb) \\ Contaminant Type: Heavy Metal
}

\section{What is lead?}

Lead is a metal in the Earth's crust that

is normally found with other metals such as zinc, silver, and copper. Lead has many uses including manufacturing of paints, batteries, and fishing weights. Lead- based solder, which had been used to connect copper water pipes, was banned in the 1980s, but may still be a source of lead in drinking water in older homes. In the United States, lead was used as a gasoline additive, but was banned beginning in 1973 and eliminated by 1996.

\section{What happens to lead when it enters the environment?}

Lead itself does not break down, but lead compounds are changed by sunlight, air, and water. When lead is released to the air, it may travel long distances before settling to the ground. Once lead falls onto soil, it usually sticks to soil particles. Ingestion (soil, food, water) is the main route of exposure in humans.

Children are most impacted by lead exposure because they often put their hands and/or toys in their mouths. Pregnant women can also expose their unborn child to lead via ingestion. Adults can be exposed via lifestyle choices (e.g., cigarette smoking) or through their occupation (e.g., plumbing, soldering, manufacturing plants, construction/remodeling companies, smelters, and auto repair shops). There are other sources of potential lead exposure which include: paints, glazed clay pots, wine, food, leaded glass (crystal), stained glass, dyes, and home remedies (e.g., azarcon or greta used to treat digestive illness).

\section{How can lead affect my health?}

Lead can affect almost every organ and system in your body, both in adults and children. Exposure to lead can seriously harm a child's health. It can damage the brain and nervous system, slow growth and development, cause learning, behavior, hearing, and speech problems. It causes lower IQ, decreased ability to pay attention, and underperformance in school. Lead exposure also causes small increases in blood pressure, particularly in middle-aged and older people and can cause anemia. In pregnant women, high levels of exposure to lead may cause miscarriage. High-level exposure in men can damage the organs responsible for sperm production.

\section{Where can I get more information on Lead?}

Agency for Toxic Substances and Disease Registry. ToxFAQsTM for Lead. Last Updated on August 24, 2016. You can access this information at: https://www.atsdr.cdc.gov/toxfaqs/tf.asp?id=93\&tid=22 


\section{A Guide to Reading the Results}

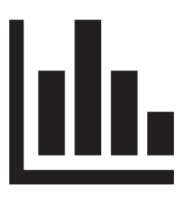

\section{Guide for reading soil, plant, water, and dust results}

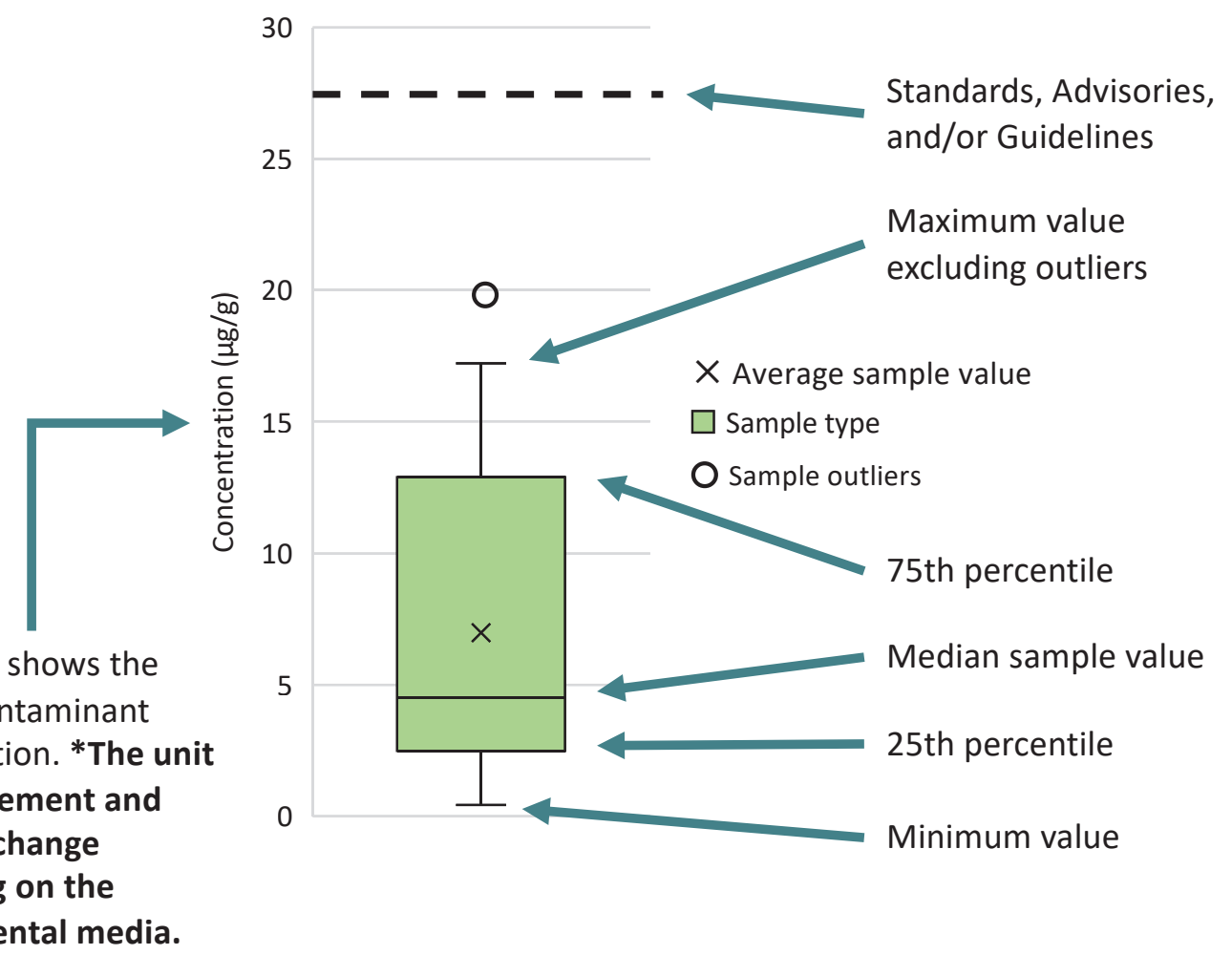

The Y-Axis shows the level of contaminant concentration. *The unit of measurement and scale will change depending on the environmental media.

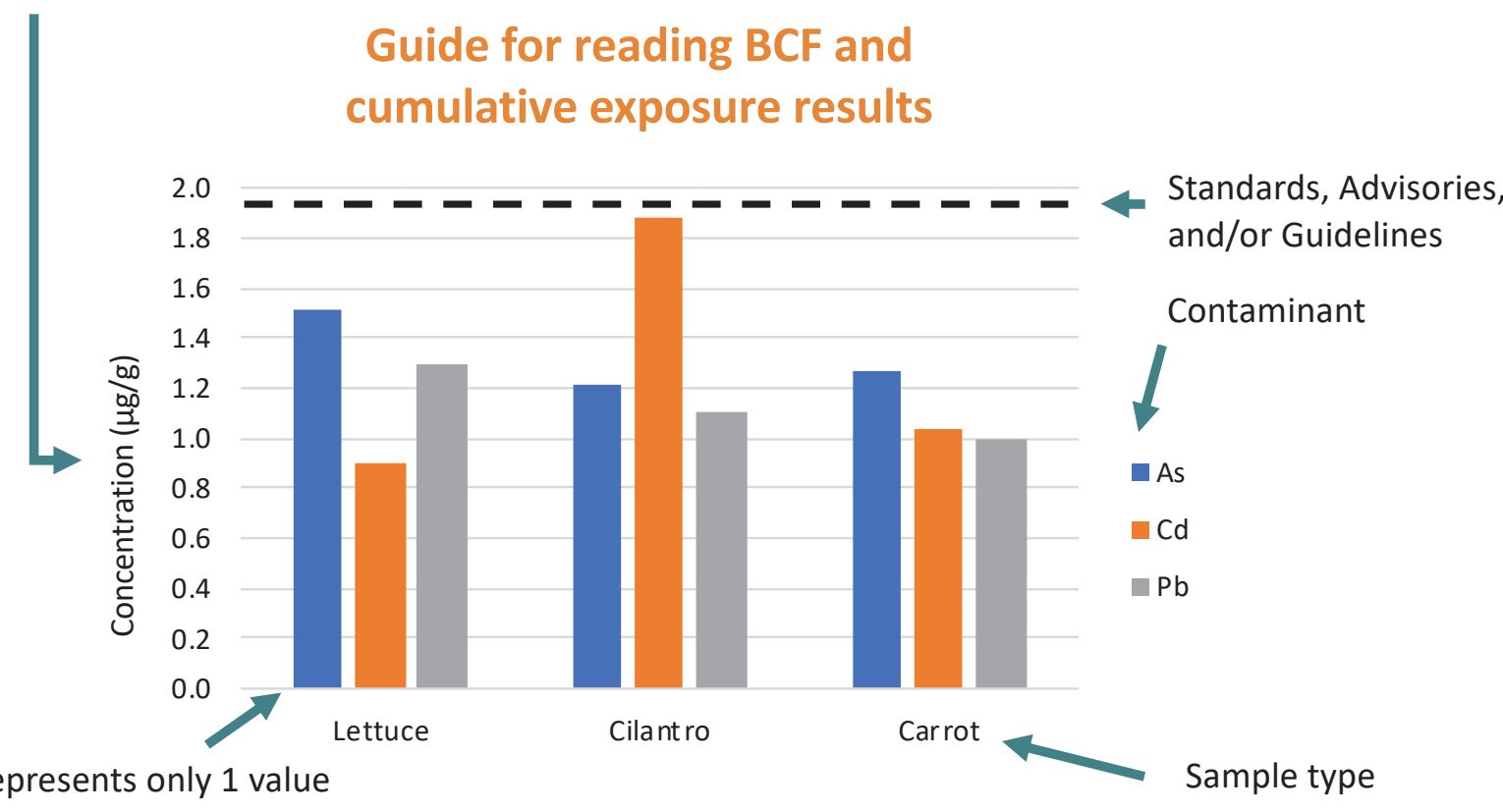

Each bar represents only 1 value unless shown as a percentage out of $100 \%$ on the Y-Axis 


\section{Vegetable Results}

Below are the measured arsenic, cadmium, and lead concentrations in vegetables that were collected at your preschool.

\section{Concentration in Garden Vegetables}

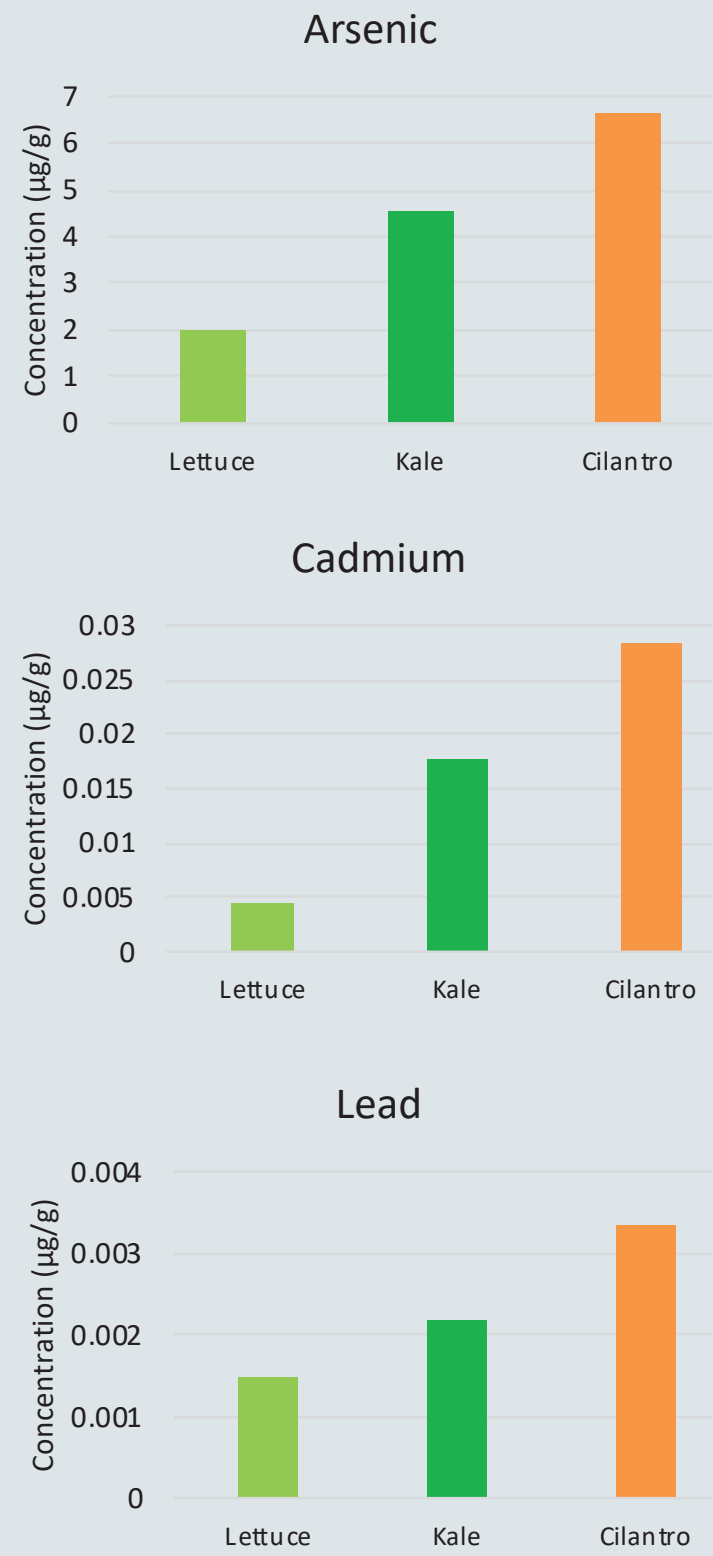

We found that in general, Apiaceae (cilantro) and Brassicaceae plants (kale) had the greatest median concentrations of $\mathrm{As}, \mathrm{Cd}$, and $\mathrm{Pb}$.

\section{Plant Bioconcentration Factor}

The plant bioconcentration factor (BCF) is the ratio of the metal concentration in the edible portion in the vegetable (dry weight) and the metal concentration in the soil.

$$
B C F=\frac{\text { Contaminant concentration in plant }}{\text { Contaminant concentration in garden soil }}
$$

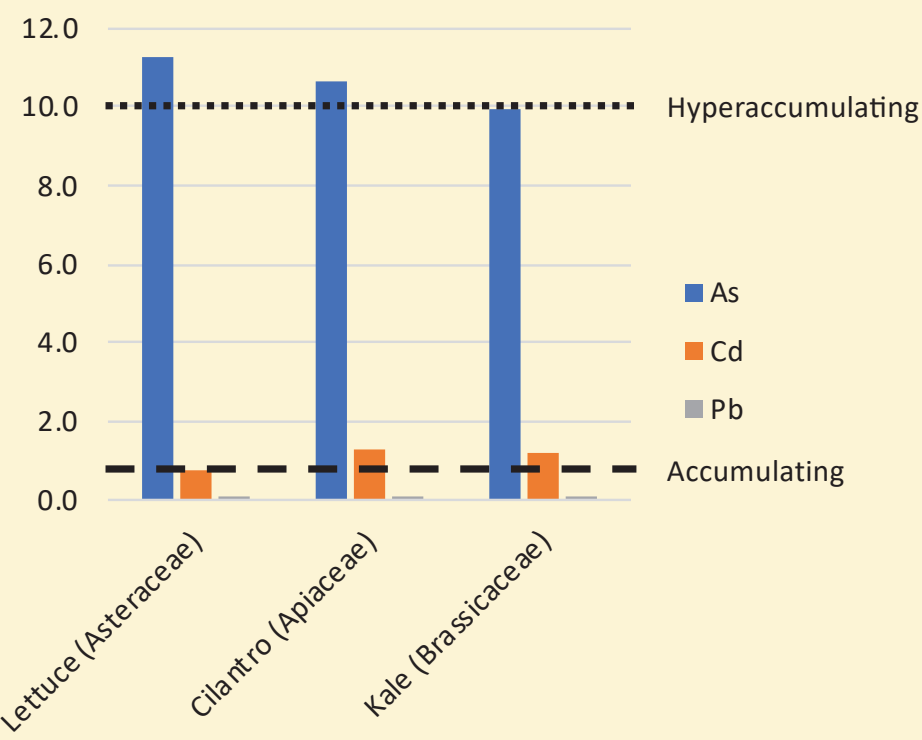

Certain members of the Asteraceae and Brassicaceae families have been previously identified as hyperaccumulator plants, meaning they may have a genetic and physiological capacity to accumulate high amounts of metals (BCF > 10). We found that nearly all of the preschool-grown vegetables hyperaccumulated As, and accumulated $\mathrm{Cd}$.

Based on these results, it is recommended that Nevada County, CA gardeners limit the use of vegetables from the Asteraceae, Apiaceae, and Brassicaceae plant family. 


\section{Soil Results}

Below are the measured arsenic, cadmium, and lead concentrations in soil samples that were collected at your preschool.

\section{Arsenic Concentration in Garden} and Playground Soil

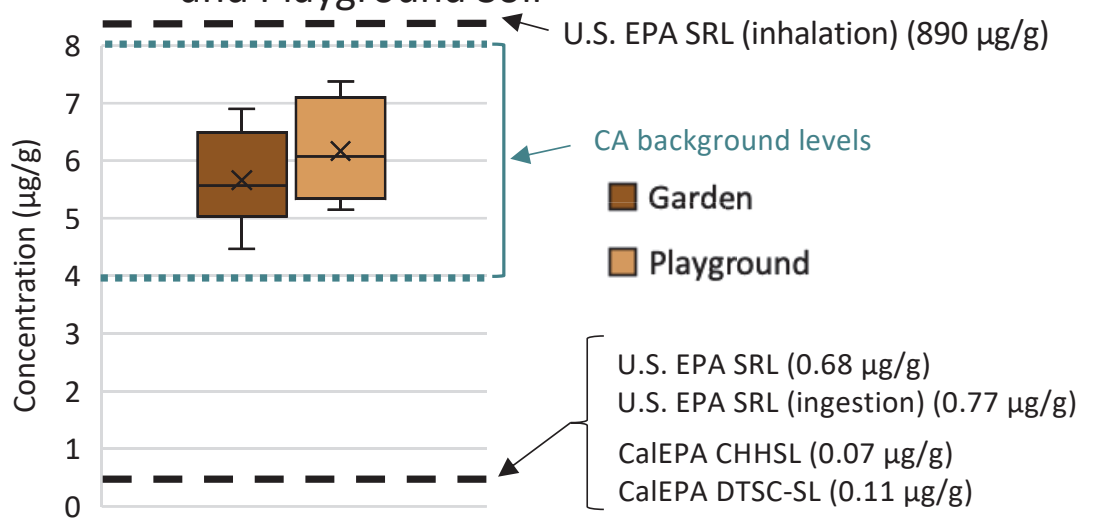

Soil samples exceeded the recommended conservative state and federal soil screening levels for As.

The measured As concentrations in garden and playground soil were similar to the CA background As levels. This suggests that in general, these levels are also not caused by human activity or historical land use.

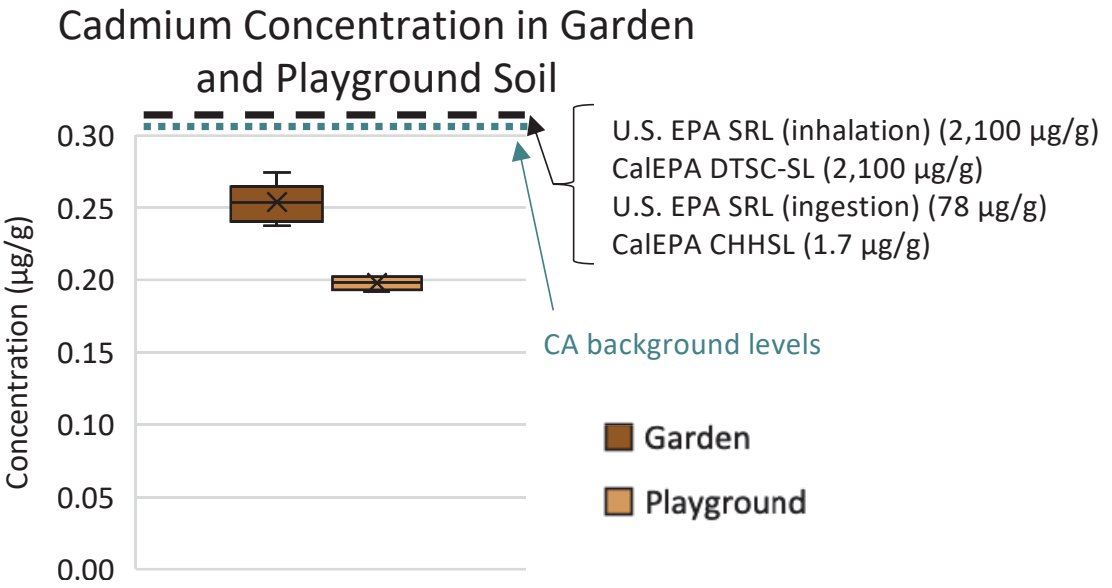

Soil samples did not exceeded the recommended conservative state and federal soil screening levels for $\mathrm{Cd}$.

The measured $\mathrm{Cd}$ concentrations in the garden and playground soil were below CA background Cd levels. This suggests that in general, these levels are also not caused by human activity or historical land use.

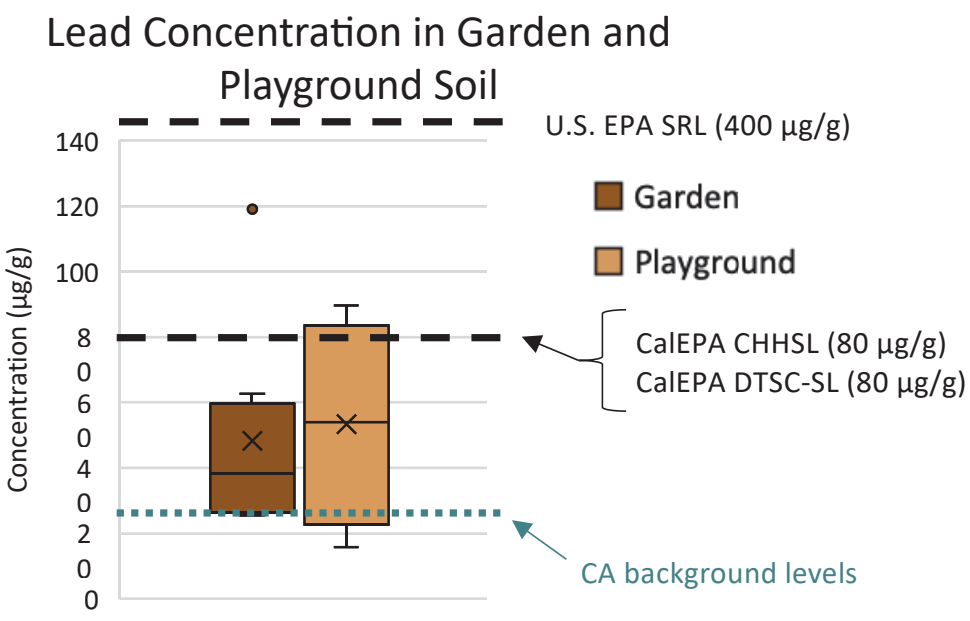

In general, soil samples did not exceeded the recommended conservative state and federal soil screening levels for $\mathrm{Pb}$.

The measured $\mathrm{Pb}$ concentrations in garden and playground soil were above $\mathrm{CA}$ background $\mathrm{Pb}$ levels. This suggests that the elevated $\mathrm{Pb}$ concentrations in preschool garden and playground soils are possibly caused by human activity. 


\section{Water \& Dust Results}

Below are the measured arsenic, cadmium, and lead concentrations in garden irrigation water and dust results from the samples collected at your preschool.

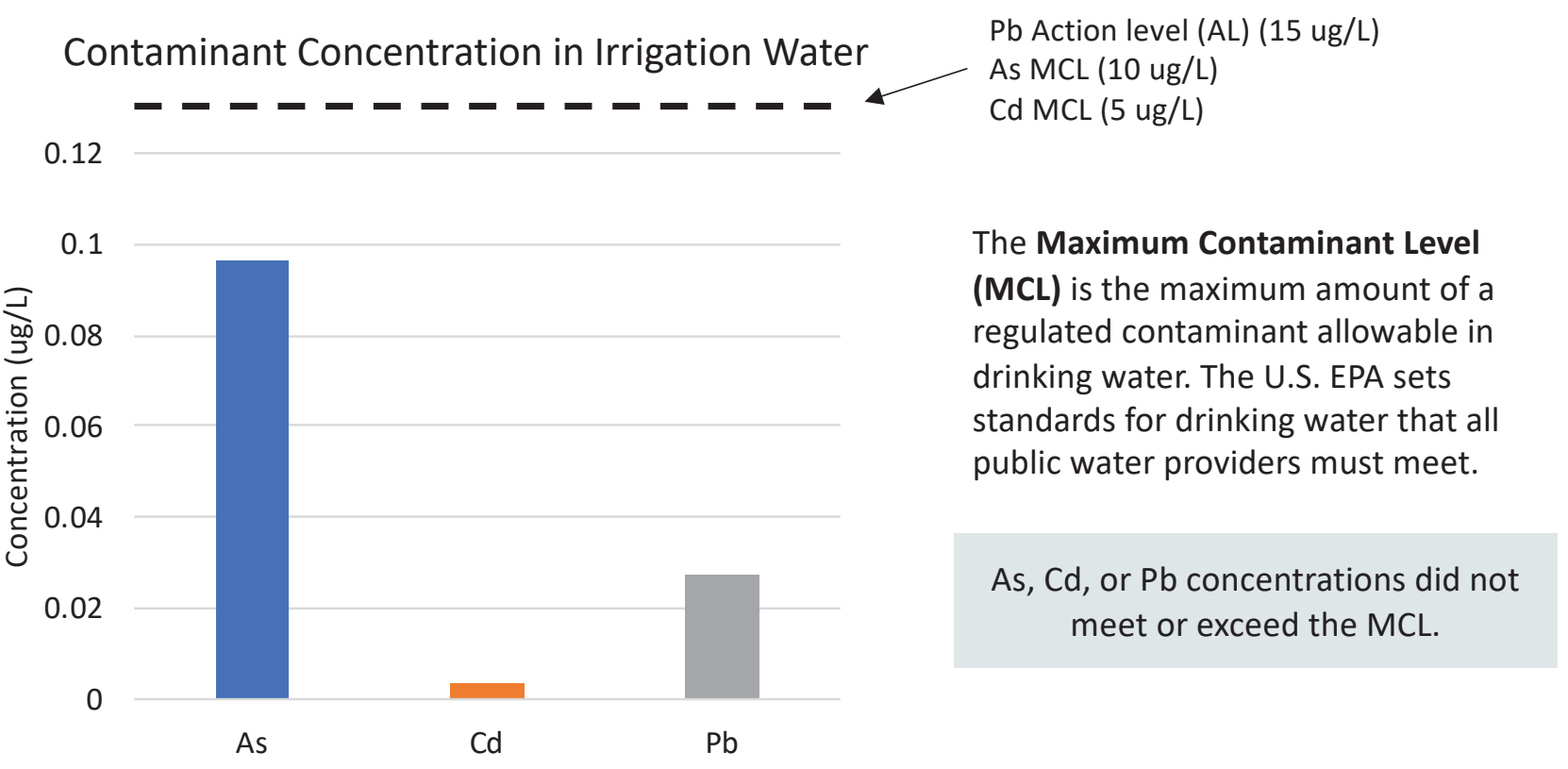

The median $\mathrm{Pb}$ concentration from garden and playground dust at this preschool were below to the U.S. EPA's National Ambient Air Quality Standard (NAAQS) of $0.15 \mu \mathrm{g} / \mathrm{m}^{3}$.

There is currently no federal or state outdoor air standard for As or $\mathrm{Cd}$ concentration available for comparison.

\section{Contaminant Concentration in Dust}

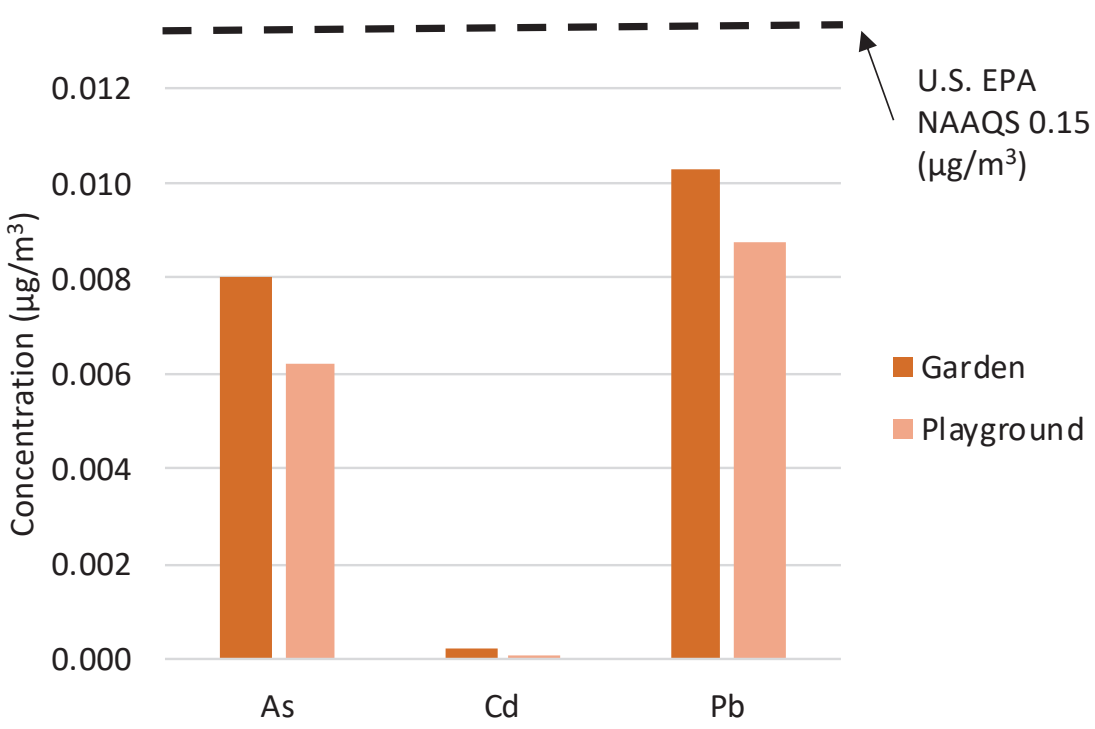




\section{What is an Exposure Assessment?}

An exposure assessment aims to answer the following questions: How much of a contaminant is present in the environment? Are we exposed? If so, how and how much are we exposed to?

In this study we estimated a preschool child's daily dose of $\mathrm{As}, \mathrm{Cd}$, and $\mathrm{Pb}$ from playing and gardening. To do this we used the equation below and the following assumptions:

- Intake rate for the vegetable, water, dust, or soil (incidental) a child would be consuming daily

- Body weight (11.4 to $18.6 \mathrm{~kg}=25$ to $40 \mathrm{lbs}$ )

- Life span equal to 78 years

- Eating that vegetable, drinking the water, incidentally ingesting soil, and inhaling dust for 181 days out of the year (average school year) for 1 year while attending the preschool

- Bioaccessibility of As, Cd, and Pb once it's in your body

Child-specific estimated values are highlighted in the orange boxes.

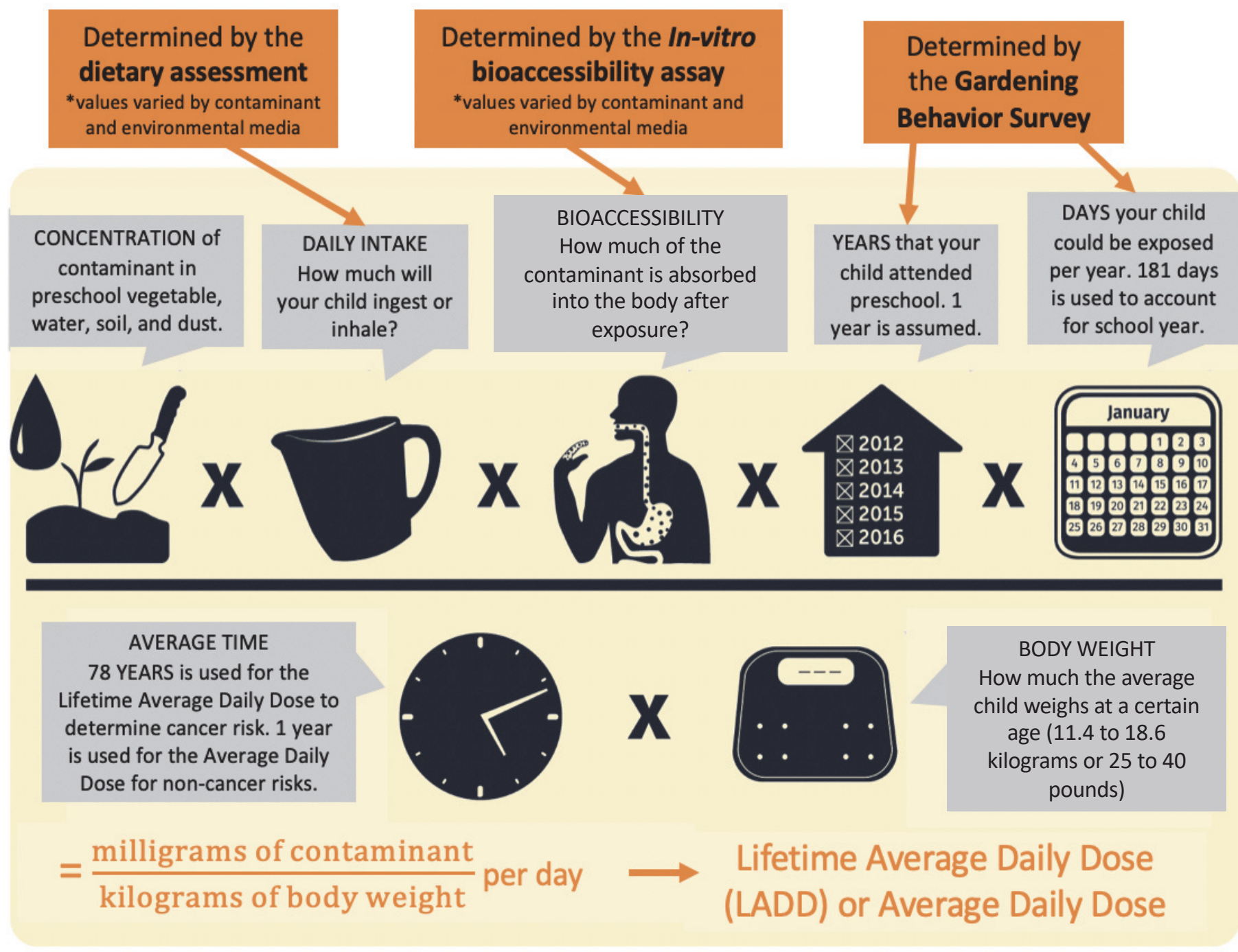




\section{Estimated Exposure (Daily Intake) to Arsenic, Cadmium, and Lead from Vegetables, Soil, Water, and Dust}

A child's cumulative exposure to $\mathrm{As}, \mathrm{Cd}$, and $\mathrm{Pb}$ was estimated for each age group. We determined how much (percentage) each potential exposure route contributed to a child's daily intake (calculated on page 12).

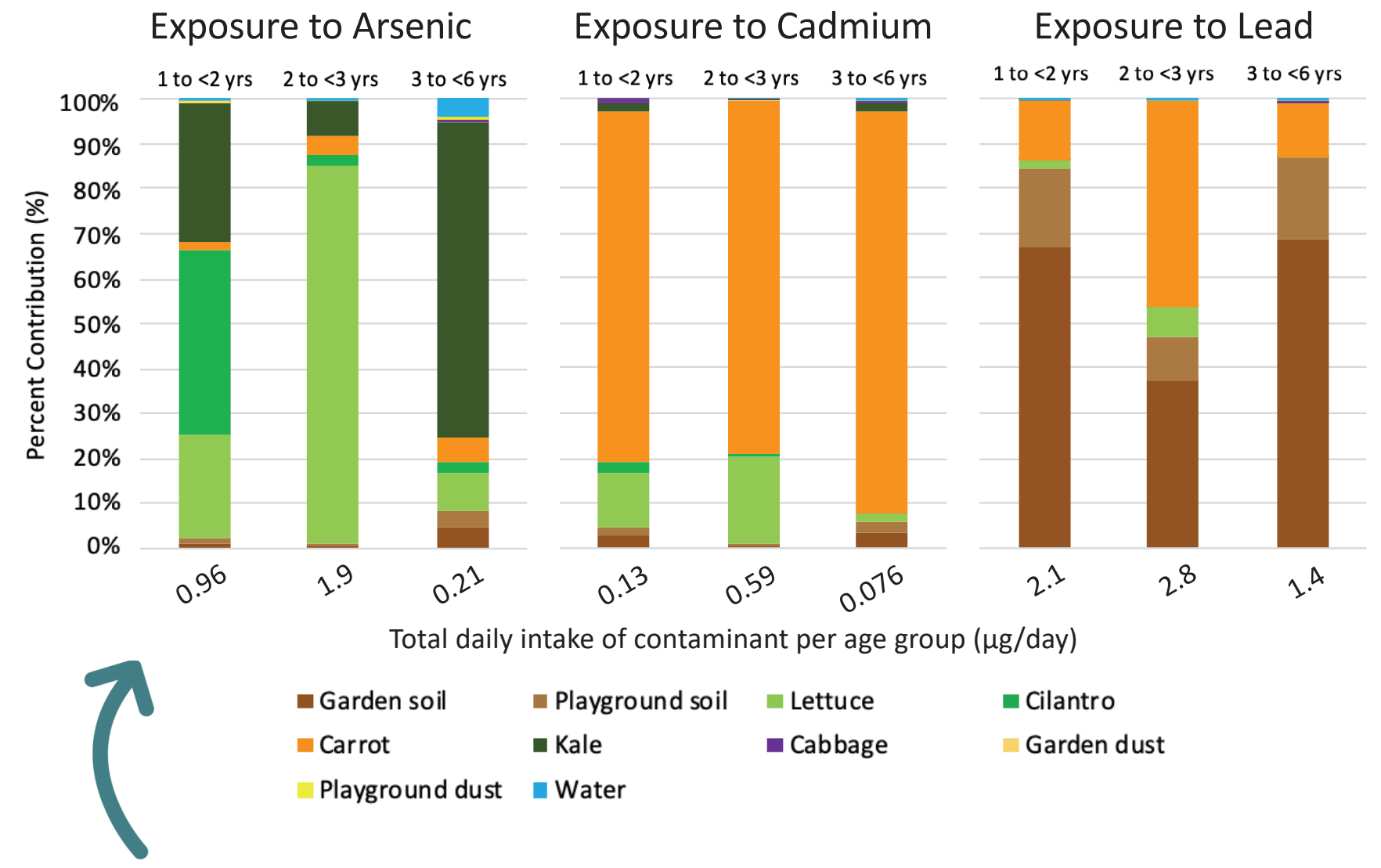

The estimated daily intake of arsenic from all measured exposure routes (vegetables, soil - garden and playground, water, and dust) DID NOT exceed the U.S. EPA's reference dose for arsenic.

Please note! The estimated daily intake of cadmium for 1 to 3 year old children DID exceed CalEPA's child-specific reference dose for cadmium. 


\section{How much can we eat from the preschool garden?} It is your choice to decide what target risk you want to use to make decisions about how many cups per week to consume from the garden.

We calculated how much of each vegetable your child would have to consume weekly to reach a target excess lifetime cancer risk from arsenic exposure. This target excess risk is in addition to our already existing cancer risk from living our normal lives. These intakes were calculated using the median arsenic concentrations in vegetables across all preschools and the same assumptions described on page 12.

\begin{tabular}{|c|c|c|c|}
\hline \multicolumn{3}{|c|}{$\begin{array}{c}\text { Cups per week that your child can eat based } \\
\text { on different target risks }\end{array}$} & \multirow[t]{2}{*}{$\begin{array}{l}\text { USDA recommended } \\
\text { amounts for 2-3 year } \\
\text { old (cups/week) }\end{array}$} \\
\hline $\begin{array}{l}\text { Target risk of } \\
1 / 1,000,000\end{array}$ & $\begin{array}{c}\text { Target risk of } \\
1 / 100,000\end{array}$ & $\begin{array}{c}\text { Target risk of } \\
1 / 10,000\end{array}$ & \\
\hline \multicolumn{3}{|c|}{ Carrot } & Carrot \\
\hline 11.5 & 115 & 1158 & 2.5 \\
\hline \multicolumn{3}{|c|}{ Lettuce } & Lettuce \\
\hline 2 & 21 & 219 & 1.5 \\
\hline \multicolumn{3}{|c|}{ Kale } & Kale \\
\hline 0.1 & 1 & 10 & 0.5 \\
\hline \multicolumn{3}{|c|}{ Cilantro } & Cilantro \\
\hline 0.2 & 2 & 21 & $\begin{array}{c}\text { No recommendation } \\
\text { available }\end{array}$ \\
\hline
\end{tabular}

\section{Please Note!}

- There are uncertainties associated with this estimation.

- For example, a child will be eating the vegetable for 181 days a year for his/her entire lifetime (78 years).

- This is unlikely due to limited vegetable growing seasons and changes in garden productivity.

- Therefore, the calculated risks are conservative, and the actual risk values would most likely be smaller.

$1 / 1,000,000=1$-in-a-million

$1 / 100,000=1$-in-a-hundred-thousand

$1 / 10,000=1$-in-ten-thousand 


\section{References for More}

\section{Information}

\section{Vegetable}

- U.S. Department of Agriculture (USDA)

- http://www.choosemyplate.gov/food-groups/vegetables amount table.html

- U.S. Environmental Protection Agency (U.S. EPA) - Exposure Factors Handbook

- $\quad$ http://cfpub.epa.gov/ncea/risk/recordisplay.cfm?deid=236252

- U.S. Food and Drug Administration

- $\quad$ http://www.fda.gov/Food/FoodSafety/FoodContaminantsAdulteration/TotalDietStudy

- USDA - What's In The Foods You Eat Search Tool

- $\quad$ http://www.ars.usda.gov/Services/docs.htm?docid=17032

Soil

- CalEPA California Human Health Screening Levels (CHHSLs)

- $\quad$ https://oehha.ca.gov/risk-assessment/california-human-health-screening-levels-chhsls

- CalEPA California Department of Toxic Substances Control Screening Levels (DTSC-SL)

- $\quad$ https://www.dtsc.ca.gov/assessingrisk/humanrisk2.cfm

- University of Arizona Superfund Research Program (UA SRP) - Community Information Sheets

- $\quad$ https://www.superfund.arizona.edu/info-material/information-sheets

- U.S. EPA - Soil Screening Guidance

- $\quad$ http://www.epa.gov/superfund/health/conmedia/soil/index.htm

\section{Water}

- Agency for Toxic Substances and Disease Registry

- http://www.atsdr.cdc.gov/

- UA SRP - Water Booklets

- https://superfund.arizona.edu/info-material/water-booklets-and-videos

- U.S. EPA - Drinking Water Contaminants - Standards and Regulations

- http://water.epa.gov/drink/contaminants/index.cfm

\section{Dust}

- U.S. EPA - Lead National Ambient Air Quality Standard

- https://www.epa.gov/criteria-air-pollutants/naaqs-table 